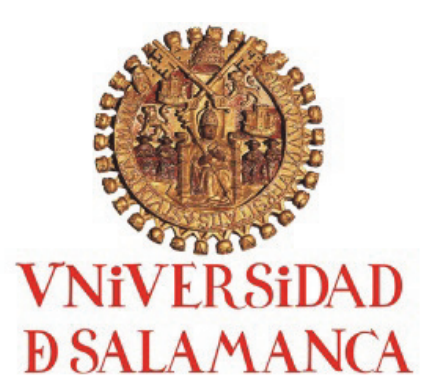

Programa de Doctorado Estudios Interdisciplinares de Género y Políticas de Igualdad

\title{
“LOS VALORES COMO ELEMENTO BÁSICO DE EFICACIA DEL SISTEMA NACIONAL DE SALUD ESPAÑOL EN UNA PROFESIÓN
} FEMINIZADA"

María Dolores Andrés Prieto

\author{
DIRECTORAS DE LA TESIS \\ Prof ${ }^{\mathrm{a}}$. Dr ${ }^{\mathrm{a}}$. M $\mathrm{M}^{\mathrm{a}}$ Dolores Calvo Sánchez \\ Prof ${ }^{\mathrm{a}}$. Dra . Ángela Figueruelo Burrieza
}

Salamanca, 2016 



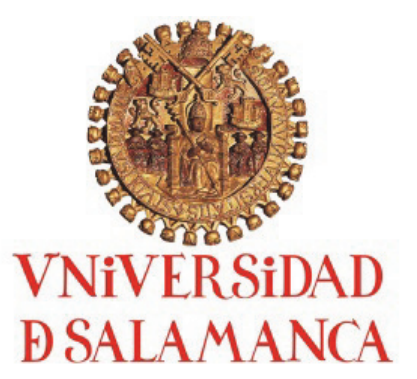

Dña. Ma Dolores Calvo Sánchez y Dña. Ángela Figueruelo Burrieza, directoras del trabajo de investigación "Los valores como elemento básico de eficacia del Sistema Nacional de Salud español en una profesión feminizada" realizado por Dña. María Dolores Andrés Prieto, profesoras doctoras de la Universidad de Salamanca, hacen constar que reúne a su juicio todos los requisitos para su defensa a los efectos de acceder al título de Doctora por la Universidad de Salamanca.

En Salamanca a 5 de diciembre de 2016 

"Los valores son palabras. Lamentablemente, en demasiadas ocasiones son sólo eso. Sin embargo, no hay duda de que las palabras que se identifican como valores tienen una especial potencia para dar sentido y encauzar los esfuerzos humanos, tanto a nivel personal como a nivel de empresa."

(Salvador García y Shimon Dolan) 

Quiero expresar mi agradecimiento:

\begin{abstract}
A mis directoras la Profesora Dra. $\mathbf{M}^{\mathrm{a}}$ Dolores Calvo Sánchez y la Profesora Dra. Ángela Figueruelo Burrieza por sus profundos conocimientos, por su apoyo permanente, por su sabia dirección sin los cuales este trabajo no hubiese sido posible.
\end{abstract}

A todas las personas que me han ayudado 



\section{ÍNDICE}

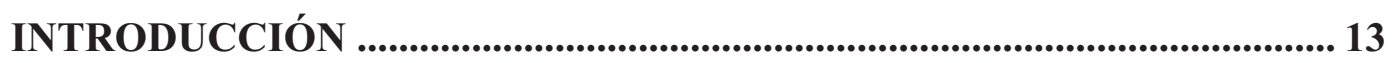

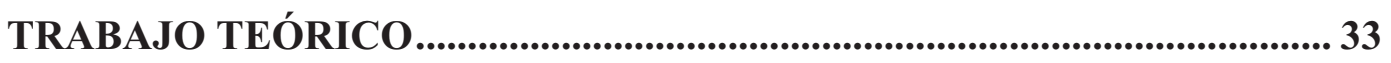

CAPÍTULO I............................................................................................. 35

ADMINISTRACIÓN PÚBLICA Y EFICIENCIA ........................................... 35

ADMINISTRACIÓN PÚBLICA …………………………………………………. 37

LA ADMINISTRACIÓN PÚBLICA EN LA CE...………………………………...... 46

EL PRINCIPIO DE EFICACIA ……………………………………………….... 50

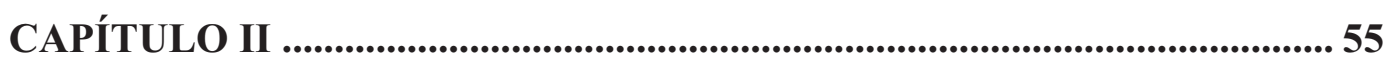

SISTEMA NACIONAL DE SALUD .................................................................. 55

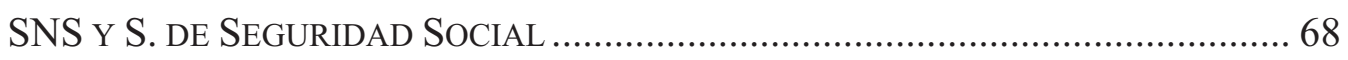

ACTUALIZACIÓN LEGAL EN MATERIA SANITARIA .............................................. 74

RASGOS ESENCIALES DEL SNS ................................................................. 75

PROCESO DE DESCENTRALIZACIÓN............................................................... 80

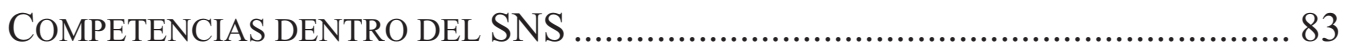

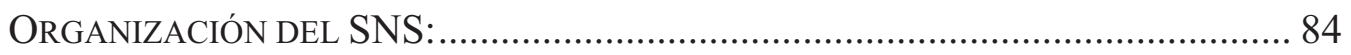

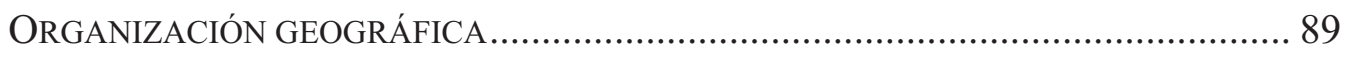

Centros y Establecimientos Sanitarios, Oferta Asistencial.................. 91

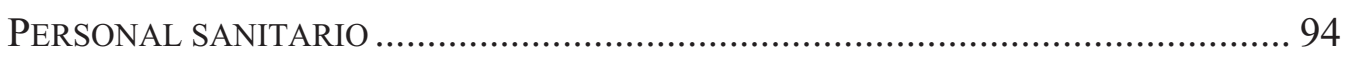

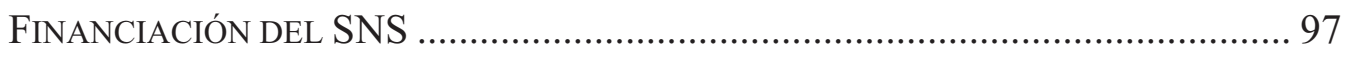

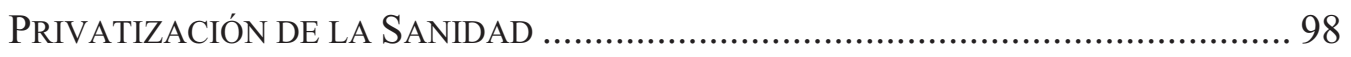

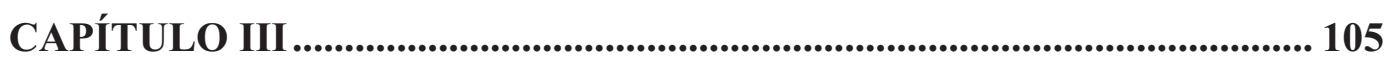

LA FEMINIZACIÓN DE LAS PROFESIONES SANITARIAS .................... 105

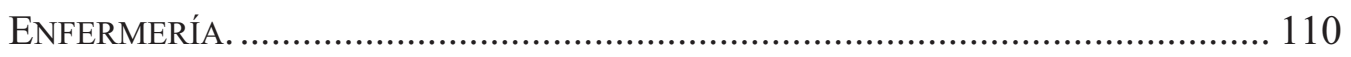

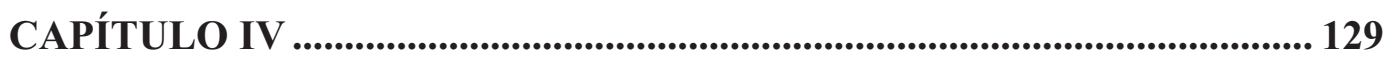

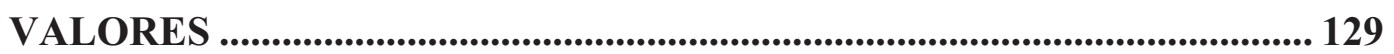

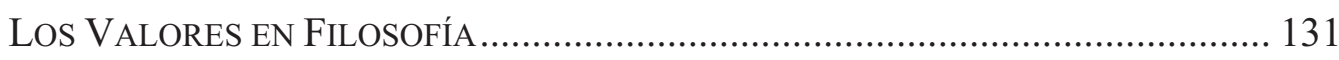

Los VALoRes EN LaS CIENCIAS Sociales. ..................................................... 149 
LOS VALORES EN PSICOLOGÍA 153

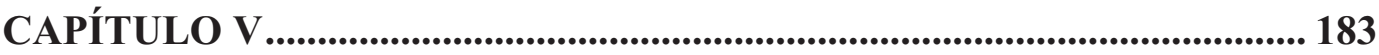

LA DIRECCIÓN POR VALORES (DPV) ................................................... 183

LA DIRECCIÓN POR INSTRUCCIONES (DPI) _.................................................... 185

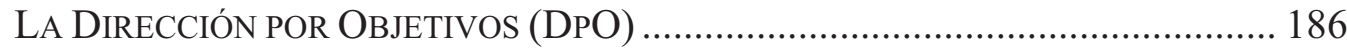

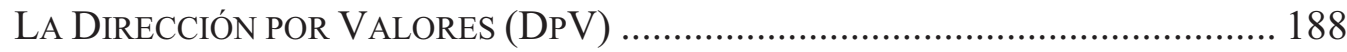

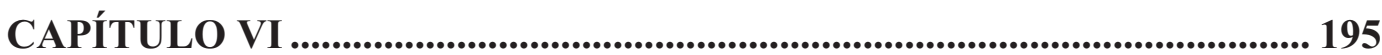

MANIFIESTO DE ESPINOSO DE COMPLUDO....................................... 195

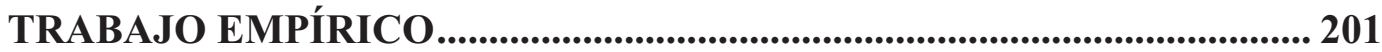

ANÁLISIS DE LAS VARIABLES ............................................................ 203

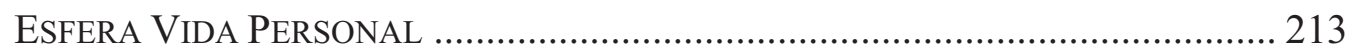

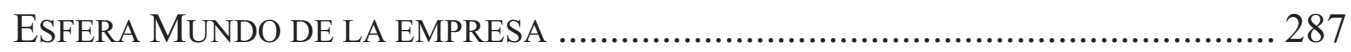

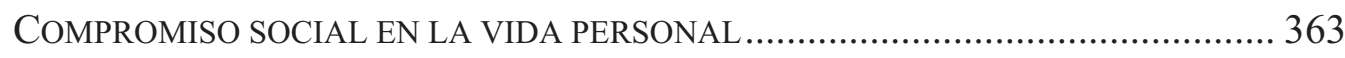

COMPROMISO SOCIAL EN EL M. DE LA EMPRESA …....................................... 373

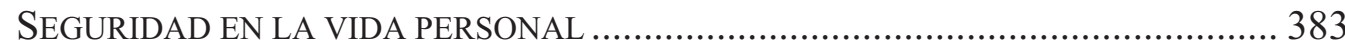

SEGURIDAD EN EL MUNDO DE LA EMPRESA ….................................................. 393

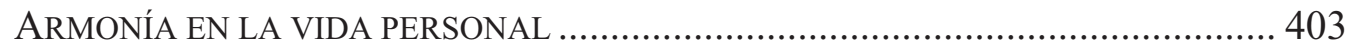

ARMONÍA EN EL MUNDO DE LA EMPRESA ……............................................. 413

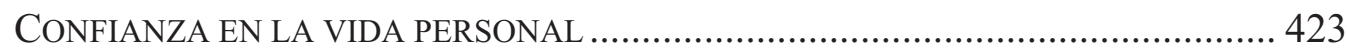

CONFIANZA EN EL MUNDO DE LA EMPRESA …................................................ 435

SostenibILIDAd EN LA VIDA PERSONAL ....................................................... 449

SOSTENIBILIDAD EN EL MUNDO DE LA EMPRESA ............................................ 457

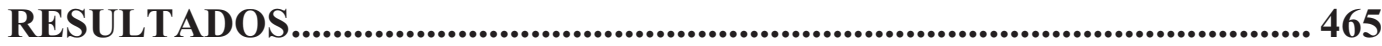

PATRONES DE COMPORTAMIENTO DE LOS VALORES DE COMPROMISO SOCIAL, SEGURIDAD, ARMONÍA, CONFIANZA Y SOSTENIBILIDAD. .................................. 478

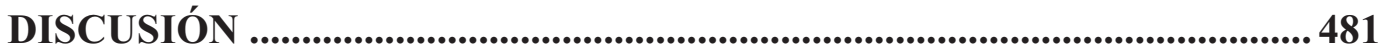

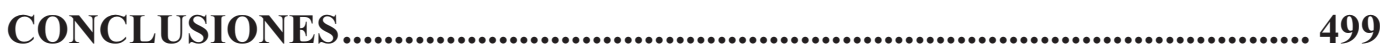

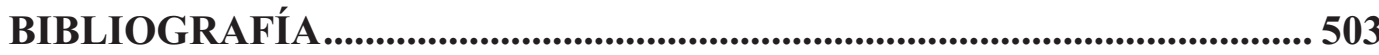




\section{SIGLAS Y ABREVIATURAS}

ACSN: Association of Collegiate Schools of Nursing

AE: Atención Especializada

AP: Atención Primaria

AME: Asociación mexicana de enfermeras

ANA: American Nurses Association

ATS: Ayudante Técnico Sanitario

CatSalut: Instituto Catalán de la Salud

CDTI: Centro para el Desarrollo Tecnológico Industrial

CE: Constitución Española

CISNS: Consejo Interterritorial Del Sistema Nacional De Salud

DpI: Dirección por Instrucciones

DpO: Dirección por Objetivos

DPpO: Dirección Participativa por Objetivos

$\mathrm{DpV}$ : Dirección por Valores

DRAE: Diccionario de la Real Academia de la lengua Española.

DUDH: Declaración Universal de los Derechos Humanos, 10 diciembre de 1948.

DUE: Diplomatura Universitaria en Enfermería.

EAP: Equipo de Atención Primaria.

EEES: Espacio Europeo de Educación Superior.

FDASP: Federación de Asociaciones para la Defensa de la Sanidad Pública

H2020: Horizonte 2020

IB-SALUD: Servicio de Salud de las Islas Baleares

INE: Instituto Nacional de Estadística

INGESA: Instituto Nacional de Gestión Sanitaria

INP: Instituto Nacional de Previsión

INSALUD: Instituto Nacional de la Salud

INSS: Instituto Nacional de la Seguridad Social

ISFAS: Instituto Social de las Fuerzas Armadas

ITV: Inspección Técnica de Vehículos

LGS: Ley 14/1986, de 25 de abril, General de Sanidad 
ME: "en el mundo de la empresa"

ME de C: Manifiesto de Espinoso de Compludo

MUFACE: Mutualidad de Funcionarios Civiles del Estado.

MUGEJU: Mutualidad General Judicial.

NANDA: North American Nursing Diagnosis Association

OMS: Organización Mundial de la Salud

OPS: Organización Panamericana de la Salud

Osakidetza: Servicio Vasco de Salud

Osasunbidea: Servicio Navarro de Salud

PAE: Proceso de Atención de Enfermería

PEIO: Plan Estratégico de Igualdad de Oportunidades 2014-2016

RAE: Real Academia Española de la Lengua

RTC: Repertorio Aranzadi del Tribunal Constitucional

SACYL: Sanidad Castilla y León

salud: Servicio Aragonés de Salud

SAS: Servicio Andaluz de Salud

SCS: Servicio Canario de la Salud

SCS: Servicio Cántabro de Salud

SERGAS: Servicio Gallego de Salud

SES: Servicio Extremeño de Salud

SESPA: Servicio de Salud del Principado de Asturias

SESCAM: Servicio de Salud de Castilla la Mancha

SMS: Servicio Murciano de Salud

SNS: Sistema Nacional de Salud

SOE: Seguro Obligatorio de Enfermedad

STC: Sentencia del Tribunal Constitucional.

VP: "en mi vida personal" 
INTRODUCCIÓN 

El objetivo del presente trabajo es analizar la percepción que tienen los estudiantes de la Diplomatura de Enfermería, como profesión feminizada por excelencia en el ámbito sanitario, de los valores que rigen su propia vida personal así como el mundo de la empresa, en este caso la sanidad desde la perspectiva del discente.

De forma específica nos proponemos el objetivo de establecer los valores que gobiernan la vida personal y el mundo de la empresa - la sanidad — en el campo de estudio: los estudiantes del tercer curso académico de la Diplomatura de Enfermería en las 3 últimas promociones antes de la implantación del título de Grado: cursos académicos 2009-2010; 2010-2011; 2011-2012.

La teoría fundamental que pretendemos defender es: "La eficiencia del Sistema Nacional de Salud se puede mejorar sobre la base de los valores que determinan el comportamiento profesional, todo ello estudiado desde una profesión feminizada: Enfermería."

La presente Tesis Doctoral está estructurada en dos partes: una dedicada a realizar una investigación teórica-doctrinales y otra en la que afrontamos una investigación empírica también llamado trabajo de campo.

Al efectuar las citas en que se basa nuestro trabajo, al tratarse de un estudio interdisciplinar, hemos utilizado el sistema Harvard-APA. Este modelo presenta las citas (apellido del autor, fecha de publicación y página citada) insertadas dentro del texto, por lo que no requiere citas de referencia bibliográfica a pie de página; sin embargo sí incluye citas a pie de página explicativas. Al apellido del autor hemos añadido el nombre de pila para impedir la invisibilización de la mujer investigadora y autora.

En el trabajo teórico nos ocupamos de analizar las distintas partes que componen el título de la tesis: Administración pública y eficiencia, Sistema Nacional de Salud, profesiones feminizadas y valores, siendo este último apartado 


\section{INTRODUCCIÓN}

el núcleo alrededor del cual giran los demás. Todo ello estudiado desde una perspectiva de género.

En el Capítulo I definimos brevemente qué es la Administración Pública y su relación con el concepto de eficiencia. La Administración pública es, siguiendo la definición de GALINDO CAMACHO, Miguel (2000, p. 1), el conjunto de organizaciones públicas encargadas de realizar la administración y la gestión del Estado; de tal forma que la Administración Pública relaciona de forma directa la ciudadanía con el poder político, sirviendo los intereses públicos de forma inmediata.

También estudiamos brevemente la teoría de la burocracia de MAX WEBER como método para hacer eficiente la gestión de las empresas. La burocracia, para Max Weber, es la organización eficiente por excelencia, la organización llamada a resolver racional y eficientemente tanto los problemas de la sociedad como los problemas de las empresas.

Terminamos este primer capítulo poniendo el foco en los conceptos de eficacia, eficiencia, efectividad y excelencia. DRUCKER, Peter (1954) mencionado por Salvador GARCÍA y Shimon DOLAN (1997, p. 22) sostiene que eficiencia es "hacer las cosas que hay que hacer" en contraposición a eficacia que es "hacer bien las cosas que se hacen" y llama la atención al tiempo sobre el esfuerzo dedicado a "ihacer correctamente y bien cosas que no interesa hacer en absoluto!”.

El concepto de eficiencia es más potente e importante que el de eficacia, a la que engloba pues no solo hace referencia a la calidad del resultado sino también a su coste, interrelacionando estas dos variables. URCOLA TELLERÍA, Juan Luis (2000, p. 78) sostiene que eficiencia "es como un pensar continuo sobre como desarrollar el hacer lo que hay que hacer consumiendo los menores recursos posibles". 
Para lograr la eficiencia en el trabajo es necesario contar con colaboradores que puedan, sepan y quieran. En este último factor, el querer, es donde entra la motivación y en la motivación, los valores.

Las empresas públicas, al estar dirigidas a la obtención de un servicio a la sociedad y contar con grandes recursos, no están sensibilizadas a la eficiencia conformándose con ser eficaces. Sin embargo, el SNS, por múltiples razones (importancia de la salud, demanda creciente por parte de la población...) debe imbuirse del concepto de eficiencia que solo se conseguirá mediante una dirección profesional y una gestión motivante de sus recursos humanos.

En el Capítulo II realizamos un estudio tanto diacrónico como sincrónico de la atención a la salud. Vemos el Sistema Nacional de Salud que, según el MINISTERIO DE SANIDAD, SERVICIOS SOCIALES E IGUALDAD, "se configura como el conjunto coordinado de los servicios de salud de la Administración del Estado y los servicios de salud de las Comunidades Autónomas que integra todas las funciones y prestaciones sanitarias que, de acuerdo con la ley, son responsabilidad de los poderes públicos.”

Hacemos un breve repaso del proceso a favor de la protección a la salud que culminará con su reconocimiento como un derecho y la inclusión del mismo a nivel constitucional. Como sostiene LEÓN ALONSO, Marta el proceso de legislación del derecho a la protección de la salud ha sido simultáneo a la gestación y consolidación del Estado social. Además, este derecho entraña la singularidad de representar la superación del antagonismo que se había establecido entre las libertades individuales y los derechos sociales. Por otro lado no se llegó al Estado social de forma fácil o inmediata, sino que vino precedido de la denominada "cuestión social".

FIGUERUELO BURRIEZA, Ángela (1996, p. 241) sostiene que "Se mantiene, prácticamente sin discusión doctrinal alguna, que el modelo del Estado social debe ser entendido como una continuación del Estado Liberal sin que se produzca una ruptura con esta forma de Estado". Sigue diciendo esta autora que se 


\section{INTRODUCCIÓN}

tiene una idea bastante exacta de lo que es el Estado Liberal: aquel en el que el estado no interviene en las relaciones sociales que quedan al libre juego de la autonomía individual, es decir, el mercado. Sin embargo, el concepto de Estado Social no está tan claro, pues no es válida una definición basada en la afirmación de la intervención del sector público, ya que ésta tiene sus límites en la propia sociedad de personas libres en que se asienta cualquier Estado Democrático. El concepto de Estado Social ha de ser por sí mismo impreciso, pues pretende lograr un equilibrio entre libertad e igualdad; "dicho equilibrio está en permanente tensión [...] como corresponde a un sistema político basado en la democracia pluralista".

El Estado Social no implica cambios en la organización del poder propia del Estado Constitucional democrático de Derecho, ya que se trata de una modalidad de esta forma de Estado. "La 'cláusula social' añadida a este Estado no afecta a la estructura sino a los fines, es decir, el Estado asume nuevas tareas como, por ejemplo, salud, educación, vivienda, orden público, seguridad... [...] con ello se pretende proteger a los sectores sociales menos favorecidos a través de una determinada forma de actuar de los poderes públicos." (FIGUERUELO BURRIEZA, Ángela, 1996, p. 242).

De esta forma, en el siglo XIX, surge la legislación social propiamente dicha incluida la legislación en materia sanitaria y van surgiendo los 3 modelos básicos de sistemas sanitarios, que según MARTÍN GARCÍA, Manuel (2015) son:

1) Modelo liberal (libre mercado) que se da en los EEUU. El Estado solamente se encarga de los grupos sociales más desfavorecidos. Los ciudadanos son libres de contratar la cobertura sanitaria que puedan pagar de entre todas las que ofrece el mercado.

2) Modelo socialista (Cuba): la asistencia sanitaria corre total y exclusivamente a cargo del Estado. No están permitidas estructuras sanitarias de tipo privado o de seguros. 
3) Modelo mixto (Europa): coexisten una sanidad pública, a cargo del Estado, y una sanidad privada ofrecida por el mercado y de libre acceso. Este modelo mixto presenta dos variantes:

- Modelo Bismark (seguros sanitarios). Nace en el siglo XIX en Alemania ante las protestas de los trabajadores industriales organizados en cooperativas. El Estado administra y organiza la asistencia sanitaria de los trabajadores que cotizan. Paralelamente existen una asistencia benéfica para los que no cotizan. Da lugar a dos tipos de ciudadanos pues cualquier asistencia benéfica conlleva estigma social. Entraña una gran complejidad administrativa e incita a proveedores y usuarios a multiplicar innecesariamente el número de servicios para ganar más. Es el modelo vigente en Alemania, Francia, Bélgica, Luxemburgo, Holanda y Austria.

- Modelo Beveridge (SNS). Surge a partir del sistema de salud británico en 1948 y está vigente en España, Portugal, Italia, Noruega, Suecia, Finlandia, Dinamarca e Islandia. La financiación, gestión y administración es pública. La prestación se da en condiciones de universalidad, equidad, gratuidad y libertad de acceso de toda la población.

En cuanto al modelo Beveridge, que es el que nos interesa, surge porque durante la II Guerra Mundial, como consecuencia de los acontecimientos bélicos de la primera mitad del siglo XX, se empieza a pensar en proteger la salud de la escasa población que va a sobrevivir a la guerra. Por lo que el 1 de diciembre de 1942 se presenta un informe "Social Insurance and Allied Services" conocido como "el primer Informe Beveridge" que da las pautas para conseguir una sociedad más justa: el informe propone por un lado crear una legislación social más amplia y menos compleja, y por otro lado unificar los sistemas e instituciones sociales y ampliar el campo de los beneficiados, es decir lo que se ha venido en llamar Welfare State o estado del bienestar. Como afirma BOWEN HERRERA, Alfredo (1992, p. 76): "El Informe Beveridge es considerado como la carta de la Seguridad Social contemporánea y provocó un movimiento político-social de tal 


\section{INTRODUCCIÓN}

envergadura que, traspasando los lindes de su propio país, hizo impacto en el campo internacional".

En España, fue la Ley 14/1986, de 25 de abril, General de Sanidad la que determinó el cambio del modelo alemán, Sistema de Seguridad Social o modelo Bismark al modelo anglosajón, Sistema Nacional de Salud, modelo Beveridge. (CALVO SÁNCHEZ, María Dolores, 2008).

Como se ha indicado, esta tesis está redactada utilizando una metodología basada en la perspectiva de género ${ }^{1}$. Por lo cual se estudia desde una profesión tradicionalmente feminizada: Enfermería, a la vez que se analiza la progresiva feminización de otras profesiones sanitarias que venían siendo coto privado masculino, como medicina, odontología, veterinaria... A esto dedicamos el Capítulo III.

Desde esta perspectiva es importante tener en cuenta, como sostiene ORTIZ-GÓMEZ, Teresa (2004) que al igual que la sociedad es algo construido, las profesiones como elementos sociales que son, han sido construidas y practicadas por personas de uno u otro sexo, asociando profesión y características de género como si fuera algo natural e inmutable.

Hasta los siglos XIX y XX en que la mujer consigue acceder a los estudios en la Universidad ${ }^{2}$, las profesiones de médico, boticario y veterinario fueron desempeñadas exclusivamente por hombres, mientras que enfermería y parteras eran practicadas por mujeres como si no pudiese ser de otra manera; pero esto en realidad era la consecuencia de políticas activas y mantenidas de exclusión de la mujer y de su reclusión en nichos laborales. La incorporación de valores a ciertas profesiones consideradas como masculinas ha sido un proceso activo e incluso

\footnotetext{
${ }^{1}$ Debido al uso de la metodología de la perspectiva de género hemos puesto el nombre de pila de los autores citados para impedir la invisibilización de la mujer investigadora.

${ }^{2}$ En España, la Real Orden de 8 de marzo de 1910 permitió el acceso de la mujer a la Universidad española en igualdad de condiciones. Anteriormente, 36 mujeres lo habían conseguido tras solicitar permisos especiales y superar innumerables problemas.(AAVV. Doctas, doctoras y catedráticas, 2010)
} 
cambiante, como ocurrió en los siglos XVIII y XIX con la atención facultativa al parto, reconvirtiendo un espacio tradicionalmente femenino en masculino. Es más, en 1988 la Organización Mundial de la Salud describe como natural lo construido: "En las sociedades occidentales, el estereotipo masculino incluye características tales como la ambición, la competitividad, la agresividad, la dominación, la racionalidad y la objetividad, mientras que el estereotipo femenino se caracteriza por la sumisión, la pasividad, la dependencia, el cuidado de los demás, la emotividad y la subjetividad" (OMS. Función de las mujeres en la asistencia sanitaria. Ginebra. Organización Mundial de la Salud 1988, nº 65. Citado por GARCÍA BAÑóN, Ana María, 2004).

Pero como muy bien apunta Simone de BEAUVOIR en el segundo sexo (2011, p. 45), tomando palabras prestadas de POULAIN DE LA BARRE: "Todo cuanto han escrito los hombres sobre las mujeres debe ser sospechoso, pues son a un tiempo juez y parte".

La feminización no solamente supone una mayor presencia de la mujer sino que trae consigo un cambio de orientación en el ejercicio de la profesión: "La mujer no repite los roles masculinos sino que aporta su singularidad." (VÁZQUEZ VEGA, Pablo, ALBERT LÓPEZ-IBOR, Rocío, C. BOSCH, José Luis, CABRILLO RODRÍGUEZ, Francisco, CHORÉN RODRÍGUEZ, Pilar; et al. 2010, p. 12). Algunos expertos señalan que la mujer presenta en el ejercicio de su profesión una mayor tendencia hacia la prevención y los cuidados, mientras que el perfil masculino se centra más en la curación. Por lo que la feminización de la Sanidad debe estudiarse desde una perspectiva cuantitativa descriptiva pero también desde una perspectiva cualitativa.

Hacemos a continuación un estudio también diacrónico y sincrónico de los cuidados de enfermería y del llamativo cambio de la población sobre la que recaen en función de que presenten un atractivo o supongan una carga.

Hallazgos fósiles como el cráneo desdentado de Dmanisi, en la República caucásica de Georgia, demuestran que hace 1,8 millones de años ya había 


\section{INTRODUCCIÓN}

personas que invertían energía en mantener con vida a miembros físicamente discapacitados del grupo o, dicho de otra manera, que los cuidaban, que prestaban cuidados al servicio de una vida ajena. (PICAS CONTRERAS, Joan, 2006).

Siendo el ser humano un individuo social y gregario, cuya fuerza y hegemonía en la naturaleza estriba en la cooperación y solidaridad, resulta que el cuidado a los demás es una necesidad que ha tenido que existir siempre, y ha recaído, desde que tenemos memoria histórica, principalmente sobre la mujer. El objetivo principal de la mujer cuidadora es el mantenimiento de la vida frente a las adversidades del medio. Como dice COLLIÈRE, Marie Françoise (1992, p. 25) 'Soigner, c'est donc entretenir la vie en assurant la satisfaction d'un ensemble de besoins indispensables à la vie, mais qui sont diversifiés dans leur manifestation".

Sin embargo, las personas de ambos sexos poseen una tendencia innata a actuar frente al desamparo o el riesgo vital, como lo demuestra la creación de la Cruz Roja por parte de un hombre: Henri Dunant, y su reconocimiento social al haberle sido concedido el Premio Nobel de la Paz en 1901.

Algo similar pasa con la aparición, tras la II Guerra Mundial, de las ONG como agentes de desarrollo, basadas en la solidaridad, y su aprobación social: "El reconocimiento definitivo a la labor de las organizaciones solidarias ha alcanzado su punto culminante con la concesión, el 15 de octubre de 1999, en Oslo, del Premio Nobel de la Paz a Médicos Sin Fronteras por su trabajo humanitario profesional, eficaz e independiente.” (PICAS CONTRERAS, Joan, 2006).

DURKHEIM, uno de los padres de la sociología, postula en varias de sus obras - su tesis doctoral La división del trabajo social (1893) y Educación y sociología (1924, obra póstuma) - que es la solidaridad el valor que mantiene unida y cohesionada la sociedad moderna.

Podemos afirmar que el cuidado y la ayuda a los demás no es algo exclusivo de la mujer, aunque haya recaído tradicionalmente en ella tanto a nivel 
familiar como a nivel profesional. Y que ha sido reconvertido en espacio masculino cuando al hombre le ha interesado. Con el cristianismo aparece una nueva cosmovisión en torno a un único Dios omnipotente, padre de un hijo crucificado. La persona enferma, que sufre, es considerada la elegida de Dios; y la enfermedad, un instrumento de salvación, tanto para quien la padece como para quien le cuida. En consecuencia, en la Edad Media aparecen varias órdenes masculinas religioso-militares. Actuaban como guerreros y enfermeros, y fundaron hospicios y hospitales jalonando el camino de la peregrinación a Jerusalén. Cuando el atractivo de la salvación eterna desaparece, los cuidados vuelven a recaer sobre la mujer como si no pudiese ser de otra forma y con las características de altruismo y ausencia de conocimientos teóricos, lo que los mantiene excluidos de la profesionalización. Fue Florence de Nightingale, en el siglo XIX, la que consigue cambiar la situación.

FRAILE CALLE, Luis (2011, p. 101) sostiene que se puede: “considerar enfermería como profesión cuando cumple tres requisitos esenciales: una formación reglada, una retribución por su práctica y un código ético que garantice su ejercicio: hablamos del siglo XIX."

Todavía tendrá que pasar un siglo hasta que dichos estudios entren en la Universidad. En julio de 1977 se aprobó el Real Decreto 2128/77 sobre "Integración en la Universidad de las actuales Escuelas de ATS como Escuelas Universitarias de Enfermería, plenamente integradas en el modelo educativo universitario." De esta forma, la Enfermería pasó de formación técnica a educación académica y el título pasó a denominarse: Diplomatura Universitaria en Enfermería (DUE).

Esto trajo como consecuencias: la disminución de la discriminación entre estudiantes por razón de sexo, el aumento del nivel de estudio tanto para el acceso a los estudios como en cuanto a los contenidos, la aparición del Área de Conocimientos de enfermería y la posibilidad de asumir funciones docentes e investigadoras. Pero la profesión siguió siendo un nicho laboral, pues fuera de la docencia, la única posibilidad de promoción era la supervisión, puestos que han 


\section{INTRODUCCIÓN}

sido confiados con preferencia a enfermeros masculinos, a pesar de las altas tasas de feminización de la profesión.

Con el Proyecto del Espacio Europeo de Educación Superior (E.E.E.S.), se elabora un nuevo modelo de formación de Grado. Las reformas afectan a todos los estudios de las universidades europeas. En el caso concreto de enfermería representa un importante cambio, pues la equipara a todas las demás titulaciones universitarias. Se establece la obtención del título de Grado, quedando abierto el libre acceso al Máster y al Doctorado.

Hoy día asistimos a un proyecto de reforma que volvería a posicionar a la Enfermería como Diplomado medio al plantearse la reforma académica del 3+2; reforma que en nuestra opinión no sería acertada si se llevase a cabo.

El Capítulo IV lo dedicamos al estudio de los valores. Pretendemos tener un adecuado conocimiento del tema central de nuestra tesis. Coincidimos con la opinión de GARCÍA, Salvador y DOLAN, Shimon (1997, p. 67) cuando afirman que "Los valores son palabras. Lamentablemente, en demasiadas ocasiones son sólo eso. Sin embargo, no hay duda de que las palabras que se identifican como valores tienen una especial potencia para dar sentido y encauzar los esfuerzos humanos, tanto a nivel personal como a nivel de empresa".

En 1923, ORTEGA Y GASSET escribía en la Revista de Occidente, de la que era director, un artículo seriado titulado ¿Qué son los valores? Introducción a una estimativa, comenzando con las siguientes palabras: "Desde hace algún tiempo, [...] aparecen con mucha insistencia los vocablos "valores", "valoración", "valorar" [...] La preocupación [...] en torno a los valores es uno de los hechos más hondamente reales del tiempo nuevo.” (ORTEGA Y GASSET, José, 2004, p. 11). En efecto, el estudio de los valores en filosofía arranca a mediados del siglo XIX y va a ocupar la primera mitad del siglo XX, sobre todo, el periodo de entreguerras. 
REMOLINA VARGAS, Gerardo (2005, p. 3) sostiene que: "surgió como una reacción contra la teoría kantiana, que reconocía tan sólo la sensibilidad y la razón e ignoraba la estimativa, facultad de apreciar y preferir.

A continuación, van a ser la Sociología, la Antropología, la Etnología, la Psicología, la Pedagogía, el Derecho, la Dirección de empresas... las que se van a interesar por el estudio de los valores.

Axiología fue el nombre que se le dio a esta rama del saber, del griego axio: valor y logos: tratado.

Pero los valores no son una cosa nueva, han sido una realidad subyacente en todas las culturas y han atraído la atención del ser humano desde los albores de la Historia. Apoyándonos en hallazgos arqueológicos de la antigua Mesopotamia como son los códigos de leyes que se conservan: Ur-Nammu, Lipit-Istar, Eshnunna, y el de Hammurabi, el más reciente (NARDONI, Enrique, 1993) podemos concluir que aquellas sociedades demuestran, a través de estos códigos, su preocupación por el valor Justicia. Hecho análogo acontece con las tablas de la ley de Moisés recordadas en la Biblia.

Estos códigos tienen en común la divinidad como fuente y la piedra como soporte buscando, así, un carácter trascendente y eterno para las normas dadas, con el objetivo de lograr en la población un determinado y perdurable modo de conducta. Idea que resuena a través de los siglos y encuentra eco en la ya clásica definición de valor que da Milton ROKEACH (1918 - 1988) en 1973: "Una convicción o creencia estable en el tiempo de que un determinado modo de conducta o una finalidad existencial es personal o socialmente preferible a su modo opuesto de conducta o a su finalidad existencial contraria.” Definición que Salvador GARCÍA y Shimon DOLAN (1997, p. 63) simplifican de la siguiente manera: "los valores son aprendizajes estratégicos relativamente estables en el tiempo de que una forma de actuar es mejor que su opuesta para conseguir nuestros fines o, lo que es lo mismo, para conseguir que nos salgan bien las cosas". 


\section{INTRODUCCIÓN}

En el siglo XIX, mientras que en Filosofía arranca el estudio de los valores, nace la Sociología como ciencia de la mano de Auguste Comte, Karl Marx, Emile Durkheim y Max Weber, entre otros.

Anteriormente, Thomas Hobbes (1588 - 1679), John Locke (1632 - 1704) y Jean-Jacques Rousseau (1712 - 1778) habían presentado cada uno su particular visión del contrato social. Charles de Montesquieu (1689 - 1755) había aportado su pensamiento y su visión crítica de la sociedad de su tiempo. Por otra parte, Europa estaba convulsionada por el impacto de la Revolución Francesa y por los problemas sociales que la Revolución industrial estaba desencadenando.

En este contexto histórico-científico, Auguste Comte (1798 - 1857), heredero del pensamiento de Henri Saint-Simon (1760 - 1825), para quien había trabajado de secretario junto al historiador Augustin Thierry (1795 - 1856), sostiene que todo conocimiento, tanto filosófico como científico, debe surgir del análisis de los hechos reales verificados por la experiencia. Se establece así el método científico como única base para la obtención rigurosa de conocimiento fiable, en contraposición a la búsqueda de causas últimas y explicaciones de los fenómenos en algo situado más allá de la experiencia (religión, metafísica). Por otro lado, Comte considera que el comportamiento social del ser humano, por su complejidad, merece ser estudiado en una ciencia específica. Surgen el Positivismo y la Sociología. (COMTE, Auguste, 1852)

Para Durkheim, los individuos adoptan e interiorizan los valores y la moral de la sociedad en la que nacen, de tal forma que esta última es más que la simple suma de individuos, pues está dentro y fuera de ellos al mismo tiempo; la sociedad tiene una vida propia que va más allá de las experiencias personales, tiene el poder de determinar los pensamientos y las acciones de los individuos que la componen.

Max Weber no se conforma con la descripción de los fenómenos sociales, quiere comprenderlos, comprender sus razones. El fundamento de esas razones, Weber lo emplaza en los valores. De esta forma establece un importante cambio de perspectiva, porque el objeto de estudio de la sociología weberiana es un sujeto 
con razones subjetivas que varían en función de los valores que tenga. En función de los valores cultivados, se genera una determinada racionalidad que a su vez origina una particular cosmovisión.

Hasta las décadas de los 60-70 del siglo XX, los estudios de lo moral o de los valores en Psicología fueron muy escasos. PÉREZ-DELGADO et al. (1991) justifican este hecho por la coincidencia en el tiempo de varios factores. Por un lado Wundt ${ }^{3}$, fundador de la Psicología científica, excluyó este campo de su laboratorio, no por considerarlo exento de interés, pero sí demasiado complejo para ser tratado experimentalmente; pensaba que su estudio debía realizarse mediante el método histórico-cultural. Así mismo, su discípulo más relevante, Titchener, hizo lo mismo en el continente americano.

Por otro lado, el Conductismo ${ }^{4}$ niega que lo moral esté vinculado a la conciencia como se creía hasta entonces, y que el ser humano tenga plena capacidad para comprenderse a sí mismo y para autogobernarse. El Conductismo afirma que la conducta humana es adquirida y no innata, las reacciones o respuestas que un individuo tiene ante los estímulos son aprendidas. Desde este planteamiento, la conciencia pierde interés de estudio, y por consecuencia también todo lo relacionado con lo moral y con los valores.

En tercer lugar, el Psicoanálisis freudiano no elimina la conciencia, sino que la sustituye por el inconsciente. NUÉVALOS RUIZ, Carmen (2008, pp. 110118) sostiene que en la Psicología moral se pueden diferenciar tres momentos o etapas (despegue, silencio y expansión) y dos posicionamientos u orientaciones sobre la forma en que se desarrolla la moral: externalista e internalista.

\footnotetext{
${ }^{3}$ Wilhelm Maximilian Wundt (1832 - 1920) filósofo y fisiólogo alemán, creó un laboratorio en el que poder estudiar las reacciones psicológicas con métodos similares a los empleados para el estudio de las reacciones fisiológicas. Por ello se le considera el padre y fundador de la Psicología científica.

${ }^{4}$ John Broadus Watson (1878 - 1958), psicólogo americano, fundó la Escuela Psicológica Conductista, inaugurada en 1913 con la publicación de su artículo "La Psicología tal como la ve el Conductista".
} 


\section{INTRODUCCIÓN}

Según la orientación externalista, el proceso de moralización se realiza desde fuera hacia dentro, mediante la transmisión de normas y valores de la sociedad al niño. Es la sociedad la que modela al individuo a su imagen, adoptando el sujeto un rol pasivo dentro de un proceso no racional. Claro exponente de esta corriente es Durkheim, para quien los fenómenos morales son fenómenos sociales.

Las teorías conductistas y freudianas, a pesar de sus diferencias, pueden englobarse, ambas, dentro de la orientación externalista.

La corriente internalista, iniciada por Piaget y continuada por Kohlberg, Carol Gilligan, Nel Noddings... defiende que el proceso de moralización es una construcción cognitiva, continuada y progresiva por parte del individuo quien, de una forma activa, elige, comprende y asume normas y valores ofrecidos por la sociedad. Para estos autores la moral es racional, y solamente se puede desarrollar desde la autonomía. El individuo, mediante unos procesos internos, mediatiza y organiza las influencias que le vienen del exterior.

Como hemos visto, los valores venían siendo estudiados por la Psicología general y social desde principios del siglo XX, pero es fundamentalmente a partir de los años 50 y 60 que el tema cobra importancia debido por una parte, al auge del paradigma educativo cognitivista-piagetiano, y por otra, a las aportaciones de Rokeach y colaboradores (momento de expansión según NUÉVALOS RUIZ, Carmen). La Psicología social estaba más interesada en las actitudes que en los valores; Rokeach, convencido de que para entender las actitudes había que profundizar en los valores, publica en 1973 The Nature of Human Values, y en 1979 Understanding human values. De esta forma, el estudio de los valores entra en el ámbito de la Psicología social cognitivista, evidenciándose la relación existente entre valores, actitudes y conductas.

Dedicamos el Capítulo V a la Dirección de empresas por Valores. 1997 fue un año crucial en el campo de la dirección de empresas. Los profesores Salvador García y Shimon Dolan acuñaron el término Dirección por Valores 
(DpV) al editar, en Barcelona, su obra LA DIRECCIÓN POR VALORES (DpV) El cambio más allá de la dirección por objetivos. Ese mismo año, en San Francisco, aparecía la obra novelada de Kenneth Blanchard y Michael O'connor: Managing by Values.

Siguiendo la obra de García y Dolan, que fue en su momento un superventas, vemos que la dirección por valores es la evolución de otras filosofías de dirección basada en instrucciones u objetivos.

En el Capítulo VI y último de la parte teórica estudiamos el Manifiesto de Espinoso de Compludo. En el año 2003, docentes y gestores de Enfermería de toda España, entre los que se encontraba una codirectora de esta tesis, María Dolores CALVO SÁNCHEZ, se reunieron en Espinoso de Compludo, municipio de Ponferrada, y con intención transformadora acordaron que los valores sobre los que se basa la profesión enfermera son esencialmente tres: Compromiso Social, Seguridad y Armonía. Siendo la Confianza el metavalor central para contribuir a la eficiencia y la humanización.

Desde entonces, en la Universidad de Salamanca, se viene impartiendo docencia en valores en la asignatura de Administración de servicios en Enfermería (código: 15742). Asignatura obligatoria del $3^{\circ}$ curos con una carga lectiva de 4,5 créditos (450 horas).

Aquí empieza nuestro trabajo empírico. Al final de los 3 últimos cursos del plan de Diplomatura (cursos académicos 2009-2010; 2010-2011; 2011-2012) hemos aplicado el cuestionario de valores "MbV-72" de (C) Salvador García, UB y Shimon Dolan, ESADE. Se trata de un cuestionario con 72 ítems en escala Likert del 0 al 5 que evalúa los valores que rigen, según la autopercepción del cuestionado, la propia vida personal y el mundo de la empresa, en este caso la sanidad desde la perspectiva del discente.

Han sido encuestados 209 estudiantes que pertenecen al Campus Miguel de Unamuno de la Universidad de Salamanca. 


\section{INTRODUCCIÓN}

Curso 2009/10: de 88 matriculados, 77 mujeres y 11 hombres; tenemos 64 encuestas. Curso 2010/11: de 92 matriculados, 76 mujeres y 16 hombres; tenemos 70 encuestas. Curso 2011/12: de 88 matriculados, 70 mujeres y 18 hombres; tenemos 75 encuestas.

Entre los 3 cursos suman 268 matriculados, de los cuales 223 son mujeres y 45 hombres. Tenemos 209 encuestas. Las mujeres representan el 83,20\%, y nuestra muestra el $77,98 \%$ de la población total.

En el momento del comienzo de nuestro trabajo, el Grado en Enfermería iniciaba su andadura, por lo que no había aún ningún graduado/a en el mercado laboral. En un futuro, nuestra intención es repetir este estudio en análisis comparativo con estudiantes de Grado.

Por cada cuestionario se obtienen 72 respuestas para la esfera de la vida personal y otras tantas para el mundo de la empresa. Los 72 ítems representan un abanico de valores terminales (relativos a la existencia) e instrumentales (relativos a la conducta). Observamos que dentro del cuestionario hay, dispersos, ítems interrelacionados en cuanto al contenido lo que permite analizar la coherencia de las respuestas dadas por los alumnos/as.

Vemos que los valores de Rokeach están recogidos, tanto los terminales: Felicidad, Respeto, Tiempo libre... como los instrumentales: Cortesía, Honradez, Obediencia, Alegría...

También encontramos ítems relacionados de forma directa con los valores expresados en le Manifiesto de Compludo. Este hecho es de gran importancia para nuestro estudio, por lo que hemos procedido a agrupar los ítems relacionados de forma evidente con los valores recogidos en el Manifiesto de Compludo y a simplificar la escala Likert. Así hemos obtenido un grupo de 8 ítems para el Compromiso social que se desglosa en respeto, dignidad y autonomía. Un segundo grupo para la Seguridad: entorno físico adecuado, calidad y competencia profesional. Un tercer grupo para la Armonía: equilibrio, bienestar, creatividad y 
alegría. Un cuarto grupo para la Confianza y por último un quinto grupo para la Sostenibilidad del sistema pues consideramos que en el momento actual es un valor principal.

Con los datos obtenidos hemos realizado un análisis estadístico descriptivo que hemos llevado a cabo con el programa SPSS.20 trabajando con porcentajes y gráficos de barras. Por cada cuestionario se obtienen 72 respuestas para la esfera de la vida personal y otras tantas para el mundo de la empresa. Así hemos obtenido dos cuadros y sendos gráficos de frecuencias y porcentajes por cada ítem del "Cuestionario de Valores 'MbV-72"”. Un cuadro y su gráfico referidos a "mi vida personal" y otro cuadro con su gráfico para el "mundo de la empresa". En total 144 cuadros con sus gráficos. Hemos coloreado los gráficos en verde y ocre respectivamente, para distinguirlos.

También hemos obtenido 8 cuadros y gráficos para el Compromiso Social en la VP y otros tantos para el ME, y así sucesivamente para la Seguridad (6x2=12), la Armonía (7x2=14), la Confianza $(10 \times 2=20)$, y la Sostenibilidad del Sistema $(5 \times 2=10)$. Sumando los cinco grupos: $16+12+14+20+10$ obtenemos 72 cuadros más sus correspondientes gráficos que sumados a los 144 iniciales forman un total de 216 cuadros con otros tantos gráficos.

Hemos coloreado los gráficos de distintos colores según los grupos de valores, utilizando tonos saturados para el área de la VP y tonos pálidos para el ME. Compromiso social: morado. Seguridad: azul. Armonía: verde. Confianza: rojo. Sostenibilidad: amarillo.

El tema presenta especial interés por varios motivos. Por un lado la calidad como valor en la asistencia sanitaria no debe considerarse un lujo sino un imperativo. Por otro lado, desde que se empezara a impartir docencia en valores en la Escuela de Enfermería de Salamanca, estaba pendiente este trabajo para poder evaluar los resultados y su realización era ya urgente. Los nuevos profesionales demuestran poseer un potencial en valores que deberá tenerse en cuenta cuando se haga planificación estratégica de recursos humanos en el sistema 


\section{INTRODUCCIÓN}

sanitario, ya que teniendo en cuenta estas cualidades contribuiremos a dar un servicio más profesional e inequívocamente más eficiente.

Por otra parte, los temas fundamentales de esta cuestión, salud sostenible y profesión feminizada estudiada a la luz de la perspectiva de género, se encuentran incardinados en la estrategia europea de crecimiento para la presente década: Europa 2020 (E2020), en el Horizonte 2020 (H2020) y en el Plan Estratégico de Igualdad de Oportunidades 2014/1016.

Y La COMUNICACIÓN DE LA COMISIÓN EUROPA 2020. Una estrategia para un crecimiento inteligente, sostenible e integrador. Bruselas, 3.3.2010, presta una especial atención a la mujer y a la salud.

Por otro lado, en 2014 arranca el Plan Estratégico de Igualdad de Oportunidades 2014-2016 (PEIO) que es la respuesta al compromiso del Gobierno español con la igualdad efectiva de mujeres y hombres. El presente trabajo se halla directamente relacionado con dos de los seis objetivos estratégicos del PEIO 2014-2016. 
TRABAJOTEÓRICO 

CAPÍTULO I

ADMINISTRACIÓN PÚBLICA Y

EFICIENCIA 

Nuestra Constitución de 1978 dedica su Título IV a las relaciones del Gobierno y de la Administración, y el artículo 103 y siguientes a la Administración Pública, artículo sobre el que volveremos más adelante, pero veamos antes qué es la Administración pública.

\section{Administración pública}

ÁLVAREZ NEBREDA, Carlos (1998, p.8) define Administración pública como la "Función del Estado que consiste en aplicar las leyes y cuidar de los intereses y el bienestar públicos."

Para GALINDO CAMACHO, Miguel, la Administración pública es el conjunto de organizaciones públicas encargadas de realizar la administración y la gestión del Estado; de tal forma que la Administración Pública relaciona de forma directa la ciudadanía con el poder político, sirviendo los intereses públicos de forma inmediata, a diferencia de los poderes legislativo y judicial que lo hacen de forma mediata.

"El término administración deriva de la palabra latina administratio, onis, administratíone, cuyo significado es administrar, compuesto de los vocablos ad y ministrare que quiere decir servir" (GALINDO CAMACHO, Miguel, 2000, p. 1)

Los antecedentes históricos de la actividad estatal que hoy conocemos con el nombre de Administración o Ciencia de la Administración se remontan lejos en el tiempo. Ya en China, India, en la civilización sumeria, en el antiguo Egipto, en Grecia y en Roma se encuentran textos de carácter comercial, legal y administrativo. Pero es a partir del siglo XVIII cuando aparece como ciencia, tras el establecimiento por parte de los soberanos prusianos de cátedras dirigidas a la enseñanza de las tareas administrativas para los servidores del Estado.

\section{Teoría de la burocracia de Weber}

Max Weber (1864 - 1920) es un referente de especial importancia en el desarrollo de la Administración como ciencia. Sus estudios se aplicaron tanto a lo 
militar como a lo civil: "En el estado moderno, el verdadero dominio, [...] se encuentra necesariamente en manos de la burocracia, tanto militar como civil. Porque también el oficial moderno superior dirige las batallas desde su despacho (Bureau).” (WEBER, Max, 1964, p. 1060). El autor sigue diciendo que el mismo modelo administrativo aparece también en la Iglesia y en la empresa privada.

La burocracia, para Max Weber, es la organización eficiente por excelencia, la organización llamada a resolver racional y eficientemente tanto los problemas de la sociedad como los problemas de las empresas.

El autor, educado en el calvinismo y en el opresivo sistema de la Universidad germánica de su época, observa un paralelismo entre la ética protestante, la organización capitalista del trabajo y el Estado burocrático moderno como modelo de eficacia administrativa.

Para Weber "las religiones construyen el 'ethos' de los individuos, es decir el orden normativo interiorizado, que da forma a la conducta." (ALCOBERRO, Ramón, 2014). Ese 'ethos' no se limita a las ideas, sino que tiene consecuencias sociales; y no surge de individuos, sino de grupos que identifican su ética como un signo distintivo.

Weber considera la burocracia como un tipo de poder. Según el diccionario de la Real Academia de la Lengua, el vocablo burocracia procede del francés bureaucratie, y este de bureau 'oficina, escritorio' y -cratie '-cracia' del griego krátos: gobierno, poder. El DRAE ofrece varios significados para el mismo vocablo, de entre los cuales los primeros son: “organización regulada por normas que establecen un orden racional para distribuir y gestionar los asuntos que le son propios" y "conjunto de los servidores públicos."

El autor define el Poder como "la probabilidad de imponer la propia voluntad dentro de una relación social..." (WEBER, Max, 1964, p. 43)

Para el autor, la autoridad proporciona poder y el poder conduce a la dominación que es "la probabilidad de encontrar obediencia a un mandato" (WEBER, Max, 1964, p. 43). Ahora bien, para que se dé una relación auténtica de poder es imprescindible un mínimo de voluntad de obediencia y el autor sostiene que “'Obediencia' significa que la acción del que obedece transcurre como si el contenido del mandato se hubiera convertido, por sí mismo, en máxima de su conducta $[\ldots]$ sin tener en cuenta la propia opinión sobre el valor o desvalor del 
mandato como tal." (WEBER, Max, 1964, p. 172). Y considera que “El concepto de disciplina encierra el de una 'obediencia habitual' por parte de las masas sin resistencia ni crítica.” (WEBER Max, 1964, p. 43)

Esto lo expresan GARCÍA y DOLAN (1997, p. 132) de forma clara diciendo que "Weber [...] entendía por poder la posibilidad de obligar a los individuos a obedecer aun en contra de su voluntad, mientras que la autoridad se manifiesta al lograr el cumplimiento voluntario de las instrucciones recibidas."

Cuando la dominación se ejerce sobre un amplio número de personas y un vasto territorio, resulta necesario un aparato administrativo para ejecutar las órdenes, y servir como punto de unión entre el gobernante y los gobernados.

Weber describe tres tipos de sociedades y tres tipos de autoridad o dominación:

\section{Tradicional}

En la que el poder de los superiores queda justificado por el carácter sagrado de las tradiciones. El dominio patriarcal del padre de familia o del monarca absoluto representan el ejemplo más puro de autoridad tradicional. En este tipo de sociedades, el Estado o la familia son administrados como una propiedad privada. El poder tradicional no es racional, es hereditario, conservador y rechaza los cambios sociales, pues implican ruptura de las tradiciones.

\section{Carismática}

Justifica la autoridad del líder por las características excepcionales de su personalidad. El poder carismático ${ }^{5}$ tampoco es racional, es inestable, adquiere características revolucionarias, no es transferible y ni hereditario.

\footnotetext{
${ }^{5}$ Weber fue contemporáneo de Von Bismark, un líder muy carismático fundador de la unificación alemana e instaurador de las primeras políticas sociales y de la Seguridad Social como sistema de salud.
} 


\section{Legal, racional o burocrática}

El grupo gobernante es elegido y adquiere autoridad en base a normas o preceptos legitimados por consenso de los que emana el poder de mando. Legitimidad y legalidad se sobreponen pues el orden procede de la ley, entendida esta como norma universal e impersonal. Es propia de las sociedades modernas. Es el tipo de autoridad técnica, meritocrática y administrativa. Se basa en la promulgación, la idea básica radica en el hecho de que las leyes pueden ser promulgadas y reglamentadas libremente por procedimientos formales y correctos, y publicadas para el conocimiento y acatamiento de todos.

La racionalidad burocrática implica la adecuación de los medios a los fines, lo cual significa eficiencia. Una organización es racional si en ella se escogen los medios más eficientes para la consecución de las metas. El término burocratización coincide con el concepto de racionalización. El vocablo racionalismo puede referirse a una visión científica del mundo, huyendo de especulaciones o explicaciones religiosas; o también, como es el caso en la burocratización, puede referirse a la elección de medios racionales en las relaciones interpersonales y su adecuación para el logro de objetivos o metas. "La administración burocrática significa: dominación gracias al saber; éste representa su carácter racional fundamental y específico.” (WEBER, 1964, p. 179).

El autor descubre y describe una serie de propiedades características del modelo burocrático:

\section{Características del modelo burocrático}

\section{a) La legalidad de las normas:}

La organización burocrática existe y se mantiene en base a "un derecho estatuido y a reglamentos concebidos racionalmente" (WEBER, 1964, p. 1061). Estos reglamentos son racionales porque son coherentes con las metas que se quieren alcanzar, y son exhaustivos porque pretenden cubrir toda la organización y todas las situaciones posibles. La legalidad de las normas confiere poder a las personas investidas de autoridad, e impone disciplina a los subordinados 
garantizando la jerarquía. Las normas están escritas para asegurar su conocimiento, interpretación y acatamiento.

\section{b) Formalidad de las comunicaciones:}

Todos los procedimientos de la organización burocrática se realizan y conservan por escrito para garantizar su comprobación.

\section{c) Racionalidad de la división del trabajo:}

La eficiencia de la organización se asegura por una división racional del trabajo. Cada individuo conoce su lugar dentro de la organización, su cargo, sus funciones, sus responsabilidades, su nivel de mando sobre los demás, todo ello para la eficiente consecución de las metas, y para no perjudicar la estructura.

\section{d) Impersonalidad en las relaciones:}

La organización burocrática viene determinada por una estructura permanente en el tiempo ocupada por personas que pasan, de tal forma que las relaciones son impersonales. Los cargos, las funciones, el mando y la obediencia son referidos a la estructura administrativa, y no a la persona que en un determinado momento ocupa un puesto.

\section{e) Jerarquía de autoridad:}

La estructura burocrática es piramidal y jerárquica. Existen diferentes rangos de mando subordinados de abajo a arriba. Cada rango queda supervisado por el inmediatamente superior, a la vez que protegido de su arbitrariedad por las normas escritas.

\section{f) Normalización de los procedimientos:}

Todo el funcionamiento interno de la organización está prefijado de acuerdo a unas normas. Las conductas de las personas están previamente 
reguladas conforme a principios racionales asegurando la disciplina laboral, y el desempeño del cargo.

\section{g) Competencia técnica y meritocracia:}

La elección de las personas se hace en base al mérito y a la competencia. Para acceder a un puesto son necesarios títulos, exámenes, pruebas y concursos que acrediten al aspirante.

\section{h) Especialización de la administración:}

La estructura de la organización burocrática pertenece a la propia organización, nunca a las personas que ocupan los puestos. Existe una total separación entre la propiedad de la organización y la propiedad personal de los funcionarios, quienes no podrán nunca comprar, vender o heredar ni el puesto ni nada que pertenezca a la organización. Cualquier actuación en este sentido es considerada delito.

\section{i) Profesionalización de los funcionarios:}

Los participantes en una organización burocrática deben haber demostrado la adquisición de conocimientos teórico-prácticos, y de destrezas que les capacitan para el desempeño del puesto o cargo a ocupar; por el que perciben un salario que varía en función del puesto ocupado.

\section{j) Previsibilidad del funcionamiento:}

El cuerpo normativo escrito sobre el que se basa la organización burocrática asegura que todos los participantes adecuen su conducta a la norma, lo que garantiza un funcionamiento previsible y eficiente.

\section{Ventajas de la burocracia}

La burocracia ofrece varias ventajas: 


\section{a) Control}

Tener un máximo control de los procedimientos administrativos al respaldar con documentos formales cada uno de ellos.

\section{b) Previsibilidad}

La previsión de su funcionamiento, ya que viene a ser una maquinaria programada y puesta en marcha.

\section{c) Eficiencia}

La Eficiencia se consigue por distintas vías: la racionalidad conduce a la adecuación de los medios a los fines; la especificidad en la definición del cargo y de sus funciones determina rapidez de decisión y de actuación; el carácter escrito de las normas evita discrepancias en su interpretación; la estandarización de las rutinas y procedimientos reduce errores y costes, la claridad y legitimidad de la estructura disminuye fricciones entre las personas; la organización administrativa, al estar desligada de las personas, tiene asegurada su continuidad en el tiempo.

\section{Inconvenientes de la burocracia}

Pero la burocracia ha presentado también grandes deficiencias

\section{a) Rigidez:}

El funcionario se apega a las normas y reglamentos, en cuyo conocimiento y aplicación se siente seguro, por lo que "los intereses y el bienestar públicos", que son por definición los verdaderos fines de la burocracia, pasan a estar al servicio de la norma.

La jerarquía de la organización le confiere poder de decisión al que ocupa el puesto superior. Si la elección por mérito y capacidad no ha sido todo lo correcta de debiera, pueden tomar decisiones quienes no están capacitados para ello, con las consecuencias que de ello se deriven. 
La rutina y estandarización de los procedimientos anulan toda libertad, creatividad e innovación, convirtiendo la burocracia en una estructura estática en el tiempo sin capacidad de adaptación, de evolución. "La burocratización es la 'nueva servidumbre', porque es la servidumbre de la ley." (ALCOBERRO, Ramón, 2014)

\section{b) Lentitud}

El excesivo formalismo y papeleo hace los procesos largos y engorrosos por un exhaustivo control, al pretender formalizar documentalmente todas las operaciones.

\section{Relación de la Ciencia de la administración con otras ciencias:}

Actualmente la burocracia prosigue su desarrollo fundamentalmente en el sector público y en algunas empresas privadas, por lo que al lado de la Ciencia de la Administración Pública existe la Ciencia de la Administración Privada compartiendo características, y oponiendo diferencias que las separan.

GALINDO CAMACHO, Miguel (2000, p. 7) sostiene que "la Ciencia de la Administración Pública se refiere solamente a la actividad de uno de los órganos del Estado: al ejecutivo o administrativo." Y sigue diciendo que aunque es una ciencia ya consolidada firmemente, siempre seguirá guardando una estrecha relación con otras muchas ciencias como:

La Sociología que estudia a los grupos sociales, a la persona dentro del grupo, y las relaciones e interacciones que mantiene con los demás sujetos. El fin de las Administraciones públicas es satisfacer las necesidades de la población, por lo que la relación entre ambas ciencias es de gran importancia.

Economía: es una de las ciencias sociales más importantes en su relación con la Administración pública, pues todas sus tareas y encomiendas dependen de presupuestos monetarios.

Psicología: facilita el conocimiento de la mente humana y el alcance de las relaciones interpersonales, por lo que proporciona herramientas de gran valor al 
momento de seleccionar a las personas que van a formar parte de la administración.

Antropología: proporciona conocimientos sobre el comportamiento del ser humano de forma individual o colectiva.

Matemáticas: fundamentales para cualquier aspecto de la vida. En la esfera profesional, las matemáticas pueden ser más o menos necesarias, pero imprescindibles siempre.

Ingeniería Industrial, Contabilidad e Informática, esta última ha supuesto una revolución en las últimas décadas.

Pero la relación más importante es con la Ciencia Política y con el Derecho.

La Ciencia Política es previa a la Ciencia administrativa, pues la determina y la programa para que esta última materialice los proyectos de la primera. "la Administración pública representa [...] parte de la actividad del Estado llevada a cabo por el titular del Ejecutivo y sus órganos secundarios" (GALINDO CAMACHO, Miguel, 2000, p. 16)

En cuanto a sus relaciones con el Derecho, la Administración Pública está sujeta a varias de sus ramas como el Derecho fiscal, el laboral, el mercantil, el financiero..., pero fundamentalmente con el Derecho Administrativo y con el Derecho Constitucional.

\section{a) Derecho Administrativo:}

Después de la revolución francesa surge el Estado de Derecho. Los poderes constituyentes elaboran una Constitución o Carta Magna a la que se somete el Estado y el pueblo, eliminando de esta forma la arbitrariedad de los poderes públicos. Surge así el Derecho Administrativo que es la rama del Derecho cuyo objetivo es la regulación de la organización y funcionamiento de las administraciones públicas. En este sentido la Administración pública depende del Derecho administrativo de forma directa. Las tareas de la Administración Pública no pueden nunca contravenir las disposiciones del Derecho Administrativo, pues 
se fundan en ellas y desarrollan su contenido concretándolo en los casos particulares que las propias leyes determinan.

Sobre las relaciones entre el Derecho constitucional y la Administración pública léase también a FIGUERUELO, Ángela (2003) Significado y funciones del Derecho constitucional.

\section{b) Derecho Constitucional:}

La Administración pública, al igual que todo el Estado, está supeditada y nunca debe contravenir la Carta Magna, "puesto que la Constitución y el Derecho constitucional determinan la naturaleza, organización, funcionamiento, fines y justificación del Estado, lo que significa la determinación de las atribuciones y funciones del órgano que lleva a cabo la Administración Pública." (GALINDO CAMACHO, Miguel, 2000, p. 12)

\section{La Administración pública en la CE}

Como decíamos al principio, nuestra Constitución de 1978, dedica su Título IV a las relaciones del Gobierno y de la Administración, y el artículo 103 dice así:

1. La Administración Pública sirve con objetividad los intereses generales y actúa de acuerdo con los principios de eficacia, jerarquía, descentralización, desconcentración y coordinación, con sometimiento pleno a la ley y al Derecho.

2. Los órganos de la Administración del Estado son creados, regidos y coordinados de acuerdo con la ley.

3. La ley regulará el estatuto de los funcionarios públicos, el acceso a la función pública de acuerdo con los principios de mérito y capacidad, las peculiaridades del ejercicio de su derecho a sindicación, el sistema de incompatibilidades y las garantías para la imparcialidad en el ejercicio de su funciones. (CE, 1978)

Estas pocas líneas encierran tanto contenido que merecen una especial atención. Para ello nos vamos a apoyar en el comentario, que de este artículo, 
hace BAENA DEL ALCÁZAR, Mariano, en la obra dirigida por ALZAGA VILLAAMIL, Oscar (1985).

El autor comenta que el artículo 103, a través de sus tres puntos, hace una declaración de lo que hace y cómo lo hace la Administración pública, de lo que es, y de quién la sirve o constituye, incluyendo la importante e imprescindible precisión de su sometimiento a la ley y al Derecho. Así pues, "el artículo 103 es el fundamento jurídico de los textos legales que hayan de dictarse sobre la Administración y sobre el régimen de sus funcionarios." (BAENA DEL ALCÁZAR, Mariano, 1985, p. 254)

El artículo 103 no es el único que se refiere a temas administrativos, pero sí el primero, y su ubicación en el texto constitucional revela una posición estratégica elegida por el legislador. Al estar incluido en el Título IV: del Gobierno y de la Administración, y precedido por el artículo 97 (el que inicia dicho Título), según el cual "El Gobierno dirige [...] la Administración civil y militar..." quedan claras dos cosas: la subordinación de la Administración al Gobierno, y la diferencia entre Gobierno y Administración. "Según el texto constitucional se trata de cosas diferentes, siendo una, instancia superior de la otra, y regulándose ambas en artículos distintos.” (BAENA DEL ALCÁZAR, Mariano, 1985, p. 255)

Esta idea presenta dos matices. Uno se refiere a la línea de separación entre Gobierno y Administración que pasa por la figura individual del ministro como jefe de su Departamento. La otra idea es la indudable continuidad entre Gobierno y Administración que configuran un conjunto orgánico. Esto queda demostrado por su inclusión en el mismo Título y por el hecho de que el texto constitucional dedique su Título III a las Cortes, el VI al poder Judicial, y no haga alusión al poder Ejecutivo como tal, sino a este conjunto que ocupa el Título IV, dejando, a la vez, clara la relación jerárquica entre ambas estructuras.

\section{Conexión con otros preceptos constitucionales}

Lo primero que hay que decir es que el artículo que nos ocupa es el primero de otros varios dedicados a temas administrativos. Si consideramos el 
artículo dentro del Título IV se observan dos partes: del 97 a 102 se refieren al Gobierno y del 103 al 107 a los temas de la Administración.

El 97 trata del Gobierno, el 98 de la composición y estatuto del Gobierno, el 99 del nombramiento del Presidente del Gobierno, el 100 del nombramiento de los Ministros, el 101 del cese del Gobierno, el 102 de la responsabilidad de los miembros del Gobierno.

El 103 trata de la Administración pública y del Estatuto de los funcionarios públicos.

El artículo 104 trata de la Fuerzas y Cuerpos de seguridad del Estado, el 105 de la participación de los ciudadanos, el 106 del control judicial de la Administración y el 107 del Consejo de Estado.

En cuanto a los artículos externos al Título IV relacionados con el 103, el de mayor interés puede ser el artículo 9, clave interpretativa del sistema político español. El artículo 9 declara, en su punto 1, que "Los ciudadanos y los poderes públicos están sujetos a la Constitución y al resto del ordenamiento jurídico”. El punto 2 dice que "Corresponde a los poderes públicos promover [...] la libertad y la igualdad [...] remover los obstáculos [...] facilitar la participación de todos los ciudadanos...", y el punto 3: "La Constitución garantiza el principio de legalidad [...] y la interdicción de la arbitrariedad de los poderes públicos."

En cuanto al control de los Poderes públicos, el artículo 103 se relaciona con el 106, referido al control judicial de la Administración; con el 136, que trata del Tribunal de Cuentas relativas al control financiero, y con el artículo 54 que instituye la figura del Defensor del Pueblo, a quien corresponde supervisar la actividad de la Administración.

Ya hemos visto como dentro del Título IV se hace mención del Consejo del Estado y de los altos cargos de la Administración. El artículo 154 trata de otro punto de la escala jerárquica, del Delegado del Gobierno en las Comunidades Autónomas. 


\section{La pluralidad de las administraciones: la extensión del precepto}

Son varios los ámbitos administrativos que existen en España y que están reflejados en la Constitución, pero no identificables plenamente con la Administración central civil del Estado; tal es el caso de las Administraciones autónomas: el municipio, la provincia y las Comunidades a las que la CE dedica su Título VIII. Además existen otras estructuras administrativas estatales que no se pueden identificar con la Administración central civil, planteándose la duda de si el artículo 103 es también aplicable a todas estas organizaciones administrativas.

BAENA DEL ALCÁZAR diferencia entre Ejército y Fuerzas Armadas en su aspecto institucional y castrense por un lado, y la organización administrativa necesaria para que los Ejércitos existan por otro; sería esta última a la que sí se le puede aplicar el artículo 103.

En cambio, La Casa Civil del Rey, el Patrimonio Nacional, las Cortes Generales, el Consejo General del Poder Judicial y el Tribunal Constitucional disponen de sus propias organizaciones administrativas que no se pueden confundir con la Administración a que se refiere el artículo 103.

En cuanto a las organizaciones administrativas de los municipios, provincias y Comunidades autónomas, BAENA DEL ALCÁZAR (1985, p. 206) sostiene que "deberán atenerse a la regulación del artículo 103".

\section{Los principios de organización}

Los "principios de organización" tienen un valor convencional tanto en la doctrina norteamericana como en la doctrina jurídica europea, si bien, ambas doctrinas ven la realidad desde perspectivas diferentes.

En la teoría norteamericana de la organización, los principios son las ideas centrales de la organización administrativa y son los de jerarquía, funcionalidad o especialización, coordinación y control, y distribución de los órganos entre estado mayor y línea jerárquica. 
Para la doctrina jurídica europea, los principios son reglas de las que se derivan importantes consecuencias para los efectos jurídicos de los actos. En España, los principios básicos de organización son los de unidad, jerarquía, competencia y coordinación.

Considerando el enunciado del artículo 103, vemos que se mencionan los principios de jerarquía y de coordinación, considerados por la doctrina jurídica tanto norteamericana como europea. Se menciona el principio de desconcentración que no es más que una alteración del de competencia. También es mencionado el de descentralización, pero no se alude a los principios doctrinales de unidad y de control.

En cambio, sí se incluye el principio de eficacia, que "no es un verdadero principio, sino un criterio general [...] pues de este deber no se desprende ninguna consecuencia en la práctica ni para la comprensión de lo que sea la Administración pública ni para el valor jurídico de sus actos y la garantía del ciudadano frente a ellos.” (BAENA DEL ALCÁZAR, 1985, p. 206)

\section{El principio de Eficacia}

El principio de eficacia, si bien no es un principio doctrinal ni norteamericano ni europeo, sí ha sido tenido en cuenta por la Jurisprudencia. Así vemos que en la STC 22/1984, de 17 de febrero (RTC 1984, 22) se dice: “...el art. 103 reconoce como uno de los principios a los que la Administración Pública ha de atenerse es el de eficacia 'con sometimiento pleno de la Ley y al Derecho'..." (PULIDO QUECEDO, Manuel, 1993, p. 1185)

Igualmente, en la STC 178/1989, de 2 de noviembre (RTC 1989, 178) podemos leer:

"No han tenido en cuenta los demandantes un principio esencial, sancionado constitucionalmente en el art. 103. 1, de la propia Carta fundamental, que debe presidir [...] toda la actuación de la Administración pública, y por lo tanto la de su elemento personal (los funcionarios y, en general, los empleados públicos): El principio de "eficacia". Un principio que debe presidir, como es obvio, lo que es previo a la actividad administrativa, la "organización” y, en 
consecuencia, el aparato burocrático o, dicho de otro modo, el régimen de la función pública, entendida ésta en sentido amplio." (PULIDO QUECEDO, Manuel, 1993, p. 1186)

La Eficacia, como principio exigido o impuesto a la Administración pública, no solamente está recogido en el art. 103 de la CE.

La Ley 14/1986, de 25 de abril, General de Sanidad desarrolla el art. 43 de la CE referido a la protección de la salud. De esta manera, la Administración sanitaria aparece como Administración institucional. ÁLVAREZ NEBREDA, Carlos (1998, p. 8) la define como: “Autoridad gubernamental competente para aplicar y hacer cumplir, en un ámbito territorial determinado, las medidas sanitarias establecidas por disposición legal. Proceso de planificación, organización, dirección, control y coordinación de los recursos sanitarios."

La Administración sanitaria se rige, como hemos dicho, por el art. 43 de la CE y por la Ley 14/1986, de 25 de abril, General de Sanidad, cuyo art. 7 dice: "Los servicios sanitarios, así como los administrativos, económicos y cualesquiera otros que sean precisos para el funcionamiento del Sistema Nacional de Salud, adecuarán su organización y funcionamiento a los principios de eficacia, celeridad, economía y flexibilidad.” Y recientemente por el R.D. Ley 16/2012, de 20 de abril, de medidas urgentes para garantizar la sostenibilidad del SNS, cuyo preámbulo dice "son necesarias reformas que permitan reforzar la sostenibilidad, mejorar la eficiencia en la gestión, promover el ahorro y las economías de escala, introducir nuevas herramientas a través de las nuevas tecnologías, ganar en cohesión territorial, coordinar los servicios sanitarios y los sociales y, sobre todo, garantizar la igualdad de trato en todo el territorio nacional con una cartera básica de servicios comunes."

Observamos que el art. $103 \mathrm{CE}$ y el art. 7 de la LGS coinciden en el principio de eficacia. El art. 7 de la LGS añade el de economía.

Según el diccionario etimológico COROMINES, el vocablo economía apareció en la lengua castellana en 1607; y procede del latín oeconomia y este del griego oikonomía que significa 'dirección o administración de una casa', derivado de oikonómos 'administrador', 'intendente', compuesto de ôikos 'casa' y némo 'yo distribuyo, administro'. El diccionario COROMINES no tiene ninguna entrada para eficacia. 
El diccionario de la Real Academia de la Lengua ofrece como primer significado de economía "administración eficaz y razonable de los bienes", y define eficacia como la "capacidad de lograr el efecto que se desea o se espera."

Por el decreto 43/2009, de 2 de julio, se regula la carrera profesional del Personal Estatutario de los Centros e Instituciones Sanitarias del Servicio de Salud de Castilla y León (Sacyl). En el glosario de términos ${ }^{6}$ adjunto aparecen las siguientes definiciones:

"Eficacia: medida del grado de realización de las actividades planificadas, lográndose en consecuencia los resultados planificados.

Eficiencia: medida del grado de productividad entre los resultados alcanzados y los recursos utilizados.

Efectividad: capacidad de lograr el efecto que se desea o se espera.

Excelencia: prácticas sobresalientes en el desempeño profesional. Es el máximo nivel de calidad al que puede llegar un profesional, organización, etc."

DRUCKER, Peter (1954) mencionado por Salvador GARCÍA y Shimon DOLAN (1997, p. 22) sostiene que eficiencia es "hacer las cosas que hay que hacer. En otro sentido, la 'eficacia' la entiendo como: hacer bien las cosas que se hacen, y llamo la atención, por contraste, sobre el caso en que se dedica tiempo y esfuerzo a ¡hacer correctamente y bien cosas que no interesa hacer en absoluto!”

El concepto de eficiencia es más potente e importante que el de eficacia, a la que engloba pues no solo hace referencia a la calidad del resultado sino también a su coste, interrelacionando estas dos variables. URCOLA TELLERÍA, Juan Luis (2000, p. 78) sostiene que eficiencia "es como un pensar continuo sobre como desarrollar el hacer lo que hay que hacer consumiendo los menores recursos posibles."

Para lograr la eficiencia en el trabajo es necesario contar con colaboradores que puedan, sepan y quieran. En este último factor, el querer, es donde entra la motivación y en la motivación los valores.

\footnotetext{
${ }^{6}$ Sacyl declara utilizar "como referente básico la norma española para el vocabulario de gestión y aseguramiento de la calidad (UNE-EN-ISO 9000:2000), (UNE-EN-ISO 8402), y como ayuda el diccionario de la Real Academia de la Lengua (DRAL), además de las normas sanitarias vigentes”
} 


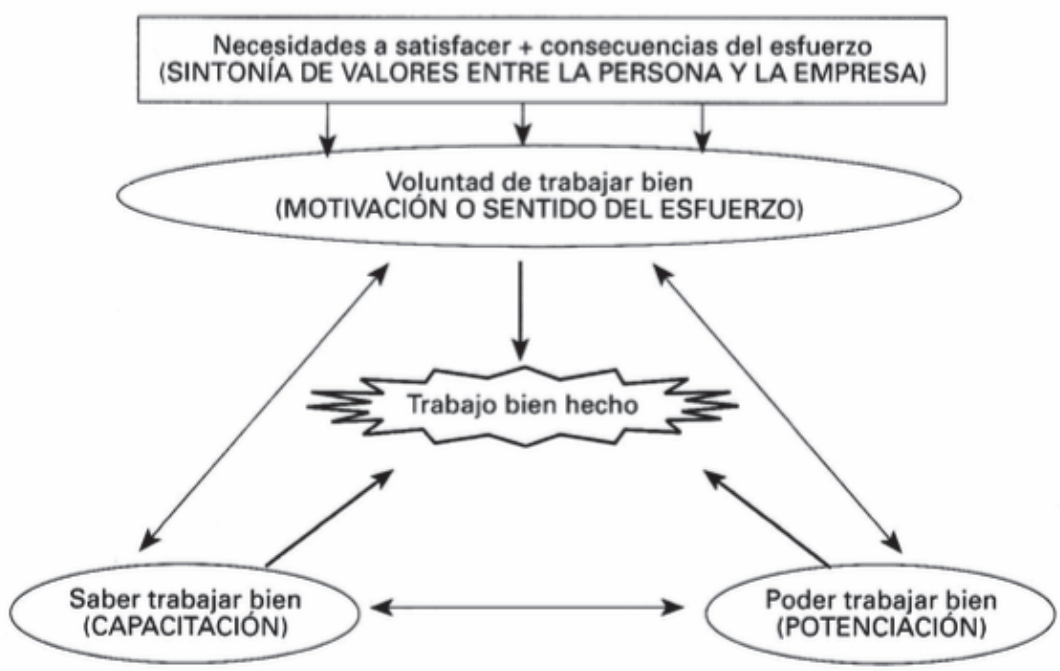

Figura 1.11. La triada clásica para el trabajo bien hecho: poder, saber y querer.

Fuente: de GARCÍA y DOLAN 1997, p. 51

Las empresas públicas, al estar dirigidas a la obtención de un servicio a la sociedad y contar con grandes recursos, no están sensibilizadas a la eficiencia conformándose con ser eficaces. Sin embargo, el SNS, por múltiples razones (importancia de la salud, demanda creciente por parte de la población...) debe imbuirse del concepto de efíciencia que solo se conseguirá mediante una dirección profesional y una gestión motivante de sus recursos humanos.

Llegados a este punto, vamos a centrarnos en el estudio de la Administración pública de carácter institucional que nos interesa: el Sistema Nacional de Salud, su eficiencia y su sostenibilidad. 



\section{CAPÍTULO II}

Sistema NaCiOnAL De SALUd 

El Ministerio de Sanidad, Servicios Sociales e Igualdad comienza su obra: “Sistema Nacional de Salud. España 2012” con estas palabras:

\section{"LA PROTECCIÓN DE LA SALUD EN ESPAÑA:}

La Constitución Española de 1978 establece, en su artículo 43, el derecho a la protección de la salud y a la atención sanitaria de todos los ciudadanos.

La regulación de las acciones que permiten hacer efectivo el derecho a la protección de la salud se recogen en un conjunto de normas con rango de Ley: Ley General de Sanidad (1986), Ley de cohesión y calidad del Sistema Nacional de Salud (2003), Ley de garantías y uso racional del medicamento (2006), Ley General de Salud Pública (2011) y el Real Decreto-Ley de medidas urgentes para la sostenibilidad del Sistema Nacional de Salud y mejora de la calidad y la seguridad (2012).

Los principios y criterios sustantivos que permiten el ejercicio de este derecho son:

- Financiación pública, universalidad y gratuidad de los servicios sanitarios en el momento del uso.

- Derechos y deberes definidos para los ciudadanos y para los poderes públicos.

- Descentralización política de la sanidad en las comunidades autónomas.

- Prestación de una atención integral de la salud procurando altos niveles de calidad debidamente evaluados $\mathrm{y}$ controlados.

- Integración de las diferentes estructuras y servicios públicos al servicio de la salud en el Sistema Nacional de Salud.

El Sistema Nacional de Salud - SNS - se configura como el conjunto coordinado de los servicios de salud de la Administración del Estado y los servicios de salud de las Comunidades Autónomas que integra todas las funciones y prestaciones sanitarias que, de acuerdo con la ley, son responsabilidad de los poderes públicos."

Sin embargo, la protección de la Salud no empezó en 1986 con la Ley General de Sanidad ni en 1978 con la Constitución Española. Lo que hemos transcrito es el final de un largo proceso que comienza con la existencia del propio ser humano, y se desarrolla fundamentalmente a partir del siglo XIX. 
Francisco Tomás y Valiente, maestro e historiador, decía que una breve reseña histórica nos ayuda a comprender mejor el momento, y sobre este pensamiento empezamos este epígrafe.

Todas las sociedades prestaron un gran interés a los problemas de salud. La búsqueda de remedios, a veces eficaces, otras no, ha sido una prioridad para el ser humano. Ante las epidemias se recurría a medidas de aislamiento (cuarentenas, cierre de murallas, exclusión de los enfermos contagiosos...), para contener la enfermedad y proteger a la población sana. La preocupación por la salud individual y colectiva ha sido una constante a lo largo de la historia, pues "El estado de salud es un indicador fundamental del bienestar social y condición imprescindible para el desarrollo económico de un país." (INFORME BAMBERG, 2011, p. 18)

Desde la Alta Edad Media hasta finales del siglo XVIII se consideraba que la asistencia al individuo pobre y enfermo era un acto de caridad, y había sido institucionalizado por parte de la Iglesia, fundándose hospitales a tal fin; pero la falta de criterios equitativos para proporcionar ayudas requirió la intervención civil.

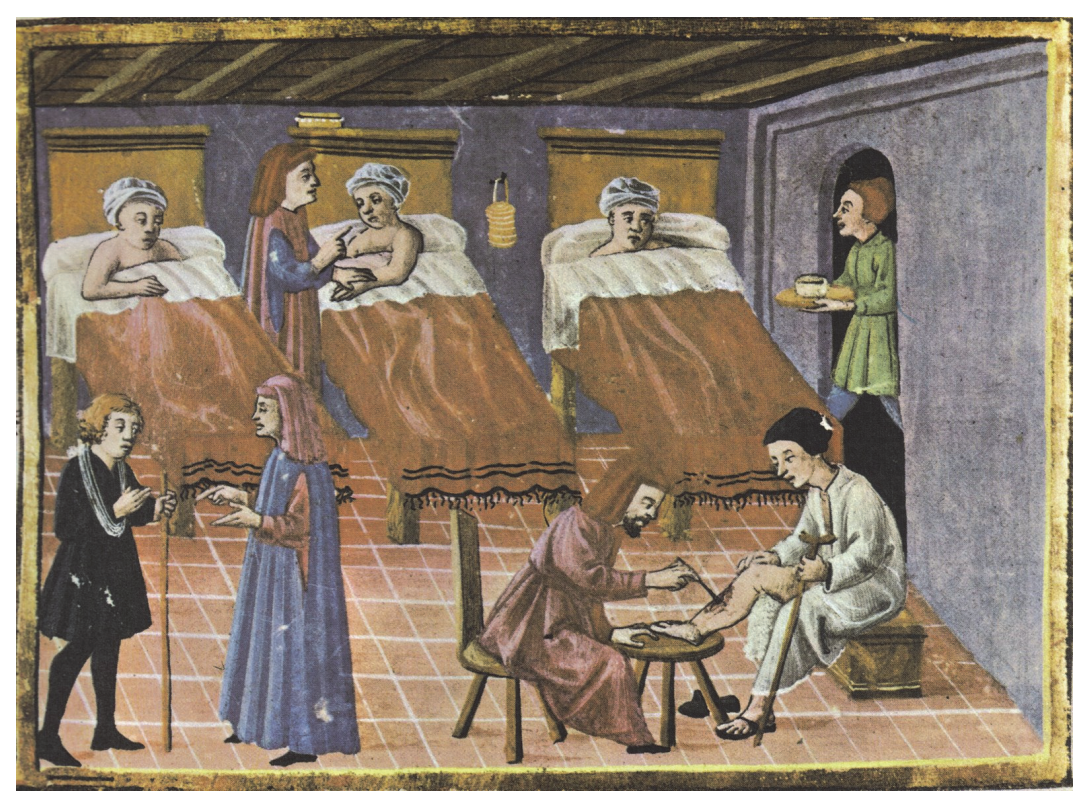

Hospital medieval, siglo XV. Miniatura del códice 2470 de la Biblioteca Laurenciana (Florencia) Disponible en: http://index-f.com/gomeres/?p=390 Consultado: agosto de 2015 
La Primera República Francesa (1792-1804) planificó la creación de Socorros públicos, pasando la asistencia pública a ser considerada como un deber de la Nación. Pero el Estado protector revolucionario no sobrevivió. Incluso así, sus ideales habían sentado las bases de la asistencia sanitaria laica.

La vacuna de la viruela, descubierta por Jenner en 1796, se extendió rápidamente por el mapa mundial. En 1804, Napoleón funda 'la Société de la vaccine': 'Le Premier Consul, donc, charge le ministre de l'Intérieur, Chaptal, de mettre en place les instruments nécessaires à la diffusion de la vaccine [...] par des campagnes de vaccination des enfants dans chaque canton, sistématiquement l'un après l'autre et de ne pas s'en tenir aux classes aisées, mais de la répandre dans tout le peuple. (BIRABEN, Jean Noël, 1979, p. 273)

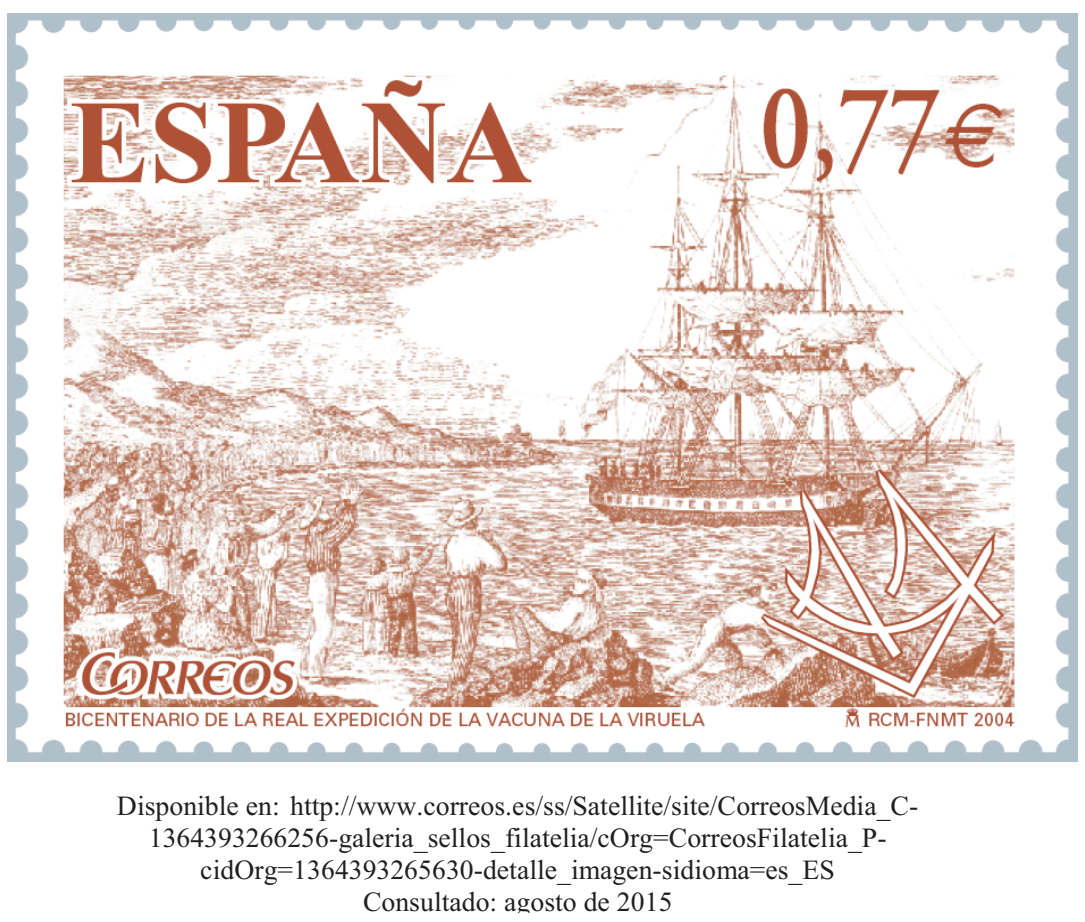

También en 1804, un médico español, Francisco Javier Balmis, puso en marcha la campaña de vacunación más importante hasta aquel momento: 'la Real 
Expedición Filantrópica de la Vacuna', conocida como Expedición Balmis, que duró desde 1803 hasta 1814, y cuyo objetivo era vacunar a toda la población infantil del Imperio Español. Esta campaña sanitaria fue apoyada por el rey Carlos IV y financiada con fondos públicos, por lo que es considerada como la primera expedición sanitaria internacional de la historia. (BALAGUER PERIGÜELL, Emilio, BALLESTER AÑÓN, Rosa, 2003)

Comienza así, desde principios del siglo XIX, un largo proceso a favor de la protección de la salud que culminará con su reconocimiento como un derecho y la inclusión del mismo a nivel constitucional. Sobre este tema se puede leer a FIGUERUELO BURRIEZA, Ángela (1996) Los derechos fundamentales en el estado social y su eficacia en las relaciones privadas así como a LEÓN ALONSO, Marta (2009) La protección constitucional de la salud en el marco del Estado social y democrático de Derecho. En palabras de LEÓN ALONSO (p. 37):

"El reconocimiento del derecho a la protección de la salud en las Constituciones contemporáneas representa la culminación de un largo proceso que se inició hace ya más de dos siglos. Desde la asistencia sanitaria benéfica, pasando por los seguros de enfermedad obligatorios de inspiración bismarckiana, se ha llegado, finalmente, a la consagración a nivel constitucional de uno de los derechos más característicos del constitucionalismo contemporáneo. El derecho a la protección de la salud es, sin lugar a dudas, uno de los derechos sociales por antonomasia."

La autora describe como el proceso de legislación del derecho a la protección de la salud ha sido simultáneo a la gestación y consolidación del Estado social. Además, este derecho entraña la singularidad de representar la superación del antagonismo que se había establecido entre las libertades individuales y los derechos sociales. Por otro lado no se llegó al Estado social de forma fácil o inmediata, sino que vino precedido de la denominada "cuestión social”. LEÓN ALONSO, Marta (2009, p. 39) cita a BALAGUER CALLEJÓN (2002, p. 93) quien indica que "el Estado liberal surge de un proceso revolucionario en el que los vencedores imponen sus condiciones, mientras que el 
Estado social surge del pacto en el que los otrora vencedores mantienen una posición de ventaja."

Por lo tanto, tras la caída del Antiguo Régimen, surge un Estado liberal abstencionista y una sociedad que se cree dotada de un orden espontáneo y de una racionalidad inmanente ("la mano invisible" de Adam Smith, el "laisser faire, laisser passer, le monde va de lui même" de Vincent de Gournay). De esta manera surge el capitalismo con sus grandes monopolios financieros que polarizan los medios de producción y los recursos económicos, mientras que el proletariado y el excedente de la población rural experimentan un progresivo proceso de depauperación y alienación. Los conflictos sociales se multiplican y los Estados se ven obligados a intervenir surgiendo así el Estado social.

FIGUERUELO BURRIEZA, Ángela (1996, p. 241) sostiene que "Se mantiene, prácticamente sin discusión doctrinal alguna, que el modelo del Estado social debe ser entendido como una continuación del Estado Liberal sin que se produzca una ruptura con esta forma de Estado". Sigue diciendo esta autora que se tiene una idea bastante exacta de lo que es el Estado Liberal: aquel en el que el estado no interviene en las relaciones sociales que quedan al libre juego de la autonomía individual, es decir, el mercado.

Sin embargo, el concepto de Estado Social no está tan claro, pues no es válida una definición basada en la afirmación de la intervención del sector público, ya que esta tiene sus límites en la propia sociedad de personas libres en que se asienta cualquier Estado Democrático. El concepto de Estado Social ha de ser por sí mismo impreciso, pues pretende lograr un equilibrio entre libertad e igualdad; "dicho equilibrio está en permanente tensión [...] como corresponde a un sistema político basado en la democracia pluralista."

El Estado Social no implica cambios en la organización del poder propia del Estado Constitucional democrático de Derecho, ya que se trata de una modalidad de esta forma de Estado. 'La 'cláusula social' añadida a este Estado no afecta a la estructura sino a los fines, es decir, el Estado asume nuevas tareas como, por ejemplo, salud, educación, vivienda, orden público, seguridad... [...] con ello se pretende proteger a los sectores sociales menos favorecidos a través de una determinada forma de actuar de los poderes públicos.” (FIGUERUELO BURRIEZA, Ángela, 1996, p. 242) 
De esta forma, en el siglo XIX, surge la legislación social propiamente dicha incluida la legislación en materia sanitaria.

En España, las Cortes de Cádiz se muestran muy desorganizadas en materia de salud lo que origina una carencia de legislación adecuada. A pesar de todo, queda sentada la base de considerar la Sanidad pública como una función de los entes locales.

A lo largo del siglo XIX, la intervención de los poderes públicos en salud se centró en dos puntos: Salud exterior y Salud pública, esta última incluía la higiene de la población, los saneamientos de focos de infección, la policía sanitaria mortuoria, la estadística sanitaria y el control de medicamentos. En cuanto a la salud individual, se procuró ayudar a las personas más necesitadas a través de la Beneficencia que llevaba implícito un estigma social.

Para regular estas cuestiones se fueron aprobando una serie de normas:

\section{Primeras normas sanitarias}

En 1822, se realiza el primer intento: el proyecto de Código Sanitario que no llegó a ver la luz por dudas de carácter técnico-sanitario sobre la eficacia de las medidas propuestas, pero también por protestas de los liberales y por el carácter centralizador del Código en un momento de tendencia descentralizadora.

En 1823 se aprueba la Instrucción para el gobierno económico y político de las provincias, regulando entre otras cosas lo que acabarán siendo los servicios sanitarios locales, dando instrucciones para que en cada municipio haya médico y veterinario.

En palabras de LEÓN ALONSO, Marta (2009, p. 51): "Esta es la primera vez que la Administración asume el cuidado de la salud individual y la primera manifestación de la actividad sanitaria de carácter asistencial”

En 1855 se aprueba la Ley de Sanidad que a pesar de su mediocridad, perdurará largo tiempo:

"Esa ley extenderá su vigencia durante una larguísima época, aunque no en razón a sus excelencias sino a la imposibilidad de llegar a un acuerdo sobre un nuevo texto de ley sanitaria, cuya formulación 
se ensayó con reiteración durante los últimos años del siglo XIX y primeros del XX sin conseguir definitiva aprobación" (LEY GENERAL DE SANIDAD, 1986, EXPOSICIÓN DE MOTIVOS).

Sigue explicando LEÓN ALONSO, Marta que en cuanto a la Beneficencia, el Estado elaboró una serie de normas: Ley Orgánica de Beneficencia de 1822, la ley General de Beneficencia de 1849 y el Real Decreto de 14 de marzo de 1899.

La asistencia benéfica estaba reservada para las personas más necesitadas, que quedaban marcadas por el desprecio social, pues recibían sin dar, y el hecho de estar necesitado/a de socorro no implicaba tener derecho alguno. Esta relación de beneficencia llevaba intrínseco el binomio caritativo-menesteroso; viéndose a este último como un elemento inútil consumidor de recursos.

Con la revolución industrial aparece el proletariado que vive en unas condiciones extremas de pobreza, a la vez que carece de medidas asistenciales. Surgen en consecuencia, en toda Europa, los Seguros Sociales Obligatorios. Los trabajadores contribuían con el pago de una cuota y a cambio recibían asistencia sanitaria. Aparecía así el concepto de derecho a la prestación, desapareciendo el estigma social.

\section{La salud como derecho}

\section{a) Alemania}

Alemania fue la pionera en esta materia. Los primeros datos que encontramos se refieren a la construcción del castillo de Neuschwanstein, auténtico capricho real. No solamente era el cuarto palacio que mandaba construir el rey de Baviera, Ludwig II, sino que además lo quería en la cima de una montaña, lo cual hacía presagiar una construcción plagada de accidentes y muertes, por lo que encontró una fuerte oposición tanto del Estado como del pueblo. Para vencer la resistencia y conseguir su propósito, diseñó importantes medidas de seguridad e impuso, de forma anual, la revisión técnica del funcionamiento y de la seguridad de las grúas de vapor por el "Bayerische Dampfkessel-Revisions-Verein" del que, con el tiempo, resultó la ITV actual: 
"Una revolución total en el sector social de Baviera y seguramente en todo el país fue la fundación de la «Asociación de obreros Hohenschwangau de la real construcción del castillo» el 3 de abril de 1870. [...] El propósito era dotar a los obreros de un seguro de enfermedad o accidente a lo largo de 15 semanas con un $65 \%$ de su paga. El obrero aportaba a este seguro una cantidad moderada y del patrimonio del rey se aportaban grandes subvenciones. Una placa conmemorativa en el patio inferior del Castillo recuerda esta institución social.” (DESING, Julios, 2002, p. 7)

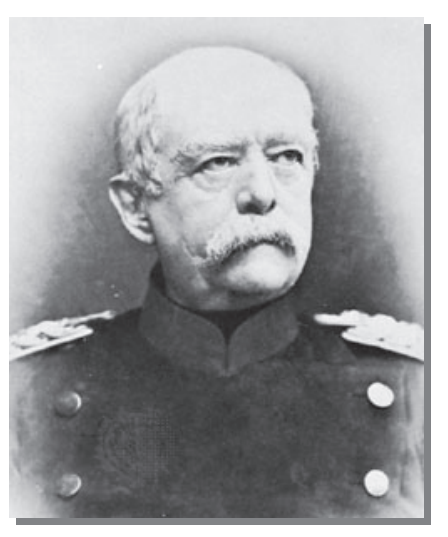

En la segunda mitad del siglo XIX, en la Alemania ya unificada, Von Bismarck ${ }^{7}$, aunque conservador, supo ver que favoreciendo un estado de bienestar para la clase trabajadora eludía demandas sociales más radicales, y lograba que la economía alemana consiguiera funcionar con la máxima eficiencia; por lo que propició la elaboración de un conjunto de leyes que configuran un sistema de seguros de enfermedad (1883), de accidentes laborales (1884), y de jubilación (1889). (LEÓN ALONSO, Marta, 2009)

\section{b) Gran Bretaña}

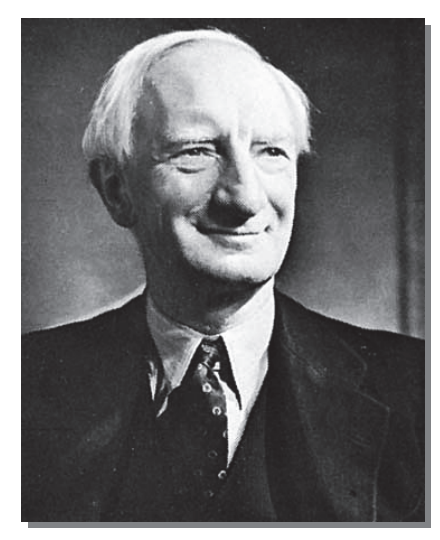

En Gran Bretaña, los trabajadores recurrían a las Trade Unions que eran sociedades de socorro mutuo sin intervención del Estado. Sin embargo, la situación de extrema indigencia del proletariado llevó al partido liberal, en 1911, a aprobar la National Insurance Act (basado en las ideas de

\footnotetext{
${ }^{7}$ Fotografía de Oto Von Bismarck disponible en: http://www.britannica.com/biography/Otto-vonBismarck/images-videos Consultado el 20 marzo de 2016
} 
William Beveridge), introduciendo, de esta manera, un seguro social de enfermedad e invalidez.

En junio de 1941, en plena guerra mundial, el Gobierno Británico, preocupado por la reconstrucción del país al término del desastre bélico, constituye una comisión interministerial para el estudio de los seguros sociales, recayendo su presidencia en William Beveridge.

Un año y medio después, el 1 de diciembre de 1942, la comisión presentó un informe: "Social Insurance and Allied Services" conocido como "el primer Informe Beveridge" que da las pautas para conseguir una sociedad más justa: el informe propone por un lado crear una legislación social más amplia y menos compleja, y por otro lado unificar los sistemas e instituciones sociales y ampliar el campo de los beneficiados, es decir lo que se ha venido en llamar Welfare State o estado del bienestar. Como afirma BOWEN HERRERA, Alfredo (1992, p. 76): "El Informe Beveridge es considerado como la carta de la Seguridad Social contemporánea y provocó un movimiento político-social de tal envergadura que, traspasando los lindes de su propio país, hizo impacto en el campo internacional.”

El mencionado informe dio lugar a una amplia reforma legal en Inglaterra: "Ley de 15 de junio de 1945, sobre Asignaciones Familiares; Ley del 26 de julio de 1946, sobre Accidentes del Trabajo; Ley del $1^{\circ}$ de agosto de 1946, sobre Seguros Sociales; Ley del 6 de noviembre de 1946 que creó el Servicio Nacional de Salud, y Ley del 13 de mayo de 1948 que reorganizó y unificó los Servicios de Asistencia y Previsión Social de Inglaterra, País de Gales y Escocia.” (BOWEN HERRERA, Alfredo, 1992, p. 77)

En 1944, había aparecido el segundo Informe Beveridge que trataba, no ya de la salud, sino de lo laboral (Full Employment in a Free society, "Trabajo para todos en una sociedad libre") convergiendo sus ideas con las del economista británico Keynes, cuya teoría económica había inspirado al presidente Franklin D. Roosevelt para tratar de resolver la crisis económica de la Gran Depresión, consecuencia del crack del 29. Roosevelt había puesto en marcha lo que él mismo llamó "New Deal" desarrollando, así, una política intervencionista. (BEVERIDGE, William, 1987) 


\section{c) España}

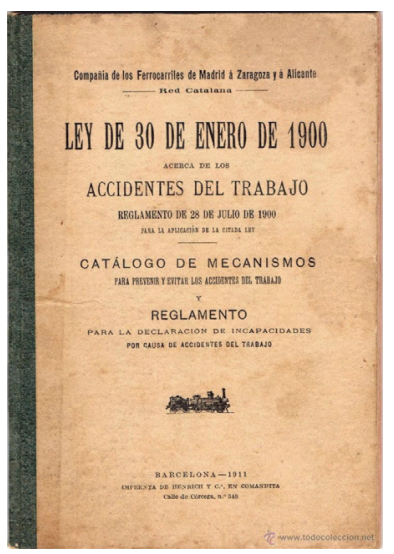

En España las leyes de 1873 y 1878 fueron dirigidas a la protección de mujeres y niños en el trabajo. En 1886, se crea la Comisión de Reformas Sociales con el fin de regular las condiciones laborales mediante el estudio de las peticiones de los trabajadores. Surge, así, la primera Ley de accidentes de trabajo ${ }^{8}$ en 1900, determinándose el riesgo que conlleva el trabajo, la responsabilidad del empresario y su obligación de indemnizar a la persona accidentada. Esta idea perdurará hasta la ley de 1922 que trae la novedad de que los empresarios hagan uso de los seguros. Esos seguros, que eran de carácter voluntario, se volverán obligatorios en 1932 con la Ley de Accidentes de Trabajo.

En 1912, siendo Canalejas presidente del Gobierno, se aprueba la Ley de la Silla, norma que obligaba a tener una silla a disposición de cada trabajadora (anteriormente, las mujeres tenían prohibido sentarse durante el horario de trabajo porque se consideraba que daba mala impresión, hecho que sigue dándose en la actualidad). Es la primera Ley que introduce el Principio de adecuación al trabajo que, más tarde, se extenderá a los varones también. (NIELFA CRISTÓBAL, Gloria, 2001)

\section{Constitucionalización del derecho a la salud}

Pero ¿cómo llega este derecho de protección de la salud a entrar dentro de la constitución? LEÓN ALONSO, Marta sostiene que los acontecimientos bélicos acaecidos en la primera mitad del siglo XX determinaron la idea del Estado social. El Estado social de Derecho será la síntesis de dos principios hasta entonces excluyentes: Libertad e Igualdad. La incorporación de la cláusula social a las Constituciones determina que el Estado asuma la obligación permanente de

\footnotetext{
8 Imagen disponible en: http://www.todocoleccion.net/libros-antiguos/libro-1911-ley-30-enero-1900-accidentes-trabajomecanismo-reglamento-leer $\sim$ x0278541

Consultado: agosto de 2015
} 
promover el desarrollo social, económico y cultural de los ciudadanos. De esta manera, se van redactando en Europa Constituciones que contienen los principios del Estado social.

Tuvieron que ser necesarias dos guerras mundiales, una gran depresión económica entre medias, la destrucción y despoblación de Europa para que la minoría que había ido acumulando los beneficios de la plusvalía producida por la industrialización aceptara compartir esos beneficios.

La Organización Mundial de la Salud (OMS), en el preámbulo de su Constitución (1946, p. 1), define "la salud como el estado de completo bienestar físico, mental y social, y no solamente la ausencia de afecciones o enfermedades."

La salud entendida así es una de las aspiraciones más profundas del ser humano, y esta aspiración individual ha traspasado al mundo jurídico. Sin embargo, en el entorno europeo más cercano, este anhelo individual no se encuentra recogido en las constituciones. Ni la Ley Fundamental de Bonn, ni la Constitución de la V República francesa contienen un precepto similar al artículo 43 de la Constitución española de 1978 (CE) que está claramente inspirado en el artículo 32, Título II de la Constitución italiana de 1948.

En palabras de LEÓN ALONSO, Marta (2009, p.173)

“Con carácter general, se proclama el derecho a la protección de la salud en el artículo 43.1 CE y se establece, en el párrafo segundo de este mismo precepto, la obligación de los poderes públicos de organizar y tutelar la salud pública a través de las medidas preventivas y de las prestaciones y servicios necesarios. De la interpretación conjunta de ambos párrafos se deduce la presencia de un derecho a la asistencia sanitaria, dispensada en el seno de una institución pública, el Sistema Nacional de Salud, que se encargará de procurar los servicios y medidas indispensables a tal fin. Así mismo, el fomento de la educación sanitaria, como medida preventiva para asegurar un buen estado de salud, se convierte en una tarea más de los poderes públicos."

Este derecho a la asistencia sanitaria determina la creación de un conjunto de servicios y prestaciones imprescindibles para su efectividad que se ordena en un sistema público de origen preconstitucional, y que en nuestro ordenamiento jurídico recibe el nombre de Sistema Nacional de Salud. Y sigue explicando la 
autora que al ser una institución recogida en la Constitución, tiene garantizada su conservación y preservados sus rasgos esenciales frente al legislador ordinario, que podrá disponer sobre su funcionamiento y su estructura, pero no suprimirlas ni desnaturalizarlas. La doctrina denomina, a esta especial protección que otorga la Constitución, garantía institucional.

De esta manera, el/la constituyente está reconociendo la existencia de una institución garantizada constitucionalmente: la salud pública, refiriéndose esta apelación, no a la salud colectiva, sino a la organización de carácter social y jurídico cuya finalidad es la protección integral de la salud. La Ley General de Sanidad, de 25 de abril de 1986, denomina a esta organización Sistema Nacional de Salud(SNS).

\section{SNS y S. de Seguridad Social}

El SNS se vincula estrechamente a otra de las instituciones más importantes del Estado social de Derecho: el Sistema de Seguridad Social.

Como hemos dicho más arriba, la intervención de los poderes públicos en salud se había centrado en Salud exterior y Salud pública, esta última incluía la higiene de la población, los saneamientos de focos de infección, la policía sanitaria mortuoria, la estadística sanitaria y el control de medicamentos. En cuanto a la salud individual, se ayudaba a las personas más necesitadas a través de la Beneficencia que llevaba implícito un estigma social.

Por esta razón se fueron creando Mutualidades y Sociedades de Socorro Mutuo, transformadas con el tiempo en los Seguros Sociales obligatorios que daban cobertura a las prestaciones económicas y asistenciales derivadas de los riesgos laborales. La obligatoriedad de estos Seguros estaba garantizada por la intervención del Estado a través de organismos como el Instituto Nacional de Previsión (INP), creado en 1908.

El más importante de estos seguros fue el Seguro Obligatorio de Enfermedad (SOE), introducido por la Ley de diciembre de 1942. En cuanto a la asistencia de los accidentes de trabajo, era regulada por la Ley de accidentes de 
trabajo de 1900.

Los Seguros Sociales, en un intento de coordinación y de unificación, dan lugar a los sistemas de la Seguridad Social. El 28 de diciembre de 1963 se promulga la Ley de Bases de la Seguridad Social y el 21 de abril de 1966 la Ley de la Seguridad Social, quedando integrados en un mismo cuerpo legal la asistencia sanitaria para la enfermedad común, para la enfermedad laboral y para los accidentes del trabajo.

Desde este momento, se distinguen perfectamente, prestaciones sanitarias de prestaciones económicas, pero ambas quedan dentro del marco de la Seguridad Social y lo mismo sucederá con el Texto Refundido de la Ley General de Seguridad Social, de 30 de mayo de 1974, manteniéndose esto hasta que el Real Decreto-Legislativo 1/1994, por el que se aprueba el actual Texto Refundido de la Ley General de Seguridad Social, que excluye la asistencia sanitaria, porque ya se había aprobado la Ley 14/1986, de 25 de abril, General de Sanidad que determinó el cambio del modelo alemán ${ }^{9}$, Sistema de Seguridad Social o modelo Bismark al modelo anglosajón, Sistema Nacional de Salud, modelo Beveridge. (CALVO SÁNCHEZ, María Dolores, 2008)

${ }^{9}$ MARTÍN GARCÍA, Manuel (2015) sostiene que actualmente existen fundamentalmente 3 modelos básicos de sistemas sanitarios:

1) Modelo liberal (libre mercado) que se da en los EEUU. El Estado solamente se encarga de los grupos sociales más desfavorecidos. Los ciudadanos son libres de contratar la cobertura sanitaria que puedan pagar de entre todas las que ofrece el mercado.

2) Modelo socialista (Cuba): la asistencia sanitaria corre total y exclusivamente a cargo del Estado. No están permitidas estructuras sanitarias de tipo privado o de seguros.

3) Modelo mixto (Europa): coexisten una sanidad pública, a cargo del Estado, y una sanidad privada ofrecida por el mercado y de libre acceso. Este modelo mixto presenta dos variantes:

- Modelo Bismark (seguros sanitarios). Nace en el siglo XIX en Alemania ante las protestas de los trabajadores industriales organizados en cooperativas. El Estado administra y organiza la asistencia sanitaria de los trabajadores que cotizan. Paralelamente existen una asistencia benéfica para los que no cotizan. Da lugar a dos tipos de ciudadanos pues cualquier asistencia benéfica conlleva estigma social. Entraña una gran complejidad administrativa e incita a proveedores y usuarios a multiplicar innecesariamente el número de servicios para ganar más. Es el modelo vigente en Alemania, Francia, Bélgica, Luxemburgo, Holanda y Austria.

- Modelo Beveridge (SNS). Surge a partir del sistema de salud británico en 1948 y está vigente en España, Portugal, Italia, Noruega, Suecia, Finlandia, Dinamarca e Islandia. La financiación, gestión y administración es pública. La prestación se da en condiciones de universalidad, equidad, gratuidad y libertad de acceso de toda la población. 
En cuanto a la salud colectiva, que pasó a llamarse salud pública o salud preventiva, los servicios de la Administración experimentaron, en la primera mitad del siglo XX, un gran desarrollo y una gran dispersión de sus competencias por lo que, para reorganizar la sanidad, se aprueba el 25 de noviembre de 1944 la Ley de Bases de Sanidad Nacional, cuyo mayor defecto fue su falta de conexión con la Ley del Seguro Obligatorio de Enfermedad de 1942. Esta separación entre salud pública y salud individual se mantendrá hasta la aprobación de la Ley General de Sanidad, de 25 de abril de 1986.

En cuanto a la evolución constitucional, vemos que la Constitución de la Segunda República mantuvo unidas las prestaciones económicas y asistenciales en su artículo 46. Durante la dictadura franquista la situación no cambió, por lo que al elaborarse la Constitución de 1978 ya existía un sistema sanitario que presentaba una serie de deficiencias: "El sistema sanitario público preconstitucional se caracterizaba por la separación entre salud colectiva y salud individual, por la inclusión de la asistencia sanitaria en el marco institucional y conceptual de la Seguridad Social, por la dispersión de competencias y por la falta de coordinación entre los distintos servicios.” (LEÓN ALONSO, Marta, 2009, p. 377).

Los últimos meses de 1978 fueron de gran importancia en el tema sanitario:

El 16 de noviembre de 1978 fue suprimido el Instituto Nacional de

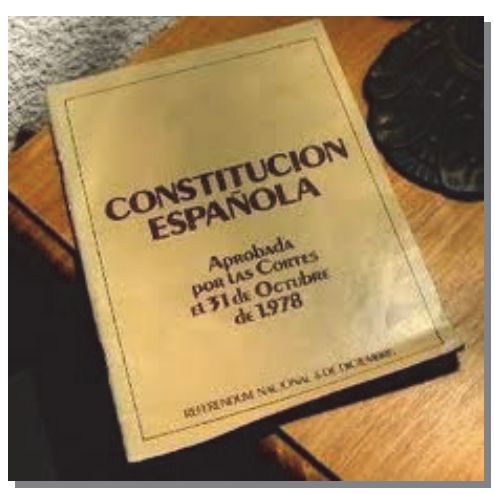
Previsión (INP); creándose las Entidades Gestoras de la Seguridad Social, Salud y Empleo; adscritas al Ministerio de Sanidad y Seguridad Social. Una de estas entidades fue el Instituto Nacional de la Salud (INSALUD).

El 6 de diciembre de 1978 es votada en referéndum la $\mathrm{CE}^{10}$, con su artículo 43 que reconoce el derecho a la protección de la salud, así como que corresponde a los poderes públicos la organización y tutela de la salud pública; y el fomento de la educación

\footnotetext{
${ }^{10}$ Imagen disponible: http://www.laconstitucion.org consultado: 12 de agosto 2015
} 
sanitaria, la educación física y el deporte; así como la facilitación de la adecuada utilización del ocio.

Fuera de España, en el mes de septiembre de ese mismo año, había tenido lugar la Conferencia Internacional sobre Atención Primaria ${ }^{11}$ (A.P.) de Alma Ata; conferencia organizada por la Organización Mundial de la Salud (OMS), la Organización Panamericana de Salud (OPS) y por el Fondo de las Naciones Unidas para la Infancia (UNICEF); patrocinada por la antigua URSS, y celebrada en Alma Ata (Kazajistán). De esta conferencia salió la DECLARACIÓN DE ALMA ATA compuesta por diez puntos, no vinculantes para los Estados miembros, a través de los que se intentaba dar las bases directrices para la creación de un sistema de salud que permitiese el ejercicio pleno del derecho a la salud para todos. El lema de la Conferencia fue "SALUD PARA TODOS EN EL AÑO 2000".

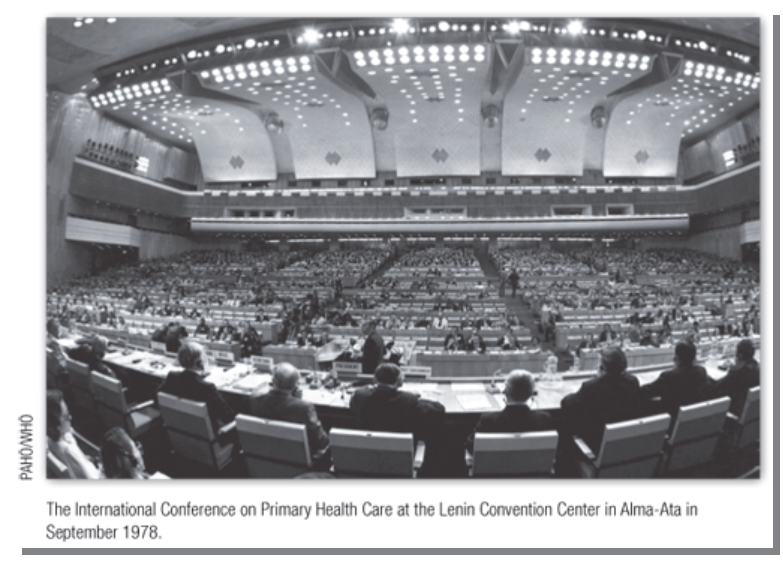

Por lo que a principios de los años 80, en España, existe una gran preocupación por los temas de salud y por la organización y unificación de las acciones de la Administración del Estado relacionadas con su tutela, tal y como podemos leer en las primeras líneas del PREÁMBULO DE LA LEY 14/1986, DE 25 DE ABRIL, GENERAL DE SANIDAD (p.9):

\footnotetext{
${ }^{11}$ Imagen disponible: http://www.scielosp.org/scielo.php?script=sci arttext\&pid=S004296862008001000007\&lng=es\&nrm=iso\&tlng=en

Consultado: agosto de 2015
} 
"De todos los empeños que se han esforzado en cumplir los poderes públicos desde la emergencia misma de la Administración contemporánea, tal vez no hay ninguno tan reiteradamente ensayado ni con tanta contumacia frustrado como la reforma de la Sanidad.

Es, en efecto, un dato histórico fácilmente verificable que las respuestas públicas al reto que en cada momento ha supuesto la atención a los problemas de salud de la colectividad, han ido siempre a la zaga de la evolución de las necesidades sin conseguir nunca alcanzarlas, de manera que se ha convertido en una constante entre nosotros la inadaptación de las estructuras sanitarias a las necesidades de cada época."

La primera gran acción fue la creación del Ministerio de Sanidad y Consumo, en 1981, del que pasa a formar parte el INSALUD, el cual, sin embargo, no perderá su condición de Entidad Gestora de la Seguridad Social hasta su desaparición en 2002.

La segunda gran acción, y seguramente la más importante, fue la aprobación de la Ley General de Sanidad, de 25 de abril de 1986 (LGS), que fue redactada de acuerdo a los artículos 43 y 149.1.16 a $\mathrm{a}^{12} \mathrm{CE}$.

CALVO SÁNCHEZ, María Dolores y RIVERO ORTEGA, Ricardo (2008, p. 899) sostienen que esta ley marca un antes y un después en nuestra ordenación sanitaria y que "su vigencia sigue siendo el elemento sinalagmático de la actual Administración Sanitaria, por cuanto determinó el cambio del Sistema de Seguridad Social o modelo Bismark al Sistema Nacional de Salud (SNS) o modelo Beveridge."

Es una Ley de bases cuyo objetivo es regular todas las acciones que permitan la realización efectiva del derecho a la protección de la salud, y que en su artículo 46 describe las características del organismo que se está creando:

"Son características fundamentales del Sistema Nacional de Salud:

a) La extensión de sus servicios a toda la población

b) La organización adecuada para prestar una atención integral a la salud, comprensiva tanto de la promoción de la salud y prevención de la enfermedad como de la curación y rehabilitación.

\footnotetext{
${ }^{12}$ El 149.1. de la CE de 1978 dice: "El Estado tiene competencia exclusiva sobre las siguientes materias: [...] 16 $6^{\text {a }}$ Sanidad exterior. Bases y coordinación general de la Seguridad Social, sin perjuicio de la ejecución de sus servicios por las Comunidades Autónomas."
} 
c) La coordinación y, en su caso, la integración de todos los recursos sanitarios públicos en un dispositivo único.

d) La financiación de las obligaciones derivadas de esta Ley se realizará mediante recursos de las Administraciones Públicas, cotizaciones y tasas por la prestación de determinados servicios.

e) La prestación de una atención integral de la salud procurando altos niveles de calidad debidamente evaluados $\mathrm{y}$ controlados."

(Si bien, el punto d. sobre financiación hay que adaptarlo hoy al Real Decreto-Ley 12/2005, de 16 de septiembre, por el que se aprueban determinadas medidas urgentes en materia de financiación sanitaria).

El/la legislador/a separa la asistencia sanitaria de las prestaciones económicas, quedando la primera a cargo del SNS (modelo Beveridge) mientras que de las segundas se sigue ocupando la Seguridad Social (modelo Bismark), produciéndose así una escisión entre ambos organismos en base a la financiación.

Otro elemento crucial para entender la relación entre la asistencia sanitaria y el sistema de Seguridad Social es el "Informe de la Ponencia para el "análisis de los problemas estructurales del sistema de seguridad social y de las principales reformas que deberán acometerse", conocido como "Pacto de Toledo" y aprobado el 6 de abril de 1995, en el Pleno del Congreso de los Diputados. Es en este informe en el que se propone la separación de las fuentes de financiación, de forma que las prestaciones de naturaleza contributiva dependerán de las cotizaciones sociales, mientras que la sanidad y los servicios sociales, considerados no contributivos y universales, dependerán exclusivamente de la imposición general. Para que esto se hiciera realidad se aprobó la Ley 24/1997, de 15 de julio, de consolidación y racionalización del sistema de Seguridad Social, haciéndose efectiva antes del ejercicio económico del año 2000.

En cuanto a la salud laboral, queda incluida en el seno de la Seguridad Social, fundamentalmente por el principio de responsabilidad empresarial: el riesgo debe quedar a cargo de quien se queda con el beneficio, riesgo y beneficio son las dos caras de la misma moneda, no se deben separar sin incurrir en una 
grave falta de justicia ${ }^{13}$. De tal forma que es la empresa la que asume la cotización completa para cubrir las contingencias derivadas de los accidentes de trabajo y de las enfermedades laborales.

\section{Actualización legal en materia sanitaria}

Como venimos diciendo, en las últimas dos décadas del siglo $\mathrm{XX}$, tienen lugar el cambio de modelo sanitario (de modelo Bismark a modelo Beveridge) y la descentralización del sistema con el traspaso de transferencias a las Comunidades Autónomas: la Administración central cuyo ente gestor es el INSALUD trasfiere las competencias en materia sanitaria a la Administración autonómica cuyo ente gestor son los Servicios de salud autonómicos. Esto exigió una intensa reforma sanitaria realizada entre los años 2002 y 2003. Así vieron la luz las siguientes leyes:

- Ley Básica Reguladora de la Autonomía del Paciente y de Derechos y Obligaciones en materia de información y documentación clínica (Ley 41/2002, de 14 de noviembre)

- Ley de Cohesión y Calidad del Sistema Nacional de Salud (Ley 16/2003, de 28 de mayo)

- Ley de Ordenación de las Profesiones Sanitarias (Ley 44/2003, de 21 de noviembre)

- Ley de Estatuto Marco (Ley 55/2003, de 16 de diciembre)

- Ley de Reforma del Marco Normativo de Prevención de Riesgos Laborales -PRL-(Ley 54/2003, de 12 de diciembre)

El/la legislador aprovecha la coyuntura para trabajar sobre puntos débiles que tenía el sistema. Así se gana terreno a favor de los derechos de los pacientes con la Ley 41/2002 de 14 de noviembre. La Ley 16/2003, de 28 de mayo consigue garantías de homologación sobre la prestación de asistencia y servicios sanitarios

\footnotetext{
${ }^{13}$ Nótese que si se avería una máquina o cualquier otro recurso técnico es el empresario el responsable de su arreglo.
} 
en todas las CCAA. La Ley 44/2003, de 21 de noviembre busca la regulación efectiva de reconocimiento de la profesionalidad del sector, de las competencias propias de cada colectivo y de su acreditación, registro y desarrollo, esta es una ley de especial relevancia para la enfermería. La Ley 55/2003, de 16 de diciembre, establece la relación laboral de un colectivo de medio millón de personas con la Administración Sanitaria. La Ley 54/2003, de 12 de diciembre intenta paliar la alta siniestralidad y potenciar la prevención, es decir que mejora la situación laboral actual en favor del trabajador. (CALVO SÁNCHEZ, María Dolores, 2008)

\section{Rasgos esenciales del SNS}

El Sistema de Salud se crea como universal, descentralizado y único. Esto último implica integrar todos los recursos sanitarios existentes hasta el momento además de ampliar sus prestaciones hasta conseguir una atención integral.

\section{1) Principio de universalidad}

Es este uno de sus rasgos esenciales, garantizado por la Constitución de 1978, que proclama en el artículo 43.1 CE el derecho a la protección de la salud sin limitación alguna. Además se hace especial mención a la salud de las personas trabajadoras (artículo 40.2 CE), de las personas consumidoras y usuarias (artículo 51.1 CE), de las madres e hijos (artículo 39.2 CE), de las personas disminuidas físicas, psíquicas y sensoriales (artículo $49 \mathrm{CE}$ ) y de la tercera edad (artículo 50 CE). Por otro lado la Ley General de Sanidad de 1986 proclama a lo largo de todo el texto su objetivo de universalidad. Pero esta universalidad depende de la legislación que regula el acceso a las prestaciones sanitarias que, siguiendo la minuciosa investigación de LEÓN ALONSO, Marta, vamos a enumerar:

A pesar de la escisión a todos los niveles del Sistema de Salud y la Seguridad Social, este último organismo sigue siendo una importante puerta de entrada porque la afiliación a la Seguridad Social es la forma habitual para poder acceder al Sistema Nacional de Salud. De esta manera, el artículo 100 del Texto 
Refundido de la Ley General de la Seguridad Social de 1974 establece que las personas con derecho a la asistencia sanitaria por enfermedad común, maternidad o accidente laboral, son las personas trabajadoras activas, las personas pensionistas y preceptoras de prestaciones periódicas, así como sus familiares o asimilados/as a su cargo.

Pero la "deslaboralización" de la asistencia sanitaria conlleva la ruptura con el principio contributivo y permite su expansión a otros colectivos: las viudas y familiares de fallecidos de la Guerra Civil; las personas emigrantes retornadas a España; las personas minusválidas, independientemente de que realicen actividad laboral y las personas desempleadas.

También tienen derecho a la asistencia, en cumplimiento con el objetivo de la universalización establecido en la Ley General de Sanidad de 1986, las personas pensionistas de clases pasivas, las personas que carecen de un nivel mínimo de recursos económicos, las personas perceptoras de prestaciones no contributivas, las personas menores de edad y, por último, las personas extranjeras que se encuentren en territorio español. Ahora bien, las vías de acceso a la asistencia sanitaria para las personas extranjeras son las siguientes: 1) mediante la afiliación y cotización a la Seguridad Social; 2) mediante el empadronamiento en el municipio donde residen habitualmente; 3) las personas menores de edad y las mujeres embarazadas, independientemente de su situación administrativa; 4) las que se encuentren en casos de urgencia; 5) si no se encuentran en las situaciones anteriores, las personas extranjeras podrán acceder a la atención sanitaria como pacientes privados/as siempre que cuenten con los recursos económicos suficientes.

El reconocimiento o denegación del derecho a la asistencia sanitaria corresponde al Instituto Nacional de la Seguridad Social a través de sus Direcciones Provinciales. Una vez reconocido este derecho y tras el alta en la Tesorería General de la Seguridad Social, se expide la tarjeta sanitaria, competencia que corresponde a las Administraciones sanitarias autonómicas y que está regulada por el artículo 57 de la Ley 16/2003, 28 de mayo, de cohesión y calidad del Sistema Nacional de Salud.

Los cobertura de asistencia sanitaria abarca a los asegurados de: Seguridad Social, MUFACE, ISFAS, MUGEJU, Salario inferior al mínimo interprofesional 
(RD 1088/1989) (CALVO SÁNCHEZ, María Dolores y MOMPART GARCÍA, María Paz, 2006)

A pesar de todo queda un colectivo excluido, la población reclusa, ya que está sometida a un régimen especial gestionado por la Dirección General de Instituciones Penitenciarias del Ministerio del Interior, con cargo a su propio presupuesto, y regulado en el Capítulo III del Título II de la Ley Orgánica 1/1979, de 26 de septiembre, General Penitenciaria.

\section{2) E1 carácter descentralizado.}

La Ley General de Sanidad, de 25 de abril de 1986, determina que el Sistema de Salud va a seguir un modelo descentralizado, donde las Comunidades Autónomas ocupan un lugar preeminente. En el preámbulo de la citada ley queda dicho: "El Sistema Nacional de Salud se concibe así como el conjunto de los servicios de salud de las Comunidades Autónomas convenientemente coordinados". El/la legislador pretende así cumplir con el mandato constitucional de descentralización política, y a la vez obtener un metaresultado que es resolver la disgregación de los servicios sanitarios obteniendo un sistema integrado. Precisamente el artículo 50.1 de la Ley General de Sanidad establece:

“en cada Comunidad Autónoma se constituirá un Servicio de Salud integrado por todos los centros, servicios y establecimientos de la propia Comunidad, Diputaciones, Ayuntamientos y cualesquiera otras Administraciones territoriales intracomunitarias, que estará gestionado, como se establece en los artículos siguientes, bajo la responsabilidad de la respectiva Comunidad Autónoma."

La descentralización sanitaria, tema sobre el que insistiremos más adelante, fue realizada de forma progresiva desde 1981 hasta 2001. CALVO SÁNCHEZ, María Dolores y RIVERO ORTEGA, Ricardo (2008, p. 901) sostienen que es un proceso inconcluso pues "hemos de tener en cuenta que Ceuta y Melilla se hallan pendientes de realizar el traspaso desde la Administración Estatal (Instituto de Gestión Sanitaria del Ministerio de Sanidad y Consumo) a su 
Administración Autonómica.”

\section{3) El carácter integral}

Una vez conseguida la integración de todos los recursos sanitarios que existían, inconexos, en el territorio español gestionados por Comunidades, Diputaciones y Ayuntamientos, otro objetivo principal ha sido conseguir una atención integral.

El Capítulo II de la LGS compuesto por dos artículos, el 18 y el 19, hace referencia a las actuaciones sanitarias del Sistema de Salud, mostrando aquí el/la legislador su intención de atención integral. El artículo 18 ha sido modificado en su redacción originaria por la Ley Orgánica 3/2007, de 22 de marzo, para la igualdad efectiva de mujeres y hombres. Y posteriormente, la Ley 33/2011, de 4 de octubre, General de Salud Pública, ha vuelto a modificar el artículo 18 así como el apartado 1 del 19.

El artículo 18 enumera las diferentes actuaciones sanitarias que corresponde desarrollar a las administraciones públicas y se expresa así:

En el punto 1 hace mención a la educación sanitaria como elemento primordial para la mejora de la salud individual y comunitaria, y se puede observar la modificación para la igualdad : “comprendiendo la educación diferenciada sobre los riesgos, características y necesidades de mujeres y hombres, y la formación contra la discriminación de las mujeres."

El punto 2 y 3 los dedica a la atención primaria (A.P.) y especializada (A.E.)

El punto 4 está dedicado a los productos terapéuticos y dice: “atendiendo a las necesidades diferenciadas de mujeres y hombres".

El punto 5 habla de las poblaciones de mayor riesgo. El 6 de los saneamientos y abastecimiento de aguas, eliminación y tratamientos de residuos, el control del aire, la contaminación atmosférica, y el medio ambiente incluyendo la vivienda. El 7 a la planificación familiar. El 8 a la salud mental.

El 9 a la salud laboral y lo modificado dice: "con especial atención al acoso sexual y al acoso por razón de sexo.” El 10 a los productos alimentarios. El 
11 a los productos farmacéuticos, terapéuticos, de diagnóstico y auxiliares. El 12 a las actividades veterinarias. El 13 a la información epidemiológica. El 14 a la formación del personal al servicio de la organización sanitaria "incluyendo actuaciones formativas dirigidas a garantizar su capacidad para detectar, prevenir y tratar la violencia de género. El 15 que también ha sido modificado, habla del fomento de la investigación científica en el campo de la salud "atendiendo a las diferencias entre mujeres y hombres."

El 16, que era originariamente el último punto de este artículo, insiste de forma general en el control y mejora de la calidad de la asistencia sanitaria en todos sus niveles.

Han sido añadidos otros dos puntos, el 17 que ordena "el tratamiento de los datos contenidos en registros, encuestas, estadísticas y otros sistemas de información médica para permitir el análisis de género, incluyendo, siempre que sea posible, su desagregación por sexo.

El punto 18 y último del artículo 18 fue añadido por la Ley 26/2011, de 1 de agosto, de adaptación normativa a la Convención Internacional sobre los Derechos de las Personas con Discapacidad y está dedicado a las discapacidades: "La promoción, extensión y mejora de los sistemas de detección precoz de discapacidades y de los servicios destinados a prevenir y reducir al máximo la aparición de nuevas discapacidades o la intensificación de las preexistentes."

El artículo 19 consta de dos apartados, el primero que estaba dedicado a la sanidad ambiental, ha sido derogado tras la entrada en vigencia de la Ley 33/2011, de 4 de octubre, General de Salud Pública.

El segundo apartado dice que las Autoridades sanitarias propondrán o participarán en la legislación sobre: calidad del aire; aguas; alimentos e industrias alimentarias; residuos orgánicos sólidos y líquidos; suelo y subsuelo; las distintas formas de energía; transporte colectivo; sustancias tóxicas y peligrosas; la vivienda y el urbanismo; el medio escolar y deportivo; el medio laboral; lugares, locales e instalaciones de esparcimiento público y cualquier otro aspecto del medio ambiente relacionado con la salud.

Nos encontramos muy lejos de las épocas en las que se emprendían acciones focalizadas a problemas de salud concretos como podía ser el aislamiento ante epidemias, la vacunación contra la viruela... 
El/la legislador crea un Sistema que trate la salud de una forma integral. Además tiene una organización territorial descentralizada y quiere integrar todos los recursos emergidos a lo largo del tiempo, desvinculados unos de otros, que daban un mapa sanitario con lagunas por un lado, y por otro con acciones repetidas, no sincronizadas y por lo tanto muy lejanas de ser eficientes.

Volvamos ahora sobre la descentralización, tema importante y cuyo desarrollo abarcó dos décadas.

\section{Proceso de descentralización.}

Convenimos con Pemán Gavín (2006) cuando afirma que con la transferencia de funciones y servicios del INSALUD a las diez últimas CCAA, el 1 de enero de 2002 se acaba con la situación de asimetría que en ese aspecto se venía viviendo en la sanidad española. El proceso de transferencia, que comienza en julio de 1981 y se da por concluido en diciembre del año 2001, entrando en vigor el 1 de enero del 2002, es en sí mismo un proceso inacabado, pues Ceuta y Melilla se hallan aún bajo la potestad del Ministerio de Sanidad y Consumo.

Las competencias transferidas fueron: planificación sanitaria, Salud Pública y Gestión de los Servicios de Salud.

En cuanto al orden cronológico, fue el siguiente: la primera Comunidad Autónoma en recibir la transferencia fue Cataluña, según el Real Decreto 1517/1981, surgiendo el Instituto Catalán de la Salud (CatSalut). Le siguió Andalucía, R.D. 400/1984: Servicio Andaluz de Salud (SAS). El País Vasco, R.D. 1536/1984 : Servicio Vasco de Salud (Osakidetza). Valencia, R.D. 1612/1987: Agencia Valenciana de la Salud. En 1990, lo hacen otras dos Comunidades, Galicia, R.D. 1679/1990: Servicio Gallego de Salud (SERGAS) y Navarra, R.D. 1680/1990, de 18 de diciembre: Servicio Navarro de Salud (Osasunbidea). En 1994 lo hace Canarias, R.D. 446/1994, de 11 de marzo: Servicio Canario de la Salud (SCS). En el año 2001 se finaliza el proceso, con la transferencia de competencias a las Comunidades Autónomas que quedaban: Asturias, R.D. 1471/2001, de 27 de diciembre: Servicio de Salud del Principado de Asturias 
(SESPA). Cantabria, R.D. 1472/2001 de 27 de diciembre: Servicio Cántabro de Salud (SCS). La Rioja, R.D. 1473/2001 de 27 de diciembre: Servicio Riojano de Salud. La Región de Murcia, R.D. 1474/2001 de 27 de diciembre: Servicio Murciano de Salud (SMS). Aragón, R.D. 1475/2001 de 27 de diciembre: Servicio Aragonés de Salud (salud). Castilla la Mancha, R.D. 1476/2001 de 27 de diciembre: Servicio de Salud de Castilla la Mancha (SESCAM). Extremadura, R.D. 1477/2001 de 27 de diciembre: Servicio Extremeño de Salud (SES). Las Islas Baleares, R.D. 1478/2001 de 27 de diciembre: Servicio de Salud de las Islas Baleares (IB-SALUD). La Comunidad de Madrid, R.D. 1479/2001 de 27 de diciembre: Servicio Madrileño de Salud. Y por último Castilla y León, R.D. 1480/2001 de 27 de diciembre: Sanidad Castilla y León (SACYL). Estos últimos traspasos de transferencias entraron en vigor el 1 de enero de 2002.

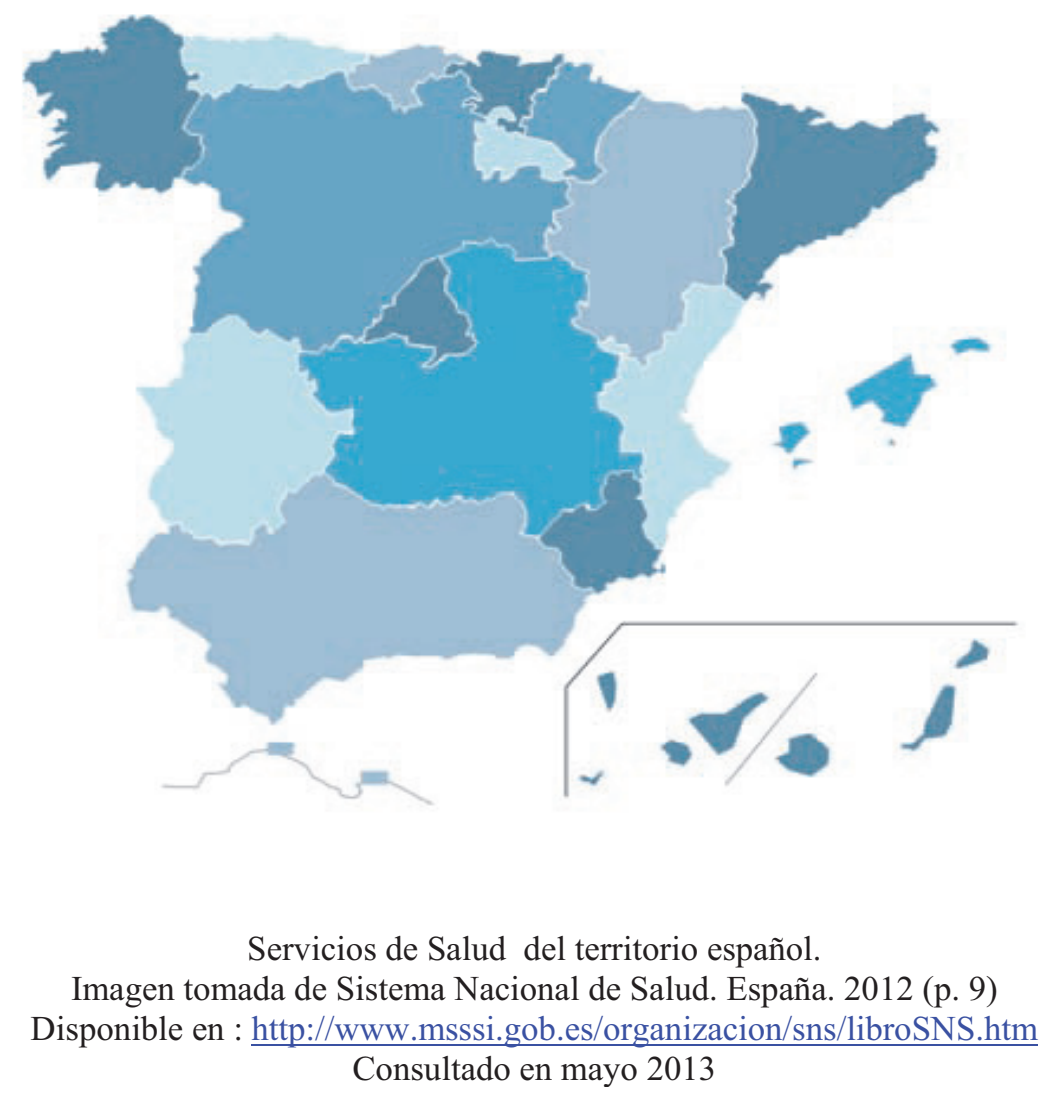

El Instituto Nacional de la Salud (INSALUD), por el R.D. 840/2002, de 2 de agosto, quedó reducido a una entidad de menor dimensión, pero que conservó la misma personalidad jurídica, económica, presupuestaria y patrimonial, la 
naturaleza de Entidad Gestora de la Seguridad Social y las funciones de gestión de los derechos y obligaciones que venía desarrollando, pasándose a denominar Instituto Nacional de Gestión Sanitaria (INGESA).

Por lo tanto, una vez culminado el proceso de transferencias, al INGESA le corresponde la gestión de los derechos y obligaciones del INSALUD y también las prestaciones sanitarias de las Ciudades de Ceuta y Melilla, además de realizar todo lo necesario para el buen funcionamiento de sus servicios, en el marco de lo establecido en la disposición transitoria tercera de la Ley 14/1986, de 25 de abril, General de Sanidad.

El INGESA está estructurado en distintos órganos: órganos de participación en el control y vigilancia de la gestión. Órganos de dirección y gestión. Organización de los servicios periféricos (Ceuta y Melilla) y Centro Nacional de Dosimetría de Valencia.

Para mantener la organización general a la vez que la autonomía de cada Comunidad, se creó El Consejo Interterritorial Del Sistema Nacional De Salud (CISNS) que de una forma permanente coordina, coopera, comunica e informa a los Servicios de Salud entre ellos y con la Administración del Estado. Su objetivo fundamental es promover la cohesión del Sistema Nacional de Salud. El CISNS está constituido por el/la Ministro/a de Sanidad que además lo preside, y por los/las consejeros/as de sanidad de las Comunidades Autónomas, uno/a de los/las cuales cumple con las funciones de vicepresidente y es elegido/a por los/las demás consejeros/as.

El Consejo Interterritorial (CISNS) dispone del Comité Consultivo a través del cual hace efectiva la participación social en el Sistema Nacional de Salud y se mantiene en permanente contacto con organizaciones sindicales y empresariales del SNS.

Según nos informa el propio Sistema Nacional de Salud, a través de su obra Sistema Nacional De Salud. España 2012, (p. 10): "Sus funciones son: informar, asesorar y formular propuestas sobre materias que resulten de especial interés para el funcionamiento del Sistema Nacional de Salud" 


\section{Competencias dentro del SNS}

\section{CALVO SÁNCHEZ, María Dolores y RIVERO ORTEGA, Ricardo} (2008, p. 901) sostienen que "Tras las trasferencias sanitarias, la estructura del Sistema Nacional de salud queda determinada en tres niveles: estatal, autonómico y local, recayendo sobre el nivel autonómico un mayor número de competencias y por ende de responsabilidad pública sanitaria."

Sin embargo, el Estado no quedó exento de competencias en materia de sanidad. A las competencias de las distintas Administraciones, dedica la Ley 14/1986, de 25 de abril, General de Sanidad, su Título II con cuatro capítulos, el primero para las competencias del Estado, el segundo para las de las Comunidades Autónomas, el tercero para las Corporaciones Locales y por fin el cuarto, para la Alta Inspección. Algunos artículos han sido modificados o derogados tras la entrada en vigor de otras normas. Siguiendo la información del Ministerio de Sanidad, Servicios Sociales e Igualdad a través de su obra Sistema Nacional de Salud. España 2012, vemos que las competencias del Estado son: Bases y coordinación de la sanidad. Sanidad exterior. Política del medicamento y gestión del INGESA.

En cuanto a las Comunidades Autónomas les corresponde la planificación sanitaria, la salud pública y la gestión de los Servicios de Salud, la asistencia farmacéutica y las prestaciones socio-sanitarias.

Las Corporaciones Locales tampoco quedan exentas de competencias y sobre ellas recae: "la protección de la salud, la participación en la Gestión de Atención Primaria, los Abastos, Mataderos, Ferias y Mercados, así como Defensa de usuarios, Cementerios, servicios Funerarios y Medio Ambiente." (CALVO SÁNCHEZ, María Dolores y RIVERO ORTEGA, Ricardo, 2008, p. 901)

Una vez vista la génesis y la organización del Sistema Nacional de Salud, nos interesa saber como funciona, a lo cual dedica la LGS su Título III, compuesto por seis capítulos. Título que también ha experimentado cambios tras la aprobación de nuevas normas como pueden ser entre otras, La Ley 16/2003, de 28 de Mayo, de Cohesión y Calidad del Sistema Nacional de Salud, la cual en la 
exposición de motivos dice: “...transcurridos más de 16 años desde la entrada en vigor de la LGS, se han producido profundos cambios en la sociedad, [...] Y se plantean nuevos retos para la organización del SNS, [...] retos todos ellos que han puesto de manifiesto la necesidad del funcionamiento cohesionado del Estado y de las Comunidades Autónomas...".

Y la Ley 41/2002, de 14 de Noviembre, Básica Reguladora de la Autonomía del Paciente y de Derechos y Obligaciones en Materia de Información y Documentación Clínica, en cuya exposición de motivos, declara que “...estas circunstancias aconsejan una adaptación de la Ley General de Sanidad con el objetivo de aclarar la situación jurídica y los derechos y obligaciones de los profesionales sanitarios, de los ciudadanos y de las instituciones sanitarias..."

\section{Organización del SNS:}

El SNS ofrece a los usuarios un conjunto de servicios encaminados a obtener la prevención, el diagnóstico, el tratamiento, la rehabilitación y la promoción y mantenimiento de la salud; para lo cual se puede decir, de una forma muy simple, que se divide funcionalmente en Atención Primaria (AP) y Atención Especializada (AE) y geográficamente en Áreas de salud, subdivididas a su vez, en Zonas Básicas de salud o Zonas de Salud. Pero la realidad de la organización sanitaria española actual llega a niveles de gran complejidad, sin entrar demasiado en esa complejidad, veamos, a grandes rasgos, sus características.

La AP y la AE son dos niveles asistenciales diferentes y subsecuentes. La AP se caracterizada por la accesibilidad, conocida también como asistencia abierta, y la AE o asistencia cerrada se caracteriza por la complejidad tecnológica. Pero además de estas dos prestaciones fundamentales hay otras prestaciones necesarias para que un sistema de salud se pueda calificar de integral.

\section{Prestación de Atención Primaria:}

Está regulada por la Ley 14/1986 de 25 de abril general de sanidad y por el artículo 12 de la Ley 16/2003, de 28 de mayo, de Cohesión y Calidad del SNS, 
que especifica que la A.P. es

"el nivel básico e inicial de atención, que garantiza la globalidad y continuidad de la atención a lo largo de toda la vida del paciente, actuando como gestor y coordinador de casos y regulador de flujos. Comprenderá actividades de promoción de la salud, educación sanitaria [...] prevención de la enfermedad, asistencia sanitaria, mantenimiento y recuperación de la salud, así como la rehabilitación física y el trabajo social”

Aplicándose estas actividades a la persona, a la familia y a la comunidad. Así mismo se realizarán funciones de docencia e investigación.

La A.P. se realizará a demanda, programada o urgente, tanto en la consulta como en el domicilio de la persona enferma. Tiene también encomendadas funciones diagnósticas y terapéuticas, la información y vigilancia en la protección de la salud, la atención paliativa a pacientes terminales, la atención a la salud mental y bucodental.

El punto f) de este artículo fue redactado por la Ley Orgánica 3/2007, de 22 de marzo, para la Igualdad efectiva de mujeres y hombres y dice que la A.P. comprenderá: “ Las atenciones y servicios específicos relativos a las mujeres, que específicamente incluirán la detección y tratamiento de las situaciones de violencia de género; la infancia; la adolescencia; los adultos; la tercera edad; los grupos de riesgo y los enfermos crónicos.”

Los dispositivos asistenciales son los centros de salud y consultorios locales, donde trabajan equipos integrados por profesionales de medicina de familia, pediatras, personal de enfermería y personal de administración, también puede haber trabajadores sociales, matronas $\mathrm{y}$ fisioterapeutas, $\mathrm{y}$ trabajadores sociales.

Los Centros de Salud ofrecen sus servicios en una isócrona de 15 minutos desde cualquier lugar de residencia. 


\section{Prestación de A. Especializada.}

Está regulada por el artículo 13 de la Ley 16/2003, de 28 de mayo, de Cohesión y Calidad del SNS.

Esta atención cuenta con los medios diagnósticos y terapéuticos de mayor complejidad y coste. Desarrolla su actividad en consultas, hospitales de día de tipo médico o quirúrgico, o a través de la hospitalización en régimen de internamiento a los que el usuario accede por indicación de los facultativos de Atención Primaria. Así mismo, apoyará a la A.P. en los casos de alta hospitalaria precoz o en la hospitalización a domicilio. Y tiene encomendadas actividades asistenciales, diagnósticas, terapéuticas, de rehabilitación, a la salud mental y paliativas a pacientes terminales. Actividades de promoción de la salud, educación sanitaria y prevención de la enfermedad cuya naturaleza aconseje que se realicen en este nivel. Así mismo tiene asignadas funciones de docencia e investigación.

Tras el proceso asistencial en una determinada especialidad, la información es llevada a la Historia del paciente en su Centro de Salud, garantizándose así una visión clínica y terapéutica global. La Historia Clínica surge del contacto entre los equipos de salud y el/la paciente, y constituye un documento médico legal. En Atención Primaria, donde se acumulan los informes clínicos con una proyección diacrónica, la Historia Clínica es denominada también Historia de Vida.

\section{Prestación de A. Sociosanitaria}

Viene regulada por el artículo 14 de la Ley 16/2003, de 28 de mayo, de Cohesión y Calidad del SNS que establece que esta atención comprende el conjunto de cuidados destinados a los/las pacientes crónicos/as, que por sus especiales características pueden beneficiarse de la acción simultánea y sinérgica de los servicios sociales y sanitarios. Esta atención comprende cuidados sanitarios de larga duración, atención sanitaria en la convalecencia y la rehabilitación en pacientes con déficit funcional recuperable. 


\section{Prestación de A. de Urgencia}

Regulada por el artículo 15 de la Ley 16/2003, de 28 de mayo, de Cohesión y Calidad del SNS. Esta asistencia se prestará cuando la situación clínica lo requiera, durante las 24 horas del día, en centros sanitarios o en el domicilio de la persona enferma, y comprenderá atención médica y de enfermería.

\section{Prestación de A. Urgencias y Emergencias}

Viene regulada por el RD 1030/2006, de 15 de septiembre, por el que se establece la cartera de servicios comunes del SNS y el procedimiento para su actualización. Su anexo IV dice: "La atención de urgencia se entiende como una atención integral y continua que se presta por atención primaria y especializada, y por los servicios específicamente dedicados a la atención urgente"

También establece que la coordinación de los diferentes intervinientes se hará a través de los teléfonos 112, 061 u otros y por los centros coordinadores de urgencias y emergencias que garantizarán el acceso a esta atención las 24 horas del día, y coordinarán los servicios sanitarios planificados para los casos de catástrofes, urgencias y emergencias, dependientes de las distintas administraciones e instituciones, como Protección Civil, Cuerpos de Prevención y Extinción de Incendios, Cuerpos y Fuerzas de Seguridad del Estado u otras.

La atención de urgencia y emergencias comprende: la atención telefónica, la atención inicial e inmediata para determinar los riesgos, la realización de procedimientos diagnósticos y procedimientos terapéuticos médico-quirúrgicos. La monitorización, observación y reevaluación. El transporte sanitario, terrestre, aéreo o marítimo, asistido o no asistido. La información al/la paciente y/o acompañantes. El alta o la derivación al nivel asistencial más adecuado y su internamiento si la situación lo requiere. La comunicación a las autoridades competentes si se sospecha violencia de género o de malos tratos a menores, personas ancianas y personas con discapacidad.

\section{Prestación farmacéutica.}

A ella se refiere el artículo 16 de la Ley 16/2003, de 28 de mayo, de 
Cohesión y Calidad del SNS que ha sido desarrollado por la Ley 29/2006, de 26 de julio, de garantías y uso racional de los medicamentos y productos sanitarios.

Las prestaciones farmacéuticas comprenden los medicamentos y productos sanitarios prescritos por facultativos a los/las pacientes, según sus necesidades clínicas, y durante el tiempo adecuado. Todos los medicamentos prescritos tienen que haber sido autorizados y registrados por la Agencia Española de Medicamentos y productos sanitarios o ser fórmulas magistrales preparadas por farmacéuticos/as licenciados/as. Quedan excluidos los productos cosméticos, dietéticos, dentífricos, publicitarios u homeopáticos.

Las prestaciones farmacéuticas están cofinanciadas por la persona usuaria según marca la ley, y uno de los objetivos prioritarios de la misma es inculcar en la mente de las personas usuarias el uso racional de los medicamentos y la elusión de la automedicación.

\section{Prestaciones ortoprotésicas.}

Regulada por el artículo 17 de la Ley 16/2003, de 28 de mayo, de Cohesión y Calidad del SNS. Consiste en la utilización de productos sanitarios implantables o no, y cuya finalidad es sustituir total o parcialmente una estructura o una función corporal (prótesis quirúrgicas fijas, prótesis externas, vehículos para inválidos, audífonos...)

\section{Prestación de productos dietéticos}

Regulada por el artículo 28 de la Ley 16/2003, de 28 de mayo, de Cohesión y Calidad del SNS. Se refiere a los tratamientos dietoterápicos para las personas que padezcan trastornos metabólicos congénitos o la nutrición enteral para pacientes que no pueden alimentarse de forma ordinaria por causa de su patología. Esta prestación se facilitará directamente por los servicios de salud o dará lugar a ayudas económicas ateniéndose al RD 1.205/2010, de 24 de septiembre, por el que se fijan las bases para la inclusión de los alimentos dietéticos para usos médicos especiales, en la prestación con productos dietéticos del Sistema Nacional de Salud, y para el establecimiento de sus importes máximos de financiación. 


\section{Prestación de transporte sanitario}

Artículo 19 de la Ley 16/2003, de 28 de mayo, de Cohesión y Calidad del SNS se refiere al desplazamiento de pacientes por causas exclusivamente clínicas. Engloba ambulancias para el transporte de personas enfermas crónicas (por ejemplo enfermos/as de hemodiálisis, trasplantados/as recientes que acuden a revisiones médicas...), vehículos con recursos técnicos y humanos adecuados a la demanda de la persona enferma: UVI móvil, helicópteros o aviones especialmente acondicionados al efecto.

\section{Prestaciones de Salud Pública}

Artículo 11 de la Ley 16/2003, de 28 de mayo, de Cohesión y Calidad del SNS y por la Ley 33/2011, de 4 de octubre, general de salud pública que es definida en su artículo 1 como "el conjunto de actividades organizadas por las Administraciones públicas, con la participación de la sociedad, para prevenir la enfermedad así como para proteger, promover y recuperar la salud de las personas, tanto en el ámbito individual como en el colectivo y mediante acciones sanitarias, sectoriales y transversales."

\section{Organización geográfica}

En cuanto a la organización geográfica, el SNS se divide en Áreas de Salud y Zonas de Salud.

\section{Áreas de salud}

El artículo 56 de la LGS recomienda a las Comunidades Autónomas delimitar en su territorio demarcaciones denominadas Áreas de Salud, considerando que tienen que organizar un Sistema Sanitario coordinado e integral. Sigue diciendo la ley, en el apartado 2 del artículo 56, que "Las Áreas de Salud son las estructuras fundamentales [...], responsabilizadas de la gestión unitaria 
[...] y de las prestaciones sanitarias y programas sanitarios a desarrollar por ellos."

Para su dirección, las Áreas de Salud contarán con un órgano propio en el que han de participar las Corporaciones Locales con una representación no inferior al 40\%.

La delimitación de las Áreas de Salud se hará en función de "factores geográficos, socioeconómicos, demográficos, laborales, epidemiológicos, culturales, climatológicos y de dotación de vías y medios de comunicación, así como las instalaciones sanitarias del Área" (L.G.S. artículo 56, punto 4).

En cuanto a la población del Área de Salud, estará comprendida entre 200.000 y 250.000 habitantes. La Ley hace la excepción de "las Comunidades Autónomas de Baleares y Canarias y las ciudades de Ceuta y Melilla, que podrán acomodarse a sus específicas peculiaridades. En todo caso, cada provincia tendrá, como mínimo, un Área”. En nuestro caso concreto, Castilla y León está estructurada en 11 Áreas de Salud y la provincia de Salamanca constituye una única Área de Salud.

Cada Área de Salud estará vinculada o dispondrá, al menos, de un hospital general donde, además de la asistencia, se realizarán funciones de promoción de la salud, prevención de las enfermedades, investigación y docencia.

En cuanto a los órganos, la Ley ordena que las Áreas de Salud contarán como mínimo con un órgano de participación, otro de dirección y otro de gestión. El primero se llama Consejo de Salud de Área, el segundo: Consejo de Dirección de Área y por último el de gestión es el/la Gerente de Área.

\section{Zonas básicas de salud}

Para una mejor función a nivel de AP, las Áreas de Salud se dividen en zonas básicas de salud o zona de salud. Los criterios para su delimitación serán el grado de concentración o dispersión de la población, las características epidemiológicas y las instalaciones y recursos sanitarios de que constan, de tal forma que la zona de salud es el marco territorial de la AP donde se desarrollarán “actividades encaminadas a la promoción, prevención, curación y rehabilitación de la salud, tanto individual como colectiva, [...] Como medio de apoyo técnico 
para desarrollar la actividad preventiva, existirá un Laboratorio de Salud encargado de realizar las determinaciones de los análisis higiénico-sanitarios del medio ambiente, higiene alimentaria y zoonosis" (LGS, artículo 63). En cuanto a lo que a nosotros se refiere, Salamanca consta de 36 zonas básicas de salud, 11 de las cuales están en la capital y las 25 restantes en la provincia.

\section{Centros y Establecimientos Sanitarios, Oferta Asistencial.}

La Ley 16/2003, de 28 de mayo, de cohesión y calidad del Sistema Nacional de Salud, en su artículo 27.3, establece que se determinará, por Real Decreto, las garantías mínimas de seguridad y calidad de los centros, servicios y establecimientos sanitarios. En su artículo 26.2 dispone que los centros serán públicos y conocidos por las personas usuarias. Asimismo, la Ley 14/1986, de 25 de abril, General de Sanidad, en su artículo 29.1, establece que los centros y establecimientos sanitarios precisarán autorización administrativa previa para su puesta en funcionamiento, para las modificaciones y también para las operaciones de calificación, acreditación y registro del establecimiento; así como que las bases generales sobre calificación, registro y autorización serán establecidas por real decreto.

Consecuencia de todo esto es el Real Decreto 1277/2003, de 10 de octubre, por el que se establecen las bases generales sobre autorización de centros, servicios y establecimientos sanitarios.

El artículo 2 del R.D. 1277/2003 ofrece una serie de definiciones de las que vamos a traer aquí solo las más utilizadas:

“a) Centro Sanitario: conjunto organizado de medios técnicos e instalaciones en el que profesionales capacitados [...] realizan básicamente actividades sanitarias con el fin de mejorar la salud de las personas...

b) Servicio sanitario: unidad asistencial, $[\ldots]$ dotada de los 
recursos técnicos y de los profesionales capacitados, $[\ldots]$ para realizar actividades sanitarias específicas...

c) Establecimiento sanitario: conjunto organizado de medios técnicos e instalaciones en el que profesionales capacitados, [...] realizan básicamente actividades sanitarias de dispensación de medicamentos o de adaptación individual de productos sanitarios.

d) Actividad sanitaria: conjunto de acciones de promoción, prevención, diagnóstico, tratamiento o rehabilitación, dirigidas a fomentar, restaurar o mejorar la salud de las personas, realizadas por profesionales sanitarios."

Por lo que hay que diferenciar entre Centros sanitarios y Establecimientos sanitarios.

\section{Centros sanitarios:}

Seguimos citando, de forma sucinta, algunas de las definiciones que ofrece el R.D. 1277/2003, de 10 de octubre:

"Hospitales (centros con internamiento): centros sanitarios destinados a la asistencia especializada y continuada de pacientes en régimen de internamiento (como mínimo una noche), cuya finalidad principal es el diagnóstico o tratamiento de los enfermos ingresados en éstos, sin perjuicio de que también presten atención de forma ambulatoria."

Los hospitales pueden ser generales, especializados, de media y larga estancia, hospitales de salud mental y tratamiento de toxicomanías y otros centros con internamiento. También se incluyen dentro de los centros sanitarios las consultas médicas y consultas de otros/as profesionales sanitarios/as.

"Centros de atención primaria: centros sanitarios sin internamiento que atienden al individuo, la familia y la comunidad, desarrollando funciones de promoción de la salud, prevención, diagnóstico, curación y rehabilitación...

"Centros de salud: son las estructuras físicas y funcionales que posibilitan el desarrollo de una atención primaria de salud 
coordinada de forma global, integral, permanente y continuada, y con base en el trabajo de equipo de los profesionales sanitarios y no sanitarios que actúan en ellos. En ellos desarrollan sus actividades y funciones los equipos de atención primaria.

"Consultorios de atención primaria: centros sanitarios que, sin tener la consideración de centros de salud, proporcionan atención sanitaria no especializada en el ámbito de la atención primaria de salud."

Como centros sanitarios, el R.D. 1277/2003, de 10 de octubre, recoge también los centros polivalentes, los centros especializados, clínicas dentales, centros de reproducción humana asistida, centros de interrupción voluntaria del embarazo, centros de cirugía mayor ambulatoria, centros de diálisis, centros de diagnósticos, centros móviles de asistencia sanitaria, centros de transfusión, bancos de tejidos, centros de reconocimiento médico, centros de salud mental y otros centros especializados.

\section{Establecimientos sanitarios}

E1 RD 1277/2003, de 10 de octubre define así:

"Oficinas de farmacia: establecimientos sanitarios privados de interés público, sujetos a la planificación sanitaria que establezcan las comunidades autónomas, en las que el farmacéutico titularpropietario de aquéllas, asistido, en su caso, de ayudantes o auxiliares, debe prestar a la población los servicios básicos recogidos en el artículo 1 de la Ley 16/1997, de 25 de abril, de regulación de los servicios de las oficinas de farmacia."

Y considera también como establecimientos sanitarios: botiquines, ópticas, ortopedias y establecimientos de audioprótesis.

\section{Oferta asistencial}

Como tal el R.D. 1277/2003, de 10 de octubre reconoce la medicina general/de familia, enfermería, enfermería obstétrico-ginecológica (matrona), podología, vacunación y todas las especialidades médicas reconocidas al día de 
hoy, así como inseminación artificial, banco de semen, laboratorio de semen para capacitación espermática, banco de embriones, recuperación de oocitos, planificación familiar, interrupción voluntaria del embarazo, tratamiento del dolor, medicina cosmética, cirugía refractaria, litotricia renal, rehabilitación, hidrología, fisioterapia, terapia ocupacional, logopedia, foniatría, cirugía menor ambulatoria, hospital de día, atención sanitaria domiciliaria, cuidados paliativos, atención sanitaria a la drogodependencia, obtención de muestras, extracción de sangre para donación, servicio de transfusión, medicina hiperbárica, medicina aeronáutica, transporte sanitario (carretera, aéreo, marítimo), terapias no convencionales, otras unidades asistenciales.

\section{Personal sanitario}

La formación del personal sanitario viene regulada por los artículos 34-39 de la Ley 16/2003, de 28 de mayo, de cohesión y calidad del Sistema Nacional de Salud. El artículo 40 trata del desarrollo profesional; el 41, de la carrera profesional; el 42 de la evaluación de competencias y el 43 de la movilidad de los/las profesionales.

En cuanto al volumen, tipos y género de los/las profesionales que trabajan al servicio del Sistema Nacional de Salud, según los datos facilitados por el MINISTERIO DE SANIDAD, SERVICIOS SOCIALES E IGUALDAD, a través de su obra SISTEMA NACIONAL DE SALUD SNS ESPAÑA 2012, vemos que en el primer nivel asistencial: centros de salud y consultorios locales trabajan más de 35.000 médicos/as (29.000 médicos/as de familia y 6.000 pediatras) con una representación femenina del 50\%.

Los/las profesionales de enfermería superan los 29.000, siendo un colectivo claramente feminizado: el $80 \%$ son mujeres. En el primer nivel asistencial, la tasa de médicos/as por 10.000 habitantes de población asignada, es de 7,6 y la de enfermería de 6,3.

En Atención especializada: hospitales y centros de especialidades, encontramos que hay más de 79.000 médicos/as (tasa de 17,2 por 10.000 
habitantes asignados), con una representación femenina del 40\%, y más de 128.000 enfermeras/os (tasa de 27,9 por 10.000), de las que el $90 \%$ son mujeres.

En cuanto a las especialidades, encontramos que el $50 \%$ se dedican a ramas médicas, el 30\% a quirúrgicas, algo más del 10\% está en servicios centrales (análisis clínicos, microbiología, radiodiagnóstico...) y alrededor del 10\% en urgencias.

En total, en la Sanidad pública trabajan alrededor de 272.000 médicos/as y enfermeros/as con un predominio femenino del $70 \%$. Los/las profesionales de medicina superan los 114.000 y enfermería alcanza los 157.000 profesionales. Entre los/las trabajadores de la Sistema Nacional de Salud predomina lo femenino y la enfermería.

También hay que considerar el personal en formación de postgrado, que llegan a ser 19.000 médicos/as internos/as y residentes.

En cuanto al Instituto Nacional de Estadística (INE) refiere sus datos a profesionales colegiados/as sin especificar el centro de trabajo.

El INE informa que en 2012, el número de enfermeros/as colegiados/as disminuyó el 1\%, quedando 265.569 personas, y dice que "es la primera vez que se registra un descenso en el número de inscritos en los colegios de enfermería desde 1977, año en que se inicia la serie comparable. Esta disminución fue más acentuada entre los menores de 35 años (-5,1\% respecto a 2011). Dentro de los/as profesionales de enfermería, 7.930 personas estaban registradas como matronas (2,8\%)". En físicos/as con especialidad sanitaria no hubo variación, siendo 49 personas. Todas las demás profesiones sanitarias aumentaron el número de colegiados/as. Los que mayor incremento presentaron fueron los/as odontólogos: 7,5 \% llegando a 31.261 personas; los/as podólogos/as: 4,1 \%, 6.050 personas; y los/as fisioterapeutas: 3,1\%, 38.630 personas.

Los que menos crecieron fueron veterinarios/as: 0,1\%, 29.096 personas, óptico-optometristas: $0,5 \%, 15.220$ personas y farmacéuticos/as: $0,8 \%, 65.471$ personas.

En cuanto a los médicos/as colegiados/as incrementaron su número en un $1,1 \%$ hasta llegar a un total de 228.917

Los psicólogos/as y protésicos/as dentales con especialidad sanitaria 
fueron incluidos/as en la estadística por primera vez en el 2012 y ofrecen los siguientes datos: 7.131 psicólogos/as y 6.185 protésicos/as dentales.

\section{Tasas de profesionales sanitarios/as}

En 2012 la tasa de profesionales de la sanidad que había por cada 100.000 habitantes era de 452,4 médicos/as, 513,3 enfermeros/as, 58,2 matronas por cada 100.000 mujeres en edad fértil. 133.0 farmacéuticos/as; 83,2 fisioterapeutas/as, 66.6 dentistas, 32,3 óptico-optometristas; 15,4 psicólogos/as; 12,8 protésicos/as dentales y 13,1 podólogos/as.

\section{Profesionales colegiados/as por sexo y edad.}

Las profesiones sanitarias están claramente feminizadas. En siete de las once profesiones analizadas en 2012, la presencia femenina predominaba. Y en las otras cuatro (medicina, veterinaria, prótesis dentales y física con especialidad sanitaria) la diferencia de género continúa disminuyendo.

Los dos colectivos más feminizados son los de Enfermería (el 84,3\% eran mujeres y en el caso de las matronas el 94,3\%) y Psicología con especialidad sanitaria $(76,7 \%)$. Los dos colectivos que siguen siendo androcentristas son los protésicos dentales (dos mujeres por cada diez hombres) y los físicos con especialidad sanitaria (tres de cada diez). Y esta feminización se hace notar más en los grupos más jóvenes.

Porcentaje de mujeres entre los colegiados/as por tipo de profesión sanitaria. (Fuente: INE 2012)

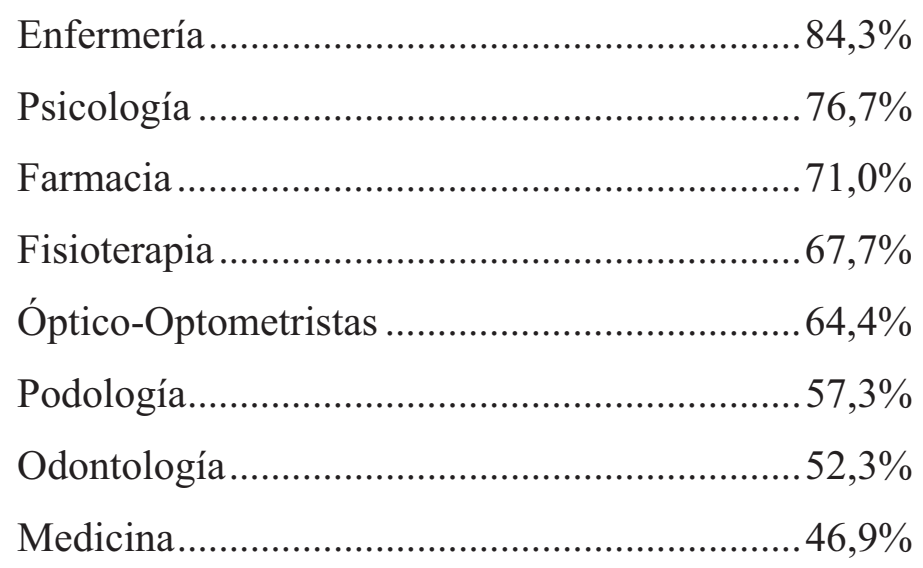


Veterinaria $43,6 \%$

Física $30,6 \%$

Protésicos Dentales $21,4 \%$

\section{Datos por Comunidades Autónomas:}

Castilla y León solo aparece en los datos referidos a las matronas: "En el caso de enfermeros/as con especialidad matronas las comunidades con mayor tasa de colegiados/as fueron Cantabria (118,5 por cada 100.000 mujeres en edad fértil) y Castilla y León $(111,8)$ y las que menos Canarias y Castilla la Mancha.

\section{Financiación del SNS}

El capítulo V del Título III de la LGS, que comprende 6 artículos, del 78 al 83, están dedicados a la financiación, siendo posteriormente modificada por la Ley 21/2001, de 27 de diciembre, de regulación de las medidas fiscales y administrativas del nuevo sistema de financiación de las Comunidades Autónomas de régimen común y Ciudades con Estatuto de Autonomía. Pero es la Ley 16/2003, de 28 de mayo de cohesión y calidad del Sistema Nacional de Salud, la que definitivamente, hasta el momento, a través de su artículo 10 establece que "la financiación es responsabilidad de las Comunidades Autónomas de conformidad con los acuerdos de transferencias y el actual sistema de financiación autonómica, sin perjuicio de la existencia de un tercero obligado al pago"

Sin embargo el legislador no deja en el aire el mínimo destinado, sino que lo marca ateniéndose a lo dispuesto por la Ley 21/2001, de 27 de diciembre, antes mencionada.

El legislador también prevé la posibilidad de la inclusión de una nueva prestación y establece que en ese caso la nueva prestación "se acompañará de una memoria económica que contenga la valoración del impacto positivo o negativo que pueda suponer" elevándose dicha memoria al Consejo de Política Fiscal y Financiera para su análisis y aprobación si procede. 


\section{Gasto sanitario}

EL MINISTERIO DE SANIDAD, SERVICIOS SOCIALES E IGUALDAD, en su obra SISTEMA NACIONAL DE SALUD SNS ESPAÑA 2012 informa del gasto sanitario público del año 2010 y lo cifra en casi 75 mil millones de euros, incluyendo el destinado a los cuidados de larga duración y el gasto sanitario total del país lo cifra 101000 millones de euros, por lo que el público viene a ser el 74,2\% del total.

Analizado en relación al PIB, el gasto sanitario total representa el 9,6 y el gasto sanitario público el $7,1 \%$, de forma que el gasto medio por habitante asciende a 1.622 euros.

Si comparamos nuestro gasto con el de la Unión Europea (EU-27) estamos algo por encima de la media que es el 9\% del PIB, siendo los países que más gastan en sanidad los Países Bajos, Alemania y Francia con un 12 y los que menos Estonia o Rumanía con un 6\%.

Desde una perspectiva funcional, el gasto se centra en la Atención especializada que se lleva el 56\%, lo que viene a ser 38.588 millones de euros, en segundo lugar viene el gasto farmacéutico: 19,4\% que son 13.380 millones de euros y la Atención Primaria con un 15,5 \% (10.651 millones de euros)

La Salud Pública, aparentemente es la que menos gasta, solo el 1,1\% lo cual es engañoso, pues en Atención Primaria se realizan muchas funciones de salud pública, prevención y promoción.

La remuneración del personal sanitario representa el 40\% (sin incluir el gasto en cuidados de larga duración) que en cifras representa casi 31.000 millones de euros, y la actividad concertada supone el 10,7\% del gasto total, es decir 7.389 millones de euros.

\section{Privatización de la Sanidad}

En 1997, el gobierno español promulgó la Ley 15/1997 de 25 de abril, sobre habilitación de nuevas formas de gestión del Sistema Nacional de Salud 
abriendo la puerta a la privatización de la gestión de la Sanidad.

Esta ley no surgió de improviso. Un amplio movimiento venía registrándose, a nivel internacional, sobre los sistemas sanitarios públicos de vocación universalista. En España, este movimiento revisionista sobre la sostenibilidad del gasto sanitario se plasmó en el Informe Abril, redactado por una comisión que presidía Fernando Abril Martorell ${ }^{14}$ de quién tomó la denominación. El informe fue presentado al Congreso de los Diputados en septiembre de 1991, suscitando una gran polémica. Sin embargo no tuvo una repercusión inmediata en la organización y gestión del SNS, pero las grandes líneas estratégicas que marcaba: el recorte directo del gasto y la reforma de la gestión "quedaron impregnando el entorno de nuestro sistema y de los legisladores" (ADSP de Salamanca, 2011, p. 94)

La primera norma de carácter nacional sobre estos aspectos es el RD-Ley 10/1996 sobre "habilitación de nuevas formas de gestión del Insalud" que dice: "La prestación y gestión de los servicios sanitarios y socio-sanitarios podrá llevarse a cabo, además de con medios propios, mediante acuerdos, convenios o contratos con personas o entidades públicas o privadas..."

En 1997, como hemos dicho más arriba, se promulga la Ley 15/1997 de 25 de abril, sobre habilitación de nuevas formas de gestión del Sistema Nacional de Salud.

Las nuevas formas de gestión fueron desarrolladas y reguladas en el Real Decreto 29/2000, de 14 de enero, sobre nuevas formas de gestión del Instituto Nacional de la Salud.

Estas normas vienen a establecer: la autonomía de gestión sanitaria, una mayor autonomía de los centros, y nuevas formas de gestión que podían adoptar las siguientes modalidades: fundaciones privadas, consorcios, sociedades mercantiles participadas mayoritariamente en el Insalud, fundaciones Públicas sanitarias, empresas públicas de derecho privado, gestión indirecta mediante acuerdos, convenios o contratos, concesión de servicios.

La mayoría de estas nuevas fórmulas de gestión han visto la luz a través de

\footnotetext{
${ }^{14}$ FERNANDO ABRIL MARTORELL (1936-1998) doctor en Ingeniería Agrónoma y Ciencias Políticas, jugó un rol en la política española desde 1969 hasta 1982, año en que abandona la política para dedicarse al mundo empresarial.
} 
fundaciones (hospitales de Verín o Salnés en Galicia, Alcorcón en Madrid, Manacor en Baleares, Arriendas en Asturias), pero también a través de empresas públicas (Hospital Costa del Sol, en Andalucía), cooperativas de EAP (Equipos de Atención Primaria) en Cataluña, y las "concesiones" como el Hospital de Alcira en Valencia. (ADSP de Salamanca, 2011)

El caso de las concesiones merece atención. En 1999, se inauguró el Hospital Universitario de la Ribera, ubicado en Alcira, en la provincia de Valencia, de donde surgió la nomenclatura Modelo Alzira, que hace referencia a una forma de gestión basada en cuatro pilares: propiedad pública, control privado, financiación pública y gestión privada. (DE LA ROSA TORNER Alberto; MARÍN FERRER M, TARAZONA GINÉS E, 2005)

Las críticas han venido por distintos motivos: por un lado, este modelo reduce a la mínima expresión las facetas de docencia e investigación, que quedan a cargo del sector público. En cuanto a lo económico, la primera Unión Temporal de Empresas (UTE) que tomó la gestión del hospital entró en pérdidas irreversibles, por lo que en 2003 rompió el contrato, a pesar de lo cual fue indemnizada con varias decenas de millones de euros. Tras un nuevo concurso, la gestión fue asignada a la misma UTE con un incremento de lo cobrado por habitante y la exclusión de las prestaciones de farmacia, oxigenoterapia, prótesis y transporte sanitario (BOIX, Andrés, 2011).

A pesar de todo, la fórmula se ha extendido. Tras el hospital de La Ribera (Alcira), llegaron Torrevieja (2006), Dénia (2006), Manises (2009) y VinalopóElche (2010).

También se ha exportado a otras comunidades, el hospital Infanta Elena de Valdemoro, es un hospital hermano del de Alzira, así como el Rey Juan Carlos de Móstoles, el Hospital de Torrejón y el de Collado Villalba. (PRATS, Jaime, 2013)

En 2012, el presidente de la Comunidad de Madrid, Ignacio González, anunció la privatización de la gestión de 6 hospitales y 27 centros de Atención Primaria, incluido el personal sanitario, viéndose afectados principalmente por esta medida el hospital de la Princesa y el Carlos III, lo cual ha provocado numerosas manifestaciones por parte del personal sanitario. (G. SEVILLANO, Elena, 2012) 


\section{Informe Bamberg}

El 25 de abril de 2011, en el vigesimoquinto aniversario de la Ley General de Sanidad, la Fundación Bamberg presentó y dio a conocer el documento: El Modelo de Futuro de Gestión de la Salud. Propuestas para un Debate, conocido como el Informe Bamberg.

La Fundación Bamberg se presenta a sí misma como "una fundación española no gubernamental de carácter estatal, miembro de la Asociación Española de Fundaciones, con presencia en Europa y América, que tiene por objeto la mejora de la gestión de la salud, mediante acciones [...] orientadas a la mejora de la salud y de la eficacia y eficiencia del sistema sanitario." La Fundación tiene por misión "desarrollar acciones orientadas a mejorar la salud de los ciudadanos" y por objetivos "la mejora de la gestión de la salud y el impulso de las tecnologías de la salud" (FUNDACIÓN BAMBERG)

El informe contiene las propuestas de la Fundación para el fortalecimiento de la sanidad en España. La Fundación aclara en su Informe (p. 15) que en su preparación han intervenido más de cien expertos e instituciones públicas y privadas, "Sin embargo, es un documento elaborado por la Fundación y, por tanto, el hecho de haber participado en su elaboración aportando ideas y documentos no implica la aceptación y el acuerdo con todo lo que en el documento se dice."

El informe asegura que no se puede interpretar de ninguna manera que desde el documento se pretenda la privatización de la sanidad, sino que por lo contrario lo que busca es "la supervivencia de nuestro Sistema Nacional de Salud”. Hace una amplia exposición de los problemas del SNS, exposición no exenta de sesgo como se puede comprobar en la p. 30 en la que dice: "Tenemos un modelo funcionarial de los recursos humanos. Los médicos, enfermeras, auxiliares, etc. todos son funcionarios con plaza de por vida." El personal sanitario no es funcionario sino estatutario, y solamente tienen plaza de por vida los que han superado el proceso de concurso-oposición, todos los demás son contratados temporales.

El informe repite con insistencia el inminente peligro de colapso en la financiación del SNS y propone "un modelo en el que estén separadas las funciones de financiación, de aseguramiento y de provisión de servicios, 
contemplando la concurrencia de aseguradoras privadas, públicas y la posibilidad de coaseguro privado." (p. 37)

Promulga como valores del nuevo modelo la solidaridad, el bien común, la libertad individual, el premio al esfuerzo, a la iniciativa, la actividad emprendedora y la innovación. Sostiene que el Estado debe garantizar los servicios pero no necesariamente producirlos.

Expone el marco legislativo sobre el que se basa el nuevo modelo así como su política sanitaria, sus concepciones sobre la financiación y el aseguramiento, su modelo de gestión asistencial y de costes. Dedica un apartado a los profesionales, analiza su situación actual y propone un nuevo modelo de personal. También trata la gestión farmacéutica, las tecnologías para la salud y la investigación.

\section{Críticas al Informe Bamberg:}

En el mismo mes de abril de 2011, la Federación de Asociaciones para la Defensa de la Sanidad Pública (FADSP) publicó su Análisis del Informe de la Fundación Bamberg: "El modelo de futuro de gestión de la Sanidad”, en el cual denuncia que la Fundación mezcla a la FADSP con grupos de corte neoliberal como el gabinete de Garrigues Walker, impulsor de la privatización de la sanidad, para legitimar sus propuestas, dando "una falsa imagen de pluralidad y equilibrio". La FADSP sostiene que la Fundación pretende dar respaldo teórico a la privatización de la Sanidad, para lo que propone un nuevo modelo sanitario que haga tabla rasa de la Constitución, de la Ley General de Sanidad y de las leyes de salud autonómicas, con el fin de acabar con el derecho a la salud transformándolo en una mercancía.

La FADSP afirma que le Informe Bamberg responde a los intereses de la industria farmacéutica, de las tecnologías sanitarias y de las aseguradoras privadas por lo que está basado en un análisis incompleto y sesgado de la información, originando una propuesta llena de contradicciones y concretada en medidas muy difíciles de llevar a la práctica, que desarticularían el SNS además de conllevar un coste muy superior al actual, sin garantía ninguna de mejorar las prestaciones.

La FADSP concluye con su absoluta desvinculación del Informe Bamberg. 
Aunque el reconocimiento de la salud como derecho es un largo proceso que se desarrolla fundamentalmente a partir del siglo XIX, el SNS de que disfrutamos hoy tiene una vida corta. La red de hospitales y centros de salud que se extiende por toda España cuenta con pocas décadas. Por citar algunos podemos decir que en Madrid, el hospital la Paz fue inaugurado en 1964; el "12 de Octubre" en 1973; el Ramón y Cajal, en 1977. En Salamanca, el Virgen Vega, en 1965, el Clínico, en 1975...

CALVO SÁNCHEZ, María Dolores (2011), afirma que la Administración Pública del siglo XXI se enfrenta a un nuevo reto: la evaluación del desempeño y la sostenibilidad del sistema sanitario español. Los avances tecnológicos, la eficacia y eficiencia como objetivos, la calidad y seguridad como exigencias, los avances en los derechos de la ciudadanía, la evolución del funcionario en empleado público, la buena gestión como valor incuestionable... justifican la necesidad de mejora en la Administración Pública en general y en la Administración Pública Sanitaria en particular.

El sistema sanitario es un instrumento social insustituible y un fundamento básico del Estado del Bienestar. La preservación de las instituciones del bienestar, como la sanidad, no es una opción, es una exigencia irrenunciable, por lo que se hace imperativo plantear políticas que garanticen la sostenibilidad y cohesión del propio sistema.

"Una estrategia pendiente es destacar el valor de los empleados públicos sanitarios (entiéndase también empleada pública) como elemento vertebrador o pilar fundamental de las Administraciones Públicas. No debemos olvidar, que los recursos humanos son la herramienta indispensable para transformar la estrategia en objetivos operativos.” (CALVO SÁNCHEZ, María Dolores, 2011, p.515) 

CAPÍTULO III

LA FEMINIZACIÓN DE LAS

PROFESIONES SANITARIAS 

Aunque en las últimas décadas la mujer ha conquistado el mundo laboral, tradicionalmente las profesiones, y las sanitarias especialmente, han estado rígidamente distribuidas por sexo. Desde esta perspectiva es importante tener en cuenta, como sostiene ORTIZ-GÓMEZ, Teresa (2004) que al igual que la sociedad es algo construido, las profesiones como elementos sociales que son, han sido construidas y practicadas por personas de uno $\mathrm{u}$ otro sexo, asociando profesión y características de género como si fuera algo natural e inmutable.

Hasta los siglos XIX y XX en que la mujer consigue poner un pie en la Universidad $^{15}$, las profesiones de médico, boticario y veterinario fueron desempeñadas exclusivamente por hombres, mientras que enfermería y parteras eran practicadas por mujeres como si no pudiese ser de otra manera; pero esto en realidad era la consecuencia de políticas activas y mantenidas de exclusión de la mujer y de su reclusión en nichos laborales. La incorporación, a ciertas profesiones, de valores considerados como masculinos ha sido un proceso activo e incluso cambiante, como ocurrió en los siglos XVIII y XIX con la atención facultativa al parto, reconvirtiendo un espacio tradicionalmente femenino en masculino. Es más, en 1988 la OMS describe como natural lo construido: "En las sociedades occidentales, el estereotipo masculino incluye características tales como la ambición, la competitividad, la agresividad, la dominación, la racionalidad y la objetividad, mientras que el estereotipo femenino se caracteriza por la sumisión, la pasividad, la dependencia, el cuidado de los demás, la emotividad y la subjetividad" (OMS. Función de las mujeres en la asistencia sanitaria. Ginebra. Organización Mundial de la Salud 1988, nº 65. Citado por GARCÍA BAÑÓN, Ana María, 2004)

Pero como muy bien apunta Simone de BEAUVOIR en el segundo sexo (2011, p. 45), tomando palabras prestadas de POULAIN DE LA BARRE: "Todo

\footnotetext{
${ }^{15}$ En España, la Real Orden de 8 de marzo de 1910 permitió el acceso de la mujer a la Universidad española en igualdad de condiciones. Anteriormente, 36 mujeres lo habían conseguido tras solicitar permisos especiales y superar innumerables problemas.(AAVV. Doctas, doctoras y catedráticas, 2010)
} 


\section{CAPÍTULO III. LA FEMINIZACIÓN DE LAS PROFESIONES SANITARIAS}

cuanto han escrito los hombres sobre las mujeres debe ser sospechoso, pues son a un tiempo juez y parte."

Como decíamos al principio, la mujer ha ido conquistando el mundo laboral, y especialmente el sanitario. Este proceso de feminización se ha debido al incremento de mujeres que estudian ciencias de la salud, y puesto que esta tendencia permanece, es de esperar que la feminización de estas profesiones siga aumentando. (ORTIZ-GÓMEZ, Teresa, 2007). Este cambio se ha visualizado más en las profesiones como medicina, odontología y veterinaria, porque partían de tasas de feminización muy bajas.

El INE proporciona datos desagregados por género desde 1994, momento a partir del cual podemos valorar la evolución.

\begin{tabular}{|c|c|c|c|c|}
\hline & \multicolumn{2}{|c|}{1994} & \multicolumn{2}{c|}{2013} \\
\hline & Mujeres & Hombres & Mujeres & Hombres \\
\hline Médicos & $33,49 \%$ & $66,51 \%$ & $47,55 \%$ & $52,45 \%$ \\
\hline Dentistas & $29,5 \%$ & $70,46 \%$ & $53,16 \%$ & $46,84 \%$ \\
\hline Farmacéuticos & $63,48 \%$ & $36,51 \%$ & $71,24 \%$ & $28,76 \%$ \\
\hline Veterinarios & $23,44 \%$ & $76,56 \%$ & $44,55 \%$ & $55,44 \%$ \\
\hline Enfermeras & $78,84 \%$ & $21,16 \%$ & $84,38 \%$ & $15,62 \%$ \\
\hline Matronas & $96 \%$ & $4 \%$ & $94 \%$ & $6 \%$ \\
\hline
\end{tabular}

Elaboración propia de los porcentajes y del gráfico a partir de los datos facilitados por el INE sobre: Profesionales Sanitarios Colegiados a 31 dic 2013. Más información en:

http://www.ine.es/jaxi/menu.do?type $=$ pcaxis\&file=pcaxis \&path $=\% 2 \mathrm{Ft} 15 \% 2 \mathrm{Fp} 416 \% 2 \mathrm{~F} \% 2 \mathrm{Fa} 2013$ Consultado 9 nov. 2014.

Observamos que las profesiones más feminizadas en 1994 eran matronas, enfermeras y farmacéuticas; y las que menos veterinarios, dentistas y médicos. Los médicos y veterinarios, que partían de un predominio masculino, evolucionan hacia una proporción equilibrada, sobre todo en medicina, y en el caso de los dentistas es incluso superada, llegando la mujer a representar el 53,16\%. 
Enfermeras y farmacéuticas, profesiones muy feminizadas ya de base, mantienen esa dirección. El caso de las matronas, colectivo compuesto casi exclusivamente por mujeres, es el único en el que la representación masculina sube del $4 \%$ al $6 \%$.

La feminización, no solamente supone una mayor presencia de la mujer, sino que trae consigo un cambio de orientación en el ejercicio de la profesión: "La mujer no repite los roles masculinos sino que aporta su singularidad." (VÁZQUEZ VEGA, Pablo, ALBERT LÓPEZ-IBOR, Rocío, C. BOSCH, José Luis, CABRILLO RODRÍGUEZ, Francisco, CHORÉN RODRÍGUEZ, Pilar; et al. 2010, p. 12). Algunos expertos señalan que la mujer presenta en el ejercicio de su profesión una mayor tendencia en la prevención y los cuidados, mientras que el perfil masculino se centra más en la curación. Por lo que la feminización de la Sanidad debe estudiarse desde una perspectiva cuantitativa descriptiva, pero también desde una perspectiva cualitativa. Atendiendo a esta última, una marcada diferenciación de género se manifiesta en cuanto a la dedicación a la profesión. Más de la mitad de los hombres tienen varias ocupaciones combinando la esfera hospitalaria con la no hospitalaria, y lo público con lo privado. Mientras que sólo una cuarta parte de las mujeres optan por el pluriempleo, priorizando la conciliación de la vida laboral y familiar sobre el máximo desarrollo de la carrera profesional.

En el caso concreto de la profesión veterinaria se han producido cambios notables. Hemos pasado del tradicional veterinario rural a un veterinario urbano que trabaja para las Administraciones Públicas o que está al frente de una clínica de animales pequeños. Estos puestos los vemos, cada vez con mayor frecuencia, ocupados por mujeres jóvenes. Por lo que "la feminización de las profesiones sanitarias en general, y de la Veterinaria, en particular, no es sólo el resultado de la incorporación acelerada de la mujer al mercado de trabajo, sino también del efecto de cambios estructurales importantes que han tenido lugar en estas profesiones." (VÁZQUEZ VEGA, Pablo et al. 2010, p. 169)

En cualquier caso, el espacio sanitario no ha sido ajeno a la mujer a lo largo del tiempo. Históricamente la encontramos como curadora y cuidadora, aunque la primera aparezca definida como bruja. No es de extrañar, por lo tanto, que la mujer se sienta atraída por "mercados laborales que le ofrecen servicios 
cercanos al papel histórico y sistema de valores de la mujer." (VÁZQUEZ VEGA, Pablo et al. 2010, p. 191)

Pero también podemos decir que aunque la lucha de la mujer por conquistar el espacio laboral se hace sentir de forma notable, no está exenta de una dura resistencia que la desvía hacia espacios donde queda recluida, apartándola de los puestos de toma de decisiones y dificultando su trabajo como investigadora.

\section{Enfermería.}

\section{Breves antecedentes históricos}

Es frecuente creer que la enfermería nació con Florence de Nightingale, sin embargo, hallazgos fósiles como el cráneo desdentado de Dmanisi, en la República caucásica de Georgia, demuestran que hace 1,8 millones de años ya había personas que invertían energía en mantener con vida a miembros físicamente discapacitados del grupo o, dicho de otra manera, que los cuidaban, que prestaban cuidados al servicio de una vida ajena. (PICAS CONTRERAS, Joan, 2006).

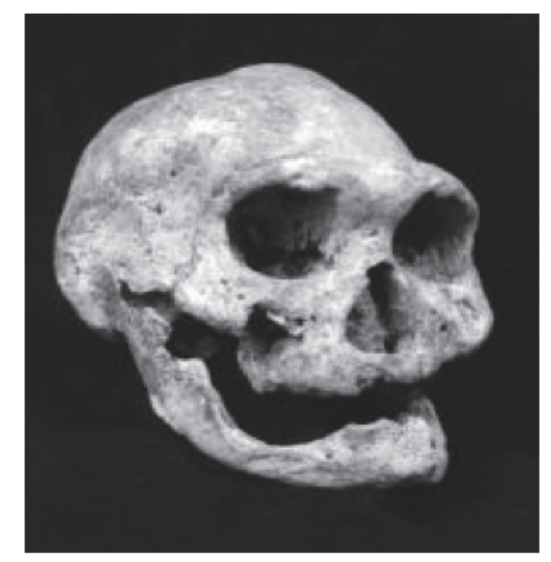

Cráneo desdentado de Dmanisi. Imagen disponible en: http://www.ugr.es/ pwlac/G22_08Joan_Picas_Contreras.html Consultado: noviembre 2014 
Este hecho concreto, la persona desdentada que precisaba cuidados de alimentación, conduce al análisis etimológico de los términos utilizados para nombrar la profesión enfermera, ya que precisamente el inglés utiliza la palabra nurse, que significa nodriza y deriva del latín nutrix, nutrire (nutrir). El español prefiere el vocablo enfermero/a: persona destinada a la asistencia del enfermo, al igual que el francés: infirmier/ère, que derivan del latín in-firmus (débil, no firme). Por su parte, el alemán utiliza el vocablo krankenschwester: hermana (schwester) del enfermo (Kranken).

Siendo el ser humano un individuo social y gregario, cuya fuerza y hegemonía en la naturaleza estriba en la cooperación y solidaridad, resulta que el cuidado a los demás es una necesidad que ha tenido que existir siempre, y ha recaído, desde que tenemos memoria histórica, principalmente en la mujer. En una primera etapa, la mujer, dentro del hogar, es la responsable de los cuidados que necesitan sus familiares. El objetivo principal de la mujer cuidadora es el mantenimiento de la vida frente a las adversidades del medio. Como dice COLLIÈRE, Marie Françoise (1992, p. 25) "Soigner, c'est donc entretenir la vie en assurant la satisfaction d'un ensemble de besoins indispensables à la vie, mais qui sont diversifiés dans leur manifestation”.

La mujer comparte con el hombre la función de engendrar, pero realiza en solitario la gestación, el amamantamiento y el mantenimiento de la vida en la etapa postnatal. Podríamos decir que por "inercia" sigue estando sola en su mantenimiento en cualquier otra fase subsiguiente. La mujer se encarga de buscar medios para mantener la limpieza y la higiene, tejidos para el vestido y el mantenimiento de la temperatura; y frutos, granos, raíces... para substituir el alimento que ella misma producía en forma de leche. Además cuenta con sus manos y abrazos, elementos fundamentales del contacto maternal, para crear bienestar. En una etapa posterior emplea vendas, curas, y todo lo que le proporcione la ciencia para mantener la salud. En este sentido DONAHUE, M. Patricia, RUSSAC, Patricia A. (1999, p.2) afirman: “A la Enfermería se la ha denominado la más antigua de las artes y la más joven de las profesiones”.

La historia de la Enfermería está intrínsecamente unida a la historia de la mujer: "La enfermera es el espejo en el que se refleja la situación de la mujer a 
través de los tiempos" (ROBINSON,1946, p. VII, citado por DONAHUE et al, 1999). Cuando la mujer estuvo confinada al hogar, la Enfermería fue un arte doméstico y su pleno desarrollo no se habría dado sin la emancipación femenina. El origen de los cuidados de enfermería en los cuidados maternos afianzó la idea de que la enfermera solo podía ser una mujer.

Sin embargo, las personas de ambos sexos poseen una tendencia innata a actuar frente al desamparo o el riesgo vital, como lo demuestra la creación de la Cruz Roja por parte de un hombre: Henri Dunant, y su reconocimiento social al haberle sido concedido el Premio Nobel de la Paz en 1901.

Otro tanto de lo mismo pasa con la aparición, tras la II Guerra Mundial, de las ONG como agentes de desarrollo, basadas en la solidaridad, y su aprobación social: "El reconocimiento definitivo a la labor de las organizaciones solidarias ha alcanzado su punto culminante con la concesión, el 15 de octubre de 1999, en Oslo, del Premio Nobel de la Paz a Médicos Sin Fronteras por su trabajo humanitario profesional, eficaz e independiente." (PICAS CONTRERAS, Joan, 2006)

Durkheim, uno de los padres de la sociología, postula en varias de sus obras - su tesis doctoral La división del trabajo social (1893) y Educación y sociología (1924, obra póstuma) - que es la solidaridad el valor que mantiene unida y cohesionada la sociedad moderna.

Podemos afirmar que el cuidado y la ayuda a los demás no es algo exclusivo de la mujer, aunque haya recaído tradicionalmente en ella tanto a nivel familiar como a nivel profesional. En esta última esfera, con el paso del tiempo, se evidenció que al amor y a la ternura había que sumarles conocimientos y habilidades, por lo que la enfermería se convirtió tanto en un arte como en una ciencia, pero esta evolución ha sido verdaderamente lenta.

\section{a) La Antigüedad}

El antiguo Egipto dejó un abundante legado de información a través de la piedra tallada y de los papiros, conocidos por el nombre de sus descubridores o sus propietarios: Ebers, Chester, Smith, Hearst, Kahoun, Berlín, Londres... Estas fuentes demuestran que el conocimiento que tenía el antiguo Egipto sobre 
medicina era amplio, hecho constatado por el historiador griego HERODOTO DE HALICARNASO (libro II párrafo LXXXIV): "Reparten en tantos ramos la medicina, que cada enfermedad tiene su médico aparte, y nunca basta uno solo para diversas dolencias. Hierve en médicos el Egipto: médicos hay para los ojos, médicos para la cabeza, para las muelas, para el vientre; médicos en fin para los achaques ocultos."

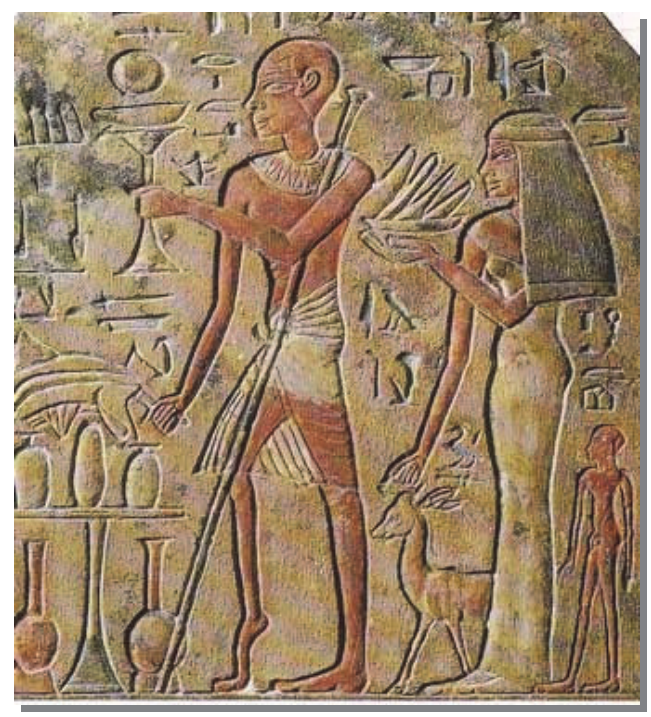

Discapacidad en el Antiguo Egipto: bajo relieve representando a un hombre con atrofia en la extremidad inferior derecha, pie equino y flexión de rodilla.

Disponible en: http://egiptomaniacos.top-forum.net/t4995p15-la-medicina-en-el-antiguo-egipto Consultado: agosto de 2015

Sin embargo no ha quedado nada recogido sobre labores de enfermería. SALAS IGLESIAS, Pedro Manuel (2012) sostiene que debido a que la posición de la mujer egipcia era elevada, quedó exonerada de los cuidados domésticos y enfermeros, realizados por sirvientes y esclavos. Pero esto no justifica la ausencia de esta información, hecho que sorprende por contraste con la riqueza de datos médicos conservados.

En la Grecia antigua florece la razón y se desarrollan considerablemente la filosofía, las artes, las letras y las ciencias. Pero la enfermería no se beneficia de avances notables por ser practicada por mujeres, esclavos y siervos, considerados todos jurídicamente inferiores; a lo que hay que añadir el desprecio griego por las actividades manuales. 
En la Roma pagana, aparte de los tradicionales cuidados aplicados dentro del ámbito familiar por la mujer como cuidadoras de niños y parteras, se desarrolla una medicina militar. Se organizaron unos primeros auxilios en los campos de batalla. Se construyeron hospitales militares denominados "Valetudinarias", donde cuidaban de los heridos una clase de ordenanzas conocidos como los "Nosocomi". Al ser atenciones aplicadas por hombres y en situaciones bélicas, dieron origen a otro tipo de ejercicio en cuanto a la práctica de los cuidados. (DONAHUE et al, 1999).

\section{La llegada del cristianismo}

Con el cristianismo aparece una nueva cosmovisión en torno a un único Dios omnipotente, padre de un hijo crucificado. La persona enferma, que sufre, es considerada la elegida de Dios; y la enfermedad, un instrumento de salvación, tanto para quien la padece como para quien le cuida. De esta manera, en los cuidados enfermeros se prioriza la espiritualidad, la entrega desinteresada y la abnegación sobre el saber y la razón, por lo que no fueron incluidos en el contexto gremial de la Baja Edad Media, como ocurrió con los barberos y sangradores (HERNÁNDEZ CONESA, Juana, 1995).

El cristianismo predica el altruismo puro, y la IGLESIA CATÓLICA ordena en su CATECISMO: dar de comer al hambriento, dar de beber al sediento, vestir al desnudo, visitar a los presos, albergar a los que carecen de hogar, cuidar a los enfermos y enterrar a los muertos, como obras de misericordia humana. Aparece la etapa vocacional de la enfermería.

SALAS IGLESIAS, Pedro Manuel (2012, p. 41) sostiene que: "los conocimientos teóricos eran casi inexistentes y los procedimientos aplicados muy rudimentarios. Lo importante era la actitud mostrada, centrada en la caridad, la sumisión, la religiosidad y la obediencia. Aparece la mujer cuidadora a la que COLLIÈRE, Marie Françoise (1992, p. 16) llama 'femme consacrée'."

En los primeros siglos de la era cristiana surgen hermandades y órdenes femeninas dedicadas al cuidado, cuyas integrantes, a menudo procedían de los estratos altos de la sociedad. SALAS IGLESIAS, Pedro Manuel (2012) hace mención de las diaconisas, las viudas, las vírgenes y las matronas. Sobre este 
punto, MATESANZ SANTIAGO, Mángeles (2012, pp. 91-92) menciona a las diaconisas y las viudas, y sostiene que "más tarde se incorporaron las vírgenes, las presbíteras, las canónigas y las monjas...”. Pero no todas se dedicaron al cuidado de enfermos y menesterosos.

El nombre de diaconisa viene del griego "diacona" que significa servir, esta nomenclatura del principio de nuestra era, reaparecerá en el siglo XIX, en el mundo protestante, con el resurgimiento de la enfermería. Las primeras diaconisas que se conocen son Febe y Olimpia. Febe es mencionada en la Biblia: "Os recomiendo a Febe, nuestra hermana, que es diaconisa de la iglesia de Cencres, para que la recibáis en el Señor de manera digna, como conviene a los santos, y la ayudéis en todo lo que necesite, porque también ella ha ayudado a muchos, y en particular a mí." (SAN PABLO, Carta a los Romanos 16, 1,2)

Las viudas, llamadas así en respeto a su edad, era otra congregación de mujeres dedicadas al cuidado de pobres y enfermos. Las vírgenes, cuyo papel no está muy claro, parece que se dedicaban a labores eclesiales y serían las precursoras de las monjas. Las matronas romanas, entre las que destacan Marcela, Fabiola y Paula, fueron mujeres de clase alta que se dedicaron al cuidado de los enfermos, crearon albergues para extranjeros, costeando los gastos ellas mismas.

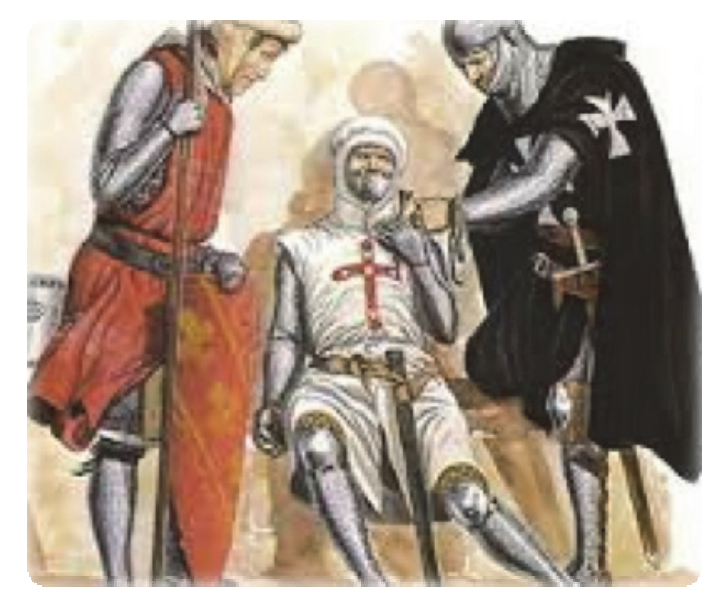

A partir del año 1095 y bajo la llamada del papa Urbano II, comienzan las Cruzadas. Con ellas surgen distintas órdenes masculinas religioso-militares. Actuaban como guerreros $\mathrm{y}$ enfermeros ${ }^{16}, \mathrm{y}$ fundaron hospicios y hospitales jalonando el camino de la peregrinación a Jerusalén. También se formaron comunidades de

\footnotetext{
${ }^{16}$ Imagen de Caballeros hospitalarios. Disponible: http://www.nursestavern.com/importedbeers/malenursingmuseum.html Consultado: agosto de 2015
} 


\section{CAPÍTULO III. LA FEMINIZACIÓN DE LAS PROFESIONES SANITARIAS}

mujeres que estuvieron subordinadas a las masculinas.

Las órdenes masculinas fueron conocidas como caballeros hospitalarios, ubicados históricamente entre los siglos XII y XIII. Entre estas órdenes de enfermeros cabe destacar las siguientes: los Caballeros de San Juan de Jerusalén, Caballeros Hospitalarios Teutónicos y Caballeros de San Lázaro. PARENTINI, Ma Rosa (2002, p. 42) sostiene: "Se sabe que las órdenes militares cuidaban de los enfermos [...] Consta que se caracterizaban por una gran severidad, con distinción de rango, y por la obediencia. [...] estas características influyen en la enfermería universal de épocas posteriores."

La orden de San Juan de Jerusalén pasó luego a llamarse Caballeros de Malta, disolviéndose en el siglo XVI. Fundaron varios hospitales, el más importante de ellos, fue el de la isla de Malta, con capacidad para mil enfermos.

Los Caballeros Teutónicos constituían una orden germánica de caballeros hospitalarios, por lo tanto aunaban funciones enfermeras, militares y religiosas.

La Orden de Caballeros de San Lázaro era también de corte militar hospitalario. El nombre les fue puesto por su especial dedicación a los leprosos. Lázaro era el leproso de la Biblia en la parábola de "El rico epulón" (LUCAS 16: 19-31) en la que el rico acaba en el infierno y Lázaro en el seno de Abraham. Esto determinó que el cuidado al leproso fuera visto como camino seguro de salvación, por lo que de todas las grandes enfermedades contagiosas de la Edad Media, solo la lepra contó con establecimientos especiales: las leproserías o lazaretos, cuyo principal objetivo era el aislamiento de los enfermos. No se intentaba la cura, pues no se conocía ni siquiera la causa, solamente se aplicaban cuidados de enfermería a base de remedios caseros.

Según surgen las Universidades, estas van ofertando estudios de Teología, Leyes, Medicina, Artes... Los barberos y cirujanos, al tener una estructura gremial de conocimientos propios, lograron integrarse con la titulación de Médico Cirujano. El sentido caritativo de los cuidados de enfermería, su realización en lo privado, y su falta de "corpus específico de conocimiento" determinaron su alejamiento por mucho tiempo del mundo Universitario. No será hasta 1623 en que aparece en Madrid el primer manual de Enfermería conocido en el mundo, titulado "La instrucción de enfermeros". Trata sobre el correcto cumplimiento de 
las órdenes médicas y de los protocolos de actuación de los enfermeros en casos de urgencias. Los cuidados de enfermería cuentan ya con una doctrina escrita, pero siguen careciendo de escuelas que impartan esas enseñanzas (GARCÍA BARRIOS, Silvia y CALVO CHARRO, Elena, 1992).

\section{El Renacimiento}

El siglo XV vino cargado de acontecimientos que cambiaron el mundo para siempre. La invención de la pólvora, de la imprenta y de la brújula; el descubrimiento de América; la expulsión del Islam de la península Ibérica, el nacimiento de España como nación y como imperio; la reforma luterana, la división de la Iglesia y la Contrarreforma religiosa, la caída de Constantinopla en manos de los turcos Otomanos, la peste negra, el Renacimiento artístico y cultural... determinaron un cambio en la cosmovisión social. El teocentrismo medieval se fue apagando, y el cuidado de enfermos y menesterosos perdió su atractivo como camino de salvación.

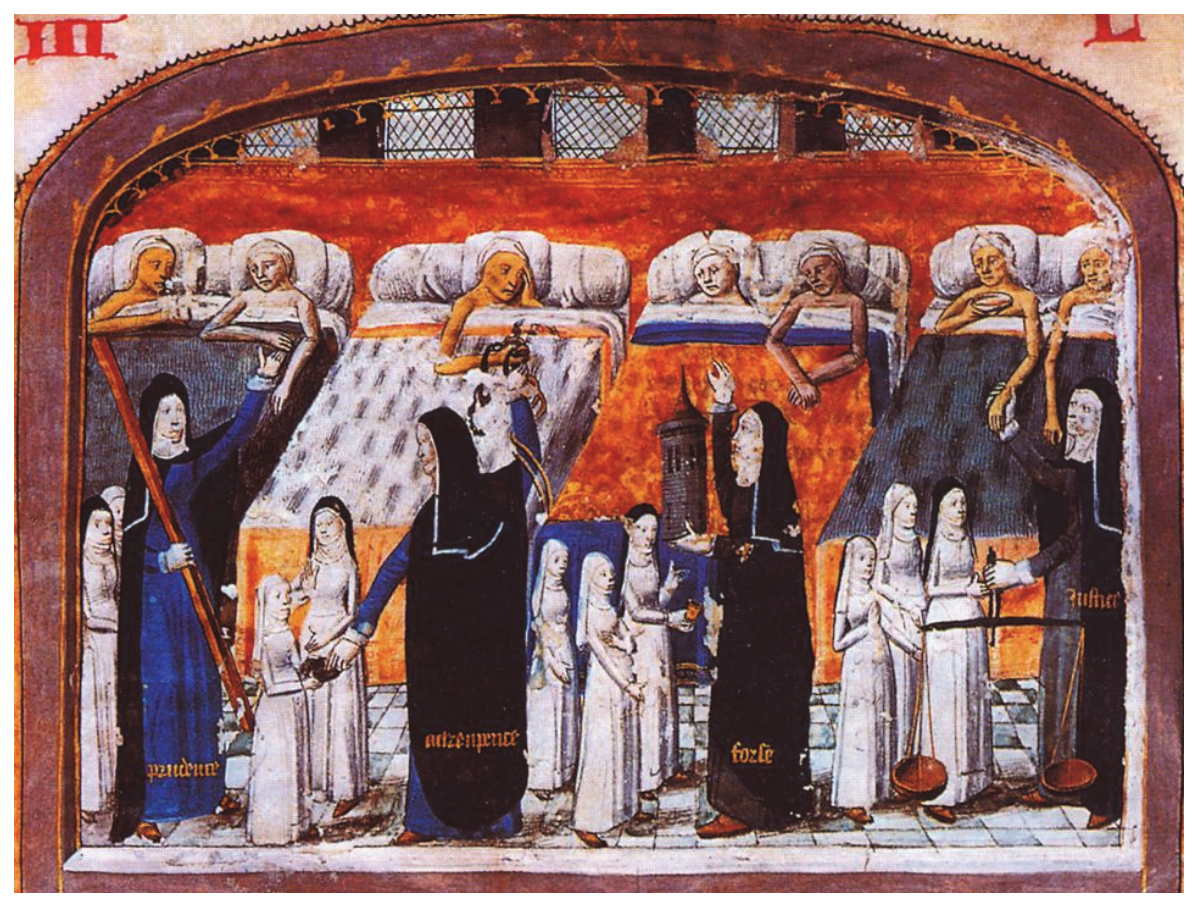

Hospital medieval. Imagen de un códice.

Disponible: http://tomascabacas.com/tag/hospitales-medievales/

Consultado: mayo 2015 
La Reforma de Lutero tiene lugar en 1517, a partir de ese momento, en los estados protestantes se produce el cierre masivo de instituciones católicas, entre ellas los hospitales, sin que por otro lado, se creara organización social sustitutiva alguna. PARENTINI, M ${ }^{a}$ Rosa (2002, p. 52) sostiene que "Los hospitales se transformaron en depósitos de enfermos; locales insalubres, carencias en materia de higiene y salas colmadas, al punto de que varias personas compartieran una misma cama."

Durante el siglo XVI continua produciéndose una confluencia de acontecimientos que conduce al abandono de los cuidados de enfermería altruistas. Por un lado, la peste negra había diezmado la población y sembrado el terror, apelando al Carpe diem. La lepra y la peste son, ambas, contagiosas, pero mientras que en el caso de la primera, la transmisión es lenta y difícil; en el caso de la segunda, la posibilidad de contagio era tan alta que arrasó Europa en pocos años. Los mendigos, enfermos y menesterosos dejaron de verse como la imagen de Cristo, pasando a ser la representación de la muerte insaciable. Los preceptos católicos de misericordia cayeron por una cuestión de vida o muerte.

Por otro lado, la Reforma Protestante basaba la salvación en la Fe, sin necesidad de obras; a la vez, estaba surgiendo el Renacimiento, llamando a las clases más favorecidas a una vida de ocio y disfrute.

Todo ello conllevó a un vacío en los cuidados al enfermo en el mundo protestante. El cierre masivo de organizaciones católicas, la sustitución del personal hospitalario religioso por mujeres laicas carentes de educación, y que en la mayoría de las ocasiones eran mujeres a las que se les sustituía penas carcelarias por trabajos en hospitales, condujo a lo que se conoce como la "época oscura de la enfermería" en el mundo protestante y que duró unos 3 siglos, desde 1550 a 1850 aproximadamente. 


\section{La enfermería en los países católicos}

Mientras tanto, en el mundo católico tenía lugar la Contrarreforma religiosa. Se crearon más de cien órdenes religiosas femeninas y masculinas, dirigidas en su gran mayoría al cuidado de los enfermos. Entre ellas cabe destacar:

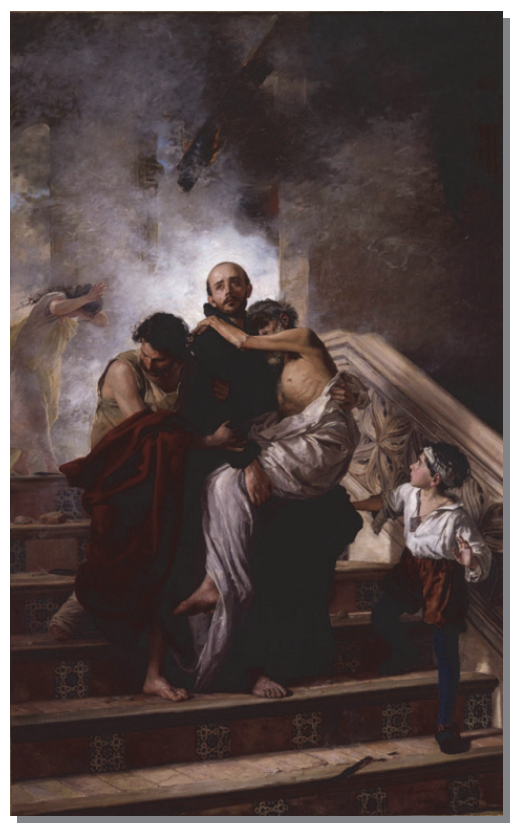

La Orden Hospitalaria de San Juan de Dios, constituida por hombres, también llamados hermanos de la misericordia. Fue fundada en 1572 en España, por discípulos de San Juan de $\operatorname{Dios}^{17}(1495$ - 1550), portugués de origen, quien dedicó su vida al cuidado de los pobres y enfermos. El primer hospital fue fundado en Granada, continuando la obra por España, Francia, Italia y por la Alemania católica, llegando incluso a las colonias.

La Orden de enfermería de los Ministros de los Enfermos y Mártires de la Caridad fue una orden masculina fundada en Roma por Camilo de Lellis (1550 1614) por lo que también fueron conocidos como Camilianos. Se dedicaban al cuidado hospitalario y al de los enfermos abandonados. Se les considera como los precursores de la Cruz Roja. Actuaron entre los siglos XVI Y XVII. Vestían una sotana en la que lucían una cruz latina roja.

La Orden de los hermanos Paules fue fundada, en Francia, por Saint Vincent de Paul (1581 - 1660), médico y sacerdote, quien, trabajando en un hospital parisino, entró en conocimiento de la labor de San Juan de Dios. Fue una

\footnotetext{
${ }^{17}$ Imagen de San Juan de Dios salvando del incendio a los enfermos del Hospital de Granada. Autor: Manuel Gómez-Moreno. 1880. Museo de Bellas Artes, Granada. Disponible: http://museovirtual.dipgra.es/es/obra/san-juan-de-dios-salvando-del-incendio-losenfermos-del-hospital-real-de-granada

Consultado: junio 2013
} 
orden mixta, pues contaba también con una rama femenina. Saint Vincent de Paul trabajó en colaboración con Sainte Louise de Marillac, a quien puso a la cabeza de las Hermanas de la Caridad. La orden tuvo una gran importancia pues las hermanas estaban dotadas de una educación básica de lectura, escritura y aritmética. Además simultaneaban los cuidados de enfermería con una obra de carácter social, organizando refugios nocturnos para los mendigos a los que se les enseñaba un oficio y se les buscaba trabajo.

PARENTINI Ma, Rosa (2002, p. 62) sostiene que: "Las H. de la Caridad desempeñaron tareas en el marco de la guerra de Crimea, cuidando a los soldados franceses [...]. Este hecho provocó una reacción en las fuerzas inglesas protestantes, que decidieron buscar en la propia Inglaterra una mujer no católica para cuidar a los soldados [...]. Esta mujer fue Florence Nightingale.”

En el tiempo que dura la "Edad oscura de la enfermería protestante" tienen lugar grandes avances de la medicina. El papado autoriza la disección de cadáveres, constituyéndose la anatomía como una ciencia base. Avanzaron los conocimientos en fisiología en cuanto a la circulación de la sangre, el pulso y la respiración fundamentalmente. Otro tanto ocurrió con las enfermedades infantiles, la ginecología, la obstetricia. Leeuwenhoek descubrió el microscopio. Malpighi hizo grandes avances en histología... Mientras tanto los hospitales carecían de organización y de cuidados profesionales.

\section{La enfermería en los países protestantes}

Como decíamos, al finalizar la Edad Media, en los países que apoyaron la reforma de Lutero, el cuidado de los enfermos cayó en lo que se llama la "Edad oscura de la enfermería”. Según van apareciendo las cofradías, transformadas después en gremios, acogen a los enfermos prestándoles cuidados, pero estos cuidados quedan excluidos de los espacios de aprendizaje gremiales (HERNÁNDEZ CONESA, Juana, 1995).

El siglo XVIII, con la Ilustración, viene teñido de ideales humanitarios. Se piensa que con la razón y el conocimiento se puede construir un mundo mejor.

John Howard (1726 - 1790), inglés de nacimiento, penalista de profesión y filántropo de vocación, dedicó 20 años de su vida a visitar cárceles y hospitales de 
toda Europa con el objetivo de mejorarlas y aliviar el sufrimiento de los presos. Sin embargo, su obra The state of the prisons no logró, de forma inmediata, respuesta estatal ni ciudadana. Pero sí encontró eco a mediados del siglo XIX, cuando la sociedad comenzó a sensibilizarse por los problemas sociales. Elizabeth Gurney Fry, (1780 - 1845) hija de banqueros por parte paterna y materna, casada también con un banquero, muy compasiva con el sufrimiento ajeno e influenciada por la obra de John Howard, logró obtener el apoyo del Estado inglés para realizar reformas sociales, carcelarias y hospitalarias.

En 1836, Theodor Fliedner (1800 - 1864) y su esposa, Frederika Munster, crean en Düsseldorf, Alemania, una sociedad de enfermeras visitadoras, "Las Diaconisas de Kaiserswerth", inspirándose en la reforma de las prisiones de Inglaterra y en el modelo de las diaconisas menonitas ${ }^{18}$ de Holanda. Este Instituto de Kaiserswerth fue uno de los factores más influyentes para la regeneración de la enfermería, pues incluía entre otras cosas la enseñanza de los cuidados durante un período que duraba 3 años, dotando de un carácter profesional actividades consideradas femeninas y altruistas.

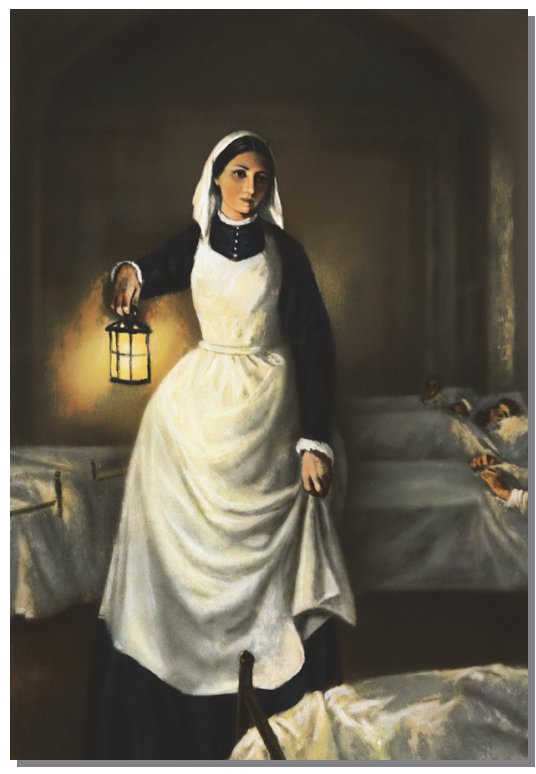

En este Instituto de Kaiserswerth, cursó estudios Florencia de Nightingale ${ }^{19}$ antes de ir a la guerra de Crimea (1853-1856) donde, aplicando sus conocimientos de estadística a la epidemiología, consiguió demostrar que la mayoría de las muertes se producían por falta de cuidados, y logró hacer caer la mortalidad del $42 \%$ al $2 \%$. A su regreso a Inglaterra, funda en 1860 su escuela de enfermería en el Hospital Saint Thomas de Londres, siendo la primera escuela laica de

\footnotetext{
${ }^{18}$ Los menonitas son una rama protestante creada en 1536 por el sacerdote católico de Frisia (Países bajos) Meno Simons (1496 - 1561).

${ }^{19}$ Imagen de Florencia de Nightingale, conocida entre sus soldados como la dama de la lámpara. Disponible en: http://florencianightingale.es.tl/BIOGRAFIA.htm

Consultado: junio 2014
} 
enfermería en el mundo. La concepción Nightingale supone la consideración de la enfermería como una opción profesional, con un contenido específico por investigar. (HERNÁNDEZ CONESA, Juana, 1995).

\section{La Cruz Roja}

Por otro lado, Henri Dunant, un hombre de negocios suizo, mientras viajaba por el norte de Italia, coincidió con la batalla de Solferino (24 de junio de 1859) entre austríacos, franceses y piamonteses. Terminada la contienda, sobre el suelo quedaron cuarenta mil soldados, muertos o heridos, de una $\mathrm{u}$ otra nacionalidad, todos abandonados a su suerte. "El sol del día 25 alumbró uno de los más espantosos espectáculos que puedan ofrecerse a la imaginación. [...] Quien recorre este interminable teatro de los combates de ayer encuentra a cada paso, y en una confusión sin igual, indecibles desesperaciones y todo género de miserias." (DUNANT, Henri, 1982, p. 10)

Dunant, movido por la compasión, se dedicó a socorrerlos con ayuda de la gente del pueblo y bajo un lema: no tener en cuenta nacionalidad ni bandera: "'Tutti fratelli', repetían con emoción. ¡Honor a estas compasivas mujeres, a estas jóvenes de Castiglione! Nada las asqueó, cansó o desanimó y su entrega sin alardes no pactó con la fatiga ni con la repugnancia ni con el sacrificio". (DUNANT, Henri, 1982, p. 16)

Tres años después publicó Recuerdos de Solferino dando lugar a la creación de la Cruz Roja, lo cual exigió la formación de personal en cuidados de Enfermería $^{20}$.

\footnotetext{
${ }^{20}$ La labor de Henri Dunant fue reconocida con el premio Nobel de la Paz en 1901.
} 


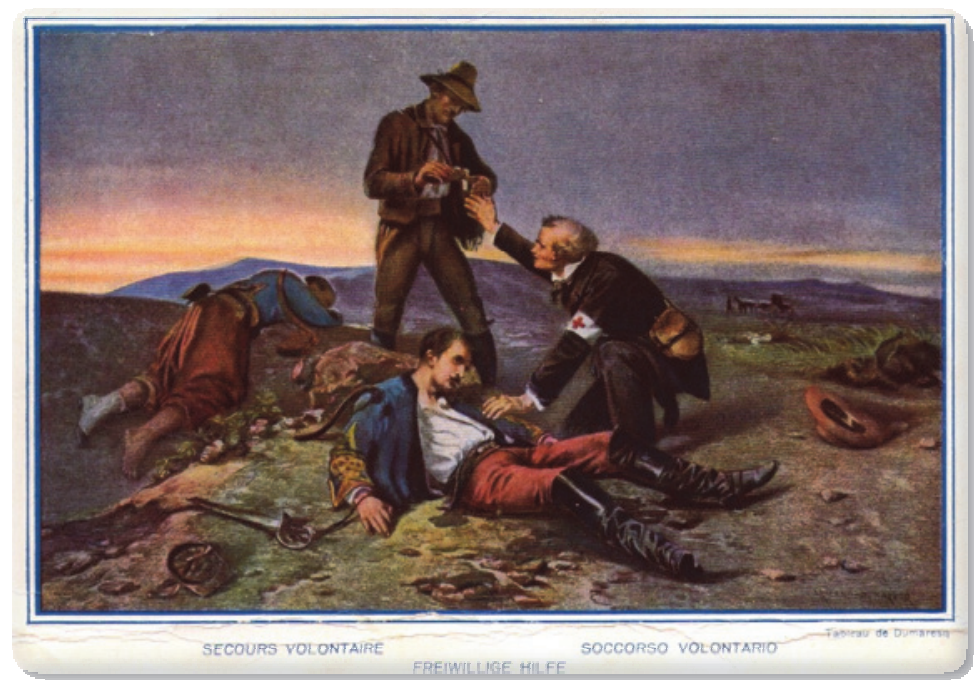

Jean Henri Dunant en la eterna tarde de Solferino.

Disponible en: https://costadamorteba.wordpress.com/2015/03/24/fragancias-de-coral-iv-la-cruz-roja/ Consultado: julio 2014.

\section{La Enfermería como profesión}

A partir de entonces surgen las asociaciones de enfermeras que fueron un elemento fundamental para el avance de la profesión.

FRAILE CALLE, Luis (2011, p. 101) sostiene que se puede: “considerar enfermería como profesión cuando cumple tres requisitos esenciales: una formación reglada, una retribución por su práctica y un código ético que garantice su ejercicio: hablamos del siglo XIX."

El primer intento de creación de una asociación de enfermeras se dio en Inglaterra en 1888 con la British Nurses Asociation. En 1899 se creó la más antigua de las organizaciones internacionales: el Consejo Internacional de Enfermeras. Siguieron la American Nurses' Association: ANA, la North American Nursing Diagnosis Association: NANDA. La Association Of Collegiate Schools Of Nursing: ACSN. La Asociación mexicana de enfermeras: AME. La Asociación Internacional de enfermeras católicas...

La enfermería anglosajona surge muy unida a las luchas feministas, pero en España la situación era otra, como sostiene GARCÍA BAÑÓN, Ana $M^{\text {a }}$ (2004): "la enfermería como profesión eminentemente femenina ha estado 
marcada históricamente por dos ideologías predominantes: una concepción religiosa sobre el cuidado y un discurso sexista sobre el rol social de la mujer."

Para recordar el recorrido histórico de los cuidados de enfermería como enseñanza reglada en España, resulta de gran interés la Tesis Doctoral de FRAILE CALLE, Luis (2011), de la que obtenemos algunos de los siguientes datos:

En 1857, la Ley Moyano reguló las enseñanzas de Matronas y Practicantes a la vez que suprime la enseñanza de Cirugía Menor o Ministrante. Los Practicantes y Matronas se formaban en 10 Facultades de Medicina: Madrid, Barcelona, Salamanca, Valladolid, Santiago de Compostela, Sevilla, Granada, Cádiz, Valencia, y Zaragoza. Los estudios duraban dos años con clases teóricas diarias de hora y media, y prácticas realizadas en hospitales públicos. Se podía acceder con la enseñanza elemental y la edad mínima requerida era de 16 años.

La primera escuela de enfermería en España fue la Escuela de Santa Isabel de Hungría, fundada en Madrid por el Doctor Federico Rubio y Galí, en 1896, instituyéndose el título de Enfermera en 1915, con unos estudios similares a los de Practicantes y Matronas. Pero las Escuelas de Enfermería eran exclusivamente femeninas, siendo el movimiento religioso y la presión médica quienes tuvieron mayor influencia en sus inicios.

En 1920, la Cruz Roja creó su primera Escuela de Enfermeras en Madrid, y algo después en Barcelona. En 1923, surge la Escuela Nacional de Puericultura adscrita al Consejo Superior de Protección a la Infancia. En 1924, aparece la Escuela Nacional de Sanidad, con el objetivo de instruir a los médicos y formar a las Enfermeras y el personal subalterno auxiliar. En 1932, aparece la Enfermera Visitadora de Higiene Mental y la especialista en la lucha antituberculosa. En 1933, se crea la Escuela de Enfermeras de la Generalitat de Catalunya.

Quedan instituidas, por lo tanto, tres formaciones académicas y profesionales; la de Practicantes, masculina; y las de Matronas y Enfermeras, femeninas; con tres Colegios Profesionales también distintos, el de Practicantes, con inscripción obligatoria, regulado por la Real Orden del 28/XII/1929; el de Matronas, mediante la Real Orden del 7/V/1930, y el de Enfermeras, creado por la Ley de Bases de Sanidad en 1944. 
Los años treinta del siglo XX son de especial relevancia para la historia de España y la de la Enfermería en particular, aconteciendo hechos que traerían importantes repercusiones en las décadas siguientes.

El ambiente prebélico que se vivía en los meses anteriores a la Guerra Civil española llevó a que la población intentara prepararse sanitariamente para lo que pudiera pasar, sin embargo, esto no evitó que la sublevación del 18 de julio de 1936 fuera un golpe que sorprendió a ambos bandos, sin medios suficientes para hacer frente a la situación. En un primer momento, la respuesta estuvo marcada por la inexperiencia y la improvisación, apareciendo una excesiva, desorganizada e ineficaz oferta sanitaria. El Gobierno tomó conciencia pronto de este problema y emitió un decreto el 22 de Agosto de 1936 que facultaba al Ministerio de Trabajo, Sanidad y Previsión a frenar la proliferación de hospitales en Madrid. En el artículo primero de esta disposición se enumeraban los 14 centros sanitarios a los que se les reservaba el nombre de "hospitales de sangre", donde se tenían que evacuar exclusivamente los heridos de guerra. El artículo tercero establecía una lista de nueve "hospitales de convalecencia", donde tenían que recibir atención los heridos leves y los enfermos de guerra.

El periodo de tiempo comprendido entre abril de 1936 y junio de 1939 marcó la mayor intensidad formativa en el campo sanitario que la mujer había conocido hasta aquel momento. Por primera vez, muchas jóvenes, tanto urbanas como rurales y que no pertenecían exclusivamente a familias acomodadas, pudieron acceder a una rápida formación y al ejercicio, una vez finalizada la contienda, de la enfermería. La gran divergencia en cuanto a la formación del personal que prestaba cuidados de enfermería, en la década de los años 40 del siglo XX, llevó al Gobierno a promulgar el Decreto de 27 de junio de 1952, por el cual se unificaban los planes de estudio existentes hasta aquel momento, Practicantes, Enfermeras y Matronas, en uno solo que otorgaba el título de Ayudante Técnico Sanitario (A.T.S.). Esto supuso, en aquel momento, un gran avance porque se unificaba en una sola carrera académica a todos los profesionales de la enfermería. El nivel formativo se elevó, por un lado por los requerimientos para el acceso: Bachillerato Elemental y Reválida; y por otro por los contenidos didácticos del plan. Las Escuelas se vincularon a las Facultades de Medicina como Escuelas Profesionales, y el título de A.T.S. fue considerado 
como de grado medio. Para completar el plan de estudios, aparecieron algunas especialidades: la antigua titulación de Matrona fue así englobada, en 1957, como especialización de los ATS. Además fueron apareciendo otras, Fisioterapia en 1957; Radiología y Electrología, 1961; Podología, 1962; Pediatría y Puericultura, 1964; Neurología, 1970; Psiquiatría, 1970; Análisis Clínicos, 1971; UrologíaNefrología, 1975.

El plan de estudios de ATS tenía contenidos teóricos y prácticos obligatorios, queriendo garantizar así que todos los profesionales recibieran una enseñanza igual. Sin embargo, hasta 1972 no se permitió la coeducación, existían Escuelas diferentes para sendos sexos. Las femeninas en régimen de internado, regido en numerosas ocasiones por monjas. La realización de las prácticas era diferente y también variaban algunas asignaturas. De esta forma, en las Escuelas femeninas se cursaba la asignatura "Enseñanzas del Hogar", que estaba sustituida en las masculinas por "Autopsia médico-legal".

Los Colegios Profesionales seguían manteniendo la diferencia por razón de sexo. La denominación genérica era "Colegio Oficial de Auxiliares Sanitarios" y presentaba tres secciones: ATS masculinos y Practicantes, ATS femeninos y Enfermeras, Matronas.

En la década de los años 60 y 70 del siglo XX, con la aparición de la Seguridad Social y la creación de grandes hospitales, la demanda de personal sanitario se incrementó exponencialmente en pocos años. Prácticamente todos los hospitales abrieron una Escuela para atender la propia demanda, coexistiendo Escuelas de las Universidades, de la Seguridad Social, privadas, de órdenes religiosas, Diputaciones, fundaciones, Cruz Roja, etc. Este aumento de la demanda trajo también consigo, una mayor incorporación masculina a la profesión enfermera.

\section{La Enfermería en la Universidad}

En julio de 1977 se aprobó el Real Decreto 2128/77 sobre “Integración en la Universidad de las actuales Escuelas de ATS como Escuelas Universitarias de Enfermería, plenamente integradas en el modelo educativo universitario.” De esta forma, la Enfermería pasó de formación técnica a educación académica. El acceso 
era el mismo que establecía la ley para todo el colectivo universitario. El plan de estudios estaba estructurado en tres años de enseñanza teórico-práctica, y el título pasó a denominarse: Diplomatura Universitaria en Enfermería (DUE).

Esto trajo como consecuencias: la disminución de la discriminación entre estudiantes por razón de sexo, el aumento del nivel de estudio tanto para el acceso a los estudios como en cuanto a los contenidos, la aparición del Área de Conocimientos de enfermería y la posibilidad de asumir funciones docentes e investigadoras. Pero la profesión siguió siendo un nicho laboral, pues fuera de la docencia, la única posibilidad de promoción era la supervisión, puestos que han sido confiados con preferencia a enfermeros masculinos, a pesar de las altas tasas de feminización de la profesión.

Con el Proyecto del Espacio Europeo de Educación Superior (E.E.E.S.), se elabora un nuevo modelo de formación de Grado, reflejado en la Ley 44/2003 de 21 de noviembre, de Ordenación de las Profesiones Sanitarias, la Ley 4/2007 de 12 de abril de Ordenación de las Enseñanzas Universitarias y la Orden de 21 de diciembre de 2009 sobre Verificación de Títulos.

Las reformas afectan a todos los estudios de las universidades europeas. En el caso concreto de enfermería representa un importante cambio, pues la equipara a todas las demás titulaciones universitarias. Se establece la obtención del título de Grado después de haber superado cuatro cursos académicos (240 ECTS) y la defensa de un trabajo de investigación, llamado trabajo fin de Grado (T.F.G.), quedando abierto el libre acceso al Máster y al Doctorado.

Hoy día asistimos a un proyecto de reforma que volvería a posicionar a la Enfermería como Diplomado medio al plantearse la reforma académica del 3+2, craso error a nuestro juicio. 

CAPÍTULO IV

VALORES 



\section{Los Valores en Filosofía}

En 1923, ORTEGA Y GASSET escribía en la Revista de Occidente, de la que era director, un artículo seriado titulado ¿Qué son los valores? Introducción a una estimativa, comenzando con las siguientes palabras: "Desde hace algún tiempo, [...] aparecen con mucha insistencia los vocablos "valores”, "valoración", "valorar" [...] La preocupación [...] en torno a los valores es uno de los hechos más hondamente reales del tiempo nuevo.” (ORTEGA Y GASSET, José, 2004, p. 11). En efecto, el estudio de los valores en filosofía arranca a mediados del siglo XIX y va a ocupar la primera mitad del siglo XX, sobre todo, el periodo de entreguerras.

REMOLINA VARGAS, Gerardo (2005, p. 3) sostiene que: "surgió como una reacción contra la teoría kantiana, que reconocía tan sólo la sensibilidad y la razón e ignoraba la estimativa, facultad de apreciar y preferir: el 'percibir sentimental' de Scheler, o 'l'ordre du cœur' de Pascal ${ }^{21}$ ".

A continuación, van a ser la Sociología, la Antropología, la Etnología, la Psicología, la Pedagogía, el Derecho, la Dirección de empresas... las que se van a interesar por el estudio de los valores.

Axiología fue el nombre que se le dio a esta rama del saber, del griego axio: valor y logos: tratado. El término fue introducido por el francés Paul Lapie en su tesis doctoral Logique de la volonté, $1902 \mathrm{y}$, posteriormente, fue definitivamente acuñado por Eduard von Hartmann en su obra Grundriss der Axiologie oder Wertwägungslehre, 1908.

También se encuentra la denominación de Estimativa, derivada del latín aestimare, que según la RAE significa: "referente a la estimación o valoración,

\footnotetext{
${ }^{21}$ Blaise Pascal (1623 - 1662) mantuvo con Descartes (1596 - 1690) una divergencia de opinión sobre la noción de orden. Descartes reconoce un único orden: el encadenamiento-lógico de las verdades, tal como se encuentra en los teoremas de geometría. En cambio Pascal habla de tres géneros de orden: “l'ordre de la chair, de l'esprit et du cœur”. 'L'ordre du cœur', según Pascal, tiene una intuición para presentir las cosas que pertenecen a su mundo y para valorarlas. (VILLAR EZCURRA, Alicia, 2010).
} 


\section{CAPÍTULO IV. VALORES}

facultad del alma racional para juzgar el aprecio que merecen las cosas, en filosofía: Teoría de los valores."

El diccionario etimológico de la lengua castellana, JOAN COROMINES, define estimar como "evaluar, apreciar, reconocer el mérito, juzgar"; e informa que la primera referencia escrita en Castellano data de 1438.

En cuanto al término valor, sustantivo del verbo valer, procede del latín valere que significa: "ser fuerte, vigoroso, potente, estar sano"; apareciendo por primera vez en Castellano escrito en 1097 (COROMINES).

Fueron los economistas del siglo XVIII como Adam Smith (1723-1790) y David Ricardo (1772-1823) los primeros en hacer un uso técnico del vocablo, e Immanuel Kant (1724-1804) uno de los primeros filósofos en incorporarlo al lenguaje filosófico, siendo luego profusamente utilizado por Friedrich Nietzsche (1844-1900), con lo que acabaría de tomar forma esta teoría. (SÁNCHEZ HERNÁNDEZ, Arturo José, 2005).

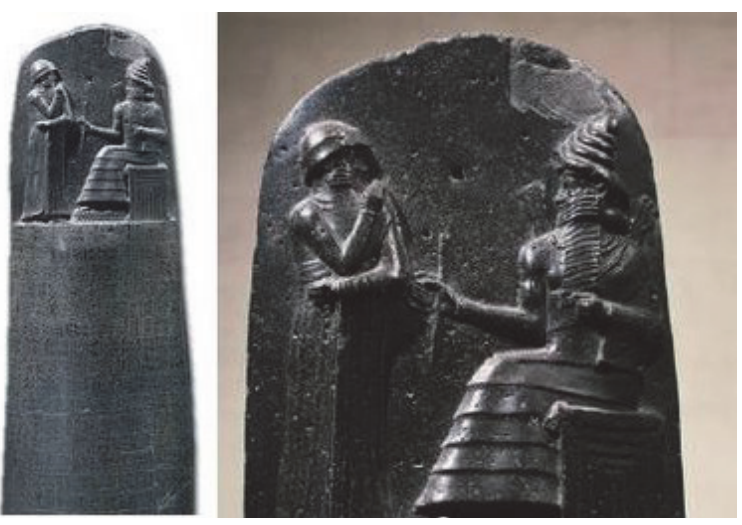

Código de Hammurabi.

Disponible en: https://unirhistoriaantigua.wordpress.com/2013/01/11/el-codigohammurabi/

Consultado: octubre 2014 
Pero los valores no son una cosa nueva, han sido una realidad subyacente en todas las culturas y han atraído la atención del ser humano desde los albores de la Historia. Apoyándonos en hallazgos arqueológicos de la antigua Mesopotamia como son los códigos de leyes que se conservan: el de Ur-Nammu, el más antiguo, fechado en el 2064-2046 a. C., escrito en lengua sumeria; el de LipitIstar, datado unos dos siglos después, también en lengua sumeria; el de Eshnunna, en lengua acadia, un siglo y medio después, y el de Hammurabi, el más conocido y el más reciente, escrito hacia 1728-1696 a. C (NARDONI, Enrique, 1993) podemos concluir que aquellas sociedades demuestran, a través de estos códigos, su preocupación por un orden de valores. Hecho análogo acontece con las tablas de la ley de Moisés. La Biblia relata así su creación: "Después dijo Yahvé a Moisés: Sube a la montaña y estate allí. Yo te daré unas tablas de piedra con la ley y los mandamientos que he escrito para instruirlos" (Éxodo 24, 12)

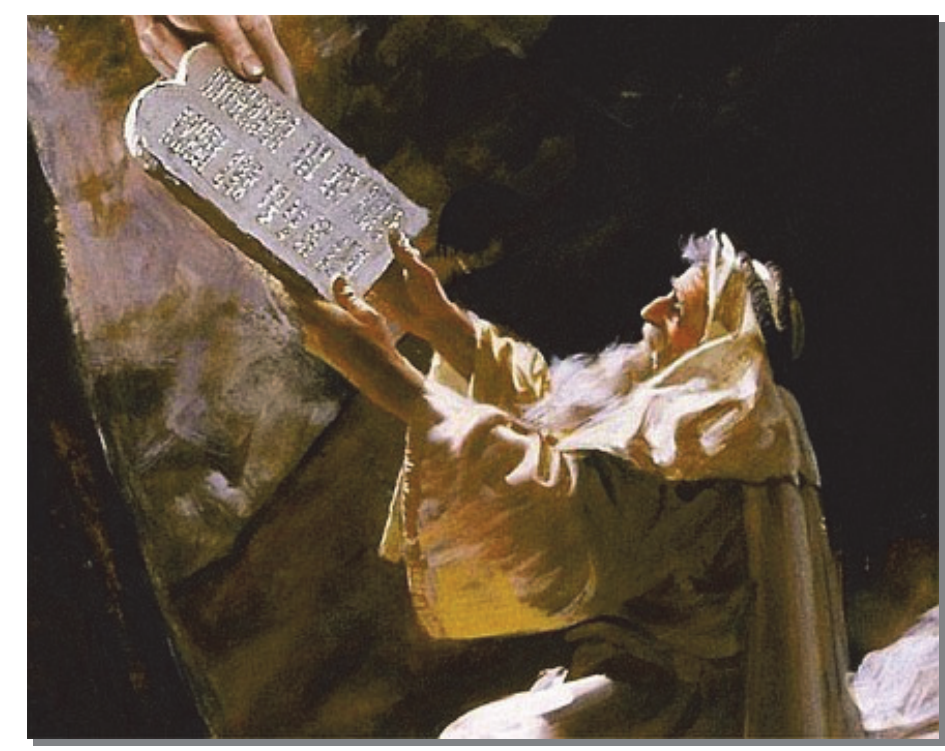

Moisés en el Monte Sinaí

Disponible: https://baxuanballahjeoqoj.wordpress.com/tag/ecclesia-iglesia/

Consultado: julio 2015

Estos códigos tienen en común la divinidad como fuente y la piedra como soporte buscando, así, un carácter trascendente y eterno para las normas dadas, con el objetivo de lograr en la población un determinado y perdurable modo de conducta. Idea que resuena a través de los siglos y encuentra eco en la ya clásica definición de valor que da Milton ROKEACH (1918 - 1988) en 1973: "Una 


\section{CAPÍTULO IV. VALORES}

convicción o creencia estable en el tiempo de que un determinado modo de conducta o una finalidad existencial es personal o socialmente preferible a su modo opuesto de conducta o a su finalidad existencial contraria." Definición que Salvador GARCÍA y Shimon DOLAN (1997, p. 63) simplifican de la siguiente manera: "los valores son aprendizajes estratégicos relativamente estables en el tiempo de que una forma de actuar es mejor que su opuesta para conseguir nuestros fines o, lo que es lo mismo, para conseguir que nos salgan bien las cosas."

Pero aunque los valores ${ }^{22}$ hayan estado siempre presentes, nunca fueron estudiados de forma expresa, en este sentido José ORTEGA Y GASSET (2004, p. 13) manifiesta su desconcierto:

"Es sobremanera extraño que problema tan esencial y tan amplio aparezca ante nosotros como una terra incógnita. Nos encontramos, en efecto, con la paradójica circunstancia de que mientras la filosofía, desde su iniciación, cavila sobre el problema del ser, su equivalente en extensión y dignidad, el problema del valor, parece, no ya escasamente atendido, sino ignorado por los filósofos."

Y sigue diciendo el autor que en realidad no ha sido rigurosamente así, pues aunque corran las épocas sin destacarlo formalmente, el tema se hace presente de una u otra manera, e incluso su presencia puede manifestarse como "una agresiva ausencia"; y que la forma en que más reiteradamente ha preferido ocultarse el valor es la idea del Bien, de lo bueno.

PÉREZ-DELGADO, Esteban; y GARCÍA-ROS, Rafael (1991, p. 3) sostienen que “'Valores” era la nueva acuñación lingüística a principios del siglo XX de lo que en buena medida se quería decir en el XIX con 'fenómeno moral'."; y BELDA PLANS, Pilar (1991, p. 79) apunta que "este concepto estuvo presente en la filosofía antigua a partir de Platón (427-347 a. C.) bajo los nombres de “Bonum", "Perfectio", "Arquetipo".

\footnotetext{
${ }^{22}$ En cuanto al pensamiento de Ortega y Gasset sobre los valores Democracia y Liberalismo léase también a FIGUERUELO BURRIEZA, Ángela (2010) Democracia y Liberalismo en el pensamiento de Ortega y Gasset.
} 
En efecto, "Sócrates pensaba que la capacidad de distinguir entre el bien y el mal estaba en la razón y no en la sociedad, además defendía que 'Quién sepa lo que es bueno también hará el bien', es decir que los conocimientos correctos conducían a acciones correctas." (NUÉVALOS RUIZ, Carmen, 2008, p.158)

Y si consultamos al discípulo de Sócrates en la República vemos por un lado que toda la obra gira en torno al valor Justicia, y por otro, la gran preocupación de Platón por la conducta humana y por el Bien, así lo manifiesta en un diálogo con Trasímaco: “¿O piensas que es cosa de poca importancia intentar definir una manera de conducirnos en la vida, guiándonos por la cual cada uno de nosotros pueda vivir una vida más provechosa?" (344e). Y al hablar del bien se expresa en estas palabras: "lo que se conoce no sólo puede ser conocido por causa del bien, sino que también se le añaden por su causa el ser y la esencia, aunque el bien no es esencia, sino que está por encima y más allá de ella en dignidad y poder" (509b). (PLATÓN, 1984)

Aristóteles (384 a. C. - 322 a. C.), como buen discípulo de Platón, no elude el tema, y en su obra Ética a Nicómaco (su hijo), trata de la templanza, cobardía, virtud, mansedumbre y cólera, de la justicia, de la bondad, de la recta razón, prudencia, sabiduría, de los deleites corporales, de la amistad... y comienza así el segundo capítulo del primer libro: "Pero si el fin de los hechos es aquel que por sí mismo es deseado [...] cosa clara es que este fin será el mismo bien y lo más perfecto..." (ARISTÓTELES, 2013)

La Escolástica, muy influenciada por Platón y más aún por Aristóteles, fue la Escuela filosófica de mayor influencia durante la Edad Media. El carácter predominante de esta época es la profunda religiosidad, de tal forma que la Filosofía se pone al servicio de la Teología y la Iglesia se erige como máxima autoridad en ética, en moral y por lo tanto en valores. La figura cumbre de la Escolástica es sin duda Tomás de Aquino (1224 - 1274), quien hace una síntesis del pensamiento antiguo llegado a través de las traducciones e interpretaciones árabes de Avicena y Averroes. Los escolásticos consideran que la formación moral consiste en la práctica de las virtudes. No lo consideran como un saber teórico sino como un obrar de modo acorde con el bien. (BEUCHOT, Mauricio, 2004). La Iglesia católica define virtud como "una disposición habitual y firme para hacer el bien". 


\section{CAPÍTULO IV. VALORES}

Fabelo Corzo sostiene que la axiología ha tratado de resolver los interrogantes sobre la naturaleza y el origen de los valores humanos, pero tampoco dentro de la Filosofía se ha llegado a un consenso único en cuanto a estas respuestas. Se pueden clasificar en cuatro grandes grupos las posiciones del pensamiento filosófico que han intentado dar una explicación: "la naturalista, la objetivista, la subjetivista y la Sociologista.” (FABELO CORZO, José Ramón, 2004, p. 21)

Otros autores, como Remolina Vargas, Gerardo (2005), distinguen solamente dos corrientes: la objetivista y la subjetivista.

\section{Concepción Naturalista}

Siguiendo a Fabelo Corzo (2004), la concepción naturalista es la de más largo recorrido en el tiempo, pues tuvo ya en Demócrito de Abdera (460-370 a. C.) un clásico representante. Para el filósofo griego el bien, lo útil, lo bello es lo que se corresponde con la naturaleza; mientras que el mal, lo perjudicial y lo horrible es lo antinatural, y la diferencia entre ambos campos de valores lo determina la capacidad humana para sentir deleite o sufrimiento. Pero aquí aparece un problema: no todas las personas se deleitan o sufren con lo mismo. Demócrito resuelve la contradicción apelando al conocimiento y a su insuficiencia, la causa del error estaría en la ignorancia, en el desconocimiento de lo mejor.

Al terminarse la Edad Media, la concepción naturalista resurgió con fuerza de la mano del Renacimiento y de la Ilustración. Los valores se asocian a las leyes naturales. El ser humano es concebido como parte de la naturaleza y por lo tanto poseedor de una bondad innata que pierde al vivir en sociedad. El desconocimiento de las leyes de la naturaleza es, para la Modernidad temprana, el origen de todo infortunio. Ignorancia y desgracia son asociadas. La fe constante en el poder de la razón humana alimenta la esperanza de construir un mundo mejor, libre de incultura, superstición y tiranía. Por lo tanto, todo lo racional es bueno y lo irracional malo. 


\section{Concepción Objetivista}

El paso del naturalismo ilustrado a la axiología contemporánea va a ser mediado por el filósofo alemán Immanuel Kant (1724 - 1804). Para Kant, el ser humano es egoísta por naturaleza, incapaz de llevar una vida moralmente valiosa, por lo que Kant concibe dos mundos: el del ser y el del deber, siendo este último suprasensible, inalcanzable a la experiencia. En la ética de Kant, el único valor es el respeto y la obediencia a la ley moral que se le impone al ser humano como un principio universal a priori, y que existe objetivamente aunque no en el mundo de la realidad empírica. (FABELO CORZO, 2004).

Kant es uno de los primeros filósofos en introducir el término valor (wert) en el lenguaje filosófico. Estas nociones de la filosofía kantiana son conocidas como prototeoría de los valores (Werttheorie). Sin embargo, en ningún momento define el término valor, lo da por entendido, lo cual puede considerarse paradójico si consideramos que Kant centró sus investigaciones en el estudio de tres valores fundamentales: La Verdad (Crítica de la Razón Pura), el Bien (Crítica de la Razón Práctica) y la Belleza (Crítica del Juicio) y su ética establece un valor supremo: el valor de la obediencia al deber, a la ley moral. (BELDA PLANS, Pilar; 1991).

Con Kant, se pasa de una ética material a otra formal en sentido $\operatorname{aristotélico~}^{23}$, pues hace depender el valor moral de una acción, no de su contenido material, sino de la adecuación de la voluntad a una ley universal; y establece una norma suprema de lo moral: “Obra de tal modo que la máxima de tu

\footnotetext{
${ }^{23}$ Aristóteles diferencia entre materia y forma, entendiendo por materia aquello de lo que está constituido algo, y por forma la morfología que adopta. Los valores eran estudiados por su contenido, por su "materia", no por la forma, de tal manera que se estudiaban atendiendo a la bondad o maldad de la acción, al contenido de la misma, es decir a la materia de la que está hecha la acción, concepción que perduraría hasta la Modernidad, por lo que todas las Éticas anteriores a la Modernidad son Éticas materiales. Y puesto que somos enfermeras y no filósofos, conviene aclarar ya la diferencia de los conceptos material y materialista. El primero ya lo hemos visto, en cuanto al segundo, se entiende por filosofía no materialista aquella en la que las ideas tienen validez con independencia de las condiciones materiales concretas, de modo que esas ideas están justificadas solo racionalmente, en base a argumentos. Por el contrario se entiende por filosofía materialista aquella que considera que los argumentos, aunque sean lógicamente válidos, es decir válidos racionalmente, pueden ser invalidados por ser incoherentes con las condiciones materiales concretas. Marx, un filósofo materialista, dice en el prólogo de su obra Contribución a la crítica de la economía política: "No es la conciencia de los hombres la que determina su ser, sino, por el contrario, es su existencia social lo que determina su conciencia”. (GARCÍA MORENTE, Manuel, 1980)
} 


\section{CAPÍTULO IV. VALORES}

voluntad, en cada caso, pueda valer como principio de legislación universal" (KANT, I., 1995, p. 49 citado por CARACUEL QUIRÓS, Ma Pilar, 2003, p. 33). Para Kant existe una ley a priori formal, por lo que será buena la acción que se realiza por puro respeto a la ley.

Friedrich Nietzsche $(1844$ - 1900) afirma que los valores de la civilización cristiana son inventados por el hombre para convencerse de su propio poder; surgen, por lo tanto, de la voluntad de poder: "el hombre ha perdido la creencia en su valor, cuando a través de él no actúa un todo infinitamente precioso: es decir, ha concebido un todo semejante para poder creer en su propio valor." (NIETZSCHE, 2006, p. 39). Afirma que los valores de la cultura occidental cristiana son convenciones admitidas para la supervivencia de los débiles, cree en la existencia de otros valores superiores, y proclama la necesidad de "preparar una transmutación de los valores para una determinada especie de hombres fuertes de grandísima fuerza de voluntad y espiritualidad..." (NIETZSCHE, 2006, p. 625).

Rudolf Hermann Lotze (1817 - 1881), médico y filósofo neokantiano, es el primero en interesarse por los valores de una forma expresa. No elabora aún una teoría de valores, pero crea un sistema en el que el concepto valor es la noción principal, según ese sistema hay objetos, hechos y valores. Lotze sostiene que el ser humano está dotado de una razón sensible a los valores o estimativa, capaz de reconocer como buenos o malos los actos de la voluntad. Lotze introduce el valor como noción principal de la Filosofía práctica, desplazando al deber que Kant había colocado en el lugar central. Para Lotze 'los valores no son, sino que valen', los saca de la esfera del ser para incluirlos en la esfera del valer, de forma que para él no son entes sino valentes. Para este pensador a los valores se les contraponen los contravalores, surgiendo en esta polaridad la propia esencia de los mismos. Lotze distingue entre 'valores' y 'cosas' abriendo dos corrientes de pensamiento: la objetivista según la cual los valores son objetivos y por lo tanto descubiertos por el sujeto; y la subjetivista, para la cual los valores son creados por el propio sujeto. (SÁNCHEZ HERNÁNDEZ, Arturo José, 2005)

Los neokantianos de la Escuela de Friburgo o Escuela de Baden, liderada por Wilhelm Windelband (1848 - 1915) y por Henrich Rickert (1863 - 1936) ven también en la filosofía de Kant una clara separación entre dos mundos: el del 
ser y el del deber, es decir, entre realidad y valor, y declaran los valores como el objeto fundamental de la filosofía. Consideran que "el reino de los valores lógicos, éticos y estéticos es trascendente, eterno, de significación universal [...] el que guía la historia humana, el que señala 'lo que debe ser' y le da una dirección al progreso [...] una especie de principios a priori, que poseen la fuerza de una ley objetiva." (FABELO CORZO, 2004, p.22). Esta línea de pensamiento ve su continuación en el neotomismo y otras variantes teológicas, pero sobre todo en las concepciones fenomenológicas de Scheler y Hartmann.

Max Scheler (1874 - 1928), neokantiano en sus principios, coincide con Kant en que hay que fundar la ética no en la vida real, sino en unos valores dados a priori, pero a diferencia de Kant, para Scheler los valores son materiales y no formales. Son esencias irracionales a las que llegamos no por la razón, sino por la intuición emocional: "una intuición que [...] viene a ser un modo de conocimiento esencial [...], una intuición apriórica. No ha de confundirse, entonces, el a priori fenomenológico con el kantiano: éste se refiere al pensar, [...] el fenomenológico a lo pensado" (SANCHEZ MIGALLÓN, Sergio, 2007). Scheler describe los valores dotados de tres propiedades fundamentales: polaridad, materia y altura. La polaridad le confiere al valor un carácter positivo o negativo. La materia se refiere al matiz valioso dentro de la totalidad de posibilidades que existen de ser atractivo o repulsivo. Y la altura revela la jerarquía dando lugar a una escala que Scheler ordena en cuatro grupos de menor a mayor:

1. Los valores del agrado: dulce-amargo.

2. Los valores vitales: sano-enfermo.

3. Los valores espirituales que, a su vez, se dividen en:

- $\quad$ Estéticos: bello-feo.

- Jurídicos: justo-injusto.

- Intelectuales: verdadero-falso.

4. Los valores religiosos: santo-profano. 


\section{CAPÍTULO IV. VALORES}

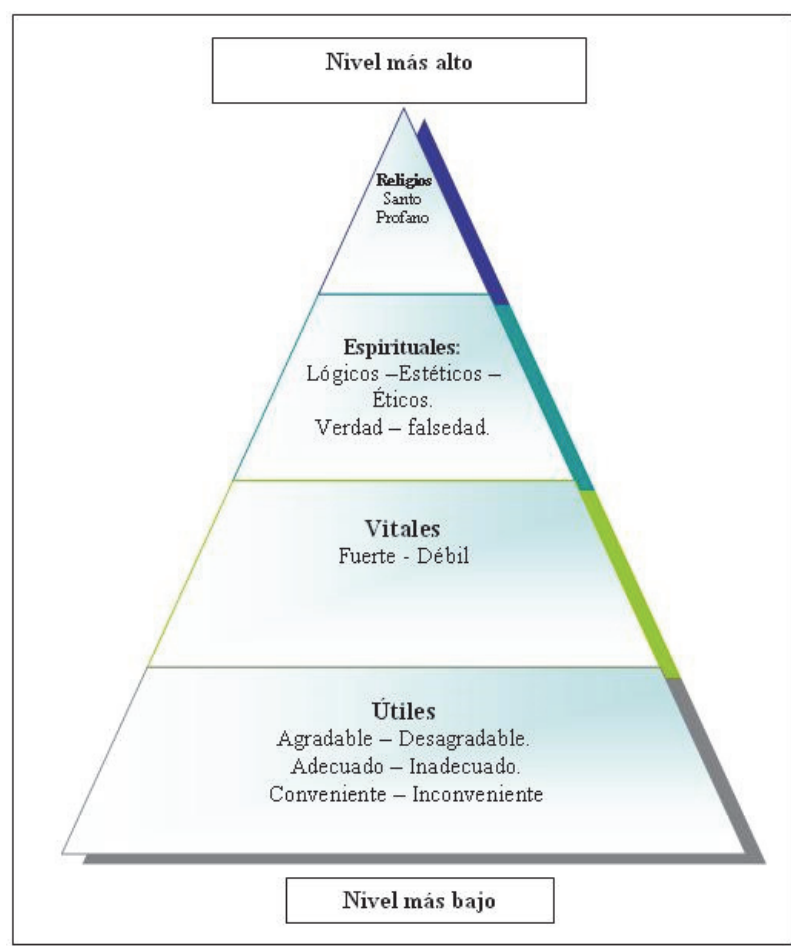

Pirámide de los valores de Scheler.

http://elfilosofosinfilosofia.blogspot.com.es/2011/03/

axiologia-de-los-valores-segun-max.html

consultado: 17 febrero de 2014

Nicolai Hartmann (1882 - 1950), al igual que Scheler considera que los valores han sido dados de una vez y para siempre, el a priori kantiano, y que son eternos, inmutables y jerárquicos. La peculiaridad de Hartmann es asimilarlos a las ideas platónicas, Hartmann sostiene que existen realmente, pero en un mundo ideal. (SÁNCHEZ MIGALLÓN, Sergio, 2007)

José Ortega y Gasset (1883 - 1955) sigue esta misma línea de pensamiento y la introduce en el mundo hispánico. Para él, los valores son algo objetivo y no subjetivo, por lo tanto no son cosas agradables, deseadas o deseables, sino que son cualidades irreales, residentes en las cosas, cuyo conocimiento es absoluto y cuasi matemático. El filósofo español se expresa en estas palabras:

"Los valores son un linaje peculiar de objetos irreales que residen en los objetos reales o cosas, como cualidades sui géneris. No se ven con los ojos, como los colores, ni siquiera se entienden, como 
los números y los conceptos. La belleza de una estatua, la justicia de un acto, la gracia de un perfil femenino no son $\operatorname{cosas}^{24}$ que quepa entender o no entender. Sólo cabe 'sentirlas', y, mejor, estimarlas o desestimarlas" (ORTEGA Y GASSET, 2004, p.32).

El autor madrileño coincide con Scheler (al que tanto admiraba), en la jerarquía de los valores e insiste en la polaridad: "un valor es siempre o positivo o negativo ${ }^{25}$. Por el contrario, las realidades no son nunca sensu stricto negativas." (ORTEGA Y GASSET, 2004, p.35).

Y elabora su propia tabla de valores: (ORTEGA Y GASSET, 2004, p. 38)

\footnotetext{
${ }^{24}$ Nótese que el autor coloca el perfil femenino a la altura de las cosas y con la autoridad que le confiere su sabiduría y le reconocimiento social de que goza, va a resultar difícil para el género femenino escapar a ese desprestigio, sobre todo cuando la palabra es escrita, lo cual le confiere mayor autoridad y perpetuación en el tiempo.

${ }^{25}$ El carácter negativo de los valores, tampoco es cosa nueva, ha sido analizado y hasta aconsejado a los príncipes para conservar el poder: “...pues un hombre que en todas partes quiera hacer profesión de bueno es inevitable que se pierda entre tantos que no lo son. Por lo cual es necesario que todo príncipe que quiera mantenerse aprenda a no ser bueno [...] Un príncipe no debe preocuparse porque lo acusen de cruel [...] cuando el príncipe está al frente de sus ejércitos y tiene que gobernar a miles de soldados, es absolutamente necesario que no se preocupe si merece fama de cruel, porque sin esta fama jamás podrá tenerse ejército alguno unido y dispuesto a la lucha. [...] De la generalidad de los hombres se puede decir esto: que son ingratos, volubles, simuladores, cobardes ante el peligro y ávidos de lucro [...] y los hombres tienen menos cuidado en ofender a uno que se haga amar que a uno que se haga temer; porque el amor es un vínculo de gratitud que los hombres, perversos por naturaleza, rompen cada vez que pueden beneficiarse; pero el temor es miedo al castigo que no se pierde nunca. [...] los hombres olvidan antes la muerte del padre que la pérdida del patrimonio. [...] No es preciso que un príncipe posea todas las virtudes citadas, pero es indispensable que aparente poseerlas. Y hasta me atreveré a decir esto: que el tenerlas y practicarlas siempre es perjudicial, y el aparentar tenerlas, útil, está bien mostrarse piadoso, fiel, humano, recto y religioso, y asimismo serlo efectivamente: pero se debe estar dispuesto a irse al otro extremo si ello fuera necesario.” (MAQUIAVELO, pp. 42-49)
} 


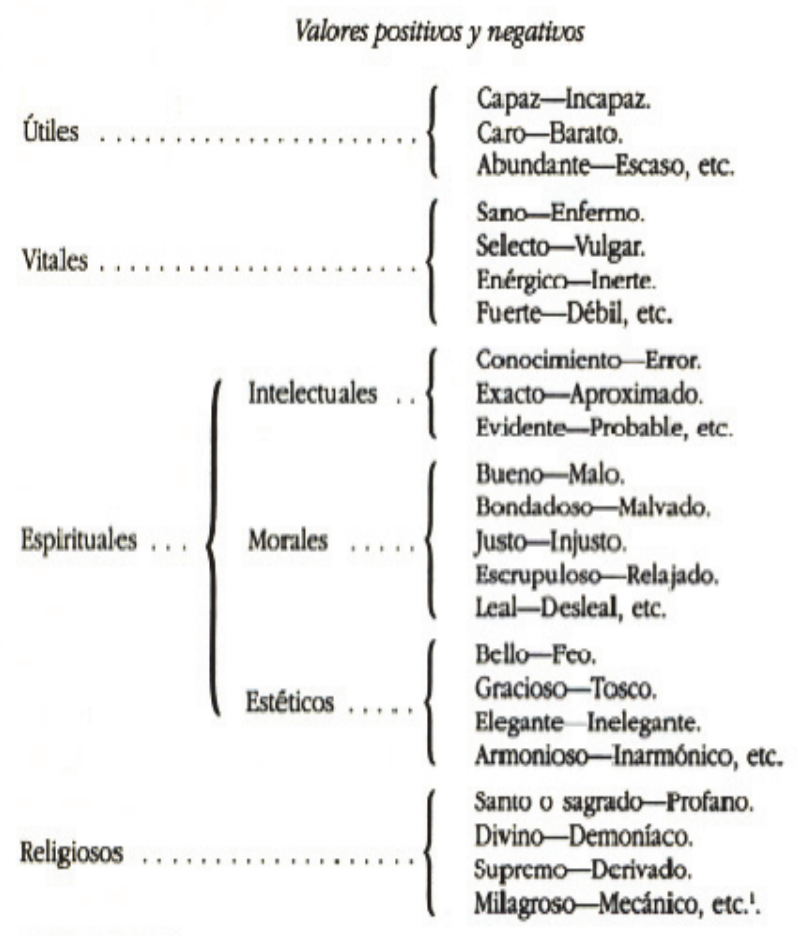

1 Nótese que es indiferente para la existencia del valor que existan de hecho cosas en que se incorporen. Para el ateo no existe Dios, pero sí el valor santidadm 0 divinidad.

Extraído de ORTEGA y GASSET, 2004, p. 38

\section{La Concepción Subjetivista}

De forma paralela, otros pensadores desarrollaron la línea subjetivista que sitúa el origen de los valores en el sujeto, en sus sentimientos, gustos, deseos, intereses y aspiraciones, en sus apetencias y en sus preferencias.

Franz Brentano (1838 - 1917) fue un filósofo alemán con más influjo que fama, pues aunque poco conocido en su época, ejerció una considerable influencia desde sus aulas. Grandes pensadores se cuentan entre sus discípulos: Edmund Husserl, Alexius Meinong, Christian von Ehrenfesl, Sigmund Freud ...

Brentano propone exclusivamente "la experiencia" como criterio de verdad, pero entendiendo la experiencia de forma que incluya fundamentalmente la "experiencia interna" lo cual supone situar a la Psicología en la base de la 
investigación filosófica. Este nuevo y riguroso método de hacer psicología, un método que obtiene conclusiones rigurosas, abrió la vía a la futura Fenomenología y a los inicios de la filosofía analítica del lenguaje. En los fenómenos psíquicos, Brentano propone como nota definitoria esencial la "intencionalidad": la tendencia del sujeto hacia un objeto. La intencionalidad, según Brentano, no solo es intelectual, sino también emocional y moral. Y en cuanto a lo bueno y lo malo, introduce el concepto "mejor y peor" o "preferible" cuando el objeto determina una emoción de atracción o de rechazo, es decir, en la intencionalidad de la emoción va a haber un "gusto" o un "disgusto", se da un "preferir" y en el preferir se da una "gradación". Para Brentano, el origen de los valores está en la preferencia y en el amor, lo valioso es lo digno de ser amado. Brentano plantea que el valor es al sentimiento lo que la verdad es al juicio. (SÁNCHEZ MIGALLÓN, Sergio, 2007).

Alexius Von Meinong (1853 - 1920) y Christian Von Ehrenfels (1859 1932) están considerados los primeros subjetivistas sistemáticos en axiología. Discípulos de Brentano, postulaban que el sujeto es la fuente de los valores, pero discrepaban entre ellos dos en un matiz lo cual originó una famosa polémica en la década de los años 90 del siglo XIX. Para Meinong, el aspecto de la subjetividad que valida al valor es el placer que causa en el sujeto. A esto Ehrenfels objeta que, entonces, solo serían valiosas las cosas existentes, pero resulta que también valoramos lo que no existe como cosa tangible, por ejemplo, la justicia perfecta, la leal amistad, el amor eterno... por lo que Ehrenfels traslada el origen del valor al deseo, a lo deseable, frente al placer de Meinong. (REMOLINA VARGAS, Gerardo, 2005).

Ralph Barton Perry (1875 - 1957), filósofo norteamericano, en su obra Teoría general del valor introduce un concepto nuevo: el de "interés" que define como una actitud afectivo-motora procedente del individuo y a favor o en contra de un objeto, siendo esta actitud la que confiere valor al objeto y no al contrario. (RINCÓN VERDERA, Joan Carles, 2006) 


\section{CAPÍTULO IV. VALORES}

A la corriente subjetivista pertenecen también algunos autores del círculo de Viena y el primer Wittgenstein ${ }^{26}(1889$ - 1951) que en su Tractatus LogicoPhilosophicus sostiene que las palabras bueno o malo se limitan a expresar el estado emotivo de la persona que pronuncia esas palabras, la cual de esta forma no confiere valor al objeto, simplemente expresa su estado de ánimo. Por lo tanto, para estos pensadores, valioso es aquello que satisface las apetencias del individuo. (ORDI I FERNÁNDEZ, Joan, 2009)

Alfred Ayer (1910 - 1989), filósofo británico, afirma que los juicios de valor no son afirmativos ni negativos, solamente informan de un estado emocional. Para Ayer, los juicios de valor son como un quejido, una risa o un grito de terror. Lo único que se podría hacer es investigar su causa y los sentimientos que expresan, lo cual corresponde a la psicología y a la sociología; no a la ética. (RINCÓN VERDERA, Joan Carles, 2006)

Charles Stevenson (1908-1979) filósofo estadounidense, propone que los juicios de valor son en parte emotivos y en parte descriptivos o imperativos. Cuando se enuncia la bondad de algo, mediante la perlocución ${ }^{27}$ del mensaje se está instando a los oyentes a realizar algo y se están provocando sentimientos de culpa en aquellos que no lo hagan. De tal forma que al emitir afirmaciones como:

\footnotetext{
${ }^{26}$ El Círculo de Viena fue fundado en 1922 por Moritz Schlick (1882 - 1936) como un organismo científico y filosófico. Su nombre original era Círculo de Viena para la concepción científica del mundo. Su cometido era ocuparse de la lógica de la ciencia y de la elaboración de un lenguaje común a todas las ciencias. En la creación de este movimiento fue determinante la publicación, en 1922, del Tractatus logico-philosophicus, obra de Ludwig Wittgenstein (18891951) investigador en ingeniería aeronáutica, matemático, filósofo, lingüista y lógico. A pesar de esta relación entre su obra y la aparición del Círculo de Viena, Wittgenstein nunca se consideró uno de sus miembros. En 1936, con el ascenso del nazismo y el asesinato de Moritz Schlick por parte de los nazis, el Círculo de Viena fue disuelto y sus miembros emigraron a los EEUU donde siguieron sus investigaciones, pero de forma diseminada. Wittgenstein emigró al Reino Unido, nacionalizándose en dicho país. Después de haber abandonado la filosofía, la volvió a retomar rebatiendo severamente las tesis expuestas en su Tractatus. Del segundo periodo surgieron las Investigaciones filosóficas, publicadas de forma póstuma. Las dos obras son tan diferentes que se habla del primer Wittgenstein o Wittgenstein del Tractatus y del segundo Wittgenstein o Wittgenstein de las Investigaciones. (ORDI I FERNÁNDEZ, Joan, 2009)

${ }^{27}$ La perlocución es una de las tres partes del discurso escrito, oral o plástico. El análisis del discurso es una disciplina estudiada en las ciencias humanas y sociales. El emisor elabora el mensaje que es reinterpretado por el receptor; el mensaje consta de tres tipos de actos discursivos: locutivos (lo dicho materialmente) diferenciando entre significantes y significado, ilocutivos: mensajes implícitos y perlocutivos: repercusiones e interacciones del acto comunicativo.
} 
“dar limosna es bueno", "la música clásica es buena", "mentir es malo”..., se está influyendo en la conducta de los oyentes. (RINCÓN VERDERA, Joan Carles, 2006)

\section{Concepción Sociologista:}

Por otro lado, el sociologismo axiológico promovido por Emile Durkheim (1858 - 1917), Lucien Lévy-Brühl (1857 - 1939) y Célestin Bouglé (1870 1940) y continuado posteriormente por numerosos sociólogos, antropólogos y etnólogos, sostiene que es valioso lo que la sociedad aprueba como tal. Los valores son convenciones sociales aceptadas por la mayoría y promovidas y reproducidas a través de la educación, la cultura y las tradiciones. En palabras de FABELO CORZO (2004, p.25):

"los valores actúan [...] como entidades objetivas con fuerza imperativa $[\ldots]$. De esta forma, cada generación se encuentra con un mundo de valores ya creado [...] del que se apropia por medio de la educación y que le permite integrarse en la identidad colectiva [...] Los individuos asumen esos valores como una realidad que los trasciende, como algo dado, incuestionable, como cierto ordenamiento que deben acatar y respetar para sentirse plenamente incorporados a la sociedad a la que pertenecen"

\section{Risieri Frondizi: la conciliación de las tendencias.}

Risieri Frondizi (1910 - 1983) filósofo argentino, considera que el objetivismo, subjetivismo y sociologismo revelan solamente una cara del valor, sin llegar a mostrar la verdadera complejidad del tema. Para Frondizi, el valor tiene un aspecto objetivo y otro subjetivo, pues surge de la relación sujeto-objeto. Cuando un sujeto entra en contacto con un objeto valioso realiza una valoración o acto valorativo. Sujeto, objeto y valoración son, para Frondizi, los componentes del valor.

Frondizi considera que los objetos tienen propiedades "primarias" o fundamentales para su existencia (forma, peso, superficie...), propiedades "secundarias" o sensibles (color, olor, sabor, textura...) y en tercer lugar unas 


\section{CAPÍTULO IV. VALORES}

propiedades no imprescindibles para la existencia del objeto, pero, que en caso de estar lo enriquecen, como puede ser la elegancia, la belleza..., es decir, los valores, propiedades irreales que no agregan ser al objeto sino valer.

Por otro lado, Frondizi afirma que el valor también está determinado por las necesidades o intereses humanos, lo cual se expresa en deseo y distingue entre lo "deseado" y lo "deseable". Por lo que, para Frondizi, el valor estaría determinado por el objeto y sus propiedades naturales por un lado, y por el sujeto y sus deseos por el otro; conectándose ambas partes a través de la "deseabilidad".

Además introduce otro elemento, en analogía con la Psicología de la Gestalt $^{28}$, Frondizi sostiene que el valor constituye una cualidad estructural, algo que no se encuentra en ninguna de las partes, ni en la simple suma de ellas, con lo cual "el valor no puede explicarse sólo por el sujeto, el objeto o la valoración. Es más que ellos y que su suma" (FABELO CORZO, 2004, pp. 30-31).

Sin embargo, Fabelo Corzo considera que Frondizi, aunque lo intenta, no acaba de superar las limitaciones de las distintas corrientes, y que incluso se inclina hacia el subjetivismo al introducir la relación sujeto-objeto/valoración como tercer elemento.

\section{José Ramón Fabelo Corzo (1956 - )}

Fabelo Corzo propone un enfoque multidimensional de los valores como un fenómeno complejo con manifestaciones en distintos planos interconectados, e interactivos entre sí. Reconoce, para los valores, 3 dimensiones fundamentales: objetiva, subjetiva e instituida.

Considera que cada objeto, fenómeno, suceso, idea o resultado de la actividad humana conlleva, de forma inherente, una función en la sociedad

\footnotetext{
${ }^{28}$ La Psicología de la Gestalt fue una escuela de psicología moderna surgida en Alemania a principios del siglo XX. Sus miembros más conocidos fueron Max Wertheimer (1880 - 1943), Kurt Koffka (1886 - 1941), Wollfang Köhler (1887 - 1967), y Kurt Lewin (1890 - 1947). El término Gestalt fue introducido por Christian von Ehrenfels y se puede traducir por 'forma', 'figura', 'configuración', 'estructura' o 'creación'. Esta escuela basa sus investigaciones en el hecho observado de que la mente, cuando entra en contacto con una cosa, para elaborar la percepción, une el fenómeno perceptivo, la memoria y la educación, lo cual se ilustra con el axioma básico: “el todo es más que la suma de sus partes". Estos psicólogos trabajaban observando la interpretación que hacían los pacientes al contemplar imágenes en las que se podían interpretar dos o más cosas: dos caras o una copa, una joven o una anciana...
} 
favorecedora u obstaculizadora del desarrollo social, y en ese sentido constituyen, para este autor, valores o antivalores objetivos, y su conjunto un sistema objetivo de valores; donde objetivo no tiene el significado trascendental tradicional, sino que es una objetividad social; de tal forma, que un fenómeno puede ser significativamente positivo para una persona o grupo de personas, pero negativo para la sociedad siendo, entonces, objetivamente un antivalor. Lo considera objetivo porque no depende de la apreciación que de él se tenga, y esta objetividad no significa que sea inmutable, muy al contrario, es dinámica y cambia en función de las condiciones histórico-concretas.

El segundo plano se refiere a la forma que tiene cada individuo de apreciar y apropiarse de ese sistema de valores en función de sus propios gustos, aspiraciones, deseos... conformando así su propio sistema subjetivo de valores, el cual va a condicionar o determinar su conducta. De tal forma que en la sociedad coexisten múltiples sistemas subjetivos de valores, pero, para evitar el caos cada sociedad tiende a organizarse en torno a un único sistema al que el autor denomina sistema de valores instituido y oficialmente reconocido, constituyendo este, el tercer plano de análisis, y no siendo más que la imposición al resto de la sociedad del sistema de valores de los que ostentan el poder. El sistema institucionalizado de valores se presenta a sí mismo como universalmente valioso estando, en la mayoría de las ocasiones, muy lejos de serlo. De esta forma, se da la contradicción de que muchos individuos se conducen en pro de unos valores que han asimilado, pero que en lugar de favorecerlos, los perjudica. (FABELO CORZO, 2004)

Después de esta sucinta aproximación a la parte filosófica del estudio de los valores, observamos que las líneas más importantes que han seguido unos y otros pensadores son:

La corriente objetivista que comprende al valor como una esencia ideal sobrehumana, eterna e inmutable, a priori y absoluta. Con una escala jerárquica también absoluta, inmutable y eterna. Ante lo cual, el ser humano no puede hacer otra cosa que tratar de descubrirla, captarla y plasmarla en la vida real. 


\section{CAPÍTULO IV. VALORES}

La corriente subjetivista que enraíza los valores en el deseo o el deleite del sujeto, dando lugar a una visión relativista del valor, al hacerlo depender de las veleidosas inclinaciones individuales.

Ambas tendencias tienen la variante individual y la sociológica, además de otras que incluso pretenden adoptar posiciones intermedias, como es el caso del naturalismo, que ve en los valores una cualidad natural de los objetos.

Tratando de salvar las distancias entre ambas tendencias, está Risieri Frondizi que propone sujeto, objeto y valoración, como componentes del valor; además de diferenciar y jerarquizar el deseo y la deseabilidad y de hablar de la estructura del valor, recordando la Gestalt.

Posterior a Frondizi, está Fabelo Corzo que propone un enfoque tridimensional de los valores: la dimensión objetiva, referida a los valores como el resultado de los procesos o acontecimientos de la vida social y que van a tener una influencia positiva o negativa sobre los individuos y su conjunto. La dimensión subjetiva que es la apreciación y apropiación que cada uno hace del sistema objetivo. Y en tercer lugar la dimensión instituida, que no es otra cosa que la oficialización del sistema subjetivo de los que ostentan el poder, y la presentación del mismo como universalmente valioso.

En cualquier caso los valores están relacionados con la acción, esta relación surge como una evidencia desde la noche de los tiempos. Platón decía: “...intentar definir una manera de "conducirnos" en la vida..."; los escolásticos consideraban que la formación moral consiste en la "práctica" de las virtudes; Kant titula su tratado de moral Crítica de la razón "práctica". La acción o la conducta social se viene rigiendo por normas, y toda norma se sustenta en un valor; Frondizi pone el ejemplo de que la norma que dice "no matarás" se apoya en el valor de la vida humana, y así en todos los casos. Ante un conflicto entre dos normas, habrá que elegir la que esté basada en un valor superior, sostiene Frondizi. De esta forma, la moralidad dejará de ser un medio de represión para transformarse en un instrumento mediante el cual los valores positivos y superiores orienten el devenir del género humano.

NUÉVALOS RUIZ, Carmen (2008) sostiene que aunque tengamos un ideal de persona sensibilizada en términos de valores, necesitamos saber cómo alcanzar esa persona ideal. La filosofía es imprescindible para lograr un 
posicionamiento epistemológico y antropológico, pero insuficiente para orientar la educación, para lo cual es necesario conocer los fenómenos morales y sus mecanismos de formación. El estudio del proceso moral y de su desarrollo compete más a las ciencias empíricas que a las especulativas. Es a finales del siglo XIX cuando la Sociología, la Psicología y la Pedagogía empiezan a interesarse por el tema moral.

\section{Los Valores en las Ciencias Sociales.}

En el siglo XIX, mientras que en Filosofía arranca el estudio de los valores, nace la Sociología como ciencia de la mano de Auguste Comte, Karl Marx, Emile Durkheim y Max Weber, entre otros.

Anteriormente, Thomas Hobbes (1588 - 1679), John Locke (1632 - 1704) y Jean-Jacques Rousseau (1712 - 1778) habían presentado cada uno su particular visión del contrato social. Charles de Montesquieu (1689 - 1755) había aportado su pensamiento y su visión crítica de la sociedad de su tiempo. Por otra parte, Europa estaba convulsionada por el impacto de la Revolución Francesa y por los problemas sociales que la Revolución industrial estaba desencadenando.

En este contexto histórico-científico, Auguste Comte (1798 - 1857), heredero del pensamiento de Henri Saint-Simon (1760 - 1825), para quien había trabajado de secretario junto al historiador Augustin Thierry (1795 - 1856), sostiene que todo conocimiento, tanto filosófico como científico, debe surgir del análisis de los hechos reales verificados por la experiencia. Se establece así el método científico como única base para la obtención rigurosa de conocimiento fiable, en contraposición a la búsqueda de causas últimas y explicaciones de los fenómenos en algo situado más allá de la experiencia (religión, metafísica). Por otro lado, Comte considera que el comportamiento social del ser humano, por su complejidad, merece ser estudiado en una ciencia específica. Surgen el Positivismo y la Sociología. (COMTE, Auguste, 1852)

Karl Marx (1818 - 1883), filósofo germánico, se adentra en el terreno de la Historia, la Economía, la Política y es, también, uno de los fundadores de la 


\section{CAPÍTULO IV. VALORES}

Sociología. Autor del materialismo histórico, sostiene que lo que mueve al mundo, lo que determina los hechos históricos no son las ideas ni la voluntad humana, sino las circunstancias materiales. Para Marx, el único valor que está detrás de todo acontecimiento histórico, de todo hecho social, es el económico. (ALTHUSSER, Louis y BALIBAR, Étienne, 2004)

Émile Durkheim (1858 - 1917), filósofo francés, se interesó por los estudios sobre la sociedad. Creó el primer departamento de sociología en la Universidad de Bordeaux, y publicó en 1895 Las reglas del método sociológico, proponiendo "estudiar los hechos sociales como si fueran cosas [...] analizar la vida social con el mismo rigor que los objetos o los acontecimientos de la naturaleza" (GIDDENS, Anthony, 2000, p. 33). Para Durkheim, los individuos adoptan e interiorizan los valores y la moral de la sociedad en la que nacen, de tal forma que esta última es más que la simple suma de individuos, pues está dentro y fuera de ellos al mismo tiempo; la sociedad tiene una vida propia que va más allá de las experiencias personales, tiene el poder de determinar los pensamientos y las acciones de los individuos que la componen. Durkheim definió los hechos sociales como modos de actuar, pensar y sentir externos al individuo, pues existían ya antes de su nacimiento; colectivos porque forman parte de la cultura social y coercitivos porque tienen el poder de imponerse al individuo. Durkheim dedicó gran parte de su investigación al estudio de la moral y de los valores sociales y consideró que uno de los más importantes es la Solidaridad pues es la base de la cohesión social. (DURKEIM, Émile, 1993)

Max Weber (1864 - 1920) filósofo, economista, jurista, historiador y politólogo alemán, es considerado el padre de la Sociología comprensiva. Weber no se conforma con la descripción de los fenómenos sociales, quiere comprenderlos, comprender sus razones. Para Weber, la sociedad está compuesta por sujetos que actúan, es decir por agentes, y quiere comprender el sentido de sus acciones: "Weber enfoca, en efecto, la investigación del racionalismo moderno hacia el descubrimiento de los fundamentos práctico-morales que hacen posible la consolidación de un estilo de vida metódico-racional..." (RUANO DE LA FUENTE, Yolanda, 1996, p.63)

El fundamento de esas razones, Weber lo emplaza en los valores. De esta forma establece un importante cambio de perspectiva, porque el objeto de estudio 
de la sociología weberiana es un sujeto con razones subjetivas que varían en función de los valores que tenga. Para él, detrás de la racionalidad, lo que hay son valores. En función de los valores cultivados, se genera una determinada racionalidad que a su vez origina una particular cosmovisión. Weber habla, por lo tanto, de la racionalidad en plural, con lo que abre la puerta a la tolerancia.

Weber sostiene que hay verdades objetivas pero no universales. Verdad objetiva es aquella que dentro de una determinada racionalidad es correcta, con lo que acaba con la idea de una verdad única, absoluta y universal. Weber está dando un paso adelante dentro del relativismo.

Weber habla del "politeísmo de los valores". Cuando la sociedad se seculariza, cae el patrón único impuesto por la religión y emergen otros patrones de conducta en función de las distintas esferas de acción social (la religiosa, económica, artística, gubernamental...) haciendo valer sus valores, por lo que Occidente pasa de un monoteísmo valorativo a un politeísmo de valores. Weber añade más, ese politeísmo valorativo que ahora aparece dentro de la cultura occidental, antes ya existía de forma intercultural.

Weber, al igual que Marx, analiza el capitalismo, la burocratización y la instrumentalización de las relaciones humanas, pero mientras que Marx explica el capitalismo a través de un solo factor: el valor económico, Weber lo enraíza con la ética protestante que ha hecho del trabajo un estilo de vida.

Weber, educado en el puritanismo calvinista, está preocupado por cómo ser moral en una sociedad con politeísmo valorativo y sostiene que se puede lograr eligiendo unos valores a los que entregarse:

"Actúa estrictamente de un modo racional con arreglo a valores quien, sin consideración a las consecuencias previsibles, obra en servicio de sus convicciones sobre lo que el deber, la dignidad, la belleza, la sabiduría religiosa, la piedad o la trascendencia de una "causa", cualquiera que sea su género, parecen ordenarle. Una acción racional con arreglo a valores es siempre una acción según mandatos o de acuerdo con exigencias que el actor cree dirigidos a él" (WEBER, Esbozo de una Sociología comprensiva, citado por RUANO DE LA FUENTE Yolanda, 1996, p. 86) 


\section{CAPÍTULO IV. VALORES}

Esto conduce a una alta tolerancia porque implica que es ético el que es coherente con su propia ética, y que ante una conducta ética diferente, no hay que condenar sino comprender. Weber está preparando el terreno para la caída de los valores patriarcales admitidos secularmente, el paradigma de que los valores patriarcales son los valores humanos cae. Weber dice que humanidad se expresa en plural, y le está abriendo así, las puertas a la tolerancia y a la igualdad, porque se las está abriendo a la comprensión. Hay que añadir que la esposa de Weber, Marianne Weber, era activista feminista y escritora por derecho propio.

Weber también habla de la "Razón desencantada". La Ilustración colocó la razón en lo más alto, concibiéndola como un único todo que incluía el conocimiento teórico, el comportamiento ético-moral y la expresión estética. Los optimistas ilustrados pensaban que si se aumentaba la educación de la población, las tres partes de la razón crecerían de forma armónica. La manera de conseguir una sociedad mejor era educar a la población. Sin embargo, a lo largo del siglo XIX y mucho más durante el XX, se vio que las tres instancias de la razón podían no crecer al unísono: el aumento del conocimiento científico-técnico no fue acompañado de un equilibrado desarrollo ético-moral, pues con la revolución industrial apareció el proletariado, explotado por la minoría que poseía los medios de producción, nada que ver con cualquier ideación de mundo perfecto y feliz: "la razón, glorificada un siglo antes, pierde ahora definitivamente su mayúscula, su unidad, su universalidad y su capacidad para fundamentar la praxis." (RUANO DE LA FUENTE, Yolanda, 1996, p. 211). Weber, muy acertadamente, observa la separación de las tres instancias de la razón y hace notar que su desarrollo no tiene por qué ser armónico:

“Una razón «desencantada» vislumbra, en suma, que cuanto mayor dominio intelectual y práctico-técnico consigue sobre lo dado, tanto más va escindiéndose: deja de integrar en sí misma todos sus tradicionales intereses (teóricos, práctico-morales y estéticoexpresivos), renunciando, entonces, a la vieja idea clásica, moderna e ilustrada que establecía la continuidad expresa entre el progreso del conocimiento y el progreso moral y religioso, político, estético y erótico." (RUANO DE LA FUENTE, Yolanda, 2001, p. 117) 


\section{Los Valores en Psicología}

Hasta las décadas de los 60-70 del siglo XX, los estudios de lo moral o de los valores en Psicología fueron muy escasos. PÉREZ-DELGADO et al. (1991) justifican este hecho por la coincidencia en el tiempo de varios factores. Por un lado Wundt ${ }^{29}$, fundador de la Psicología científica, excluyó este campo de su laboratorio, no por considerarlo exento de interés, pero sí demasiado complejo para ser tratado experimentalmente; pensaba que su estudio debía realizarse mediante el método histórico-cultural. Así mismo, su discípulo más relevante, Titchener, hizo lo mismo en el continente americano.

Por otro lado, el Conductismo ${ }^{30}$ niega que lo moral esté vinculado a la conciencia como se creía hasta entonces, y que el ser humano tenga plena capacidad para comprenderse a sí mismo y para autogobernarse. El Conductismo afirma que la conducta humana es adquirida y no innata, las reacciones o respuestas que un individuo tiene ante los estímulos son aprendidas. Desde este planteamiento, la conciencia pierde interés de estudio, y por consecuencia también todo lo relacionado con lo moral y con los valores.

En tercer lugar, el Psicoanálisis freudiano no elimina la conciencia, sino que la sustituye por el inconsciente.

NUÉVALOS RUIZ, Carmen (2008, pp. 110-118) sostiene que en la Psicología moral se pueden diferenciar tres momentos o etapas (despegue, silencio y expansión) y dos posicionamientos u orientaciones sobre la forma en que se desarrolla la moral: externalista e internalista.

\footnotetext{
${ }^{29}$ Wilhelm Maximilian Wundt $(1832$ - 1920) filósofo y fisiólogo alemán, creó un laboratorio en el que poder estudiar las reacciones psicológicas con métodos similares a los empleados para el estudio de las reacciones fisiológicas. Por ello se le considera el padre y fundador de la Psicología científica.

30 JOHN BROADUS WATSON (1878 - 1958), psicólogo americano, fundó la Escuela Psicológica Conductista, inaugurada en 1913 con la publicación de su artículo "La Psicología tal como la ve el Conductista".
} 


\section{CAPÍTULO IV. VALORES}

Según la orientación externalista, el proceso de moralización se realiza desde fuera hacia dentro, mediante la transmisión de normas y valores de la sociedad al niño. Es la sociedad la que modela al individuo a su imagen, adoptando el sujeto un rol pasivo dentro de un proceso no racional. Claro exponente de esta corriente es Durkheim, para quien los fenómenos morales son fenómenos sociales.

Las teorías conductistas y freudianas, a pesar de sus diferencias, pueden englobarse, ambas, dentro de la orientación externalista.

La corriente internalista, iniciada por Piaget y continuada por Kohlberg, defiende que el proceso de moralización es una construcción cognitiva, continuada y progresiva por parte del individuo quien, de una forma activa, elige, comprende y asume normas y valores ofrecidos por la sociedad. Para estos autores la moral es racional, y solamente se puede desarrollar desde la autonomía. El individuo, mediante unos procesos internos, mediatiza y organiza las influencias que le vienen del exterior.

En cuanto a los momentos, NUÉVALOS defiende la existencia de tres etapas. "Un primer momento de despegue" que abarca finales del siglo XIX y principios del XX en el que los estudios son escasos y poco significativos. En Psicología brilla la figura de Wundt que diferencia entre la psicología individual y la de los pueblos, considerando lo moral como el producto de las "costumbres morales" por lo que se posiciona en la corriente externalista. Pero la psicología moral de Wundt no tuvo apenas influjo y prácticamente desapareció con él (Wundt murió en 1920).

La segunda etapa va desde la década de los veinte hasta la de los sesenta. Se caracteriza por el olvido de lo moral en Psicología debido principalmente al auge de los paradigmas psicoanalítico y conductista predominando, además, lo teórico sobre lo empírico.

Sin embargo, a esta época pertenecen dos trabajos de gran importancia que dejarán huella: uno es la Character Education Inquiry de Hartshorne y $\mathrm{May}^{31}$, y el otro es Le jugement moral chez l'enfant que Jean Piaget publica en 1932.

\footnotetext{
${ }^{31}$ Hugh Hartshorne y Mark May, psicólogos de Yale, llevaron a cabo, entre 1925 y 1930, un estudio con unos diez mil escolares, de entre 8 y 15 años, a los que se les proporcionaba amplias posibilidades de realizar actos deshonestos como puede ser mentir, robar o hacer trampas tanto en el ambiente escolar como deportivo. Los resultados fueron sorprendentes para los investigadores
} 
La obra de Hartshorne y May se alinea en la corriente externalista mientras que la de Piaget representa la internalista.

Después de este silencio en la investigación de lo moral en psicología, surge, en torno a 1970, el interés por este tema tanto en las ciencias sociales, como en psicología y pedagogía, consolidándose lo moral como un área de estudio en expansión.

\section{Jean Piaget: el desarrollo moral}

Jean Piaget (1896 - 1980), de nacionalidad suiza, se doctoró en ciencias naturales y posteriormente estudió psicología y filosofía, centrando el interés de su investigación en el desarrollo de la inteligencia. Pero no solo se ocupó de la cognición, sino que también trató el afecto, sosteniendo que ambos procesos de desarrollo, el cognitivo y el moral, evolucionan paralelamente. Para Piaget, la inteligencia opera en ambos campos, de tal forma que "no puede haber conocimiento sin afecto, ni afecto sin conocimiento. [...] Una persona que está emocionalmente aislada no puede funcionar cognitivamente. [...] El afecto motiva las operaciones del conocimiento y el conocimiento estructura las operaciones del afecto." Estas relaciones, entre lo afectivo y lo cognitivo, Piaget las trata explícitamente en el juicio moral: "Porque, ¿qué es el juicio moral ${ }^{32}$ si no una estructura cognitiva de cómo sentimos que debemos tratar a otros y de cómo los demás nos deben tratar?” (HERSH, Richard H., REIMER, Joseph, PAOLLITO, Diana P., 2002, pp. 40-41).

que esperaban demostrar una relación entre las acciones y la personalidad, el carácter, el razonamiento moral, la educación o la clase social... Por el contrario, descubrieron que la honestidad no estaba en relación con rasgos de la personalidad ni con la capacidad de razonamiento moral: "el engaño era una función de las situaciones. [...] el niño que no infringía las reglas en su casa, [...] no era menos propenso a copiar en un examen de la escuela. Que un niño copiara en un examen de ortografía no indicaba que lo hiciera en uno de matemáticas, y mucho menos que actuara con deshonestidad en un evento deportivo." (KWAME ANTHONY, Appiah, 2010, p. 57).

${ }^{32}$ Una de las críticas que posteriormente se le han hecho a Piaget reside en que no especificaba con claridad lo que él entendía por juicio moral: ¿la capacidad humana específica de juicio o el juicio que trata de lo moral específicamente? La respuesta es la primera alternativa, por lo que la literatura psicológica posterior ha preferido sustituir la expresión por 'razonamiento moral'. (PÉREZ DELGADO et al. 1991 ) 


\section{CAPÍTULO IV. VALORES}

Interesado por entender cómo se orientan los niños ante lo social, e influenciado por Emile Durkheim que defendía la base establecida por Kant de que lo moral es un sistema de normas a respetar, Piaget, a través del método de la observación y análisis de los juegos sociales infantiles y de sus reglas, estudia el proceso por el cual la conciencia desarrolla el respeto por las reglas, y el sentido de solidaridad con su sociedad. Observa que un aspecto importante de ese proceso de maduración es el tránsito del egocentrismo a la descentración: "El juicio moral evoluciona positiva y progresivamente cuando se produce en el sentido de la descentración. Sale del centro del individuo hacia el encuentro con el otro." (PÉREZ-DELGADO et al.,1991, p. 55).

Piaget además considera que, en el crecimiento del individuo, las funciones cognitivas y afectivas se desarrollan reguladas por un tercer factor: los intereses y valores; ya que el interés es la prolongación de la necesidad. Algo es interesante en la medida en que responde a una necesidad. A la vez, el interés interviene de dos formas complementarias: "Por una parte, es un regulador de energía [...] su intervención moviliza las reservas internas de fuerza, basta que un trabajo interese para que parezca fácil y la fatiga disminuya. [...] por otra parte, el interés implica un sistema de valores [...] que se diferencian precisamente en el curso del desarrollo mental.” (PIAGET, Jean, 1977, pp. 54-56).

También se interesó por las normas morales en el adulto, el desarrollo de la noción de justicia, y la coincidencia entre el juicio de valor enunciado y lo ejecutado en la realidad. PÉREZ-DELGADO et al. (1991, p. 52) sostienen que "Es posible que la contribución más importante de Piaget (1932) haya sido la formulación explícita [...] entre lo que podríamos llamar una moral convencional y una moral derivada de un código racional." Entendiendo por "moral convencional' aquella según la cual el individuo hace lo acostumbrado o lo ordenado, y si se le pregunta que por qué lo hace, apela a la autoridad, a la costumbre o a la normalización social de esa acción, sin plantearse la validez del código. Por 'Moral derivada de un código racional' entiende aquella que es aceptada tras una reflexión y está fundamentada en razones.

Al concepto kantiano de autonomía moral o autonomía de la razón práctica, Piaget le asoció la idea de cooperación social, esto es, infundió la noción 
de bien en la forma kantiana de deber. (BASANTA, Elisa; ORMART, Elizabeth y BRUNETTI, Juan, 2002)

Piaget establece dos etapas para el desarrollo moral: Heteronomía (presión moral del adulto) el niño no es aún capaz de realizar razonamientos abstractos por lo que acepta las reglas como una imposición procedente de una autoridad exterior a él y superior, por lo tanto inalterable. Autonomía: las reglas son percibidas como un consenso arbitrario modificable con el consentimiento de los demás. (HERSH et al., 2002)

Piaget extendió su trabajo sobre el juicio moral de los niños hasta llegar al nivel de ley, responsabilidad y justicia; pero no profundizó en los niveles de juicio moral, ni trabajó con niños mayores de doce años; sino que siguió estudiando sobre el desarrollo del área cognitiva.

HERSH et al. (2002) sostienen que cuando, en 1932, fue publicado "le jugement moral chez l'enfant", la Psicología de aquel momento no era susceptible de aceptar esta visión de lo moral. Freud situaba la conciencia bajo el control del inconsciente y del superego, y los que no compartían las teorías freudianas pensaban que, para entender la moralidad, había que estudiar los procesos de socialización en los que el niño aprende a obedecer las reglas por condicionamiento y refuerzo. Pero por distintas razones, entre las que destacan los acontecimientos acaecidos en torno a la II Guerra Mundial, a partir de los años cincuenta, y sobre todo de los sesenta, el estudio de lo moral atrae y absorbe la atención de las ciencias psicosociales, destacándose los trabajos de David Riesman, Erik Erikson, Erich Fromm entre otros, sin embargo, el primero en volver a Piaget fue Kohlberg.

\section{Lawrence Kohlberg (1927 - 1987)}

Psicólogo estadounidense, presentó en 1958 su tesis doctoral sobre el desarrollo del juicio moral: "El desarrollo del pensamiento moral y opción moral entre los diez y diecisiete años". La metodología utilizada fue la proposición de dilemas morales que incitaran el interés de las personas entrevistadas, preguntándoles cual sería la solución y por qué. La hipótesis de la que partía era que el individuo no se limita a interiorizar las normas que le presenta la sociedad, 


\section{CAPÍTULO IV. VALORES}

sino que construye nuevas estructuras como consecuencia de su interacción con el medio. "El objetivo principal de Kohlberg es encontrar las características estructurales por las que atraviesa el razonamiento moral en su desarrollo y demostrar su universalidad y progresiva superioridad.” (DIAZ-AGUADO, 1982 citado por PÉREZ-DELGADO et al. 1991, p. 56)

Las personas, desde la infancia, aprenden los valores en su medio social, sin cuestionarlos hasta que no entran en conflicto, en cuyo caso se pasa de la acción al discurso, al razonamiento para decidirse por uno u otro valor. Se da entonces un proceso cognitivo que permite reflexionar sobre los propios valores y ordenarlos en una jerarquía lógica. "Sobre lo moral también se puede razonar y preferir.” (PÉREZ-DELGADO et al., 1991, p. 58).

El niño, en su aprendizaje, no se limita a acumular valores sino que modifica desde dentro la estructura presentada. El medio externo ofrece valores y el medio interno los estructura y jerarquiza de modo subjetivo, de forma, que en función de esa jerarquía se puede valorar la competencia moral del individuo.

Esta estructuración, que se produce en el interior de cada persona, es previsible, sigue un orden lógico constante (Kohlberg obtuvo los mismos resultados en México, Estados Unidos y Taiwán). La moral sería relativa a las distintas culturas en cuanto a contenidos, pero la forma del desarrollo sería universal.

El juicio moral, al ser un razonamiento, exige haber alcanzado previamente esa capacidad lógica. De tal forma que una persona no puede estar nunca en un estadio moral superior al estadio lógico alcanzado, aunque lo inverso sí puede encontrarse: "El pensamiento lógico tiene prioridad cronológica sobre el razonamiento moral.” (PÉREZ-DELGADO et al. 1991, p. 60)

"Mientras que el desarrollo lógico es necesario para el desarrollo moral y le marca límites a éste, la mayor parte de los sujetos pertenecen a un estadio de desarrollo lógico superior al que se encuentran en los estadios del desarrollo moral" (KOHLBERG, 1987, citado por PÉREZ-DELGADO et al. 1991, p. 59)

Ahora bien, al igual que el 'razonamiento lógico' es imprescindible, aunque no suficiente para la madurez del 'juicio moral'; la madurez del juicio moral es imprescindible, pero no suficiente para la madurez de la 'acción moral'; 
de tal forma que se puede razonar en términos de principios, y no vivir según esos principios.

Por otro lado, está el desarrollo social que se refiere a la capacidad de asumir roles, lo cual supone la capacidad de ponerse en el lugar del otro, de empatizar, de imaginar lo que siente el otro, por lo que resulta evidente que el desarrollo social comparte componentes lógicos y emocionales necesarios para alcanzar el desarrollo moral. Para Kohlberg, el desarrollo lógico, moral y social progresan en paralelo.

Los estadios del juicio moral constituyen como un conjunto de tramos de escaleras en las que cada tramo corresponde a un nivel, y cada escalón a un estadio. El desarrollo moral es universal, ascendente e irreversible. Por lo que queda excluido que varias personas lleguen al mismo objetivo por vías evolutivas distintas, que una persona retroceda a un nivel evolutivo inferior, o que el curso del desarrollo se salte una etapa; y el conjunto constituye una jerarquía en el sentido de que cada estadio supera a los anteriores: los integra y los sustituye, con lo que se produce un crecimiento, de forma que una persona rechazará resolver los conflictos según las vías ofrecidas por estadios inferiores al alcanzado: "Cada estadio puede caracterizarse como un todo estructurado, que supone una diferencia cualitativa en el modo de pensar con respecto a los estadios anteriores y posteriores.” (PÉREZ-DELGADO et al. 1991, p. 60)

\section{a) Propuesta teórica de Kohlberg}

Kohlberg propone seis estadios agrupados en tres niveles que vienen determinados por la relación entre el yo y las reglas morales.

Nivel preconvencional: el individuo no conoce las reglas y por lo tanto tampoco las defiende. Hay una clara separación entre el ego y las normas sociales. A nivel social el individuo tiene una perspectiva individual concreta, defiende sus intereses y evita los riesgos. Este nivel corresponde a los niños menores de 9 años, a algunos adolescentes y a muchos delincuentes.

Nivel convencional: el individuo conoce las reglas y se somete a ellas, las hace suyas y las defiende. Se siente miembro de la sociedad, sabe lo que el grupo 


\section{CAPÍTULO IV. VALORES}

espera que haga, cumple su rol, defiende los intereses de la sociedad y los propios. Este nivel corresponde a la mayoría de los adolescentes y adultos.

Nivel posconvencional: el individuo no solo conoce las reglas, sino que las comprende y las puede rebatir; pues ha descubierto los principios éticos universales desde los que define sus propios valores. Separa, por lo tanto, su yo de las reglas. A nivel social tiene una posición pre-social. Enfoca los problemas desde una perspectiva superior a una sociedad concreta, lo hace desde los principios en que se sustenta cualquier sociedad humana. Es un nivel minoritario y existen pocas pruebas empíricas que lo avalen. El pensamiento de Kohlberg sobre este nivel ha estado muy influenciado por el filósofo de Harvard John Rawls ${ }^{33}$.

Los niveles preconvencional y posconvencional coinciden en que el individuo se ve a sí mismo separado del grupo, pero en el primero es porque

\footnotetext{
33 John Rawls (1921 - 2002), filósofo norteamericano, profesor de filosofía política en la Universidad de Harvard, representa el neocontractualismo contemporáneo (los clásicos teóricos del contrato social son Hobbes, Locke y Rousseau). Su obra maestra, A Theory of Justice publicada en 1971, constituye una de las obras primarias de la filosofía política. Rawls comienza su argumento con la siguiente afirmación: "La justicia es la primera virtud de las instituciones sociales, al igual que la verdad lo es de los sistemas de pensamientos." (RAWLS, JOHN, 1995, p. 17). Todo sistema de pensamiento que no produzca verdad es rechazable, de la misma manera, las instituciones sociales tienen como función básica producir Justicia, si no lo hacen, hay que rechazarlas.

La idea de justicia surge de la idea de "corporación social": si los individuos de una sociedad trabajan aisladamente, en suma, originan una producción x; pero la corporación social origina un producción $\mathrm{x}^{\mathrm{n}}$. La cuestión es ¿cómo se va a repartir esa producción? La pregunta por la Justicia es la pregunta por la estructura básica de la sociedad. Lo que vincula a Rawls con Hobbes, Locke y Rousseau es que esos principios que estructuran la sociedad tienen su raíz en el contrato social. El problema es cómo llegar a un acuerdo social justo. Rawls aboga por un acuerdo de los gobernados que, además, debe ser imparcial; de aquí surge su conocida noción de Justicia como imparcialidad. Rawls sostiene que ese acuerdo debe hacerse desde una posición inicial justa a la que llama "posición original", y que equivale al estado de naturaleza en la teoría del contrato social. Rawls se centra en dos puntos. En primer lugar, ¿por qué nuestra sociedad es injusta? y responde diciendo que la injusticia no tiene que ver con su estructura sino con el hecho de que no refleja un acuerdo libre e imparcial, lo cual ya quedó dicho por Rousseau. En segundo lugar propone una manera de deliberar sobre nuevos principios, pero de forma que la deliberación se realice tras "un velo de ignorancia": nadie deberá saber cual es su lugar en la sociedad ni tampoco nada con respecto a sus talentos naturales, fortaleza... al ignorar estas cosas, la deliberación será imparcial (de hecho, la Justicia se ha representado tradicionalmente con los ojos vendados). El problema radica en que es imposible llegar a esa situación de falta de información sobre sí mismo. Rawls, basándose en la teoría de la elección racional, propone realizar el acuerdo partiendo de dos principios de justicia. Principio de la Libertad: todos tienen derecho a la misma gama de libertades, no habrá privilegiados. Y Principio de la Diferencia: las desigualdades socioeconómicas se permiten solo si conducen a una mejor situación para los menos aventajados. (RAWLS John, 1995)
} 
todavía no se ha fusionado, mientras que en el segundo es porque adopta una posición universal, por encima de una sociedad concreta.

El nivel convencional se diferencia de los otros dos porque el individuo busca la aprobación social; le preocupa la lealtad a personas, grupos y autoridades.

Ya desde su tesis doctoral, Kohlberg estableció 3 niveles y 6 estadios que reformuló numerosas veces a lo largo de su carrera. Su última formulación aparece en la siguiente tabla extraída de HERCH et al. (2002, pp. 55-56)*

\section{TABLA I}

LOS SEIS ESTADÍO DEL JUICIO MORAL

\begin{tabular}{|c|c|c|c|}
\hline Nivel y estadio & Lo que está bien & $\begin{array}{l}\text { Razones para } \\
\text { hacer el bien }\end{array}$ & $\begin{array}{c}\text { Perspectiva social } \\
\text { del estadio }\end{array}$ \\
\hline $\begin{array}{l}\text { Nivel I: } \\
\text { Preconvencional }\end{array}$ & $\begin{array}{l}\text { Someterse a } \\
\text { reglas apoyadas } \\
\text { por el castigo; } \\
\text { obediencia por sí } \\
\text { misma; evitar } \\
\text { daño físico a } \\
\text { personas y } \\
\text { propiedad }\end{array}$ & $\begin{array}{l}\text { Evitar el castigo, } \\
\text { poder superior de } \\
\text { las autoridades }\end{array}$ & $\begin{array}{l}\text { Punto de vista } \\
\text { ego-céntrico. No } \\
\text { considera los } \\
\text { intereses de otros } \\
\text { o reconoce que } \\
\text { son distintos de } \\
\text { los de él; no } \\
\text { relaciona dos } \\
\text { puntos de vista. } \\
\text { Las acciones se } \\
\text { consideran } \\
\text { físicamente más } \\
\text { que en términos } \\
\text { de los intereses } \\
\text { psicológicos de } \\
\text { los demás. } \\
\text { Confusión de la } \\
\text { perspectiva de la } \\
\text { autoridad propia }\end{array}$ \\
\hline $\begin{array}{l}\text { Estadio II: } \\
\text { Individualismo, } \\
\text { fines } \\
\text { instrumentales e } \\
\text { intercambio }\end{array}$ & $\begin{array}{l}\text { Seguir reglas sólo } \\
\text { cuando es por el } \\
\text { propio interés } \\
\text { inmediato; actuar } \\
\text { para cumplir los } \\
\text { propios intereses } \\
\text { y necesidades y } \\
\text { dejar a otros hacer } \\
\text { lo mismo. El bien }\end{array}$ & $\begin{array}{l}\text { Servir los propios } \\
\text { intereses en un } \\
\text { mundo donde se } \\
\text { debe reconocer } \\
\text { que los demás } \\
\text { también tienen } \\
\text { intereses. }\end{array}$ & $\begin{array}{l}\text { Perspectiva } \\
\text { concreta } \\
\text { individualista. } \\
\text { Consciente de que } \\
\text { todos tienen } \\
\text { intereses que } \\
\text { perseguir y que } \\
\text { pueden entrar en } \\
\text { conflicto; el bien }\end{array}$ \\
\hline
\end{tabular}




\begin{tabular}{|c|c|c|c|}
\hline & $\begin{array}{l}\text { es lo que es justo, } \\
\text { y es un } \\
\text { intercambio igual, } \\
\text { pacto, acuerdo. }\end{array}$ & & $\begin{array}{l}\text { es relativo (en el } \\
\text { sentido concreto } \\
\text { individualista). }\end{array}$ \\
\hline $\begin{array}{l}\text { Nivel II: } \\
\text { Convencional. } \\
\\
\text { Estadio III: } \\
\text { Expectativas } \\
\text { interpersonales } \\
\text { mutuas. } \\
\text { Relaciones y } \\
\text { conformidad } \\
\text { interpersonal. }\end{array}$ & $\begin{array}{l}\text { Vivir de acuerdo } \\
\text { con lo que espera } \\
\text { la gente cercana } \\
\text { de un buen hijo, } \\
\text { hermano, amigo, } \\
\text { etc.... "Ser } \\
\text { bueno" es } \\
\text { importante y } \\
\text { quiere decir tener } \\
\text { buenos motivos, } \\
\text { mostrar interés } \\
\text { por los demás. } \\
\text { También significa } \\
\text { mantener } \\
\text { relaciones mutuas } \\
\text { como confianza, } \\
\text { lealtad, respeto y } \\
\text { gratitud. }\end{array}$ & $\begin{array}{l}\text { La necesidad de } \\
\text { ser buena persona } \\
\text { a los propios ojos } \\
\text { y a los de los } \\
\text { demás: } \\
\text { preocuparse de } \\
\text { los demás; creer } \\
\text { en la regla de } \\
\text { Oro; deseo de } \\
\text { mantener las } \\
\text { reglas y la } \\
\text { autoridad que } \\
\text { apoyan la típica } \\
\text { buena conducta }\end{array}$ & $\begin{array}{l}\text { Perspectiva del } \\
\text { individuo en } \\
\text { relación a otros } \\
\text { individuos. } \\
\text { Conciencia de } \\
\text { sentimientos } \\
\text { compartidos, } \\
\text { acuerdos, y } \\
\text { expectativas que } \\
\text { toman primacía } \\
\text { sobre los intereses } \\
\text { individuales. } \\
\text { Relaciona puntos } \\
\text { de vista a través } \\
\text { de la Regla de } \\
\text { Oro concreta } \\
\text { poniéndose en el } \\
\text { lugar del otro. } \\
\text { Todavía no } \\
\text { considera una } \\
\text { perspectiva de } \\
\text { sistema } \\
\text { generalizado. }\end{array}$ \\
\hline $\begin{array}{l}\text { Estadio IV: } \\
\text { Sistema social y } \\
\text { conciencia }\end{array}$ & $\begin{array}{l}\text { Cumplir deberes a } \\
\text { los que se han } \\
\text { comprometido; } \\
\text { las leyes se han } \\
\text { de mantener } \\
\text { excepto en casos } \\
\text { extremos cuando } \\
\text { entran en } \\
\text { conflicto con } \\
\text { otras reglas } \\
\text { sociales fijas. El } \\
\text { bien está también } \\
\text { en contribuir a la } \\
\text { sociedad, grupo o } \\
\text { institución. }\end{array}$ & $\begin{array}{l}\text { Mantener la } \\
\text { institución en } \\
\text { marcha y evitar } \\
\text { un parón en el } \\
\text { sistema "si todos } \\
\text { lo hicieran"; } \\
\text { imperativo de la } \\
\text { consciencia de } \\
\text { cumplir las } \\
\text { obligaciones } \\
\text { definidas de uno. } \\
\text { (Fácilmente } \\
\text { confundido con la } \\
\text { creencia del } \\
\text { estadio } 3 \text { en las } \\
\text { reglas y la } \\
\text { autoridad.) }\end{array}$ & $\begin{array}{l}\text { Diferencia el } \\
\text { punto de vista de } \\
\text { la sociedad de } \\
\text { acuerdos o } \\
\text { motivos } \\
\text { interpersonales. } \\
\text { Toma el punto de } \\
\text { vista del sistema } \\
\text { que define roles y } \\
\text { reglas; considera } \\
\text { las relaciones } \\
\text { interpersonales en } \\
\text { términos de lugar } \\
\text { en el sistema. }\end{array}$ \\
\hline $\begin{array}{l}\text { Nivel III: } \\
\text { Postconvencional }\end{array}$ & $\begin{array}{l}\text { Ser consciente de } \\
\text { que la gente tiene }\end{array}$ & $\begin{array}{l}\text { Sentido de } \\
\text { obligación de ley }\end{array}$ & $\begin{array}{l}\text { Perspectiva } \\
\text { anterior a la }\end{array}$ \\
\hline
\end{tabular}




\begin{tabular}{|c|c|c|c|}
\hline $\begin{array}{l}\text { o de principios. } \\
\text { Estadio } 5 \text { : } \\
\text { Contrato social o } \\
\text { utilidad y } \\
\text { derechos } \\
\text { individuales }\end{array}$ & $\begin{array}{l}\text { una variedad de } \\
\text { valores y } \\
\text { opiniones y que la } \\
\text { mayoría de sus } \\
\text { valores y reglas } \\
\text { son relativas a su } \\
\text { grupo. Las reglas } \\
\text { son normalmente } \\
\text { mantenidas por el } \\
\text { bien de al } \\
\text { imparcialidad y } \\
\text { porque son el } \\
\text { contrato social. } \\
\text { Algunos valores y } \\
\text { reglas no relativas } \\
\text { (ej. La vida y la } \\
\text { libertad) se deben } \\
\text { mantener en } \\
\text { cualquier } \\
\text { sociedad, sea cual } \\
\text { sea la opinión de } \\
\text { la mayoría. }\end{array}$ & $\begin{array}{l}\text { a causa del } \\
\text { contrato social de } \\
\text { ajustarse a las } \\
\text { leyes por el bien } \\
\text { de todos y la } \\
\text { protección de los } \\
\text { derechos de } \\
\text { todos. Un } \\
\text { sentimiento de } \\
\text { compromiso de } \\
\text { contrato que se } \\
\text { acepta libremente, } \\
\text { para con la } \\
\text { familia, amistad, } \\
\text { confianza y las } \\
\text { obligaciones del } \\
\text { trabajo. } \\
\text { Preocupación de } \\
\text { que las lees y los } \\
\text { deberes se basen } \\
\text { en cálculos } \\
\text { racionales de } \\
\text { utilidad general } \\
\text { "el mayor bien } \\
\text { para el mayor } \\
\text { número posible". }\end{array}$ & $\begin{array}{l}\text { sociedad. El } \\
\text { individuo racional } \\
\text { consciente de los } \\
\text { valores y } \\
\text { derechos antes de } \\
\text { acuerdos sociales } \\
\text { y contratos. } \\
\text { Integra las } \\
\text { perspectivas por } \\
\text { mecanismos } \\
\text { formales de } \\
\text { acuerdo, contrato, } \\
\text { imparcialidad } \\
\text { objetiva y proceso } \\
\text { debido. Considera } \\
\text { puntos de vista } \\
\text { legales y morales; } \\
\text { reconoce que a } \\
\text { veces están en } \\
\text { conflicto y } \\
\text { encuentra difícil } \\
\text { integrarlos. }\end{array}$ \\
\hline $\begin{array}{l}\text { Estadio 6: } \\
\text { Principios éticos } \\
\text { universales. }\end{array}$ & $\begin{array}{l}\text { Según principios } \\
\text { éricos escogidos } \\
\text { por uno mismo. } \\
\text { Las leyes y los } \\
\text { acuerdos sociales } \\
\text { son normalmente } \\
\text { válidos porque se } \\
\text { apoyan en tales } \\
\text { principios; } \\
\text { cuando las leyes } \\
\text { los violan, uno } \\
\text { actúa de acuerdo } \\
\text { con sus propios } \\
\text { principios. Los } \\
\text { principios son } \\
\text { principios } \\
\text { universales de } \\
\text { justicia: la } \\
\text { igualdad de los } \\
\text { derechos } \\
\text { humanos y } \\
\text { respeto por la } \\
\text { dignidad de los } \\
\text { seres humanos }\end{array}$ & $\begin{array}{l}\text { La creencia como } \\
\text { persona racional } \\
\text { en la validez de } \\
\text { los principios } \\
\text { morales } \\
\text { universales y un } \\
\text { sentido de } \\
\text { compromiso } \\
\text { personal con } \\
\text { ellos. }\end{array}$ & $\begin{array}{l}\text { Perspectiva de un } \\
\text { punto de vista } \\
\text { moral del que } \\
\text { parten los } \\
\text { acuerdos } \\
\text { sociales. La } \\
\text { perspectiva es la } \\
\text { de un individuo } \\
\text { racional que } \\
\text { reconoce la } \\
\text { naturaleza de la } \\
\text { moralidad o el } \\
\text { hecho de que las } \\
\text { personas son fines } \\
\text { en sí mismas y } \\
\text { como tales se las } \\
\text { debe tratar. }\end{array}$ \\
\hline
\end{tabular}


como individuos.

* Tomado de L. Kohlberg, "Moral stages and moralization: The cognitive developmental approach", en Moral development and behavior: theory, research and social issues, Nueva York, Holt, Rienehart and Winston, 1976, pp. 34-45.

\section{La propuesta educativa de Kohlberg}

Kohlberg rechaza la propuesta psicoanalista para la estructura moral del ser humano, porque no ha podido ser demostrada de forma empírica; rechaza también las teorías de la maduración, porque no explican el inicio del proceso. Así mismo, añade que los hallazgos del estudio de Hartshorne y May demuestran la invalidez de las teorías del aprendizaje. Rechaza también la hipótesis de Piaget, tomada de Durkheim, de que los grupos de compañeros determinen un rol principal en el desarrollo moral, es decir, en la interiorización de las normas por parte del individuo.

Kohlberg propone que la secuencia de niveles y estadios constituye el desarrollo moral, y que es una constante cultural. El niño empieza percibiendo las normas como algo externo a él mismo, procedente de la autoridad, y coercitivo; sigue viéndolas como un instrumento para obtener recompensas; después como un medio para obtener la aprobación de los demás; luego como soportes de un determinado orden ideal y finalmente como estructuras de principios sociales necesarios para la convivencia social, por ejemplo, la justicia. Kohlberg sostiene que la evolución a través de los estadios es el resultado de la interacción del niño con el mundo que le rodea. Kohlberg propone como pedagogía moral la discusión de dilemas y el favorecimiento de la asunción de la perspectiva de los demás. (PÉREZ-DELGADO et al. 1991)

Sin embargo, Kohlberg se da cuenta de que esto no es suficiente para una buena formación moral, por lo que propone la "comunidad escolar justa". Con respecto al concepto de Justicia, propio del estadio VI del nivel postconvencional, Kohlberg acepta la concepción de Justicia tal y como la formula Rawls: lo ético es lo justo. Rawls parte de la idea de contrato social para llegar a 
una justicia de equidad, y considera la justicia como una virtud de las instituciones sociales; propone la idea del equilibrio reflexivo considerando que todos los ciudadanos tienen igual capacidad para ejercer la razón, y el mismo sentido de la justicia; el cual viene determinado por el uso de la facultad intelectual y la emisión de un juicio. Desde estas premisas, Kohlberg propone la "escuela justa" en la que los integrantes de la "comunidad educativa" abordan, en un plano de igualdad, las normas y sanciones para llegar a acuerdos sobre ellas, con el fin de vincular el ambiente escolar con los objetivos de formación moral, y conectar los debates morales a la realidad diaria. (LAZARTE MORO, Ana M., 2005)

\section{Carol Gilligan (1936 - )}

Filósofa y psicóloga estadounidense, profesora de la Universidad de Harvard, publica en 1982 su libro In a different voice: psychological theory and women's development.

BONETE PERALES, Enrique (2009, p. 67) sostiene que: “A partir de entonces una voz diferente en el ámbito de la filosofía moral sonó con fuerza: el modo feminista de abordar los problemas teóricos y prácticos. Originó no sólo lo que ha venido a llamarse la ética del cuidado, sino también una sólida crítica a diversas teorías éticas de inspiración kantiana."

Gilligan, discípula de Kohlberg, estaba muy familiarizada con sus trabajos. Kohlberg había concluido que las niñas de once años alcanzaban solamente el estadio (III), en cambio, los varones a esa edad desarrollaban capacidades morales propias de los estadios (IV) o (V), y había interpretado esto como un rasgo de inferioridad moral femenina.

Gilligan, en desacuerdo con esos resultados, revisó los experimentos de su maestro encontrando lo siguiente:

"La crítica que hace Freud al sentido de justicia de las mujeres, al que (Gilligan) considera viciado al rechazar la ciega imparcialidad, reaparece no sólo en la obra de Piaget sino también en la de Kohlberg. Mientras que en la versión de Piaget (1932) Del juicio moral del niño, las niñas son como un "apéndice", una curiosidad a la 


\section{CAPÍTULO IV. VALORES}

que dedica breves líneas de un índice que omite por completo a los "muchachos" porque se supone que al hablar del "niño" se habla del varón, en la investigación de la que Kohlberg deriva su teoría, las mujeres simplemente no existen. Las seis etapas de Kohlberg (1958, 1981) que describen el desarrollo del juicio moral, de la infancia a la adultez, se basan empíricamente en un estudio de 84 niños varones cuyo desarrollo siguió Kohlberg durante un periodo de más de veinte años. [...] Entre quienes así parecen deficientes en desarrollo moral, si se le mide por la escala de Kohlberg, están las mujeres cuyos juicios parecen ejemplificar la tercera etapa de su secuencia de seis. En esta etapa, la moral se concibe en términos interpersonales y la bondad es equiparada a ayudar y complacer a otros. Este concepto de la bondad es considerado por Kohlberg y Kramer (1969) como funcional en las vidas de mujeres maduras, mientras sus vidas se desarrollen en el hogar. Kohlberg y Kramer implican que sólo si las mujeres entran en la arena tradicional de la actividad masculina reconocerán lo inadecuado de esta perspectiva moral y progresarán como los hombres hacia etapas superiores en que las relaciones se subordinan a las reglas (etapa cuatro) y las reglas a principios universales de justicia (etapas cinco y seis).

$\mathrm{Y}$ sin embargo hay en esto una paradoja, pues las características mismas que tradicionalmente han definido la "bondad" de las mujeres, su atención y sensibilidad a las necesidades de otros, son las que vienen a marcarlas como deficientes en desarrollo moral..." (GILLIGAN, Carol, 1985, pp. 40-41)

Ante tal sesgo en la muestra, Gilligan decidió realizar de nuevo el estudio, pero con sujetos femeninos y dilemas que fueran casos reales, no hipotéticos. El resultado fue la aparición de un modelo ético diferente. Como dice ella misma: "En los diez años pasados, he estado escuchando a personas que hablan de moral y de ellas mismas. A mitad de ese periodo, empecé a notar una distinción en estas voces, dos modos de hablar de problemas morales, dos modos de describir la relación entre el otro y el yo.” (GILLIGAN Carol, 1985, p. 13)

Si Kohlberg presentaba como modelo de desarrollo moral una ética de la justicia, con Gilligan emergió la ética del cuidado o de la responsabilidad.

CONRADI, Elizabeth; BILLER-ADORNO, Nikola; BOOS, Margaret; SOMMER, Christina y WIESEMANN, Claudia (2006, p. 61) sostienen que 
pensamiento ético de Immanuel Kant $(1997,1998)$ y John Rawls (1971). Se caracteriza por hacer referencia a los derechos individuales y a las normas y obligaciones generales. [...] En comparación con la ética de la justicia, la ética del cuidado que desarrolló Gilligan hace referencia a la relación, comunicación y responsabilidad de las personas."

Para Gilligan, el desarrollo moral discurre a través de tres niveles separados por dos periodos de transición. El esquema es similar al de Kohlberg pero los contenidos difieren. El primer nivel se caracteriza por la atención al Yo, al cuidado de sí mismo, priorizando la propia supervivencia. Sucede un periodo de transición en el que se ve el primer nivel como egoísta. En el segundo nivel, se produce la conexión del Yo con los otros a través del concepto de responsabilidad, priorizando a los otros y relegando al Yo a un segundo plano. Sucede un segundo periodo de transición en el que se analiza el desequilibrio entre el autosacrificio y el cuidado a los demás, reconsiderándose la relación entre el Yo y los otros. En el tercer nivel se incluye el Yo como receptor, junto con los otros, de la atención y de los cuidados. (GILLIGAN Carol, 1985)

Sin embargo, es importante tener en cuenta que la voz moral atribuida a lo femenino no es en sí una voz de género, pues se puede encontrar en ambos sexos; y si hay hombres que no la perciben han de aprender a escucharla, pues en realidad pertenece a todo ser humano, ya que ambas éticas son igualmente importantes formando, en conjunto, un desarrollo moral pleno. Atrofiándose cualquiera de ellas, ningún ser humano puede alcanzar la plena madurez moral; y una oposición entre ambas origina estereotipos que violentan la realidad. Hay, pues, que evitar la contraposición de ambas éticas, y fomentar la síntesis para poder alcanzar la verdadera complejidad del mundo moral. Toda conducta ética emana de los sentimientos, y en particular de la compasión, como motor de la acción. (BONETE PERALES Enrique, 2009)

Las consecuencias de los estudios de Gilligan han sido numerosas e importantes. Llamó la atención científica hacia el tema, hecho traducido por la aparición de multitud de estudios desde las distintas disciplinas de las ciencias humanas, psico-sociales, de la salud, de la educación... Por otro lado, la Ética del 


\section{CAPÍTULO IV. VALORES}

cuidado ha sido la base sobre la que se ha instrumentado la Ley de la Dependencia, que no es más que el planteamiento del cuidado como objetivo político-social. Además el concepto de 'cuidar' no había sido contemplado por la ética occidental a la altura de conceptos como 'libertad', 'justicia', 'amor', 'solidaridad', etc. GASULL VILELLA, María (2005, p. 9) sostiene que "Gilligan al contemplar el cuidar desde la perspectiva del desarrollo moral de las mujeres, estimula a que rápidamente colectivos femeninos, y de una manera especial las enfermeras, analicen la ética del cuidar en su práctica profesional.”

Como quedó dicho más arriba, cuidar es mantener la vida, por lo tanto sin cuidados no habría vida. La vida necesita cuidados desde que comienza hasta que termina, y a lo largo de su discurrir, siempre que la persona carezca de autosuficiencia para satisfacer sus necesidades vitales por enfermedad, invalidez... o porque decline esas tareas (figura masculina patriarcal). Sin cuidados no hay vida, y sin vida no hay nada. Estos cuidados, los viene dando tradicionalmente la mujer con el amor y la generosidad propios de la ética del cuidado, y no han sido nunca valorados, incluso han sido menospreciados, no porque carezcan de valor, sino porque quien los recibe no necesita esforzarse para conseguirlos. Paradójicamente, el ser humano no aprecia el valor de una cosa, sino mas bien el valor de su propio esfuerzo por conseguir esa cosa. Por lo que la ética del cuidado viene a hacer justicia a la mujer cuidadora, tanto en la esfera privada como en la profesional: la enfermería.

\section{Nel Noddings (1929 - )}

Nel Noddings, licenciada en ciencias exactas y físicas, doctorada en educación; ocupa hoy en el mundo anglosajón, uno de los primeros puestos en filosofía de la educación moral. Mientras que Carol Gilligan, con su obra In a different voice (1982), introduce la ética del cuidado en el discurso ético y académico; Nel Noddings, con la publicación de su libro Caring: A Feminine Approach to Ethics and Moral Education (1984), marca el camino para una educación feminista de lo moral. La autora sostiene que las relaciones de cuidado son la base de toda relación ética; tanto entre padres-hijos, profesores-alumnos; 
como en la filosofía de la educación e incluso en el área de la política social, de cara a los más desvalidos de la sociedad.

La necesidad de ser cuidados es una constante humana universal, y "This dependency is, for Noddings, the 'original condition', which I suspect she means us to hear as a corrective or complement to John Rawls's famously abstract and impersonal 'original position' behind a 'veil of ignorance"”. (BERGMAN, Roger, 2004 p. 2).

La persona que tiene el recuerdo de haber sido cuidada por una madre amorosa y responsable, según Noddings, tiene la clave para entender las obligaciones de una vida moral; no solo para la perspectiva materna, sino también paterna y, sobre todo, para la de cualquier persona en todas las dimensiones de la condición humana.

La autora sostiene que:

"One might say that ethics has been discussed largely in the language of the father: in principles and propositions, in terms such as justification, fairness, justice. The mother's voice has been silent. Human caring and the memory of caring and being cared for, which I shall argue form the foundation of ethical response, have not received attention except as outcomes of ethical behavior. One is tempted to say that ethics has so far been guided by logos, the masuculine spirit, whereas the more natural and perhaps stronger approach would be through Eros, the feminine spirit." (NODDINGS, Nel, 1984, p. 1)

Noddings considera, pues, que todo comportamiento ético proviene de los sentimientos, y distingue entre 'el cuidado natural' y 'el cuidado ético'. El primero impulsa a proteger a otra persona porque queremos hacerlo, el ejemplo típico es el materno-filial; en este caso, no es que una madre o un padre se sientan obligados a proteger a su pequeño, es que quieren protegerlo. El 'deber' y el 'querer' coinciden. Según Noddings, el cuidado ético surge cuando entran en conflicto el 'deber' cuidar a alguien, y el 'querer' atender los propios intereses; conflicto que requiere un esfuerzo de voluntad para ser resuelto.

En principio, el cuidado ético puede parecer superior al cuidado natural, Noddings sostiene que no; es más, afirma que es al revés, el ético depende del 


\section{CAPÍTULO IV. VALORES}

natural y se apoya en él. Si alguien no tiene experiencia del cuidado natural, si no ha sido iniciado en la relación de cuidados, si no tiene memoria de haber sido cuidado, no podrá resolver el conflicto de intereses. (BONETE PERALES Enrique, 2009)

La propuesta educativa de Noddings parte de la ética del cuidado como enfoque de pedagogía moral. La autora sostiene que la clave de cualquier educación exitosa es la formación de individuos que sepan dar y recibir amor, y que el medio para conseguirlo es lograr que las alumnas y alumnos se sientan queridos. Su método cuenta con cuatro estrategias: la primera, el ejemplo; el o la educadora debe ser un ejemplo vivo y permanente de relaciones de cuidado. La segunda, el diálogo; escuchar y responder las dudas de los/las alumnas de forma abierta y honesta. La tercera, la confirmación; toda relación de cuidado o protección parte de la base de la buena fe de la persona cuidada. Hay que olvidar la tradicional desconfianza hacia las/los alumnos y sus motivaciones. La relación de cuidado y la sospecha de mala fe son incompatibles. Por último, la práctica; hay que brindar oportunidades para llevar a la realidad diaria actitudes de cuidado. (MARTÍNEZ FRANCO, Yuly Adriana, RUBIANO LAMPREA, Alejandra, VENEGAS FORERO, Martha Lucía, 2008).

\section{Milton Rokeach (1928-1988)}

Como hemos visto, los valores venían siendo estudiados por la Psicología general y social desde principios del siglo XX, pero es fundamentalmente a partir de los años 50 y 60 que el tema cobra importancia debido; por una parte, al auge del paradigma educativo cognitivista-piagetiano ${ }^{34}$; y por otra, a las aportaciones

\footnotetext{
${ }^{34}$ La Psicología de la Educación data de principios del siglo XX, cuando se ponen en marcha las primeras pruebas psicológicas para la medida de la inteligencia. Esta ciencia, que es la intersección de otras dos: Psicología y Educación, se ha visto enriquecida por la influencia de distintos paradigmas que enfocan el fenómeno educativo desde diferentes perspectivas. (BELTRÁN LLERA J., BUENO ÁLVAREZ J.A., 1995).

El paradigma Conductista, representado por John B. Watson (1878 - 1958), define el aprendizaje como un cambio en la conducta o comportamiento del individuo. Se basa en el modelo de estímulo y respuesta, por lo que es la precursora de asignación de calificaciones, recompensas y/o castigos. Desarrolla el aprendizaje memorístico. El alumno tiene un rol de receptor pasivo y obediente. El docente tiene el control del conocimiento, de los estímulos y de la evaluación que es cuantitativa. La relación profesor-alumno es muy poco interactiva.
} 
de Rokeach y colaboradores. La Psicología social estaba más interesada en las actitudes que en los valores; Rokeach, convencido de que para entender las actitudes había que profundizar en los valores, publica en 1973 The Nature of Human Values, y en 1979 Understanding human values. De esta forma, el estudio de los valores entra en el ámbito de la Psicología social cognitivista, evidenciándose la relación existente entre valores, actitudes y conductas.

Anteriormente, Eduard Spranger (1882 - 1963), filósofo, pedagogo y psicólogo alemán, había utilizado ya los valores en 1928 para explicar la conducta. Describió seis tipos básicos de personalidad: Teorética (búsqueda de la verdad, predominio de lo cognoscitivo), Económica (valora lo útil, aquello que puede satisfacer las necesidades), Estética (centra su interés en lo artísticoestético), Social (focaliza su atención en la sociedad de una forma altruista, su

El paradigma Cognitivista, representado por Jean Piaget (1896 - 1980), David P. Ausubel (1918 - 2008), Jerome Bruner (1915 - ) y Lev S. Vigotsky (1896 - 1934). Aparece para sustituir al conductista. Se basa en el estudio de las distintas dimensiones cognitivas: atención, percepción, memoria, capacidad de comprensión, imaginación, lenguaje y pensamiento. El alumno es visto como un ser activo que procesa información adquiriendo la capacidad de resolver problemas, a través del desarrollo de planes y estrategias. El docente parte de la base de que el alumno aprende a aprender y a pensar, por lo que promueve la reflexión y el desarrollo de aptitudes. Este paradigma alcanza a un mayor número de alumnos al no ser restrictivo en cuanto a los tipos de inteligencia, por lo que ofrece a cada alumno la posibilidad de desarrollar los propios talentos.

El paradigma Constructivista, representado por Jean Piaget (1896 - 1980), David P. Ausubel (1918 - 2008), Jerome Bruner (1915 - ) y Lev S. Vigotsky (1896 - 1934). Considera que el conocimiento previo origina conocimiento nuevo, lo nuevo aprendido se incorpora a lo ya sabido creando estructuras mentales propias. El alumno "construye" conocimiento integrando la información nueva a la experiencia previa. El alumno es activo, responsable y protagonista del proceso de aprendizaje. El docente es guía y promueve el desarrollo y autonomía de los alumnos. Los alumnos que tengan desarrollada la inteligencia intrapersonal tendrán más fácil aprender, pues al conocerse a sí mismos sabrán qué dirección tomar para la búsqueda de conocimiento.

El paradigma Histórico-social, representado por Lev S. Vigotsky (1896 - 1934), defiende que el proceso de desarrollo cognitivo está en función del contexto histórico-social al que pertenece el alumno. En el proceso de aprendizaje se tiene en cuenta la interacción social (padres, profesores, alumnos, amigos...) e instrumental (libros, ordenadores...), el aprendizaje es cooperativo. El aprendizaje es una construcción realizada por el alumno, como resultado de la interacción de su proceso personal con lo obtenido de la colaboración social e instrumental. Aparece el concepto de "Zona de Desarrollo próximo". El alumno es concebido como un ente social activo. El docente dirige el proceso de enseñanza y promueve las zonas de desarrollo próximo. Este método también desarrolla todas las inteligencias. La diferencia con el cognitivista es que este considera que la limitación en el aprendizaje viene determinada por la sociedad, la cultura y el momento histórico. (Componente Docente Básico en Educación. ULA 2012. Disponible en: http://portafoliodayana.wordpress.com/2012/06/10/paradigmas-psicologicos-de-laeducacion/ consultado el 28-6-14) 
tendencia es el amor al prójimo), Política (persona social que sustituye el amor por el poder, trata de imponer a los demás su voluntad), Religiosa (búsqueda de un significado último a la vida, de una existencia escatológica). (GARCÉS FERRER, Jorge, 1988)

A raíz de los estudios de Spranger, numerosos psicólogos se interesaron por el tema ${ }^{35}$, pero ninguno ha sido tan influyente como Milton Rokeach ${ }^{36}$; quien considera que los valores se pueden entender desde dos perspectivas: como criterios en base a los cuales actúan las personas, o bien como propiedades positivas o negativas de los objetos. Rokeach, influenciado por Kohlberg, se adscribe a la primera concepción; y considera que el estudio de los valores capacita para una mejor comprensión del mundo de la motivación, y de las actitudes:

\footnotetext{
${ }^{35}$ Allport y Vernon (1931) construyeron un cuestionario para la clasificación de las personas en función de sus sistemas de Valores. Lurie (1937) aplica un análisis factorial al test de Allport y Vernon delimitando cuatro factores, y por lo tanto cuatro núcleos en los que se articulan los valores: el social-altruista, interesado en las relaciones humanas; el 'filisteo', más complejo que el anterior y que incluye lo económico y político; el teorético y el religioso. Brodgen (1962), aplicando también el análisis factorial al test de Allport y Vernon, llega a un resultado más sintético: ve un solo factor con dos polos: Idealismo y pragmatismo. Posteriormente, Eysenck (1964), sobre la base de los anteriores estudios, elabora su modelo R-T (radicalismo-dureza mental) relacionando los Valores con las actitudes políticas básicas. Charles Morris (1986) inclina sus estudios sobre valores hacia la forma de vida elegida por el individuo como preferible. Del análisis factorial realizado obtuvo cinco factores que, según Morris, revelarían los valores subyacentes a las perspectivas vitales preferibles: autocontrol, acción, retraimiento y autosuficiencia, altruismo y autosatisfacción excesiva. Kluckhohn (1955) se interesa también por el tema definiendo valor como: "concepción de lo deseable que influye sobre la selección de modos, pensamientos y metas de acción, tanto distintivas de un sujeto como de un grupo"; este modo de entender el término valor será luego retomado por los teóricos modernos. (SERRANO MARTÍNEZ, Gonzalo, 1984)

${ }^{36}$ Rokeach, psicólogo social estadounidense de origen polaco, estaba inicialmente interesado por el estudio de la identidad: los mecanismos mentales por los que la persona construye su propia identidad, y las causas por las que esta entra en crisis. Para lo cual llevó a cabo, en 1959, un experimento no exento de polémica. Reunió, durante 25 meses, en un mismo pabellón del hospital psiquiátrico de Ypsilanti (Michigan), a tres enfermos de esquizofrenia que compartían un mismo delirio: los tres decían ser Jesucristo. Al principio se produjeron conflictos que llegaron hasta a la agresividad física, pero luego se adaptaron a la situación sin confrontaciones ni curación. Resultaba imposible hacerlos razonar sobre su identidad, porque lo que habían perdido era, precisamente, la razón. En 1964, Rokeach publicó el libro The three christs of Ypsilanti. A narrative study of three lost men sobre el que se hicieron dos óperas, una película y una obra de teatro. (ALONSO PEÑA, José Ramón, disponible en: http://jralonso.es/2013/01/27/los-tresjesucristos-de-michigan/ consultado 29-6-14).
} 
"Values, our theoretical orientation would predict, should enter into motivation in two main ways: first, by defining the gratifications which establish and reinforce motives; second, by defining the source of gratification. Conversely, a particular kind or type of motivation should affect behaviour in different way, depending upon the presence and the particular content of relevant values" (KOHLBERG, 1968, p. 484, citado por ROKEACH, 1979, p. 24).

Comienza por analizar y definir los conceptos de creencia, actitud y valor. CADUTO, Michael, en su obra Guía para la enseñanza de valores ambientales, 1992, hace una muy interesante síntesis de las teorías de este autor.

Para Rokeach "una creencia es una proposición simple, consciente o no, que se puede inferir de lo que una persona dice o hace, y que puede ir precedida por las palabras 'creo que", (ROKEACH, Milton, 1976, citado por CADUTO, Michael J., 1992, p. 7).

Descubre en las creencia tres componentes básicos: cognitivo, afectivo y conativo; y las clasifica en tres categorías principales: descriptivas o existenciales (la afirmación descriptiva de algo: el sol sale por el este), evaluativas (la manifestación de una valoración: yo creo que el mar es hermoso); y prescriptivas o exhortatorias (las que matizando el componente conativo, exhortan a los demás a hacer o no hacer algo: la naturaleza debe respetarse, robar es malo).

Por otro lado, las creencias pueden ser verdaderas o falsas; independientemente de lo cual, tienen poder de influencia sobre las personas que las creen, pues las creen como verdaderas. Ahora bien, no todas comprometen en la misma medida; de entre las dos siguientes creencias 'matar es malo' y 'los peces nadan', la primera tiene más poder de acción sobre la conducta humana que la segunda. Rokeach sostiene que las creencias se generan durante la infancia, y denomina sistema de creencias al conjunto de creencias que tiene un individuo acerca del mundo que le rodea, de tal manera que un subconjunto de creencias relacionadas da lugar a una actitud. Rokeach afirma que "Una actitud es una organización relativamente duradera de creencias en torno a un objeto o situación que predispone a la persona a responder de determinada manera ante ese objeto o situación" (ROKEACH, 1976, citado por CADUTO Michael J., 1992, p. 7). 
La diferencia fundamental entre creencias y actitudes es que el componente emotivo de las últimas es mayor, y su influencia sobre la conducta también.

Un conjunto de conductas interrelacionadas dan origen a un valor: "los valores son convicciones duraderas de que determinada conducta o modo ideal de vida es personal o socialmente preferible a la conducta o modo ideal de vida opuesto" (ROKEACH, 1976, citado por CADUTO Michael J., 1992, p. 7).

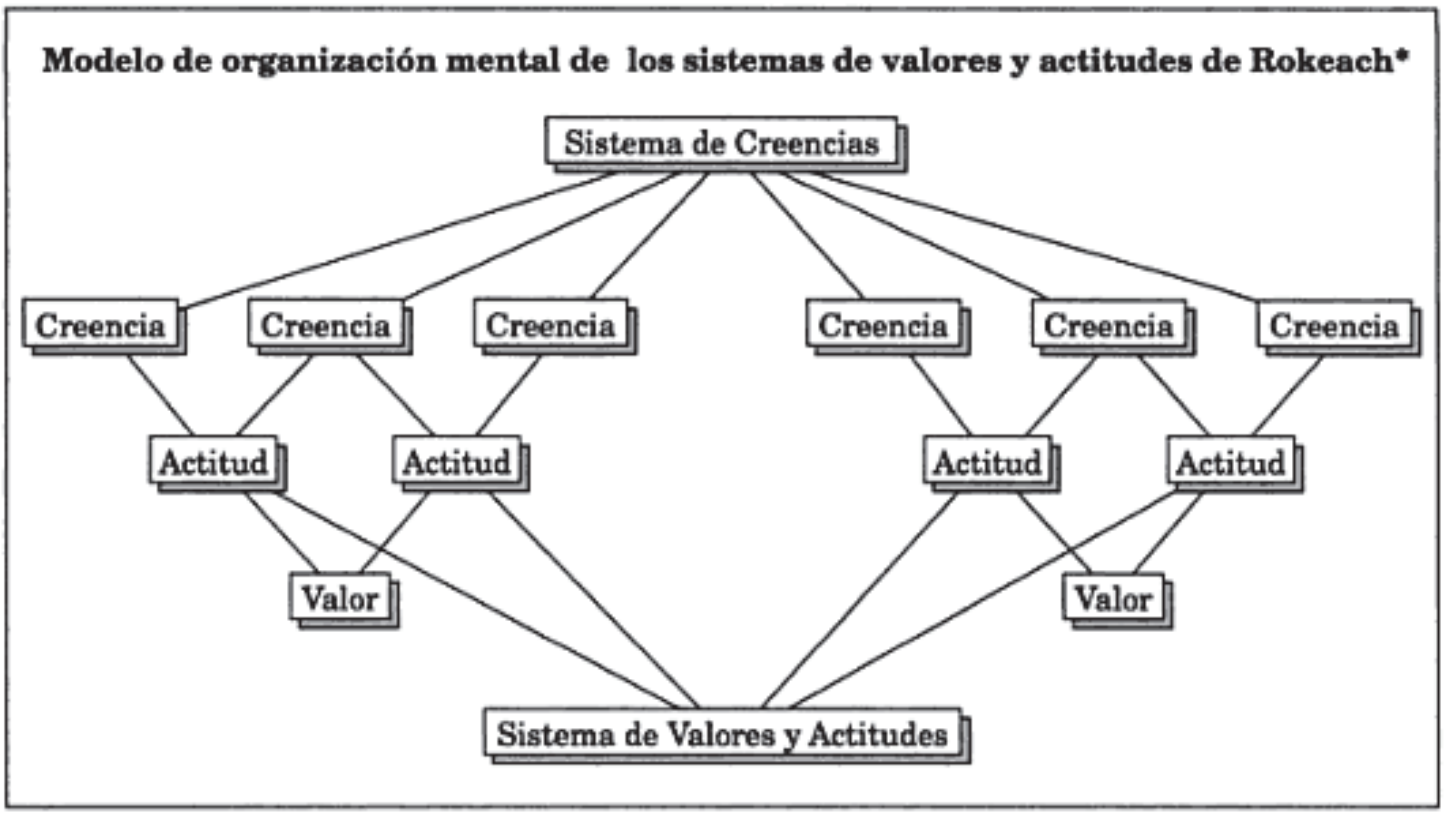

Extraído CADUTO, Michael J., 1992, p. 8

En función de la importancia otorgada a cada valor por el individuo, estos quedan ordenados en sistemas jerarquizados, de tal forma, que un adulto alberga centenares o miles de creencias, un número más pequeño de actitudes y tan solo unas docenas de valores que, para Rokeach, son creencias prescriptivas/proscriptivas duraderas. Cuanto más compartido esté un valor dentro de una sociedad, mayor será la presión ejercida por esa sociedad sobre cada individuo con respecto a ese valor y, por lo tanto, mayor será la sensación de obligatoriedad que cada uno experimenta. 
Una característica primordial de los valores es su estabilidad o durabilidad en el tiempo; ya veíamos antes, que las civilizaciones antiguas usaban la piedra como soporte y la divinidad como origen para conseguir este carácter. Rokeach descubre y describe los mecanismos por los que se produce:

Por un lado los valores determinan la existencia de estructuras sociales, estableciéndose un feed-back positivo entre ambos, de tal forma que las estructuras sociales derivadas de un valor lo mantienen por mecanismos de presión social.

Por otro lado, el sistema de valores fundamenta la conciencia de la propia identidad.

Finalmente, está la manera en que los valores son enseñados y aprendidos: de forma aislada y absoluta. Las actitudes y los valores son adquiridos a través de la socialización.

\section{a) Clasificación de los valores}

Muchos autores han aportado a la ciencia distintas clasificaciones. Sin embargo, la mas aceptada a nivel universal es la que propone Rokeach en 1973; distinguiendo entre valores terminales, referidos a la existencia, e instrumentales, relativos a la conducta. Los primeros son más estables que los segundos.

Los terminales pueden ser intrapersonales, referidos al individuo; 0 interpersonales, referidos al grupo. Los valores instrumentales pueden ser de competencia, conectados con los intrapersonales; o morales, conectados con los interpersonales y pueden generar sentimientos de culpa.

La importancia de esta clasificación es que establece un criterio de diferenciación operativa entre los dos tipos de valores y facilita establecer la relación que existe entre los valores y el comportamiento. Además, con una perspectiva supraindividual, resulta posible establecer "grupos de valores", “organización de valores" (ROKEACH, 1979, citado por SERRANO MARTÍNEZ, Gonzalo, 1984, p. 13)

Tras muchos análisis, Rokeach llegó a identificar un reducido número de valores, dieciocho para los terminales y no más de cincuenta o sesenta para los 
instrumentales; que vienen determinados por la cultura, la sociedad y la personalidad, y generan actitudes y conductas.

\section{VALORES TERMINALES DE ROKEACH*}

1. Felicidad (satisfacción)

2. Auto-respeto (autoestima)

3. Tiempo libre (una vida agradable y pausada)

4. Salvación (sentirse salvado en la vida eterna)

5. Seguridad familiar (cuidado a los seres queridos)

6. Satisfacción con la tarea realizada (sentimiento de que mi vida es útil)

7. Una vida confortable (una vida próspera)

8. Amistad verdadera (relaciones comunicativas)

9. Armonía interna (libre de conflictos internos)

10. Madurez (una comprensión madura de la vida)

11. Un mundo en paz (libre de guerras y conflictos)

12. Igualdad (hermandad, igualdad de oportunidades)

13. Reconocimiento social (respeto, admiración) ${ }^{37}$

14. Amor maduro (intimidad sexual y emocional)

15. Seguridad nacional (protección de los ataques)

16. Un mundo de belleza (belleza natural y artística)

17. Libertad (independencia, libre elección)

18. Una vida excitante (una vida activa, estimulante)

\section{VALORES INSTRUMENTALES DE ROKEACH*}

1. Valiente (defender las propias ideas)

2. Educado (correcto, de buenas maneras)

\footnotetext{
${ }^{37}$ En nuestra encuesta sobre la que basamos nuestro trabajo empírico, tenemos la pregunta 61. Sentido de la vergüenza por lo que necesitamos ahondar sobre este punto para poder hacer luego un análisis adecuado. A propósito de este valor Reconocimiento social (respeto, admiración) y buscando sobre la importancia que puede tener para los distintos sectores sociales, NOBLE, Vicki (1992) recoge en $A$ helping hand from the guys una encuesta en la que pregunta a hombres y a mujeres cual es su mayor miedo. Para ellas, ser violadas y asesinadas; para ellos, ser motivo de risa.

Ser motivo de risa está íntimamente relacionado con sentir vergüenza, con la pérdida de respeto o admiración.
} 
3. Intelectual (inteligente, reflexivo)

4. Honrado (sincero, verdadero)

5. Obediente (deferente, respetuoso)

6. Lógico (consciente, racional)

7. Imaginativo (atrevido, creativo)

8. Capaz (competente, afectivo)

9. Alegre (de corazón abierto, gozoso)

10. Auto-controlado (discreto, auto-disciplinado)

11. Capaz de perdonar (dispuesto a perdonar a otros)

12. Capaz de amar (afectivo, tierno)

13. Responsable (fiable, digno de confianza)

14. Independiente (confianza en sí mismo, autosuficiente)

15. Limpio (aseado, ordenado)

16. Ambicioso (buen trabajador, con aspiraciones)

17. Liberal (abierto de mente)

18. Servicial (trabaja por el bienestar ajeno)

* (Tomado de GARCÉS FERRER, Jorge, 1988)

\section{Función de los valores}

Rokeach sostiene que los valores son motivantes, permiten generar autoestima, presentarnos ante otras personas, posicionarnos ante ideologías y religiones, evaluar, juzgar, tomar decisiones, resolver conflictos; los valores facilitan la estructuración del mundo circundante.

Tienen una función adaptativa porque determinan conductas de adaptación social como es la educación, el autocontrol o el confort. También tienen una función ego-defensiva: algunas actitudes inconfesables se convierten en socialmente aceptables a través de mecanismos de racionalización; esto ocurre con algunos valores políticos y religiosos. 


\section{Diferencias entre valor $y$ actitud:}

El valor es una creencia única; la actitud, varias creencias organizadas y centradas en un objeto o situación dadas.

El valor trasciende objetos y situaciones, la actitud se centra en un objeto o situación concreta.

El valor induce a una norma de comportamiento, la actitud no.

El valor evoca una deseabilidad, la actitud se encuentra directamente con algo.

En la estructura cognitiva de la persona, los valores son más centrales que las actitudes: "La teoría sobre el sistema de creencias coloca los valores en el núcleo de la personalidad del individuo. En este sentido los valores se convierten en elementos centrales que sirven al self para mantener, siempre que sea necesario, la autoestima de cada uno y para hacerla crecer cuando sea posible" (PALACIOS NAVARRO, Santiago, 1997, p. 114)

Los valores tienen mayor diferenciación en sus funciones que las actitudes.

Los valores tienen un importante carácter predictivo sobre la conducta, que además está influenciada por las disposiciones personales y los factores circunstanciales.

\section{Valores y normas sociales:}

Los valores se refieren a modos de conducta o estados finales de existencia. Las normas sociales son patrones de comportamiento.

Los valores tienen un carácter general y abstracto que queda por encima de situaciones específicas. Las normas sociales no.

Los valores son personales e internos. Las normas son consensos sociales, externos a la persona. 


\section{Valores y necesidades:}

Maslow $^{38}$, en 1954, y Frech y Kahn, en 1962, postularon que valores y necesidades eran equivalentes. Rokeach, en 1979, refuta esta concepción de equivalencia; mantiene que los valores son específicamente humanos por ser representaciones cognitivas y transformaciones de las necesidades, y que valores y necesidades no son estructuras isomorfas, porque no siempre se pueden inferir necesidades de valores.

\section{Valores e intereses:}

Para Rokeach (1977), el interés es una manifestación del valor por lo que comparte atributos con este. El interés está más cerca de la actitud que el valor, puesto que representa un posicionamiento positivo o negativo hacia objetos o acciones. (SERRANO MARTÍNEZ, Gonzalo, 1984).

\section{Valores e ideologías}

Rokeach replanteó la interpretación de las ideologías políticas al criticar como simplista la dualidad liberalismo-conservadurismo, liberalismo-radicalismo o izquierda-derecha. Consideraba que el mundo de la política es más complejo, y

\footnotetext{
38 ABRAHAM H. MASLOW (1908 - 1970) publica en 1954 su obra Motivación y personalidad en la que expone su teoría sobre las necesidades humanas, clasificándolas en cinco categorías: 1. Necesidades fisiológicas (respiración, sed, hambre, sexo...), 2. Necesidades de seguridad (protección, estabilidad...), 3. Necesidades de amor y pertenencia (amistad, familia, afectivas...), 4. Necesidades de estima (estatus, reconocimiento, aprecio...), 5. Necesidades de auto-realización.

El autor sostiene que "las necesidades humanas básicas están organizadas dentro de una jerarquía de relativa prepotencia o predominio" (MASLOW, 1991, p. 25), de tal forma que el individuo trata de satisfacer primero las más básicas, y en orden de urgencia (ante la sed y el hambre, predomina la primera; y entre esta y la necesidad de respirar, predomina la última). Maslow denomina los cuatro primeros niveles necesidades de déficit o Necesidades-D (D-needs); porque si nos falta algo, sentimos su necesidad; pero si satisfacemos la demanda, no sentimos nada.

Al último nivel lo denomina necesidades de ser o necesidades B (B-needs); porque cuanto más se satisfacen más se hacen sentir, más ansia de auto-realización o auto-actualización siente el individuo. El autor sostiene que "Las necesidades emocionales, cognitivas, expresivas y estéticas de la persona prestan a la ciencia su origen y sus metas. La gratificación de cualquier necesidad de ese tipo es ya un valor" (MASLOW, 1991, p. 278).
} 
que no se puede reducir a una expresión lineal con dos polos opuestos. En su investigación, parte de la hipótesis de que las ideologías políticas se asientan sobre valores que las justifican, y generan relaciones de poder que se reparten de forma desigual. Los más favorecidos defenderían el estatus quo, y los otros reivindicarían ideologías de reparto justo. Llevó a cabo su trabajo realizando el análisis del discurso de políticos e intelectuales adscritos a las cuatro ideologías primarias: fascismo (Hitler), comunismo (Lenin), capitalismo (Goldwater) y socialismo (Fromm).

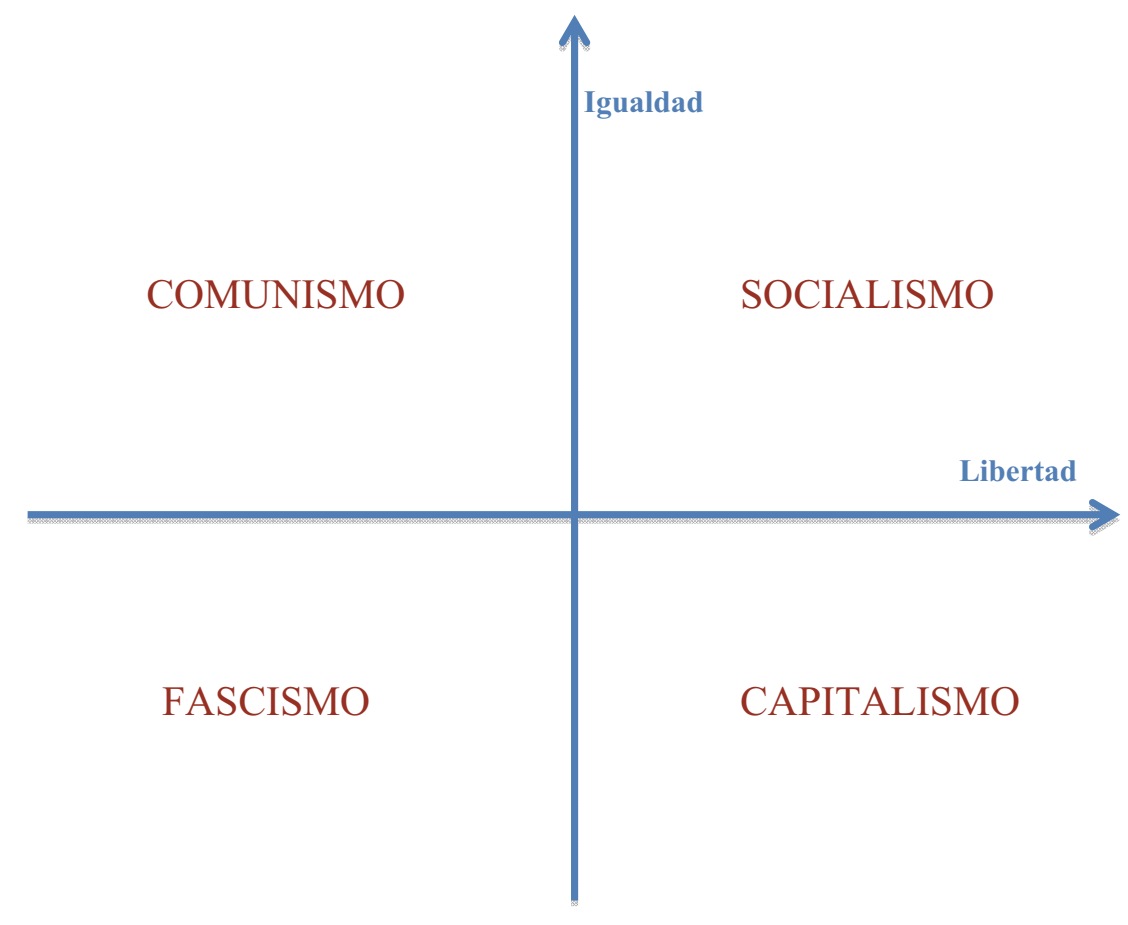

Realizado a partir del gráfico de GARCÉS FERRER, Jorge, (1988, p. 5)

Observó que las ideologías políticas se articulan en base a dos valores terminales: Igualdad y Libertad, de forma que se pueden clasificar en un cuadrante de dos ejes que representen sendos valores. Llegó a la conclusión de que el socialismo es alto en Igualdad y libertad; el fascismo, bajo en ambos valores; el comunismo, presenta alta igualdad y baja libertad; mientras que el capitalismo es justo lo contrario, alta libertad y baja igualdad. (GARCÉS FERRER, Jorge, 1988) 


\section{Medición de los valores}

Existen varios métodos para realizar esta medición. En primer lugar, se pueden deducir tras la observación de la conducta; este método tiene el inconveniente de la subjetividad del observador, y de la dificultad que entraña la identificación de valores. Otra forma es preguntar a la persona directamente por sus valores, el problema que se presenta aquí es la carencia de autoconocimiento. El tercer procedimiento, elegido por Rokeach, consiste en presentar a la persona una lista de valores, pidiéndole que los numere por orden de importancia. El cuestionario de Rokeach, que consta de dos listas: 18 valores terminales y 18 valores instrumentales, ha sido utilizado en numerosas investigaciones por lo que cuenta con una amplia base empírica, y es el que goza de mayor aceptación. Sin embargo, no está exento de dudas referidas fundamentalmente a su validez intercultural y semántica. (GARCÉS FERRER, Jorge, 1988).

\section{El cambio de valores: cambio cognitivo y conductual}

Son las contradicciones internas del sistema cognitivo global las que originan cambios en los valores. En esto están de acuerdo la mayoría de las teorías de la Psicología Social, por lo que proponen identificar los subsistemas del cognitivo global que pueden entrar en contradicción entre sí, arrastrando al cambio.

La existencia de contradicciones internas es muy frecuente entre los seres humanos, pero el cambio solo se da cuando estas contradicciones son conscientes y afectan al auto-concepto, al self-concept, el cual “...incluye cogniciones de sí mismo, habilidades, posición socioeconómica, identidad religiosa, papeles sociales, etc.; en suma, se configura como el eje en torno al cual se articulan creencias, actitudes y valores.” (SERRANO MARTÍNEZ, Gonzalo, 1984, p. 24).

El auto-concepto se apoya sobre los valores que conforman su estructura cognitiva más próxima jugando, por lo tanto, el rol más decisivo en el cambio cognitivo y conductual. 


\section{CAPÍTULO IV. VALORES}

La disonancia que se produce entre el auto-concepto y la auto-realización en una situación dada, origina el sentimiento de auto-insatisfacción, punto de arranque del cambio. Se trata, por lo tanto, de algo afectivo más que cognitivo.

La auto-insatisfacción se deriva principalmente de la moralidad y de la competencia, campos que vienen regidos por la sociedad y el círculo en el que se integre el individuo. La auto-insatisfacción genera ansiedad, para reducirla se puede recurrir a la negación o represión de la contradicción que no siempre es posible, o a cambiar la cognición que entra en conflicto con otra; son más fáciles de cambiar las periféricas que las centrales, y las actitudes que los valores que enlazan ya con el auto-concepto.

"Frente a otras teorías, que se ocupan del cambio a corto plazo, la escuela de Rokeach pone el acento en el largo plazo. Con ello se opone al modelo persuasivo vigente, más preocupado del cambio de actitudes independientes que del desarrollo del self." (GRANDMONTAGNE, Alfredo Goñi, 1998, p.178) 
CAPÍTULO V

LA DIRECCIÓN POR VALORES (DPV) 

1997 fue un año crucial en el campo de la dirección de empresas. Los profesores Salvador García y Shimon Dolan acuñaron el término Dirección por Valores (DpV) al editar, en Barcelona, su obra LA DIRECCIÓN POR VALORES (DpV) El cambio más allá de la dirección por objetivos. Ese mismo año, en San Francisco, aparecía la obra novelada de Kenneth Blanchard y Michael O'connor Managing by Values.

Siguiendo la obra de García y Dolan, que fue en su momento un superventas, vemos que la dirección por valores es la evolución de otras filosofías de dirección basada en instrucciones u objetivos.

\section{La Dirección por Instrucciones (DpI)}

La DpI, fue propuesta por los Científicos de la Administración (Frederick Taylor, Henri Fayol, el matrimonio Gilbreth...), hacia la década de los años veinte del pasado siglo. Se pretendía aumentar la productividad individual mediante la creación de ambientes estables en los que se realizaban acciones repetitivas de baja complejidad (cadenas de montajes), o por la ejecución de tareas puntuales por parte de personal poco cualificado (operarios).

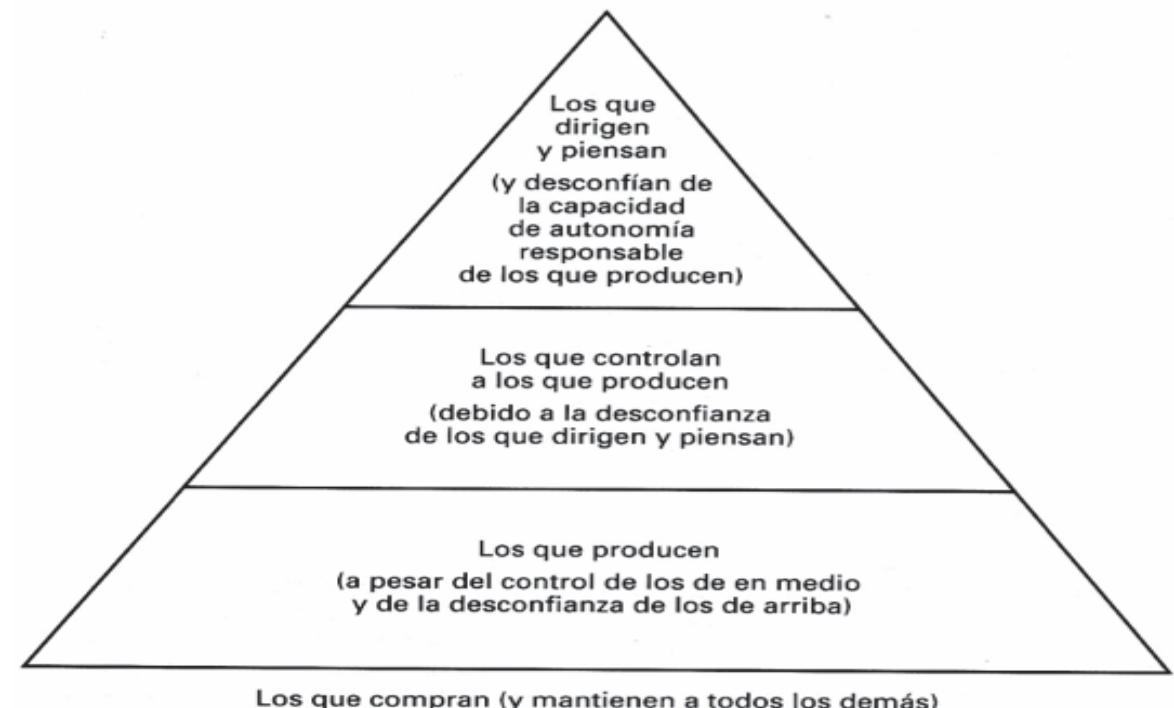


La DpI es conocida también como "Dirección de operarios", y responde a un organigrama piramidal muy jerarquizado. Tiene su lugar de ser en dos situaciones concretas: en las empresas industriales de la primera mitad del siglo $\mathrm{XX}$, con sus cadenas de montaje, en las que se buscaba una alta producción cuantitativa; y en los casos de emergencia (incendios, catástrofes...), cuando hay que actuar de forma rápida y automática, siguiendo protocolos de acción conocidos y entrenados con anterioridad, para evitar tener que pensar en el momento de la acción.

Ambos casos, rutinas y emergencias, tienen un denominador común: no hay que pensar, hay que ejecutar con precisión y celeridad las instrucciones dadas.

Este tipo de trabajo, monótono y nada creativo, es muy aburrido; y es vivido como un sufrimiento impuesto, acarreando absentismo físico y psíquico.

\section{La Dirección por Objetivos (DpO)}

Si la DpI hacía referencia a una "dirección de operarios", la DpO entraña la idea de "dirección de empleados".

El fundamento científico de la DpO está basado en los principios del "éxito psicológico" de Chris Argyris ${ }^{39}$, y en el establecimiento de metas de Edwin

\footnotetext{
${ }^{39}$ Chris Argyris (1923 - 2013), estadounidense de origen griego, psicólogo y profesor de la Universidad de Harvard, centró sus investigaciones en el cambio organizacional, y más concretamente en el comportamiento de los altos cargos directivos. Argyris observó que los empleados, al ser tratados por sus jefes como dependientes e irresponsables a los que hay que "controlar y mandar", se mantenían en una inmadurez psicológica. Argyris propone dos paradigmas organizativos básicos: el burocrático/controlador (Modelo I), y el orientado al aprendizaje mutuo continuo (Modelo II). El modelo I sería equiparable a la DpI, y solo serviría para situaciones rutinarias o de emergencia. Pero en situaciones no estables, situaciones de cambio en las que se presentan problemas a resolver, se hace necesaria otra forma de pensar en la que el individuo llega a poder "triunfar psicológicamente" en su trabajo. Sin embargo las empresas tienen tendencia a no ver la necesidad de triunfo psicológico individual, creando situaciones de dependencia y subordinación que llevan a los empleados a una inhibición, falta de compromiso, y absentismo físico o psíquico como medidas de adaptación.
} 
Locke $^{40}$.

El objetivo principal de cualquier empresa es maximizar la rentabilidad de los recursos que utiliza, pero esto es algo demasiado amplio y abstracto. Para hacerlo realidad ha de descomponerse en objetivos más concretos, fáciles de transmitir al personal, y dejarle un amplio margen de libertad al momento de gestionarlos y cumplirlos. La DpO es "una filosofía de dirección para convertir las necesidades de la empresa en objetivos de los individuos." (GARCÍA y DOLAN, 1997, p.22).

\section{a) Ventajas de la $\mathrm{DpO}$ :}

Aumenta notablemente la motivación del personal. Al dejar marcados claramente los objetivos, todos saben a qué atenerse, teniendo a la vez mayor autonomía y responsabilidad. El control se centra en el resultado, no en el método. Facilita la dirección a distancia por lo que los directivos disponen de más tiempo. La aplicación de remuneraciones se facilita.

\section{Inconvenientes de la $\mathrm{DpO}$ :}

Encontrar un objetivo equilibrado es bastante difícil, por lo que viene a ser el mayor inconveniente. La motivación no suele ir más allá de los directivos y los mandos intermedios. La cúpula directiva pierde control sobre la empresa, que queda en manos de la capacidad de planificación y resolución de los mandos intermedios.

Muchas de las veces en que la DpO no ha tenido los resultados esperados, puede haber sido porque se ha tratado de implementar una técnica basada en la necesidad humana de éxito individual, dentro de un ambiente empresarial dirigido al control jerárquico de las personas.

\footnotetext{
${ }^{40}$ Edwin A. Locke (1938 - ), psicólogo estadounidense y profesor de la Universidad de Maryland, desarrolló la teoría de que las metas y los objetivos que se propone una persona determinan su motivación para la acción, es decir, que cuanto más desafiante sea el objetivo mayor será el rendimiento.
} 


\section{La Dirección por Valores (DpV)}

García y Dolan sostienen que los valores son palabras, quedándose por desgracia, demasiadas veces solo en eso, pero que las palabras que identifican valores (por ejemplo: honestidad, felicidad, verdad, sinceridad...) tienen un alto potencial para dirigir las acciones humanas.

Los autores, influenciados por los trabajos de Rokeach, adoptan su definición de valor y la matizan así: "Los valores son aprendizajes estratégicos relativamente estables en el tiempo de que una forma de actuar es mejor que su opuesta para conseguir nuestros fines o, lo que es lo mismo, para conseguir que nos salgan bien las cosas." (GARCÍA y DOLAN, 1997, p. 63). Más adelante expresan la misma idea con menos palabras (p. 71): "los valores pueden entenderse como elecciones estratégicas con respecto a lo que es adecuado para conseguir nuestros fines."

Los valores constituyen el núcleo duro de la libertad, puesto que en base a los valores los seres humanos eligen un modo u otro de actuar; por ejemplo, se puede escoger la calidad en el trabajo frente a la chapuza, el interés por las personas versus el desprecio por ellas, autonomía versus dependencia, honestidad versus fraude...

GARCÍA y DOLAN (1997) diferencian claramente entre valores y valores éticos, sostienen que estos dos conceptos se confunden frecuentemente como iguales, sin embargo, para ellos los valores éticos son medios para conseguir fines. Por ejemplo, la lealtad es un valor instrumental para conservar la amistad (valor final).

Los autores cuestionan la jerarquización de los valores; no la niegan, pero plantean dudas en cuanto a su valor absoluto universal; se decantan por un valor relativo de esa jerarquía en función de cada sociedad, individuo, y momento del tiempo individual o histórico-social.

GARCÍA y DOLAN proponen el modelo triaxial de valores pragmáticos, éticos y emocionales. 


\section{Modelo triaxial de valores}

Para estos autores existen tres ejes que engloban todos los valores.

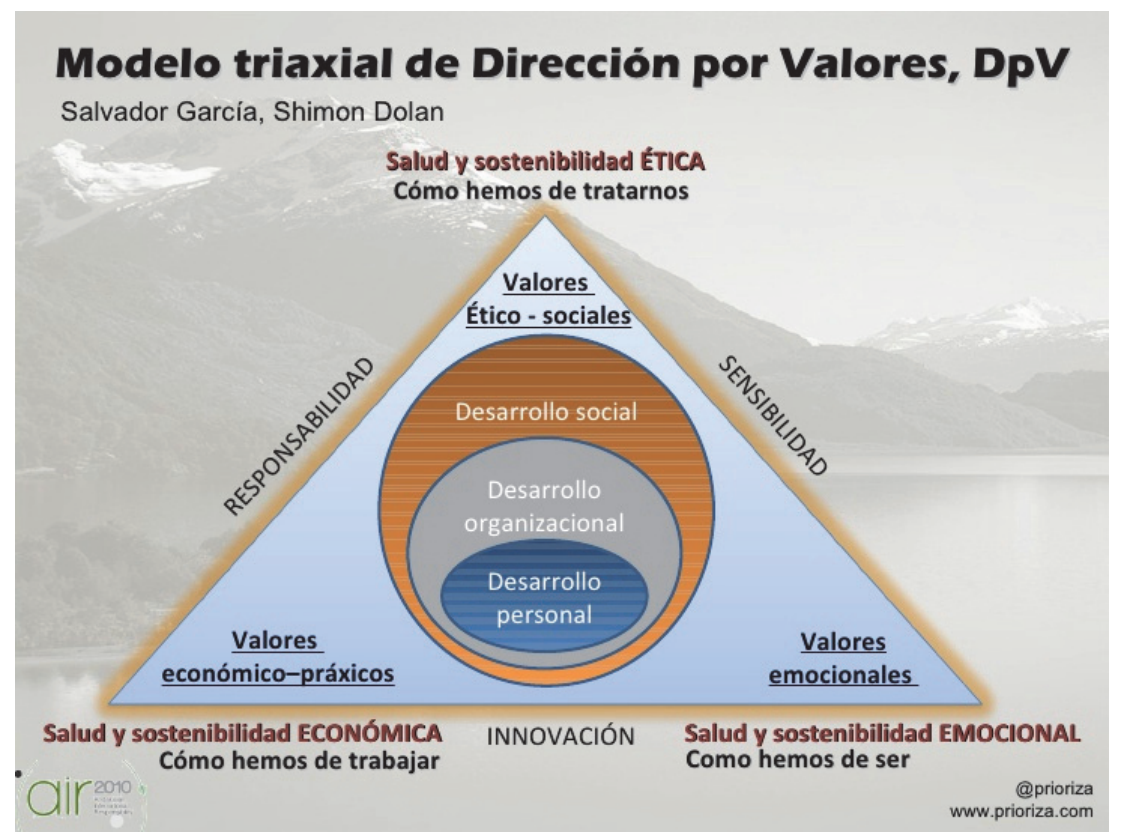

Modelo Triaxial de Dirección por Valores. Salvador García y Shimon Dolan. Disponible en: http://es.slideshare.net/prioriza/socialconfirming-air2010-by-prioriza-6244033 Consultado: noviembre de 201@6

\section{a) Dimensión ético-estratégica o ético-sociales: las elecciones preferenciales.}

Los valores ético-sociales van desde el yo hacia fuera y hablan de cómo interacciona el individuo con su mundo circundante. Son las normas de trato social. Tienen que ver con la ética y con la sociedad: honestidad, honradez, honor, generosidad, compartir, compromiso social, transparencia, orgullo-humildad, amistad, familia...

\section{b) La dimensión económica-pragmática:}

Estos valores nos conectan con el día a día. Ejemplo de ellos son la 
organización, orden, puntualidad, disciplina, agilidad, planificación, perseverancia, eficiencia, resultados, productividad, calidad, el tener dinero, la comunicación... Tienen que ver con aspectos prácticos que nos permiten estar en este mundo.

\section{c) La dimensión psicológica-emocional:}

Son los valores considerados emocionales. Todo aquello que conecta al individuo consigo mismo, hablan de cómo somos: autoestima, alegría, salud, bienestar, valentía, pasión, ilusión, iniciativa, innovación, creatividad, optimismo, equilibrio entre trabajo y vida, autonomía...

García y Dolan aceptan la visión de Rokeach de distinguir entre valores finales e instrumentales: "Los valores instrumentales son modos de conducta adecuados o necesarios para llegar a conseguir nuestras finalidades o valores existenciales" (GARCÍA y DOLAN, 1997, p. 66)

También aceptan que el número de valores finales es corto, no más de una docena; mientras que los instrumentales pueden llegar al centenar. No se da una función biyectiva entre ambos conjuntos, sino que un valor instrumental se relaciona con varios finales y viceversa.

Hay algo que los autores recalcan: existen valores instrumentales a los que, por acción de las circunstancias, publicidad... se les atribuye un valor extraordinario, de tal forma, que ese valor pasa a ser percibido como final o existencial por la persona. Esto ocurre, por ejemplo, con el dinero en el caso de la avaricia, o con la belleza o la forma física en nuestro tiempo, en que la moda y la publicidad tienen un especial protagonismo.

Proponen su propia clasificación de valores: 


\begin{tabular}{|c|c|}
\hline \multicolumn{2}{|c|}{ VALORES FINALES (objetivos existenciales) } \\
\hline $\begin{array}{l}\text { Valores personales } \\
\text { (2Qué es para usted lo mas } \\
\text { importante en la vida?) }\end{array}$ & $\begin{array}{l}\text { Vivir, felicidad, salud, «salvaciónw, familia, éxito o } \\
\text { realización personal, tener prestigio, demostrar es- } \\
\text { tatus, bienestar material, sabiduria, amistad, traba- } \\
\text { jo, ser respetado, demostrar valia, amor, etc. }\end{array}$ \\
\hline $\begin{array}{l}\text { Valores ético-sociales } \\
\text { (¿Qué quiere usted para el } \\
\text { mundo?) }\end{array}$ & $\begin{array}{l}\text { Paz, supervivencia ecologica del planeta, justicia } \\
\text { social, etc. }\end{array}$ \\
\hline \multicolumn{2}{|c|}{ VALORES INSTRUMENTALES (medios operativos para alcanzar los valores finales) } \\
\hline $\begin{array}{l}\text { Valores ético-morales } \\
\text { (¿Cómo cres que hay quê } \\
\text { comportarse con quienes le } \\
\text { rodean?) }\end{array}$ & $\begin{array}{l}\text { Honestidad, educación con los demás, sinceridad, } \\
\text { réspónsabibilidad, lealtad, solidaridad, confianza } \\
\text { mutua, respeto de los derechos humanos, etc. }\end{array}$ \\
\hline $\begin{array}{l}\text { Valores de competencia } \\
\text { (¿Qué cree que hay que te- } \\
\text { ner para poder competir en } \\
\text { la vida?) }\end{array}$ & $\begin{array}{l}\text { Cultura, dinero, imaginación, Iógica, buena forma } \\
\text { fisica, inteligencia, belleza, capacidad de ahorro, } \\
\text { iniciativa, pensamiento positivo, constancia, flexi- } \\
\text { bilidad, vitalidad, simpatía, capacidad de trabajo en } \\
\text { equipo, coraje, vida sana, etc. }\end{array}$ \\
\hline
\end{tabular}

Tabla de Valores. Extraído de GARCÍA y DOLAN, (1997, p. 67)

GARCÍA y DOLAN (1997, p. 4) definen la DpV como "una nueva herramienta de liderazgo estratégico. La DpV [...] es un nueva forma de entender y aplicar conocimientos planteados por la Psicología Social y otras Ciencias de la Conducta desde mediados del siglo XX." Sostienen que está orientada a simplificar, orientar y comprometer; como se puede ver en el gráfico extraído de García y Dolan, 1997, p. 8; en el que se representa la evolución de la dirección de empresas, desde la DpI de 1920 hasta la DpV del siglo XXI, pasando por la DpO de 1960, encuadrada por cuatro ejes que la rigen.

1. Necesidad de ofrecer una mayor calidad y orientación al cliente/usuario/paciente.

2. Necesidad de autonomía y responsabilidad profesional: la autonomía es el criterio que diferencia al profesional del operario, y es fundamental para llegar a ser responsable. Claro, que es más difícil dirigir a profesionales que a operarios. 


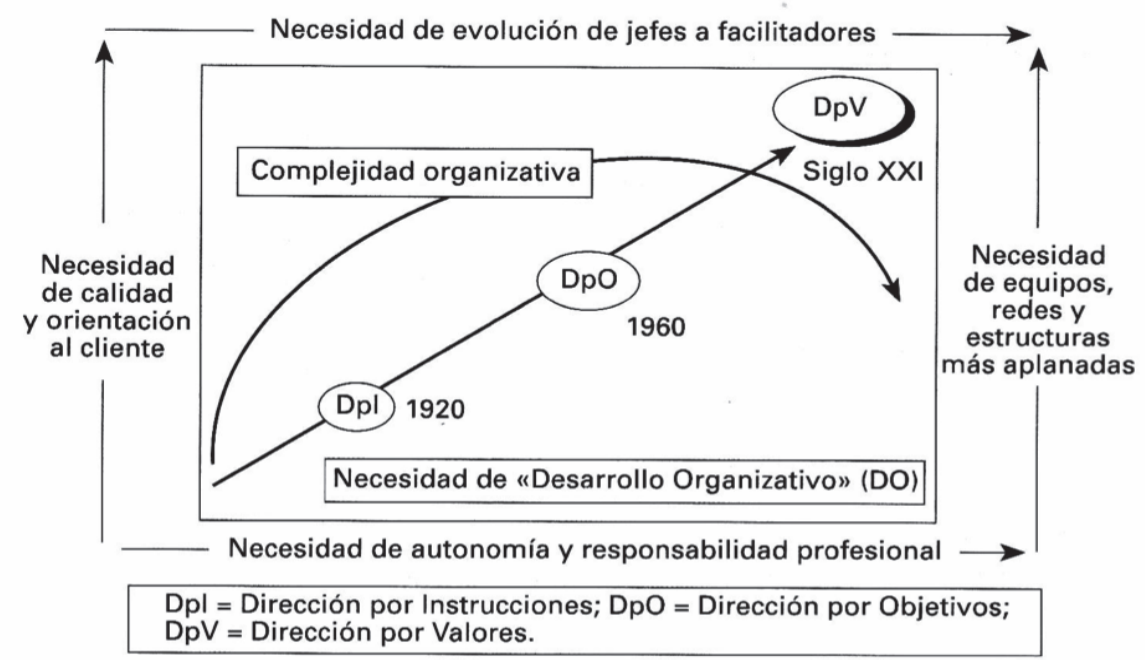

Fuente: GARCÍA v DOI.AN 1997 n 8

3. Necesidad de evolucionar de jefes a líderes facilitadores: la filosofía de Hewlett-Packard se basa en que un jefe debe ser un facilitador del triunfo de sus colaboradores. Las instrucciones son herramientas al servicio de los jefes, los objetivos de los gestores y los valores de los líderes que en lugar de "ordenar y mandar" ilusionan, encauzan y cohesionan equipos.

4. Necesidad de estructuras organizativas más aplanadas y ágiles: la disminución del número de niveles jerárquicos da lugar a una mayor eficiencia organizacional. "Los 'jefes', pocos y buenos, han de seguir siendo necesarios, pero no como controladores de irresponsables, sino como transmisores de valores, facilitadores de procesos, y distribuidores y coordinadores de recursos. La tan necesaria iniciativa de los empleados no surge por arte de magia.” (GARCÍA y DOLAN, 1997, p. 11)

Estas cuatro variables generan una complejidad organizativa creciente representada en el gráfico por una curva ascendente que decae en su parte más alta, indicando la absorción de complejidad por parte de la $\mathrm{DpV}$; que no solo hace eso, sino que también rediseña culturas empresariales, y facilita el control de los cambios de estrategias por parte de la empresa para adaptarse al entorno y superar 
tensiones internas. La cultura de una empresa es un concepto similar al de personalidad a nivel individual, es la forma característica de pensar y hacer las cosas en esa empresa, y se genera mediante distintos mecanismos: rituales como pueden ser cenas de navidad, celebraciones, reuniones... símbolos: uniformes, logotipos... lenguajes propios, memoria de la fundación o de la génesis de la Institución... Pero sobre todo a través de dos puntos fundamentales: "• Los sistemas de recompensa económica y no económica de los esfuerzos por cumplir con los valores esenciales de la empresa. - El mantenimiento de diálogos de calidad entre la dirección y los empleados" (GARCÍA y DOLAN, 1997, p. 35)

\section{Visión, misión y cultura operativa de la empresa}

En los estudios sobre estrategias de empresas existe una gran confusión sobre términos como visión, objetivos, tácticas, estrategias, misión... la DpV ofrece una simplificación al distinguir solamente entre visión, misión y otros valores operativos, de tal forma, que una empresa con una cultura bien estructurada ha de tener bien definidos dos grupos de valores:

- Los valores finales: su visión, a donde quiere llegar (en el caso del SNS, a la salud) y su misión (su razón de ser, en nuestro caso, combatir la enfermedad y el sufrimiento que entraña).

- Los valores instrumentales: con los que la empresa va a operar para alcanzar su visión y su misión.

GARCÍA y DOLAN (1999, p. 35) sostienen que "Lo que da coherencia a una organización es precisamente la claridad y consenso de sus metas (fines) y de sus principios (valores)."

Entre las metas del SNS están, sin miedo a equivocarnos, la salud de la población y la calidad de vida del enfermo. Nos interesa saber qué valores encontramos entre sus profesionales, y en nuestro caso concreto entre sus profesionales de enfermería, al momento de salir de la Universidad y comenzar la vida laboral. 

CAPÍTULO VI

MANIFIESTO DE ESPINOSO DE

COMPLUDO 

En el año 2003, docentes y gestores de Enfermería de toda España, entre los que se encontraba una codirectora de esta tesis, María Dolores CALVO SÁNCHEZ, se reunieron en Espinoso de Compludo, municipio de Ponferrada, y con intención transformadora acordaron:

"que los valores, éticos, prácticos y emocionales, que han de inspirar la buena práctica de nuestra profesión enfermera son esencialmente tres:

\section{Compromiso Social}

Cuidamos desde el compromiso de velar por el respeto, la dignidad y la autonomía de las personas.

\section{Seguridad}

Cuidamos de que se asegure el entorno físico adecuado, la calidad y la competencia profesional.

\section{Armonía}

Cuidamos del equilibrio como fuente del bienestar y lo hacemos con creatividad y alegría.

Siendo la CONFIANZA el metavalor central que nos comprometemos a impulsar, para contribuir a la eficiencia y a la humanización de la atención a la salud, desde nuestros entornos de trabajo."

Los y las firmantes del Manifiesto acordaron tres valores que a su vez se subdividen en otros tres, con la confianza como metavalor central que contribuyen a la eficiencia, y a la humanización de la atención a la salud.

Algunos de estos valores se hallan definidos en los diccionarios.

El diccionario OXFORD UNIVERSITY PRESS ${ }^{41}$ ofrece las siguientes:

"Respeto: consideración, deferencia.

Dignidad: Cualidad del que se hace valer como persona, se comporta con responsabilidad, seriedad y con respeto hacia sí mismo y hacia los demás y no deja que lo humillen ni degraden.

\footnotetext{
${ }^{41}$ Consultados varios diccionarios, en primer lugar el DRAE, nos inclinamos por el diccionario online de Oxford University Press porque presenta definiciones mas acordes con los conceptos manejados en Enfermería. El DRAE define dignidad como: "calidad de digno. / Excelencia, realce. / Gravedad y decoro de las personas en la manera de comportarse. / Cargo o empleo honorífico y de autoridad."
} 
Autonomía: Facultad de la persona o la entidad que puede obrar según su criterio, con independencia de la opinión o el deseo de otros.

Seguridad: Ausencia de peligro o riesgo / Sensación de total confianza que se tiene en algo o alguien.

Calidad: Superioridad o excelencia de algo o de alguien.

Competencia: capacidad para el desarrollo de algo.

Armonía: Relación de paz, concordia y entendimiento entre dos o más personas.

Equilibrio: Proporción adecuada en la distribución de los elementos constitutivos de una cosa.

Bienestar: Estado de la persona cuyas condiciones físicas y mentales le proporcionan un sentimiento de satisfacción y tranquilidad.

Creatividad: Capacidad o facilidad para inventar o crear.

Alegría: Sentimiento de placer producido normalmente por un suceso favorable que suele manifestarse con un buen estado de ánimo, la satisfacción y la tendencia a la risa o la sonrisa.

Confianza: Esperanza firme que una persona tiene en que algo suceda, sea o funcione de una forma determinada, o en que otra persona actúe como ella desea. / Seguridad, especialmente al emprender una acción difícil o comprometida. / Familiaridad, naturalidad y sencillez en el trato, propias de la amistad o el parentesco."

Tres de estos valores están recogidos en la DECLARACIÓN UNIVERSAL DE LOS DERECHOS HUMANOS (DUDH) de 10 de diciembre de 1948; en cuyo preámbulo se dice que "los Estados Miembros se han comprometido a asegurar, en cooperación con la Organización de las Naciones Unidas, el respeto universal y efectivo a los derechos y libertades fundamentales del ser humano". El artículo 1 está dedicado a la dignidad: “Todos los seres humanos nacen libres e iguales en dignidad y derechos."; y la seguridad aparece en el artículo 3: "Todo individuo tiene derecho a la vida, a la libertad y a la seguridad de su persona."

El compromiso y la confianza componen dos de las 5 C's del modelo de cuidado de Mary Simone Roach. Esta autora, enfermera y filósofa canadiense, sostiene que el cuidado es una actitud integrada de forma inherente a la propia condición del ser humano, y que la Enfermería es la profesionalización de la 
capacidad humana de cuidar a través de la adquisición de conocimientos y habilidades.

Roach propone y describe las cinco C's que las profesiones de la salud deben presentar siempre: Compasión, Competencia, Confianza, Conciencia y Compromiso; entendiendo que compasión es la empatía con el mundo del enfermo; competencia es la adquisición de conocimientos; la confianza surge de la honestidad por parte del profesional, de forma que el paciente sienta seguridad y respeto hacia su autonomía; conciencia es la sensibilización con cuestiones morales y éticas; y compromiso es la devoción constante a las necesidades del paciente. (ROACH, Mary Simone, 1987)

El respeto y la confianza se hallan en el modelo de cuidado de Milton Mayeroff (1925-1979), para quien cuidar es ayudar a otro a crecer, independientemente de que ese otro sea una persona, una obra, un proyecto, una idea... y sostiene que el cuidado implica una serie de virtudes: dedicación, confianza, humildad, honestidad, conocimiento del otro, respeto al proceso del otro, esperanza y valentía. (MAYERHOFF, Milton, 1971)

La alegría, cuya muestra de expresión más patente es la sonrisa, ha sido considerada tradicionalmente como rasgo indispensable de la mujer y especialmente destacado en la idealización de la enfermera (GONZALEZ ALLENDE, Iker, 2009)

El entorno físico adecuado se halla con especial importancia en la obra de Florence Nightingale (1820-1910), quien sostiene que "la palabra enfermería [...] debería significar el uso apropiado del aire, la luz, el calor, la limpieza, la tranquilidad y la selección de la dieta y su administración” (NIGHTINGALE, Florence, 1990, p. 2). De tal forma que el modelo de Nightingale se basa en cinco factores esenciales: aire puro, agua potable, alcantarillado adecuado, higiene y luz.

Los valores del Manifiesto de Espinoso de Compludo se hallan también entre los valores recogidos por Rokeach para su clasificación. Así entre los terminales encontramos el 2. Auto-respeto (autoestima), 5. Seguridad familiar (cuidado a los seres queridos), 9. Armonía interna (libre de conflictos internos), 11. Un mundo en paz (libre de guerras y conflictos), 13. Reconocimiento social 
(respeto, admiración), 15. Seguridad nacional (protección de los ataques); y entre los instrumentales hallamos: 7. Imaginativo (atrevido, creativo), 8. Capaz (competente, afectivo), 9. Alegre (de corazón abierto, gozoso), 13. Responsable (fiable, digno de confianza), 14. Independiente (confianza en sí mismo, autosuficiente) y 18. Servicial (trabaja por el bienestar ajeno).

SALVADOR GARCÍA (2011) considera la confianza (creer en) junto con la coherencia (pensar-decir-hacer) como metavalores que se encuentran en el núcleo del modelo triaxial. Defiende esta centralidad con argumentos como que la confianza es un valor simplificador y antiburocrático, generador de fluidez vital y organizativa. Un valor que atrae a clientes, inversores, proveedores y futuros empleados, y que genera cohesión grupal y organizativa.

La confianza es esencial para el bienestar emocional y genera el ambiente necesario para que aparezca la iniciativa, la creatividad, el diálogo y el aprendizaje organizativo.

El miedo y la confianza son polos opuestos, igual que el amor y el odio, o la guerra y la paz.

$$
\text { Amor - Paz - Confianza } \longrightarrow \text { Miedo - Guerra - Odio }
$$

Extraído de Salvador García, 2011, p. 16

El autor distingue entre la autoconfianza, creencia en uno mismo; la heteroconfianza, dirigida hacia los demás y la confiabilidad que es la confianza que inspiramos en los demás. Y sostiene que "atreverse a construir el valor de la confianza en los sistemas sociales es el lubricante crítico para prevenir conflictos y gestionar el cambio". 
TRABAUOEMPÍRICO 

ANÁLISIS DE LAS VARIABLES 

Para la investigación empírica, hemos utilizado el cuestionario de valores "MbV72" de (C) Salvador García, UB y Shimon Dolan, ESADE, que adjuntamos a continuación.

Se trata de un cuestionario con 72 ítems en escala Likert del 0 al 5 que evalúa los valores que rigen, según la autopercepción del cuestionado, la propia vida personal y el mundo de la empresa, en este caso la sanidad desde la perspectiva del discente. Los 72 ítems representan un abanico de valores terminales (relativos a la existencia) e instrumentales (relativos a la conducta).

Observamos que dentro del cuestionario hay, dispersos, ítems interrelacionados en cuanto al contenido lo que permite analizar la validez de las respuestas. De esta forma, grupos de ítems como "23. Derechos humanos, dignidad"; “32. Honestidad, honradez, transparencia, sinceridad”; “38. Inconformismo, rebeldía ante la injusticia social”; “43. Mundo en paz” permiten medir la coherencia de las respuestas.

Vemos como los valores de Rokeach están recogidos, tanto los terminales: Felicidad, Respeto, Tiempo libre... como los instrumentales: Cortesía, Honradez, Obediencia, Alegría...

También encontramos ítems relacionados de forma directa con los valores expresados en le Manifiesto de Compludo. Este hecho es de gran importancia para nuestro estudio, por lo que hemos procedido a agrupar los ítems relacionados de forma evidente con los valores recogidos en el Manifiesto de Compludo y a simplificar la escala Likert. Hemos agrupado las respuestas 0, 1 y 2 en una sola categoría simplificada que hemos llamado: poco ("Realmente gobierna poco mi vida personal, ...el mundo de la empresa"); la 3: medianamente ("Realmente gobierna medianamente mi vida personal, ... el mundo de la empresa"), y la 4 y 5: mucho ("Realmente gobierna mucho mi vida personal, ...el mundo de la empresa").

Hemos seleccionado los siguientes grupos de ítems en función de los valores del Manifiesto de Compludo: 
Cuidamos desde el compromiso de velar por el respeto, la dignidad y la autonomia de las personas. 8 valores

12. Compartir, generosidad

23. Derechos humanos, dignidad

26. Equidad, justicia en el día a día

32. Honestidad, honradez, transparencia, sinceridad

38. Inconformismo, rebeldía ante la injusticia social

39. Independencia, iniciativa, autonomía de acción

43. Mundo en paz

65. Solidaridad, generosidad

Seguridad,

Cuidamos de que se asegure el entorno físico adecuado, la calidad y la competencia profesional. 6 valores

1. Adaptación a los cambios, flexibilidad

7. Aprendizaje continuo

48. Placer intelectual

58. Rigor técnico-profesional

60. Seguridad

72. Verdad/sabiduría (búsqueda de la)

\section{Armonía}

Cuidamos del equilibrio como fuente del bienestar y lo hacemos con creatividad y alegría. 7 valores

3. Alegría, sentido del humor

27. Equilibrio entre trabajo y vida familiar y personal

37. Imaginación, creatividad, fantasía 
54. Respeto y armonía con los demás

55. Respeto y armonía con uno mismo

56. Respeto y armonía medioambiental

59. Salud/bienestar

Siendo la CONFIANZA el metavalor central que nos comprometemos a impulsar para contribuir a la eficiencia y a la humanización de la atención a la salud desde nuestros entornos de trabajo. 10 valores

9. Calidez, cercanía

15. Confianza

21. Creer y poner cariño en lo que se hace

24. Disfrutar en el trabajo

25. Eficacia/planificación/eficiencia

45. Pasión, entusiasmo

47. Perseverancia/paciencia

50. Productividad, resultados

62. Ser querido por los demás

63. Servicio/vocación

Por último hemos hecho otro grupo para explorar la actitud de los nuevos profesionales en relación al uso de los recursos y su contribución a la sostenibilídad del sistema. Hemos seleccionado los siguientes ítems:

2. Ahorro, austeridad

25. Eficacia/Planificación/Eficiencia

28. Éxito económico

50. Productividad, resultados

66. Supervivencia material 
El cuestionario ha sido aplicado a los estudiantes del último curso de la Diplomatura de Enfermería, en la asignatura de Administración de servicios en Enfermería (código: 15742) en las 3 últimas promociones de dicho plan: cursos académicos 2009-2010; 2010-2011; 2011-2012. Han sido encuestados 209 estudiantes que pertenecen al Campus Miguel de Unamuno de la Universidad de Salamanca.

Curso 2009/10: de 88 matriculados, 77 mujeres y 11 hombres; tenemos 64 encuestas.

Curso 2010/11: de 92 matriculados, 76 mujeres y 16 hombres; tenemos 70 encuestas.

Curso 2011/12: de 88 matriculados, 70 mujeres y 18 hombres; tenemos 75 encuestas.

Entre los 3 cursos suman 268 matriculados, de los cuales 223 son mujeres y 45 hombres. Tenemos 209 encuestas. Las mujeres representan el 83,20\%, y nuestra muestra el 77,98\% de la población total.

Con los datos obtenidos hemos realizado un análisis estadístico descriptivo que hemos llevado a cabo con el programa SPSS.20 trabajando con porcentajes y gráficos de barras. Por cada cuestionario se obtienen 72 respuestas para la esfera de la vida personal y otras tantas para el mundo de la empresa. Así hemos obtenido dos cuadros y sendos gráficos de frecuencias y porcentajes por cada ítem del "Cuestionario de Valores 'MbV-72"”. Un cuadro y su gráfico referidos a "mi vida personal" y otro cuadro con su gráfico para el "mundo de la empresa". En total 144 cuadros con sus gráficos. Hemos coloreado los gráficos en verde y ocre respectivamente, para distinguirlos.

También hemos obtenido 8 cuadros y gráficos para el Compromiso Social en la VP y otros tantos para el ME, y así sucesivamente para la Seguridad $(6 \times 2=12)$, la Armonía $(7 \times 2=14)$, la Confianza $(10 \times 2=20)$, y la Sostenibilidad del Sistema $(5 \times 2=10)$. Sumando los cinco grupos: $16+12+14+20+10$ obtenemos 72 cuadros más sus correspondientes gráficos que sumados a los 144 iniciales forman un total de 216 cuadros con otros tantos gráficos. 
Hemos coloreado los gráficos de distintos colores según los grupos de valores, utilizando tonos saturados para el área de la VP y tonos pálidos para el ME. Compromiso social: morado. Seguridad: azul. Armonía: verde. Confianza: rojo. Sostenibilidad: amarillo. 


\section{Cuestionario de valores "MbV-72"}

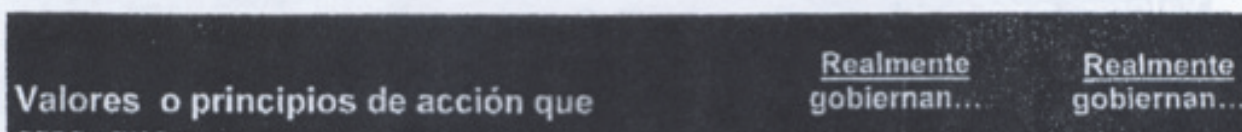
creo que ...

\section{gobiernan}

mi vida

personal gobiernan.

el mundo de la empresa

\begin{tabular}{|c|c|c|c|}
\hline 1. & Adaptación a los cambios, flexibillidad & $0123 \times 5$ & $0 \sqrt{23 \times 45}$ \\
\hline 2. & Ahorro, austeridad & 012355 & 012348 \\
\hline 3. & Alegria, sentido del humor & $0123.5 \times$ & 012348 \\
\hline 4. & Amistad & $0 1 2 3 \longdiv { 3 }$ & 012345 \\
\hline s. & Anticipsción, previsión & $0 1 2 \longdiv { 3 4 5 }$ & $0123 \times 5$ \\
\hline 8. & Apertura, dlálogo, Igualdad, franqueza & 012345 & 012348 \\
\hline 7. & Aprendizaje continuo & 0122354 & 012348 \\
\hline 8. & Arte/belleza, armonia estética & $0123 \times 5$ & 012325 \\
\hline 9. & Calldez, cercania & $012 \times 48$ & 012358 \\
\hline 10. & Coherencia & $0123 \times 5$ & 012358 \\
\hline 11. & Comodidad, vida confortable & 012 शेद & 012945 \\
\hline 12. & Compartir, generosidad & $0123 \times 18$ & $0123 \times 5$ \\
\hline 13. & Compotitividad, ambición, trabajo duro & $012 \times 45$ & 012549 \\
\hline 14. & Comunicación finformación & 012345 & 012355 \\
\hline 16. & Confianze & $0125 \% 5$ & $0123 \times 0$ \\
\hline 16. & Contemplación, meditación, serenldad & 012345 & $0123 \times 6$ \\
\hline 17. & Control/Orden/Disciplina & 012345 & $0123 \times 5$ \\
\hline 18. & Cooperación, colaboración, espiritu de equipo & 0123,45 & 0123435 \\
\hline 18. & Cortesia & 012345 & 012345 \\
\hline 20. & Crecimiento/expansión & 012345 & 012345 \\
\hline 21. & Creer y poner carlfo en lo que se hace & 012345 & 012355 \\
\hline 22. & Delelte físico, hedonismo & 012355 & 012345 \\
\hline 23. & Derechos humanos, dignidad & $0123 \times 5$ & $0123 \times 5$ \\
\hline 24. & Disfrutar en el trabajo & 012345 & 012345 \\
\hline 26. & Eflcacia/Planlficación/Eficiencia & 012345 & 012345 \\
\hline 28. & Equidad, Justicia on ol dia a dia & 012345 & 012345 \\
\hline 27. & Equilibrio entre trabajo y vida familiar y personal & 012335 & $012,3 / 5$ \\
\hline 28. & Exito oconómico & $012 \times 45$ & $012 \sqrt[35]{3}$ \\
\hline 28. & Exito familiar & 012348 & $0 \sqrt{2} 3 \sqrt{4,6}$ \\
\hline 30. & Expresivided/libertad & 012355 & 012346 \\
\hline 31. & Fellcidad (búsqueda de la) & 012345 & 012344 \\
\hline 32. & Honestidad, honradez, transparencia, sinceridad & $012 \times 45$ & $012 \times 48$ \\
\hline 33. & Humlidad, modestla & 012345 & 012348 \\
\hline 34. & Ideallemo & $01 \times 345$ & $01 \frac{24}{3}$ \\
\hline 38. & Igualdad/liberacion & 0123.8 & $01234 \sqrt{5}$ \\
\hline 36. & Imagen/prestigio social & 01234.8 & $0123 \times 5$ \\
\hline 37. & Imaginación, creatividad, fantasia & 012345 & 012345 \\
\hline 38. & Inconformismo, rebeldia ante la Injusticis social & $0123 \times 5$ & $012,3+6$ \\
\hline & & Del lodo & Del todo \\
\hline
\end{tabular}

'๑s Salvador Garcla, UB y Shimon Dolan, ESADE 


\begin{tabular}{|c|c|c|}
\hline $\begin{array}{l}\text { Valores o principios de acción que } \\
\text { creo que ... }\end{array}$ & $\frac{\text { Realmente }}{\text { gobiernan... }}$ & $\begin{array}{l}\text { el mundo de la } \\
\text { empresa }\end{array}$ \\
\hline Independencia, iniclativa, autonomia de accion & $0123 \times 15$ & 0112348 \\
\hline Influencla /poder social (búsqueda de) & 012345 & 012345 \\
\hline Loaltad/ Fidolidad & 812348 & 012.34 .6 \\
\hline Moderación, tener pocos deseos & $012: 3,15$ & $0123+45$ \\
\hline Mundo on paz & $0123 \times 5$ & $0123+46$ \\
\hline Obediencia, cumplimiento & 012348 & $01254=$ \\
\hline Pasión, entuslasmo & 012345 & 012345 \\
\hline Patriotiemo & 012245 & 0120848 \\
\hline Porseverancla/paclencla & 012348 & $01234 \sqrt{5}$ \\
\hline Placer Intelectual & 0123368 & $0123 \% 3$ \\
\hline Placer soxual & $012 \times 46$ & 0120245 \\
\hline Productividad, resultados & 0123245 & 012475 \\
\hline Reallsmo, pragmatismo, raclonalldad & $012 \times 48$ & 0123045 \\
\hline Reconocimiento emocional (darlo y buscarlo) & 012245 & $01723 \% 5$ \\
\hline Religlosidad & 012378 & 0127346 \\
\hline Respeto y armonla con los demás & $0123 \times 5$ & $0123 \div 8$ \\
\hline Respoto y armonía con uno mismo & $012 \times 345$ & $012 \times 46$ \\
\hline Respeto y armonia medioambiental & $0123{ }^{6} 6$ & 012305 \\
\hline Rlesgo, aventura, estimulo, novedad & $0123 \times 6$ & $0123 \times 5$ \\
\hline Rlgor t6enlco-profesional & 012306 & 012345 \\
\hline Salud/blenestar & $0123 \div 6$ & $0123 \times 5$ \\
\hline Sequrldad & 012348 & 012345 \\
\hline Sentido de la vergOlenza & 0123415 & 012346 \\
\hline Ser querldo por los demás & 012545 & 012345 \\
\hline Serviciolvocación & 012345 & $0123 X^{5}$ \\
\hline Simplicidad, rapidez, aglilidad & $0123 \div 6$ & $012,3 \times 45$ \\
\hline Solidaridad, generosidad & $0123 \times 5$ & 012375 \\
\hline Supervivencla material & $0123 \times 5$ & $0123 \times 5$ \\
\hline Tecnologia/clencla, Innovación & $0123 \times 18$ & $0123 \times 5$ \\
\hline Tlempo Ilibre & $0123 \times 5$ & $0123 \times 5$ \\
\hline Tradición, conservación & 012306 & 012355 \\
\hline Trascedencla, utillidad para otros & 0123,85 & $0123 \times 5$ \\
\hline Valentia, coraje & $0123 \times 5$ & $0123 \leq 5$ \\
\hline Verdad/sablduria (búsqueda de la) & $012 \times 48$ & $0123 \sqrt{4}$ \\
\hline 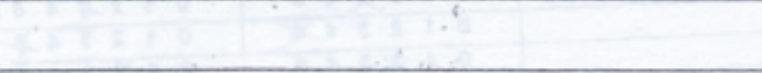 & Del todo & Del tode \\
\hline
\end{tabular}

${ }^{1} \odot$ Salvador Garcla, UB y Shimon Dolan, ESADE 



\section{Esfera Vida Personal}





\section{Cuadro $n^{0} 1.1$}

1. Adaptación a los cambios, flexibilidad

\begin{tabular}{|l|r|r|r|r|}
\hline & Frecuencia & Porcentaje & $\begin{array}{c}\text { Porcentaje } \\
\text { válido }\end{array}$ & \multicolumn{1}{c|}{$\begin{array}{c}\text { Porcentaje } \\
\text { acumulado }\end{array}$} \\
\hline 1 mínimo & 1 &, 5 &, 5 &, 5 \\
2 poco & 5 & 2,4 & 2,4 & 2,9 \\
3 medianamente & 30 & 14,4 & 14,4 & 17,2 \\
4 bastante & 95 & 45,5 & 45,5 & 62,7 \\
5 del todo & 78 & 37,3 & 37,3 & 100,0 \\
Total & 209 & 100,0 & 100,0 & \\
\hline
\end{tabular}

Elaboración propia, mayo 2015

Gráfico $n^{\circ} 1.1$

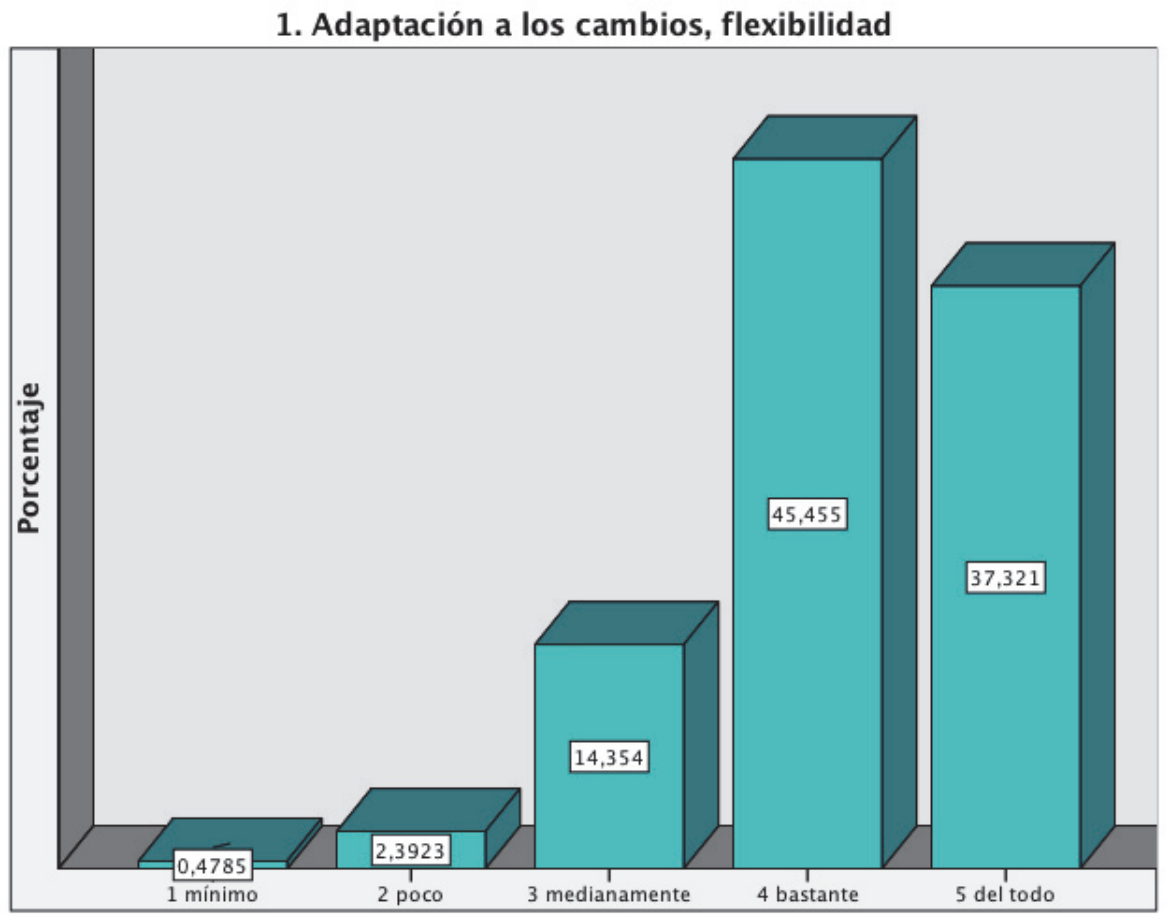

Elaboración propia, mayo de 2015

Análisis: el cero no existe, el 1 y el 2 representan porcentajes muy bajos. Este valor es claramente importante para la muestra en estudio VP, pues el 4 y 5 suman el $82,776 \%$. A este modelo de distribución lo denominamos pirámide asimétrica con sesgo a la derecha.

Valor relacionado con la Seguridad, competencia profesional que constituye el segundo valor del ME de C. Las respuestas obtenidas responden al perfil de enfermería pues teniendo competencias generalistas ha de adaptarse a servicios diversos. 
Cuadro $n^{\circ} 1.2$

2. Ahorro, austeridad

\begin{tabular}{|l|r|r|r|r|}
\hline & Frecuencia & Porcentaje & $\begin{array}{c}\text { Porcentaje } \\
\text { válido }\end{array}$ & $\begin{array}{c}\text { Porcentaje } \\
\text { acumulado }\end{array}$ \\
\hline 0 nada & 1 &, 5 &, 5 &, 5 \\
1 mínimo & 9 & 4,3 & 4,3 & 4,8 \\
2 poco & 21 & 10,0 & 10,0 & 14,8 \\
3 medianamente & 77 & 36,8 & 36,8 & 51,7 \\
4 bastante & 75 & 35,9 & 35,9 & 87,6 \\
5 del todo & 26 & 12,4 & 12,4 & 100,0 \\
Total & 209 & 100,0 & 100,0 & \\
\hline
\end{tabular}

Elaboración propia, mayo de 2015

Gráfico 1.2

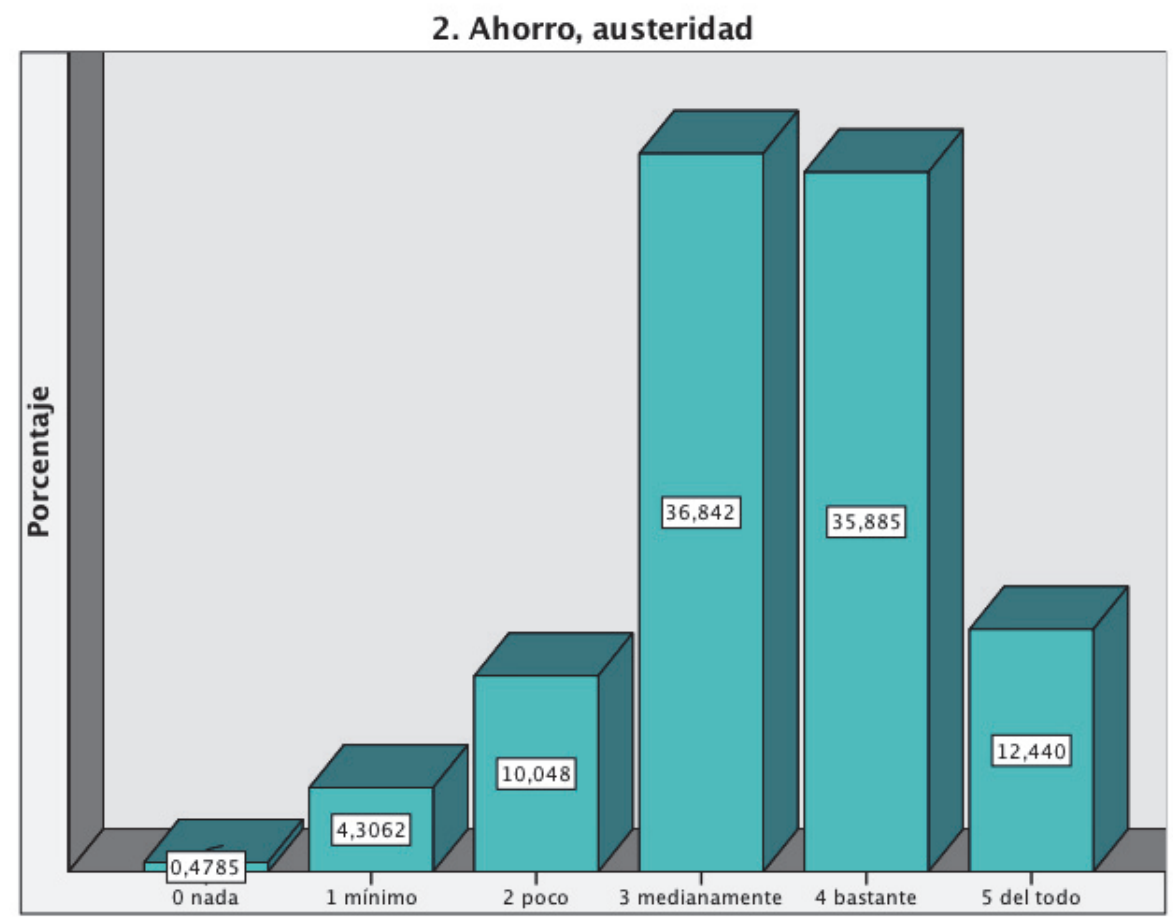

Elaboración propia, mayo de 2015

Análisis: aquí el 0 ha sido marcado por un alumno, y los porcentajes más altos son para el 3 y el 4 que juntos suman el 72,727. Las respuestas se distribuyen en todas las opciones concentrándose el peso en el medio. Vemos un gráfico que denominamos en pirámide.

Esta respuesta se adecua al perfil enfermero por cuanto enfermería cuida de la salud y de la vida a la vez que administra un alto porcentaje de los recursos sanitarios. 
Cuadro $n^{\circ} 1.3$

\section{Alegría, sentido del humor}

\begin{tabular}{|l|r|r|r|r|}
\hline & Frecuencia & Porcentaje & $\begin{array}{c}\text { Porcentaje } \\
\text { válido }\end{array}$ & \multicolumn{1}{|c|}{$\begin{array}{c}\text { Porcentaje } \\
\text { acumulado }\end{array}$} \\
\hline 2 poco & 1 &, 5 &, 5 &, 5 \\
3 medianamente & 15 & 7,2 & 7,2 & 7,7 \\
4 bastante & 74 & 35,4 & 35,4 & 43,1 \\
5 del todo & 119 & 56,9 & 56,9 & 100,0 \\
Total & 209 & 100,0 & 100,0 & \\
\hline
\end{tabular}

Elaboración propia, mayo de 2015

Gráfico 1.3

\section{Alegría, sentido del humor}

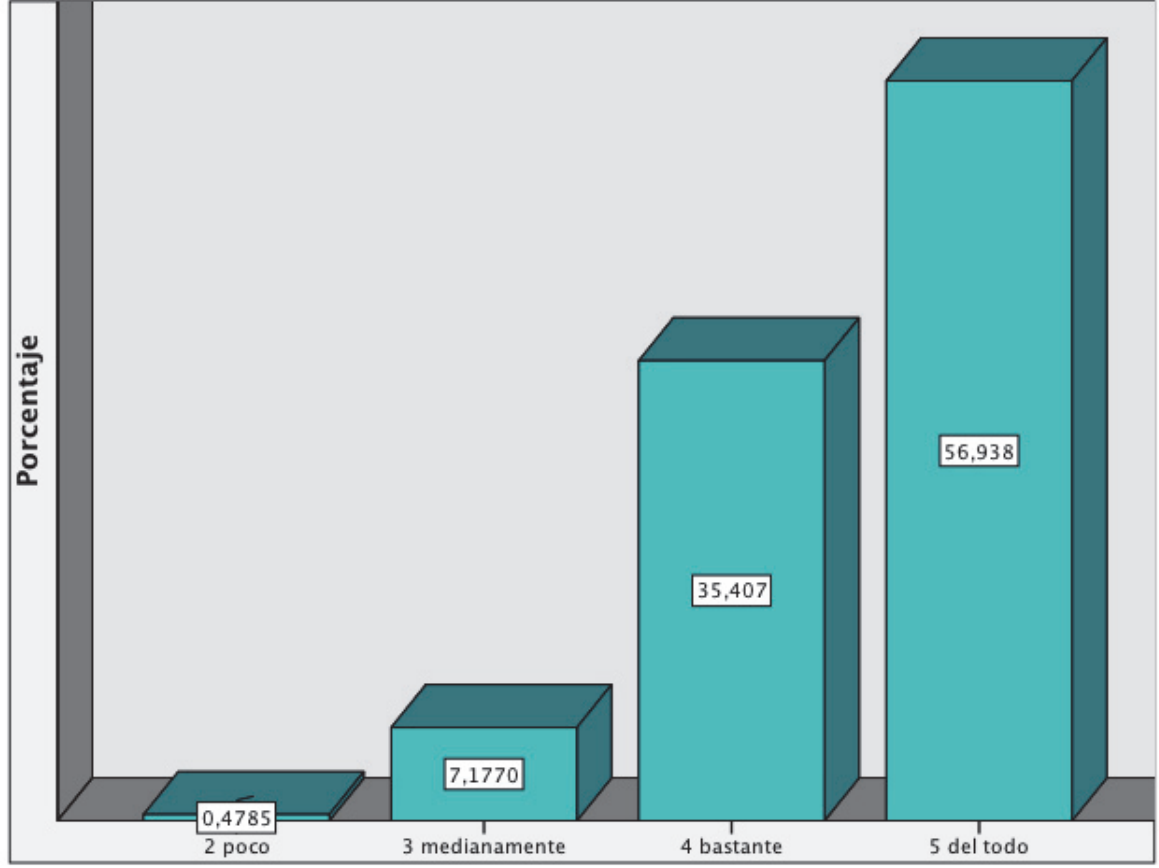

Elaboración propia, mayo de 2015

Análisis: la "Alegría, sentido del humor" en VP es claramente importante para la muestra encuestada. Los valores 0 y 1 no aparecen, mientras que el 5 representa el 56,9\%, y el 4 y 5 suman el $92,3 \%$. Vemos un gráfico en escalera ascendente.

Responde al perfil femenino y al de enfermería en cuanto profesión feminizada. Como hemos visto antes, la alegría y la sonrisa han constituido un rasgo esencial de la mujer en general. Consideramos también que este valor está relacionado con la Armonía del ME de C. 
Cuadro $\mathrm{n}^{\mathrm{o}} 1.4$

4. Amistad

\begin{tabular}{|l|r|r|r|r|}
\hline & Frecuencia & Porcentaje & $\begin{array}{c}\text { Porcentaje } \\
\text { válido }\end{array}$ & $\begin{array}{r}\text { Porcentaje } \\
\text { acumulado }\end{array}$ \\
\hline 2 poco & 1 &, 5 &, 5 &, 5 \\
3 medianamente & 15 & 7,2 & 7,2 & 7,7 \\
4 bastante & 60 & 28,7 & 28,7 & 36,4 \\
5 del todo & 133 & 63,6 & 63,6 & 100,0 \\
Total & 209 & 100,0 & 100,0 & \\
\hline
\end{tabular}

Elaboración propia, mayo de 2015

Gráfico 1.4

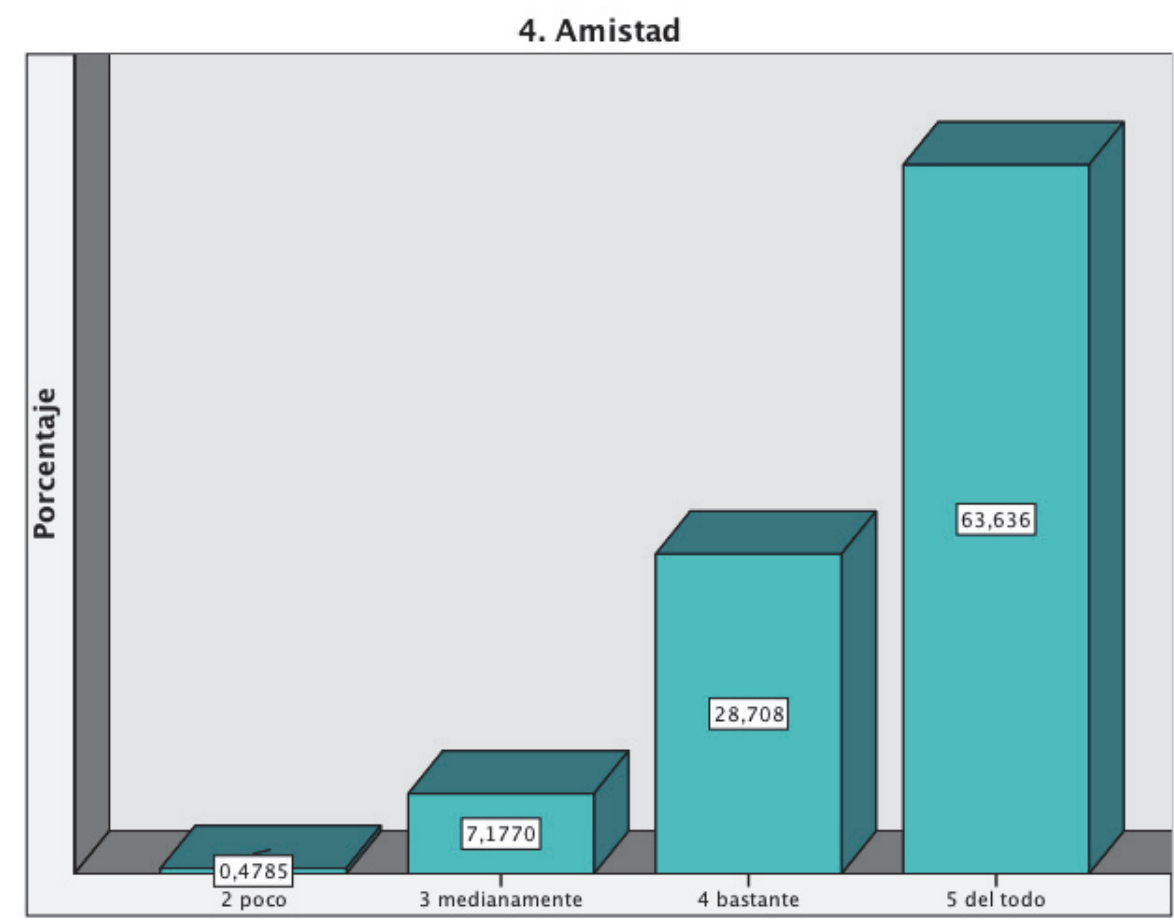

Elaboración propia, mayo de 2015

Análisis: de nuevo un gráfico en escalera ascendente. El 5 es el más representativo, el 4 y 5 suman el $92,3 \%$ pesando el 5 más del doble que el 4 . La “Amistad" es aún mas importante para el muestra en estudio que la "Alegría, sentido del humor".

La amistad está en relación con la solidaridad, valor que Durkheim consideraba el más importante de la sociedad pues determina la supervivencia de esta. Lo vemos también en el cráneo desdentado de Dmanisi y en la actitud de Henri Dunant en Solferino (véase la investigación teórica de este trabajo). Los resultados responden al perfil de enfermería, profesión eminentemente solidaria. 
Cuadro $\mathrm{n}^{\mathrm{o}} 1.5$

5. Anticipación, previsión

\begin{tabular}{|l|r|r|r|r|}
\hline & Frecuencia & Porcentaje & $\begin{array}{c}\text { Porcentaje } \\
\text { válido }\end{array}$ & $\begin{array}{c}\text { Porcentaje } \\
\text { acumulado }\end{array}$ \\
\hline 1 mínimo & 1 &, 5 &, 5 &, 5 \\
2 poco & 14 & 6,7 & 6,7 & 7,2 \\
3 medianamente & 54 & 25,8 & 25,8 & 33,0 \\
4 bastante & 109 & 52,2 & 52,2 & 85,2 \\
5 del todo & 31 & 14,8 & 14,8 & 100,0 \\
Total & 209 & 100,0 & 100,0 & \\
\hline
\end{tabular}

Elaboración propia, mayo de 2015

Gráfico $n^{0} 1.5$

\section{Anticipación, previsión}

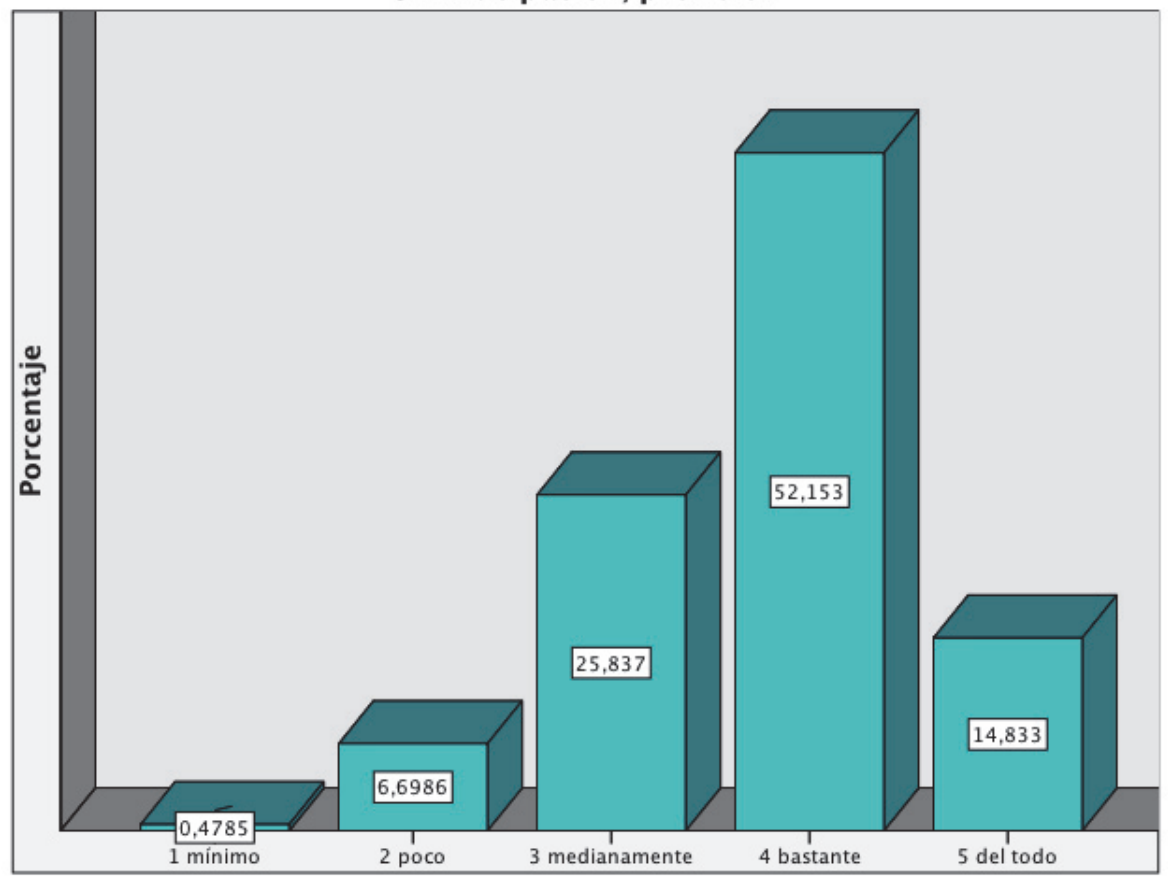

Elaboración propia, mayo de 2015

Análisis: en este valor observamos ausencia del 0, incremento progresivo del porcentaje hasta el 4 que representa el máximo con algo más del 50\%, y caída para el 5. El 4 representa más de la mitad de las respuestas. Patrón en pirámide.

Resultados adecuados al perfil de enfermería por cuanto la enfermera debe realizar para cada paciente un plan de cuidados o proceso de atención de enfermería (PAE) dentro del cual debe anticiparse a los riesgos para prevenirlos. 
Cuadro $\mathrm{n}^{\circ} 1.6$

6. Apertura, diálogo, igualdad, franqueza

\begin{tabular}{|l|r|r|r|r|}
\hline & Frecuencia & Porcentaje & $\begin{array}{c}\text { Porcentaje } \\
\text { válido }\end{array}$ & $\begin{array}{r}\text { Porcentaje } \\
\text { acumulado }\end{array}$ \\
\hline 2 poco & 1 &, 5 &, 5 &, 5 \\
3 medianamente & 19 & 9,1 & 9,1 & 9,6 \\
4 bastante & 92 & 44,0 & 44,0 & 53,6 \\
5 del todo & 97 & 46,4 & 46,4 & 100,0 \\
Total & 209 & 100,0 & 100,0 & \\
\hline
\end{tabular}

Elaboración propia, mayo de 2015

Gráfico n ${ }^{\circ} 1.6$

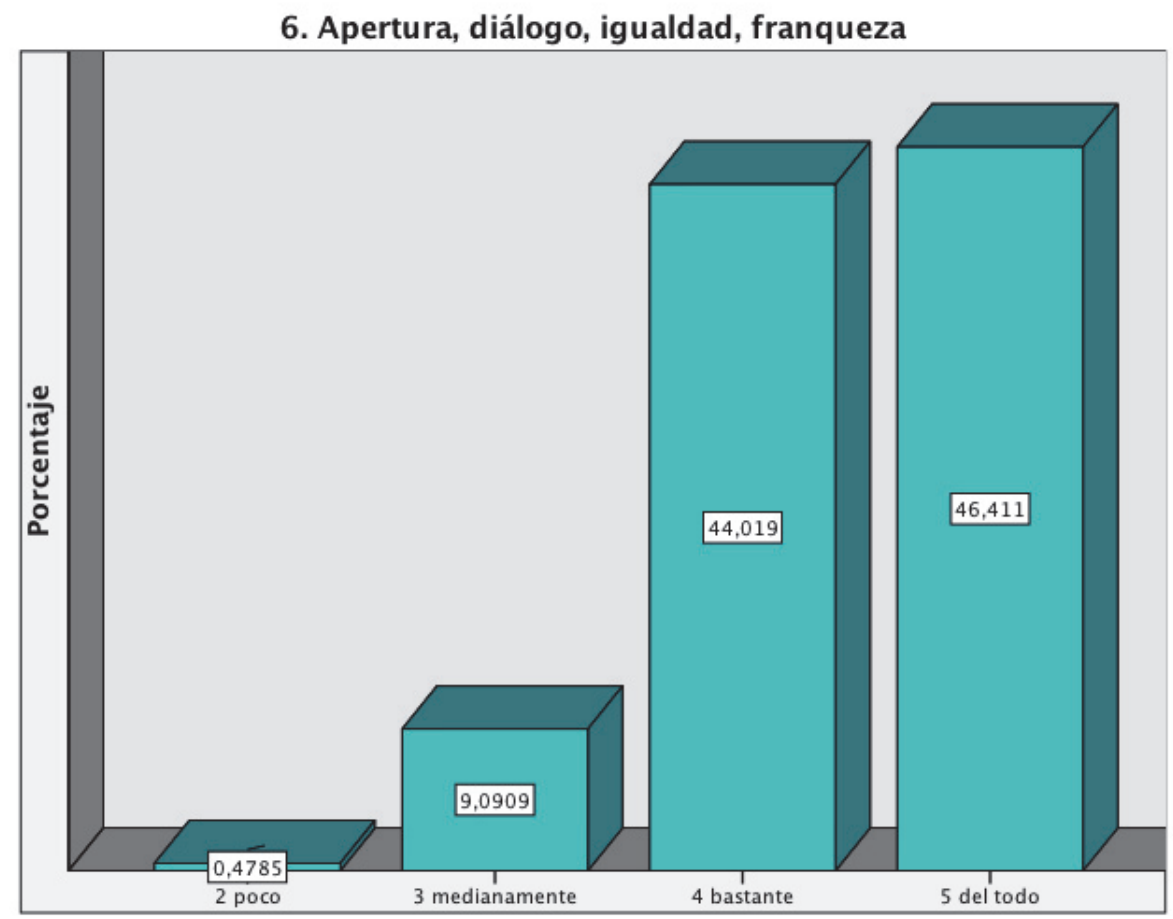

Elaboración propia, mayo de 2015

Análisis: es evidente la importancia de este valor para la muestra en estudio: el 0 y 1 no aparecen, el 2 tan solo tiene menos del 0,5\%, mientras que el 4 y 5 suman el 90,43\% con mayor peso del 5. Patrón en escalera ascendente.

Valor es fundamental para desarrollar empatía que es imprescindible para cuidar con dignidad al que sufre. 
Cuadro $\mathrm{n}^{\mathrm{0}} 1.7$

7. Aprendizaje continuo

\begin{tabular}{|c|c|c|c|c|}
\hline & Frecuencia & Porcentaje & $\begin{array}{c}\text { Porcentaje } \\
\text { válido }\end{array}$ & $\begin{array}{c}\text { Porcentaje } \\
\text { acumulado }\end{array}$ \\
\hline 2 poco & 4 & 1,9 & 1,9 & 1,9 \\
3 medianamente & 26 & 12,4 & 12,4 & 14,4 \\
4 bastante & 74 & 35,4 & 35,4 & 49,8 \\
5 del todo & 105 & 50,2 & 50,2 & 100,0 \\
Total & 209 & 100,0 & 100,0 & \\
\hline
\end{tabular}

Elaboración propia, mayo de 2015

Gráfico $n^{\circ} 1.7$

7. Aprendizaje contínuo

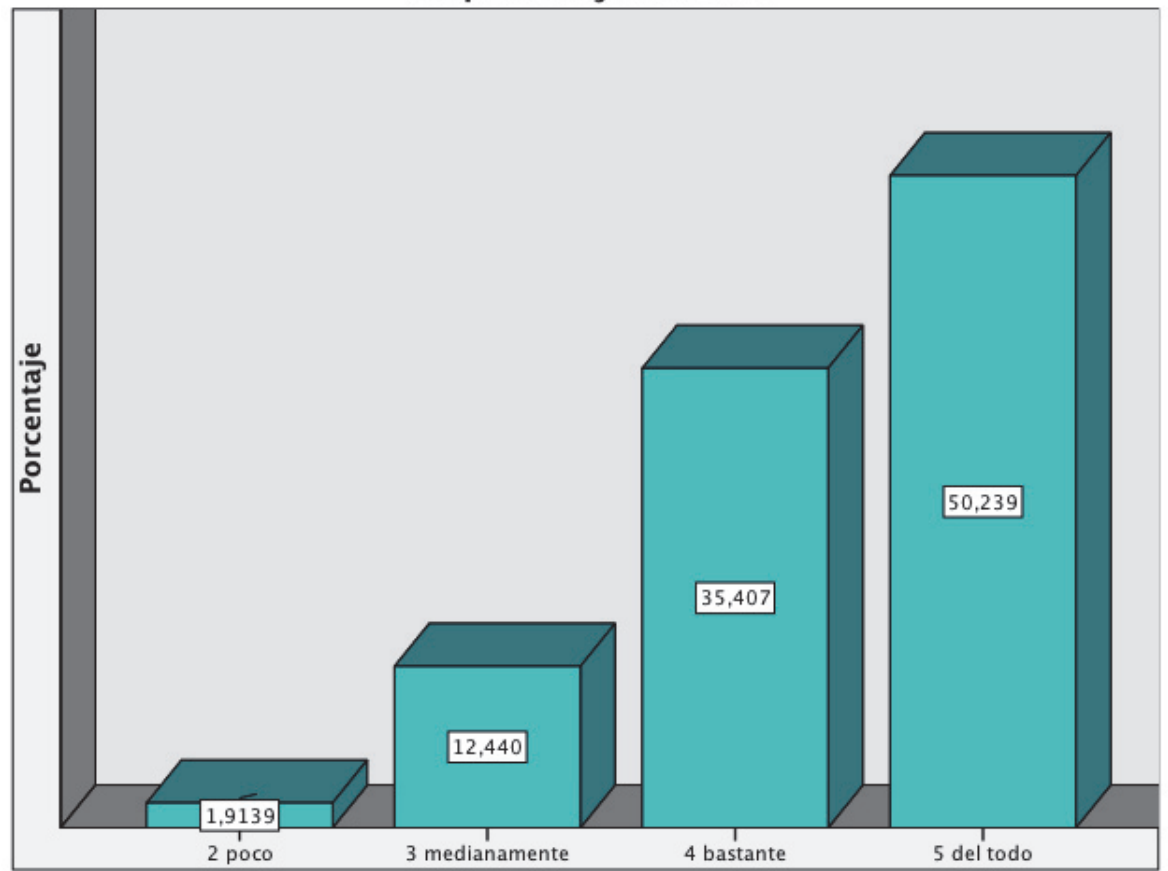

Elaboración propia. Mayo de 2015

Análisis: el aprendizaje continuo también es valorado como muy importante. Presenta un porcentaje creciente desde el 2 ( 0 y 1 inexistentes) hasta el 5. El 4 y 5 suman 85,646\%. Patrón en escalera.

Relacionado con la seguridad en el ejercicio de la profesión y con la confianza que ha de inspirar en el paciente. Arroja resultados acordes con una profesión que exige estar permanentemente al día dados los avances de las ciencias de la salud. 
Cuadro $n^{\circ} 1.8$

8. Arte/belleza, armonía estética

\begin{tabular}{|l|r|r|r|r|}
\hline & Frecuencia & Porcentaje & $\begin{array}{c}\text { Porcentaje } \\
\text { válido }\end{array}$ & $\begin{array}{l}\text { Porcentaje } \\
\text { acumulado }\end{array}$ \\
\hline 0 nada & 2 & 1,0 & 1,0 & 1,0 \\
1 mínimo & 1 &, 5 &, 5 & 1,4 \\
2 poco & 17 & 8,1 & 8,1 & 9,6 \\
3 medianamente & 67 & 32,1 & 32,1 & 41,6 \\
4 bastante & 86 & 41,1 & 41,1 & 82,8 \\
5 del todo & 36 & 17,2 & 17,2 & 100,0 \\
Total & 209 & 100,0 & 100,0 & \\
\hline
\end{tabular}

Elaboración propia. Mayo de 2015

Gráfico $\mathrm{n}^{\mathrm{0}} 1.8$

8. Arte/belleza, armonía estética

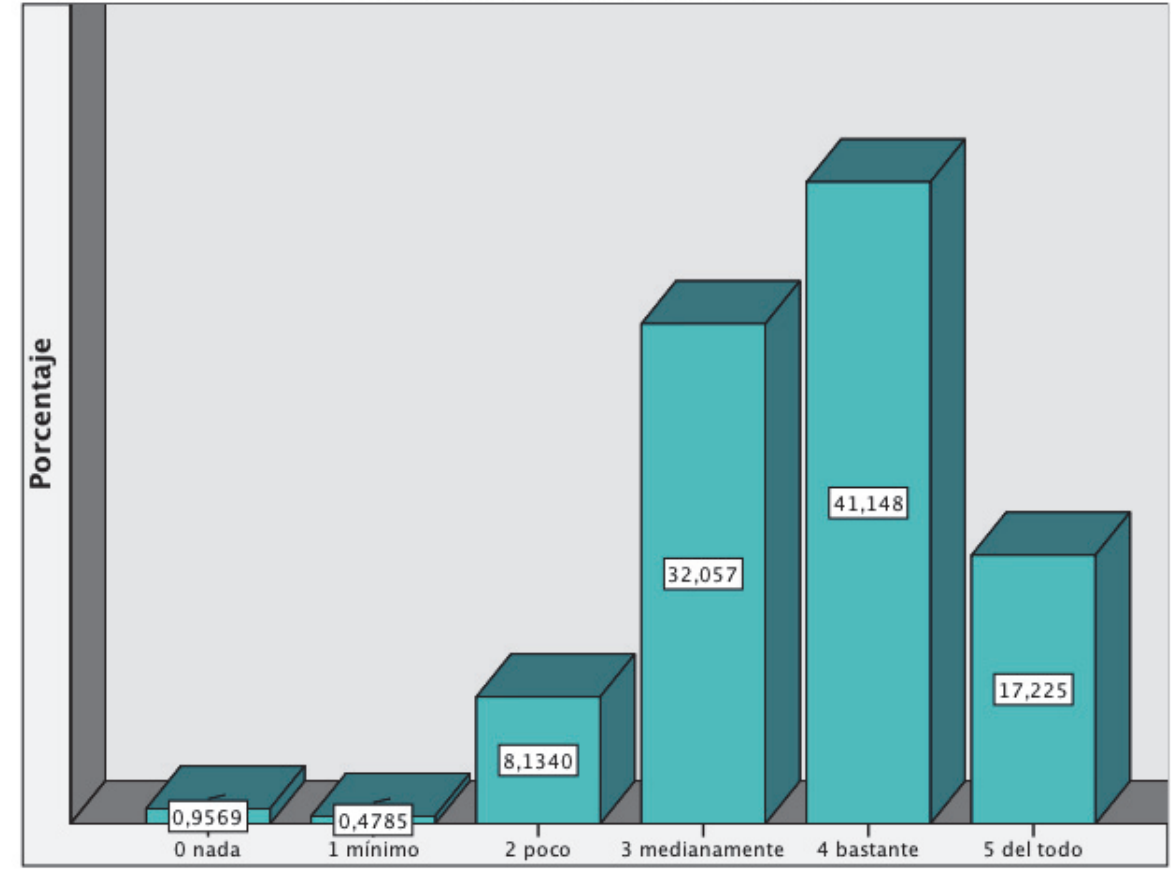

Elaboración propia. Mayo de 2015

Análisis: distribución en las 6 posibilidades. La mayoría se ubica en el 4 y baja a menos de la quinta parte para el 5 . Los valores 3 y 4 suman casi las $3 / 4$ partes: $73,205 \%$. Patrón en pirámide.

Este ítem y 54, 55 y 56 hablan de la armonía. Estos 3 últimos en relación con el respeto y arrojan puntuaciones similares entre ellos y diferentes al presente, lo cual evidencia la validez y coherencia de las encuestas. El alumnado percibe este valor más importante en la VP que en el ME, lo cual tiene lógica interna. 
Cuadro $n^{\circ} 1.9$

9. Calidez, cercanía

\begin{tabular}{|l|r|r|r|r|}
\hline & Frecuencia & Porcentaje & $\begin{array}{c}\text { Porcentaje } \\
\text { válido }\end{array}$ & $\begin{array}{r}\text { Porcentaje } \\
\text { acumulado }\end{array}$ \\
\hline 2 poco & 3 & 1,4 & 1,4 & 1,4 \\
3 medianamente & 19 & 9,1 & 9,1 & 10,5 \\
4 bastante & 92 & 44,0 & 44,0 & 54,5 \\
5 del todo & 95 & 45,5 & 45,5 & 100,0 \\
Total & 209 & 100,0 & 100,0 & \\
\hline
\end{tabular}

Elaboración propia. Mayo de 2015

Gráfico n ${ }^{\mathrm{o}} 1.9$

\section{Calidez, cercanía}

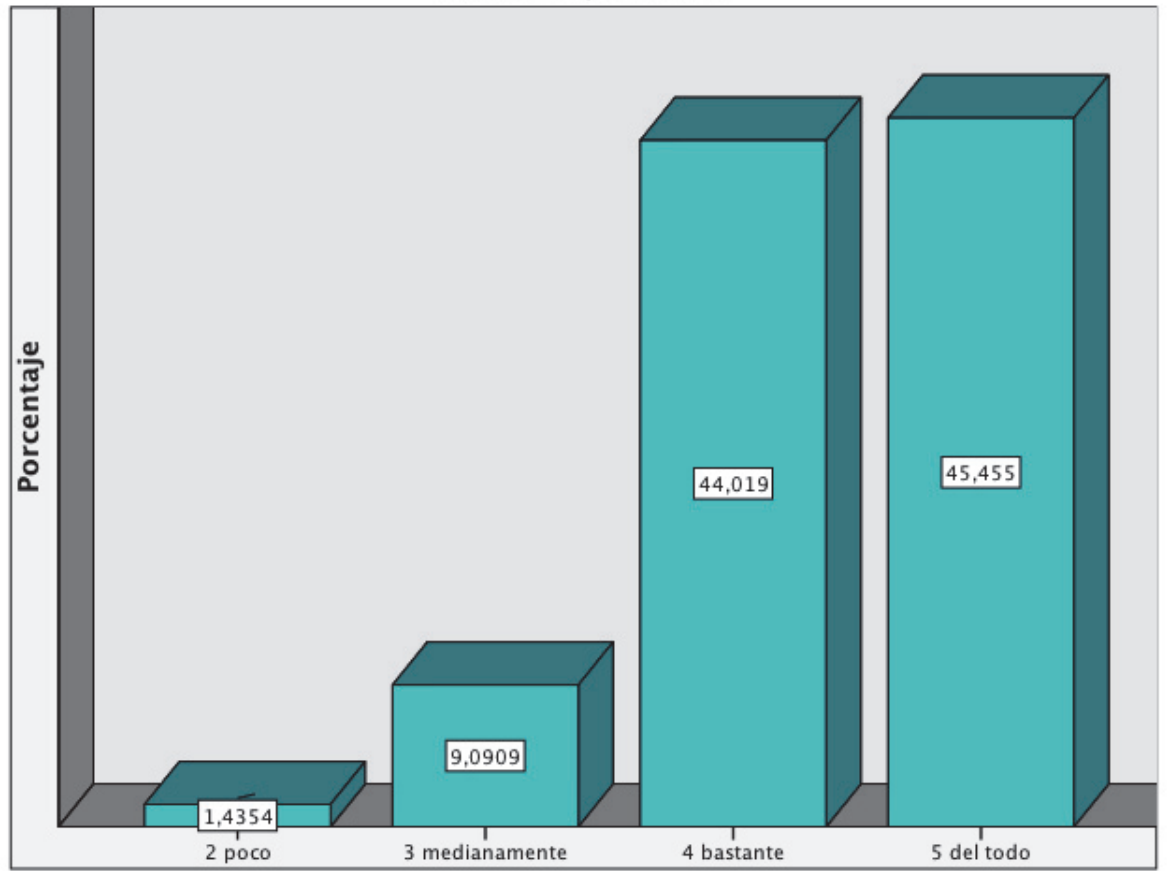

Elaboración propia. Mayo de 2015

Análisis: patrón en escalera. El 0 y el 1 no aparecen. El 2 ha sido marcado tan solo por 3 personas: el 1,4354\%. El 4 y 5 suman el 89,474\%. La "calidez, cercanía" es un valor claramente importante para la muestra en estudio.

Valor que establece un ambiente proclive a la Confianza, metavalor del $\mathrm{ME}$ de $\mathrm{C}$ por el que se quiere contribuir a la eficiencia y a la humanización de la atención a la salud en el trabajo. 
Cuadro $n^{\circ} 1.10$

10. Coherencia

\begin{tabular}{|ll|r|r|r|r|}
\hline & Frecuencia & Porcentaje & $\begin{array}{c}\text { Porcentaje } \\
\text { válido }\end{array}$ & $\begin{array}{c}\text { Porcentaje } \\
\text { acumulado }\end{array}$ \\
\hline \multirow{6}{*}{ Válidos } & &, 5 &, 5 &, 5 \\
& 0 nada & 1 &, 5 & 1,9 & 2,4 \\
& 2 poco & 4 & 1,9 & 16,3 & 18,7 \\
& 4 medianamente & 34 & 16,3 & 50,2 & 68,9 \\
& 5 del todo & 105 & 50,2 & 31,1 & 100,0 \\
& Total & 65 & 31,1 & 100,0 & \\
\hline
\end{tabular}

Elaboración propia. Mayo de 2015

Gráfico $\mathrm{n}^{\mathrm{0}} 1.10$

\section{Coherencia}

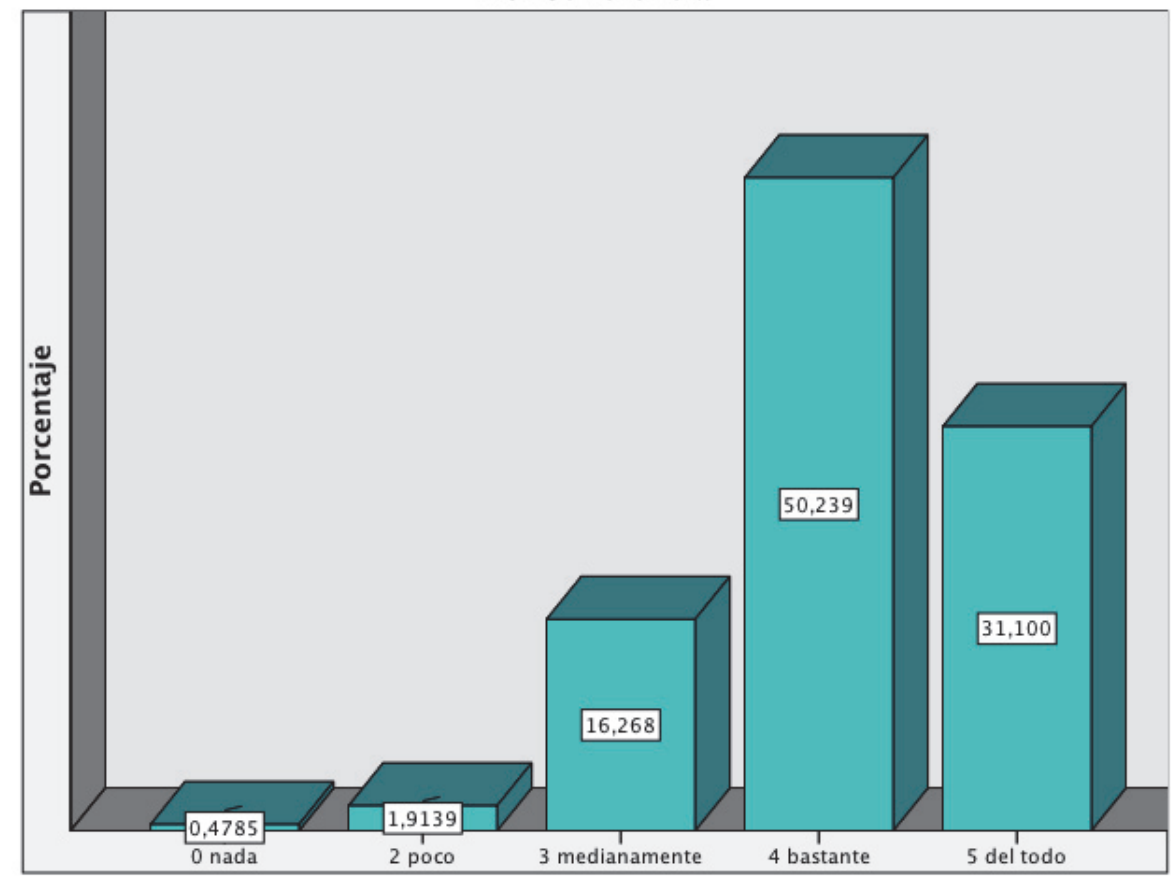

Elaboración propia. Mayo de 2015

Análisis: el 0 ha sido marcado por una persona: 0,4785\%, el 1 no aparece, y el 2 por cuatro: $1,9139 \%$. El gráfico tiene aspecto de pirámide, pero el peso se focaliza en la parte alta con más del $80 \%$, y la suma del 3, 4 y 5 representa más del 97\%. Lo catalogamos como modelo de pirámide asimétrica con sesgo a la derecha, valor importante para la muestra en estudio.

Valor esencial en general pues la falta de coherencia determinaría contradicciones internas que pondrían en peligro la eficiencia. 
Cuadro $n^{\circ} 1.11$

11. Comodidad, vida confortable

\begin{tabular}{|l|r|r|r|r|}
\hline & Frecuencia & Porcentaje & $\begin{array}{c}\text { Porcentaje } \\
\text { válido }\end{array}$ & $\begin{array}{r}\text { Porcentaje } \\
\text { acumulado }\end{array}$ \\
\hline 1 mínimo & 3 & 1,4 & 1,4 & 1,4 \\
2 poco & 6 & 2,9 & 2,9 & 4,3 \\
3 medianamente & 44 & 21,1 & 21,1 & 25,4 \\
4 bastante & 89 & 42,6 & 42,6 & 67,9 \\
5 del todo & 67 & 32,1 & 32,1 & 100,0 \\
Total & 209 & 100,0 & 100,0 & \\
\hline
\end{tabular}

Elaboración propia. Mayo de 2015

Gráfico $n^{0} 1.11$

\section{Comodidad, vida confortable}

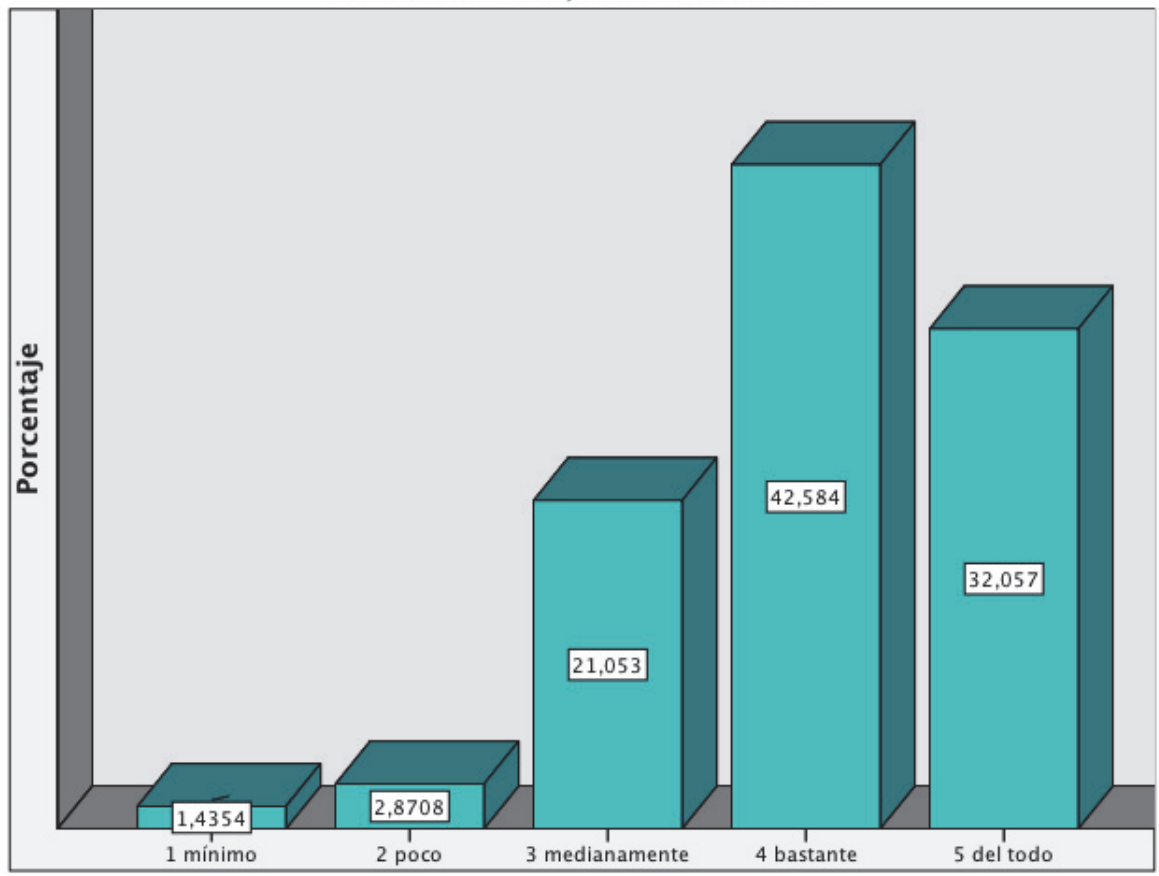

Elaboración propia. Mayo de 2015

Análisis: el 0 no aparece, el 1 y 2 a penas superan el 4\%, mientras que más del $95 \%$ se concentran en los valores altos. Modelo en pirámide asimétrica con sesgo a la derecha.

Este valor enlaza con el bienestar ubicado en la armonía del ME de C. No se pueden dar cuidados de calidad si no se considera que la comodidad del paciente es un valor importante 
Cuadro ${ }^{\circ} 1.12$

12. Compartir, generosidad

\begin{tabular}{|l|r|r|r|r|}
\hline & Frecuencia & Porcentaje & $\begin{array}{c}\text { Porcentaje } \\
\text { válido }\end{array}$ & $\begin{array}{c}\text { Porcentaje } \\
\text { acumulado }\end{array}$ \\
\hline 2 poco & 1 &, 5 &, 5 &, 5 \\
3 medianamente & 18 & 8,6 & 8,6 & 9,1 \\
4 bastante & 107 & 51,2 & 51,2 & 60,3 \\
5 del todo & 83 & 39,7 & 39,7 & 100,0 \\
Total & 209 & 100,0 & 100,0 & \\
\hline
\end{tabular}

Elaboración propia. Mayo de 2015

Gráfico $\mathrm{n}^{\mathrm{o}} 1.12$

12. Compartir, generosidad

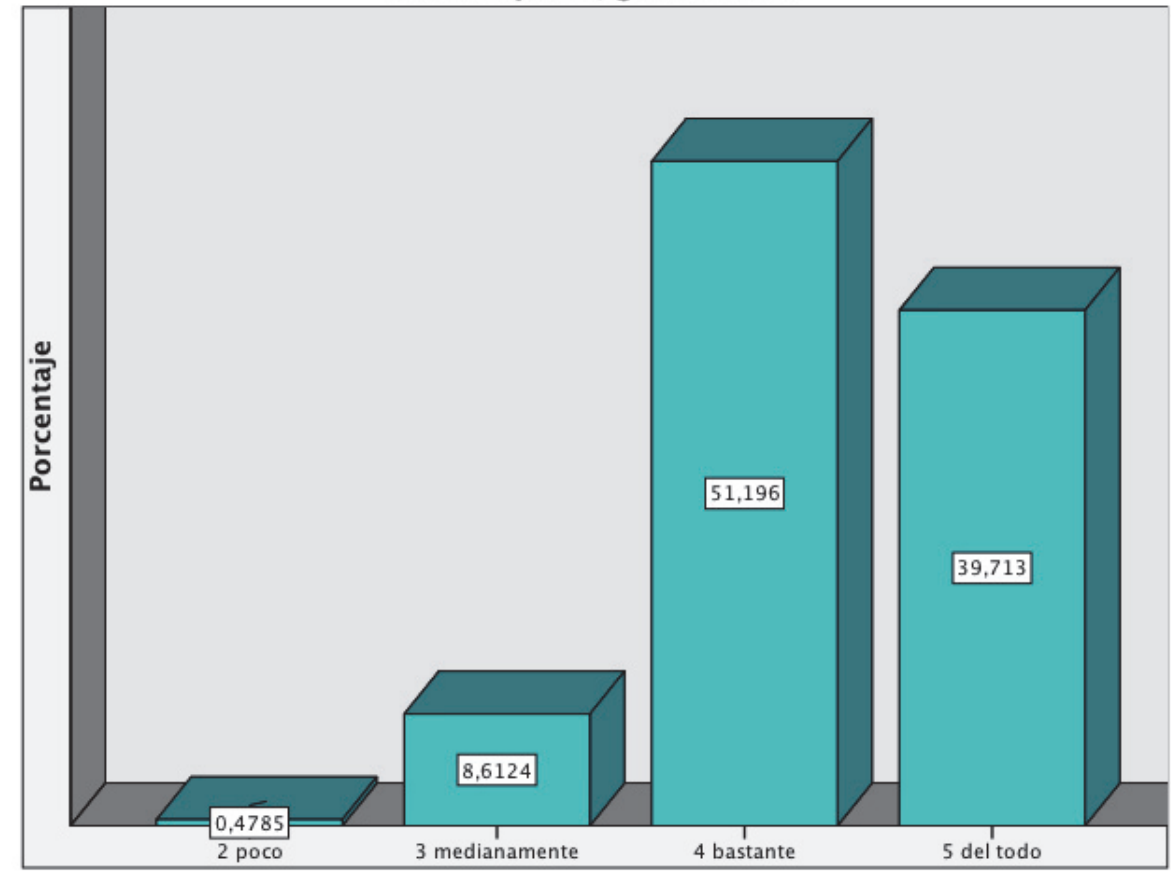

Elaboración propia. Mayo de 2015

Análisis: valor altamente estimado por la muestra en estudio. El 0 y el 1 no han sido marcados ninguna vez. El 2 no llega al 0,5\%. El 4 y 5 representan más del 90\%, pesando más el 4. Modelo en pirámide asimétrica con sesgo a la derecha.

Valor relacionado con el Compromiso social que es el primero del ME de $\mathrm{C}$ y también con el valor 65. Solidaridad, generosidad que arroja resultados similares lo cual evidencia la validez de las respuestas dadas por la muestra en estudio. Por otro lado los resultados obtenidos son muy favorables para dar por cierta nuestra hipótesis. 
Cuadro $n^{\circ} 1.13$

13. Competitividad, ambición, trabajo duro

\begin{tabular}{|l|r|r|r|r|}
\hline & Frecuencia & Porcentaje & $\begin{array}{c}\text { Porcentaje } \\
\text { válido }\end{array}$ & $\begin{array}{r}\text { Porcentaje } \\
\text { acumulado }\end{array}$ \\
\hline 1 mínimo & 6 & 2,9 & 2,9 & 2,9 \\
2 poco & 25 & 12,0 & 12,0 & 14,8 \\
3 medianamente & 60 & 28,7 & 28,7 & 43,5 \\
4 bastante & 73 & 34,9 & 34,9 & 78,5 \\
5 del todo & 45 & 21,5 & 21,5 & 100,0 \\
Total & 209 & 100,0 & 100,0 & \\
\hline
\end{tabular}

Elaboración propia. Mayo de 2015

Gráfico $\mathrm{n}^{\mathrm{0}} 1.13$

13. Competitividad, ambición, trabajo duro

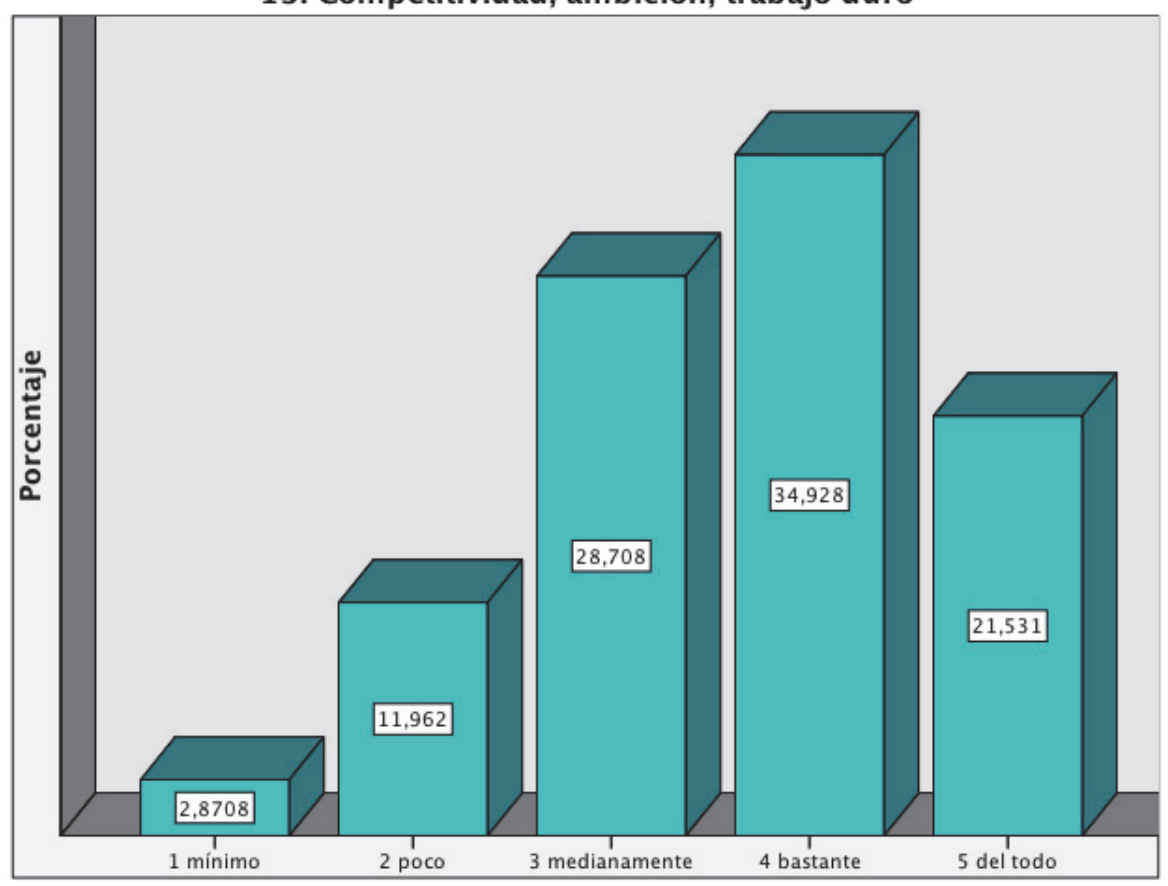

Elaboración propia. Mayo de 2015

Análisis: falta el 0. El peso se centraliza en el 3 y 4 que suman más del $63 \%$. El 5 representa aproximadamente una quinta parte. Modelo en pirámide.

Este ítem, el 36. Imagen, prestigio social y el 50. Productividad, resultados tienen en común que responden a características tradicionalmente atribuidas a lo masculino y observamos que arrojan resultados similares, medianamente importante en VP y muy importantes en ME. Son resultados acordes en la VP para una profesión feminizada, y en el ME en cuanto a que la gestión y dirección de empresas sigue en manos masculinas. 
Cuadro $n^{\circ} 1.14$

14. Comunicación/información

\begin{tabular}{|l|r|r|r|r|}
\hline & Frecuencia & Porcentaje & $\begin{array}{c}\text { Porcentaje } \\
\text { válido }\end{array}$ & $\begin{array}{r}\text { Porcentaje } \\
\text { acumulado }\end{array}$ \\
\hline 2 poco & 1 &, 5 &, 5 &, 5 \\
3 medianamente & 31 & 14,8 & 14,8 & 15,3 \\
4 bastante & 95 & 45,5 & 45,5 & 60,8 \\
5 del todo & 82 & 39,2 & 39,2 & 100,0 \\
Total & 209 & 100,0 & 100,0 & \\
\hline
\end{tabular}

Elaboración propia. Mayo de 2015

Gráfico $n^{\circ} 1.14$

\section{Comunicación/información}

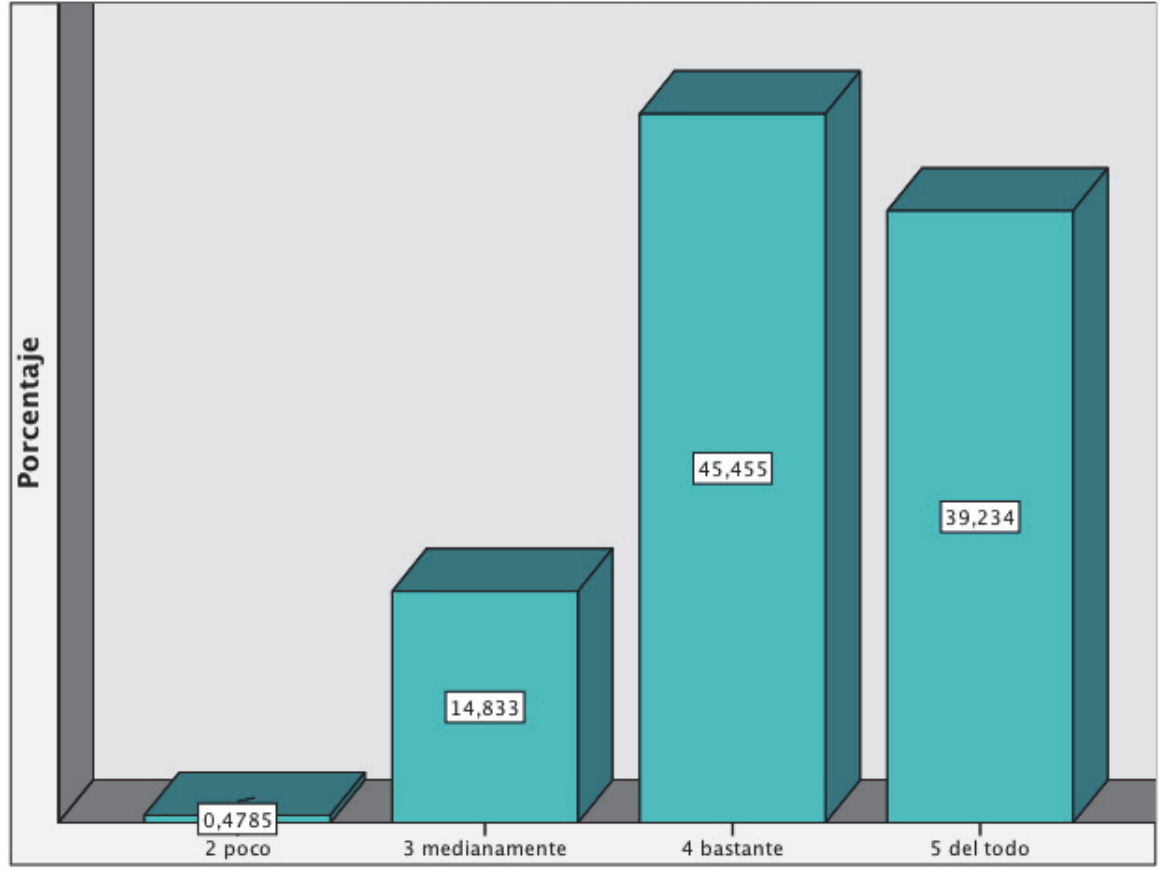

Elaboración propia. Mayo de 2015

Análisis: las dos puntuaciones más bajas no aparecen. Las dos más altas suman más del $84 \%$ con mayor peso en el 4 . Modelo en pirámide asimétrica con sesgo a la derecha.

Valor relacionado con la Competencia profesional, que aparece recogido en el apartado de Seguridad del ME de C. Por otro lado, al igual que veíamos para el valor 6. Apertura, diálogo, igualdad, franqueza, es fundamental para desarrollar empatía, imprescindible para cuidar con dignidad al que sufre. 
Cuadro $\mathrm{n}^{\mathrm{o}} 1.15$

15. Confianza

\begin{tabular}{|l|r|r|r|r|}
\hline & Frecuencia & Porcentaje & $\begin{array}{c}\text { Porcentaje } \\
\text { válido }\end{array}$ & $\begin{array}{r}\text { Porcentaje } \\
\text { acumulado }\end{array}$ \\
\hline 1 mínimo & 2 & 1,0 & 1,0 & 1,0 \\
2 poco & 3 & 1,4 & 1,4 & 2,4 \\
3 medianamente & 36 & 17,2 & 17,2 & 19,6 \\
4 bastante & 79 & 37,8 & 37,8 & 57,4 \\
5 del todo & 89 & 42,6 & 42,6 & 100,0 \\
Total & 209 & 100,0 & 100,0 & \\
\hline
\end{tabular}

Elaboración propia. Mayo de 2015

Gráfico $\mathrm{n}^{\mathrm{0}} 1.15$

15. Confianza

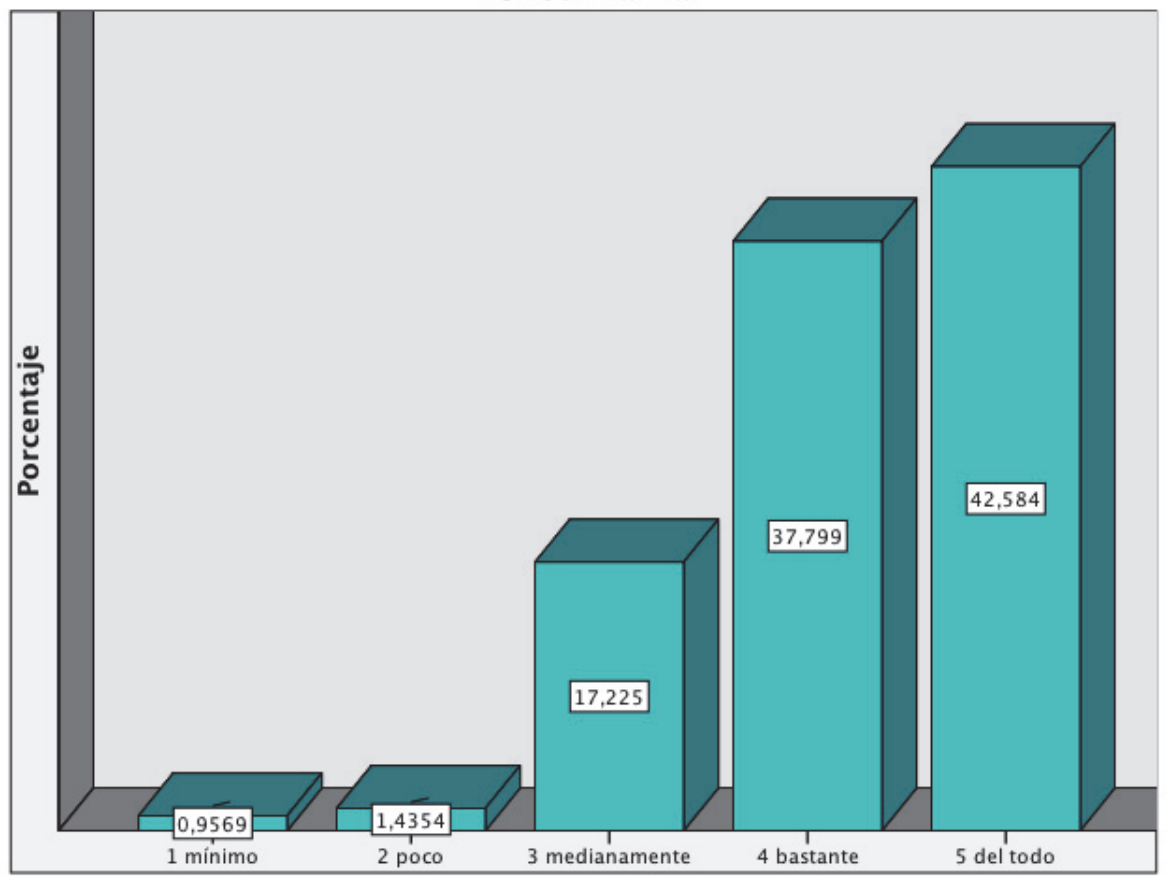

Elaboración propia. Mayo de 2015

Análisis: modelo en escalera ascendente con más del $80 \%$ en los valores 4 y 5. La "Confianza" se manifiesta como un valor considerado importante por la muestra en estudio.

Es el metavalor central que desde el ME de C. Para SALVADOR GARCÍA (2011) la confianza (creer en) es un metavalor que se encuentran en el núcleo del modelo triaxial. La confianza es esencial para el bienestar emocional y genera el ambiente necesario para que aparezca la iniciativa, la creatividad, el diálogo y el aprendizaje organizativo. 
Cuadro $n^{\circ} 1.16$

16. Contemplación, meditación, serenidad

\begin{tabular}{|l|r|r|r|r|}
\hline & Frecuencia & Porcentaje & $\begin{array}{c}\text { Porcentaje } \\
\text { válido }\end{array}$ & $\begin{array}{r}\text { Porcentaje } \\
\text { acumulado }\end{array}$ \\
\hline 1 mínimo & 4 & 1,9 & 1,9 & 1,9 \\
2 poco & 13 & 6,2 & 6,2 & 8,1 \\
3 medianamente & 71 & 34,0 & 34,0 & 42,1 \\
4 bastante & 82 & 39,2 & 39,2 & 81,3 \\
5 del todo & 39 & 18,7 & 18,7 & 100,0 \\
Total & 209 & 100,0 & 100,0 & \\
\hline
\end{tabular}

Elaboración propia. Mayo de 2015

Gráfico $\mathrm{n}^{\mathrm{0}} 1.16$

16. Contemplación, meditación, serenidad

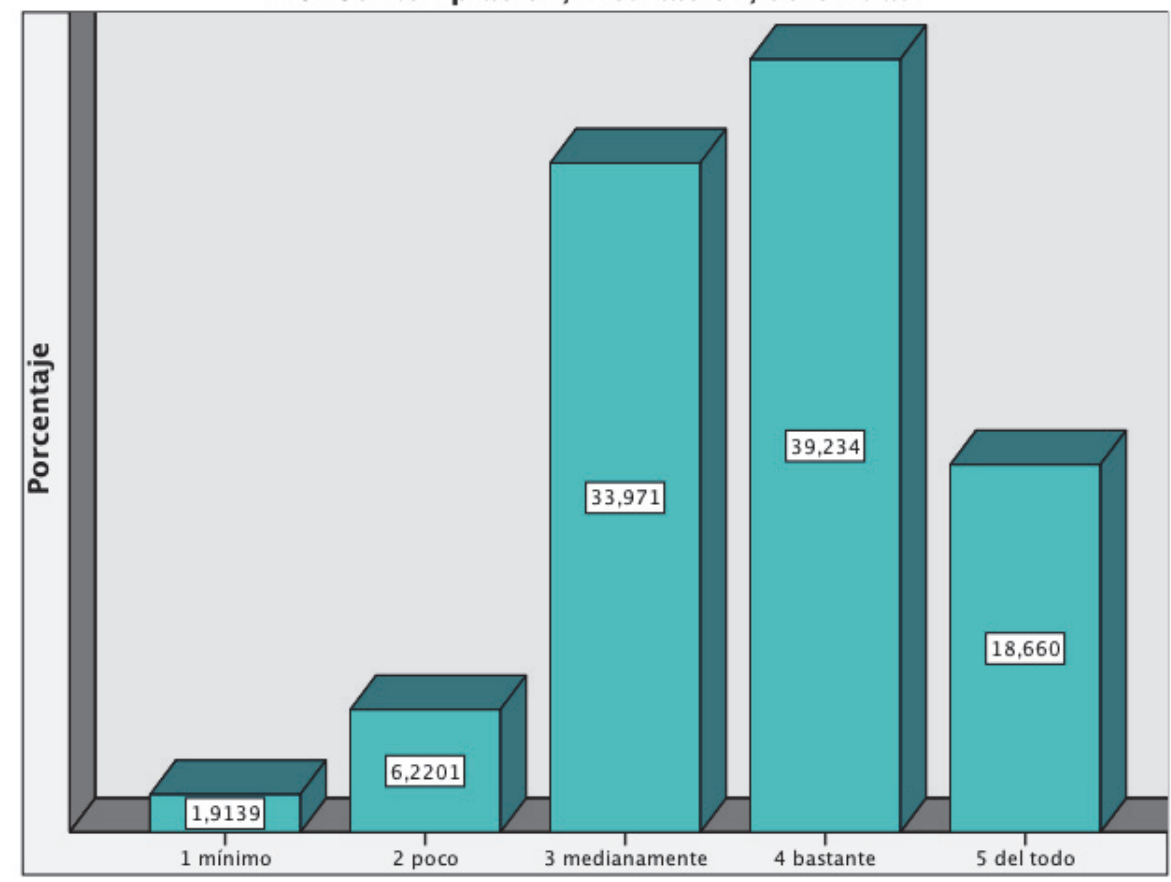

Elaboración propia. Mayo de 2015

Análisis: el 0 no aparece. El 73\% se concentra entre el 3 y el 4 , con predominio de este último, decayendo para el 5 a menos de una quinta parte. Modelo en pirámide.

Valor intrínsecamente ligado a la seguridad que debe tener la enfermera en el desempeño de su trabajo y debe y transmitir a sus enfermos. 
Cuadro $n^{\circ} 1.17$

17. Control, orden, disciplina

\begin{tabular}{|l|r|r|r|r|}
\hline & Frecuencia & Porcentaje & $\begin{array}{c}\text { Porcentaje } \\
\text { válido }\end{array}$ & $\begin{array}{c}\text { Porcentaje } \\
\text { acumulado }\end{array}$ \\
\hline 0 nada & 1 &, 5 &, 5 &, 5 \\
1 mínimo & 3 & 1,4 & 1,4 & 1,9 \\
2 poco & 8 & 3,8 & 3,8 & 5,7 \\
3 medianamente & 46 & 22,0 & 22,0 & 27,8 \\
4 bastante & 88 & 42,1 & 42,1 & 69,9 \\
5 del todo & 63 & 30,1 & 30,1 & 100,0 \\
Total & 209 & 100,0 & 100,0 & \\
\hline
\end{tabular}

Elaboración propia. Mayo de 2015

Gráfico $\mathrm{n}^{\mathrm{0}} 1.17$

17. Control, orden, disciplina

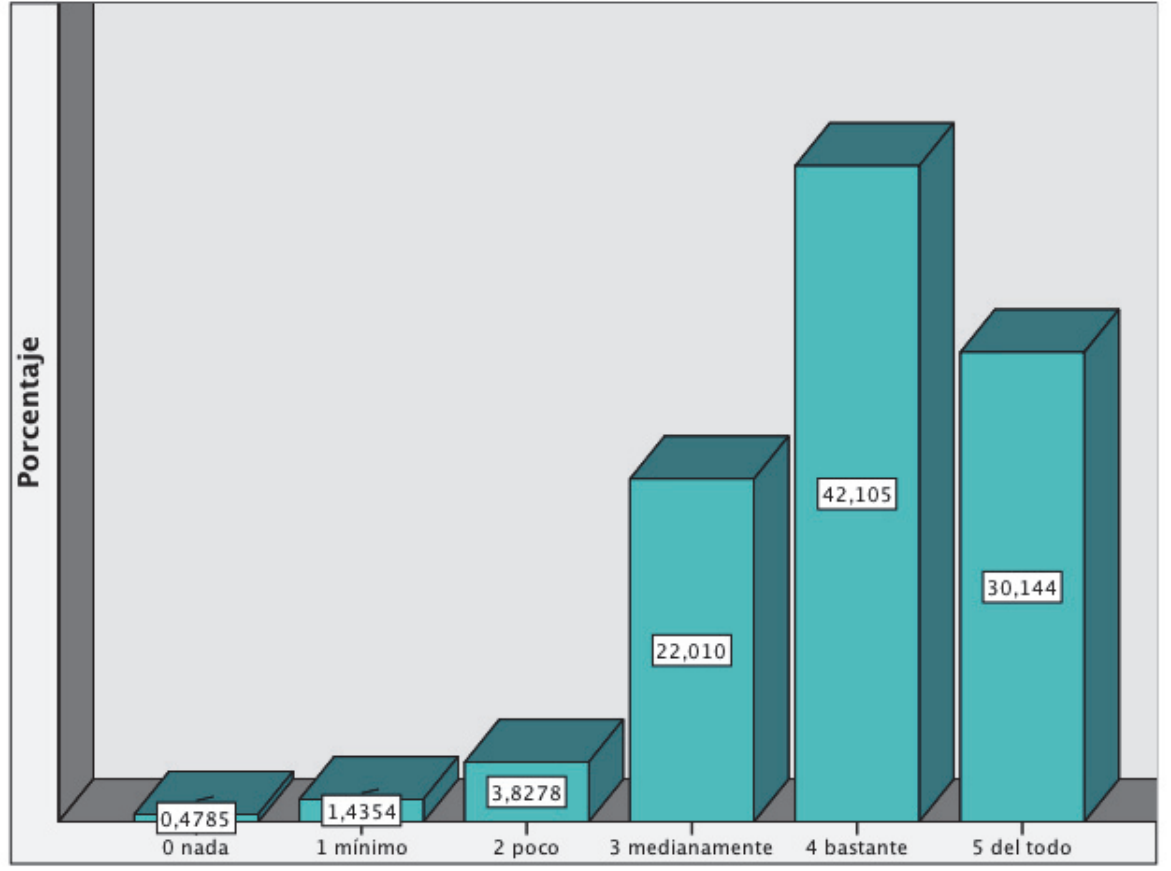

Elaboración propia. Mayo de 2015

Análisis: aunque todas las puntuaciones están presentes, más del 94\% puntúan este valor desde el 3 al 5 con mayor peso en el 4, y casi un tercio para el 5 . Modelo en pirámide asimétrica con sesgo a la derecha.

Este valor es la base de la calidad, la competencia profesional y por lo tanto de la seguridad. 
Cuadro $n^{\circ} 1.18$

18. Cooperación, colaboración, espíritu de equipo

\begin{tabular}{|l|r|r|r|r|}
\hline & Frecuencia & Porcentaje & $\begin{array}{c}\text { Porcentaje } \\
\text { válido }\end{array}$ & $\begin{array}{c}\text { Porcentaje } \\
\text { acumulado }\end{array}$ \\
\hline 1 mínimo & 1 &, 5 &, 5 &, 5 \\
2 poco & 3 & 1,4 & 1,4 & 1,9 \\
3 medianamente & 25 & 12,0 & 12,0 & 13,9 \\
4 bastante & 87 & 41,6 & 41,6 & 55,5 \\
5 del todo & 93 & 44,5 & 44,5 & 100,0 \\
Total & 209 & 100,0 & 100,0 & \\
\hline
\end{tabular}

Elaboración propia. Mayo de 2015

Gráfico $\mathrm{n}^{\mathrm{o}} 1.18$

18. Cooperación, colaboración, espíritu de equipo

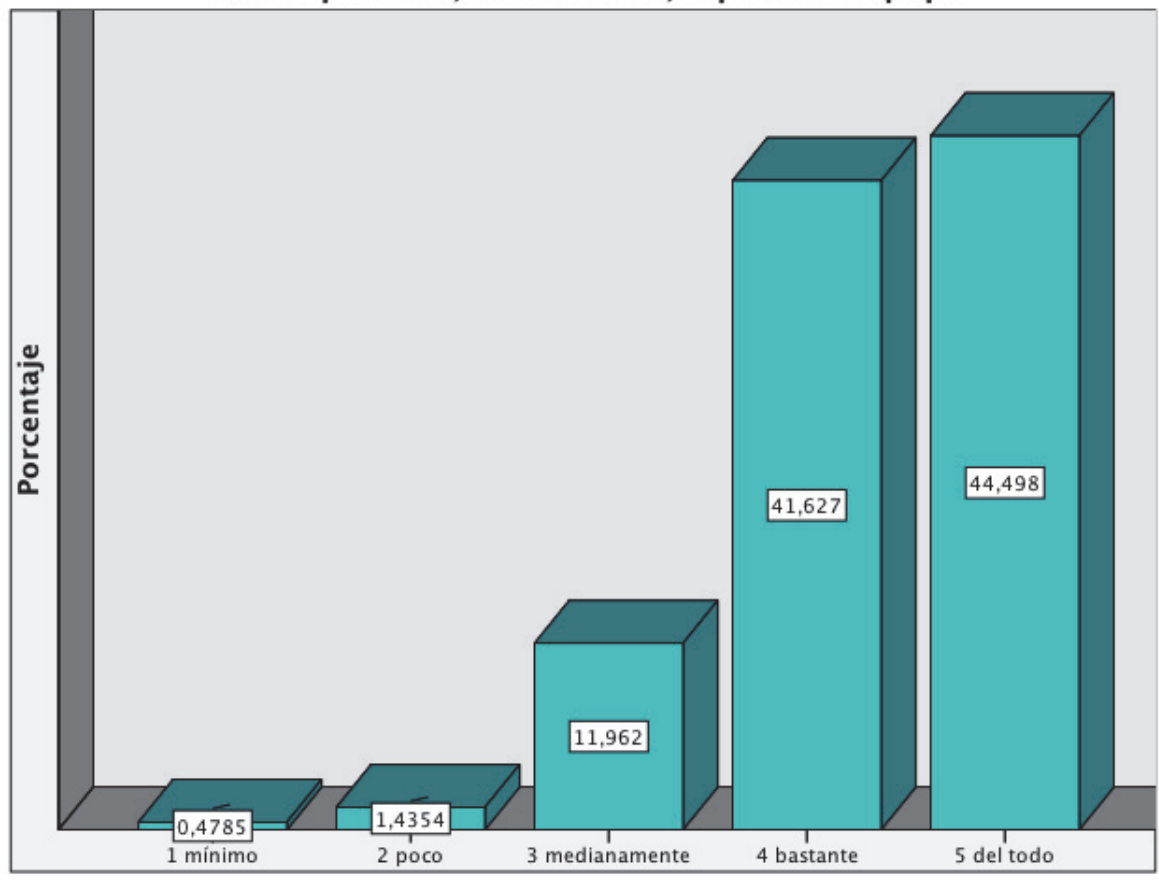

Elaboración propia. Mayo de 2015

Análisis: el 0 no aparece y más del 85\% se concentra en el 4 y 5 . Modelo en escalera ascendente. El valor "Cooperación, colaboración, trabajo en equipo" se muestra como muy importante para la muestra en estudio.

Valor fundamental para el trabajo sanitario y en particular para enfermería, pues se halla en el centro del equipo, enlazando los distintos niveles. Las respuestas obtenidas nos inclinan a esperar unos resultados muy eficientes. 
Cuadro $n^{0} 1.19$

19. Cortesía

\begin{tabular}{|l|c|c|c|c|}
\hline & Frecuencia & Porcentaje & $\begin{array}{c}\text { Porcentaje } \\
\text { válido }\end{array}$ & $\begin{array}{c}\text { Porcentaje } \\
\text { acumulado }\end{array}$ \\
\hline 2 poco & 3 & 1,4 & 1,4 & 1,4 \\
3 medianamente & 30 & 14,4 & 14,4 & 15,8 \\
4 bastante & 101 & 48,3 & 48,3 & 64,1 \\
5 del todo & 75 & 35,9 & 35,9 & 100,0 \\
Total & 209 & 100,0 & 100,0 & \\
\hline
\end{tabular}

Elaboración propia. Mayo de 2015

\section{Gráfico ${ }^{\circ} 1.19$}

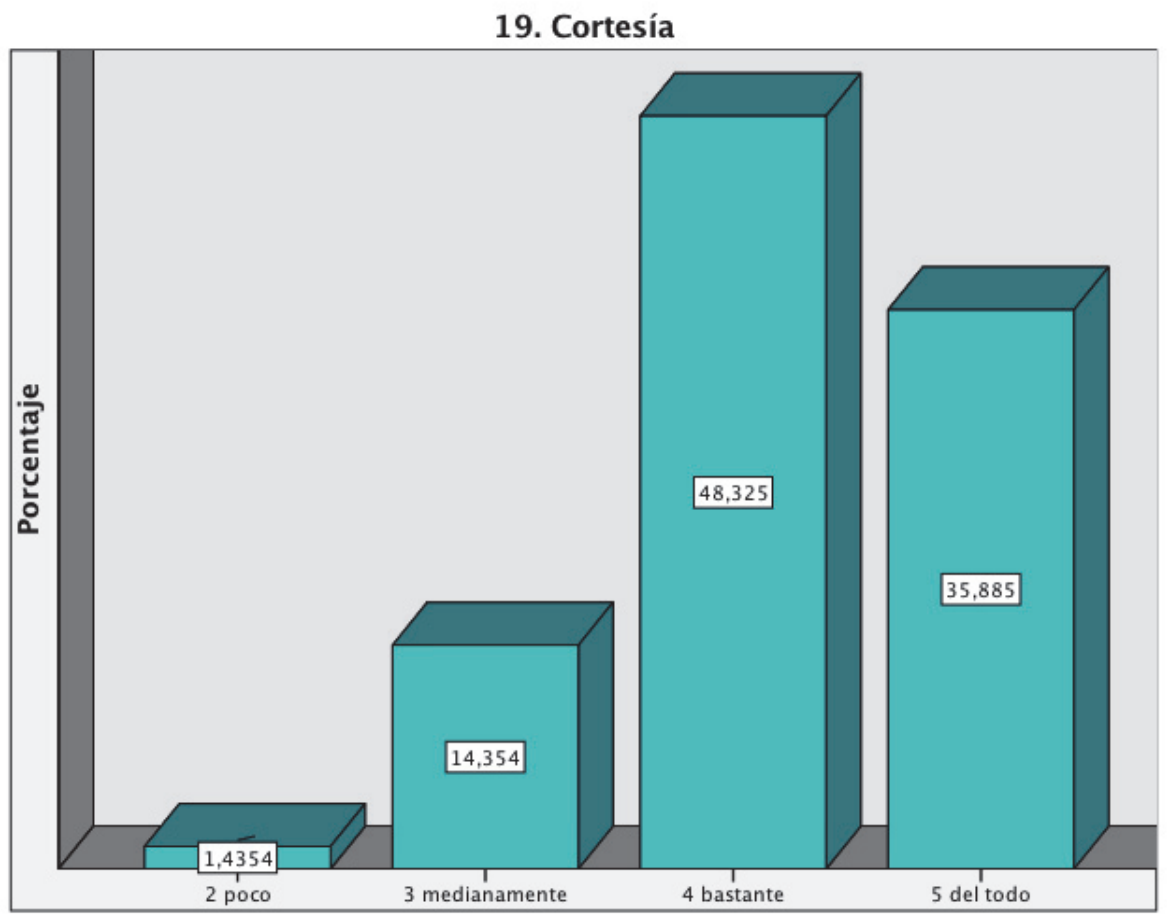

Elaboración propia. Mayo de 2015

Análisis: más del $84 \%$ de las puntuaciones se concentran ente el 4 y 5 con más peso en el 4 . El 0 y 1 no aparecen. Modelo en pirámide asimétrica con sesgo a la derecha. La "Cortesía" es un valor catalogado como importante dentro de la esfera VP por la muestra en estudio.

Relacionada con el respeto, la enfermera ha de ser cortés, que no servil. Los resultados obtenidos son compatibles con un trabajo eficiente. 
Cuadro $n^{\circ} 1.20$

20. Crecimiento/expansión

\begin{tabular}{|l|r|r|r|r|}
\hline & Frecuencia & Porcentaje & $\begin{array}{c}\text { Porcentaje } \\
\text { válido }\end{array}$ & $\begin{array}{c}\text { Porcentaje } \\
\text { acumulado }\end{array}$ \\
\hline 1 mínimo & 1 &, 5 &, 5 &, 5 \\
2 poco & 6 & 2,9 & 2,9 & 3,3 \\
3 medianamente & 45 & 21,5 & 21,5 & 24,9 \\
4 bastante & 87 & 41,6 & 41,6 & 66,5 \\
5 del todo & 70 & 33,5 & 33,5 & 100,0 \\
Total & 209 & 100,0 & 100,0 & \\
\hline
\end{tabular}

Elaboración propia. Mayo de 2015

Gráfico $\mathrm{n}^{\mathrm{0}} 1.20$

\section{Crecimiento/expansión}

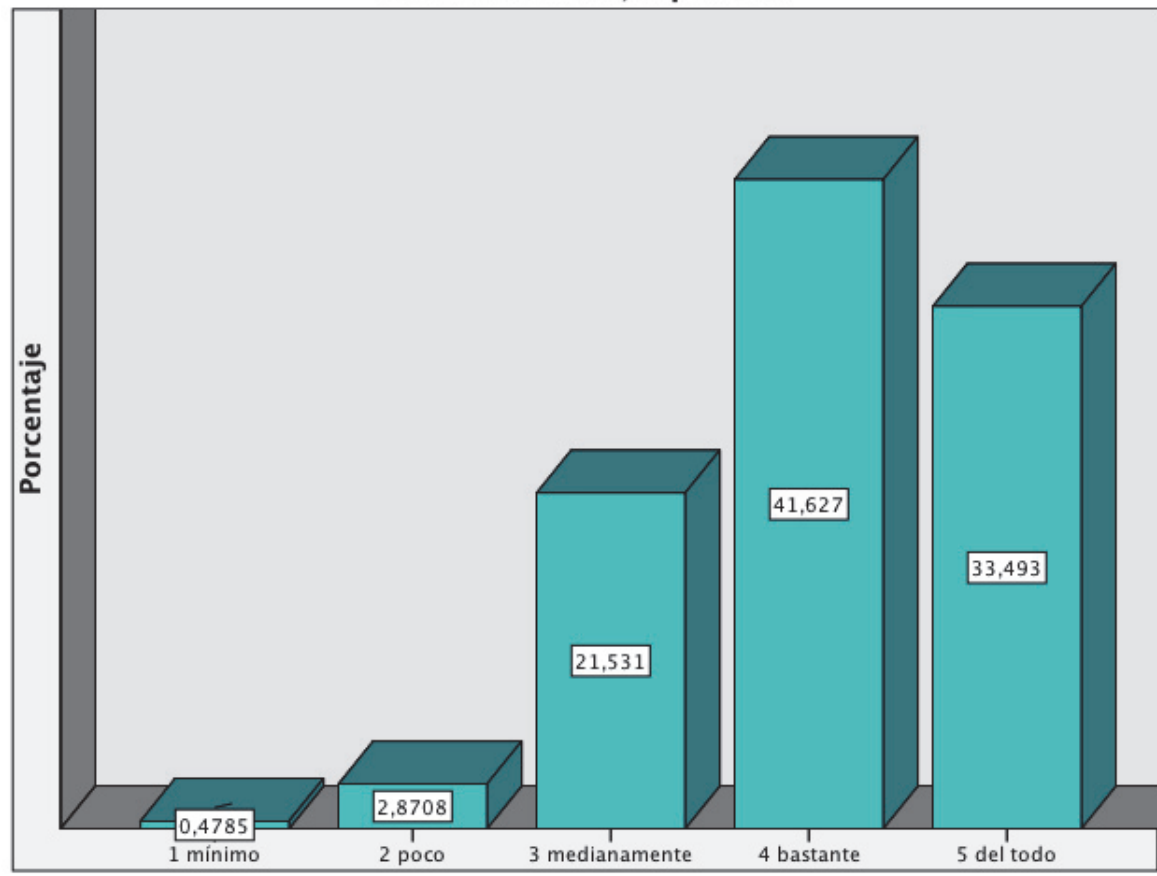

Elaboración propia. Mayo de 2015

Análisis: nadie ha marcado el 0 y el 1 ha sido marcado por una sola persona. El 75\% corresponde al 4 y 5 con predominio del 4 . Modelo en pirámide asimétrica con sesgo a la derecha. Valor importante en VP.

Valor relacionado con la Competencia profesional. Los resultados obtenidos se ajustan a profesionales de las ciencias de la salud en continua expansión, y especialmente de enfermería que procede de un pasado de exclusión y debe crecer para recuperar el terreno que le pertenece. 
Cuadro $n^{\circ} 1.21$

21. Creer y poner cariño en lo que se hace

\begin{tabular}{|l|r|r|r|r|}
\hline & Frecuencia & Porcentaje & $\begin{array}{c}\text { Porcentaje } \\
\text { válido }\end{array}$ & $\begin{array}{r}\text { Porcentaje } \\
\text { acumulado }\end{array}$ \\
\hline 2 poco & 4 & 1,9 & 1,9 & 1,9 \\
3 medianamente & 10 & 4,8 & 4,8 & 6,7 \\
4 bastante & 67 & 32,1 & 32,1 & 38,8 \\
5 del todo & 128 & 61,2 & 61,2 & 100,0 \\
Total & 209 & 100,0 & 100,0 & \\
\hline
\end{tabular}

Elaboración propia. Mayo de 2015

Gráfico $\mathrm{n}^{\mathrm{o}} 1.21$

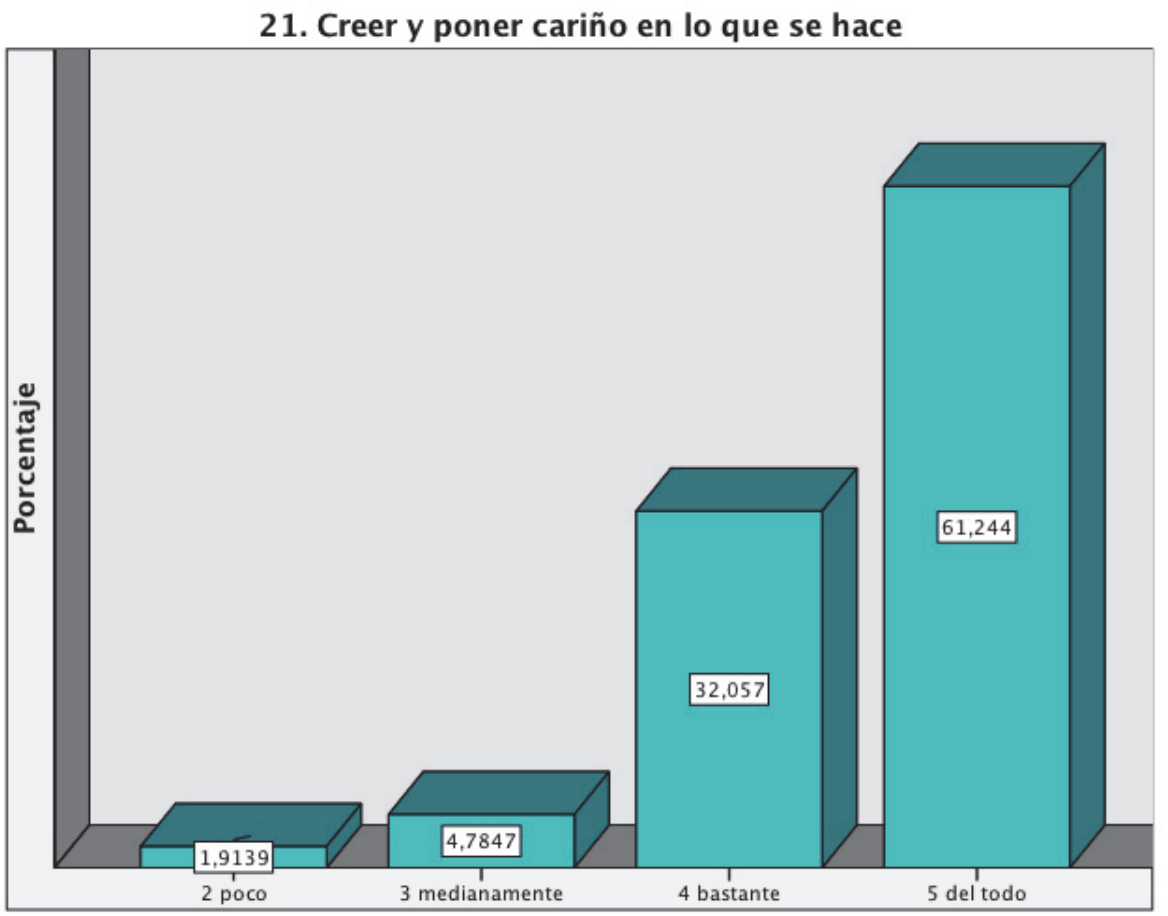

Elaboración propia. Mayo de 2015

Análisis: modelo en escalera ascendente, el 4 y 5 suman más del 93\%.

"Creer y poner cariño en lo que se hace" es considerado muy importante por la muestra en estudio.

Valor intrínsecamente relacionado con la Confianza que es el metavalor de Espinoso de Compludo para contribuir a la eficiencia y a la humanización. Resultados que nos hacen esperar conclusiones favorables a nuestra hipótesis. 
Cuadro $n^{\circ} 1.22$

22. Deleite físico, Hedonismo

\begin{tabular}{|l|r|r|r|r|}
\hline & Frecuencia & Porcentaje & $\begin{array}{c}\text { Porcentaje } \\
\text { válido }\end{array}$ & $\begin{array}{c}\text { Porcentaje } \\
\text { acumulado }\end{array}$ \\
\hline 0 nada & 5 & 2,4 & 2,4 & 2,4 \\
1 mínimo & 12 & 5,7 & 5,7 & 8,1 \\
2 poco & 21 & 10,0 & 10,0 & 18,2 \\
3 medianamente & 78 & 37,3 & 37,3 & 55,5 \\
4 bastante & 57 & 27,3 & 27,3 & 82,8 \\
5 del todo & 36 & 17,2 & 17,2 & 100,0 \\
Total & 209 & 100,0 & 100,0 & \\
\hline
\end{tabular}

Elaboración propia. Mayo de 2015

Gráfico $\mathrm{n}^{\mathrm{0}} 1.22$

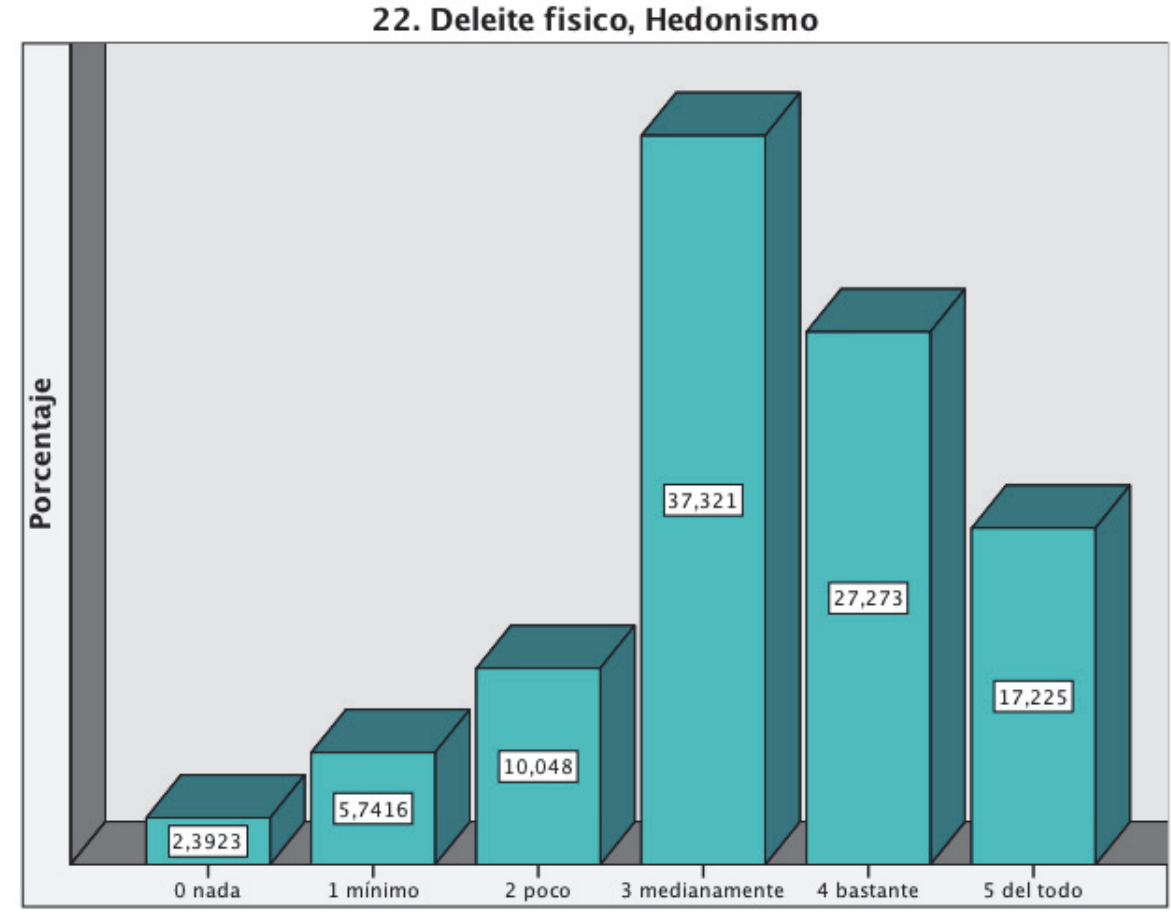

Elaboración propia. Mayo de 2015

Análisis: modelo en pirámide con el mayor peso recayendo en el valor central 3. Todas las puntuaciones, desde las más bajas, han sido marcadas. El "Deleite físico, hedonismo" es medianamente valorado por la muestra en estudio.

Lógicamente, una profesión a la que siempre se le ha pedido autosacrificio y entrega no puede ver este valor como muy importante. Resultado coherente en nuestro estudio. 
Cuadro $n^{\circ} 1.23$

23. Derechos humanos, Dignidad

\begin{tabular}{|l|r|r|r|r|}
\hline & Frecuencia & Porcentaje & $\begin{array}{c}\text { Porcentaje } \\
\text { válido }\end{array}$ & $\begin{array}{c}\text { Porcentaje } \\
\text { acumulado }\end{array}$ \\
\hline 0 nada & 1 &, 5 &, 5 &, 5 \\
1 mínimo & 1 &, 5 &, 5 & 1,0 \\
2 poco & 1 &, 5 &, 5 & 1,4 \\
3 medianamente & 26 & 12,4 & 12,4 & 13,9 \\
4 bastante & 58 & 27,8 & 27,8 & 41,6 \\
5 del todo & 122 & 58,4 & 58,4 & 100,0 \\
Total & 209 & 100,0 & 100,0 & \\
\hline
\end{tabular}

Elaboración propia. Mayo de 2015

Gráfico $n^{\circ} 1.23$

23. Derechos humanos, Dignidad

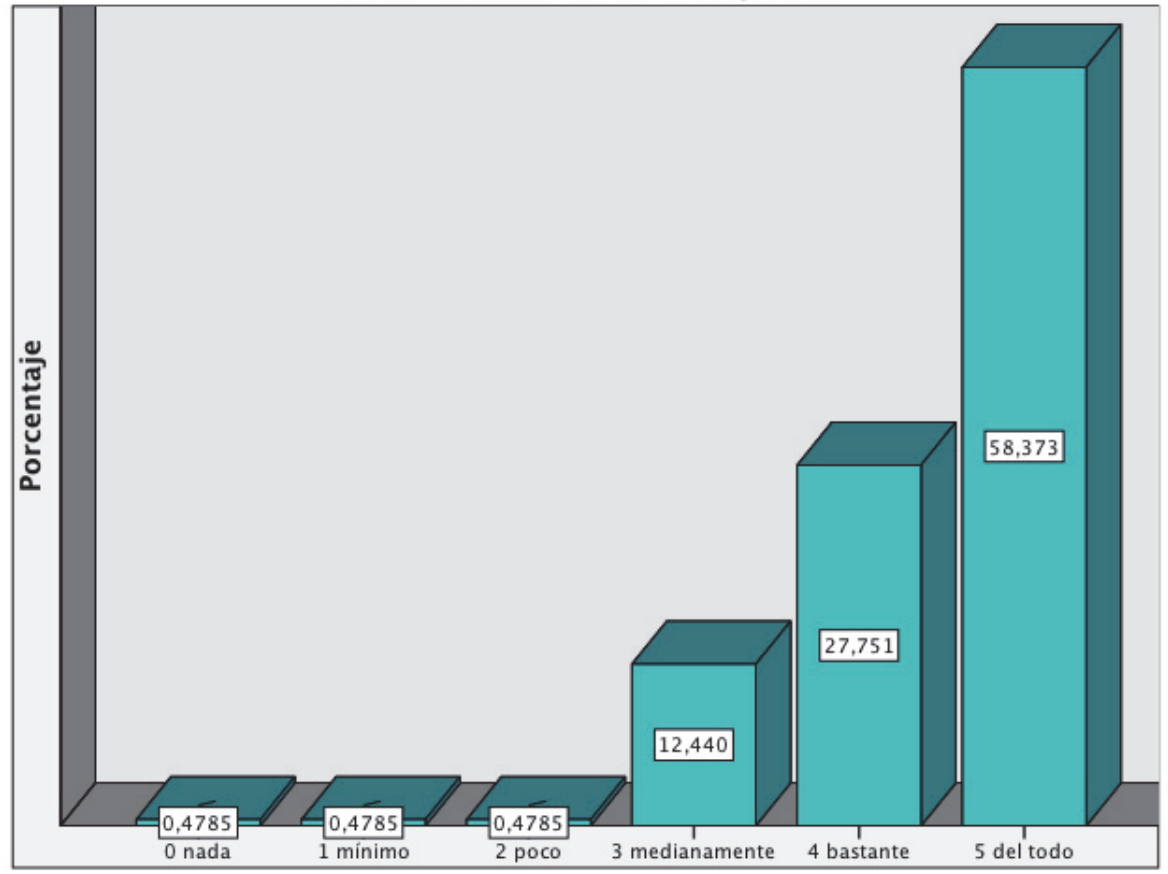

Elaboración propia. Mayo de 2015

Análisis: modelo en escalera ascendente con predominio del 5. El valor "Derechos humanos, Dignidad" es catalogado como importante. Sin embargo llama la atención que el 0,1 y 2 hayan sido marcados por una persona cada uno. Todavía hay alguien que dice que este valor es nada significativo en su VP.

La coherencia se hace gráfico con este valor. Evidentemente, esperábamos que enfermería arrojara estos resultados para este valor que es uno de los que compone el Compromiso social en el ME de C. 
Cuadro $n^{0} 1.24$

24. Disfrutar del trabajo

\begin{tabular}{|l|r|r|r|r|}
\hline & Frecuencia & Porcentaje & $\begin{array}{c}\text { Porcentaje } \\
\text { válido }\end{array}$ & $\begin{array}{c}\text { Porcentaje } \\
\text { acumulado }\end{array}$ \\
\hline 0 nada & 2 & 1,0 & 1,0 & 1,0 \\
2 poco & 3 & 1,4 & 1,4 & 2,4 \\
3 medianamente & 23 & 11,0 & 11,0 & 13,4 \\
4 bastante & 80 & 38,3 & 38,3 & 51,7 \\
5 del todo & 101 & 48,3 & 48,3 & 100,0 \\
Total & 209 & 100,0 & 100,0 & \\
\hline
\end{tabular}

Elaboración propia. Mayo de 2015

Gráfico $n^{\circ} 1.24$

\section{Disfrutar del trabajo}

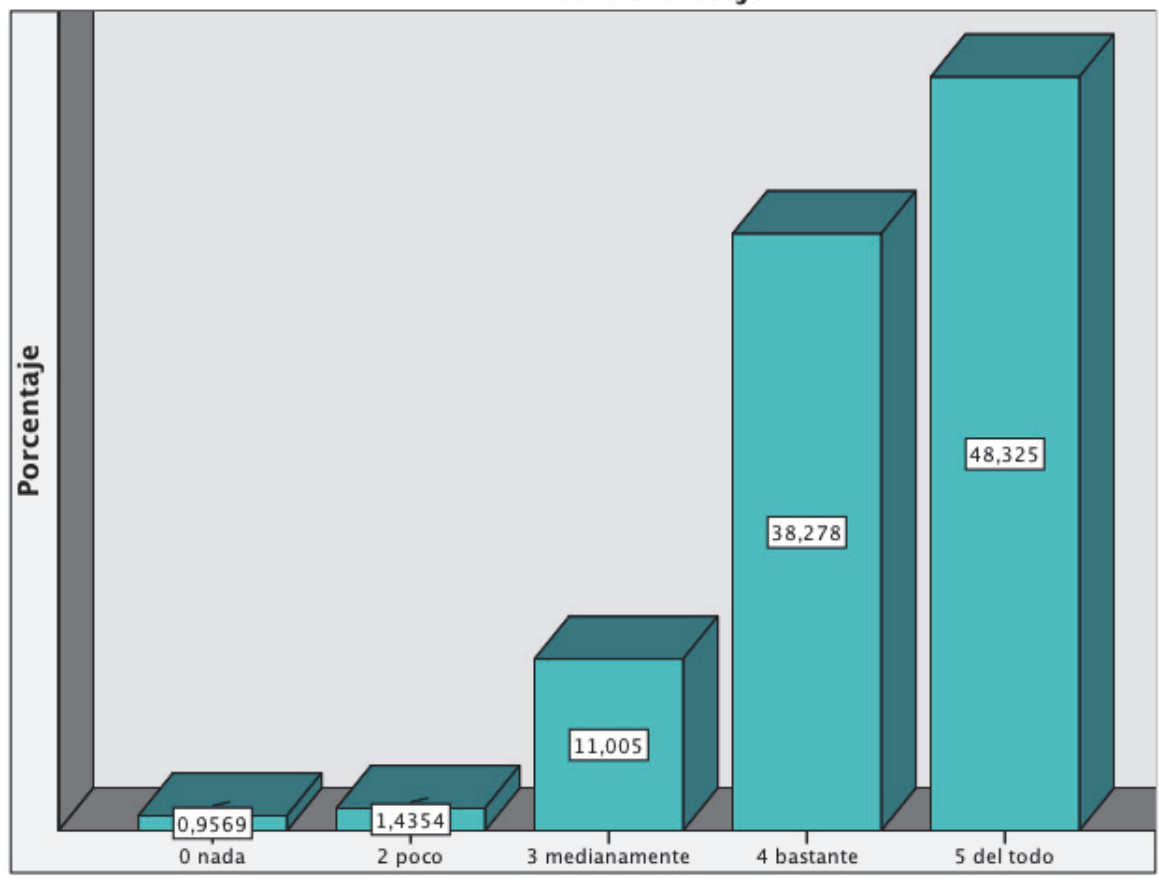

Elaboración propia. Mayo de 2015

Análisis: modelo similar al anterior, con cinco de las seis puntuaciones marcadas, solo falta el 1. El peso recae de forma progresiva en los valores altos. Modelo en escalera ascendente. Valor catalogado como importante.

Nuevamente resultados favorables para nuestra hipótesis. Este valor, junto con el "21. Creer y poner cariño en lo que se hace", están relacionados con la Confianza, metavalor central para la eficiencia y la humanización de la atención a la salud desde nuestros entornos de trabajo. 
Cuadro $n^{0} 1.25$

25. Eficacia, Planificación, Eficiencia

\begin{tabular}{|l|r|r|r|r|}
\hline & Frecuencia & Porcentaje & $\begin{array}{c}\text { Porcentaje } \\
\text { válido }\end{array}$ & $\begin{array}{c}\text { Porcentaje } \\
\text { acumulado }\end{array}$ \\
\hline 1 mínimo & 1 &, 5 &, 5 &, 5 \\
2 poco & 4 & 1,9 & 1,9 & 2,4 \\
3 medianamente & 46 & 22,0 & 22,0 & 24,4 \\
4 bastante & 94 & 45,0 & 45,0 & 69,4 \\
5 del todo & 64 & 30,6 & 30,6 & 100,0 \\
Total & 209 & 100,0 & 100,0 & \\
\hline
\end{tabular}

Elaboración propia. Mayo de 2015

Gráfico $\mathrm{n}^{\mathrm{0}} 1.25$

25. Eficacia, Planificación, Eficiencia

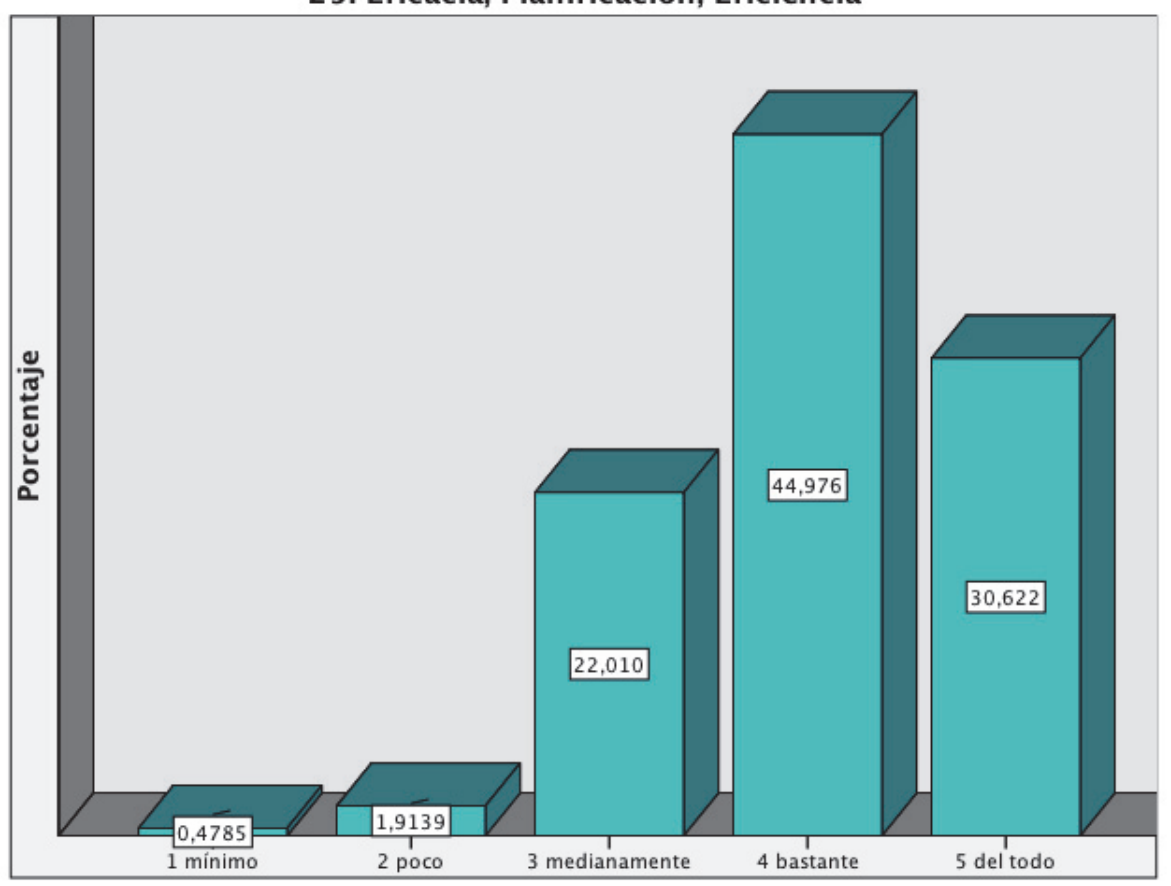

Elaboración propia. Mayo de 2015

Análisis: observamos ausencia del 0 , el 4 y 5 suman más del $75 \%$. La "Eficacia, Planificación, Eficiencia" es catalogada como muy importante en la VP por el muestra en estudio, dato significativo en nuestro trabajo.

Este es el valor "princeps" de nuestro estudio. El alumnado ha captado la importancia que tiene y se pueden esperar muy buenos resultados en la vida laboral de estos profesionales. 
Cuadro $n^{\circ} 1.26$

26. Equidad, justicia en el día a día

\begin{tabular}{|l|r|r|r|r|}
\hline & Frecuencia & Porcentaje & $\begin{array}{c}\text { Porcentaje } \\
\text { válido }\end{array}$ & $\begin{array}{r}\text { Porcentaje } \\
\text { acumulado }\end{array}$ \\
\hline 2 poco & 3 & 1,4 & 1,4 & 1,4 \\
3 medianamente & 29 & 13,9 & 13,9 & 15,3 \\
4 bastante & 81 & 38,8 & 38,8 & 54,1 \\
5 del todo & 96 & 45,9 & 45,9 & 100,0 \\
Total & 209 & 100,0 & 100,0 & \\
\hline
\end{tabular}

Elaboración propia. Mayo de 2015

\section{Gráfico ${ }^{\circ} 1.26$}

26. Equidad, justicia en el día a día

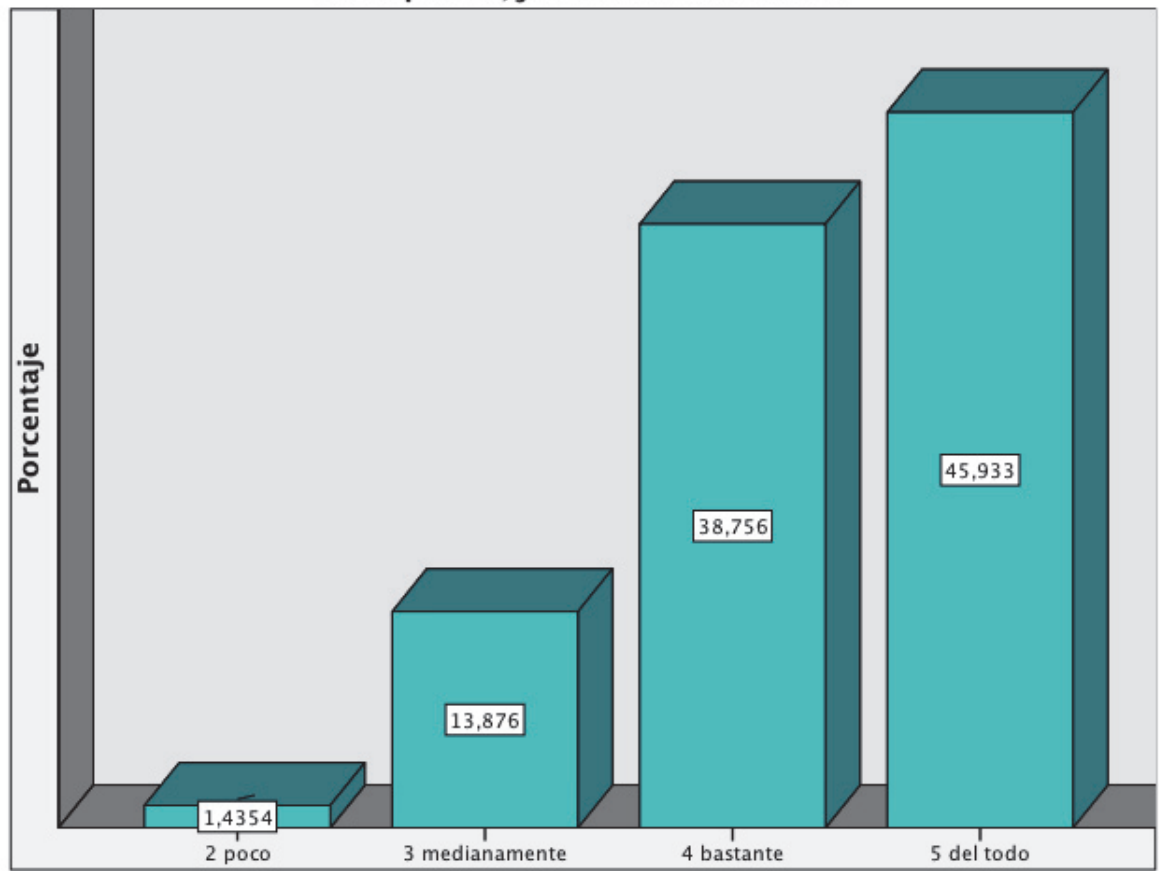

Elaboración propia. Mayo de 2015

Análisis: el 0 y 1 están ausentes, más del 84\% de las puntuaciones están entre el 4 y 5 con predominio del 5. Modelo en escalera ascendente. La "equidad, justicia día a día" se revela como un valor importante en la VP.

Valor relacionado con el Compromiso social. Revela los resultados esperables para una profesión de responsabilidad y compromiso como es enfermería. 
Cuadro $n^{\circ} 1.27$

27. Equilibrio entre el trabajo y vida familiar y personal

\begin{tabular}{|l|r|r|r|r|}
\hline & Frecuencia & Porcentaje & $\begin{array}{c}\text { Porcentaje } \\
\text { válido }\end{array}$ & $\begin{array}{c}\text { Porcentaje } \\
\text { acumulado }\end{array}$ \\
\hline 1 mínimo & 1 &, 5 &, 5 &, 5 \\
2 poco & 3 & 1,4 & 1,4 & 1,9 \\
3 medianamente & 28 & 13,4 & 13,4 & 15,3 \\
4 bastante & 75 & 35,9 & 35,9 & 51,2 \\
5 del todo & 102 & 48,8 & 48,8 & 100,0 \\
Total & 209 & 100,0 & 100,0 & \\
\hline
\end{tabular}

Elaboración propia. Mayo de 2015

Gráfico $\mathrm{n}^{\mathrm{0}} 1.27$

27. Equilibrio entre el trabajo y vida familiar y personal

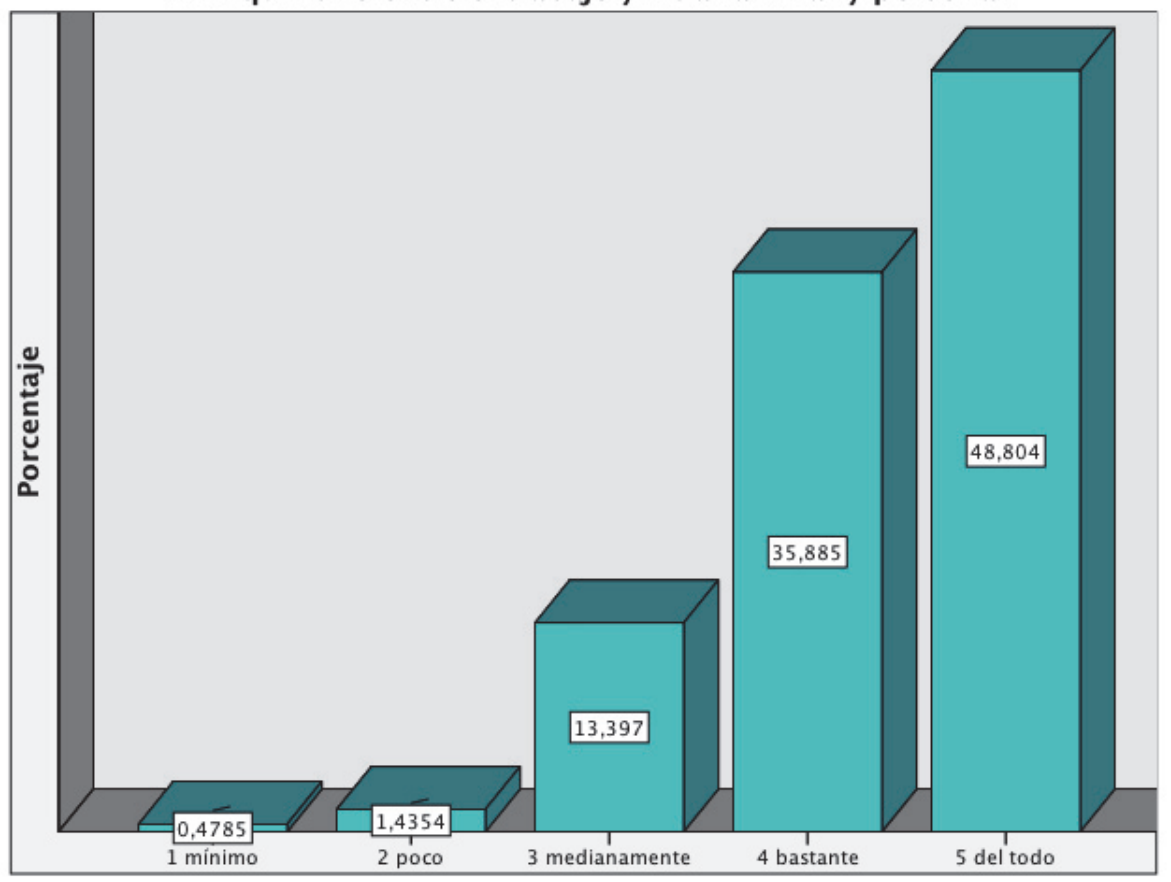

Elaboración propia. Mayo de 2015

Análisis: al igual que el anterior, el valor "equilibrio entre el trabajo y vida familiar y personal" sigue un modelo de escalera ascendente con casi el 50\% de las puntuaciones para el 5. Valor considerado importante.

En una profesión tan feminizada como enfermería, no se podía prever otros resultados para este valor. En el ME de C se habla de cuidar del equilibrio como fuente del bienestar. 
Cuadro $n^{\circ} 1.28$

28. Éxito económico

\begin{tabular}{|l|r|r|r|r|}
\hline & Frecuencia & Porcentaje & $\begin{array}{c}\text { Porcentaje } \\
\text { válido }\end{array}$ & $\begin{array}{r}\text { Porcentaje } \\
\text { acumulado }\end{array}$ \\
\hline 0 nada & 5 & 2,4 & 2,4 & 2,4 \\
1 mínimo & 5 & 2,4 & 2,4 & 4,8 \\
2 poco & 12 & 5,7 & 5,7 & 10,5 \\
3 medianamente & 68 & 32,5 & 32,5 & 43,1 \\
4 bastante & 87 & 41,6 & 41,6 & 84,7 \\
5 del todo & 32 & 15,3 & 15,3 & 100,0 \\
Total & 209 & 100,0 & 100,0 & \\
\hline
\end{tabular}

Elaboración propia. Mayo de 2015

Gráfico $\mathrm{n}^{\mathrm{0}} 1.28$

28. Éxito económico

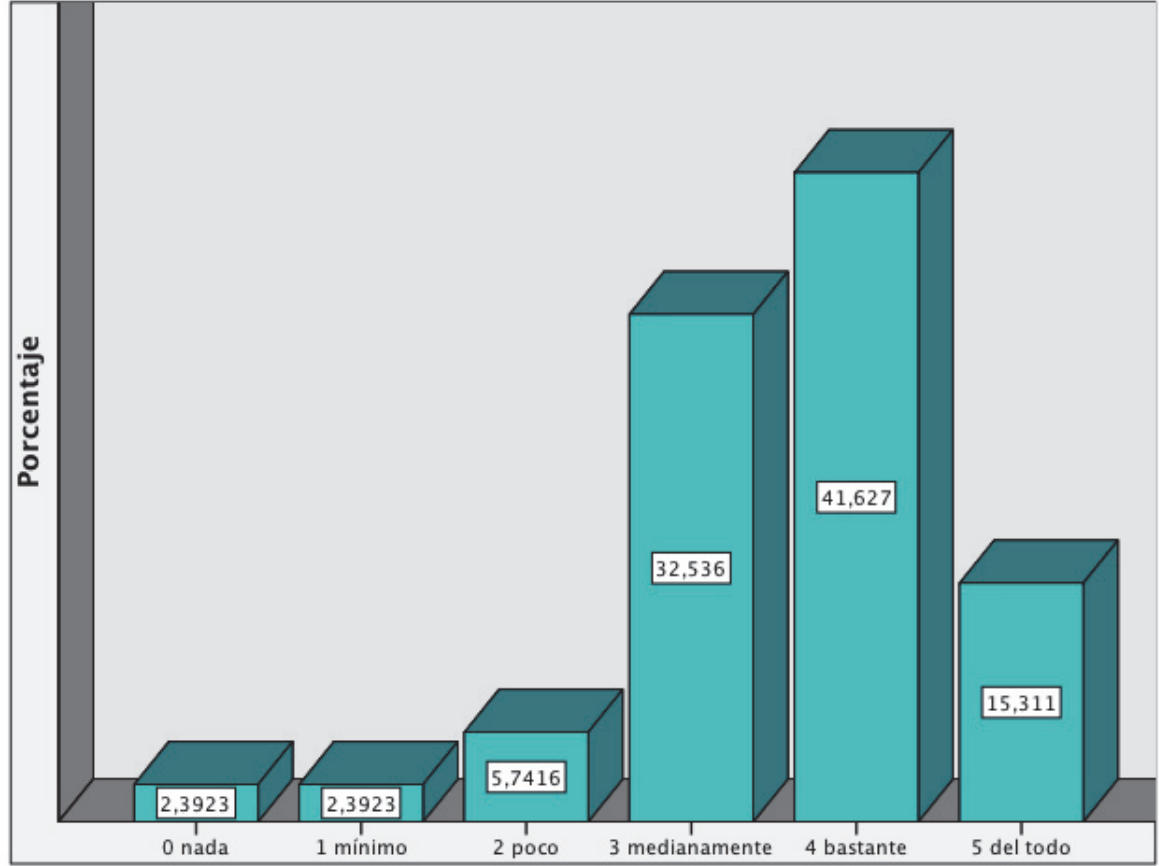

Elaboración propia. Mayo de 2015

Análisis: el valor "éxito económico" aparece puntuado desde el 0 hasta el 5. Para algo más del $2 \%$ es nada importante o mínimo, y del todo tan solo para algo más del 15\%. La mayor parte del peso recae sobre las puntuaciones centrales. Modelo en pirámide. Moderadamente considerado en la VP.

Enfermería, siendo una profesión de vocación y compromiso social, a la que tradicionalmente se le ha pedido sacrificio y renuncia, arroja resultados coherentes pues valora el éxito económico como moderadamente importante. 
Cuadro $n^{\circ} 1.29$

29. Éxito familiar

\begin{tabular}{|l|r|r|r|r|}
\hline & Frecuencia & Porcentaje & $\begin{array}{c}\text { Porcentaje } \\
\text { válido }\end{array}$ & $\begin{array}{r}\text { Porcentaje } \\
\text { acumulado }\end{array}$ \\
\hline 2 poco & 7 & 3,3 & 3,3 & 3,3 \\
3 medianamente & 17 & 8,1 & 8,1 & 11,5 \\
4 bastante & 57 & 27,3 & 27,3 & 38,8 \\
5 del todo & 128 & 61,2 & 61,2 & 100,0 \\
Total & 209 & 100,0 & 100,0 & \\
\hline
\end{tabular}

Elaboración propia. Mayo de 2015

Gráfico ${ }^{\circ} 1.29$

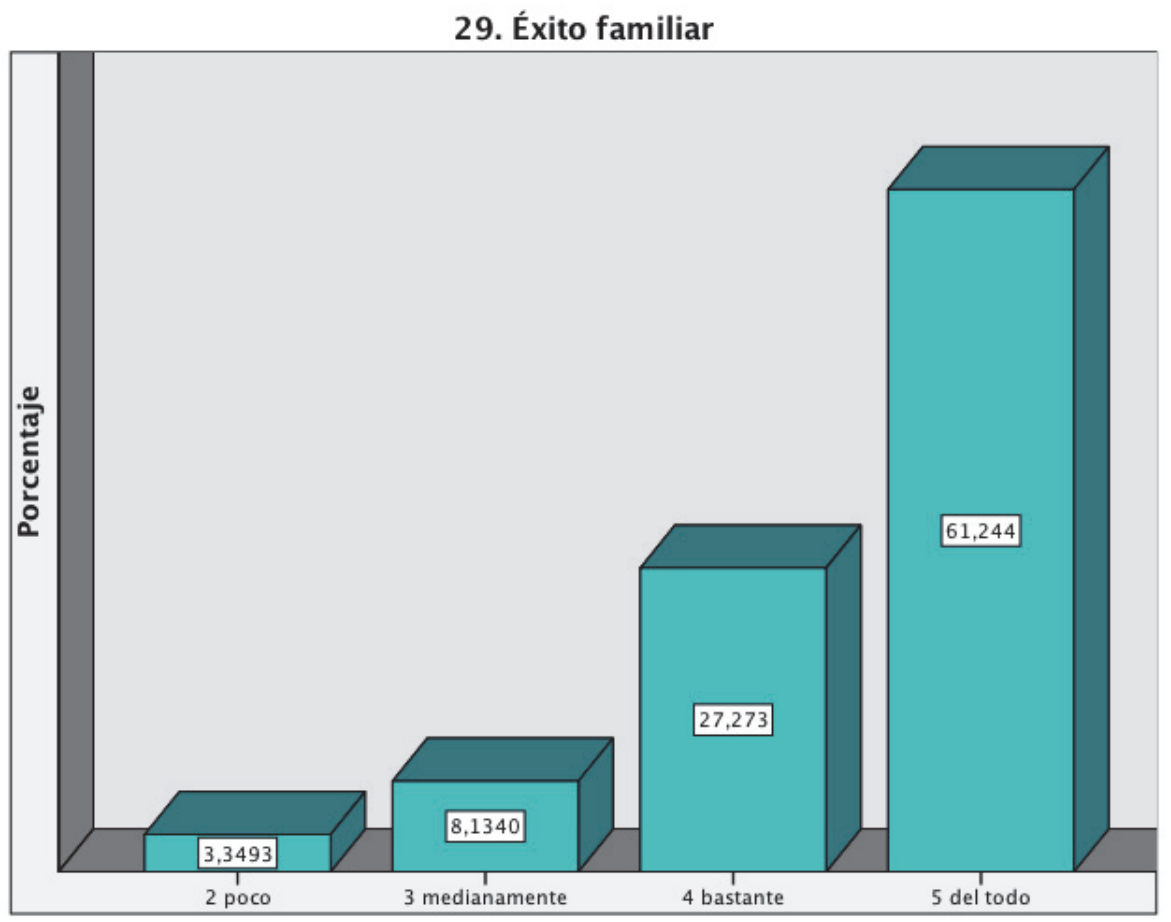

Elaboración propia. Mayo de 2015

Análisis: el "éxito familiar" muestra un modelo en escalera ascendente con más del $60 \%$ para el 5 , sumando el 4 y 5 casi el 90\%. Lo podemos considerar como muy importante a nivel de la VP.

Resultado coherente en una profesión tan feminizada. A su vez, el valor “éxito familiar" se relaciona indefectiblemente con el valor "humanización” que Espinoso de Compludo persigue para una mejor atención a la salud en el entorno de trabajo de enfermería. 
Cuadro $n^{\circ} 1.30$

30. Expresividad/libertad

\begin{tabular}{|l|r|r|r|r|}
\hline & Frecuencia & Porcentaje & $\begin{array}{l}\text { Porcentaje } \\
\text { válido }\end{array}$ & $\begin{array}{c}\text { Porcentaje } \\
\text { acumulado }\end{array}$ \\
\hline 2 poco & 1 &, 5 &, 5 &, 5 \\
3 medianamente & 28 & 13,4 & 13,4 & 13,9 \\
4 bastante & 71 & 34,0 & 34,0 & 47,8 \\
5 del todo & 109 & 52,2 & 52,2 & 100,0 \\
Total & 209 & 100,0 & 100,0 & \\
\hline
\end{tabular}

Elaboración propia. Mayo de 2015

Gráfico $n^{\circ} 1.30$

30. Expresividad/libertad

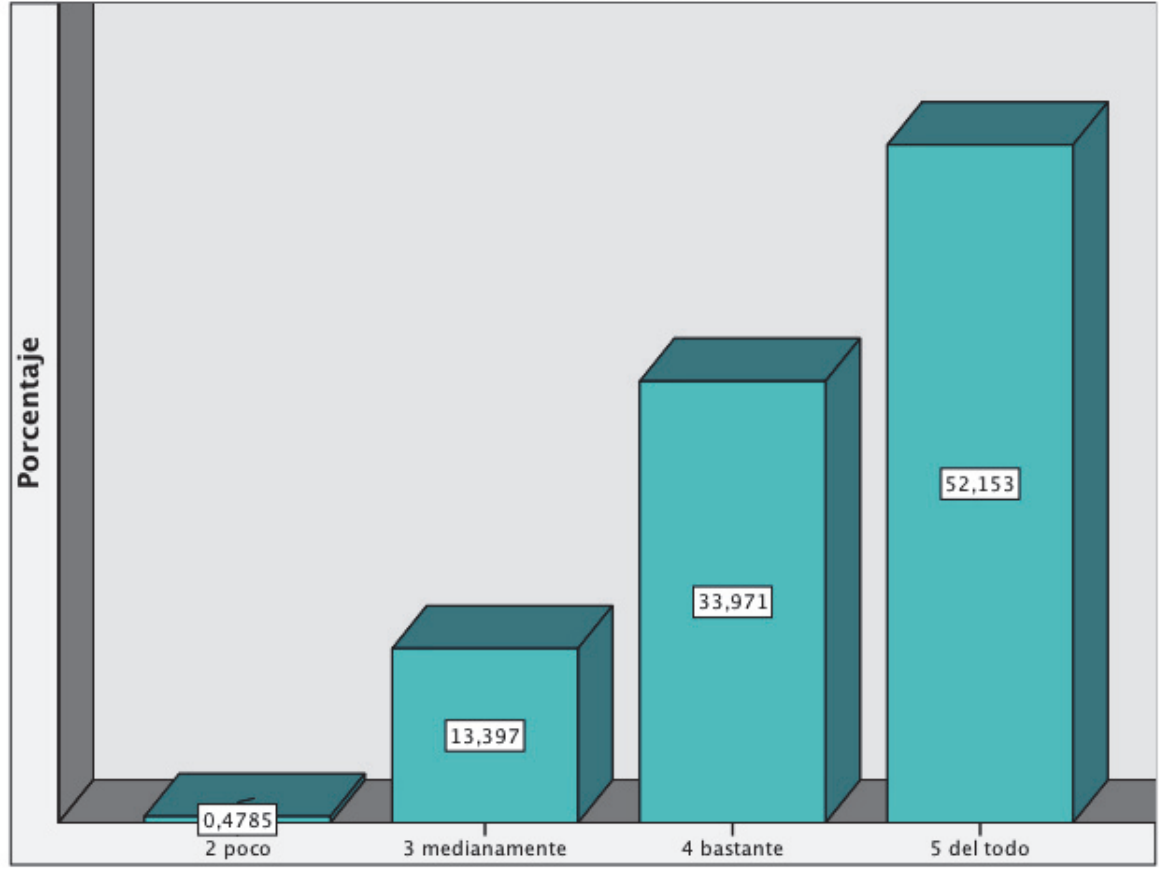

Elaboración propia. Mayo de 2015

Análisis: el valor "expresividad/libertad" sigue un modelo de escalera ascendente con más del $50 \%$ para el 5 y más del $85 \%$ para el 4 y 5 . Valor importante.

El alumnado de enfermería ha sabido captar la importancia de este valor que es básico dentro del Compromiso Social y el Respeto, Dignidad y Autonomía de las personas. Con acierto, la muestra encuestada lo puntúa como importante. 
Cuadro $n^{\circ} 1.31$

31. Felicidad (búsqueda de la )

\begin{tabular}{|rl|r|r|r|r|}
\hline & Frecuencia & Porcentaje & $\begin{array}{r}\text { Porcentaje } \\
\text { válido }\end{array}$ & $\begin{array}{r}\text { Porcentaje } \\
\text { acumulado }\end{array}$ \\
\hline \multirow{4}{*}{ Válidos } & & 15 & 7,2 & 7,2 & 7,2 \\
& 3 medianamente & 28 & 13,4 & 13,4 & 20,6 \\
& 4 bastante & 166 & 79,4 & 79,4 & 100,0 \\
& 5 del todo & 209 & 100,0 & 100,0 & \\
\hline
\end{tabular}

Elaboración propia. Mayo de 2015

\section{Gráfico $n^{\circ} 1.31$}

31. Felicidad (búsqueda de la )

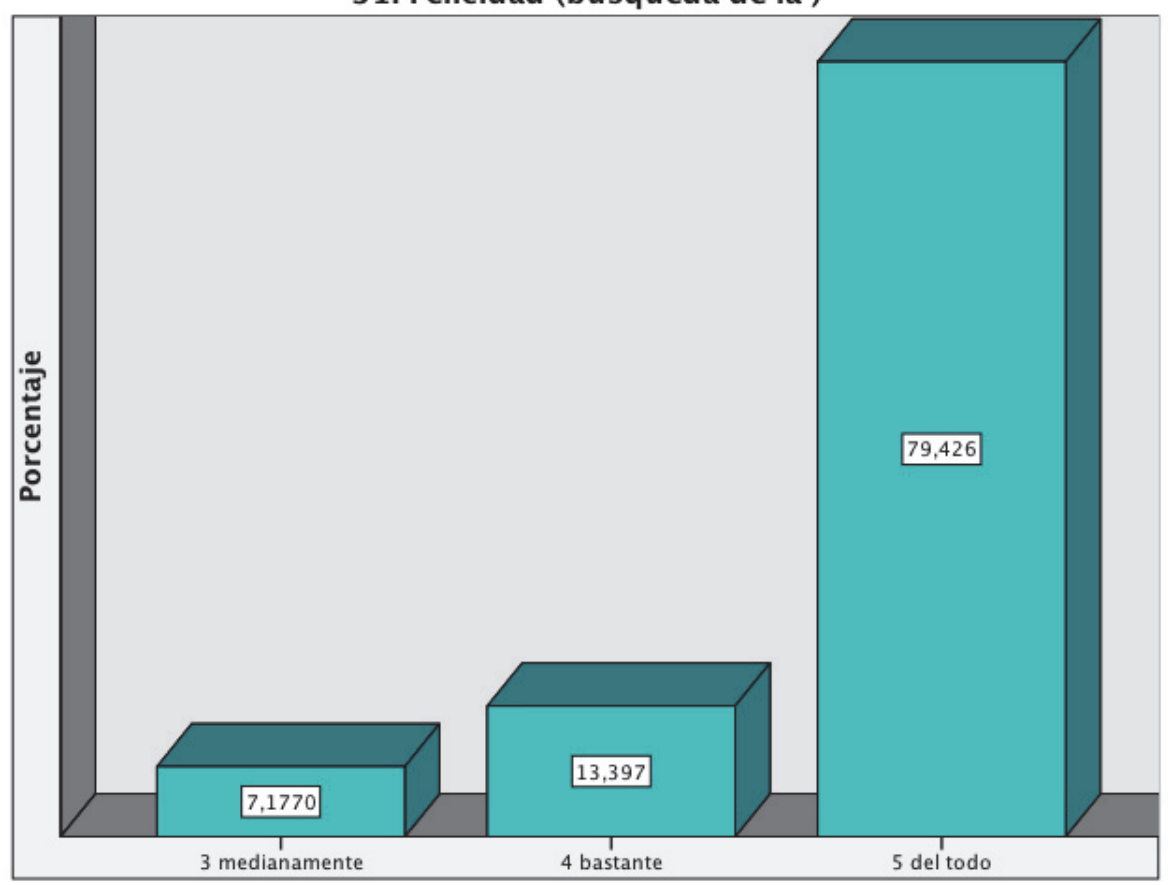

Elaboración propia. Mayo de 2015

Análisis: "la búsqueda de la felicidad" muestra ausencia de las puntuaciones 0,1 y 2; llegando casi al $80 \%$ el 5 . Claramente es considerado muy importante.

"La búsqueda de la felicidad" para sí mismo y para los demás debe ser un objetivo para profesionales al cuidado de la salud y de la vida; pues ambas, salud y vida, se relacionan intrínsecamente con la felicidad que no puede ser plena si falta alguna de aquellas. 
Cuadro $n^{\circ} 1.32$

32. Honestidad, honradez, transparencia, sinceridad

\begin{tabular}{|l|r|r|r|r|}
\hline & Frecuencia & Porcentaje & $\begin{array}{c}\text { Porcentaje } \\
\text { válido }\end{array}$ & $\begin{array}{r}\text { Porcentaje } \\
\text { acumulado }\end{array}$ \\
\hline 2 poco & 2 & 1,0 & 1,0 & 1,0 \\
3 medianamente & 15 & 7,2 & 7,2 & 8,1 \\
4 bastante & 69 & 33,0 & 33,0 & 41,1 \\
5 del todo & 123 & 58,9 & 58,9 & 100,0 \\
Total & 209 & 100,0 & 100,0 & \\
\hline
\end{tabular}

Elaboración propia. Mayo de 2015

\section{Gráfico $n^{\circ} 1.32$}

\section{Honestidad, honradez, transparencia, sinceridad}

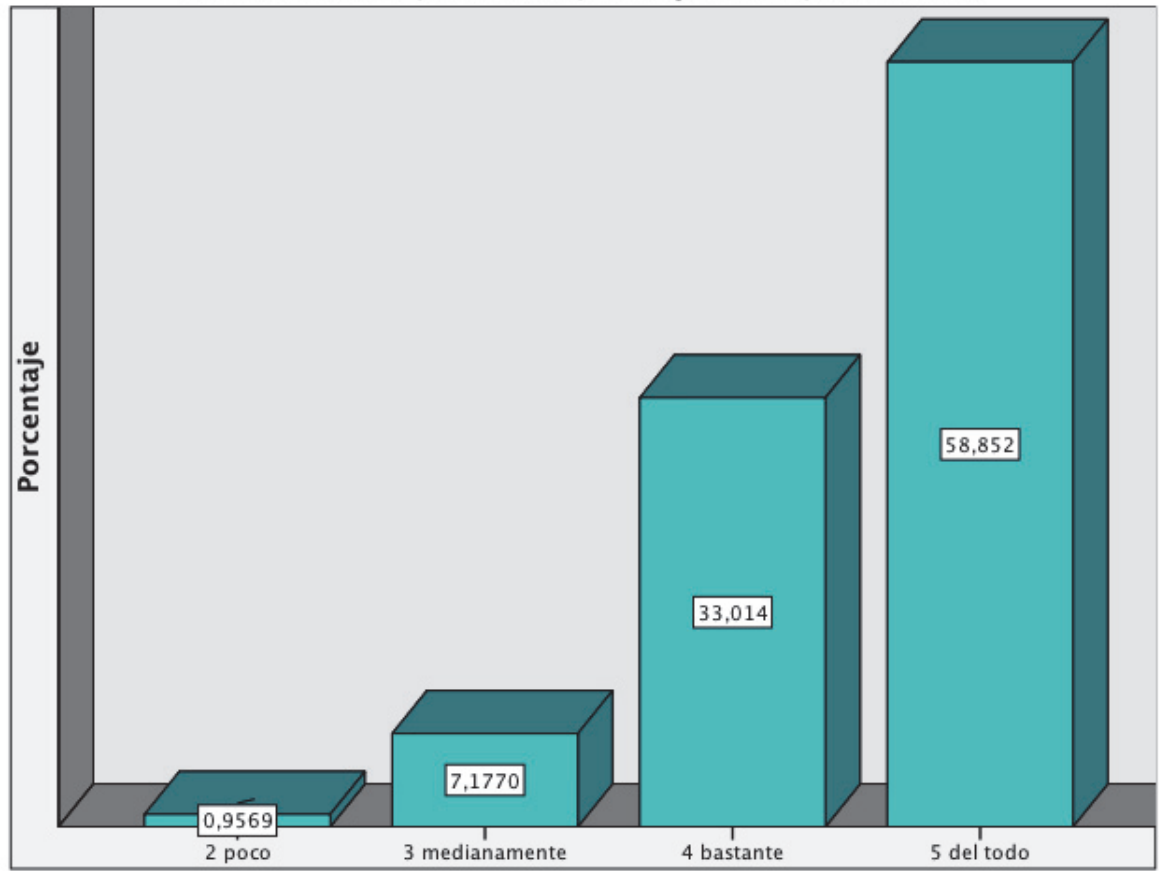

Elaboración propia. Mayo de 2015

Análisis: el valor "honestidad, honradez, transparencia, sinceridad" revela claramente su importancia para la muestra en estudio a través de un modelo en escalera ascendente en el que el 0 y 2 no aparecen y el 5 concentra cerca del $60 \%$.

En este valor, fundamental dentro de lo que es el Compromiso social, observamos unos resultados acordes a la docencia dada. Nos hacen intuir que alcanzaremos favorablemente nuestra hipótesis. 
Cuadro $n^{\circ} 1.33$

33. Humildad, modestia

\begin{tabular}{|l|r|r|r|r|}
\hline & Frecuencia & Porcentaje & $\begin{array}{c}\text { Porcentaje } \\
\text { válido }\end{array}$ & $\begin{array}{c}\text { Porcentaje } \\
\text { acumulado }\end{array}$ \\
\hline 0 nada & 1 &, 5 &, 5 &, 5 \\
2 poco & 2 & 1,0 & 1,0 & 1,4 \\
3 medianamente & 29 & 13,9 & 13,9 & 15,3 \\
4 bastante & 87 & 41,6 & 41,6 & 56,9 \\
5 del todo & 90 & 43,1 & 43,1 & 100,0 \\
Total & 209 & 100,0 & 100,0 & \\
\hline
\end{tabular}

Elaboración propia. Mayo de 2015

Gráfico $\mathrm{n}^{\mathrm{0}} 1.33$

33. Humildad, modestia

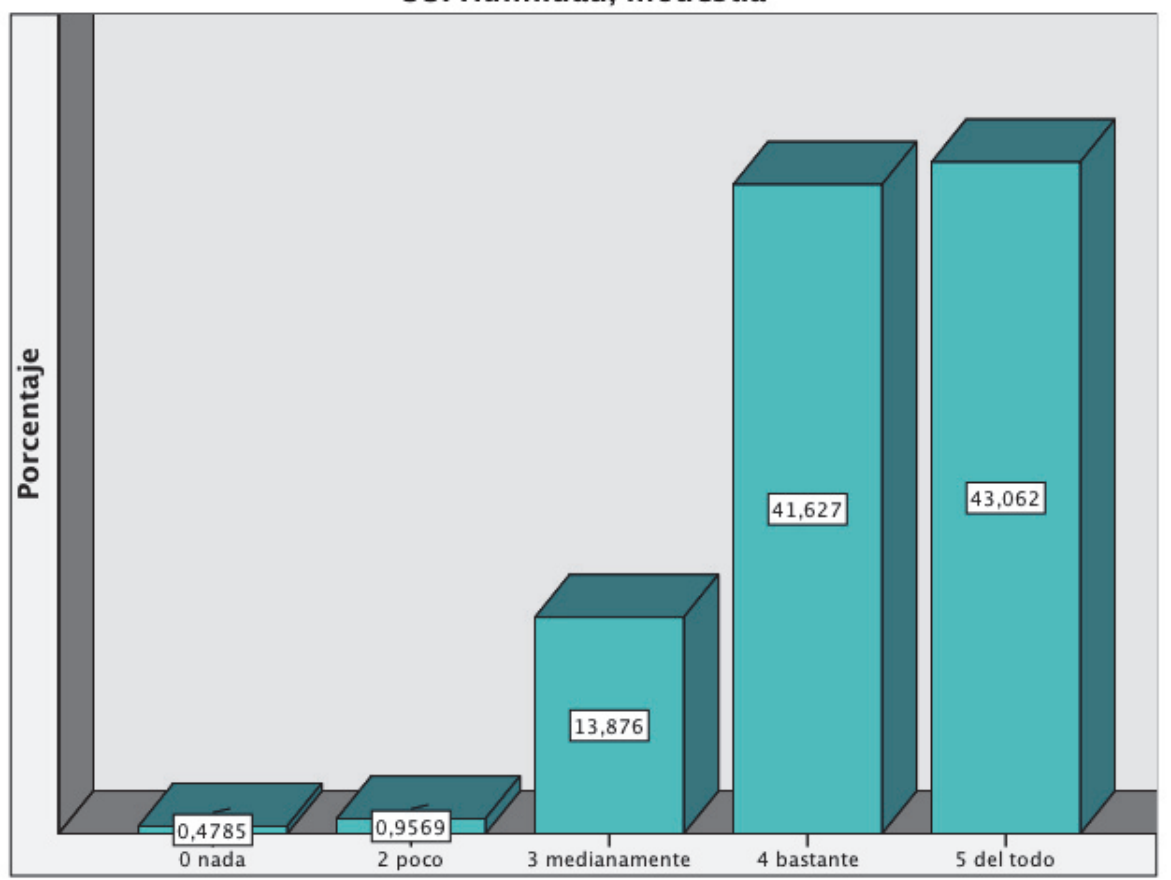

Elaboración propia. Mayo de 2015

Análisis: la "humildad, modestia" también se muestra importante a través de un modelo en escalera ascendente, sin embargo hay que hacer notar que el 0 sí ha sido marcado, no aparece el 1 y la mayor parte de las puntuaciones se reparten de forma equitativa entre el 4 y 5.

Resultados coherentes en una profesión tradicionalmente feminizada y que ha estado tan marcada, en tiempos pasados, por las enseñanzas de la religión para la mujer. 
Cuadro $n^{0} 1.34$

34. Idealismo

\begin{tabular}{|l|r|r|r|r|}
\hline & Frecuencia & Porcentaje & $\begin{array}{c}\text { Porcentaje } \\
\text { válido }\end{array}$ & $\begin{array}{r}\text { Porcentaje } \\
\text { acumulado }\end{array}$ \\
\hline 0 nada & 2 & 1,0 & 1,0 & 1,0 \\
1 mínimo & 5 & 2,4 & 2,4 & 3,3 \\
2 poco & 8 & 3,8 & 3,8 & 7,2 \\
3 medianamente & 76 & 36,4 & 36,4 & 43,5 \\
4 bastante & 73 & 34,9 & 34,9 & 78,5 \\
5 del todo & 45 & 21,5 & 21,5 & 100,0 \\
Total & 209 & 100,0 & 100,0 & \\
\hline
\end{tabular}

Elaboración propia. Mayo de 2015

Gráfico $n^{\circ} 1.34$

34. Idealismo

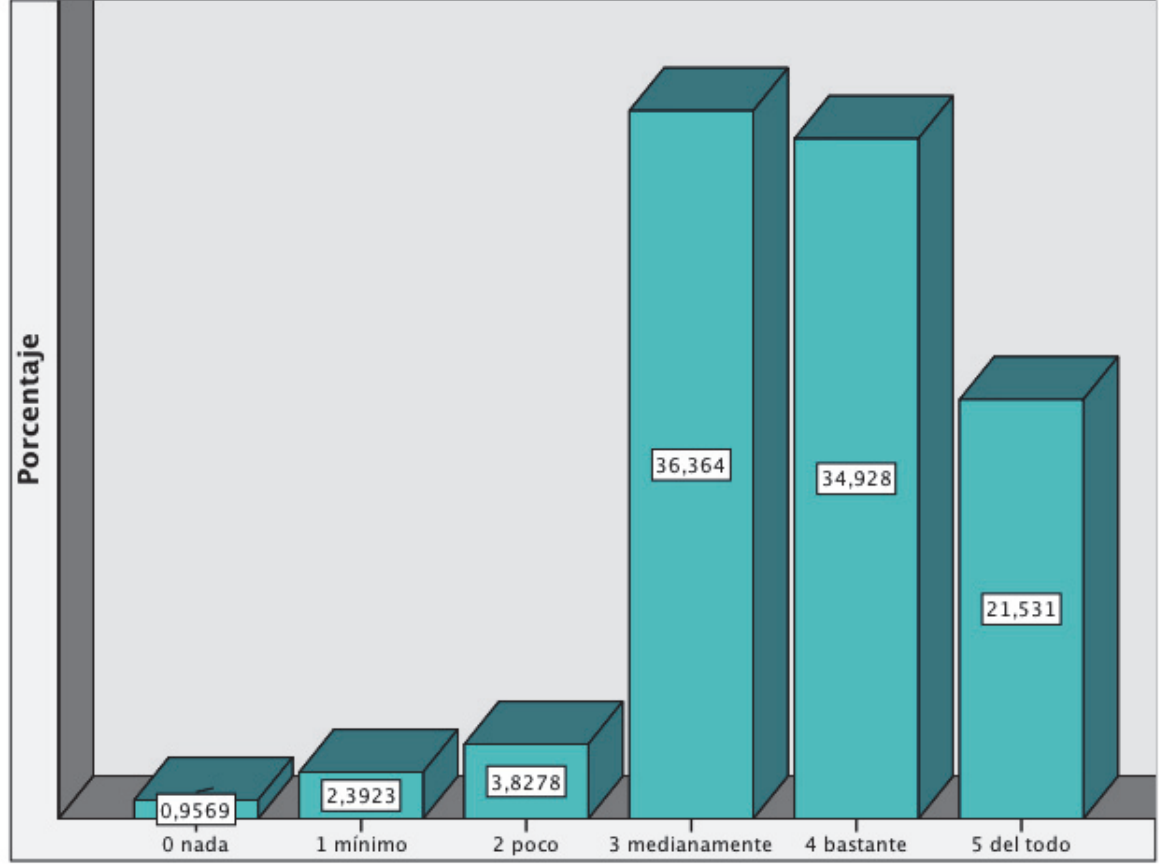

Elaboración propia. Mayo de 2015

Análisis: el "idealismo" ha sido puntuado desde el 0 hasta el 5. Concentrándose la mayor parte en los valores centrales. Modelo en pirámide. Lo consideramos moderadamente importante para la muestra en estudio.

Resultado coherente con el perfil de enfermería en la que la vocación por un lado y la praxis por otro, son ambas fundamentales. 
Cuadro $\mathrm{n}^{\mathrm{o}} 1.35$

35. Igualdad/Liberación

\begin{tabular}{|l|r|r|r|r|}
\hline & Frecuencia & Porcentaje & $\begin{array}{c}\text { Porcentaje } \\
\text { válido }\end{array}$ & \multicolumn{1}{|c|}{$\begin{array}{c}\text { Porcentaje } \\
\text { acumulado }\end{array}$} \\
\hline 1 mínimo & 1 &, 5 &, 5 &, 5 \\
3 medianamente & 30 & 14,4 & 14,4 & 14,8 \\
4 bastante & 95 & 45,5 & 45,5 & 60,3 \\
5 del todo & 83 & 39,7 & 39,7 & 100,0 \\
Total & 209 & 100,0 & 100,0 & \\
\hline
\end{tabular}

Elaboración propia. Mayo de 2015

Gráfico $\mathrm{n}^{\mathrm{o}} 1.35$

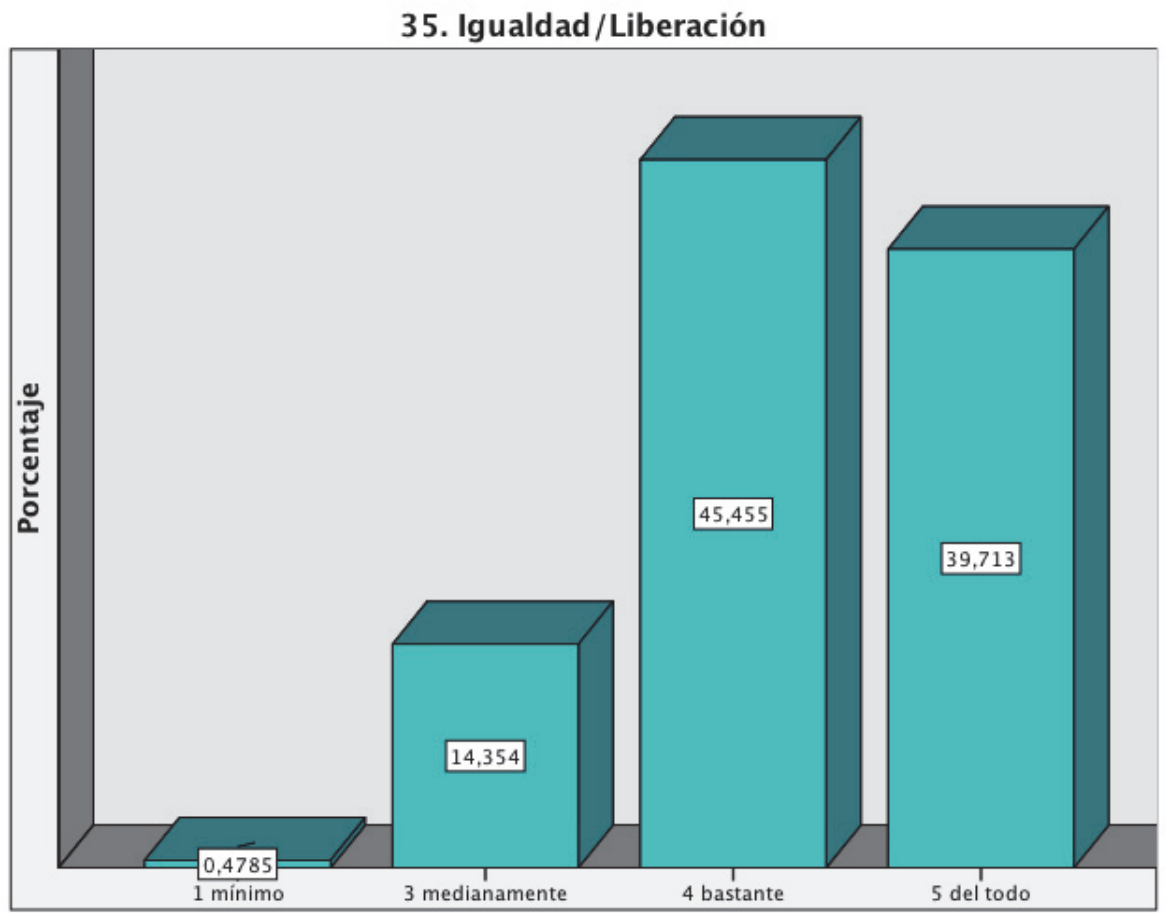

Elaboración propia. Mayo de 2015

Análisis: en la "igualdad/liberación" no aparecen el 0 ni el 2, cayendo la mayor parte del peso entre el 4 y 5 de forma bastante parecida. Lo consideramos como importante. Modelo en escalera asimétrica con sesgo a la derecha.

Valor propio de la enfermería por cuanto el enfermo debe recibir el mejor tratamiento siempre, independientemente de su origen social. Sería una gravísima falta de ética tratar a unos mejor o peor que a otros. 
Cuadro $n^{\circ} 1.36$

36. Imagen, prestigio social

\begin{tabular}{|l|r|r|r|r|}
\hline & Frecuencia & Porcentaje & $\begin{array}{c}\text { Porcentaje } \\
\text { válido }\end{array}$ & $\begin{array}{r}\text { Porcentaje } \\
\text { acumulado }\end{array}$ \\
\hline 0 nada & 2 & 1,0 & 1,0 & 1,0 \\
mínimo & 6 & 2,9 & 2,9 & 3,8 \\
poco & 19 & 9,1 & 9,1 & 12,9 \\
3 medianamente & 56 & 26,8 & 26,8 & 39,7 \\
4 bastante & 80 & 38,3 & 38,3 & 78,0 \\
5 del todo & 46 & 22,0 & 22,0 & 100,0 \\
Total & 209 & 100,0 & 100,0 & \\
\hline
\end{tabular}

Elaboración propia. Mayo de 2015

Gráfico $\mathrm{n}^{\mathrm{o}} 1.36$

36. Imagen, presigio social

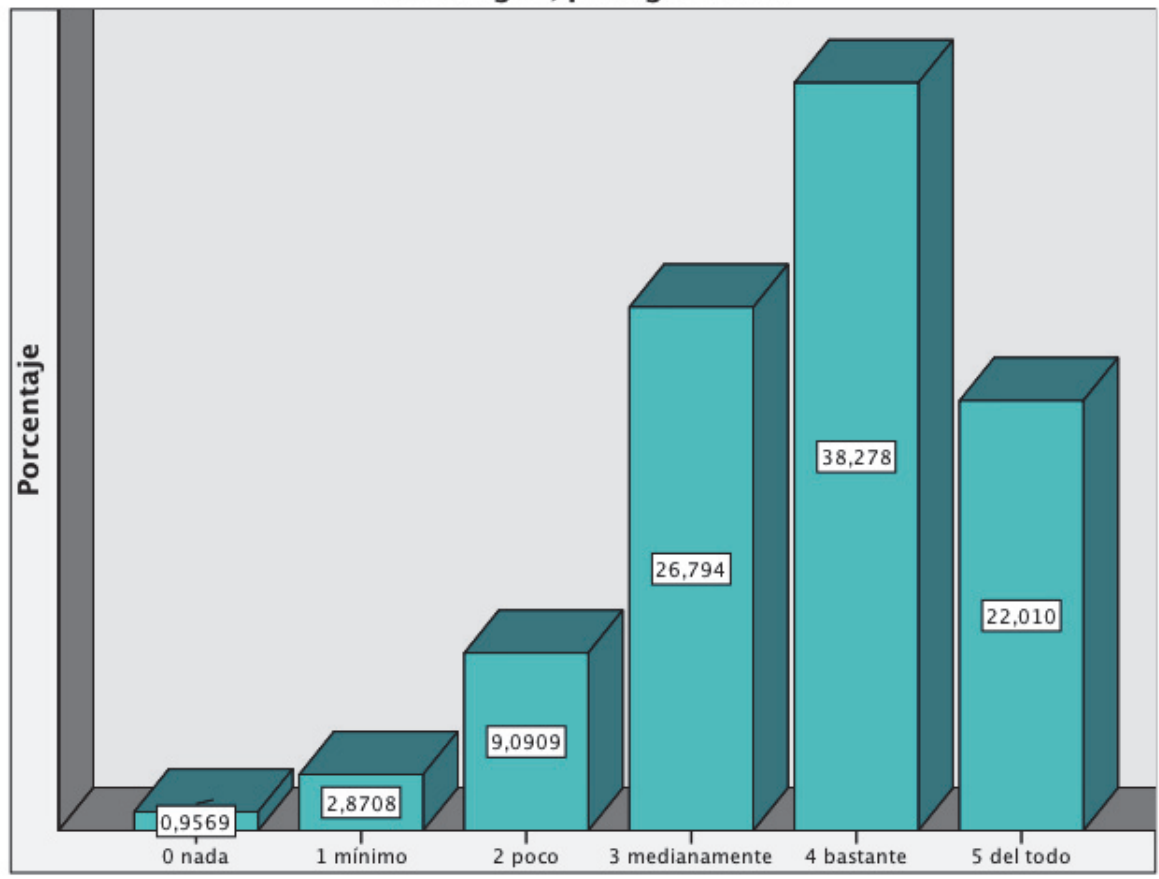

Elaboración propia. Mayo de 2015

Análisis: observamos un modelo en pirámide cayendo el peso sobre todo en el 3 y 4. El valor "imagen, prestigio social" es moderadamente importante para la muestra en estudio en el área de VP.

Este ítem, el 13. Competitividad, ambición y el 50. Productividad, resultados comparten características tradicionalmente masculinas y observamos que arrojan resultados similares. Son resultados acordes en la VP para una profesión feminizada, y en el ME en cuanto a que la gestión y dirección de empresas sigue en manos masculinas. 
Cuadro $n^{\circ} 1.37$

37. Imaginación, creatividad, fantasía

\begin{tabular}{|l|r|r|r|r|}
\hline & Frecuencia & Porcentaje & $\begin{array}{c}\text { Porcentaje } \\
\text { válido }\end{array}$ & $\begin{array}{c}\text { Porcentaje } \\
\text { acumulado }\end{array}$ \\
\hline 0 nada & 1 &, 5 &, 5 &, 5 \\
1 mínimo & 3 & 1,4 & 1,4 & 1,9 \\
2 poco & 11 & 5,3 & 5,3 & 7,2 \\
3 medianamente & 53 & 25,4 & 25,4 & 32,5 \\
4 bastante & 79 & 37,8 & 37,8 & 70,3 \\
5 del todo & 62 & 29,7 & 29,7 & 100,0 \\
Total & 209 & 100,0 & 100,0 & \\
\hline
\end{tabular}

Elaboración propia. Mayo de 2015

Gráfico ${ }^{\circ} 1.37$

37. Imaginación, creatividad, fantasia

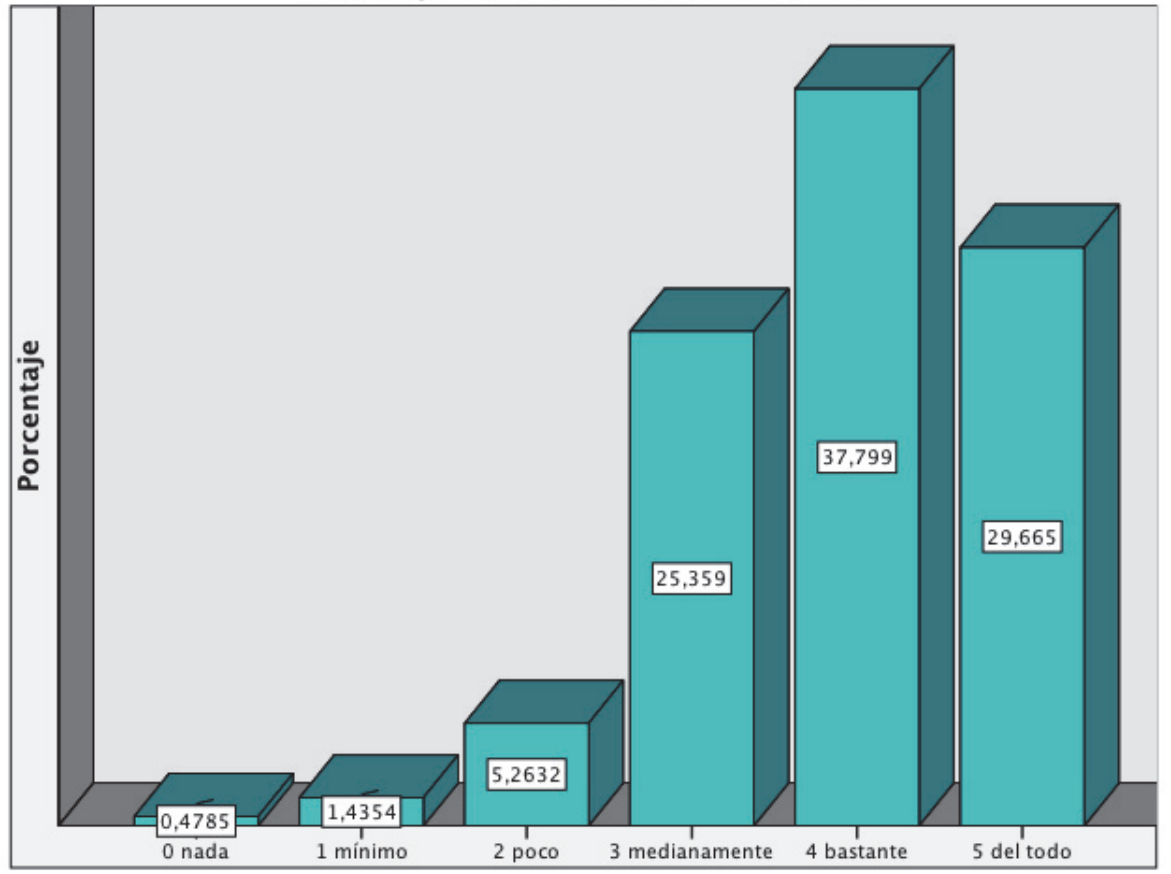

Elaboración propia. Mayo de 2015

Análisis: observamos que todas las puntuaciones están presentes. El mayor peso recae sobre el 4 y 5 con predominio del 4 . Modelo en pirámide asimétrica con sesgo a la derecha. Valor puntuado como importante.

Nos hace esperar un resultado favorable a nuestra tesis pues este valor en alza permite innovación, cosa que necesita toda profesión, y más la enfermería que ha estado tan oprimida. En el ME de $\mathrm{C}$ se habla expresamente de la creatividad. 
Cuadro $n^{\circ} 1.38$

38. Inconformismo, rebeldía ante la injusticia social

\begin{tabular}{|l|r|r|r|r|}
\hline & Frecuencia & Porcentaje & $\begin{array}{c}\text { Porcentaje } \\
\text { válido }\end{array}$ & $\begin{array}{r}\text { Porcentaje } \\
\text { acumulado }\end{array}$ \\
\hline 0 nada & 5 & 2,4 & 2,4 & 2,4 \\
1 mínimo & 4 & 1,9 & 1,9 & 4,3 \\
2 poco & 18 & 8,6 & 8,6 & 12,9 \\
3 medianamente & 50 & 23,9 & 23,9 & 36,8 \\
4 bastante & 62 & 29,7 & 29,7 & 66,5 \\
5 del todo & 70 & 33,5 & 33,5 & 100,0 \\
Total & 209 & 100,0 & 100,0 & \\
\hline
\end{tabular}

Elaboración propia. Mayo de 2015

Gráfico $n^{\circ} 1.38$

38. Inconformismo, rebeldía ante la injusticia social

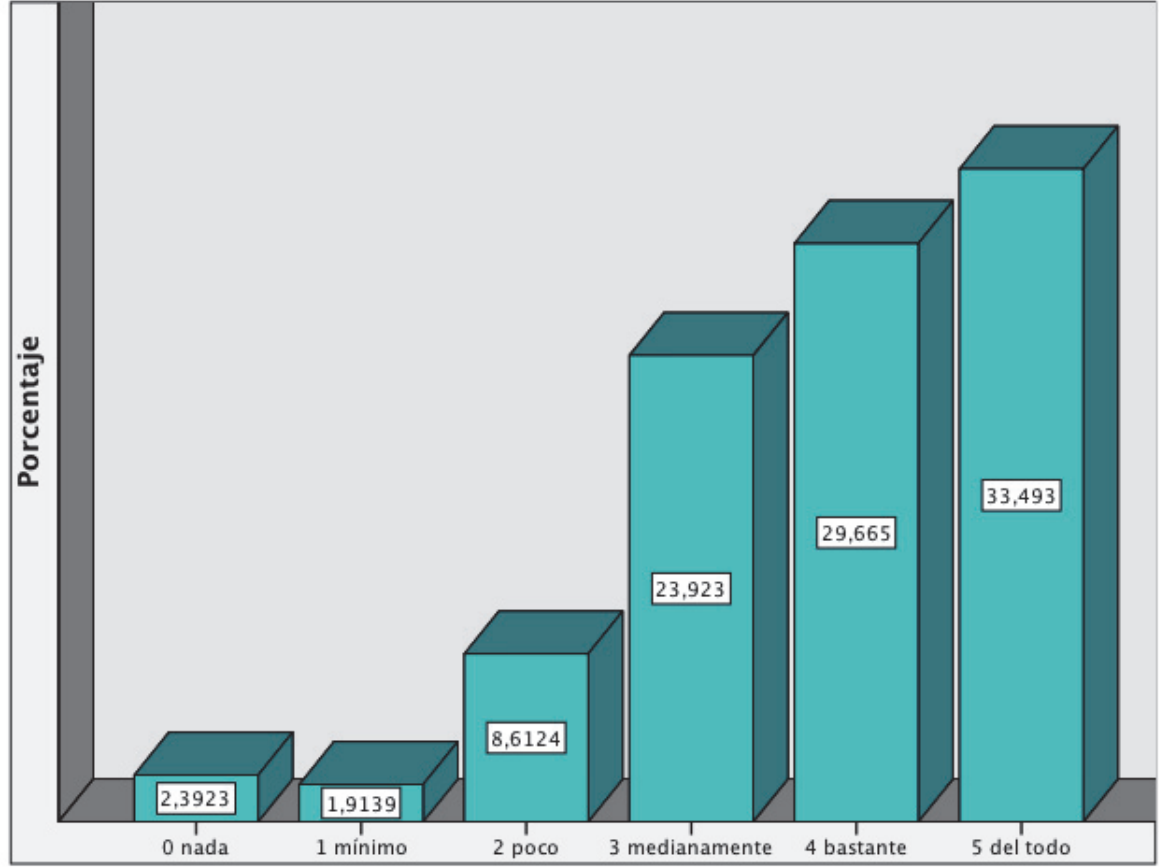

Elaboración propia. Mayo de 2015

Análisis: gráfico que recorre todas las puntuaciones y presenta un modelo de escalera ascendente. El valor "inconformismo, rebeldía ante la injusticia" es puntuado como importante.

Valor íntimamente relacionado con el Compromiso social, primero de los valores de Espinoso de Compludo. Su puntuación como importante está a favor de nuestra hipótesis. 
Cuadro $n^{\circ} 1.39$

39. Independencia, iniciativa, autonomía de acción

\begin{tabular}{|l|r|r|r|r|}
\hline & Frecuencia & Porcentaje & $\begin{array}{c}\text { Porcentaje } \\
\text { válido }\end{array}$ & $\begin{array}{c}\text { Porcentaje } \\
\text { acumulado }\end{array}$ \\
\hline 1 mínimo & 1 &, 5 &, 5 &, 5 \\
2 poco & 8 & 3,8 & 3,8 & 4,3 \\
3 medianamente & 27 & 12,9 & 12,9 & 17,2 \\
4 bastante & 65 & 31,1 & 31,1 & 48,3 \\
5 del todo & 108 & 51,7 & 51,7 & 100,0 \\
Total & 209 & 100,0 & 100,0 & \\
\hline
\end{tabular}

Elaboración propia. Mayo de 2015

Gráfico ${ }^{\circ} 1.39$

39. Independencia, iniciativa, autonomía de acción

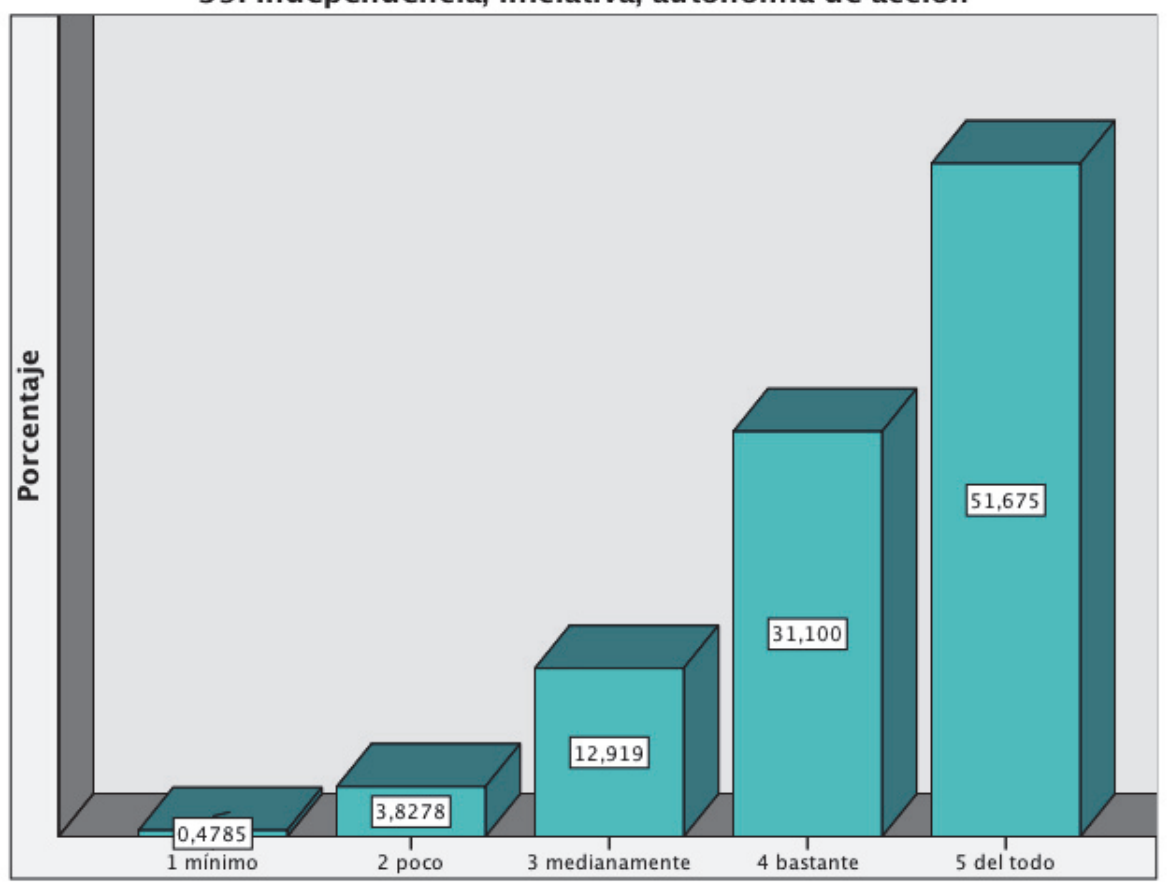

Elaboración propia. Mayo de 2015

Análisis: gráfico en escalera ascendente con más del 50\% para el 5. La “independencia, iniciativa, autonomía de acción” es un valor puntuado como importante.

Valor clave en una profesión, que al margen de acatar órdenes médicas, debe liderar la organización del servicio y los cuidados prestados al paciente. Y la autonomía del enfermo es uno de los objetivos de enfermería recogido en el ME de C. 
Cuadro ${ }^{\circ} 1.40$

40. Influencia, poder social (búsqueda de)

\begin{tabular}{|l|r|r|r|r|}
\hline & Frecuencia & Porcentaje & $\begin{array}{c}\text { Porcentaje } \\
\text { válido }\end{array}$ & $\begin{array}{r}\text { Porcentaje } \\
\text { acumulado }\end{array}$ \\
\hline 0 nada & 5 & 2,4 & 2,4 & 2,4 \\
1 mínimo & 9 & 4,3 & 4,3 & 6,7 \\
2 poco & 29 & 13,9 & 13,9 & 20,6 \\
3 medianamente & 92 & 44,0 & 44,0 & 64,6 \\
4 bastante & 51 & 24,4 & 24,4 & 89,0 \\
5 del todo & 23 & 11,0 & 11,0 & 100,0 \\
Total & 209 & 100,0 & 100,0 & \\
\hline
\end{tabular}

Elaboración propia. Mayo de 2015

Gráfico $n^{\circ} 1.40$

40. Influencia, poder social (búsqueda de)

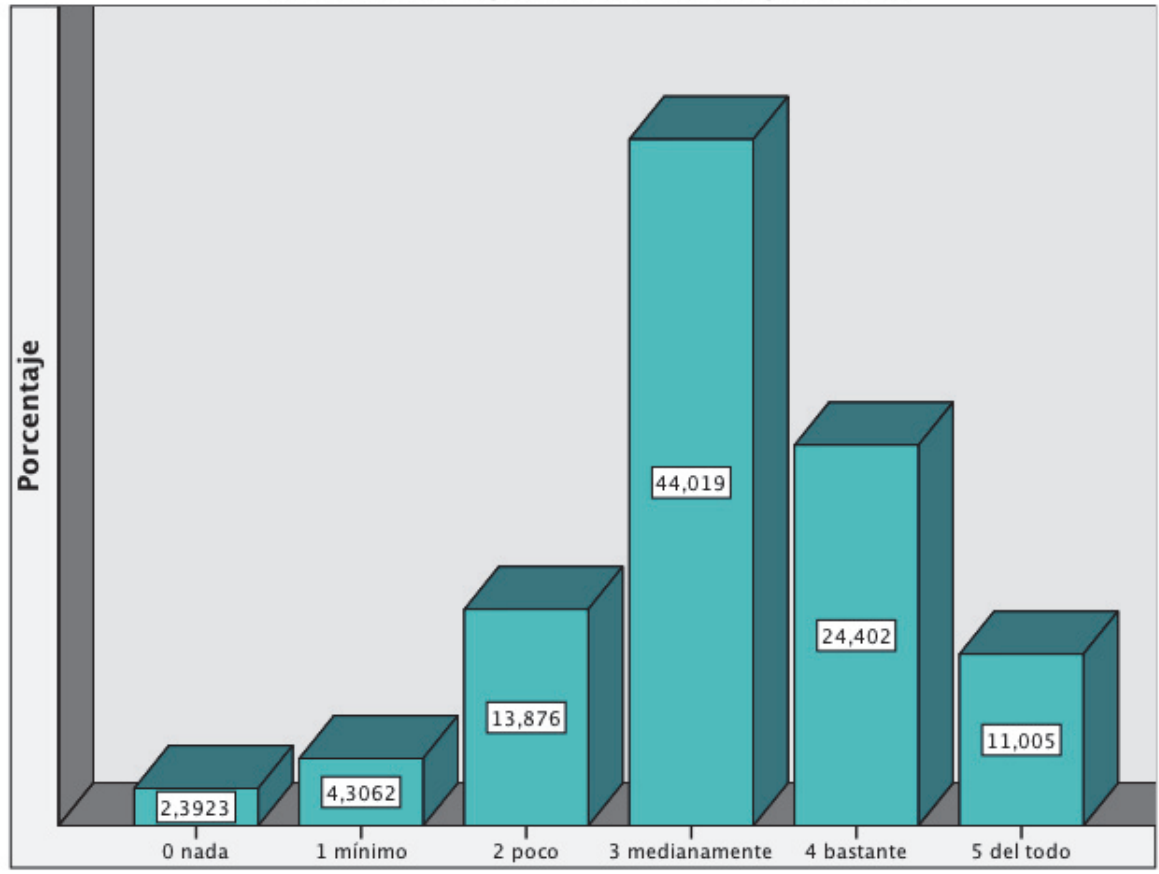

Elaboración propia. Mayo de 2015

Análisis: típico gráfico en pirámide con cerca de la mitad de las puntuaciones para el 3. La "influencia, poder social (búsqueda) no es considerada como prioritaria por la muestra en estudio en el área VP.

Al igual que decíamos para el valor 36. Imagen/prestigio social, encontramos unos resultados que responden al perfil de una profesión feminizada y por lo tanto desprovista de prestigio social en una sociedad patriarcal. 
Cuadro n ${ }^{\circ} 1.41$

41. Lealtad/Fidelidad

\begin{tabular}{|l|r|r|r|r|}
\hline & Frecuencia & Porcentaje & $\begin{array}{c}\text { Porcentaje } \\
\text { válido }\end{array}$ & $\begin{array}{c}\text { Porcentaje } \\
\text { acumulado }\end{array}$ \\
\hline 0 nada & 1 &, 5 &, 5 &, 5 \\
2 poco & 1 &, 5 &, 5 & 1,0 \\
3 medianamente & 9 & 4,3 & 4,3 & 5,3 \\
4 bastante & 43 & 20,6 & 20,6 & 25,8 \\
5 del todo & 155 & 74,2 & 74,2 & 100,0 \\
Total & 209 & 100,0 & 100,0 & \\
\hline
\end{tabular}

Elaboración propia. Mayo de 2015

Gráfico $n^{\circ} 1.41$

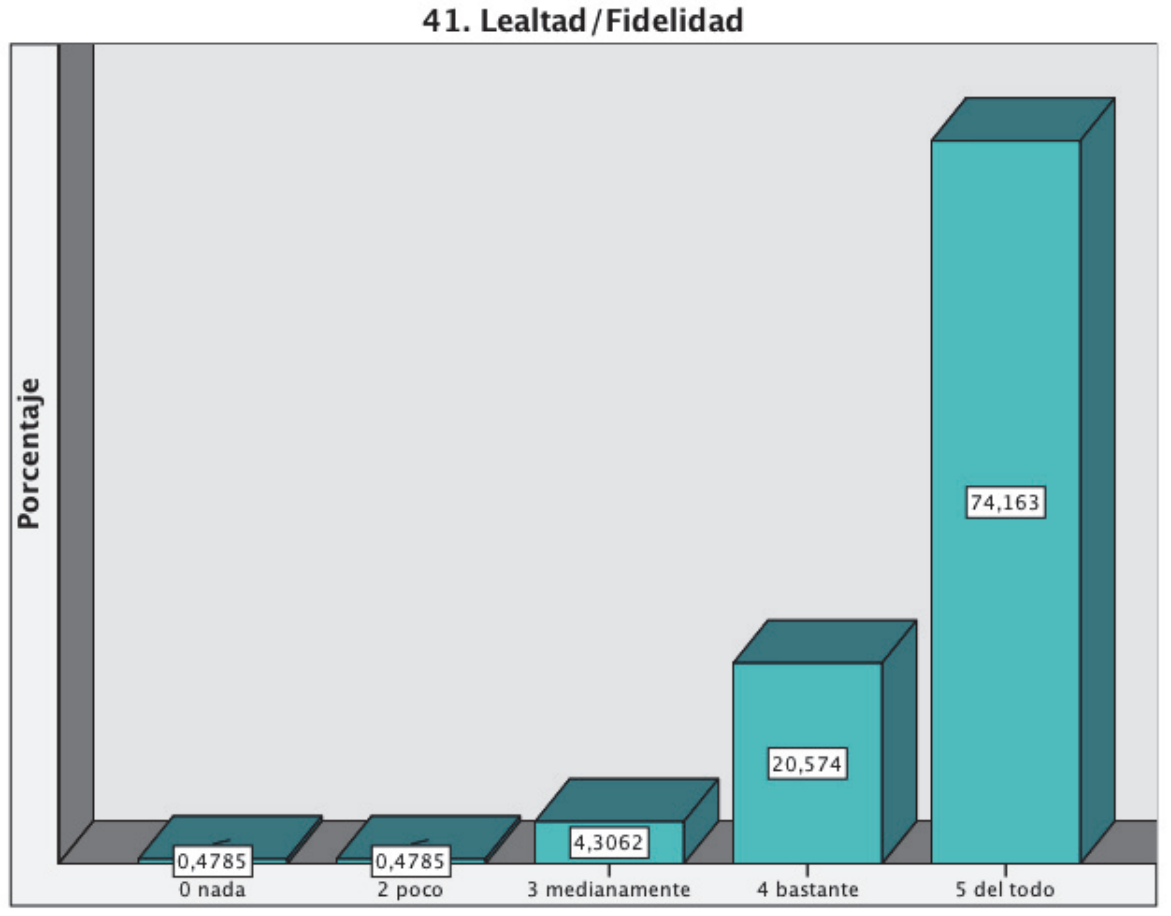

Elaboración propia. Mayo de 2015

Análisis: es evidente que la "Lealtad/Fidelidad" es muy valorada por la muestra en estudio. Modelo en escalera ascendente con más del 74\% para el 5.

Vemos de nuevo altos resultados en un valor tradicionalmente exigido a la mujer, lo que demuestra la coherencia de las encuestas. 
Cuadro ${ }^{\circ} 1.42$

42. Moderación, tener pocos deseos

\begin{tabular}{|l|r|r|r|r|}
\hline & Frecuencia & Porcentaje & $\begin{array}{c}\text { Porcentaje } \\
\text { válido }\end{array}$ & $\begin{array}{c}\text { Porcentaje } \\
\text { acumulado }\end{array}$ \\
\hline 0 nada & 21 & 10,0 & 10,0 & 10,0 \\
1 mínimo & 24 & 11,5 & 11,5 & 21,5 \\
2 poco & 39 & 18,7 & 18,7 & 40,2 \\
3 medianamente & 73 & 34,9 & 34,9 & 75,1 \\
4 bastante & 35 & 16,7 & 16,7 & 91,9 \\
5 del todo & 17 & 8,1 & 8,1 & 100,0 \\
Total & 209 & 100,0 & 100,0 & \\
\hline
\end{tabular}

Elaboración propia. Mayo de 2015

Gráfico $n^{\circ} 1.42$

42. Moderación, tener pocos deseos

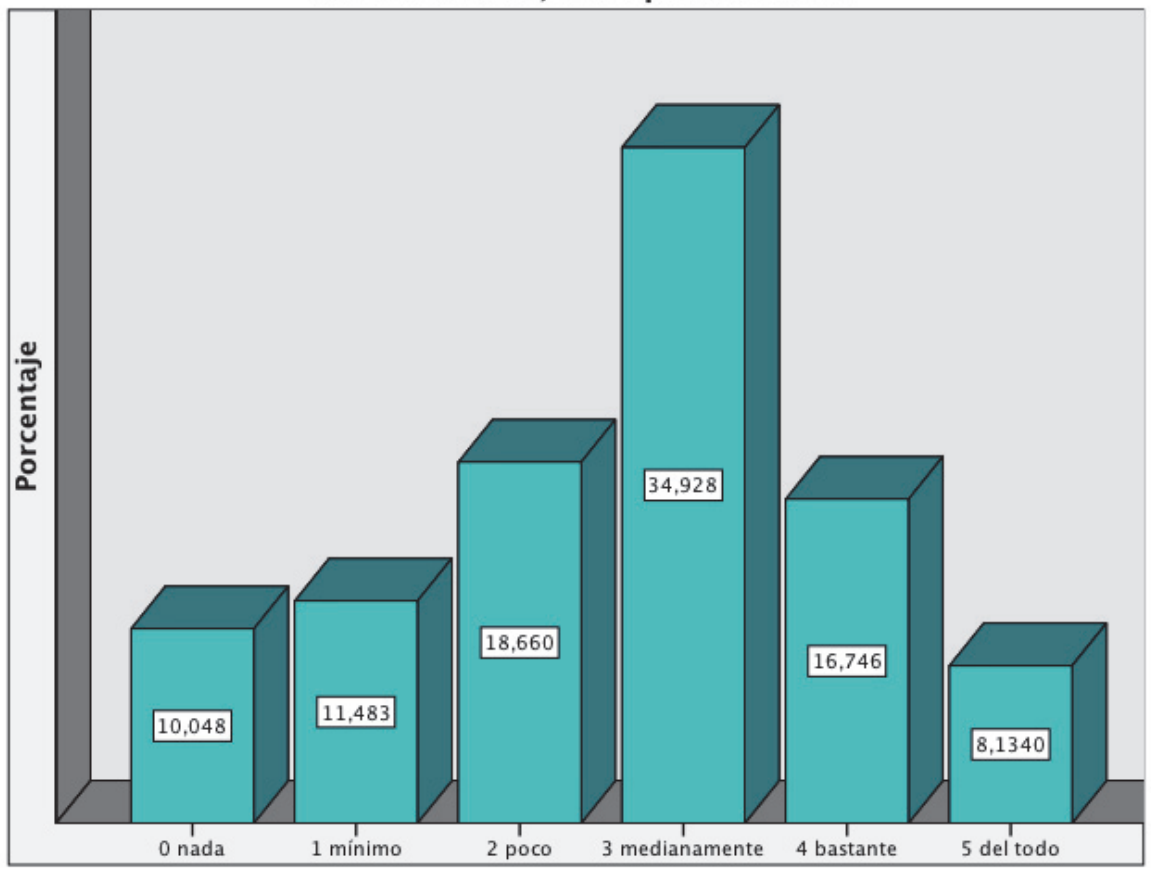

Elaboración propia. Mayo de 2015

Análisis: la "Moderación, tener pocos deseos" presenta un gráfico en pirámide con más peso en las puntuaciones bajas que en las altas. El 0, 1 y 2 suman el 39\% mientras que el 4 y 5 suman el 24\% quedando el 3 con casi el $35 \%$. Es la primera vez que encontramos un valor puntuado de esta forma.

Los resultados de este valor y los del 22. Deleite físico, Hedonismo son similares, para ambas esferas, presentan predominio del 3. Resulta llamativo que valores tan opuestos presenten resultados similares. 
Cuadro $\mathrm{n}^{\mathrm{o}} 1.43$

43. Mundo en paz

\begin{tabular}{|l|r|r|r|r|}
\hline & Frecuencia & Porcentaje & $\begin{array}{c}\text { Porcentaje } \\
\text { válido }\end{array}$ & $\begin{array}{c}\text { Porcentaje } \\
\text { acumulado }\end{array}$ \\
\hline 1 mínimo & 3 & 1,4 & 1,4 & 1,4 \\
2 poco & 3 & 1,4 & 1,4 & 2,9 \\
3 medianamente & 36 & 17,2 & 17,2 & 20,1 \\
4 bastante & 50 & 23,9 & 23,9 & 44,0 \\
5 del todo & 117 & 56,0 & 56,0 & 100,0 \\
Total & 209 & 100,0 & 100,0 & \\
\hline
\end{tabular}

Elaboración propia. Mayo de 2015

Gráfico $\mathrm{n}^{\mathrm{0}} 1.43$

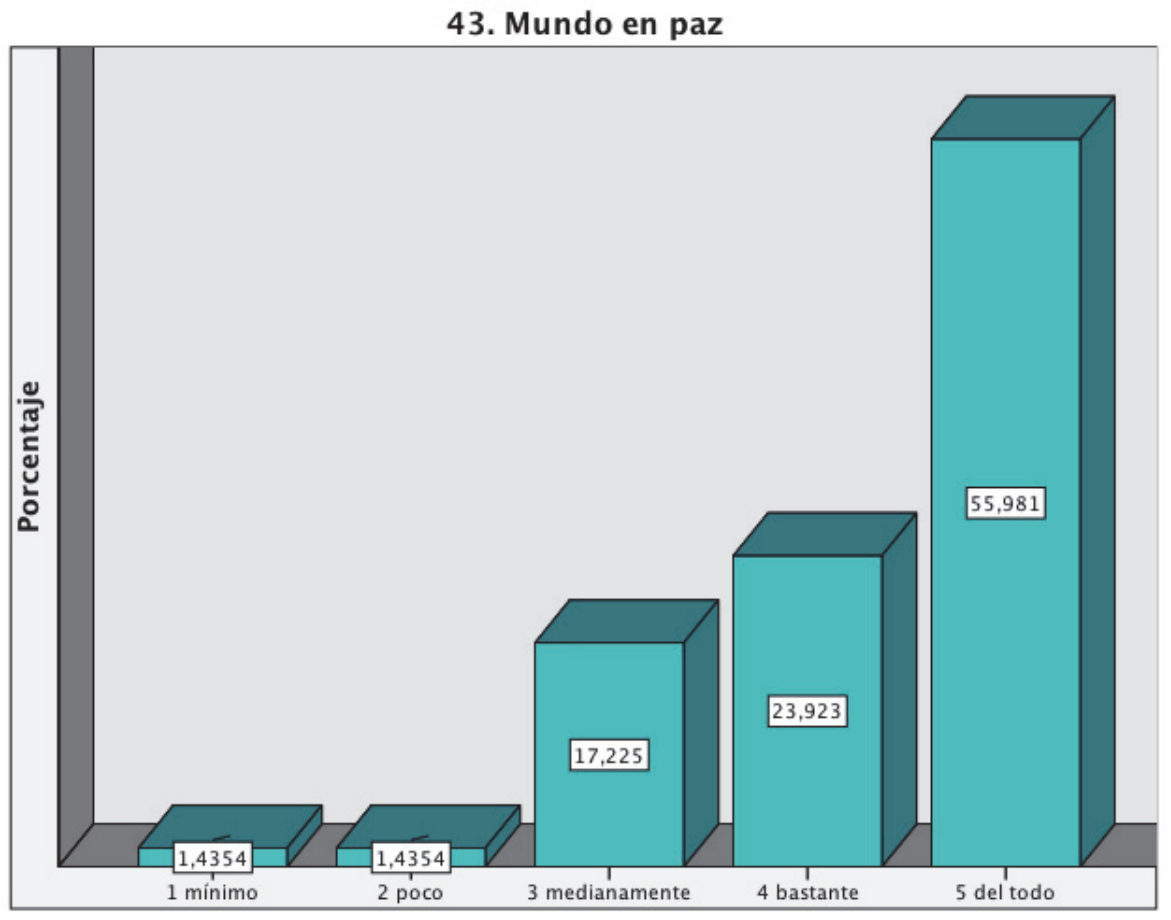

Elaboración propia. Mayo de 2015

Análisis: no aparece el 0. Modelo en escalera ascendente. "Mundo en paz" es un valor catalogado como importante. Más de la mitad de los encuestados reconocen que este valor gobierna su VP "del todo".

Resultado esperable que muestra la coherencia de las encuestas. Valor en relación directa con el Compromiso social, primero de los valores de Espinoso de Compludo. 
Cuadro $n^{\circ} 1.44$

44. Obediencia, cumplimiento

\begin{tabular}{|l|r|r|r|r|}
\hline & Frecuencia & Porcentaje & $\begin{array}{c}\text { Porcentaje } \\
\text { válido }\end{array}$ & $\begin{array}{r}\text { Porcentaje } \\
\text { acumulado }\end{array}$ \\
\hline 1 mínimo & 2 & 1,0 & 1,0 & 1,0 \\
2 poco & 9 & 4,3 & 4,3 & 5,3 \\
3 medianamente & 54 & 25,8 & 25,8 & 31,1 \\
4 bastante & 85 & 40,7 & 40,7 & 71,8 \\
5 del todo & 59 & 28,2 & 28,2 & 100,0 \\
Total & 209 & 100,0 & 100,0 & \\
\hline
\end{tabular}

Elaboración propia. Mayo de 2015

Gráfico $n^{\circ} 1.44$

44. Obediencia, cumplimiento

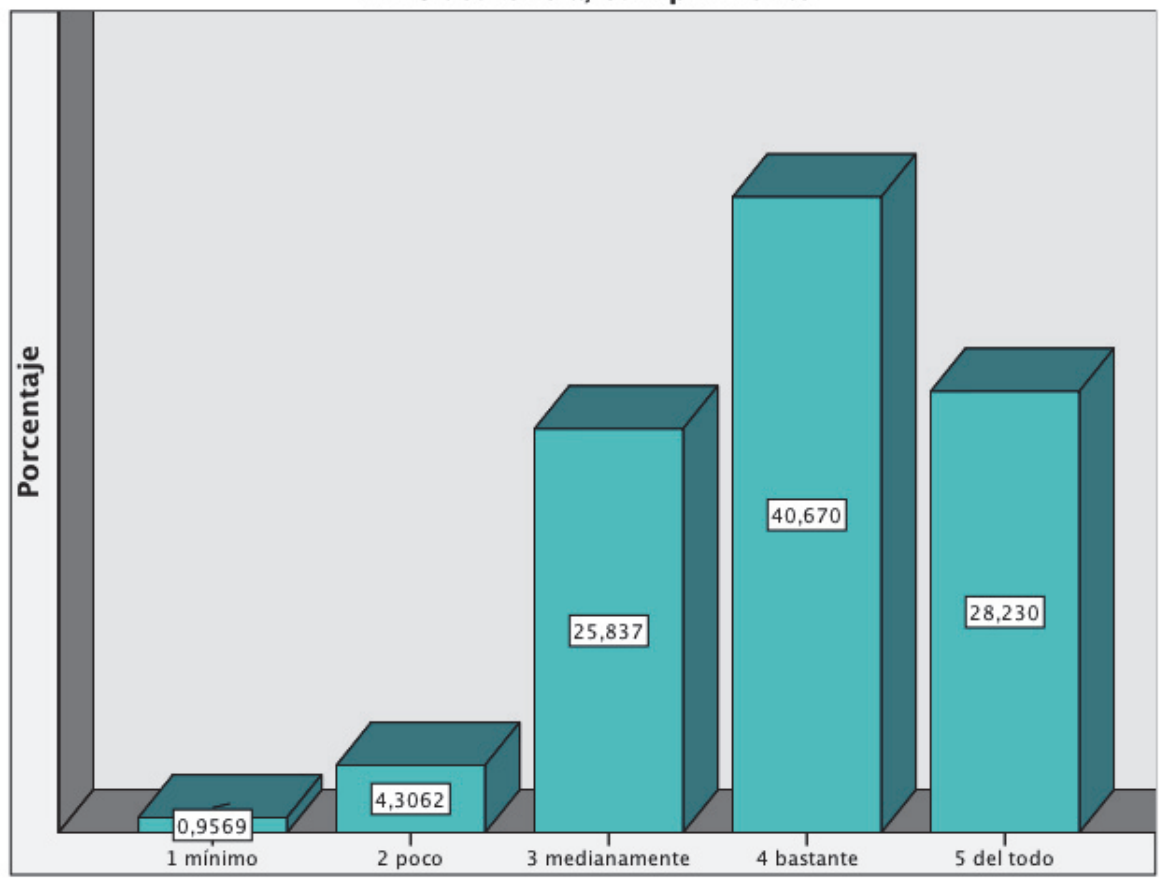

Elaboración propia. Mayo de 2015

Análisis: gráfico en pirámide asimétrica con sesgo a la derecha concentrando la mayor parte de los porcentajes entre el 3, 4 y 5 con predominio del 4. A la luz de la encuesta consideramos el valor "obediencia, cumplimiento" como importante.

En una profesión feminizada y de responsabilidad vital ante el paciente, este resultado muestra la coherencia de las encuestas. En cuanto al matiz cumplimiento, el resultado favorece nuestra hipótesis. 
Cuadro $n^{\circ} 1.45$

45. Pasión, entusiasmo

\begin{tabular}{|l|r|r|r|r|}
\hline & Frecuencia & Porcentaje & $\begin{array}{c}\text { Porcentaje } \\
\text { válido }\end{array}$ & $\begin{array}{c}\text { Porcentaje } \\
\text { acumulado }\end{array}$ \\
\hline 0 nada & 1 &, 5 &, 5 &, 5 \\
2 poco & 2 & 1,0 & 1,0 & 1,4 \\
3 medianamente & 23 & 11,0 & 11,0 & 12,4 \\
4 bastante & 80 & 38,3 & 38,3 & 50,7 \\
5 del todo & 103 & 49,3 & 49,3 & 100,0 \\
Total & 209 & 100,0 & 100,0 & \\
\hline
\end{tabular}

Elaboración propia. Mayo de 2015

Gráfico $\mathrm{n}^{\mathrm{o}} 1.45$

45. Pasión, entusiasmo

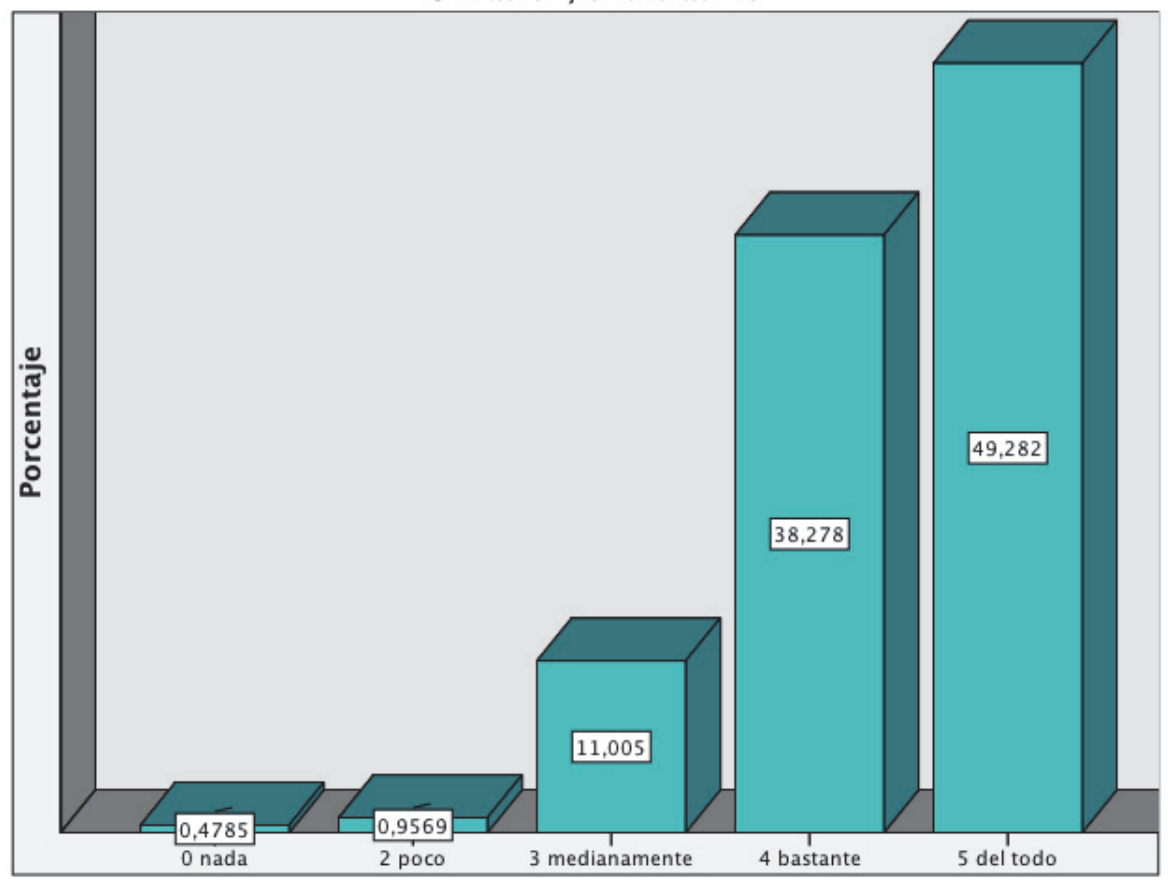

Elaboración propia. Mayo de 2015

Análisis: gráfico en escalera ascendente con casi el 50\% para el 5. El valor "Pasión, entusiasmo" puede considerarse como muy importante.

Valor relacionado con la eficiencia, humanización y por lo tanto con la Confianza como metavalor. Este resultado está a favor de nuestra hipótesis. 
Cuadro ${ }^{\circ} 1.46$

46. Patriotismo

\begin{tabular}{|l|r|r|r|r|}
\hline & Frecuencia & Porcentaje & $\begin{array}{c}\text { Porcentaje } \\
\text { válido }\end{array}$ & $\begin{array}{r}\text { Porcentaje } \\
\text { acumulado }\end{array}$ \\
\hline 0 nada & 28 & 13,4 & 13,4 & 13,4 \\
1 mínimo & 27 & 12,9 & 12,9 & 26,3 \\
2 poco & 38 & 18,2 & 18,2 & 44,5 \\
3 medianamente & 60 & 28,7 & 28,7 & 73,2 \\
4 bastante & 36 & 17,2 & 17,2 & 90,4 \\
5 del todo & 20 & 9,6 & 9,6 & 100,0 \\
Total & 209 & 100,0 & 100,0 & \\
\hline
\end{tabular}

Elaboración propia. Mayo de 2015

Gráfico 1.46

46. Patriotismo

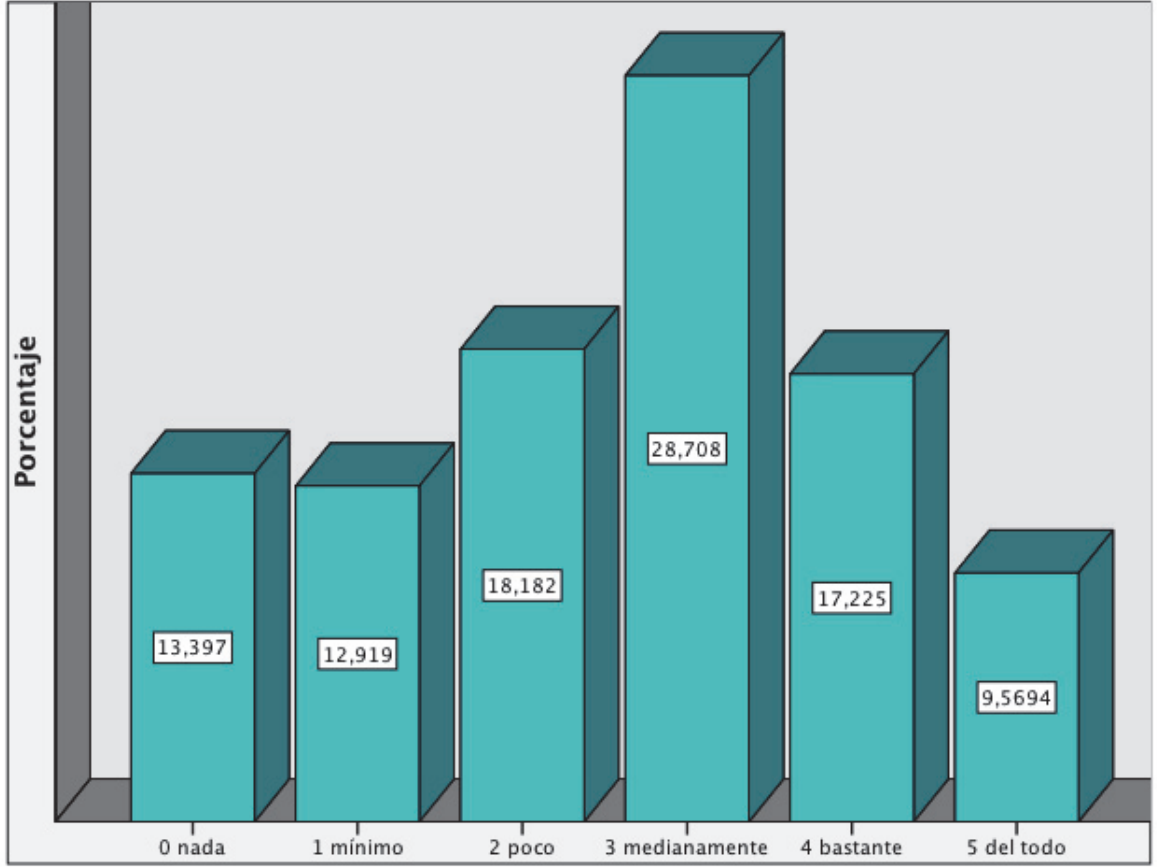

Elaboración propia. Mayo de 2015

Análisis: gráfico en pirámide. Las puntuaciones 0,1 y 2 suman más del 44\%. El valor "patriotismo" se muestra como poco atractivo. Los resultados son similares en el ME.

Tratándose de un valor tan controvertido hoy, los resultados obtenidos demuestran la seriedad del alumnado al momento de elaborar las respuestas y por lo tanto, la validez de las encuestas. 
Cuadro $n^{\circ} 1.47$

47. Perseverancia/Paciencia

\begin{tabular}{|l|c|c|c|c|}
\hline & Frecuencia & Porcentaje & $\begin{array}{c}\text { Porcentaje } \\
\text { válido }\end{array}$ & $\begin{array}{c}\text { Porcentaje } \\
\text { acumulado }\end{array}$ \\
\hline 0 nada & 2 & 1,0 & 1,0 & 1,0 \\
1 mínimo & 7 & 3,3 & 3,3 & 4,3 \\
2 poco & 12 & 5,7 & 5,7 & 10,0 \\
3 medianamente & 35 & 16,7 & 16,7 & 26,8 \\
4 bastante & 73 & 34,9 & 34,9 & 61,7 \\
5 del todo & 80 & 38,3 & 38,3 & 100,0 \\
Total & 209 & 100,0 & 100,0 & \\
\hline
\end{tabular}

Elaboración propia. Mayo de 2015

Gráfico ${ }^{\circ} 1.47$

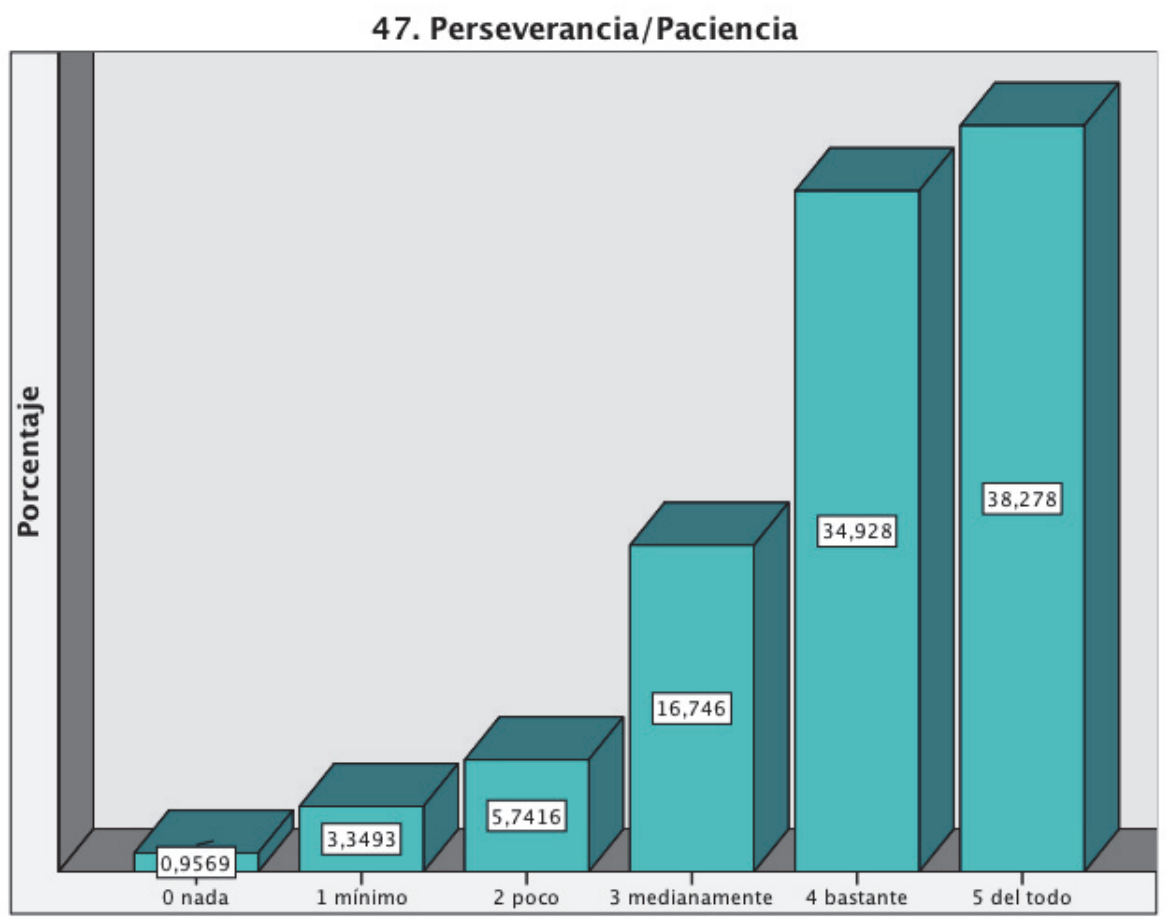

Elaboración propia. Mayo de 2015

Análisis: gráfico en escalera ascendente con más del $73 \%$ para las puntuaciones 4 y 5. El valor "Perseverancia/Paciencia" se revela como importante en el área de la VP.

Resultados que responden al perfil de enfermería y de feminización. Valor en relación directa con la eficiencia, humanización y la Confianza como metavalor. 
Cuadro $n^{\circ} 1.48$

48. Placer intelectual

\begin{tabular}{|l|r|r|r|r|}
\hline & Frecuencia & Porcentaje & $\begin{array}{c}\text { Porcentaje } \\
\text { válido }\end{array}$ & $\begin{array}{r}\text { Porcentaje } \\
\text { acumulado }\end{array}$ \\
\hline 2 poco & 5 & 2,4 & 2,4 & 2,4 \\
3 medianamente & 36 & 17,2 & 17,2 & 19,6 \\
4 bastante & 99 & 47,4 & 47,4 & 67,0 \\
5 del todo & 69 & 33,0 & 33,0 & 100,0 \\
Total & 209 & 100,0 & 100,0 & \\
\hline
\end{tabular}

Elaboración propia. Mayo de 2015

Gráfico $n^{\circ} 1.48$

48. Placer intelectual

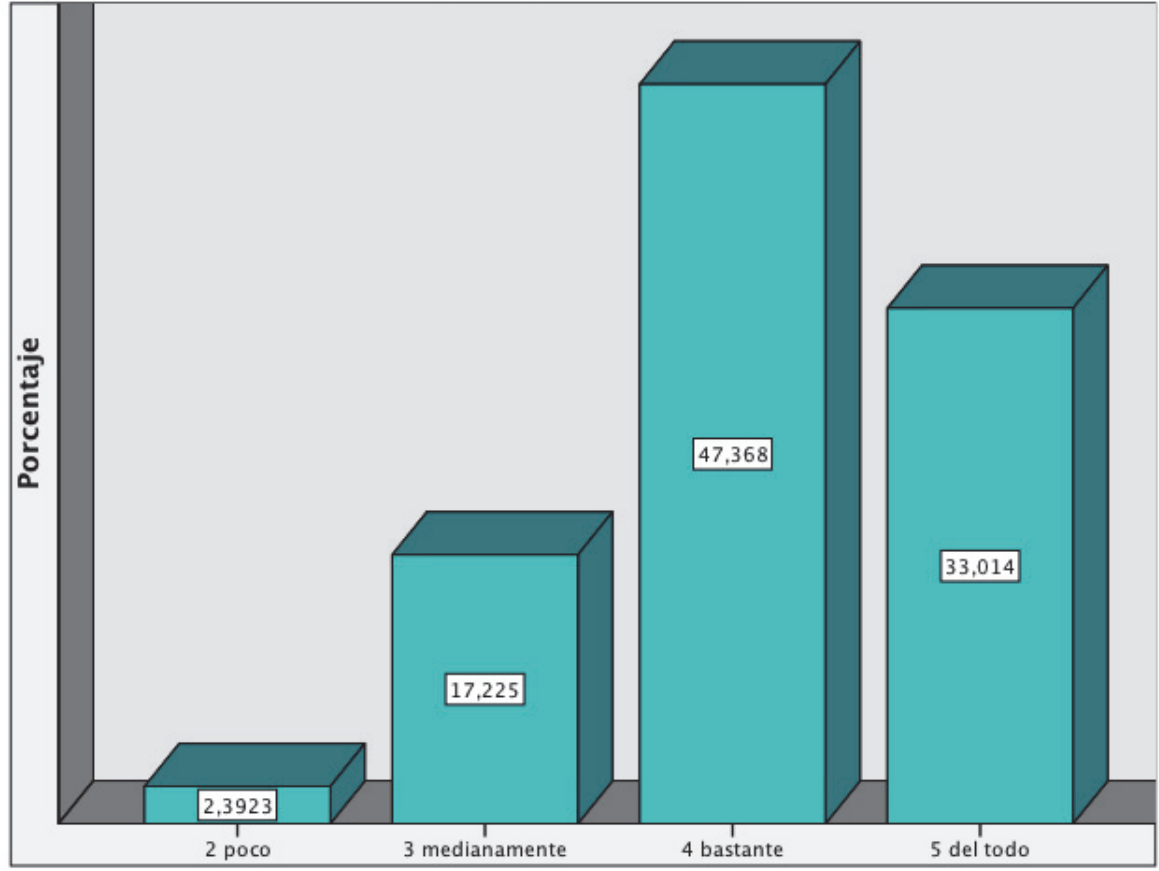

Elaboración propia. Mayo de 2015

Análisis: el 0 y 1 no están presentes, el 2 con un porcentaje muy bajo, la mayoría de las respuestas se concentran entre el 4 y 5 con predominio del 4 . Modelo en pirámide asimétrica con sesgo a la derecha. Valor importante.

Al igual que el valor 7. Aprendizaje continuo está relacionado con la seguridad en el ejercicio de la profesión y con la confianza que ha de inspirar en el paciente. También arroja resultados altos, acordes con una profesión que exige estar permanentemente al día dados los avances de las ciencias de la salud. 
Cuadro n ${ }^{\circ} 1.49$

49. Placer sexual

\begin{tabular}{|l|r|r|r|r|}
\hline & Frecuencia & Porcentaje & $\begin{array}{c}\text { Porcentaje } \\
\text { válido }\end{array}$ & $\begin{array}{r}\text { Porcentaje } \\
\text { acumulado }\end{array}$ \\
\hline 0 nada & 2 & 1,0 & 1,0 & 1,0 \\
1 mínimo & 2 & 1,0 & 1,0 & 1,9 \\
2 poco & 6 & 2,9 & 2,9 & 4,8 \\
3 medianamente & 32 & 15,3 & 15,3 & 20,1 \\
4 bastante & 60 & 28,7 & 28,7 & 48,8 \\
5 del todo & 107 & 51,2 & 51,2 & 100,0 \\
Total & 209 & 100,0 & 100,0 & \\
\hline
\end{tabular}

Elaboración propia. Mayo de 2015

Gráfico ${ }^{\circ} 1.49$

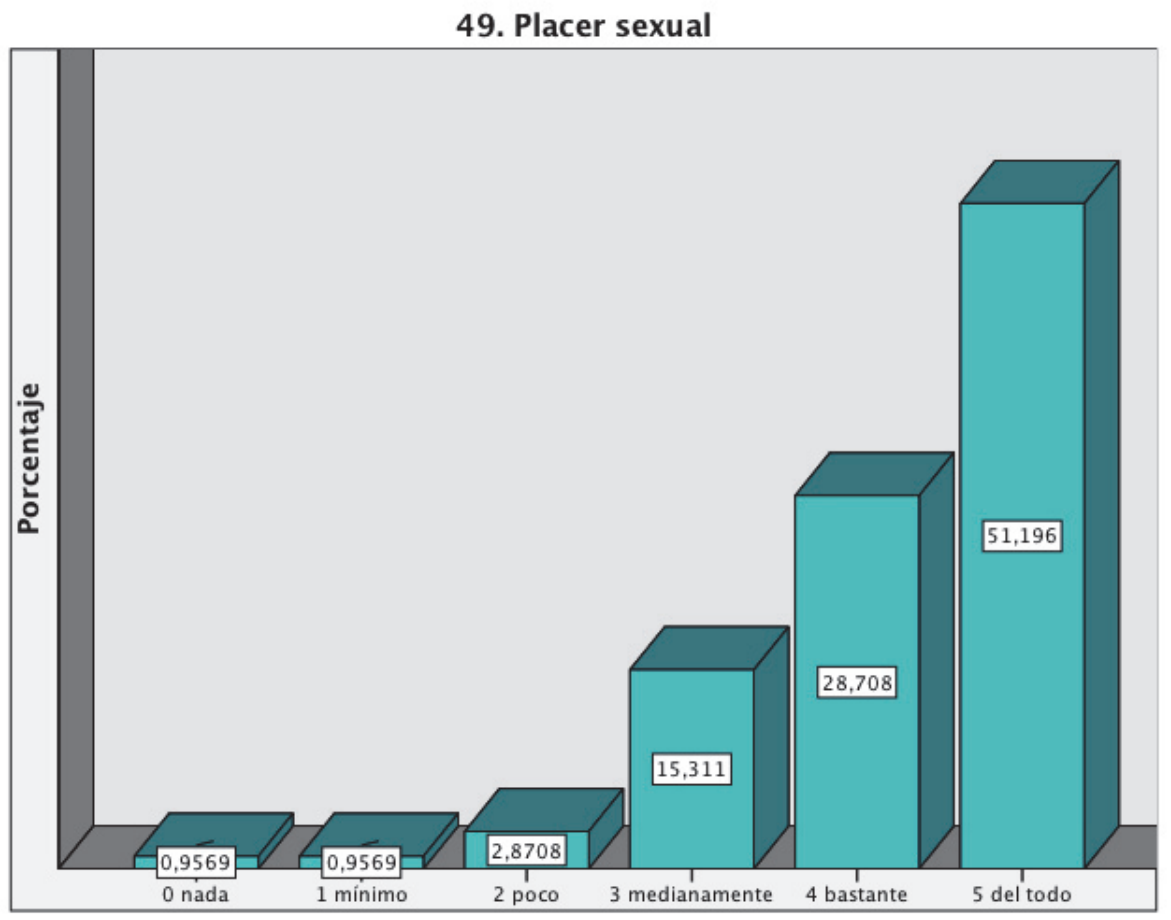

Elaboración propia. Mayo de 2015

Análisis: modelo en escalera ascendente con más del $50 \%$ para el 5. El valor "Placer sexual" es considerado importante en el área VP.

Pregunta que pone de manifiesto la sinceridad con la que ha contestado el alumnado y por lo tanto la validez de las encuestas. 
Cuadro $n^{\circ} 1.50$

50. Productividad, resultados

\begin{tabular}{|l|r|r|r|r|}
\hline & Frecuencia & Porcentaje & $\begin{array}{c}\text { Porcentaje } \\
\text { válido }\end{array}$ & $\begin{array}{c}\text { Porcentaje } \\
\text { acumulado }\end{array}$ \\
\hline 1 mínimo & 1 &, 5 &, 5 &, 5 \\
2 poco & 6 & 2,9 & 2,9 & 3,3 \\
3 medianamente & 39 & 18,7 & 18,7 & 22,0 \\
4 bastante & 93 & 44,5 & 44,5 & 66,5 \\
5 del todo & 70 & 33,5 & 33,5 & 100,0 \\
Total & 209 & 100,0 & 100,0 & \\
\hline
\end{tabular}

Elaboración propia. Mayo de 2015

Gráfico 1.50

\section{Productividad, resultados}

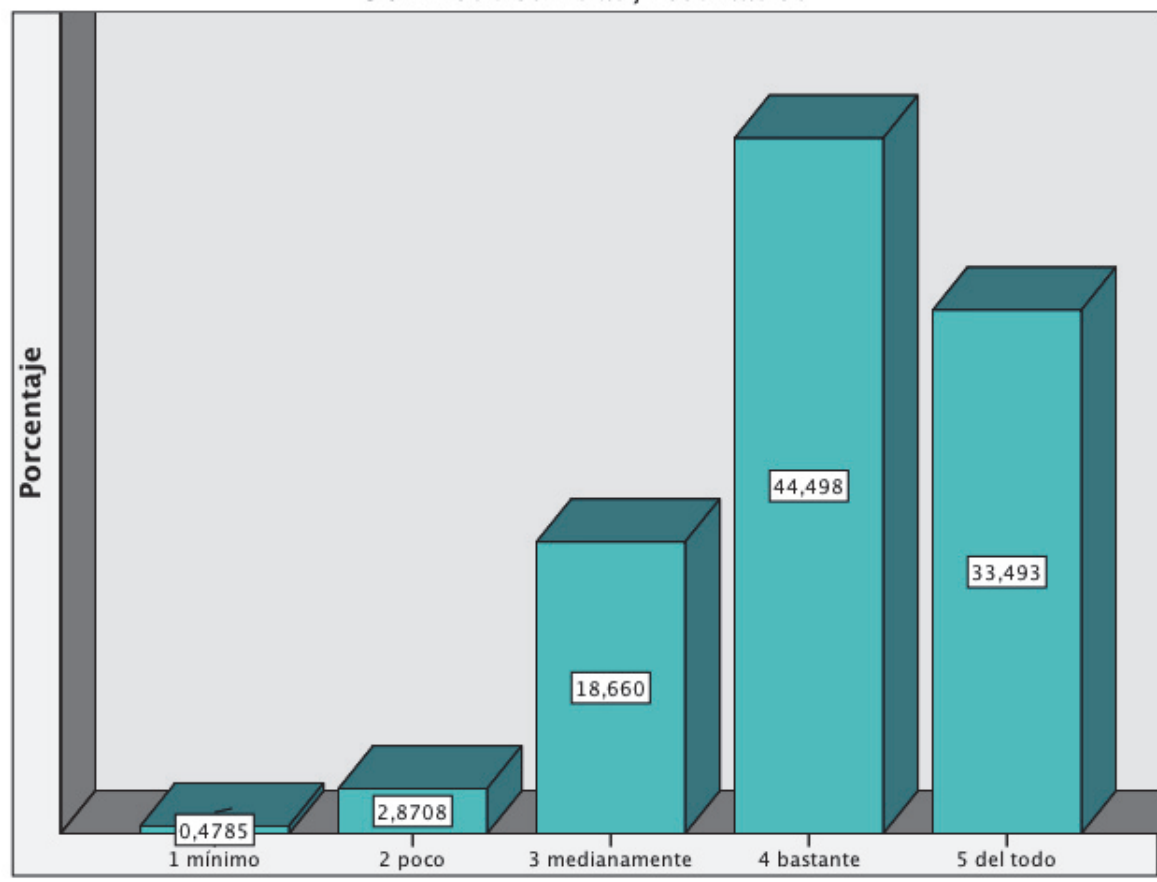

Elaboración propia. Mayo de 2015

Análisis: se observa ausencia del $0 \mathrm{y}$ modelo en pirámide asimétrica con sesgo a la derecha. El 4 y 5 suman más $78 \%$ con predominio del 4 . Valor importante.

Este ítem, el 13. Competitividad, ambición y el 36. Imagen, prestigio social comparten características tradicionalmente masculinas y observamos que arrojan resultados similares. Son resultados acordes en la VP para una profesión feminizada, y en el ME en cuanto a que la gestión y dirección de empresas sigue en manos masculinas. 
Cuadro $n^{\circ} 1.51$

51. Realismo, pragmatismo, racionalidad

\begin{tabular}{|l|r|r|r|r|}
\hline & Frecuencia & Porcentaje & $\begin{array}{c}\text { Porcentaje } \\
\text { válido }\end{array}$ & $\begin{array}{c}\text { Porcentaje } \\
\text { acumulado }\end{array}$ \\
\hline 1 mínimo & 1 &, 5 &, 5 &, 5 \\
2 poco & 2 & 1,0 & 1,0 & 1,4 \\
3 medianamente & 38 & 18,2 & 18,2 & 19,6 \\
4 bastante & 88 & 42,1 & 42,1 & 61,7 \\
5 del todo & 80 & 38,3 & 38,3 & 100,0 \\
Total & 209 & 100,0 & 100,0 & \\
\hline
\end{tabular}

Elaboración propia. Mayo de 2015

Gráfico $\mathrm{n}^{\mathrm{0}} 1.51$

51. Realismo, pragmatismo, racionalidad

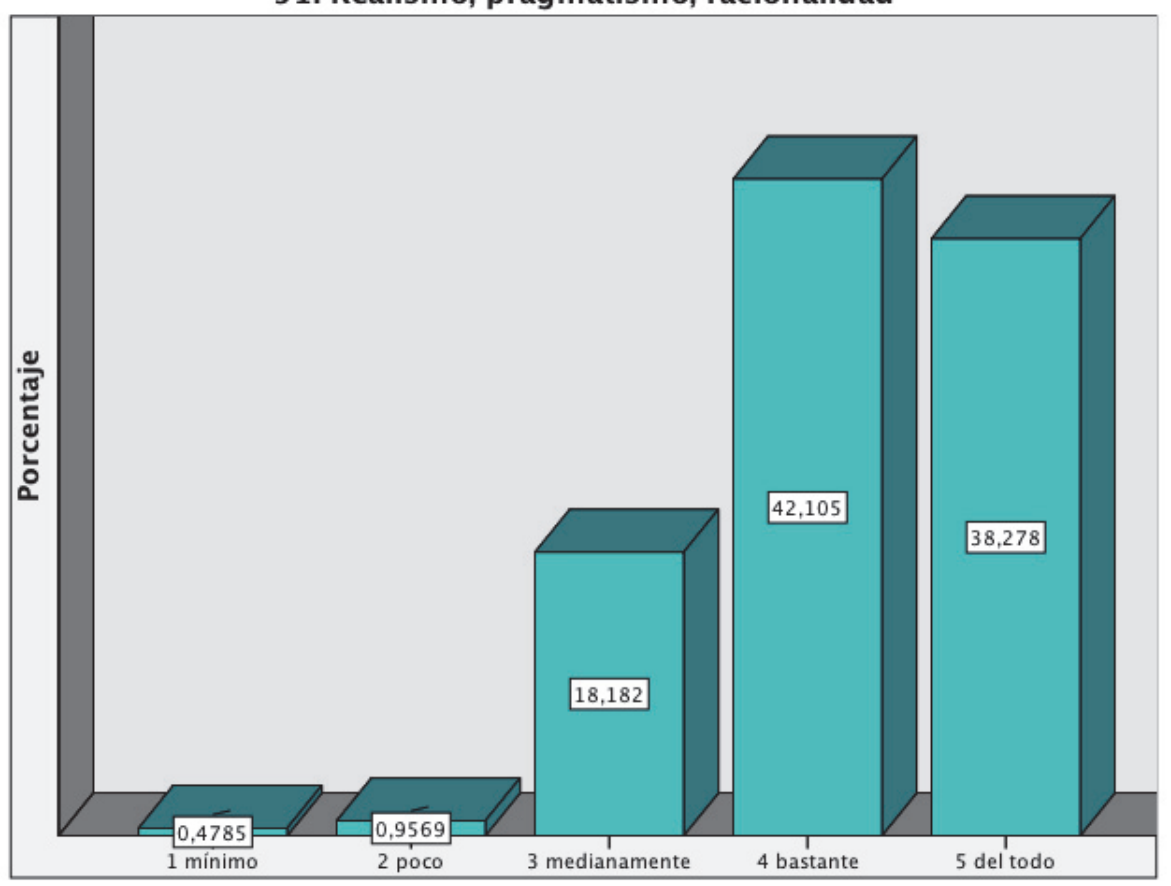

Elaboración propia. Mayo de 2015

Análisis: al igual que en el caso anterior, el 0 está ausente y el gráfico sigue un modelo de pirámide asimétrica con sesgo a la derecha. El 4 y 5 suman más del $80 \%$ con predominio del 4 . Valor importante.

Para el valor 34. Idealismo hemos obtenido un resultado de medianamente importante. En cambio este aparece como muy importante. Vemos que el alumnado da más importancia a lo positivo, real, racional, práctico que a lo ideal. 
Cuadro $n^{\circ} 1.52$

52. Reconocimiento emocional (darlo y buscarlo)

\begin{tabular}{|l|r|r|r|r|}
\hline & Frecuencia & Porcentaje & $\begin{array}{c}\text { Porcentaje } \\
\text { válido }\end{array}$ & $\begin{array}{r}\text { Porcentaje } \\
\text { acumulado }\end{array}$ \\
\hline 0 nada & 1 &, 5 &, 5 &, 5 \\
3 medianamente & 30 & 14,4 & 14,4 & 14,8 \\
4 bastante & 75 & 35,9 & 35,9 & 50,7 \\
5 del todo & 103 & 49,3 & 49,3 & 100,0 \\
Total & 209 & 100,0 & 100,0 & \\
\hline
\end{tabular}

Elaboración propia. Mayo de 2015

Gráfico $n^{\circ} 1.52$

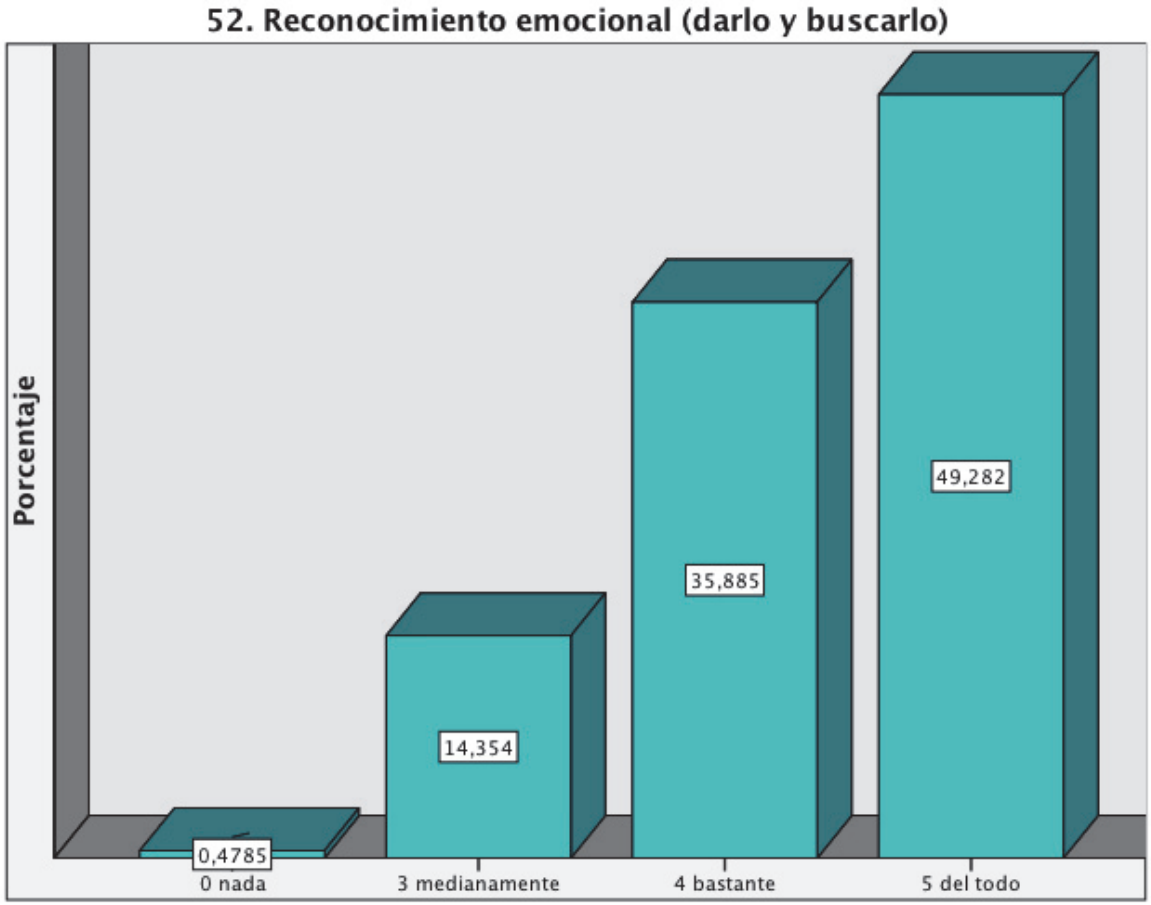

Elaboración propia. Mayo de 2015

Análisis: ausencia del 1 aunque observamos presencia del 2. Modelo en escalera ascendente. El valor "reconocimiento emocional, (darlo y buscarlo) se manifiesta como importante.

El resultado concuerda con una profesión altamente feminizada, el área emocional está altamente puntuada. 
Cuadro $n^{\circ} 1.53$

53. Religiosidad

\begin{tabular}{|l|r|r|r|r|}
\hline & Frecuencia & Porcentaje & $\begin{array}{c}\text { Porcentaje } \\
\text { válido }\end{array}$ & $\begin{array}{r}\text { Porcentaje } \\
\text { acumulado }\end{array}$ \\
\hline 0 nada & 78 & 37,3 & 37,3 & 37,3 \\
1 mínimo & 24 & 11,5 & 11,5 & 48,8 \\
2 poco & 30 & 14,4 & 14,4 & 63,2 \\
3 medianamente & 32 & 15,3 & 15,3 & 78,5 \\
4 bastante & 27 & 12,9 & 12,9 & 91,4 \\
5 del todo & 18 & 8,6 & 8,6 & 100,0 \\
Total & 209 & 100,0 & 100,0 & \\
\hline
\end{tabular}

Elaboración propia. Mayo de 2015

Gráfico ${ }^{\circ} 1.53$

53. Religiosidad

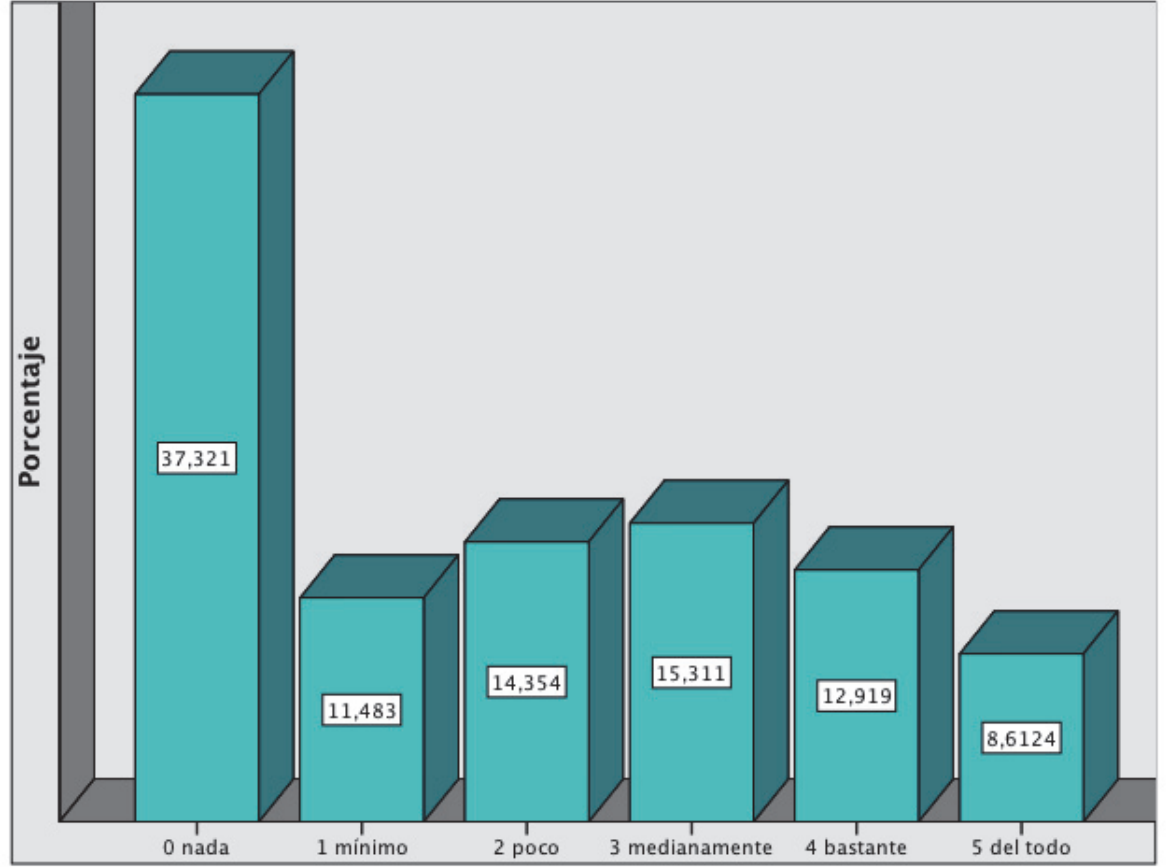

Elaboración propia. Mayo de 2015

Análisis: la puntuación que acumula mayor porcentaje es el 0 , distribuyéndose el resto entre los demás números sin grandes diferencias. Modelo en L. El valor "Religiosidad" no gobierna la VP de forma importante.

Llama la atención como una profesión tradicionalmente feminizada y ejercida durante siglos por monjas, secularizada no hace mucho, presente este resultado. 
Cuadro $n^{\circ} 1.54$

54. Respeto y armonía con los demás

\begin{tabular}{|l|r|r|r|r|}
\hline & Frecuencia & Porcentaje & $\begin{array}{c}\text { Porcentaje } \\
\text { válido }\end{array}$ & $\begin{array}{r}\text { Porcentaje } \\
\text { acumulado }\end{array}$ \\
\hline 0 nada & 1 &, 5 &, 5 &, 5 \\
1 mínimo & 1 &, 5 &, 5 & 1,0 \\
2 poco & 4 & 1,9 & 1,9 & 2,9 \\
3 medianamente & 13 & 6,2 & 6,2 & 9,1 \\
4 bastante & 73 & 34,9 & 34,9 & 44,0 \\
5 del todo & 117 & 56,0 & 56,0 & 100,0 \\
Total & 209 & 100,0 & 100,0 & \\
\hline
\end{tabular}

Elaboración propia. Mayo de 2015

Gráfico $n^{\circ} 1.54$

54. Respeto y armonía con los demás

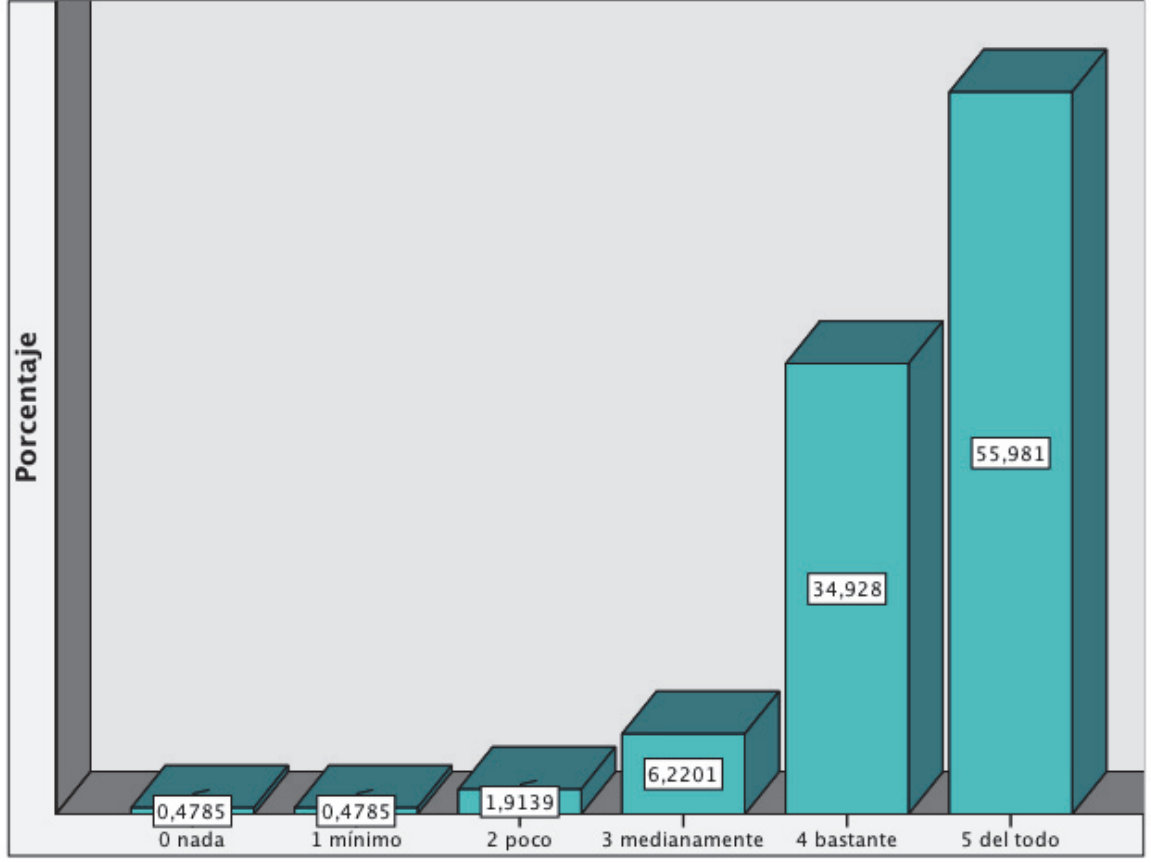

Elaboración propia. Mayo de 2015

Análisis: modelo en escalera ascendente con predominio del 5. El valor "Respeto y armonía con los demás” gobierna de forma notoria la VP.

El tercer valor del ME de C es armonía. Resultado que responde al perfil de enfermería. 
Cuadro $n^{\circ} 1.55$

55. Respeto y armonía con uno mismo

\begin{tabular}{|l|r|r|r|r|}
\hline & Frecuencia & Porcentaje & $\begin{array}{l}\text { Porcentaje } \\
\text { válido }\end{array}$ & $\begin{array}{c}\text { Porcentaje } \\
\text { acumulado }\end{array}$ \\
\hline 2 poco & 3 & 1,4 & 1,4 & 1,4 \\
3 medianamente & 19 & 9,1 & 9,1 & 10,5 \\
4 bastante & 50 & 23,9 & 23,9 & 34,4 \\
5 del todo & 137 & 65,6 & 65,6 & 100,0 \\
Total & 209 & 100,0 & 100,0 & \\
\hline
\end{tabular}

Elaboración propia. Mayo de 2015

Gráfico $n^{0} 1.55$

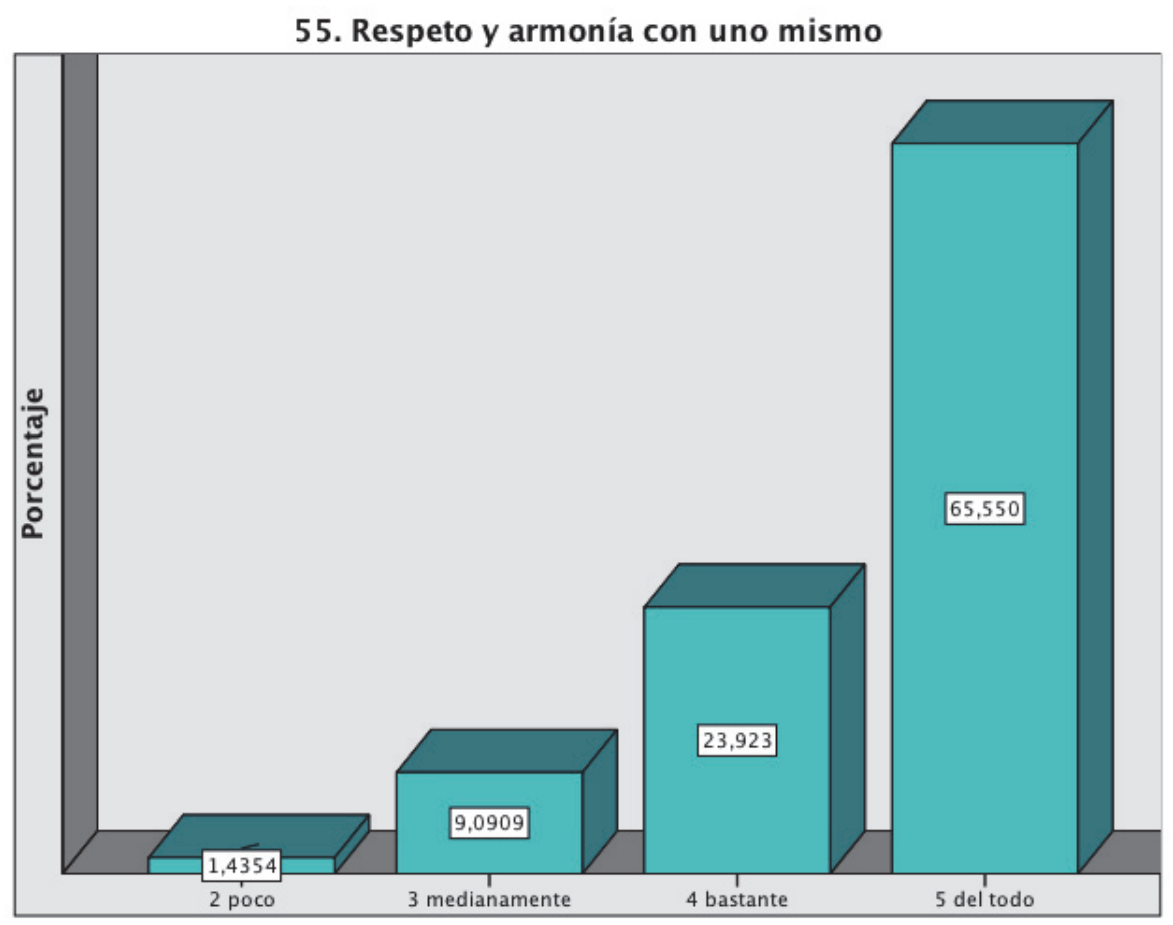

Elaboración propia. Mayo de 2015

Análisis: el valor "Respeto y armonía con uno mismo" sigue el mismo comportamiento que el anterior pero con mayor importancia pues no aparece el 0 y el 5 tiene mayor porcentaje.

El tercer valor del ME de C es armonía y vemos que la armonía consigo mismo es la mas importante para el alumnado. 
Cuadro $n^{\circ} 1.56$

56. Respeto y armonía medioambiental

\begin{tabular}{|l|r|r|r|r|}
\hline & Frecuencia & Porcentaje & $\begin{array}{c}\text { Porcentaje } \\
\text { válido }\end{array}$ & $\begin{array}{r}\text { Porcentaje } \\
\text { acumulado }\end{array}$ \\
\hline 2 poco & 5 & 2,4 & 2,4 & 2,4 \\
3 medianamente & 50 & 23,9 & 23,9 & 26,3 \\
4 bastante & 72 & 34,4 & 34,4 & 60,8 \\
5 del todo & 82 & 39,2 & 39,2 & 100,0 \\
Total & 209 & 100,0 & 100,0 & \\
\hline
\end{tabular}

Elaboración propia. Mayo de 2015

Gráfico $\mathrm{n}^{\mathrm{o}} 1.56$

56. Respeto y armonía medioambiental

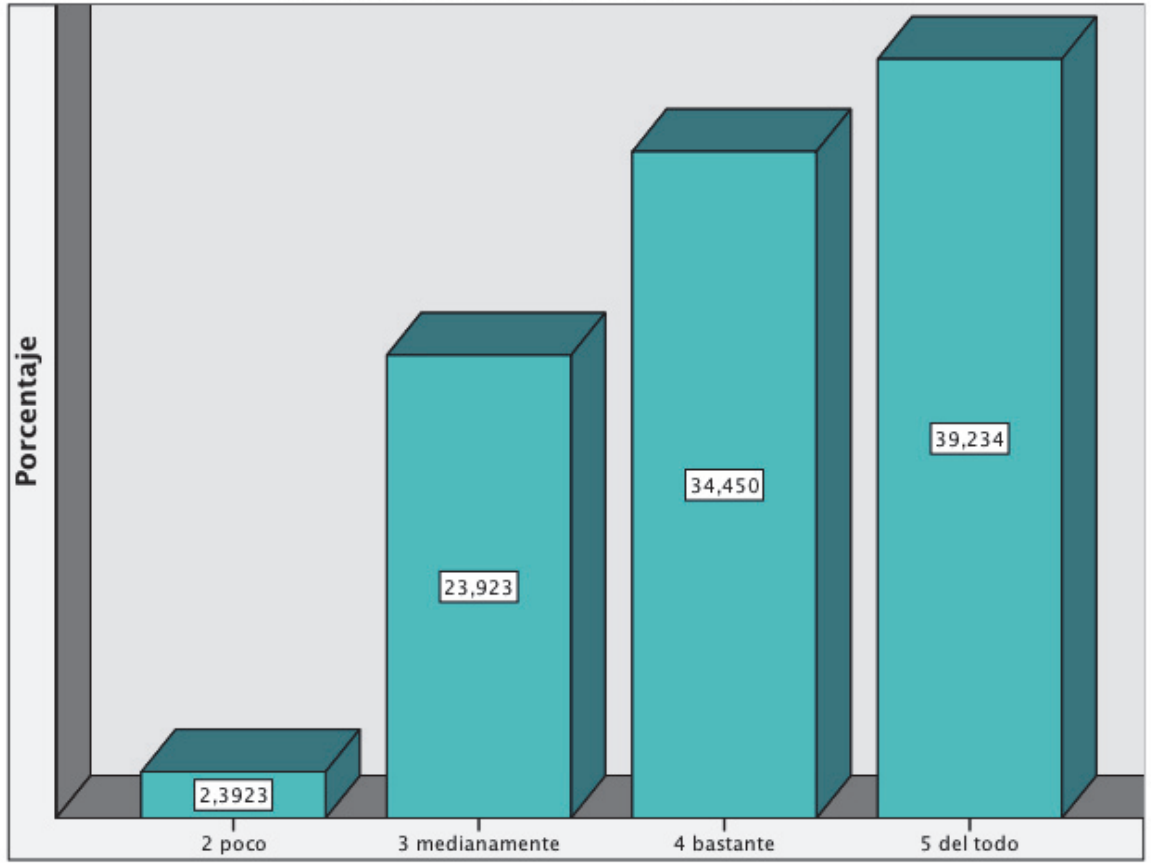

Elaboración propia. Mayo de 2015

Análisis: el valor "Respeto y armonía medioambiental" sigue el mismo comportamiento que los dos anteriores pero los porcentajes se distribuyen mas entre el 3, 4 y 5.

El tercer valor del ME de C es armonía y la armonía con el medio ambiente es también muy apreciado por la muestra en estudio. 
Cuadro $n^{\circ} 1.57$

57. Riesgo, aventura, estímulo, novedad

\begin{tabular}{|l|r|r|r|r|}
\hline & Frecuencia & Porcentaje & $\begin{array}{c}\text { Porcentaje } \\
\text { válido }\end{array}$ & $\begin{array}{c}\text { Porcentaje } \\
\text { acumulado }\end{array}$ \\
\hline 0 nada & 1 &, 5 &, 5 &, 5 \\
1 mínimo & 1 &, 5 &, 5 & 1,0 \\
2 poco & 6 & 2,9 & 2,9 & 3,8 \\
3 medianamente & 55 & 26,3 & 26,3 & 30,1 \\
4 bastante & 80 & 38,3 & 38,3 & 68,4 \\
5 del todo & 66 & 31,6 & 31,6 & 100,0 \\
Total & 209 & 100,0 & 100,0 & \\
\hline
\end{tabular}

Elaboración propia. Mayo de 2015

Gráfico $n^{\circ} 1.57$

57. Riesgo, aventura, estímulo, novedad

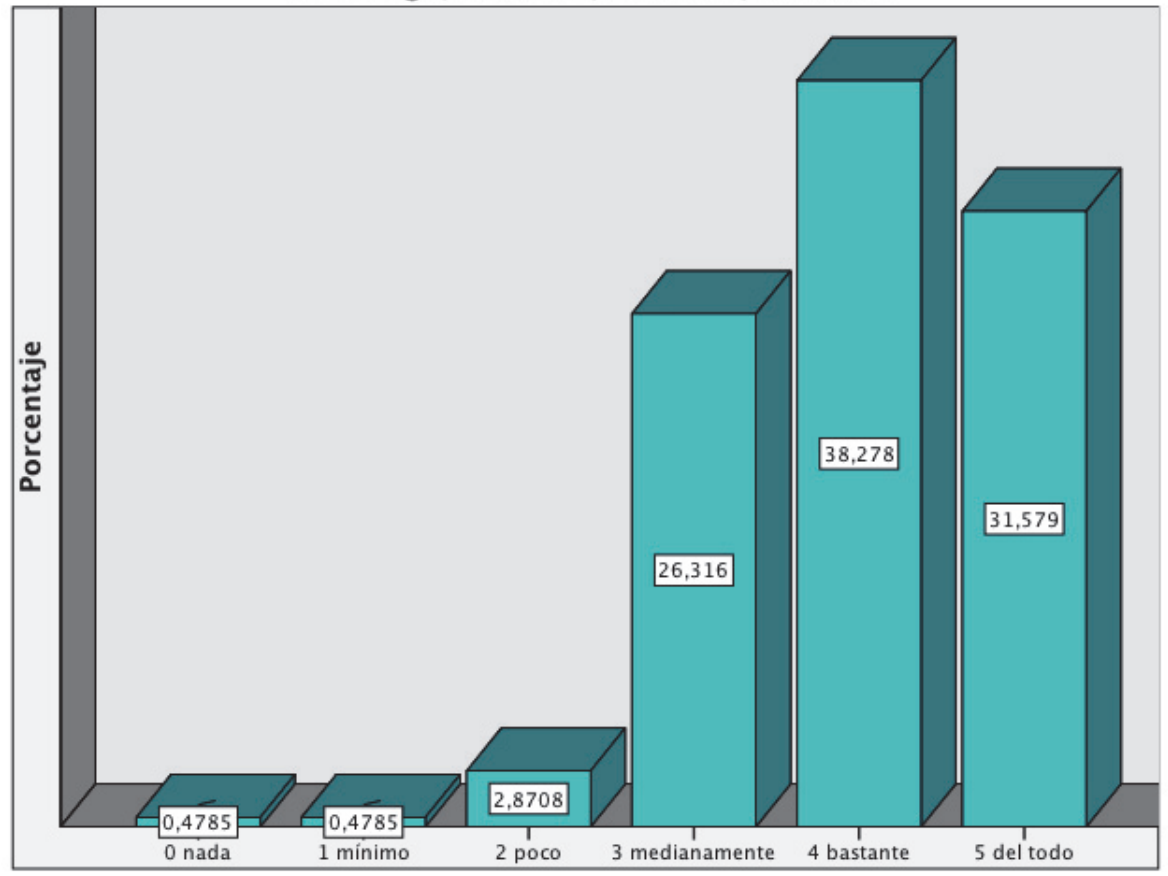

Elaboración propia. Mayo de 2015

Análisis: modelo en pirámide asimétrica sesgada a la derecha. El "Riesgo, aventura, estímulo, novedad" es un valor apreciado por la muestra en estudio.

Este valor encuentra una sintonía con el 67. Tecnología/ciencia, innovación en cuanto a la innovación y los dos han sido puntuados como importantes. Observamos coherencia en las respuestas y este resultado responde al perfil de una profesión con ansias de crecer. 
Cuadro $n^{\circ} 1.58$

58. Rigor técnico-profesional

\begin{tabular}{|l|r|r|r|r|}
\hline & Frecuencia & Porcentaje & $\begin{array}{c}\text { Porcentaje } \\
\text { válido }\end{array}$ & $\begin{array}{c}\text { Porcentaje } \\
\text { acumulado }\end{array}$ \\
\hline 1 mínimo & 1 &, 5 &, 5 &, 5 \\
2 poco & 11 & 5,3 & 5,3 & 5,7 \\
3 medianamente & 45 & 21,5 & 21,5 & 27,3 \\
4 bastante & 97 & 46,4 & 46,4 & 73,7 \\
5 del todo & 55 & 26,3 & 26,3 & 100,0 \\
Total & 209 & 100,0 & 100,0 & \\
\hline
\end{tabular}

Elaboración propia. Mayo de 2015

Gráfico $n^{\circ} 1.58$

58. Rigor técnico-profesional

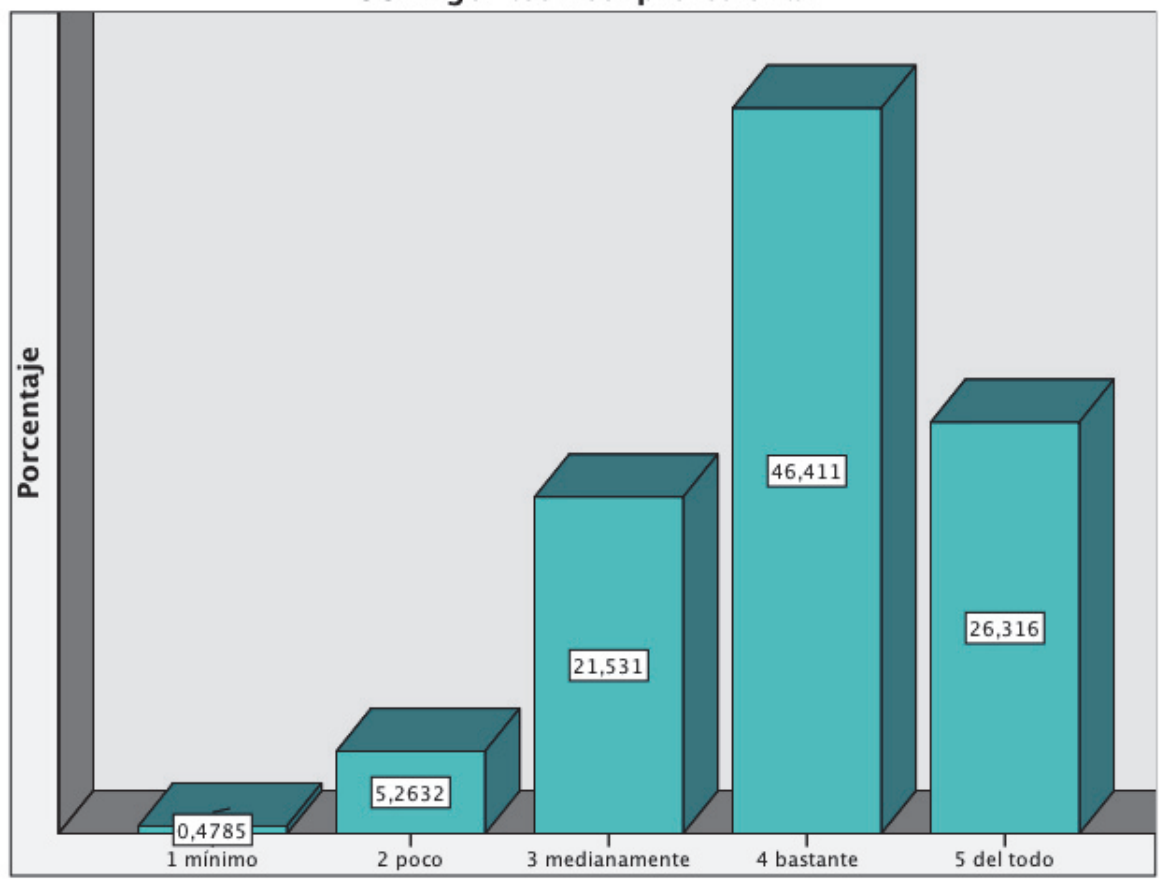

Elaboración propia. Mayo de 2015

Análisis: en le valor "Rigor técnico-profesional" observamos que no aparece el 0 , que los porcentajes del 4 y 5 suman casi las 3/4 partes. Modelo de pirámide asimétrica con sesgo a la derecha. Valor bastante importante para la muestra en estudio.

Valor relacionado con seguridad y la competencia profesional que forman el segundo bloque del ME de C. Resultado a favor de nuestra hipótesis. 
Cuadro $n^{\circ} 1.59$

59. Salud/bienestar

\begin{tabular}{|l|r|r|r|r|}
\hline & Frecuencia & Porcentaje & $\begin{array}{c}\text { Porcentaje } \\
\text { válido }\end{array}$ & $\begin{array}{c}\text { Porcentaje } \\
\text { acumulado }\end{array}$ \\
\hline 1 mínimo & 1 &, 5 &, 5 &, 5 \\
2 poco & 5 & 2,4 & 2,4 & 2,9 \\
3 medianamente & 12 & 5,7 & 5,7 & 8,6 \\
4 bastante & 63 & 30,1 & 30,1 & 38,8 \\
5 del todo & 128 & 61,2 & 61,2 & 100,0 \\
Total & 209 & 100,0 & 100,0 & \\
\hline
\end{tabular}

Elaboración propia. Mayo de 2015

Gráfico $\mathrm{n}^{\mathrm{0}} 1.59$

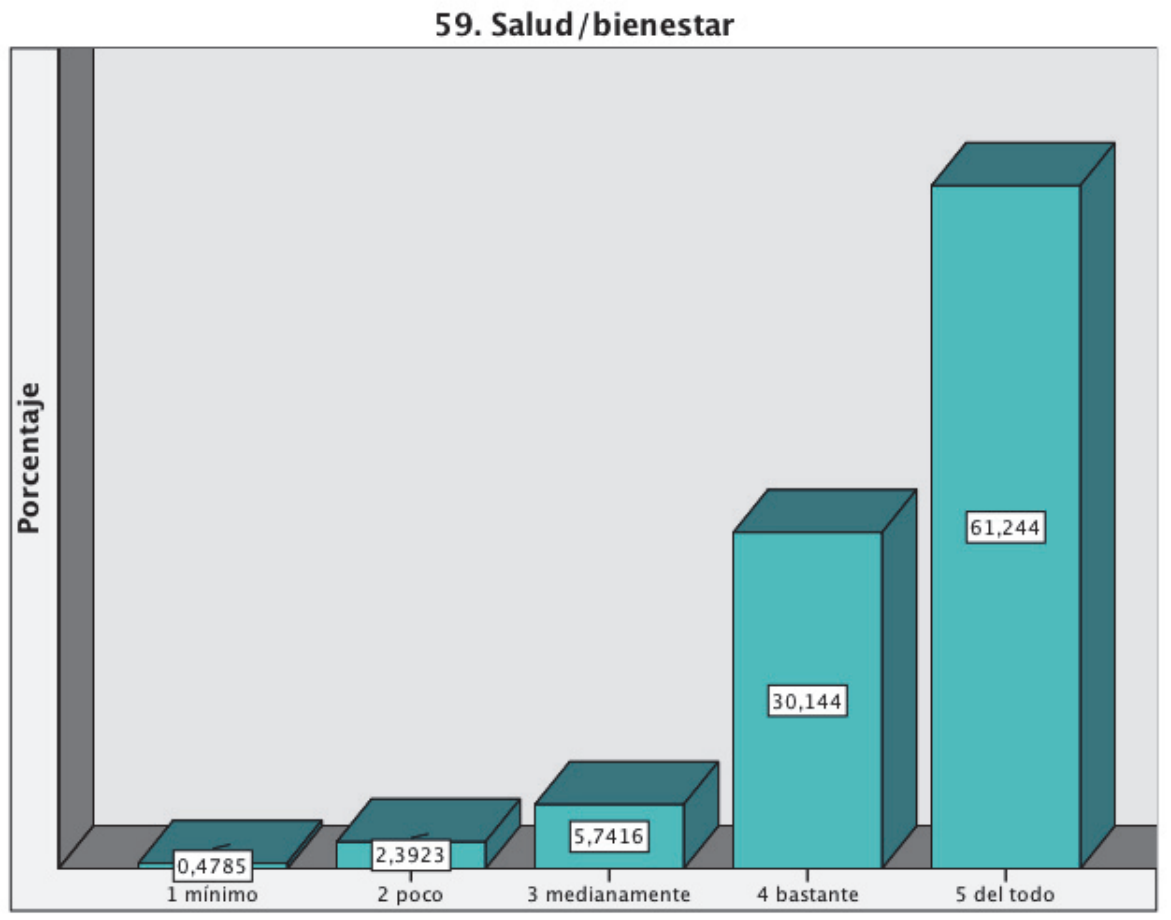

Elaboración propia. Mayo de 2015

Análisis: el valor "Salud, bienestar" carece del 0 y presenta un modelo de escalera ascendente con más de un $61 \%$ para el 5 . Valor considerado muy importante.

El bienestar forma parte del tercer bloque del ME de C, la armonía. El resultado responde al perfil de enfermería. 
Cuadro $n^{\circ} 1.60$

60. Seguridad

\begin{tabular}{|l|r|r|r|r|}
\hline & Frecuencia & Porcentaje & $\begin{array}{c}\text { Porcentaje } \\
\text { válido }\end{array}$ & $\begin{array}{r}\text { Porcentaje } \\
\text { acumulado }\end{array}$ \\
\hline 1 mínimo & 2 & 1,0 & 1,0 & 1,0 \\
2 poco & 4 & 1,9 & 1,9 & 2,9 \\
3 medianamente & 23 & 11,0 & 11,0 & 13,9 \\
4 bastante & 87 & 41,6 & 41,6 & 55,5 \\
5 del todo & 93 & 44,5 & 44,5 & 100,0 \\
Total & 209 & 100,0 & 100,0 & \\
\hline
\end{tabular}

Elaboración propia. Mayo de 2015

Gráfico $n^{\circ} 1.60$

60. Seguridad

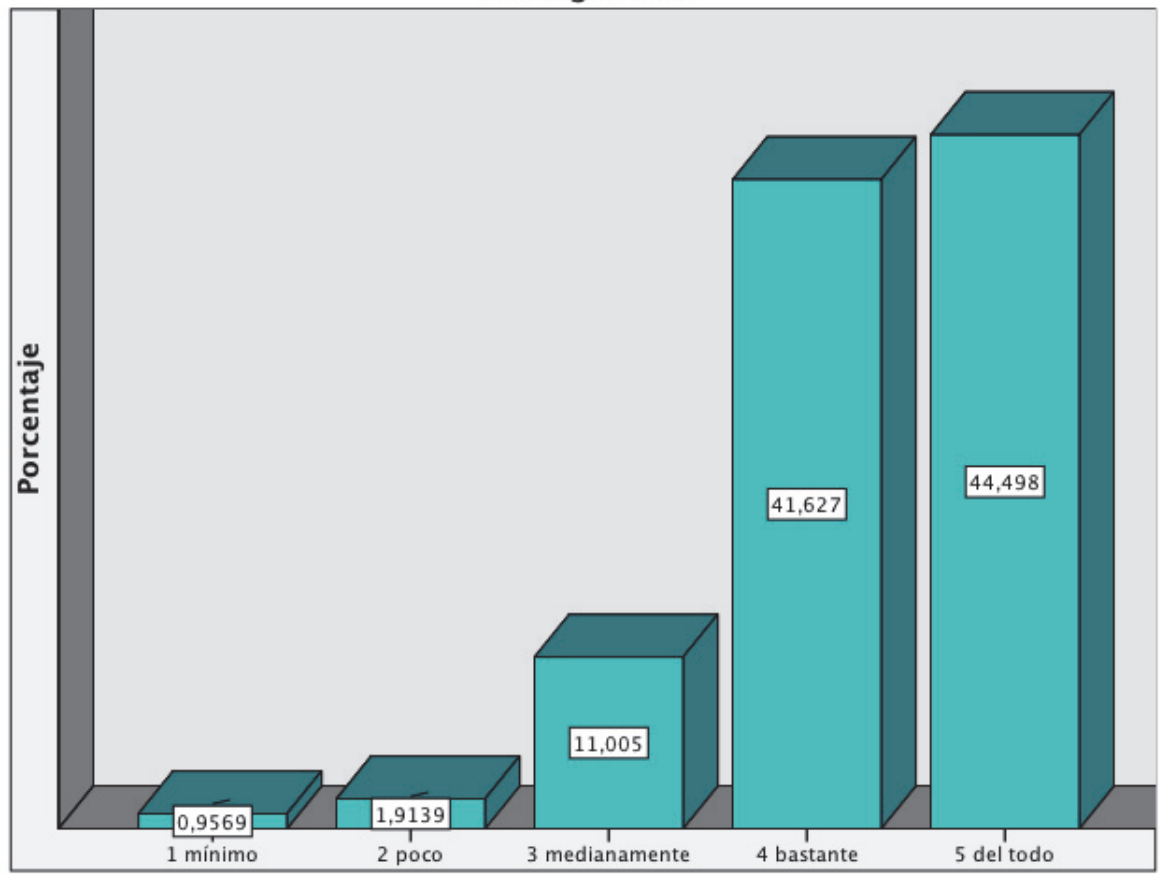

Elaboración propia. Mayo de 2015

Análisis: el valor "Seguridad" carece del 0 y presenta un modelo de escalera ascendente sumando el 4 y 5 mas $86 \%$. Valor catalogado como muy importante.

La seguridad constituye el segundo bloque en el ME de C. Los resultados obtenidos son acordes a la docencia impartida. 
Cuadro $n^{\circ} 1.61$

61. Sentido de la vergüenza

\begin{tabular}{|l|r|r|r|r|}
\hline & Frecuencia & Porcentaje & $\begin{array}{c}\text { Porcentaje } \\
\text { válido }\end{array}$ & $\begin{array}{r}\text { Porcentaje } \\
\text { acumulado }\end{array}$ \\
\hline 0 nada & 11 & 5,3 & 5,3 & 5,3 \\
1 mínimo & 9 & 4,3 & 4,3 & 9,6 \\
2 poco & 21 & 10,0 & 10,0 & 19,6 \\
3 medianamente & 62 & 29,7 & 29,7 & 49,3 \\
4 bastante & 53 & 25,4 & 25,4 & 74,6 \\
5 del todo & 53 & 25,4 & 25,4 & 100,0 \\
Total & 209 & 100,0 & 100,0 & \\
\hline
\end{tabular}

Elaboración propia. Mayo de 2015

Gráfico ${ }^{\circ} 1.61$

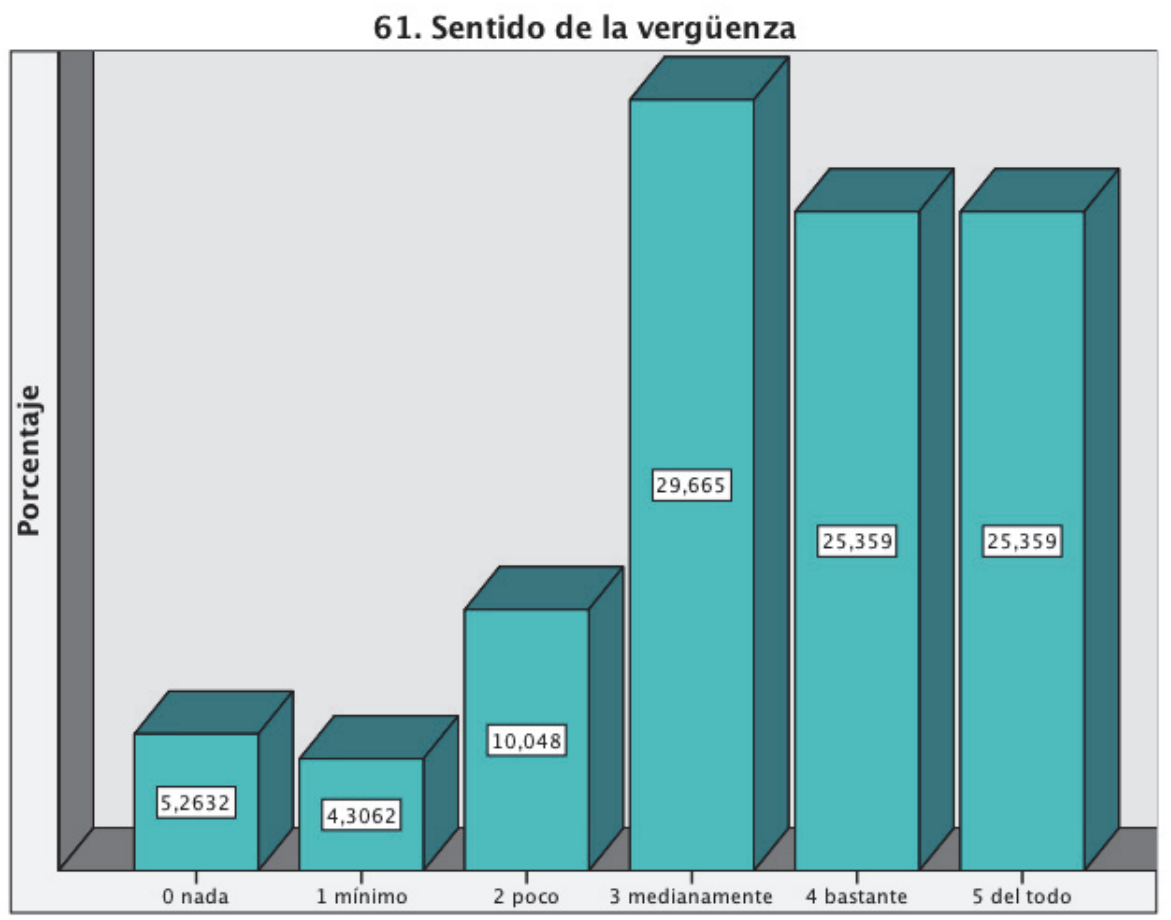

Elaboración propia. Mayo de 2015

Análisis: todas las puntuaciones están marcadas, con predominio del 3 que no llega al 30\%. Valor medianamente importante.

Veíamos en la parte teórica que la vergüenza es el mayor miedo masculino, mientras que para las mujeres es ser violadas o asesinadas. Los resultados para este valor corresponden al perfil de enfermería en cuanto a profesión feminizada. 
Cuadro $n^{\circ} 1.62$

62. Ser querido por los demás

\begin{tabular}{|l|r|r|r|r|}
\hline & Frecuencia & Porcentaje & $\begin{array}{c}\text { Porcentaje } \\
\text { válido }\end{array}$ & $\begin{array}{c}\text { Porcentaje } \\
\text { acumulado }\end{array}$ \\
\hline 1 mínimo & 2 & 1,0 & 1,0 & 1,0 \\
2 poco & 3 & 1,4 & 1,4 & 2,4 \\
3 medianamente & 19 & 9,1 & 9,1 & 11,5 \\
4 bastante & 79 & 37,8 & 37,8 & 49,3 \\
5 del todo & 106 & 50,7 & 50,7 & 100,0 \\
Total & 209 & 100,0 & 100,0 & \\
\hline
\end{tabular}

Elaboración propia. Mayo de 2015

Gráfico $n^{0} 1.62$

62. Ser querido por los demás

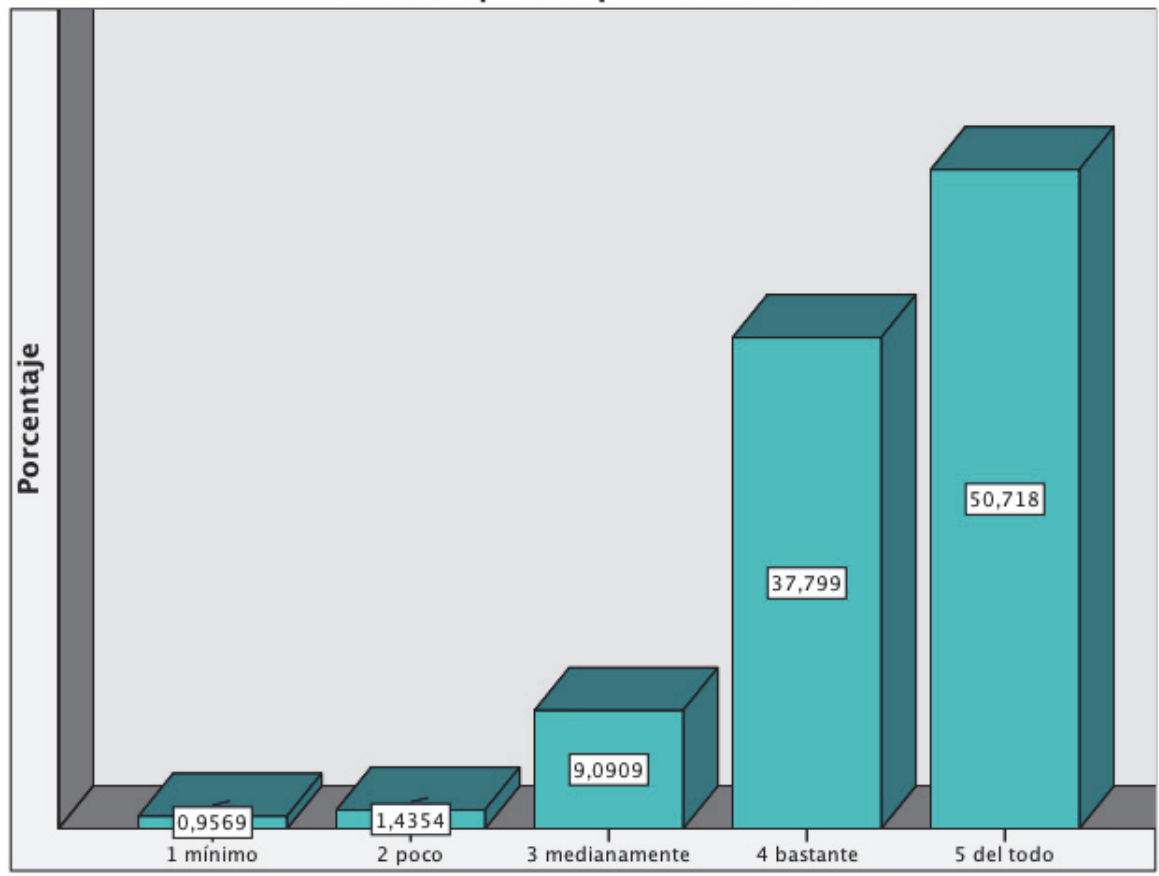

Elaboración propia. Mayo de 2015

Análisis: no aparece el 0 , el 1 y el 2 tienen porcentajes muy bajos, mientras que el 5 presenta más del $50 \%$ y el 4 y 5 suman casi el $89 \%$. Valor percibido como importante.

El ME de C quiere impulsar la eficiencia y también la humanización. Ser querido por los demás está en íntima relación con la humanización. Resultado muy a favor de nuestra hipótesis. 
Cuadro $n^{\circ} 1.63$

63. Servicio/vocación

\begin{tabular}{|l|r|r|r|r|}
\hline & Frecuencia & Porcentaje & $\begin{array}{c}\text { Porcentaje } \\
\text { válido }\end{array}$ & $\begin{array}{r}\text { Porcentaje } \\
\text { acumulado }\end{array}$ \\
\hline 0 nada & 3 & 1,4 & 1,4 & 1,4 \\
1 mínimo & 2 & 1,0 & 1,0 & 2,4 \\
2 poco & 6 & 2,9 & 2,9 & 5,3 \\
3 medianamente & 33 & 15,8 & 15,8 & 21,1 \\
4 bastante & 69 & 33,0 & 33,0 & 54,1 \\
5 del todo & 96 & 45,9 & 45,9 & 100,0 \\
Total & 209 & 100,0 & 100,0 & \\
\hline
\end{tabular}

Elaboración propia. Mayo de 2015

Gráfico $n^{\circ} 1.63$

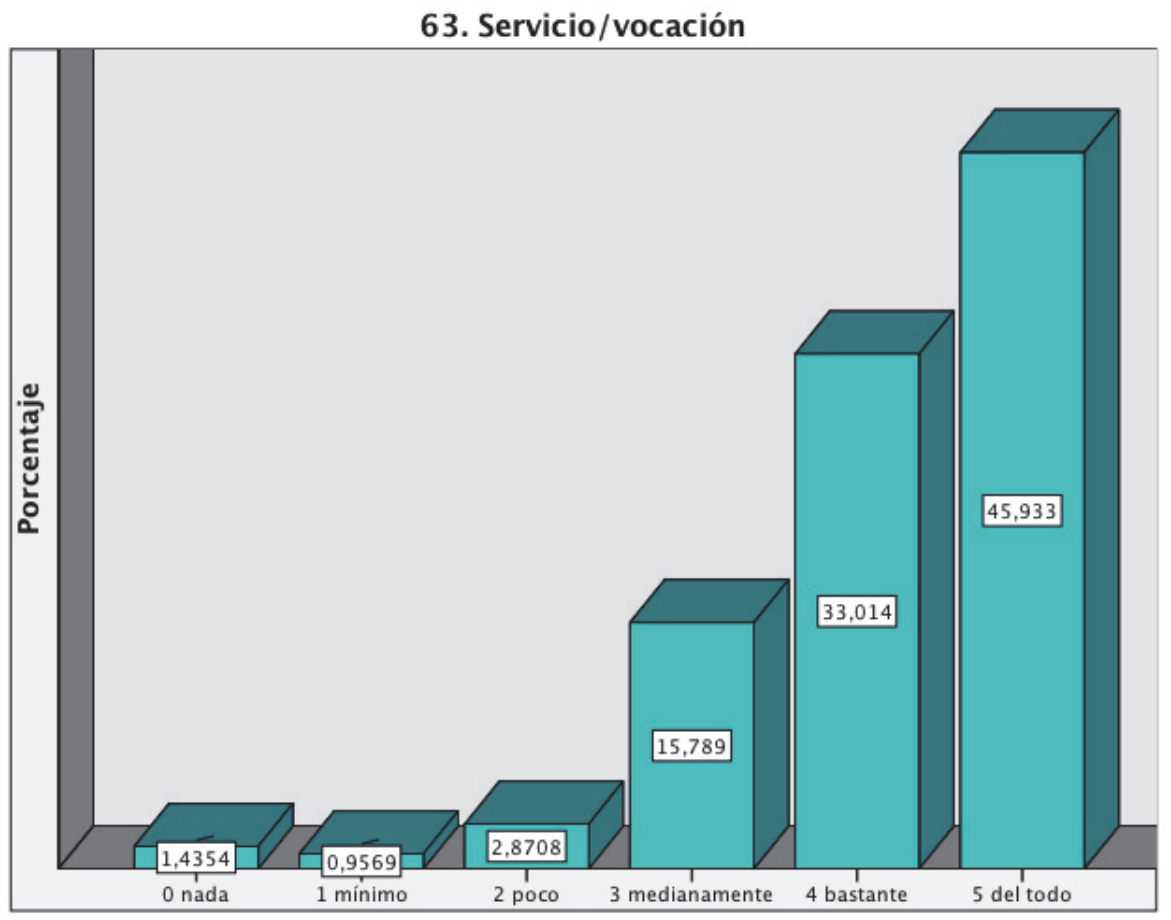

Elaboración propia. Mayo de 2015

Análisis: nos llama la atención que en una carrera típicamente vocacional, este valor presente las 3 puntuaciones más bajas marcadas. Por el resto vemos un modelo de escalera ascendente, con casi el $46 \%$ para el 5 . Es un valor que rige la VP para una gran parte de la muestra en estudio.

Resultados totalmente de acuerdo con el perfil de enfermería. Valor relacionado con humanización. 
Cuadro $n^{\circ} 1.64$

64. Simplicidad, rapidez, agilidad

\begin{tabular}{|l|r|r|r|r|}
\hline & Frecuencia & Porcentaje & $\begin{array}{c}\text { Porcentaje } \\
\text { válido }\end{array}$ & $\begin{array}{r}\text { Porcentaje } \\
\text { acumulado }\end{array}$ \\
\hline 0 nada & 2 & 1,0 & 1,0 & 1,0 \\
1 mínimo & 2 & 1,0 & 1,0 & 1,9 \\
2 poco & 10 & 4,8 & 4,8 & 6,7 \\
3 medianamente & 40 & 19,1 & 19,1 & 25,8 \\
4 bastante & 86 & 41,1 & 41,1 & 67,0 \\
5 del todo & 69 & 33,0 & 33,0 & 100,0 \\
Total & 209 & 100,0 & 100,0 & \\
\hline
\end{tabular}

Elaboración propia. Mayo de 2015

Gráfico $n^{\circ} 1.64$

64. Simplicidad, rapidez, agilidad

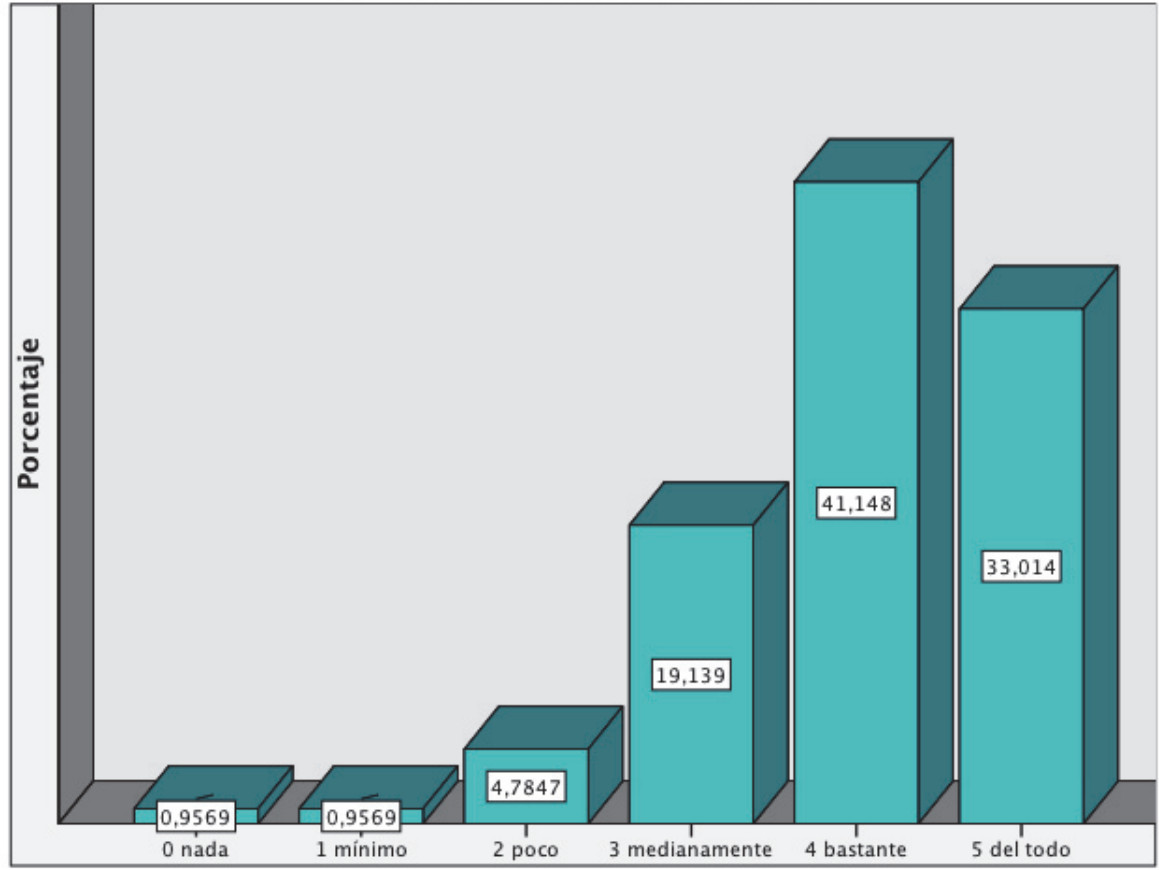

Elaboración propia. Mayo de 2015

Análisis: todas las puntuaciones están marcadas, con claro predominio de las más altas. Modelo en pirámide asimétrica con sesgo a la derecha. La "simplicidad, rapidez, agilidad" es un valor que gobierna de forma importante la VP.

Valor fundamental para obtener buenos resultados con menos medios, es decir para una alta eficiencia. 
Cuadro $n^{\circ} 1.65$

65. Solidaridad, generosidad

\begin{tabular}{|l|r|r|r|r|}
\hline & Frecuencia & Porcentaje & $\begin{array}{c}\text { Porcentaje } \\
\text { válido }\end{array}$ & $\begin{array}{c}\text { Porcentaje } \\
\text { acumulado }\end{array}$ \\
\hline 1 mínimo & 1 &, 5 &, 5 &, 5 \\
2 poco & 4 & 1,9 & 1,9 & 2,4 \\
3 medianamente & 20 & 9,6 & 9,6 & 12,0 \\
4 bastante & 72 & 34,4 & 34,4 & 46,4 \\
5 del todo & 112 & 53,6 & 53,6 & 100,0 \\
Total & 209 & 100,0 & 100,0 & \\
\hline
\end{tabular}

Elaboración propia. Mayo de 2015

Gráfico $\mathrm{n}^{\mathrm{0}} 1.65$

65. Solidadaridad, generosidad

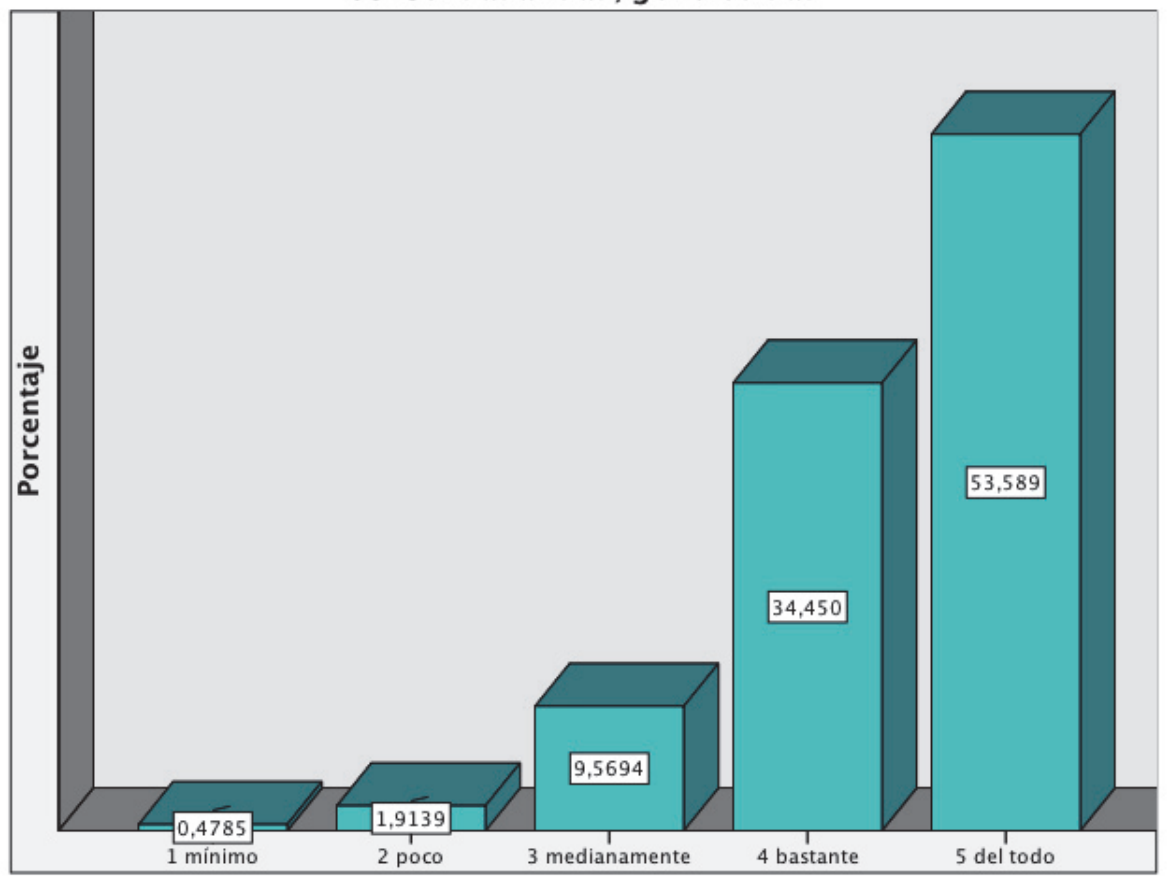

Elaboración propia. Mayo de 2015

Análisis: para nadie es "nada" significativo el valor "Solidaridad, generosidad" que presenta un modelo es escalera ascendente con más del 54\% para el 5 y el $88 \%$ para la suma del 4 y 5 . Valor considerado importante.

Valor relacionado con el Compromiso social que es el primero del ME de C y también con el valor 12. Compartir, generosidad que arroja resultados similares, lo cual evidencia la validez de las respuestas obtenidas. Estos resultados son muy favorables para dar por cierta nuestra hipótesis. 
Cuadro $n^{\circ} 1.66$

\section{Supervivencia material}

\begin{tabular}{|l|r|r|r|r|}
\hline & Frecuencia & Porcentaje & $\begin{array}{c}\text { Porcentaje } \\
\text { válido }\end{array}$ & $\begin{array}{r}\text { Porcentaje } \\
\text { acumulado }\end{array}$ \\
\hline 0 nada & 3 & 1,4 & 1,4 & 1,4 \\
2 poco & 16 & 7,7 & 7,7 & 9,1 \\
3 medianamente & 74 & 35,4 & 35,4 & 44,5 \\
4 bastante & 75 & 35,9 & 35,9 & 80,4 \\
5 del todo & 41 & 19,6 & 19,6 & 100,0 \\
Total & 209 & 100,0 & 100,0 & \\
\hline
\end{tabular}

Elaboración propia. Mayo de 2015

Gráfico $n^{0} 1.66$

66. Supervivencia material

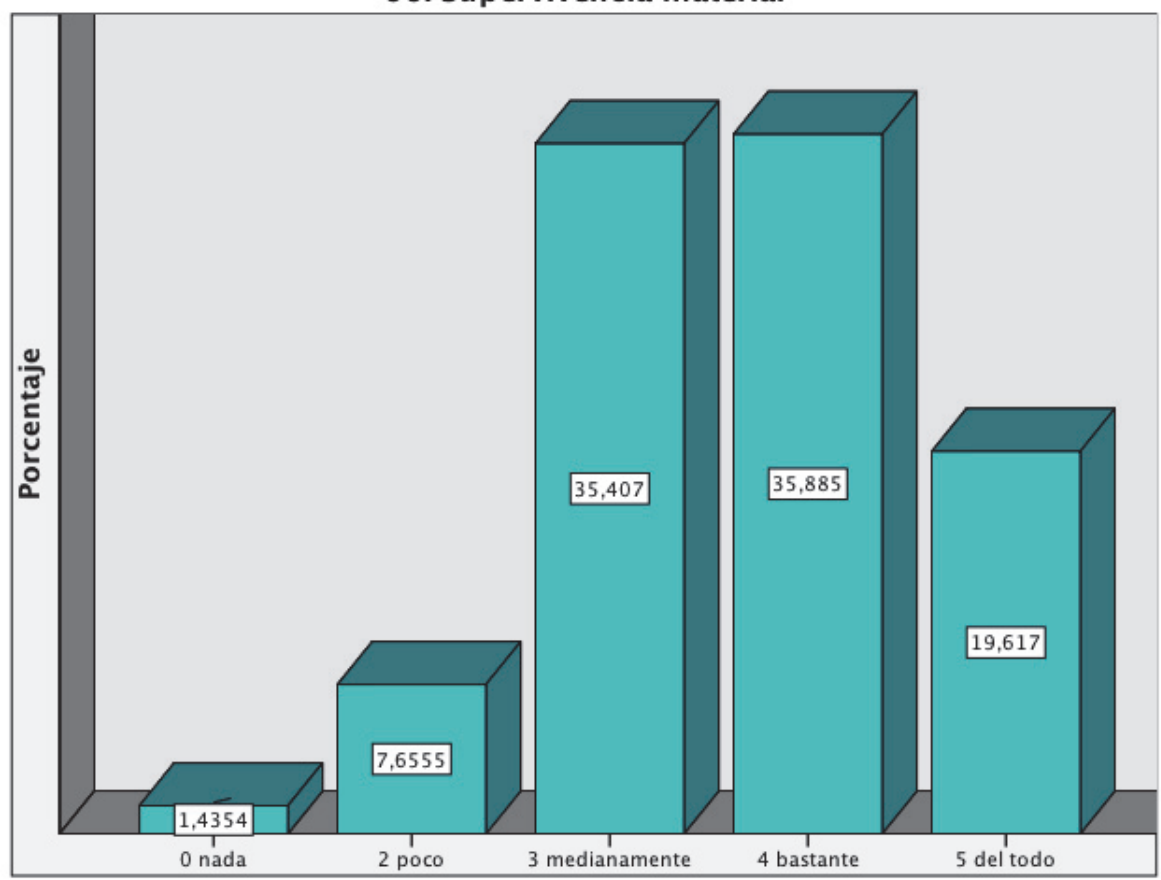

Elaboración propia. Mayo de 2015

Análisis: la "Supervivencia material" se muestra con un modelo de pirámide cayendo la mayor parte del peso en los valores centrales 3 y 4 . Valor moderadamente importante.

Los resultados evidencian que nos encontramos ante una profesión tradicionalmente feminizada que se ha desarrollado a través de la abnegación y la entrega. 
Cuadro $n^{\circ} 1.67$

67. Tecnología/ciencia, innovación

\begin{tabular}{|l|r|r|r|r|}
\hline & Frecuencia & Porcentaje & $\begin{array}{c}\text { Porcentaje } \\
\text { válido }\end{array}$ & $\begin{array}{r}\text { Porcentaje } \\
\text { acumulado }\end{array}$ \\
\hline 1 mínimo & 2 & 1,0 & 1,0 & 1,0 \\
2 poco & 14 & 6,7 & 6,7 & 7,7 \\
3 medianamente & 59 & 28,2 & 28,2 & 35,9 \\
4 bastante & 78 & 37,3 & 37,3 & 73,2 \\
5 del todo & 56 & 26,8 & 26,8 & 100,0 \\
Total & 209 & 100,0 & 100,0 & \\
\hline
\end{tabular}

Elaboración propia. Mayo de 2015

Gráfico $\mathrm{n}^{\mathrm{0}} 1.67$

\section{Tecnología/ciencia, innovación}

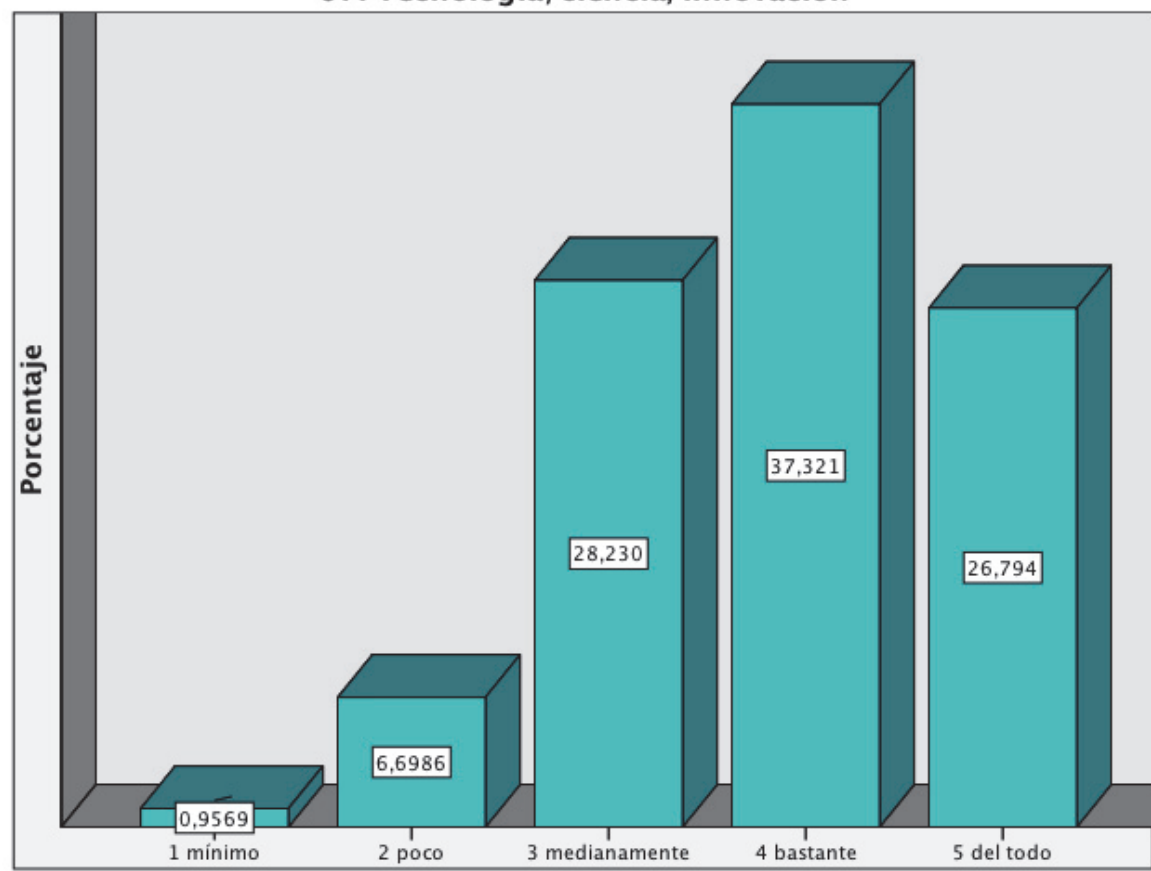

Elaboración propia. Mayo de 2015

Análisis: ausencia del 0 con más del 63\% para el 4 y 5 . Modelo de pirámide asimétrica con sesgo a la derecha. El valor "Tecnología/ciencia, innovación" se puede considerar bastante importante en la VP.

Al igual que decíamos para 57. Riesgo, aventura, estímulo, novedad, ambos valores coinciden en la innovación y ambos han sido muy bien puntuados, lo cual responde al perfil de una profesión con ansias de crecer. 
Cuadro $n^{\circ} 1.68$

68. Tiempo libre

\begin{tabular}{|l|r|r|r|r|}
\hline & Frecuencia & Porcentaje & $\begin{array}{c}\text { Porcentaje } \\
\text { válido }\end{array}$ & $\begin{array}{r}\text { Porcentaje } \\
\text { acumulado }\end{array}$ \\
\hline 0 nada & 3 & 1,4 & 1,4 & 1,4 \\
1 mínimo & 4 & 1,9 & 1,9 & 3,3 \\
2 poco & 10 & 4,8 & 4,8 & 8,1 \\
3 medianamente & 49 & 23,4 & 23,4 & 31,6 \\
4 bastante & 63 & 30,1 & 30,1 & 61,7 \\
5 del todo & 80 & 38,3 & 38,3 & 100,0 \\
Total & 209 & 100,0 & 100,0 & \\
\hline
\end{tabular}

Elaboración propia. Mayo de 2015

Gráfico n ${ }^{\circ} 1.68$

68. Tiempo libre

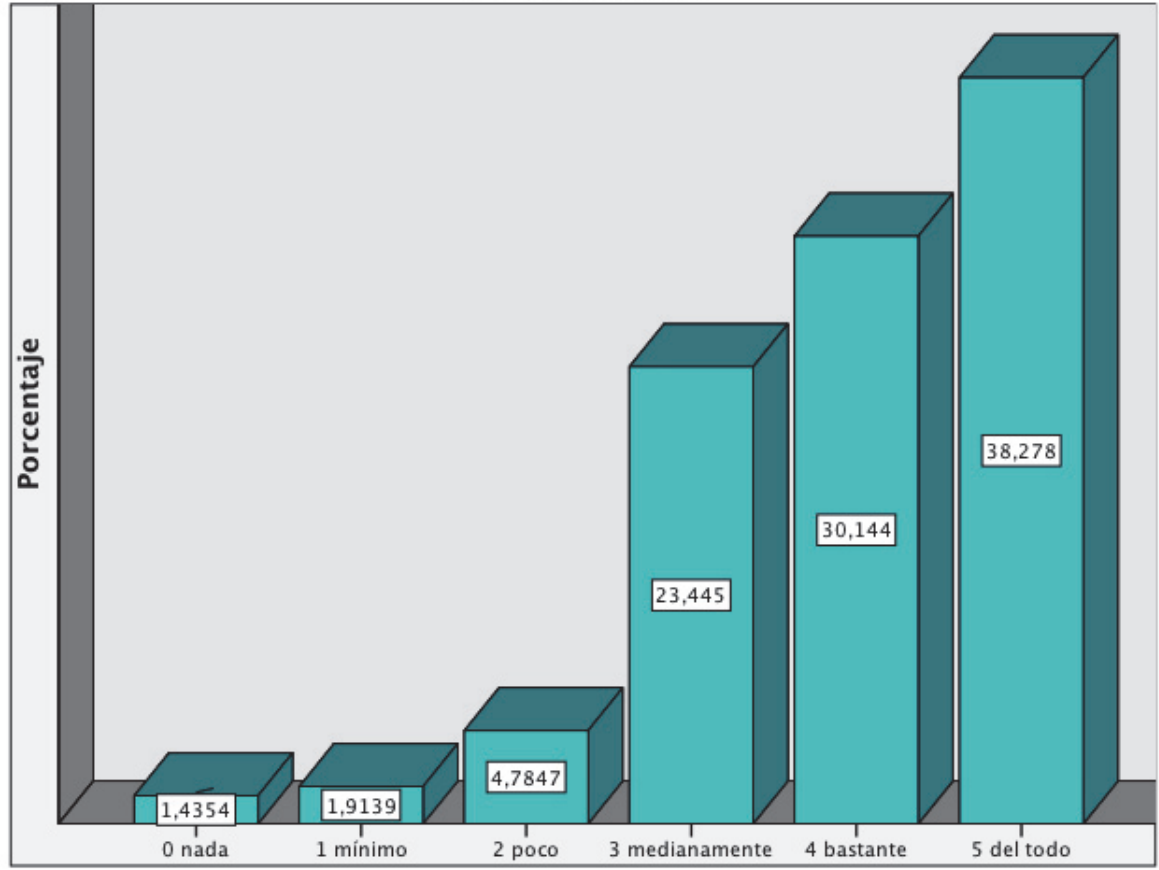

Elaboración propia. Mayo de 2015

Análisis: presencia de todas las puntuaciones en un modelo de escalera ascendente. El "Tiempo libre" es percibido como importante por la muestra en estudio.

Hace 50 años los resultados hubieran sido diferentes, estamos inmersos en la cultura del ocio y las respuestas se muestran coherentes con el momento en que vivimos. 
Cuadro $n^{0} 1.69$

69. Tradición, conservación

\begin{tabular}{|l|r|r|r|r|}
\hline & Frecuencia & Porcentaje & $\begin{array}{c}\text { Porcentaje } \\
\text { válido }\end{array}$ & $\begin{array}{c}\text { Porcentaje } \\
\text { acumulado }\end{array}$ \\
\hline 0 nada & 21 & 10,0 & 10,0 & 10,0 \\
1 mínimo & 15 & 7,2 & 7,2 & 17,2 \\
2 poco & 39 & 18,7 & 18,7 & 35,9 \\
3 medianamente & 53 & 25,4 & 25,4 & 61,2 \\
4 bastante & 55 & 26,3 & 26,3 & 87,6 \\
5 del todo & 26 & 12,4 & 12,4 & 100,0 \\
Total & 209 & 100,0 & 100,0 & \\
\hline
\end{tabular}

Elaboración propia. Mayo de 2015

Gráfico n ${ }^{\circ} 1.69$

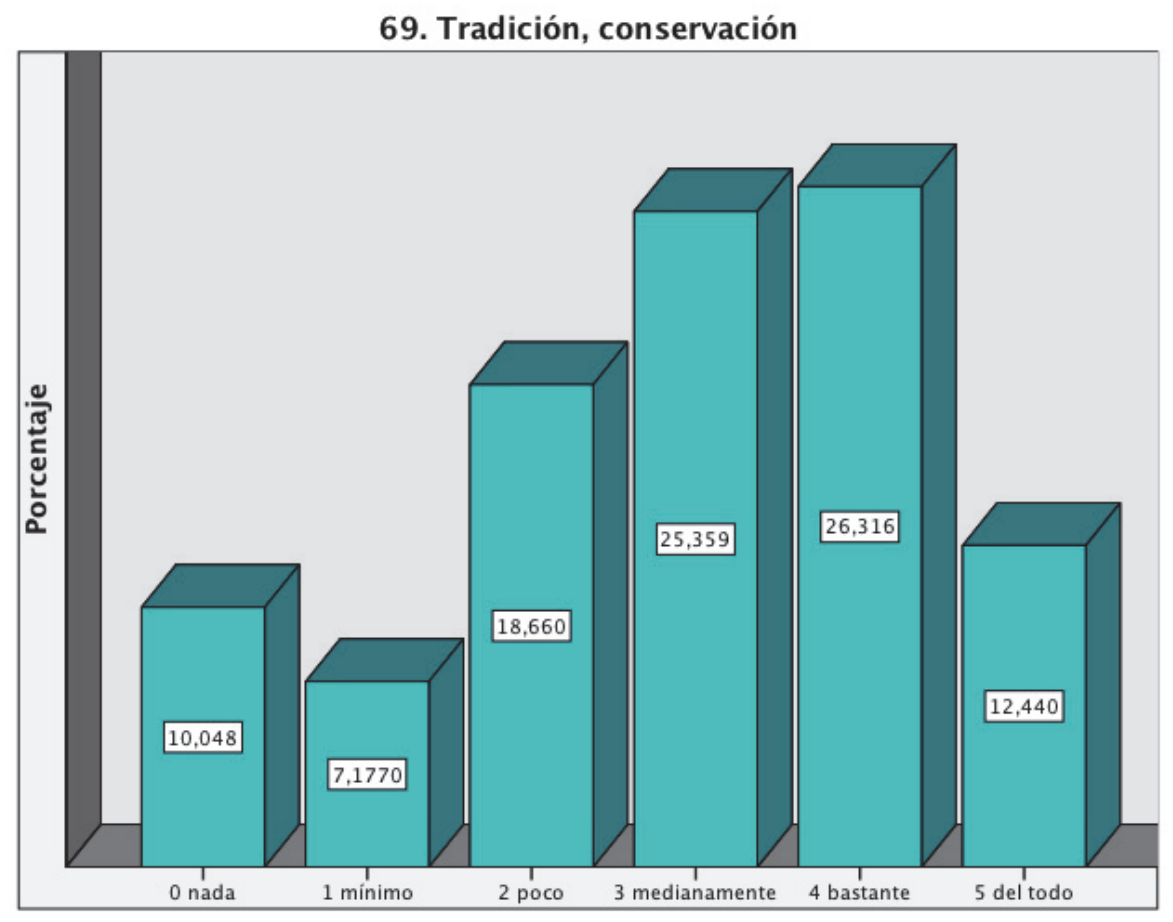

Elaboración propia. Mayo de 2015

Análisis: todas las puntuaciones están marcadas de forma significativa. Modelo de pirámide. Los porcentajes más altos que corresponden al 3 y 4, representan algo más del 50\% entre ambos de forma equitativa, el 5 no llega al $13 \%$ y las puntuaciones 0,1 y 2 suman casi un $36 \%$. Este no es un valor catalogado como importante en la VP.

Al igual que para el ítem anterior, estos resultados traducen coherentemente el momento de hoy, en que los cambios acontecen a velocidad exponencial. 
Cuadro $n^{\circ} 1.70$

70. Trascendencia, utilidad para otros

\begin{tabular}{|l|r|r|r|r|}
\hline & Frecuencia & Porcentaje & $\begin{array}{c}\text { Porcentaje } \\
\text { válido }\end{array}$ & $\begin{array}{r}\text { Porcentaje } \\
\text { acumulado }\end{array}$ \\
\hline 1 mínimo & 2 & 1,0 & 1,0 & 1,0 \\
2 poco & 8 & 3,8 & 3,8 & 4,8 \\
3 medianamente & 61 & 29,2 & 29,2 & 34,0 \\
4 bastante & 93 & 44,5 & 44,5 & 78,5 \\
5 del todo & 45 & 21,5 & 21,5 & 100,0 \\
Total & 209 & 100,0 & 100,0 & \\
\hline
\end{tabular}

Elaboración propia. Mayo de 2015

Gráfico $n^{\circ} 1.70$

70. Trascendencia, utilidad para otros

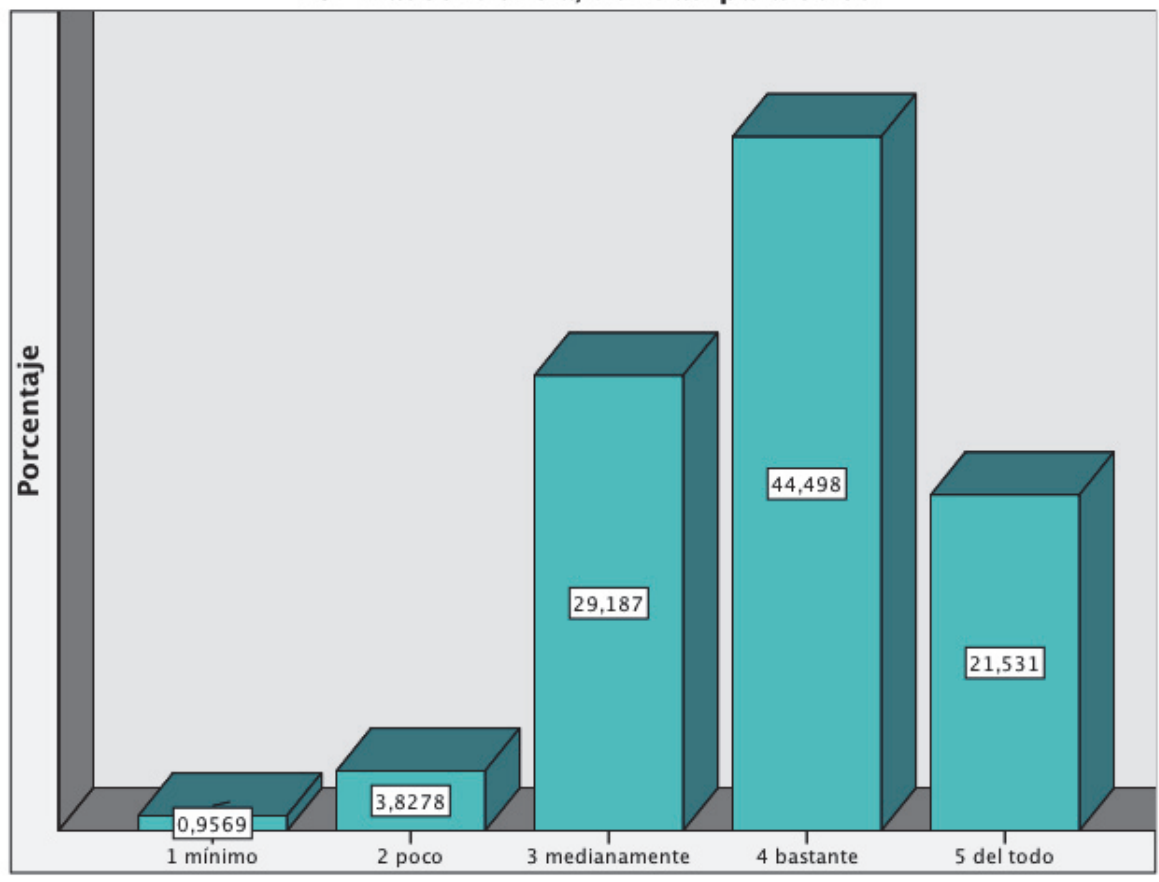

Elaboración propia. Mayo de 2015

Análisis: ausencia del 0.1 y 2 con una representación muy baja. Las puntuaciones se concentran en el 3, 4, y 5. Modelo en pirámide asimétrica sesgada a la derecha. El valor "Trascendencia, utilidad para otros" realmente gobierna la VP de la muestra en estudio.

Resultados acordes con el perfil de enfermería, profesión que está al servicio de la salud ajena y del bienestar del enfermo. 
Cuadro $n^{\circ} 1.71$

71. Valentía, coraje

\begin{tabular}{|l|r|r|r|r|}
\hline & Frecuencia & Porcentaje & $\begin{array}{c}\text { Porcentaje } \\
\text { válido }\end{array}$ & $\begin{array}{c}\text { Porcentaje } \\
\text { acumulado }\end{array}$ \\
\hline 1 mínimo & 1 &, 5 &, 5 &, 5 \\
2 poco & 3 & 1,4 & 1,4 & 1,9 \\
3 medianamente & 58 & 27,8 & 27,8 & 29,7 \\
4 bastante & 80 & 38,3 & 38,3 & 67,9 \\
5 del todo & 67 & 32,1 & 32,1 & 100,0 \\
Total & 209 & 100,0 & 100,0 & \\
\hline
\end{tabular}

Elaboración propia. Mayo de 2015

Gráfico $\mathrm{n}^{\mathrm{0}} 1.71$

71. Valentia, coraje

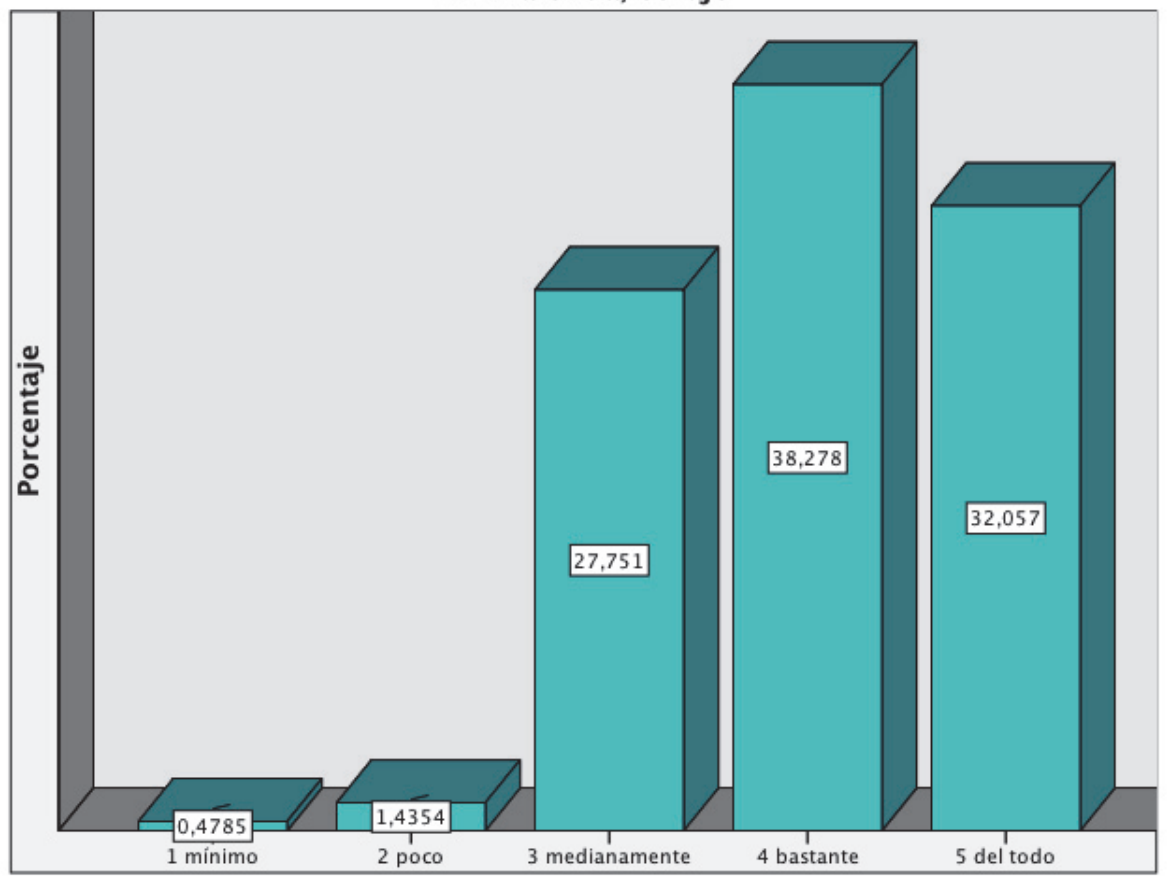

Elaboración propia. Mayo de 2015

Análisis: ausencia del 0, escasa expresión del 1 y 2, y concentración de los porcentajes para el 3, 4 y 5. Modelo de pirámide. Valor considerado como importante.

La RAE define valor como "Cualidad del ánimo, que mueve a acometer resueltamente grandes empresas y a arrostrar los peligros."; y que de hecho esta definición engloba las tres dimensiones: la psicológica o coraje, la éticoestratégica y la económico-empresarial. Vemos que vamos obteniendo resultados muy buenos para nuestra investigación. 
Cuadro $\mathrm{n}^{\mathrm{o}} 1.72$

72. Verdad/sabiduría (búsqueda de la)

\begin{tabular}{|l|r|r|r|r|}
\hline & Frecuencia & Porcentaje & $\begin{array}{c}\text { Porcentaje } \\
\text { válido }\end{array}$ & $\begin{array}{r}\text { Porcentaje } \\
\text { acumulado }\end{array}$ \\
\hline 2 poco & 2 & 1,0 & 1,0 & 1,0 \\
3 medianamente & 23 & 11,0 & 11,0 & 12,0 \\
4 bastante & 71 & 34,0 & 34,0 & 45,9 \\
5 del todo & 113 & 54,1 & 54,1 & 100,0 \\
Total & 209 & 100,0 & 100,0 & \\
\hline
\end{tabular}

Elaboración propia. Mayo de 2015

Gráfico $n^{\circ} 1.72$

72. Verdad/sabiduría (búsqueda de la)

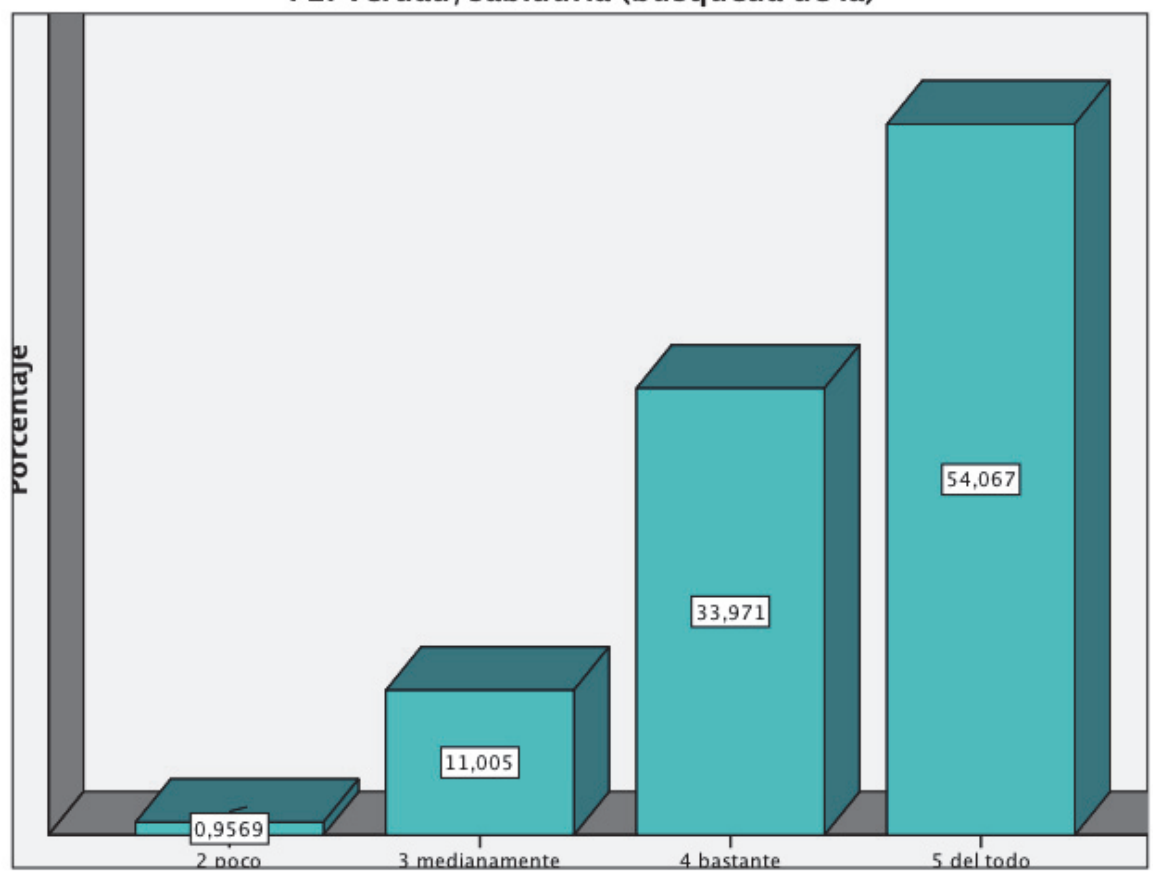

Elaboración propia. Mayo de 2015

Análisis: ausencia del 0 y 1. Escasa expresión del 2. Modelo de escalera ascendente con más de un 54\% para el 5. "La verdad/sabiduría (búsqueda de la)" gobierna realmente la VP.

Existe evidentemente una relación de este valor con otros como 58. Rigor técnico-profesional, 60. Seguridad, 67. Tecnología/ciencia, innovación y en todos hemos obtenido resultados similares que coinciden con el perfil de enfermería, profesión en desarrollo. 
Esfera Mundo de la empresa 

Cuadro $n^{\circ} 2.1$

1. Adaptación a los cambios, flexibilidad

\begin{tabular}{|l|r|r|r|r|}
\hline & Frecuencia & Porcentaje & $\begin{array}{c}\text { Porcentaje } \\
\text { válido }\end{array}$ & $\begin{array}{r}\text { Porcentaje } \\
\text { acumulado }\end{array}$ \\
\hline 0 nada & 2 & 1,0 & 1,0 & 1,0 \\
1 mínimo & 7 & 3,3 & 3,3 & 4,3 \\
2 poco & 25 & 12,0 & 12,0 & 16,3 \\
3 medianamente & 50 & 23,9 & 23,9 & 40,2 \\
4 bastante & 74 & 35,4 & 35,4 & 75,6 \\
5 del todo & 51 & 24,4 & 24,4 & 100,0 \\
Total & 209 & 100,0 & 100,0 & \\
\hline
\end{tabular}

Elaboración propia. Mayo de 2015

Gráfico $n^{\circ} 2.1$

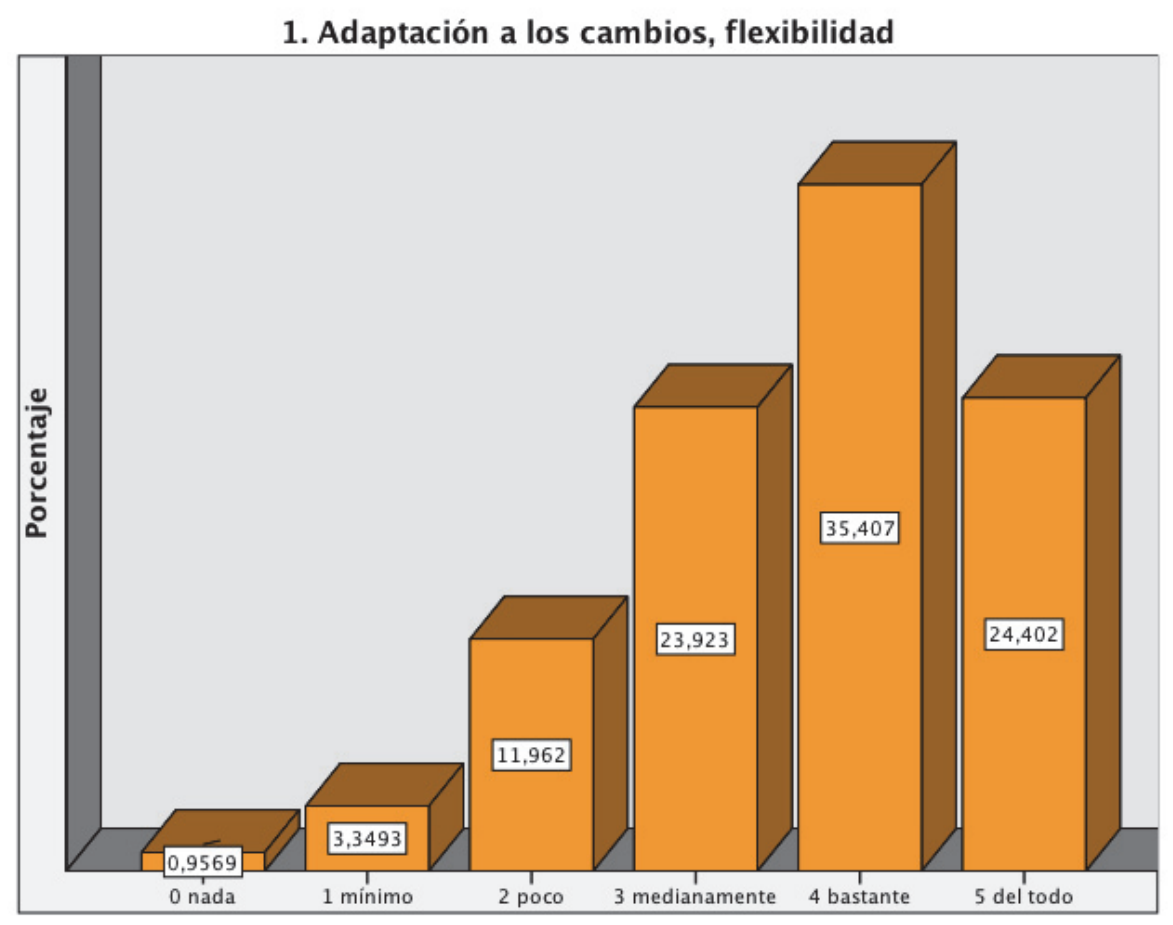

Elaboración propia. Mayo de 2015

Análisis: modelo en pirámide asimétrica con sesgo a la derecha, al igual que en el área de mi VP. El peso recae sobre los valores altos con predominio del 4. El valor "Adaptación a los cambios, flexibilidad" en el "mundo de la empresa" (M.E.) aparece algo más repartido entre todas las puntuaciones que para VP, pero sigue un comportamiento similar en ambas áreas.

El alumnado percibe que la flexibilidad y la adaptación a los cambios es algo muy importante para el SNS. No observamos divergencias entre la percepción personal y la que corresponde al mundo de la empresa. 
Cuadro $n^{\circ} 2.2$

2. Ahorro, austeridad

\begin{tabular}{|l|r|r|r|r|}
\hline & Frecuencia & Porcentaje & $\begin{array}{c}\text { Porcentaje } \\
\text { válido }\end{array}$ & $\begin{array}{c}\text { Porcentaje } \\
\text { acumulado }\end{array}$ \\
\hline 0 nada & 1 &, 5 &, 5 &, 5 \\
1 mínimo & 6 & 2,9 & 2,9 & 3,3 \\
2 poco & 25 & 12,0 & 12,0 & 15,3 \\
3 medianamente & 59 & 28,2 & 28,2 & 43,5 \\
4 bastante & 64 & 30,6 & 30,6 & 74,2 \\
5 del todo & 54 & 25,8 & 25,8 & 100,0 \\
Total & 209 & 100,0 & 100,0 & \\
\hline
\end{tabular}

Elaboración propia. Mayo de 2015

Gráfico $\mathrm{n}^{\mathrm{o}} 2.2$

\section{Ahorro, austeridad}

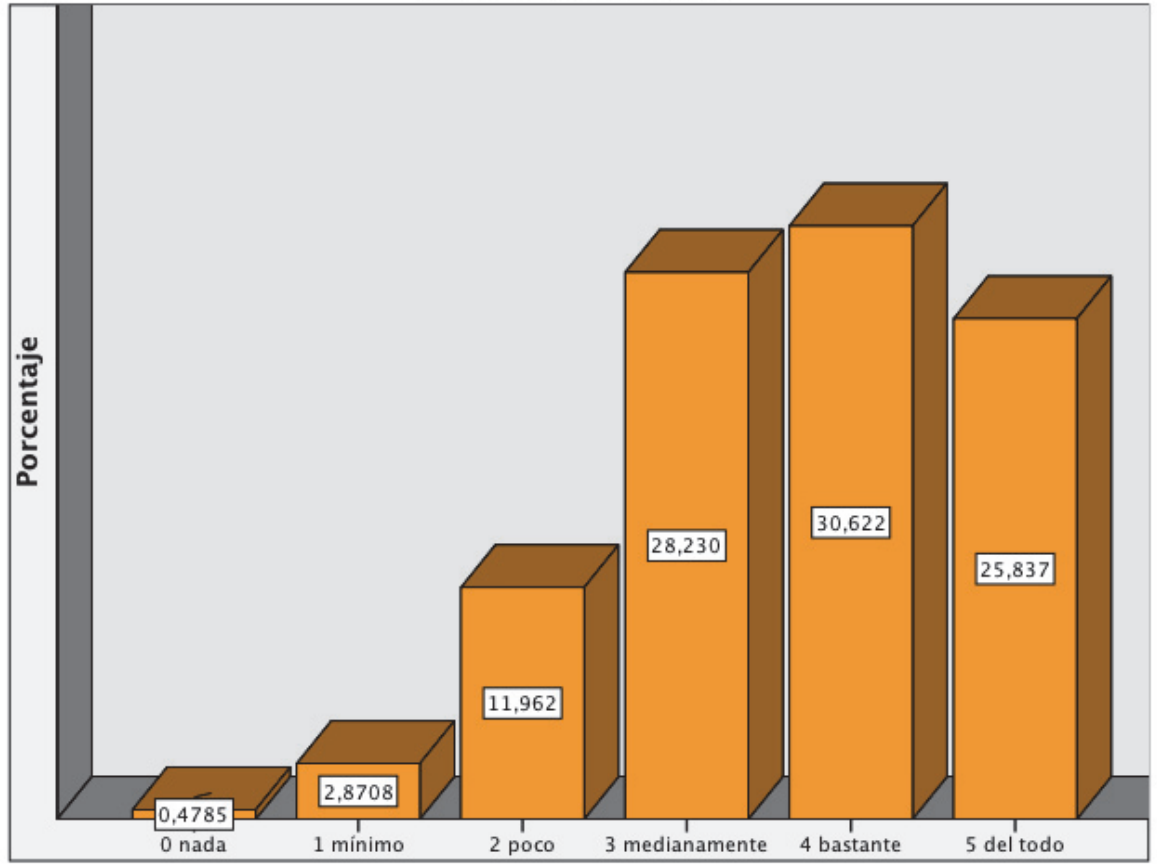

Elaboración propia. Mayo de 2015

Análisis: modelo de escalera aplanada: los porcentajes van subiendo en escalera a nivel de las puntuaciones bajas para luego variar poco a nivel de las puntuaciones más altas. Más del 25\% considera que "Ahorro, austeridad" gobierna "del todo" el ME frente al 12\% que piensa lo mismo para la VP.

El alumnado percibe mayor importancia para ahorro/austeridad dentro de la empresa que en la propia vida personal, demuestra ser consciente de la necesidad del buen uso de los recursos en el SNS. 
Cuadro $n^{\circ} 2.3$

3. Alegría, sentido del humor

\begin{tabular}{|l|r|r|r|r|}
\hline & Frecuencia & Porcentaje & $\begin{array}{c}\text { Porcentaje } \\
\text { válido }\end{array}$ & $\begin{array}{r}\text { Porcentaje } \\
\text { acumulado }\end{array}$ \\
\hline 0 nada & 5 & 2,4 & 2,4 & 2,4 \\
1 mínimo & 13 & 6,2 & 6,2 & 8,6 \\
2 poco & 36 & 17,2 & 17,2 & 25,8 \\
3 medianamente & 52 & 24,9 & 24,9 & 50,7 \\
4 bastante & 55 & 26,3 & 26,3 & 77,0 \\
5 del todo & 48 & 23,0 & 23,0 & 100,0 \\
Total & 209 & 100,0 & 100,0 & \\
\hline
\end{tabular}

Elaboración propia. Mayo de 2015

Gráfico $\mathrm{n}^{\circ} 2.3$

\section{Alegría, sentido del humor}

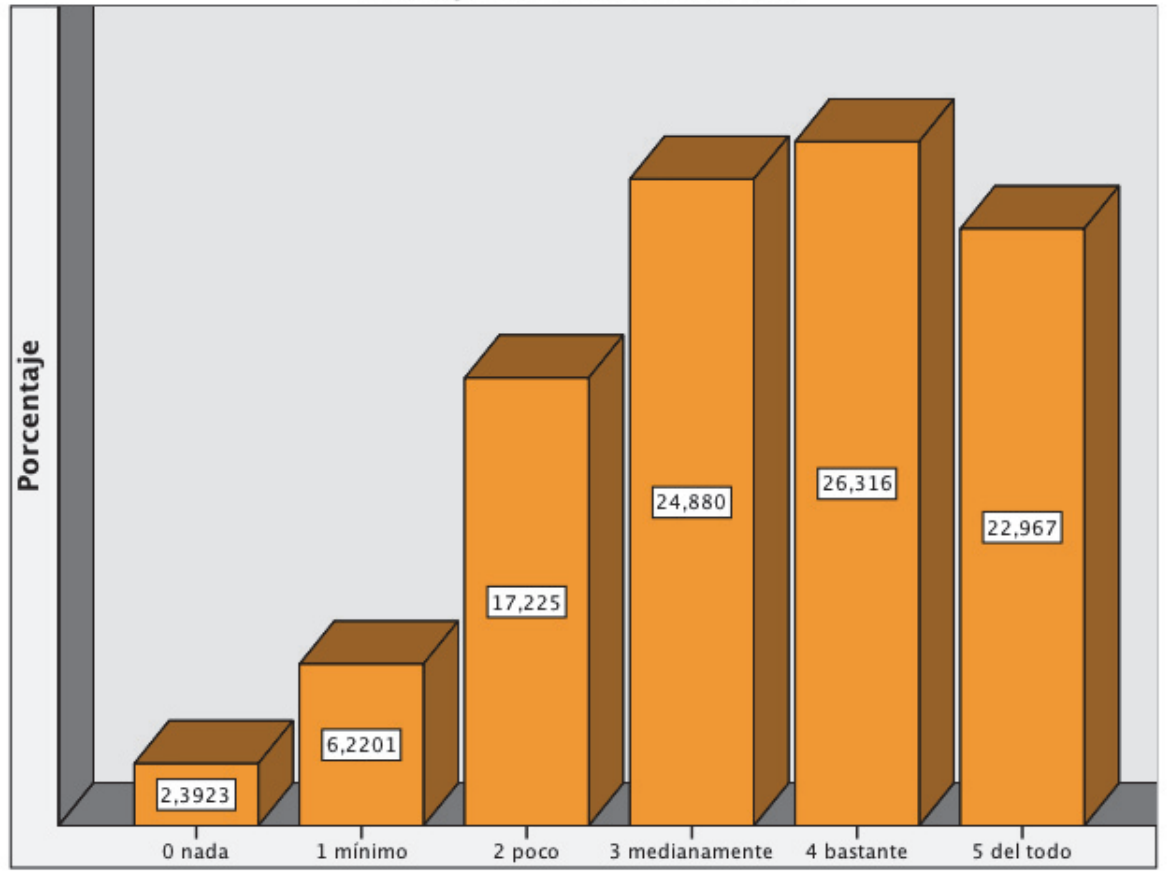

Elaboración propia. Mayo de 2015

Análisis: modelo en escalera aplanada. Comparando el mismo valor en mi VP observamos que los encuestados consideran que "Alegría, sentido del humor" interviene más en el gobierno de la VP que en el del ME.

Estas respuestas ponen de manifiesto que el alumnado ve su futuro profesional con alegría, y no es una profesión exenta de esfuerzo, lo que hace pensar que tienen vocación. 
Cuadro $n^{\circ} 2.4$

\section{Amistad}

\begin{tabular}{|l|r|r|r|r|}
\hline & Frecuencia & Porcentaje & $\begin{array}{c}\text { Porcentaje } \\
\text { válido }\end{array}$ & $\begin{array}{r}\text { Porcentaje } \\
\text { acumulado }\end{array}$ \\
\hline 0 nada & 7 & 3,3 & 3,3 & 3,3 \\
1 mínimo & 16 & 7,7 & 7,7 & 11,0 \\
2 poco & 39 & 18,7 & 18,7 & 29,7 \\
3 medianamente & 48 & 23,0 & 23,0 & 52,6 \\
4 bastante & 61 & 29,2 & 29,2 & 81,8 \\
5 del todo & 38 & 18,2 & 18,2 & 100,0 \\
Total & 209 & 100,0 & 100,0 & \\
\hline
\end{tabular}

Elaboración propia. Mayo de 2015

Gráfico $\mathrm{n}^{\circ} 2.4$

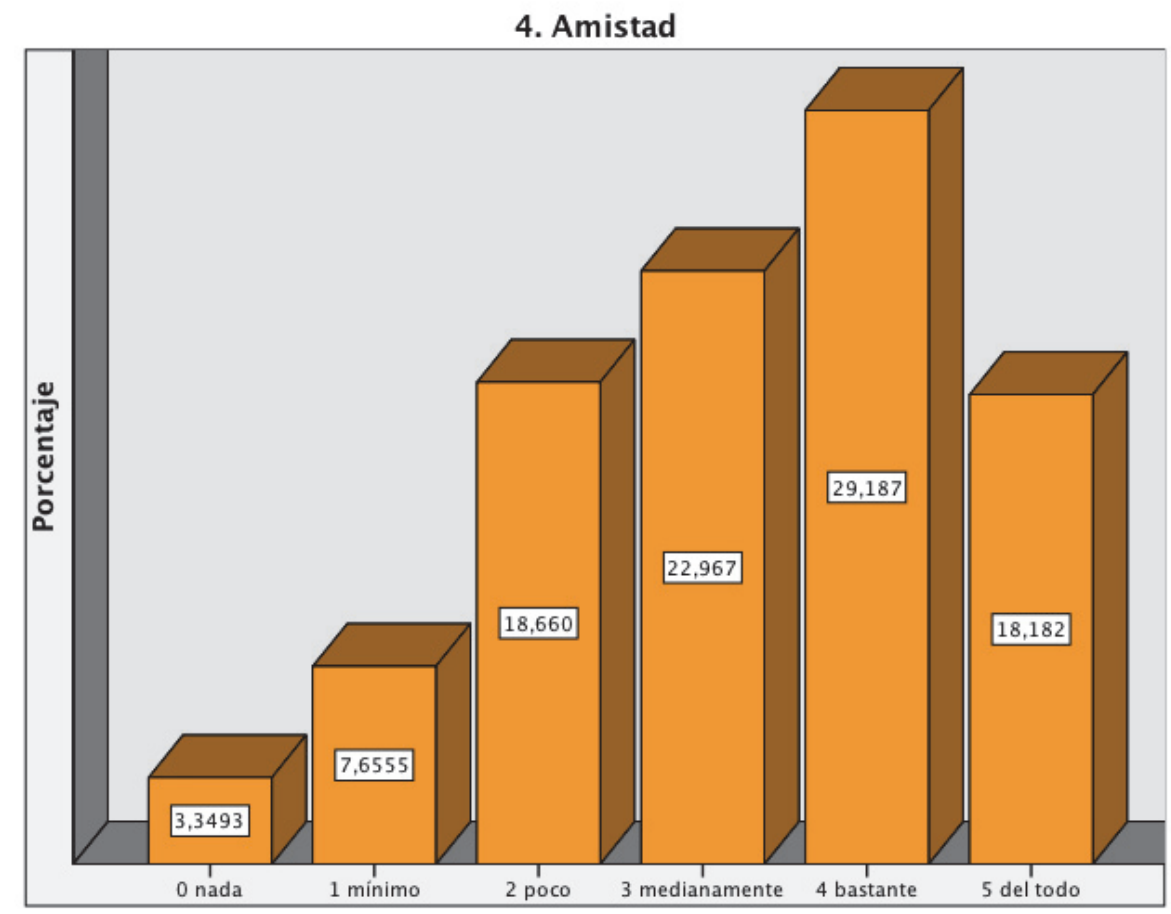

Elaboración propia. Mayo de 2015

Análisis: modelo en pirámide con mayor peso en los valores altos pero con representación de todos las puntuaciones, incluidas las más bajas. Las respuestas indican una mayor importancia de este valor en la VP que en el ME:

Como decíamos al comentar este valor para la VP, la amistad está íntimamente relacionada con la solidaridad, valor fundamental en enfermería. 
Cuadro $n^{\circ} 2.5$

5. Anticipación, previsión

\begin{tabular}{|l|r|r|r|r|}
\hline & Frecuencia & Porcentaje & $\begin{array}{c}\text { Porcentaje } \\
\text { válido }\end{array}$ & $\begin{array}{c}\text { Porcentaje } \\
\text { acumulado }\end{array}$ \\
\hline 0 nada & 1 &, 5 &, 5 &, 5 \\
1 mínimo & 2 & 1,0 & 1,0 & 1,4 \\
2 poco & 8 & 3,8 & 3,8 & 5,3 \\
3 medianamente & 53 & 25,4 & 25,4 & 30,6 \\
4 bastante & 102 & 48,8 & 48,8 & 79,4 \\
5 del todo & 43 & 20,6 & 20,6 & 100,0 \\
Total & 209 & 100,0 & 100,0 & \\
\hline
\end{tabular}

Elaboración propia. Mayo de 2015

Gráfico $n^{\circ} 2.5$

\section{Anticipación, previsión}

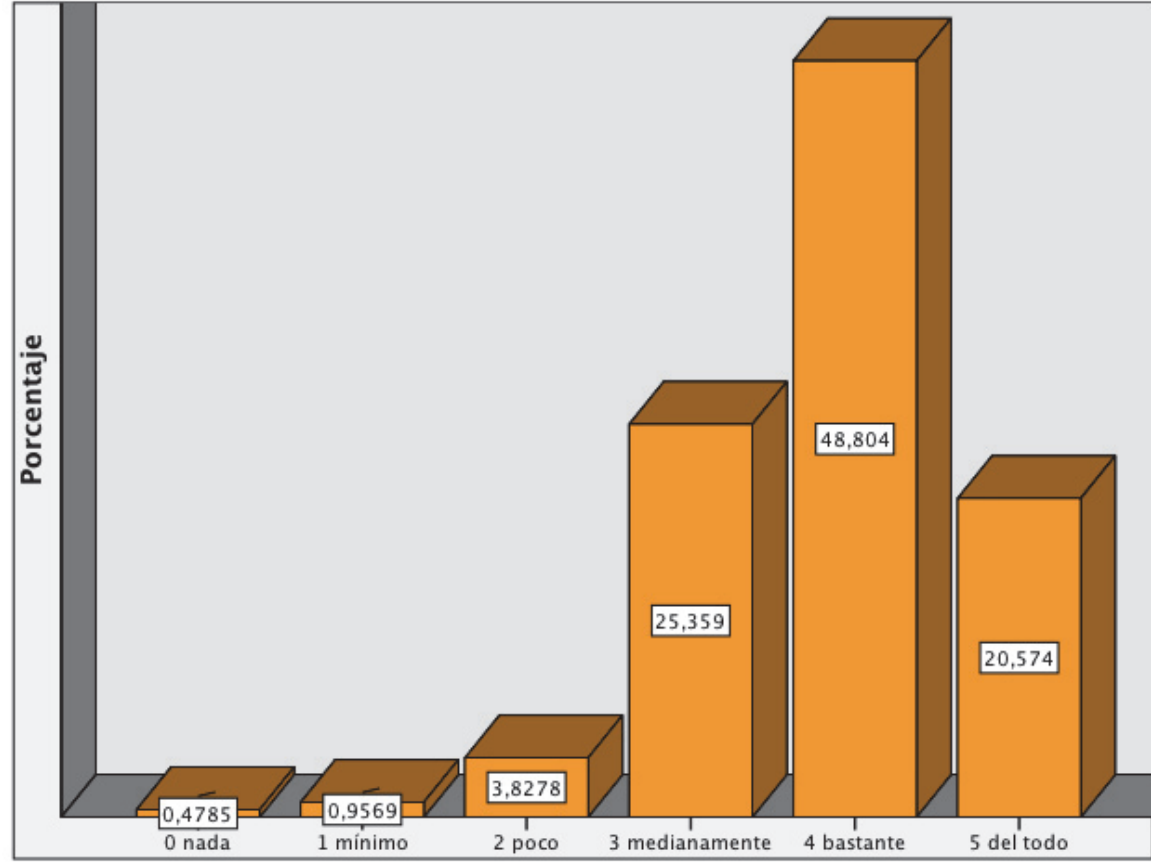

Elaboración propia. Mayo de 2015

Análisis: gráfico muy similar al 1.5: patrón en pirámide. Aquí observamos la presencia del 0. El valor “Anticipación, previsión” es considerado como importante tanto en la VP como en el ME con pocas diferencias entre ambos mundos.

Resultados muy similares en VP y en ME, y que se adecuan al perfil de enfermería pues es una profesión que trabaja sobre el plan de cuidados o proceso de atención de enfermería (PAE). 
Cuadro $\mathrm{n}^{\circ} 2.6$

6. Apertura, diálogo, igualdad, franqueza

\begin{tabular}{|l|r|r|r|r|}
\hline & Frecuencia & Porcentaje & $\begin{array}{c}\text { Porcentaje } \\
\text { válido }\end{array}$ & $\begin{array}{r}\text { Porcentaje } \\
\text { acumulado }\end{array}$ \\
\hline 0 nada & 3 & 1,4 & 1,4 & 1,4 \\
1 mínimo & 11 & 5,3 & 5,3 & 6,7 \\
2 poco & 29 & 13,9 & 13,9 & 20,6 \\
3 medianamente & 52 & 24,9 & 24,9 & 45,5 \\
4 bastante & 65 & 31,1 & 31,1 & 76,6 \\
5 del todo & 49 & 23,4 & 23,4 & 100,0 \\
Total & 209 & 100,0 & 100,0 & \\
\hline
\end{tabular}

Elaboración propia. Mayo de 2015

Gráfico n ${ }^{\circ} 2.6$

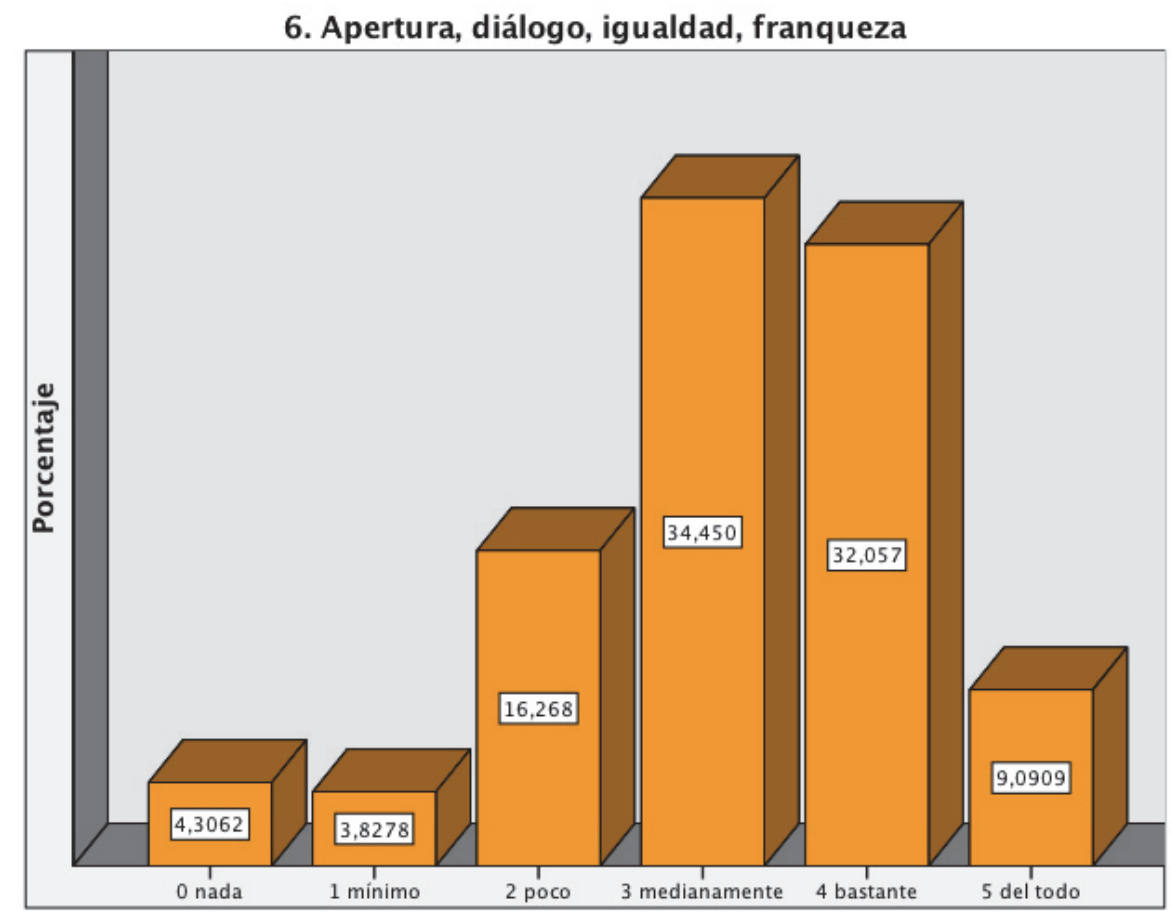

Elaboración propia. Mayo de 2015

Análisis: presencia de todas las puntuaciones. Modelo en pirámide mientras que la VP obteníamos un modelo en escalera ascendente. La muestra en estudio considera que el valor "Apertura, diálogo, igualdad, franqueza” gobierna más la VP que el ME.

Estos resultados ponen de manifiesto que el alumnado distingue su propia actividad en la que la apertura, el diálogo, la igualdad y la franqueza son muy importantes, de la actividad empresarial en la que estos valores no son tan marcados. Esta diferencia pone en evidencia la coherencia de las respuestas. 
Cuadro $n^{\circ} 2.7$

7. Aprendizaje continuo

\begin{tabular}{|l|r|r|r|r|}
\hline & Frecuencia & Porcentaje & $\begin{array}{c}\text { Porcentaje } \\
\text { válido }\end{array}$ & $\begin{array}{r}\text { Porcentaje } \\
\text { acumulado }\end{array}$ \\
\hline 1 mínimo & 3 & 1,4 & 1,4 & 1,4 \\
2 poco & 13 & 6,2 & 6,2 & 7,7 \\
3 medianamente & 26 & 12,4 & 12,4 & 20,1 \\
4 bastante & 64 & 30,6 & 30,6 & 50,7 \\
5 del todo & 103 & 49,3 & 49,3 & 100,0 \\
Total & 209 & 100,0 & 100,0 & \\
\hline
\end{tabular}

Elaboración propia. Mayo de 2015

Gráfico $n^{\circ} 2.7$

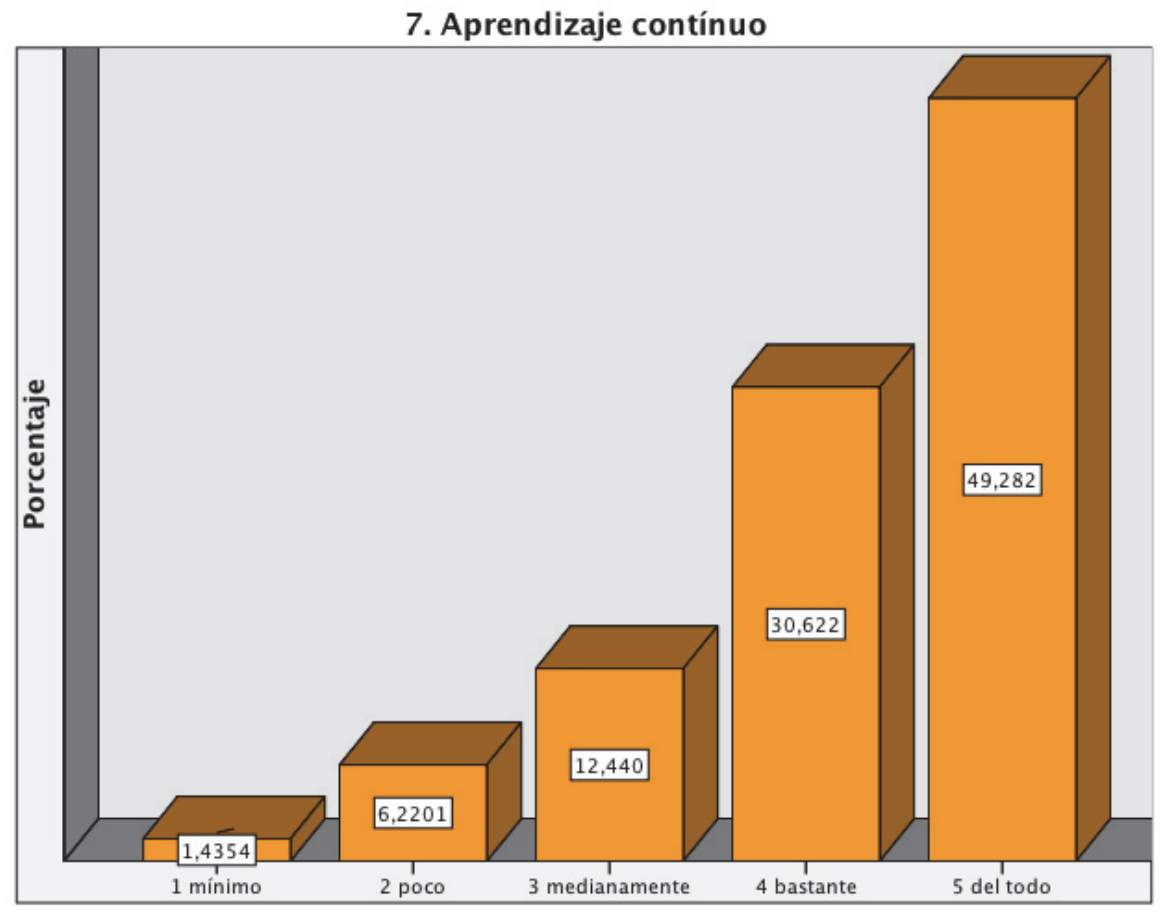

Elaboración propia. Mayo de 2015

Análisis: gráfico similar en mi VP y en el ME. Modelo en escalera ascendente. El valor "Aprendizaje continuo" es considerado que gobierna igual la VP como el ME. Es importante en ambas esferas.

Siendo el SNS, empresa pública al servicio de las ciencias de la salud en perpetuo desarrollo, los resultados obtenidos en este ítem responden al perfil esperado. Para el alumnado el aprendizaje continuo no solo es importante a nivel VP sino también a nivel del ME. 
Cuadro $\mathrm{n}^{\circ} 2.8$

8. Arte/belleza, armonía estética

\begin{tabular}{|l|r|r|r|r|}
\hline & Frecuencia & Porcentaje & $\begin{array}{c}\text { Porcentaje } \\
\text { válido }\end{array}$ & $\begin{array}{c}\text { Porcentaje } \\
\text { acumulado }\end{array}$ \\
\hline 0 nada & 9 & 4,3 & 4,3 & 4,3 \\
1 mínimo & 8 & 3,8 & 3,8 & 8,1 \\
2 poco & 34 & 16,3 & 16,3 & 24,4 \\
3 medianamente & 72 & 34,4 & 34,4 & 58,9 \\
4 bastante & 67 & 32,1 & 32,1 & 90,9 \\
5 del todo & 19 & 9,1 & 9,1 & 100,0 \\
Total & 209 & 100,0 & 100,0 & \\
\hline
\end{tabular}

Elaboración propia. Mayo de 2015

Gráfico $n^{\circ} 2.8$

\section{Arte/belleza, armonía estética}

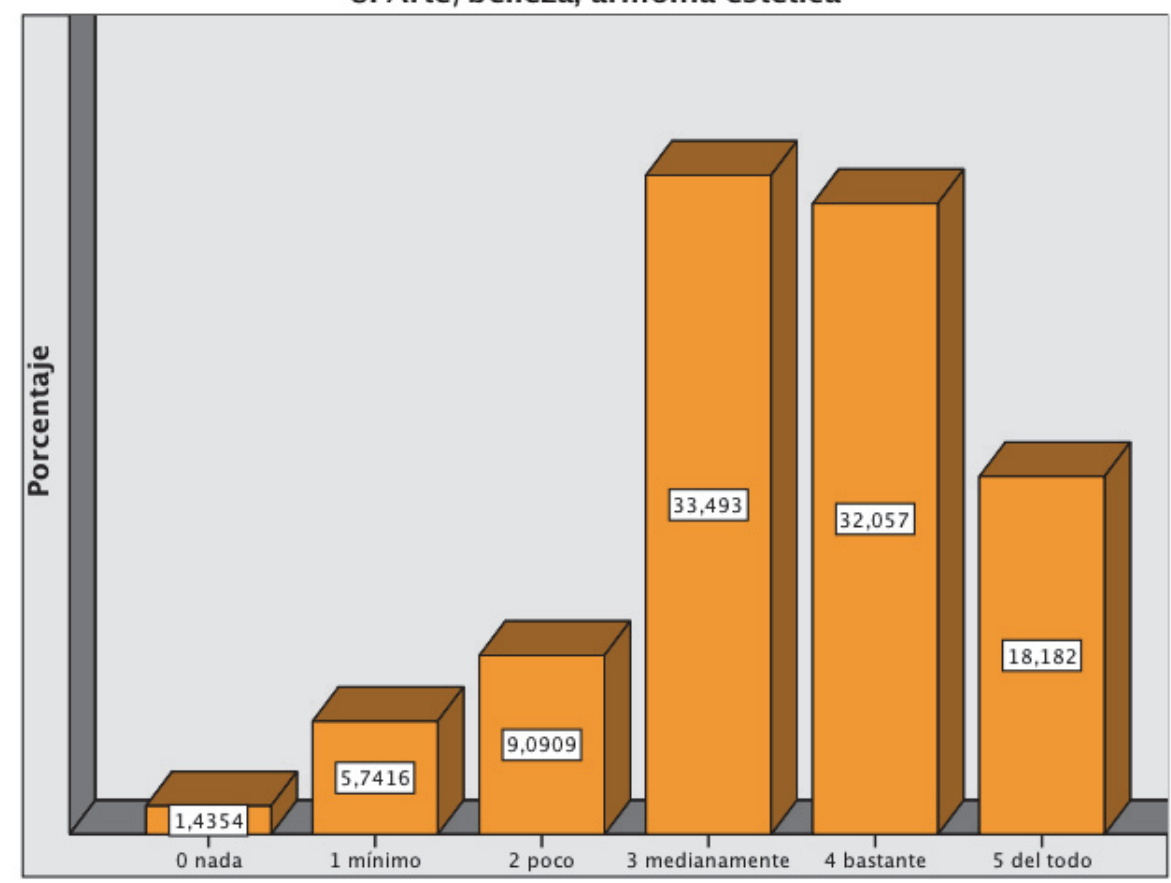

Elaboración propia. Mayo de 2015

Análisis: comparando los gráficos del mismo valor en las dos esferas encuestadas, observamos gráficos similares aunque vemos que el 4 , en la VP presenta un $41 \%$ frente al 32\% del ME. Observamos una mayor preponderancia de este valor en la VP que en el ME.

Este y otros 3 ítems: 54, 55 y 56 hablan de la armonía pero estos 3 últimos en relación con el respeto y arrojan puntuaciones similares entre ellos y diferentes al presente, lo cual evidencia la validez y coherencia de las encuestas. 
Cuadro $n^{\circ} 2.9$

9. Calidez, cercanía

\begin{tabular}{|l|r|r|r|r|}
\hline & Frecuencia & Porcentaje & $\begin{array}{c}\text { Porcentaje } \\
\text { válido }\end{array}$ & $\begin{array}{r}\text { Porcentaje } \\
\text { acumulado }\end{array}$ \\
\hline 0 nada & 3 & 1,4 & 1,4 & 1,4 \\
1 mínimo & 12 & 5,7 & 5,7 & 7,2 \\
2 poco & 19 & 9,1 & 9,1 & 16,3 \\
3 medianamente & 70 & 33,5 & 33,5 & 49,8 \\
4 bastante & 67 & 32,1 & 32,1 & 81,8 \\
5 del todo & 38 & 18,2 & 18,2 & 100,0 \\
Total & 209 & 100,0 & 100,0 & \\
\hline
\end{tabular}

Elaboración propia. Mayo de 2015

Gráfico $\mathrm{n}^{\circ} 2.9$

9. Calidez, cercanía

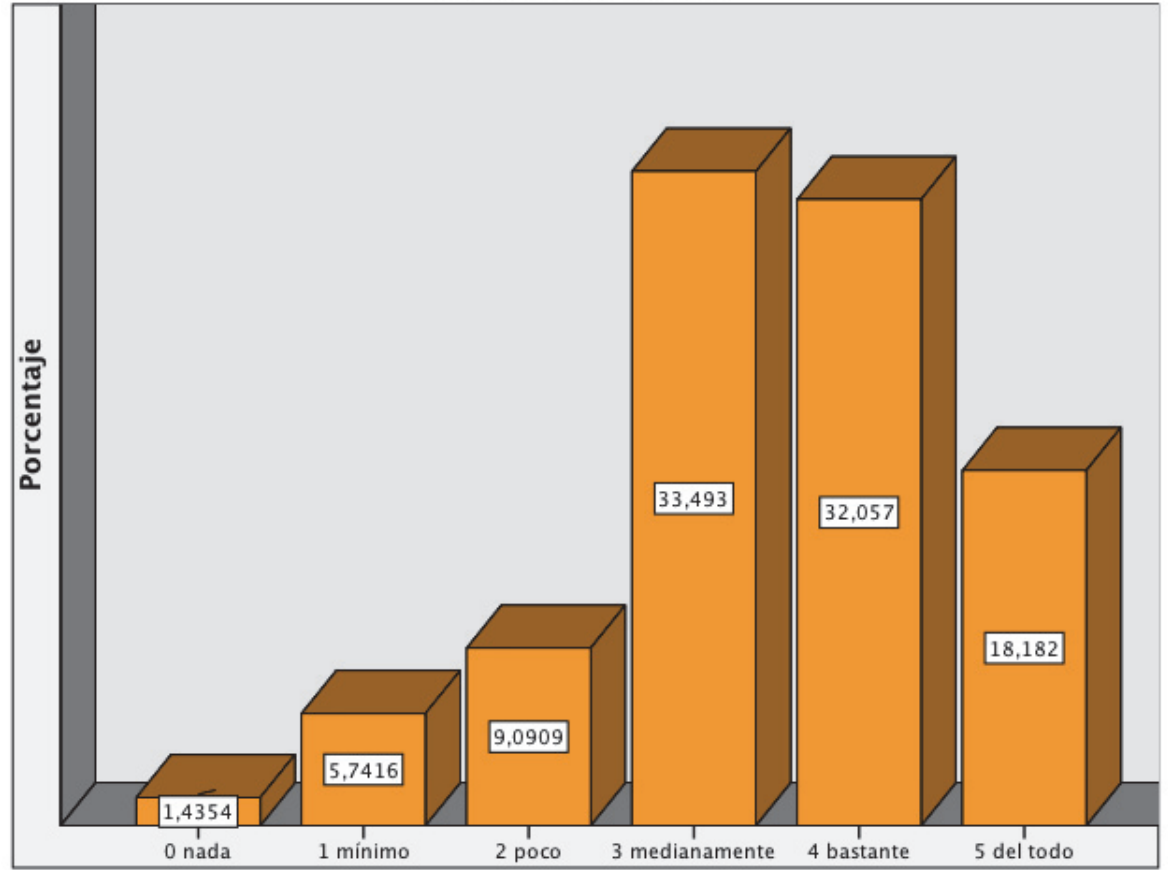

Elaboración propia. Mayo de 2015

Análisis: todos las puntuaciones están presentes. Modelo en pirámide. El mayor porcentaje es para el 3 seguido del 4, mientras que en la VP es para el 5 seguido del 4. El valor "Calidez, cercanía" es percibido como más importante en al VP que en el ME.

Para el ME, el alumnado no considera que la calidez, cercanía sea un valor muy importante. Respuesta coherente con lo esperable. Sin embargo, tampoco la consideran poco importante, hecho de relevancia para una empresa sanitaria. 
Cuadro $n^{\circ} 2.10$

10. Coherencia

\begin{tabular}{|l|r|r|r|r|}
\hline & Frecuencia & Porcentaje & $\begin{array}{c}\text { Porcentaje } \\
\text { válido }\end{array}$ & $\begin{array}{c}\text { Porcentaje } \\
\text { acumulado }\end{array}$ \\
\hline 0 nada & 1 &, 5 &, 5 &, 5 \\
1 mínimo & 3 & 1,4 & 1,4 & 1,9 \\
2 poco & 15 & 7,2 & 7,2 & 9,1 \\
3 medianamente & 34 & 16,3 & 16,3 & 25,4 \\
4 bastante & 105 & 50,2 & 50,2 & 75,6 \\
5 del todo & 51 & 24,4 & 24,4 & 100,0 \\
Total & 209 & 100,0 & 100,0 & \\
\hline
\end{tabular}

Elaboración propia. Mayo de 2015

Gráfico n ${ }^{\circ} 2.10$

10. Coherencia

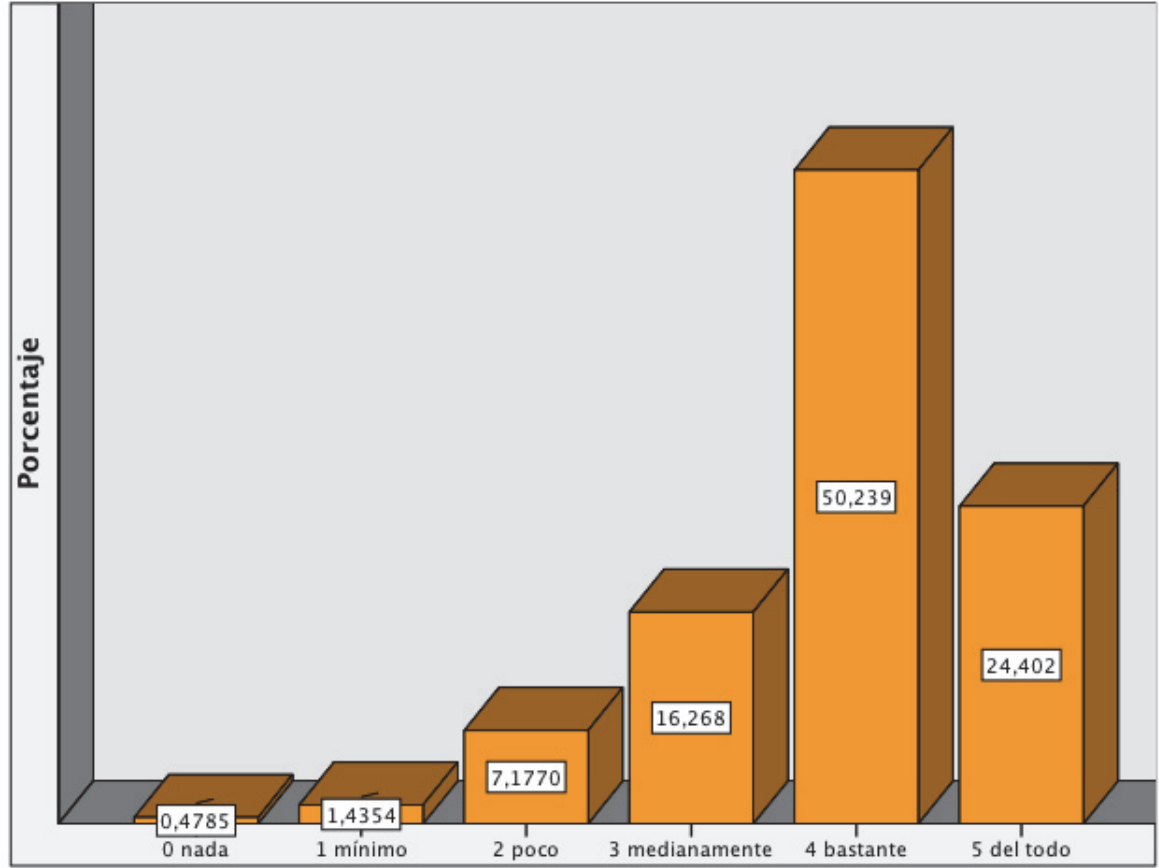

Elaboración propia. Mayo de 2015

Análisis: modelo de pirámide asimétrica con sesgo a la derecha, valor importante para la muestra en estudio. Gráfico muy similar al 1.10. Los encuestados perciben que el valor "Coherencia" incide de forma similar en la VP como en el ME.

Podemos decir lo mismo que para el gráfico 1.10, la coherencia es esencial para todo, tanto a nivel de la VP como del ME. Su ausencia provocaría contradicciones internas que pondrían en peligro los resultados y la eficiencia. 
Cuadro $n^{0} 2.11$

11. Comodidad, vida confortable

\begin{tabular}{|l|r|r|r|r|}
\hline & Frecuencia & Porcentaje & $\begin{array}{c}\text { Porcentaje } \\
\text { válido }\end{array}$ & $\begin{array}{r}\text { Porcentaje } \\
\text { acumulado }\end{array}$ \\
\hline 0 nada & 7 & 3,3 & 3,3 & 3,3 \\
1 mínimo & 7 & 3,3 & 3,3 & 6,7 \\
2 poco & 24 & 11,5 & 11,5 & 18,2 \\
3 medianamente & 83 & 39,7 & 39,7 & 57,9 \\
4 bastante & 62 & 29,7 & 29,7 & 87,6 \\
5 del todo & 26 & 12,4 & 12,4 & 100,0 \\
Total & 209 & 100,0 & 100,0 & \\
\hline
\end{tabular}

Elaboración propia. Mayo de 2015

Gráfico ${ }^{\circ} 2.11$

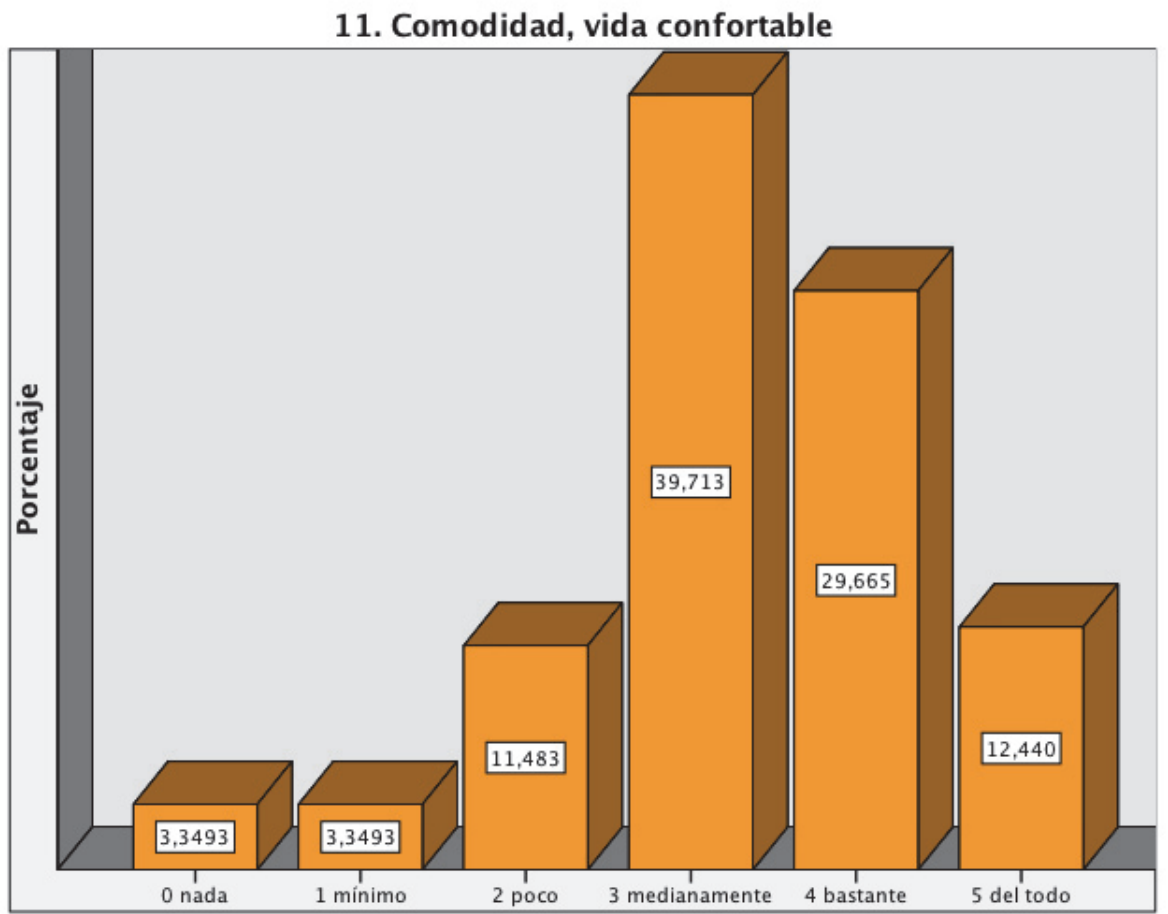

Elaboración propia. Mayo de 2015

Análisis: modelo en pirámide con tendencia central mientras que el gráfico 1.11 presenta un modelo en pirámide asimétrica con sesgo a la derecha. Las respuestas a las encuestas hablan de una mayor importancia de este valor en la VP que en el ME.

Seguimos observando la lógica de las respuestas. Los resultados obtenidos guardan coherencia entre la pregunta, y la esfera para la que se pregunta. 
Cuadro $n^{\circ} 2.12$

12. Compartir, generosidad

\begin{tabular}{|l|r|r|r|r|}
\hline & Frecuencia & Porcentaje & $\begin{array}{c}\text { Porcentaje } \\
\text { válido }\end{array}$ & $\begin{array}{r}\text { Porcentaje } \\
\text { acumulado }\end{array}$ \\
\hline 0 nada & 7 & 3,3 & 3,3 & 3,3 \\
1 mínimo & 12 & 5,7 & 5,7 & 9,1 \\
2 poco & 29 & 13,9 & 13,9 & 23,0 \\
3 medianamente & 47 & 22,5 & 22,5 & 45,5 \\
4 bastante & 66 & 31,6 & 31,6 & 77,0 \\
5 del todo & 48 & 23,0 & 23,0 & 100,0 \\
Total & 209 & 100,0 & 100,0 & \\
\hline
\end{tabular}

Elaboración propia. Mayo de 2015

Gráfico no 2.12

\section{Compartir, generosidad}

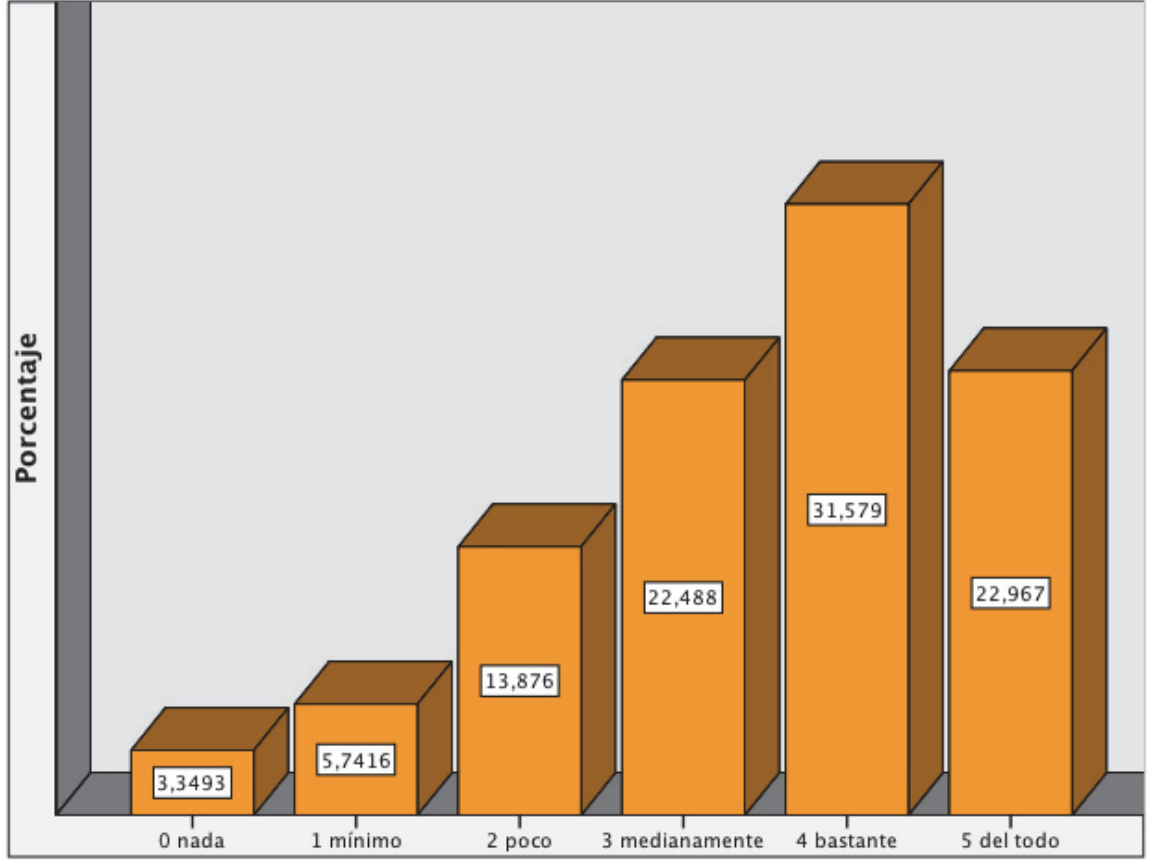

Elaboración propia. Mayo de 2015

Análisis: esta distribución se reparte entre todas las puntuaciones. El porcentaje más alto corresponde al 4 con solo el 31\%. El 4 y el 5 suman algo más del 54\% mientras que en la figura 1.12 suman más del 90\%. El valor "Compartir, generosidad" se revela más importante en la VP que en el ME.

Los resultados se ajustan al perfil de una empresa, como es el SNS, dedicada a mantener la salud de la población. 
Cuadro n ${ }^{\circ} 2.13$

13. Competitividad, ambición, trabajo duro

\begin{tabular}{|l|r|r|r|r|}
\hline & Frecuencia & Porcentaje & $\begin{array}{c}\text { Porcentaje } \\
\text { válido }\end{array}$ & $\begin{array}{c}\text { Porcentaje } \\
\text { acumulado }\end{array}$ \\
\hline 0 nada & 1 &, 5 &, 5 &, 5 \\
1 mínimo & 5 & 2,4 & 2,4 & 2,9 \\
2 poco & 6 & 2,9 & 2,9 & 5,7 \\
3 medianamente & 32 & 15,3 & 15,3 & 21,1 \\
4 bastante & 73 & 34,9 & 34,9 & 56,0 \\
5 del todo & 92 & 44,0 & 44,0 & 100,0 \\
Total & 209 & 100,0 & 100,0 & \\
\hline
\end{tabular}

Elaboración propia. Mayo de 2015

\section{Gráfico n ${ }^{\circ} 2.13$}

13. Competitividad, ambición, trabajo duro

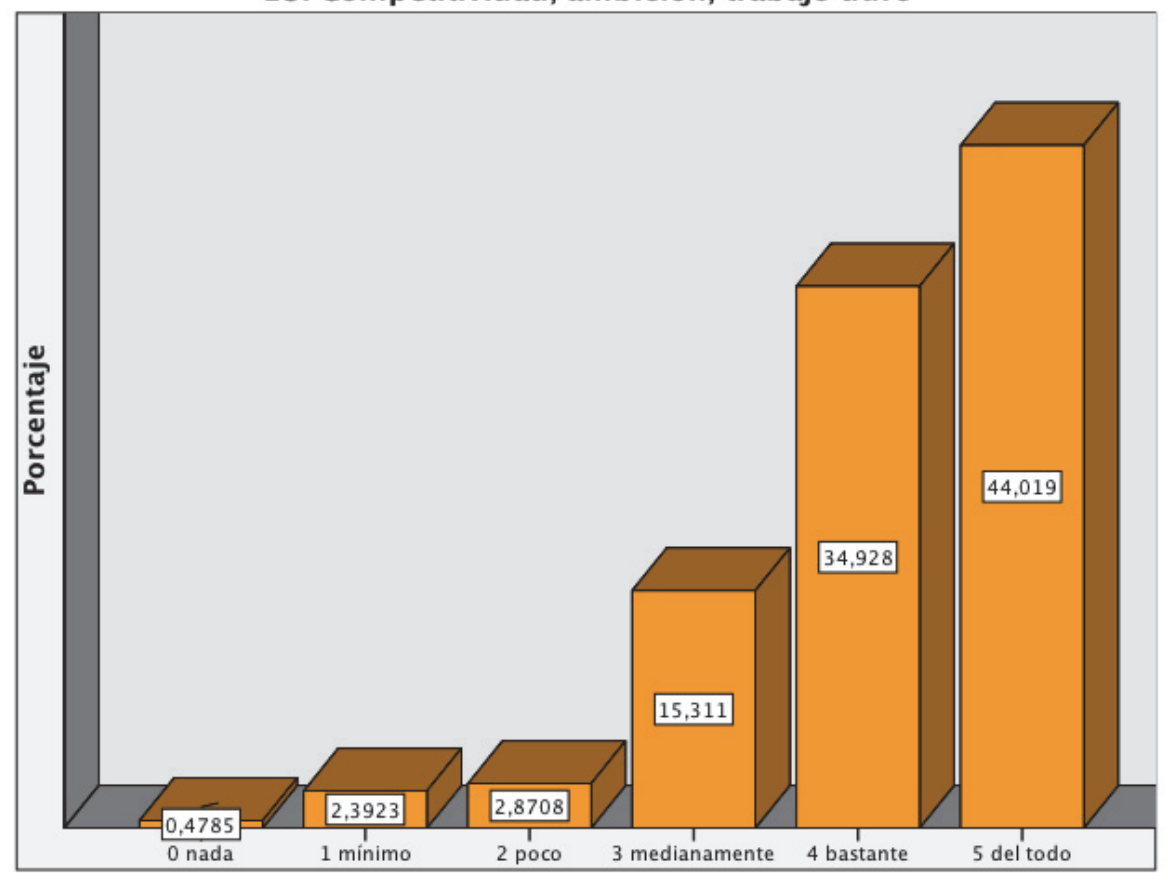

Elaboración propia. Mayo de 2015

Análisis: modelo en escalera ascendente, 4 y 5 suman casi el $80 \%$. El valor "Competitividad, ambición, trabajo duro" se revela como más importante en el ME que en la VP donde vemos un modelo en pirámide con mayor peso en el centro. 
Este ítem y el 36. Imagen, prestigio social y el 50. Productividad, resultados, comparten características consideradas masculinas y observamos que arrojan resultados similares. Son resultados acordes para una profesión feminizada en cuanto a que la gestión y dirección de empresas sigue en manos masculinas. 
Cuadro $n^{\circ} 2.14$

14. Comunicación/información

\begin{tabular}{|l|r|r|r|r|}
\hline & Frecuencia & Porcentaje & $\begin{array}{c}\text { Porcentaje } \\
\text { válido }\end{array}$ & $\begin{array}{c}\text { Porcentaje } \\
\text { acumulado }\end{array}$ \\
\hline 0 nada & 1 &, 5 &, 5 &, 5 \\
1 mínimo & 1 &, 5 &, 5 & 1,0 \\
2 poco & 5 & 2,4 & 2,4 & 3,3 \\
3 medianamente & 44 & 21,1 & 21,1 & 24,4 \\
4 bastante & 75 & 35,9 & 35,9 & 60,3 \\
5 del todo & 83 & 39,7 & 39,7 & 100,0 \\
Total & 209 & 100,0 & 100,0 & \\
\hline
\end{tabular}

Elaboración propia. Mayo de 2015

Gráfico $n^{\circ} 2.14$

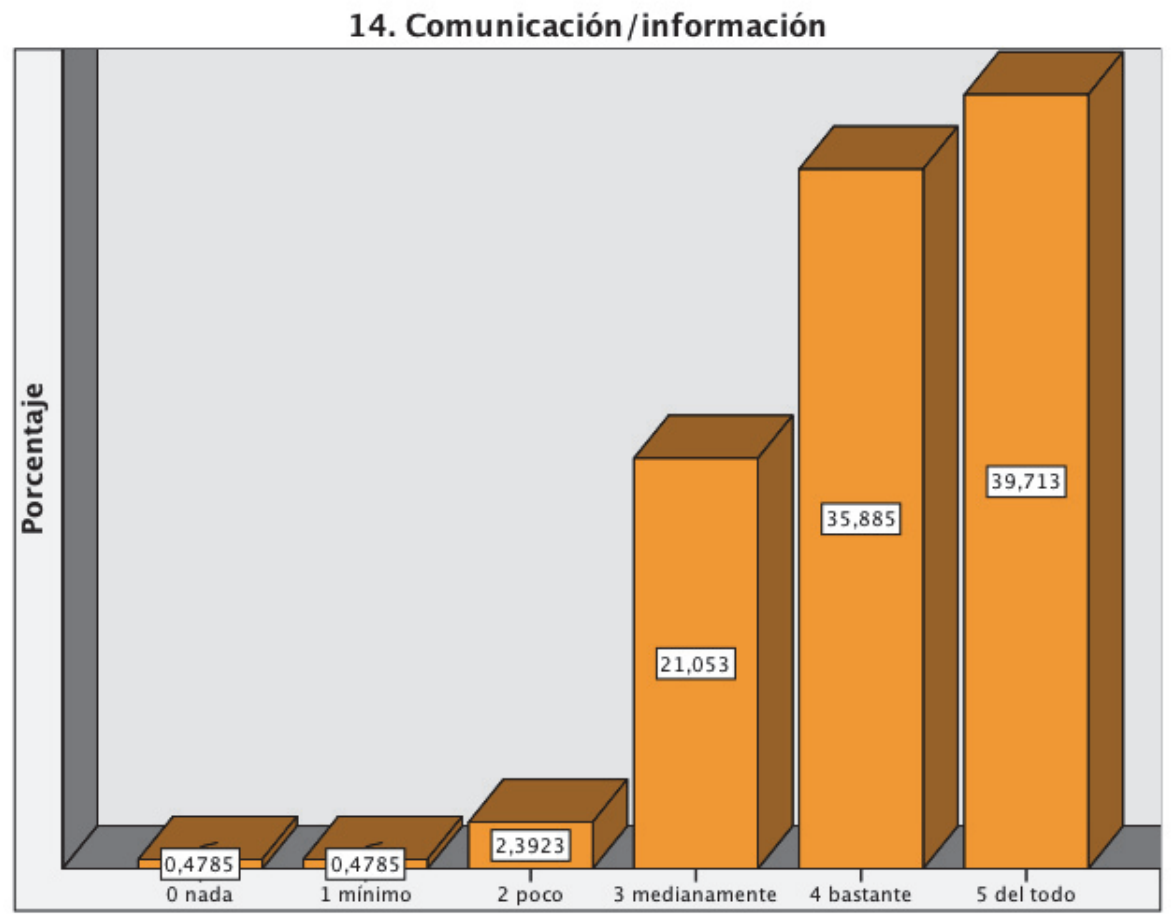

Elaboración propia. Mayo de 2015

Análisis: esta distribución muestra un modelo de escalera ascendente donde los valores 4 y 5 suman el 75,5\%. En la figura 1.14, el 4 y 5 suman algo más del 84\%. El valor “Comunicación/información” es catalogado como importante en ambas esferas: VP y ME.

Los resultados responden al perfil de la profesión pues la comunicación/información son imprescindibles para el trabajo en equipo y para la coordinación entre servicios y especialidades. 
Cuadro $n^{\circ} 2.15$

15. Confianza

\begin{tabular}{|l|r|r|r|r|}
\hline & Frecuencia & Porcentaje & $\begin{array}{c}\text { Porcentaje } \\
\text { válido }\end{array}$ & $\begin{array}{r}\text { Porcentaje } \\
\text { acumulado }\end{array}$ \\
\hline 0 nada & 2 & 1,0 & 1,0 & 1,0 \\
1 mínimo & 9 & 4,3 & 4,3 & 5,3 \\
2 poco & 23 & 11,0 & 11,0 & 16,3 \\
3 medianamente & 57 & 27,3 & 27,3 & 43,5 \\
4 bastante & 71 & 34,0 & 34,0 & 77,5 \\
5 del todo & 47 & 22,5 & 22,5 & 100,0 \\
Total & 209 & 100,0 & 100,0 & \\
\hline
\end{tabular}

Elaboración propia. Mayo de 2015

Gráfico $n^{\circ} 2.15$

15. Confianza

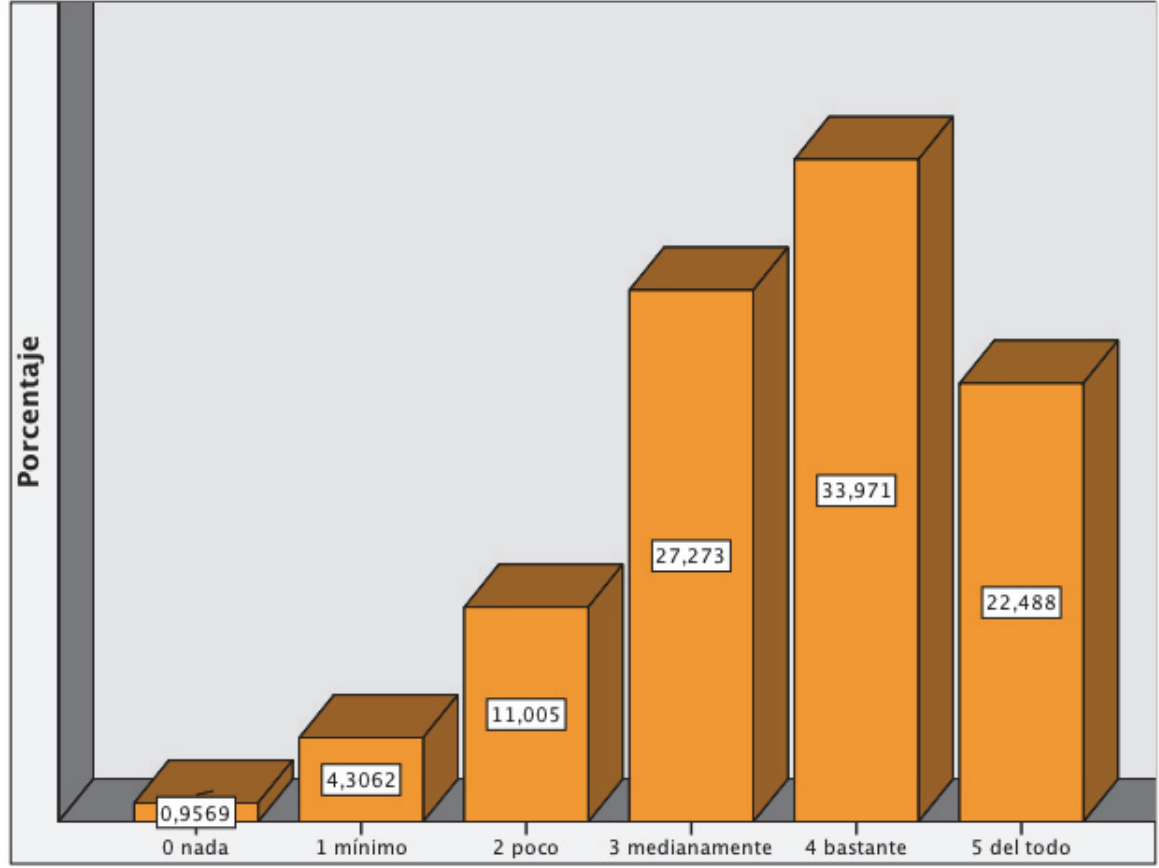

Elaboración propia. Mayo de 2015

Análisis: modelo de pirámide asimétrica con sesgo a la derecha. 4 y 5 suman casi el 56\% mientras que en la VP llega a más del $80 \%$.

Es el metavalor central del ME de $\mathrm{C}$ y del modelo triaxial de Salvador García y Shimon Dolan. La confianza es esencial para el bienestar emocional y genera el ambiente necesario para que aparezca la iniciativa, la creatividad, el diálogo y el aprendizaje organizativo. El miedo y la confianza son polos opuestos, igual que el amor y el odio, o la guerra y la paz. 
Cuadro ${ }^{\circ} 2.16$

16. Contemplación, meditación, serenidad

\begin{tabular}{|l|r|r|r|r|}
\hline & Frecuencia & Porcentaje & $\begin{array}{c}\text { Porcentaje } \\
\text { válido }\end{array}$ & $\begin{array}{r}\text { Porcentaje } \\
\text { acumulado }\end{array}$ \\
\hline 0 nada & 4 & 1,9 & 1,9 & 1,9 \\
1 mínimo & 13 & 6,2 & 6,2 & 8,1 \\
2 poco & 27 & 12,9 & 12,9 & 21,1 \\
3 medianamente & 68 & 32,5 & 32,5 & 53,6 \\
4 bastante & 74 & 35,4 & 35,4 & 89,0 \\
5 del todo & 23 & 11,0 & 11,0 & 100,0 \\
Total & 209 & 100,0 & 100,0 & \\
\hline
\end{tabular}

Elaboración propia. Mayo de 2015

Gráfico ${ }^{\circ} 2.16$

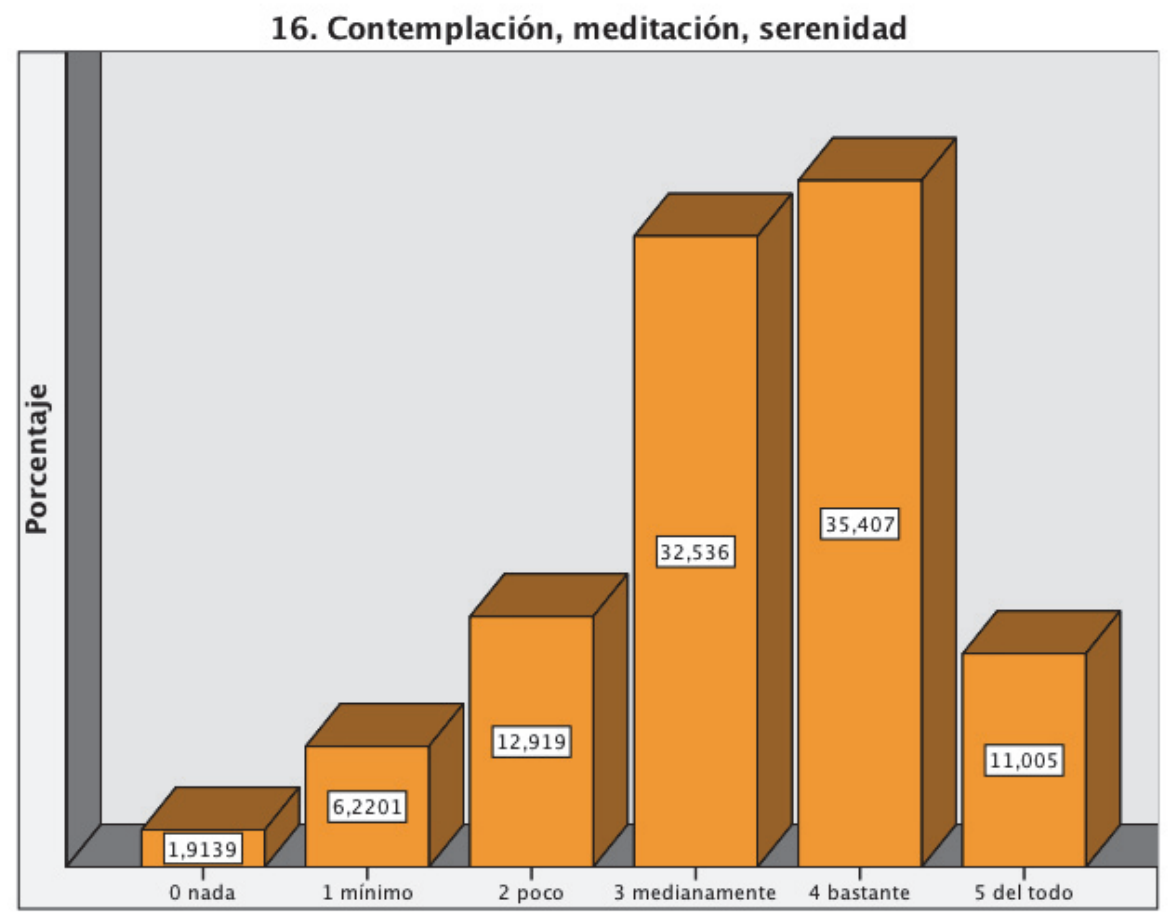

Elaboración propia. Mayo de 2015

Análisis: modelo en pirámide, muy similar a la figura 1.16. El valor “Contemplación, meditación, serenidad” es considerado como moderadamente importante tanto en la VP como en el ME.

El alumnado percibe este valor de forma casi idéntica para el área de la VP que para el ME. 
Cuadro $n^{\circ} 2.17$

17. Control, orden, disciplina

\begin{tabular}{|l|r|r|r|r|}
\hline & Frecuencia & Porcentaje & $\begin{array}{c}\text { Porcentaje } \\
\text { válido }\end{array}$ & $\begin{array}{c}\text { Porcentaje } \\
\text { acumulado }\end{array}$ \\
\hline 1 mínimo & 2 & 1,0 & 1,0 & 1,0 \\
2 poco & 7 & 3,3 & 3,3 & 4,3 \\
3 medianamente & 36 & 17,2 & 17,2 & 21,5 \\
4 bastante & 74 & 35,4 & 35,4 & 56,9 \\
5 del todo & 90 & 43,1 & 43,1 & 100,0 \\
Total & 209 & 100,0 & 100,0 & \\
\hline
\end{tabular}

Elaboración propia. Mayo de 2015

Gráfico $\mathrm{n}^{\mathrm{0}} 2.17$

\section{Control, orden, disciplina}

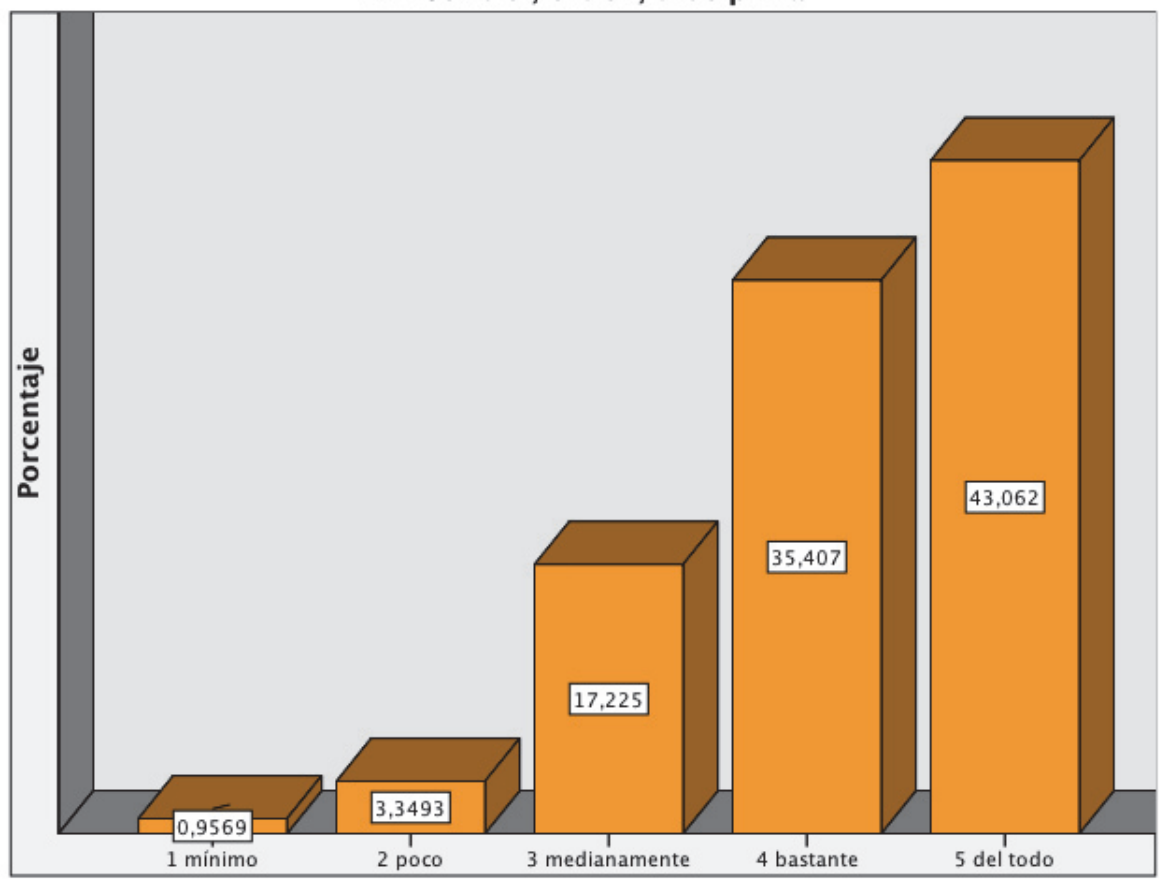

Elaboración propia. Mayo de 2015

Análisis: modelo en escalera ascendente, con un más del 95\% para el 3, 4 y 5, con mayor peso para el 5. El "Control, orden, disciplina" es considerado importante tanto en la VP como en el ME.

Los resultados siguen evidenciando la coherencia de las respuestas dadas por la muestra en estudio. El control, orden, disciplina son importantes para cualquier empresa y más si la salud y la vida están en juego. 
Cuadro $n^{\circ} 2.18$

18. Cooperación, colaboración, espíritu de equipo

\begin{tabular}{|l|r|r|r|r|}
\hline & Frecuencia & Porcentaje & $\begin{array}{c}\text { Porcentaje } \\
\text { válido }\end{array}$ & $\begin{array}{c}\text { Porcentaje } \\
\text { acumulado }\end{array}$ \\
\hline 0 nada & 1 &, 5 &, 5 &, 5 \\
1 mínimo & 2 & 1,0 & 1,0 & 1,4 \\
2 poco & 13 & 6,2 & 6,2 & 7,7 \\
3 medianamente & 37 & 17,7 & 17,7 & 25,4 \\
4 bastante & 53 & 25,4 & 25,4 & 50,7 \\
5 del todo & 103 & 49,3 & 49,3 & 100,0 \\
Total & 209 & 100,0 & 100,0 & \\
\hline
\end{tabular}

Elaboración propia. Mayo de 2015

Gráfico $n^{\circ} 2.18$

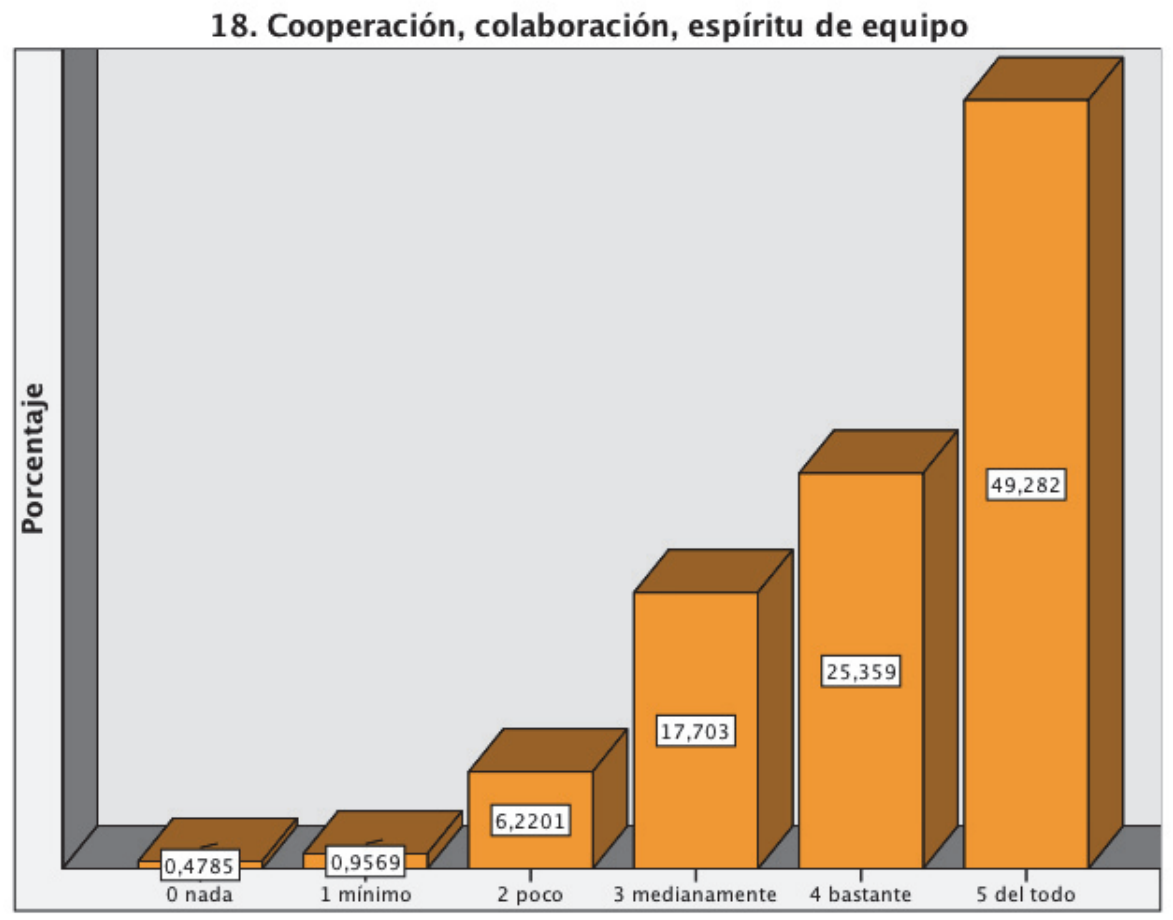

Elaboración propia. Mayo de 2015

Análisis: gráfico en escalera ascendente con el mayor porcentaje para el 5 con más del 49\% y casi el 75\% para el 4 y 5 . En la VP, el 4 y 5 suman más del $85 \%$.

Como era de esperar en una profesión destinada a trabajar en equipo, el valor "Cooperación, colaboración, espíritu de equipo" es catalogado como importante tanto en la VP como en el ME. 
Cuadro n ${ }^{\circ} 2.19$

19. Cortesía

\begin{tabular}{|l|r|r|r|r|}
\hline & Frecuencia & Porcentaje & $\begin{array}{c}\text { Porcentaje } \\
\text { válido }\end{array}$ & $\begin{array}{r}\text { Porcentaje } \\
\text { acumulado }\end{array}$ \\
\hline 0 nada & 3 & 1,4 & 1,4 & 1,4 \\
1 mínimo & 6 & 2,9 & 2,9 & 4,3 \\
2 poco & 22 & 10,5 & 10,5 & 14,8 \\
3 medianamente & 40 & 19,1 & 19,1 & 34,0 \\
4 bastante & 80 & 38,3 & 38,3 & 72,2 \\
5 del todo & 58 & 27,8 & 27,8 & 100,0 \\
Total & 209 & 100,0 & 100,0 & \\
\hline
\end{tabular}

Elaboración propia. Mayo de 2015

Gráfico n ${ }^{\circ} 2.19$

19. Cortesía

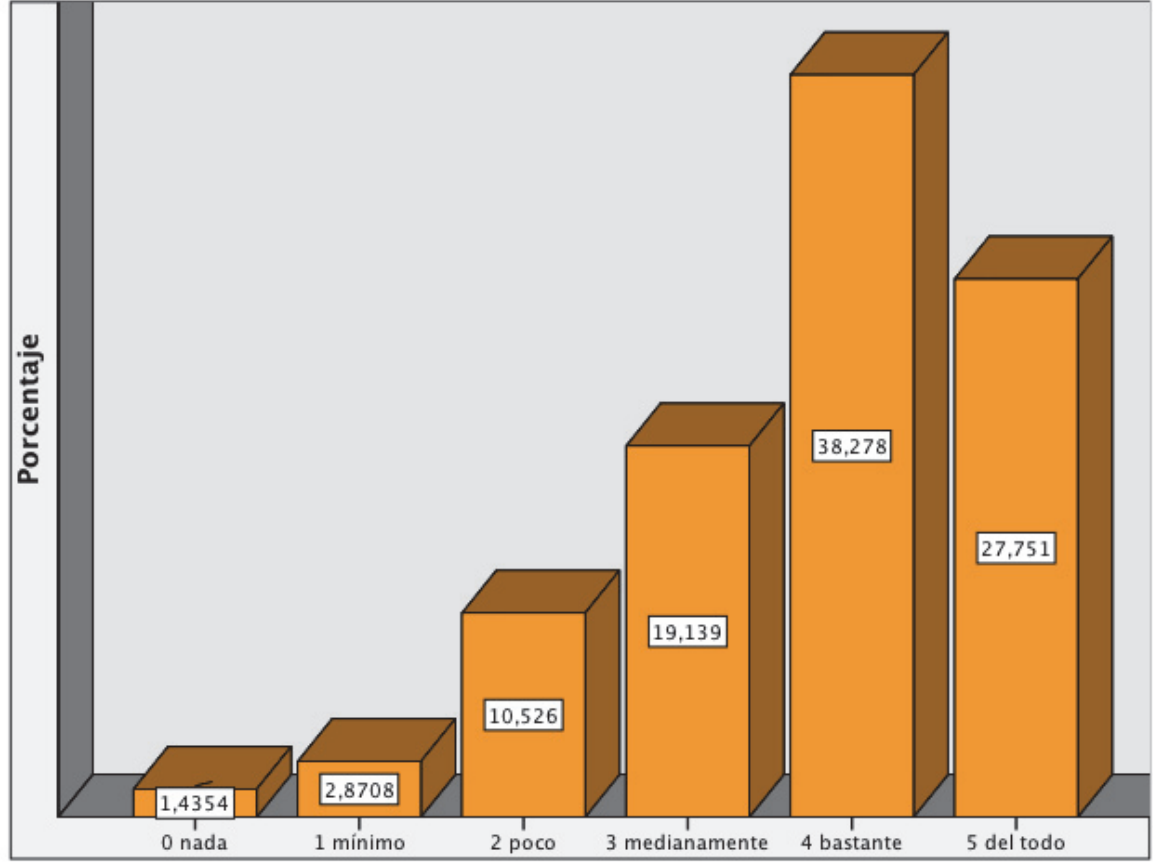

Elaboración propia. Mayo de 2015

Análisis: distribución similar a la del gráfico 1.19 salvo que aquí sí están presentes el 0 y 1 . Modelo en pirámide sesgada a la derecha. Valor considerado importante en ambas esferas.

Los resultados, similares a los de la VP, ponen de manifiesto que la cortesía, muy relacionada con el respeto va a intervenir en el trato más humano que esperamos en el SNS. 
Cuadro $n^{\circ} 2.20$

20. Crecimiento/expansión

\begin{tabular}{|l|r|r|r|r|}
\hline & Frecuencia & Porcentaje & $\begin{array}{c}\text { Porcentaje } \\
\text { válido }\end{array}$ & $\begin{array}{c}\text { Porcentaje } \\
\text { acumulado }\end{array}$ \\
\hline 0 nada & 4 & 1,9 & 1,9 & 1,9 \\
1 mínimo & 1 &, 5 &, 5 & 2,4 \\
2 poco & 10 & 4,8 & 4,8 & 7,2 \\
3 medianamente & 38 & 18,2 & 18,2 & 25,4 \\
4 bastante & 81 & 38,8 & 38,8 & 64,1 \\
5 del todo & 75 & 35,9 & 35,9 & 100,0 \\
Total & 209 & 100,0 & 100,0 & \\
\hline
\end{tabular}

Elaboración propia. Mayo de 2015

Gráfico ${ }^{\circ} 2.20$

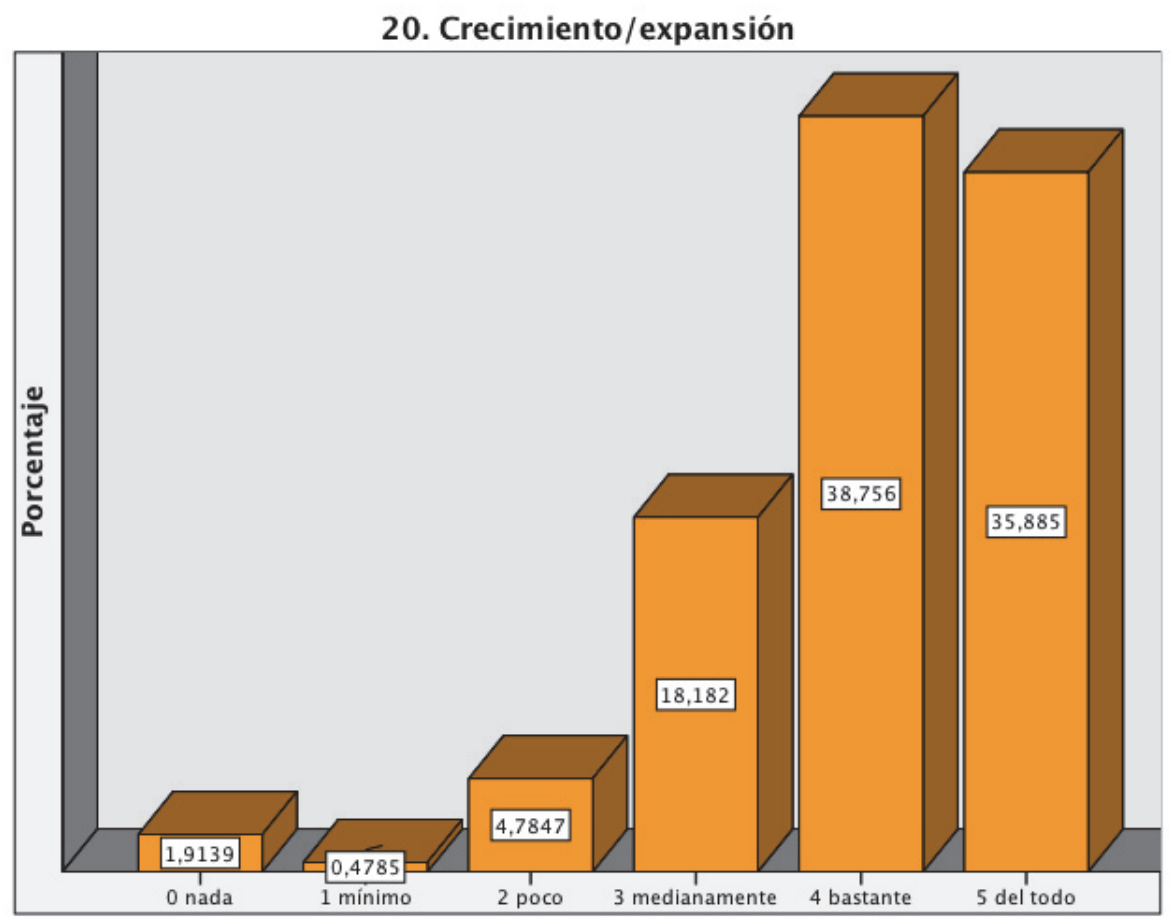

Elaboración propia. Mayo de 2015

Análisis: al igual que en el valor anterior la distribución se comporta de forma similar en ambas esferas. Llama la atención la presencia del 0 solo en el ME. Modelo en pirámide asimétrica con sesgo a la derecha. Valor catalogado como importante.

Continuamos con una coherencia interna propia al mundo de la empresa. Toda empresa conlleva el espíritu de crecimiento/expansión. Otro resultado diferente sería dudoso. 
Cuadro $n^{\circ} 2.21$

21. Creer y poner cariño en lo que se hace

\begin{tabular}{|l|r|r|r|r|}
\hline & Frecuencia & Porcentaje & $\begin{array}{c}\text { Porcentaje } \\
\text { válido }\end{array}$ & $\begin{array}{r}\text { Porcentaje } \\
\text { acumulado }\end{array}$ \\
\hline 0 nada & 4 & 1,9 & 1,9 & 1,9 \\
1 mínimo & 7 & 3,3 & 3,3 & 5,3 \\
2 poco & 17 & 8,1 & 8,1 & 13,4 \\
3 medianamente & 37 & 17,7 & 17,7 & 31,1 \\
4 bastante & 80 & 38,3 & 38,3 & 69,4 \\
5 del todo & 64 & 30,6 & 30,6 & 100,0 \\
Total & 209 & 100,0 & 100,0 & \\
\hline
\end{tabular}

Elaboración propia. Mayo de 2015

Gráfico n 2.21

21. Creer y poner cariño en lo que se hace

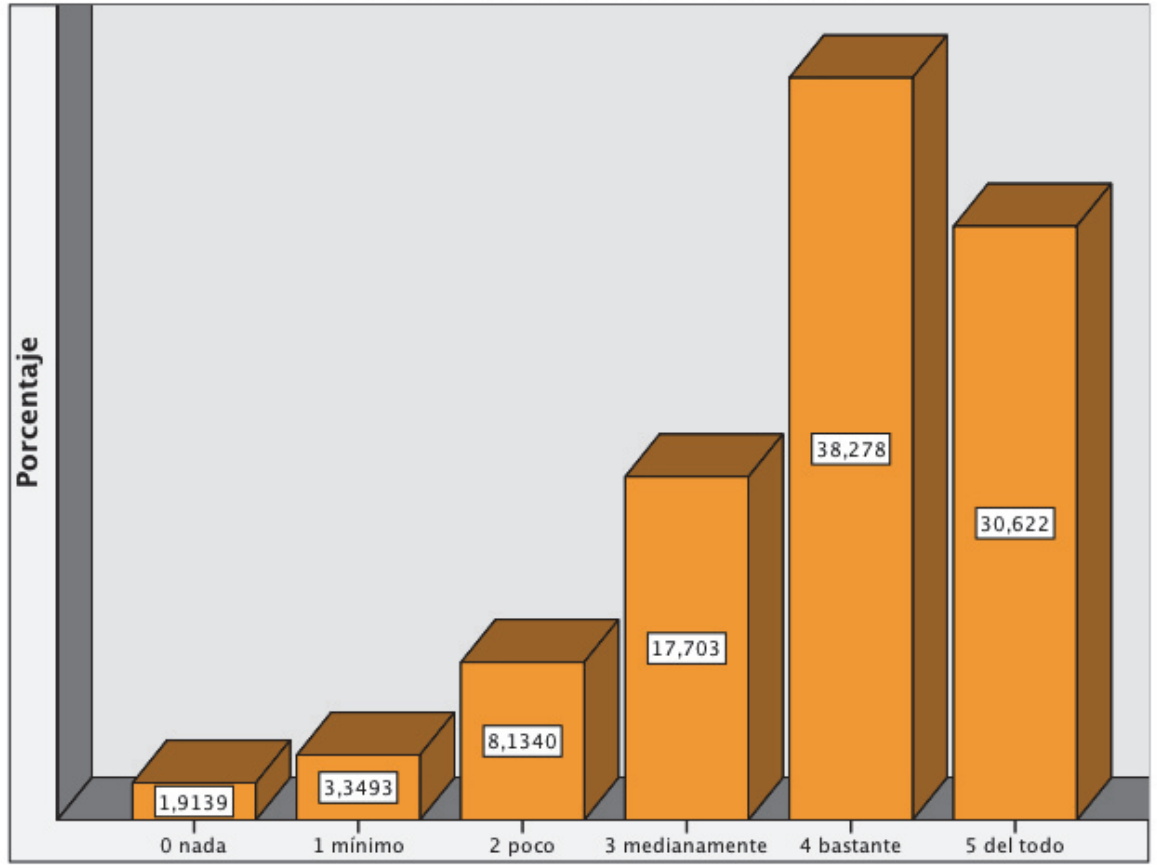

Elaboración propia. Mayo de 2015

Análisis: pirámide asimétrica con sesgo a la derecha. El 4 y 5 suman más del 68\% (en VP: 93\%). El valor "Creer y poner cariño en lo que se hace" se revela como importante y más en la VP que en el ME.

En cuanto al análisis cualitativo nos vale lo dicho para mi VP. Este es un valor relacionado con la Confianza, metavalor de Espinoso de Compludo para contribuir a la eficiencia y a la humanización. Resultados que nos hacen esperar conclusiones favorables a nuestra hipótesis. 
Cuadro $n^{\circ} 2.22$

22. Deleite físico, Hedonismo

\begin{tabular}{|l|r|r|r|r|}
\hline & Frecuencia & Porcentaje & $\begin{array}{c}\text { Porcentaje } \\
\text { válido }\end{array}$ & $\begin{array}{r}\text { Porcentaje } \\
\text { acumulado }\end{array}$ \\
\hline 0 nada & 11 & 5,3 & 5,3 & 5,3 \\
1 mínimo & 15 & 7,2 & 7,2 & 12,4 \\
2 poco & 22 & 10,5 & 10,5 & 23,0 \\
3 medianamente & 95 & 45,5 & 45,5 & 68,4 \\
4 bastante & 50 & 23,9 & 23,9 & 92,3 \\
5 del todo & 16 & 7,7 & 7,7 & 100,0 \\
Total & 209 & 100,0 & 100,0 & \\
\hline
\end{tabular}

Elaboración propia. Mayo de 2015

Gráfico ${ }^{\circ} 2.22$

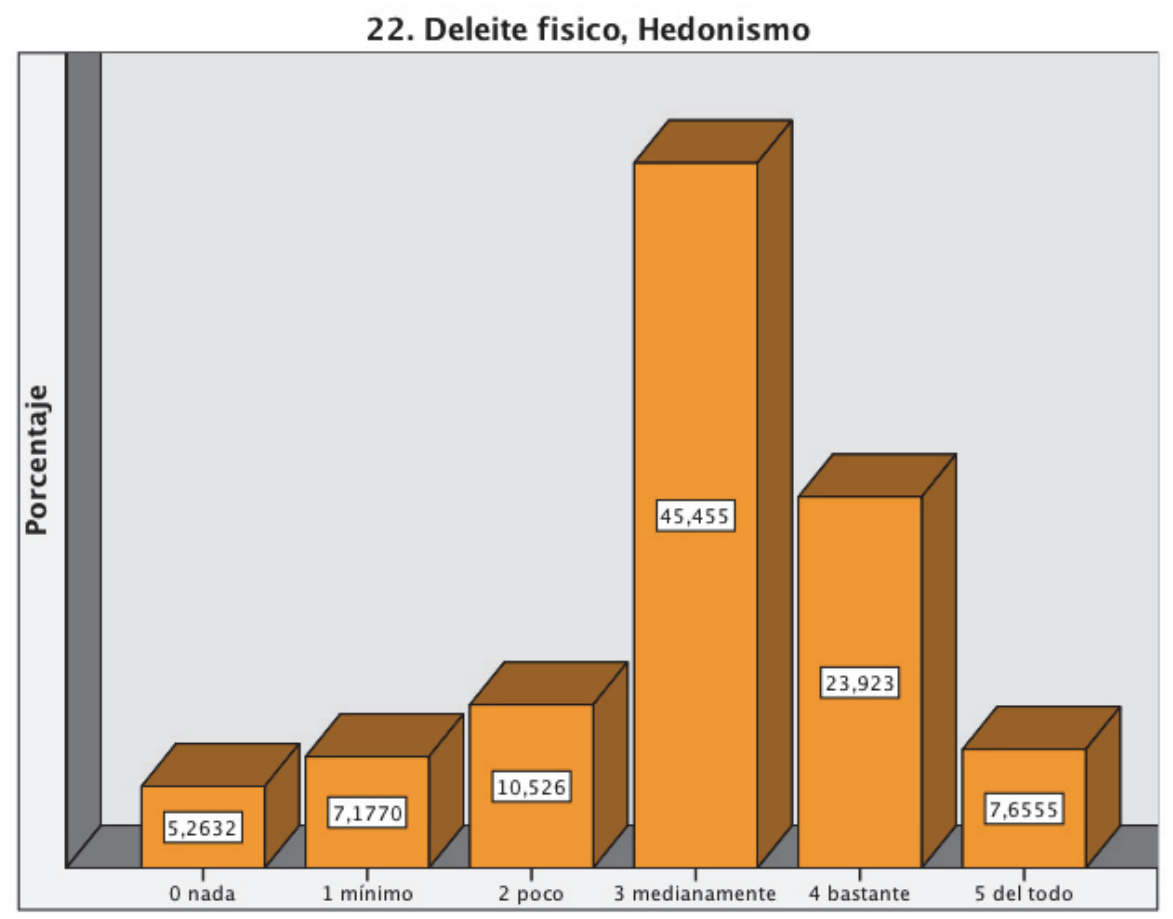

Elaboración propia. Mayo de 2015

Análisis: modelo en pirámide muy similar al del gráfico $\mathrm{n}^{\mathrm{o}} 1.22$. La muestra en estudio percibe este valor como medianamente importante tanto en un área como en la otra.

Resultados acordes al perfil de enfermería y de la empresa sanitaria por excelencia, el SNS en la que el centro del trabajo es la lucha contra la enfermedad, el dolor y la muerte. 
Cuadro $n^{\circ} 2.23$

23. Derechos humanos, Dignidad

\begin{tabular}{|l|r|r|r|r|}
\hline & Frecuencia & Porcentaje & $\begin{array}{c}\text { Porcentaje } \\
\text { válido }\end{array}$ & $\begin{array}{r}\text { Porcentaje } \\
\text { acumulado }\end{array}$ \\
\hline 0 nada & 4 & 1,9 & 1,9 & 1,9 \\
1 mínimo & 12 & 5,7 & 5,7 & 7,7 \\
2 poco & 8 & 3,8 & 3,8 & 11,5 \\
3 medianamente & 37 & 17,7 & 17,7 & 29,2 \\
4 bastante & 69 & 33,0 & 33,0 & 62,2 \\
5 del todo & 79 & 37,8 & 37,8 & 100,0 \\
Total & 209 & 100,0 & 100,0 & \\
\hline
\end{tabular}

Elaboración propia. Mayo de 2015

Gráfico $n^{\circ} 2.23$

\section{Derechos humanos, Dignidad}

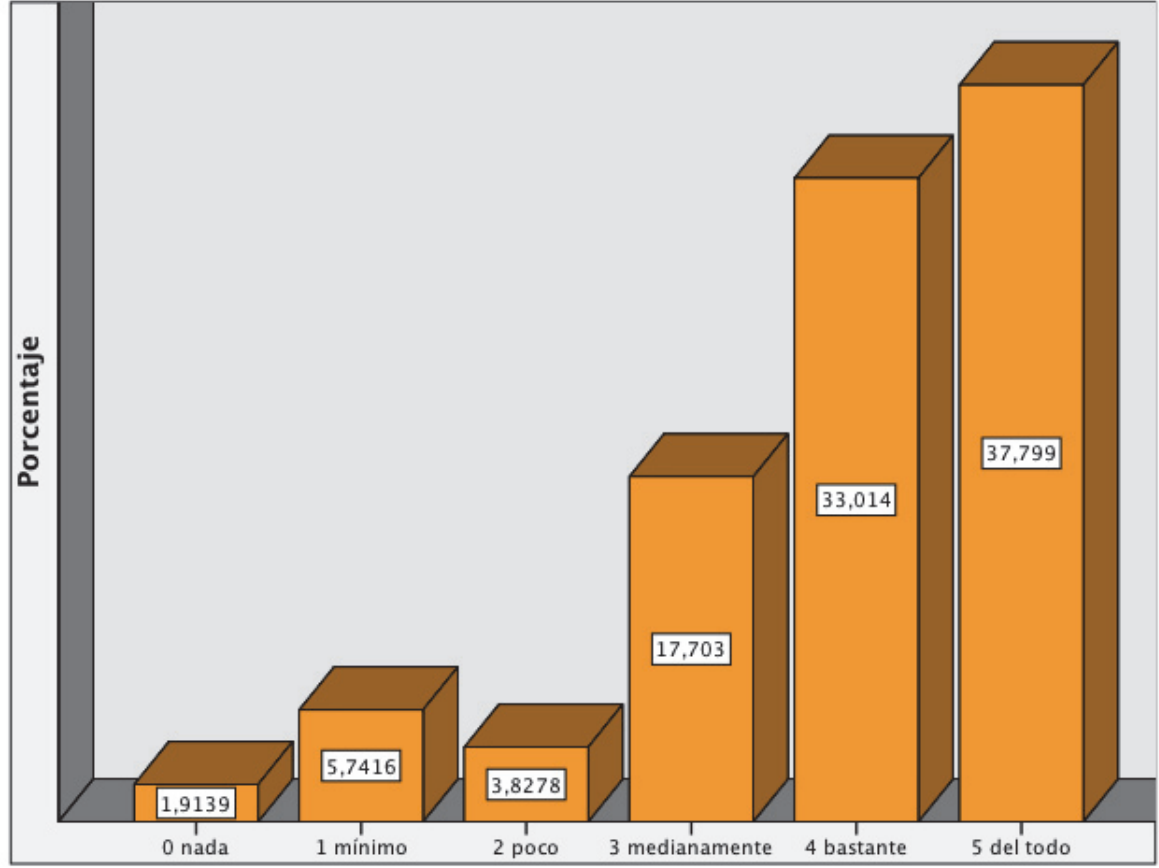

Elaboración propia. Mayo de 2015

Análisis: modelo en escalera ascendente percibido como importante en el ME pero algo menos que en la VP por la comparación con el gráfico $\mathrm{n}^{\circ} 1.23$ en el que la suma del 4 y 5 llega al 76\% y el 0,1 y 2 han sido marcados por una sola persona $(0,4785 \%)$, mientras que aquí tienen mayores porcentajes.

Responde al perfil de enfermería y del SNS por cuanto los derechos humanos y la dignidad de la persona forman parte intrínseca del Compromiso social del ME de C. 
Cuadro $n^{\circ} 2.24$

24. Disfrutar del trabajo

\begin{tabular}{|l|r|r|r|r|}
\hline & Frecuencia & Porcentaje & $\begin{array}{c}\text { Porcentaje } \\
\text { válido }\end{array}$ & $\begin{array}{r}\text { Porcentaje } \\
\text { acumulado }\end{array}$ \\
\hline 0 nada & 7 & 3,3 & 3,3 & 3,3 \\
1 mínimo & 6 & 2,9 & 2,9 & 6,2 \\
2 poco & 12 & 5,7 & 5,7 & 12,0 \\
3 medianamente & 47 & 22,5 & 22,5 & 34,4 \\
4 bastante & 67 & 32,1 & 32,1 & 66,5 \\
5 del todo & 70 & 33,5 & 33,5 & 100,0 \\
Total & 209 & 100,0 & 100,0 & \\
\hline
\end{tabular}

Elaboración propia. Mayo de 2015

Gráfico ${ }^{\circ} 2.24$

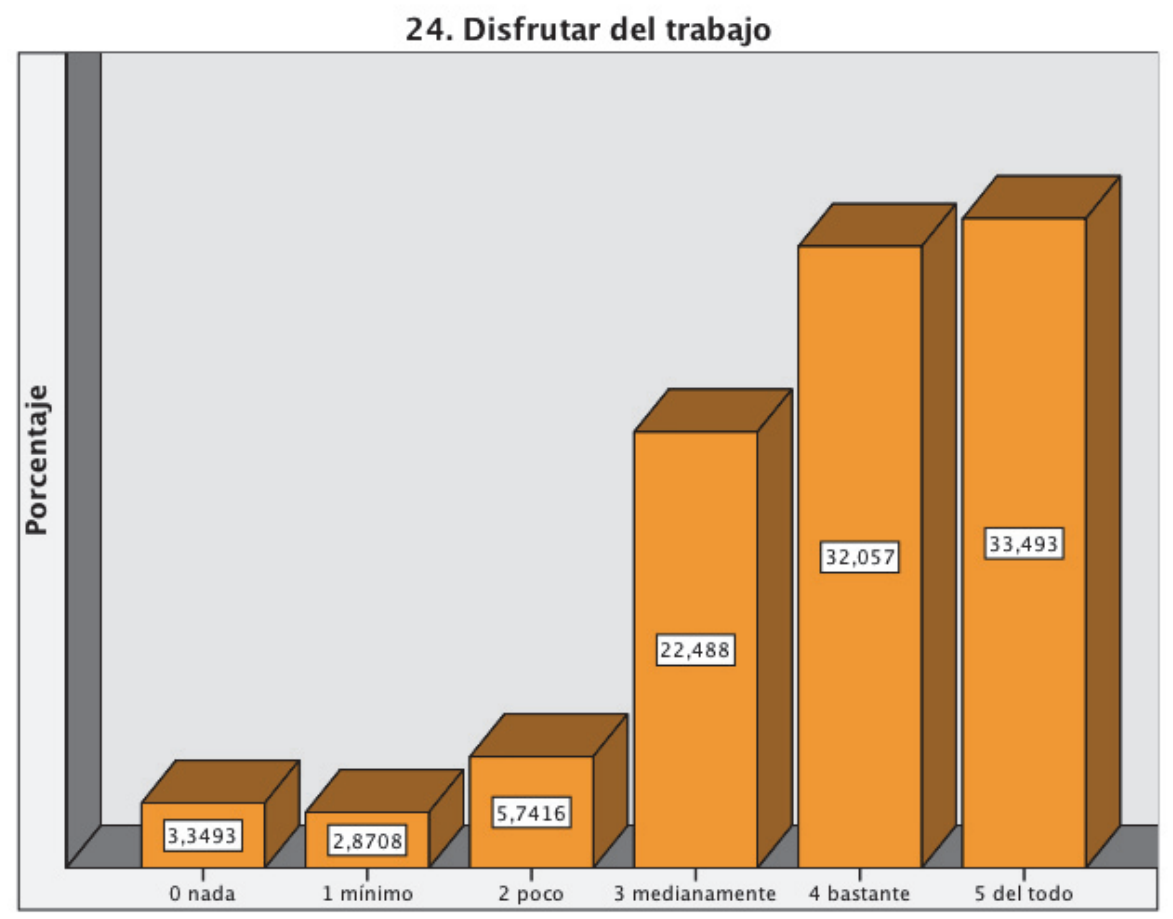

Elaboración propia. Mayo de 2015

Análisis: modelo en escalera ascendente similar a la figura $n^{\circ} 1.24$ pero con mayor representación de los valores más bajos.

En cuanto al análisis cualitativo, vale lo mismo que hemos dicho para el área VP. Este valor, junto con el "21. Creer y poner cariño en lo que se hace", están relacionados con la Confianza, metavalor central para la eficiencia y la humanización de la atención a la salud desde nuestros entornos de trabajo. 
Cuadro $n^{\circ} 2.25$

25. Eficacia, Planificación, Eficiencia

\begin{tabular}{|l|r|r|r|r|}
\hline & Frecuencia & Porcentaje & $\begin{array}{c}\text { Porcentaje } \\
\text { válido }\end{array}$ & $\begin{array}{c}\text { Porcentaje } \\
\text { acumulado }\end{array}$ \\
\hline 0 nada & 1 &, 5 &, 5 &, 5 \\
1 mínimo & 1 &, 5 &, 5 & 1,0 \\
2 poco & 7 & 3,3 & 3,3 & 4,3 \\
3 medianamente & 42 & 20,1 & 20,1 & 24,4 \\
4 bastante & 75 & 35,9 & 35,9 & 60,3 \\
5 del todo & 83 & 39,7 & 39,7 & 100,0 \\
Total & 209 & 100,0 & 100,0 & \\
\hline
\end{tabular}

Elaboración propia. Mayo de 2015

Gráfico $n^{\circ} 2.25$

25. Eficacia, Planificación, Eficiencia

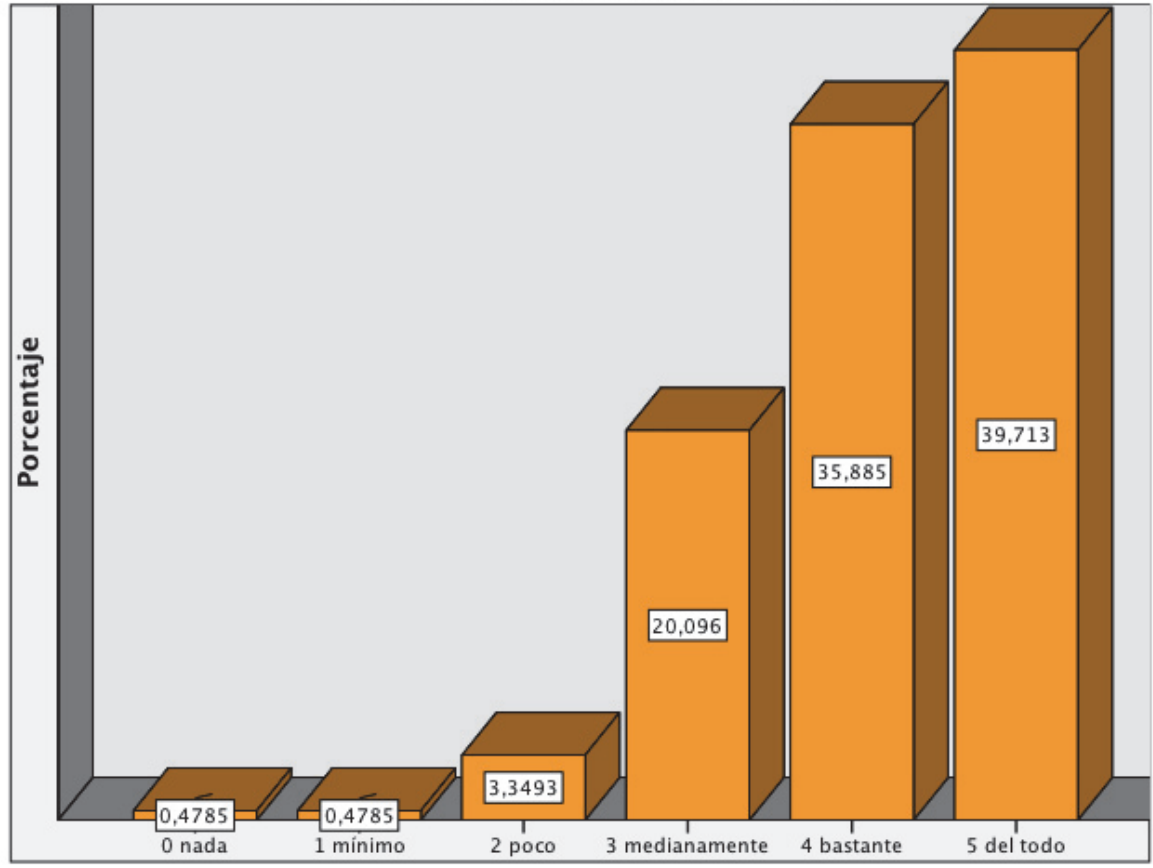

Elaboración propia. Mayo de 2015

Análisis: modelo en escalera ascendente donde el 4 y 5 suman más del $75 \%$ al igual que en la figura $n^{\circ} 1.25$ pero en la VP el peso recae en el 4 mientras que en el ME lo hace en el 5. La mayoría de la muestra encuestada considera que este valor gobierna bastante su VP y que gobierna del todo el ME.

Este es el valor principal de nuestra investigación. Se pueden esperar muy buenos resultados en la vida laboral de estos nuevos profesionales. 
Cuadro $n^{\circ} 2.26$

26. Equidad, justicia en el día a día

\begin{tabular}{|l|r|r|r|r|}
\hline & Frecuencia & Porcentaje & $\begin{array}{c}\text { Porcentaje } \\
\text { válido }\end{array}$ & $\begin{array}{r}\text { Porcentaje } \\
\text { acumulado }\end{array}$ \\
\hline 0 nada & 4 & 1,9 & 1,9 & 1,9 \\
1 mínimo & 12 & 5,7 & 5,7 & 7,7 \\
2 poco & 17 & 8,1 & 8,1 & 15,8 \\
3 medianamente & 58 & 27,8 & 27,8 & 43,5 \\
4 bastante & 55 & 26,3 & 26,3 & 69,9 \\
5 del todo & 63 & 30,1 & 30,1 & 100,0 \\
Total & 209 & 100,0 & 100,0 & \\
\hline
\end{tabular}

Elaboración propia. Mayo de 2015

Gráfico ${ }^{\circ} 2.26$

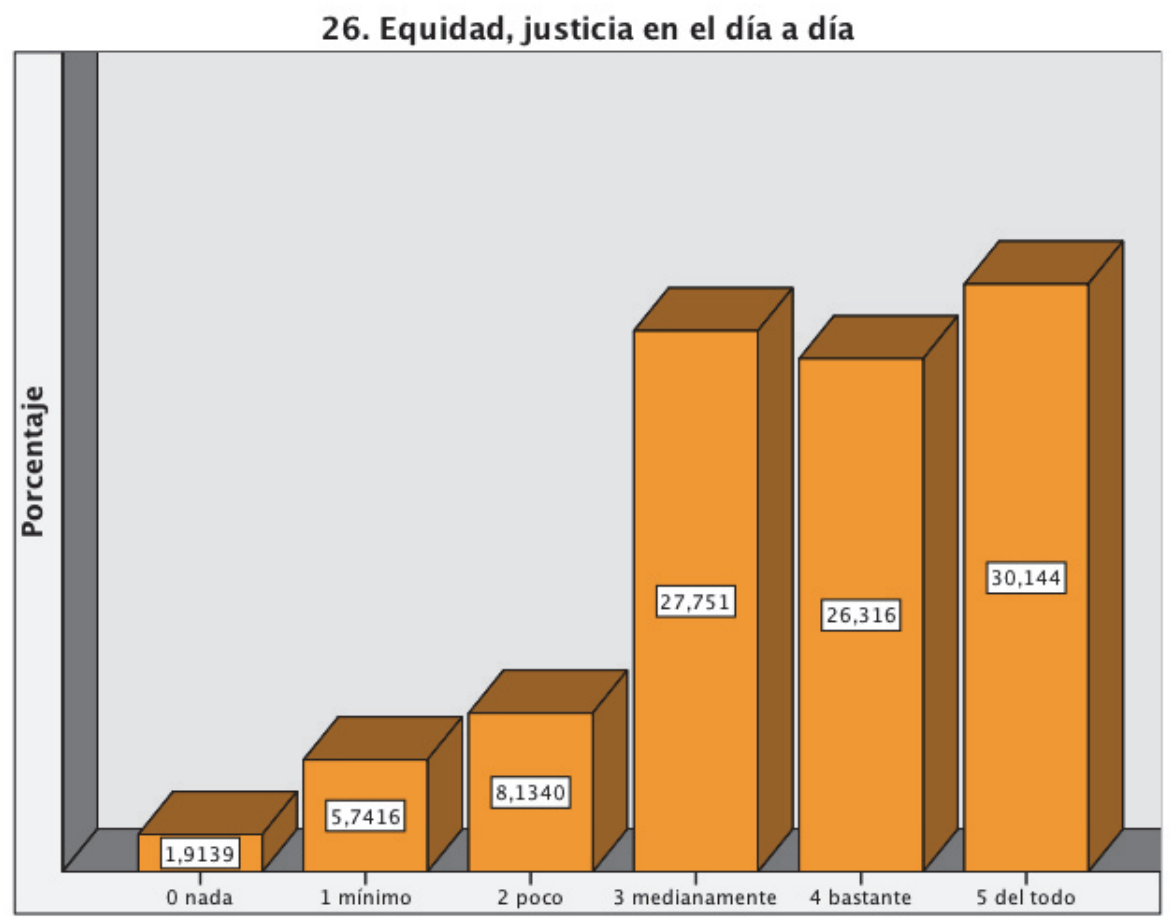

Elaboración propia. Mayo de 2015

Análisis: modelo de escalera aplanada con porcentajes muy similares para las puntuaciones 3, 4 y 5, pero con mayor peso del 5. El valor "Equidad, justicia en el día a día" se revela como más importante en la VP que en el ME.

Ítem relacionado con el Compromiso social. Resultados acordes al tipo de empresa que está al servicio de los valores salud y vida, valores de categoría absoluta, por encima de connotaciones sociales. 
Cuadro $n^{\circ} 2.27$

27. Equilibrio entre el trabajo y vida familiar y personal

\begin{tabular}{|l|r|r|r|r|}
\hline & Frecuencia & Porcentaje & $\begin{array}{c}\text { Porcentaje } \\
\text { válido }\end{array}$ & $\begin{array}{r}\text { Porcentaje } \\
\text { acumulado }\end{array}$ \\
\hline 0 nada & 2 & 1,0 & 1,0 & 1,0 \\
1 mínimo & 9 & 4,3 & 4,3 & 5,3 \\
2 poco & 20 & 9,6 & 9,6 & 14,8 \\
3 medianamente & 65 & 31,1 & 31,1 & 45,9 \\
4 bastante & 52 & 24,9 & 24,9 & 70,8 \\
5 del todo & 61 & 29,2 & 29,2 & 100,0 \\
Total & 209 & 100,0 & 100,0 & \\
\hline
\end{tabular}

Elaboración propia. Mayo de 2015

Gráfico $\mathrm{n}^{\mathrm{0}} 2.27$

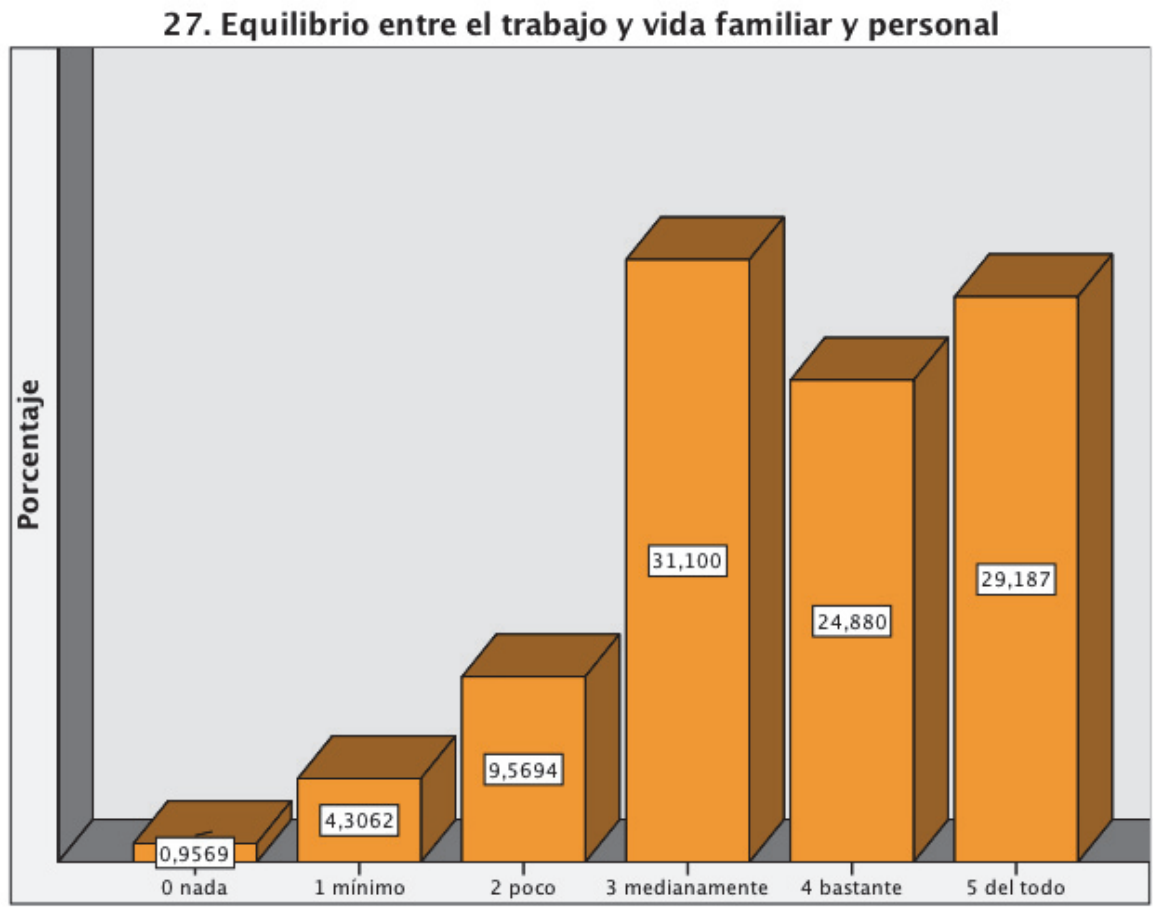

Elaboración propia. Mayo de 2015

Análisis: modelo de escalera aplanada en la que el porcentaje más alto corresponde al 3. El valor "Equilibrio entre el trabajo y vida familiar y personal" es percibido como más importante en la VP que en el ME.

El alumnado considera que la empresa mira menos por este valor que ellos mismos en su vida personal, resultado coherente con la vida real. 
Cuadro $n^{\circ} 2.28$

28. Éxito económico

\begin{tabular}{|l|r|r|r|r|}
\hline & Frecuencia & Porcentaje & $\begin{array}{c}\text { Porcentaje } \\
\text { válido }\end{array}$ & $\begin{array}{r}\text { Porcentaje } \\
\text { acumulado }\end{array}$ \\
\hline 0 nada & 4 & 1,9 & 1,9 & 1,9 \\
1 mínimo & 9 & 4,3 & 4,3 & 6,2 \\
2 poco & 11 & 5,3 & 5,3 & 11,5 \\
3 medianamente & 48 & 23,0 & 23,0 & 34,4 \\
4 bastante & 65 & 31,1 & 31,1 & 65,6 \\
5 del todo & 72 & 34,4 & 34,4 & 100,0 \\
Total & 209 & 100,0 & 100,0 & \\
\hline
\end{tabular}

Elaboración propia. Mayo de 2015

Gráfico $n^{\circ} 2.28$

28. Éxito económico

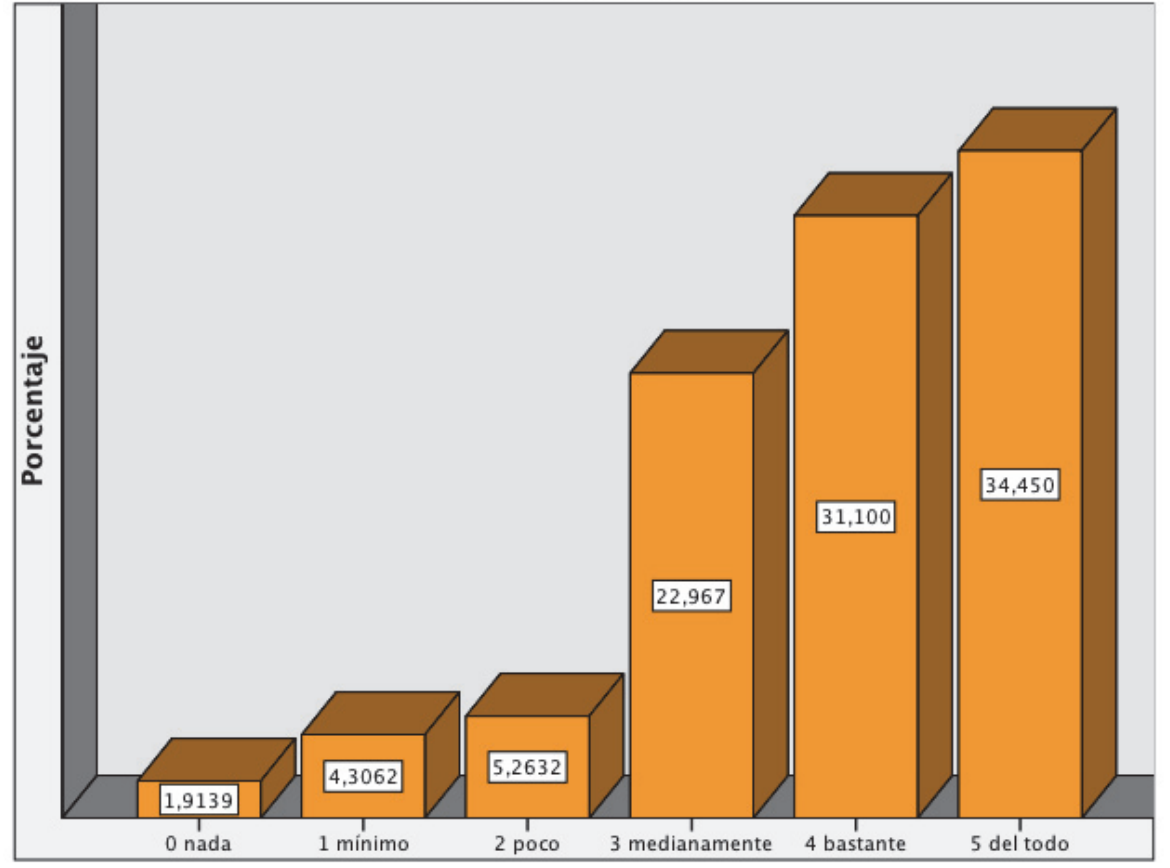

Elaboración propia. Mayo de 2015

Análisis: modelo de escalera ascendente en el que el mayor porcentaje, más del 34\%, es para el 5 mientras que en la VP al 5 le corresponde un 15,311\%. La muestra en estudio considera que el valor "Éxito económico" es más importante en el ME que en sus VP.

Resultados acordes con la percepción por parte del alumnado de que el éxito económico es importante para la sostenibilidad del sistema. 
Cuadro $n^{\circ} 2.29$

29. Éxito familiar

\begin{tabular}{|l|r|r|r|r|}
\hline & Frecuencia & Porcentaje & $\begin{array}{c}\text { Porcentaje } \\
\text { válido }\end{array}$ & $\begin{array}{r}\text { Porcentaje } \\
\text { acumulado }\end{array}$ \\
\hline 0 nada & 6 & 2,9 & 2,9 & 2,9 \\
1 mínimo & 13 & 6,2 & 6,2 & 9,1 \\
2 poco & 39 & 18,7 & 18,7 & 27,8 \\
3 medianamente & 49 & 23,4 & 23,4 & 51,2 \\
4 bastante & 48 & 23,0 & 23,0 & 74,2 \\
5 del todo & 54 & 25,8 & 25,8 & 100,0 \\
Total & 209 & 100,0 & 100,0 & \\
\hline
\end{tabular}

Elaboración propia. Mayo de 2015

Gráfico n ${ }^{\circ} 2.29$

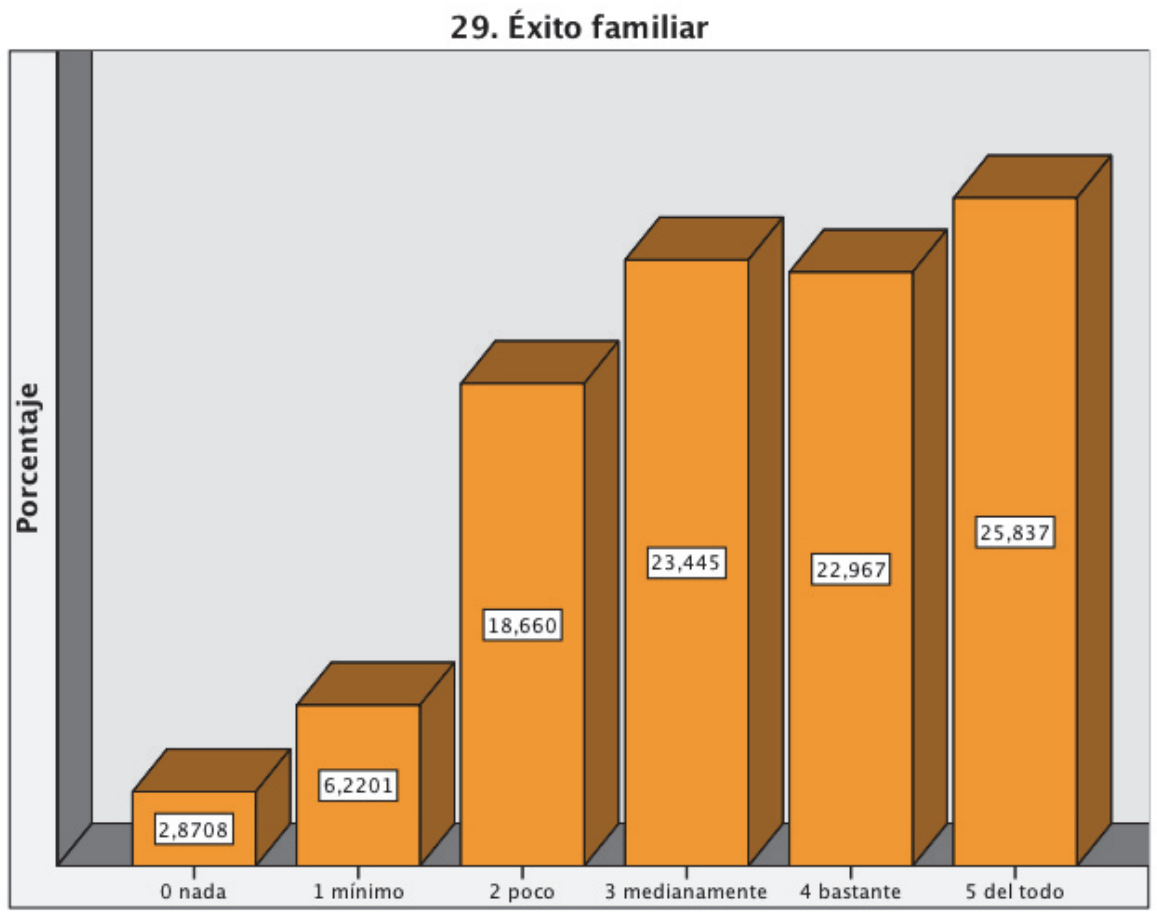

Elaboración propia. Mayo de 2015

Análisis: distribución bastante homogénea para las puntuaciones del 2 al 5 , modelo en escalera aplanada, mientras que en la VP se presenta como una escalera ascendente con un $61,244 \%$ para el 5. El valor "Éxito familiar" es percibido como más importante en la VP que para el ME.

Hecho coherente con la realidad. Podemos decir que los resultados son bastante buenos y que responde a la población laboral feminizada. 
Cuadro $n^{\circ} 2.30$

30. Expresividad/libertad

\begin{tabular}{|l|r|r|r|r|}
\hline & Frecuencia & Porcentaje & $\begin{array}{c}\text { Porcentaje } \\
\text { válido }\end{array}$ & $\begin{array}{r}\text { Porcentaje } \\
\text { acumulado }\end{array}$ \\
\hline 0 nada & 7 & 3,3 & 3,3 & 3,3 \\
1 mínimo & 11 & 5,3 & 5,3 & 8,6 \\
2 poco & 35 & 16,7 & 16,7 & 25,4 \\
3 medianamente & 61 & 29,2 & 29,2 & 54,5 \\
4 bastante & 48 & 23,0 & 23,0 & 77,5 \\
5 del todo & 47 & 22,5 & 22,5 & 100,0 \\
Total & 209 & 100,0 & 100,0 & \\
\hline
\end{tabular}

Elaboración propia. Mayo de 2015

Gráfico ${ }^{\circ} 2.30$

30. Expresividad/libertad

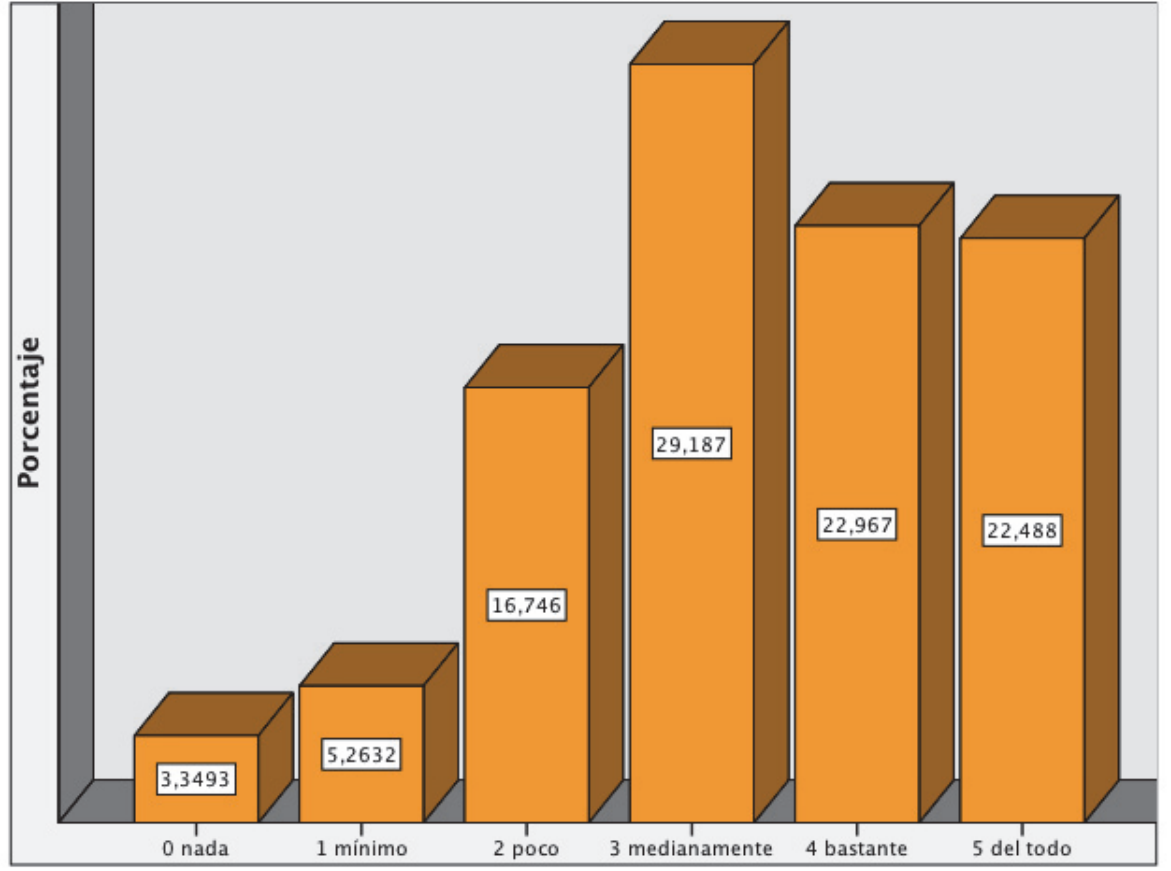

Elaboración propia. Mayo de 2015

Análisis: modelo en pirámide en el que el mayor peso recae sobre el 3. El valor "Expresividad/libertad" en el área del $\mathrm{ME}$ se manifiesta como medianamente importante, sin embargo el mismo valor en el área VP aparece como claramente importante.

Valor básico dentro del Compromiso Social, el Respeto, Dignidad y Autonomía de las personas. Los resultados responden al perfil de una empresa al servicio de la salud nacional. 
Cuadro $n^{\circ} 2.31$

31. Felicidad (búsqueda de la )

\begin{tabular}{|l|r|r|r|r|}
\hline & Frecuencia & Porcentaje & $\begin{array}{c}\text { Porcentaje } \\
\text { válido }\end{array}$ & $\begin{array}{r}\text { Porcentaje } \\
\text { acumulado }\end{array}$ \\
\hline 0 nada & 7 & 3,3 & 3,3 & 3,3 \\
1 mínimo & 17 & 8,1 & 8,1 & 11,5 \\
2 poco & 18 & 8,6 & 8,6 & 20,1 \\
3 medianamente & 42 & 20,1 & 20,1 & 40,2 \\
4 bastante & 46 & 22,0 & 22,0 & 62,2 \\
5 del todo & 79 & 37,8 & 37,8 & 100,0 \\
Total & 209 & 100,0 & 100,0 & \\
\hline
\end{tabular}

Elaboración propia. Mayo de 2015

Gráfico no 2.31

\section{Felicidad (búsqueda de la )}

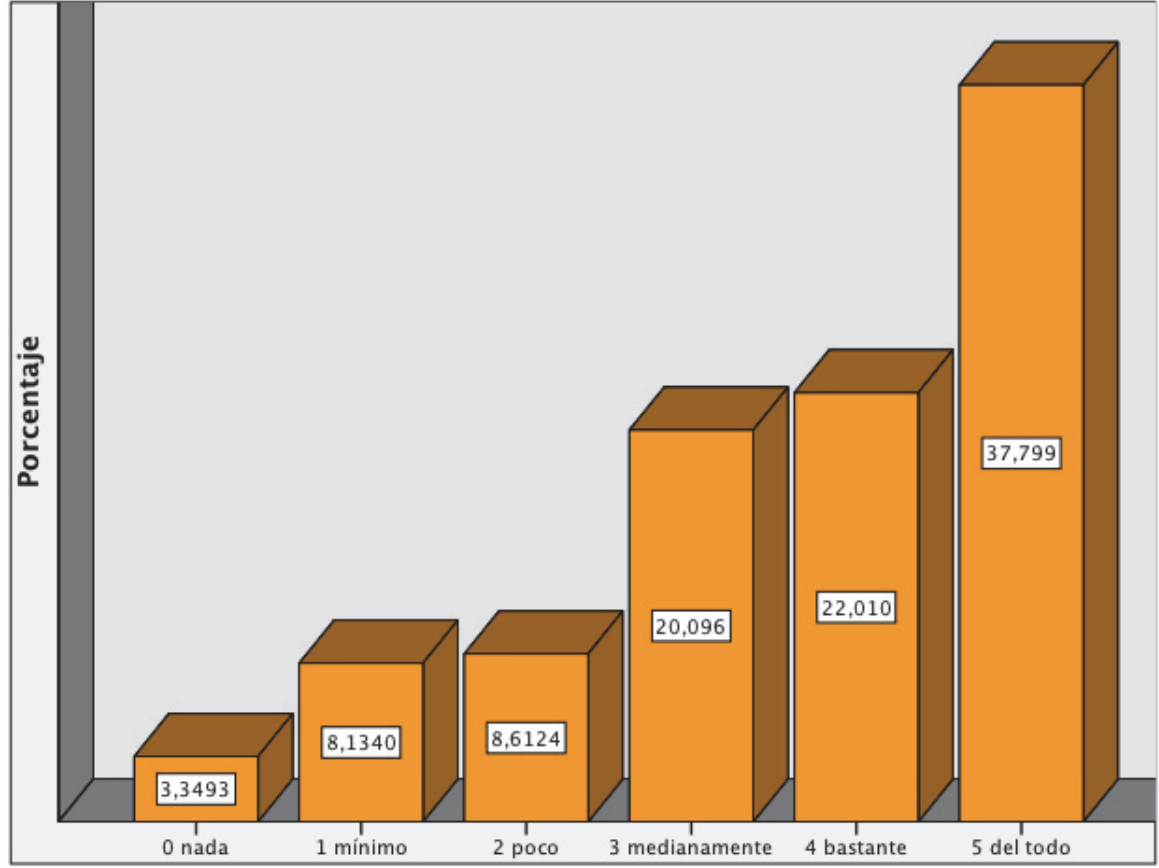

Elaboración propia. Mayo de 2015

Análisis: mientras que en la figura $\mathrm{n}^{0} 1.31$ vemos ausencia de las puntuaciones 0,1 y 2 y un $80 \%$ para el 5, en el ME vemos todas las puntuaciones marcadas y una distribución que, aunque sea una escalera ascendente con casi un $38 \%$ para el 5 , está muy repartida.

Trabajar a favor de la salud y de la vida es buscar la felicidad de las personas, en este sentido los resultados son acordes al tipo de empresa que se está valorando. 
Cuadro $n^{\circ} 2.32$

32. Honestidad, honradez, transparencia, sinceridad

\begin{tabular}{|l|r|r|r|r|}
\hline & Frecuencia & Porcentaje & $\begin{array}{c}\text { Porcentaje } \\
\text { válido }\end{array}$ & $\begin{array}{r}\text { Porcentaje } \\
\text { acumulado }\end{array}$ \\
\hline 0 nada & 6 & 2,9 & 2,9 & 2,9 \\
1 mínimo & 12 & 5,7 & 5,7 & 8,6 \\
2 poco & 19 & 9,1 & 9,1 & 17,7 \\
3 medianamente & 58 & 27,8 & 27,8 & 45,5 \\
4 bastante & 51 & 24,4 & 24,4 & 69,9 \\
5 del todo & 63 & 30,1 & 30,1 & 100,0 \\
Total & 209 & 100,0 & 100,0 & \\
\hline
\end{tabular}

Elaboración propia. Mayo de 2015

Gráfico ${ }^{\circ} 2.32$

32. Honestidad, honradez, transparencia, sinceridad

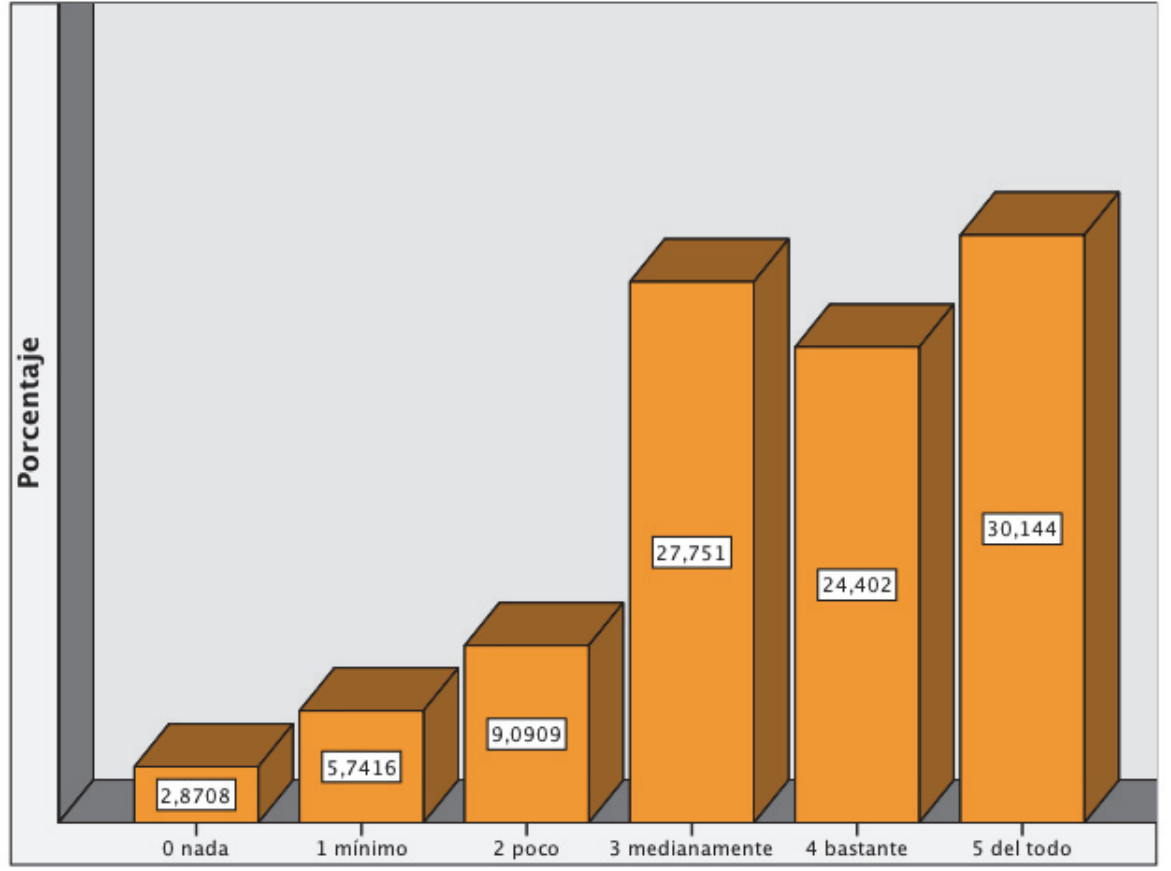

Elaboración propia. Mayo de 2015

Análisis: carece de las puntuaciones 0 y 1 y presenta una distribución en escalera ascendente con casi el 59\% para el 5, en cambio en el ME, aparecen todas las puntuaciones marcadas y un patrón en escalera aplanada.

El alumnado considera que la vigencia de este valor es menos clara en el ME que en su VP. Aún así, los resultados no son malos para que se establezca una relación laboral buena, basada en la confianza. 
Cuadro $n^{0} 2.33$

33. Humildad, modestia

\begin{tabular}{|l|r|r|r|r|}
\hline & Frecuencia & Porcentaje & $\begin{array}{c}\text { Porcentaje } \\
\text { válido }\end{array}$ & $\begin{array}{c}\text { Porcentaje } \\
\text { acumulado }\end{array}$ \\
\hline 0 nada & 9 & 4,3 & 4,3 & 4,3 \\
1 mínimo & 11 & 5,3 & 5,3 & 9,6 \\
2 poco & 20 & 9,6 & 9,6 & 19,1 \\
3 medianamente & 57 & 27,3 & 27,3 & 46,4 \\
4 bastante & 66 & 31,6 & 31,6 & 78,0 \\
5 del todo & 46 & 22,0 & 22,0 & 100,0 \\
Total & 209 & 100,0 & 100,0 & \\
\hline
\end{tabular}

Elaboración propia. Mayo de 2015

Gráfico n ${ }^{\circ} 2.33$

33. Humildad, modestia

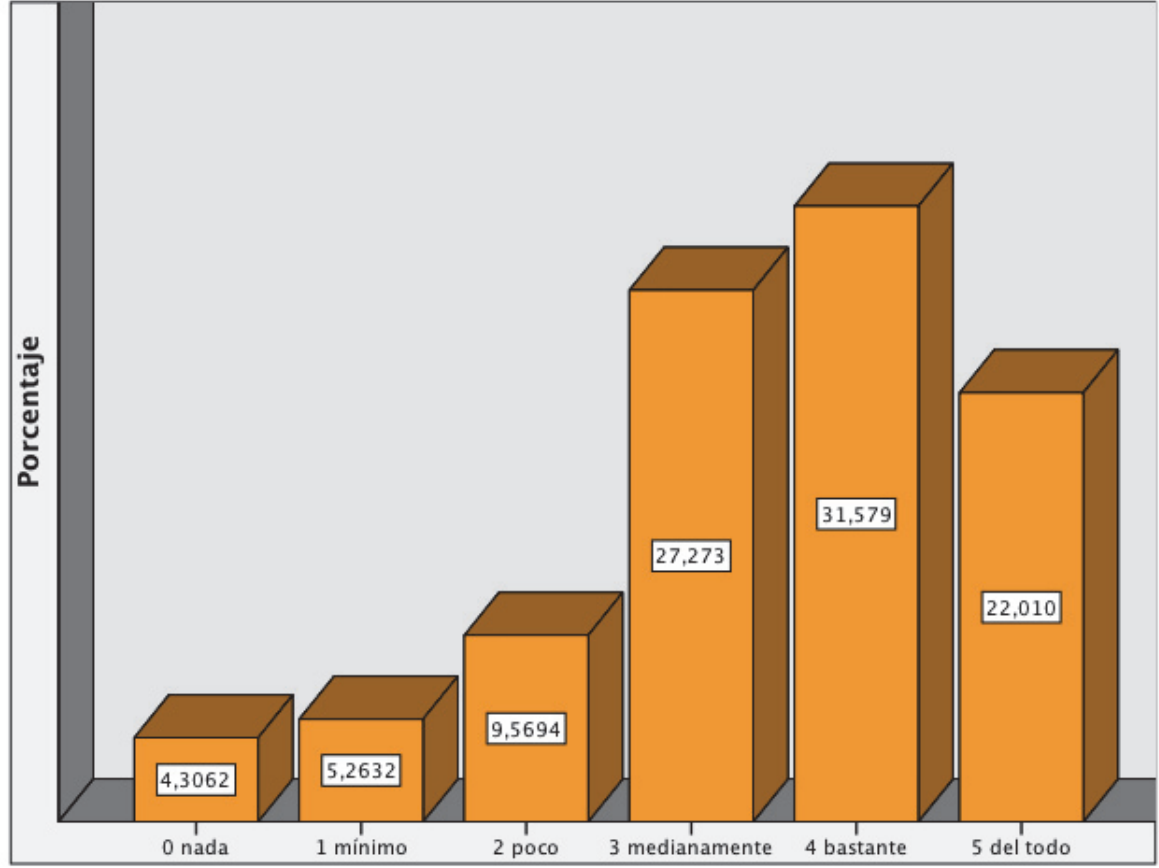

Elaboración propia. Mayo de 2015

Análisis: la "Humildad, modestia" en la VP es claramente importante, mientras que en el ME aparece una distribución más repartida con un patrón de pirámide sesgada hacia la derecha.

En cuanto al análisis cualitativo, podemos decir lo mismo que en el valor anterior, aunque el alumnado considera que la empresa da menos importancia a la humildad, modestia que ellos mismos en su VP, sí se puede esperar una buena relación laboral, en función de los resultados obtenidos. 
Cuadro $n^{\circ} 2.34$

34. Idealismo

\begin{tabular}{|l|r|r|r|r|}
\hline & Frecuencia & Porcentaje & $\begin{array}{c}\text { Porcentaje } \\
\text { válido }\end{array}$ & $\begin{array}{r}\text { Porcentaje } \\
\text { acumulado }\end{array}$ \\
\hline 0 nada & 9 & 4,3 & 4,3 & 4,3 \\
1 mínimo & 15 & 7,2 & 7,2 & 11,5 \\
2 poco & 15 & 7,2 & 7,2 & 18,7 \\
3 medianamente & 68 & 32,5 & 32,5 & 51,2 \\
4 bastante & 67 & 32,1 & 32,1 & 83,3 \\
5 del todo & 35 & 16,7 & 16,7 & 100,0 \\
Total & 209 & 100,0 & 100,0 & \\
\hline
\end{tabular}

Elaboración propia. Mayo de 2015

Gráfico ${ }^{\circ} 2.34$

34. Idealismo

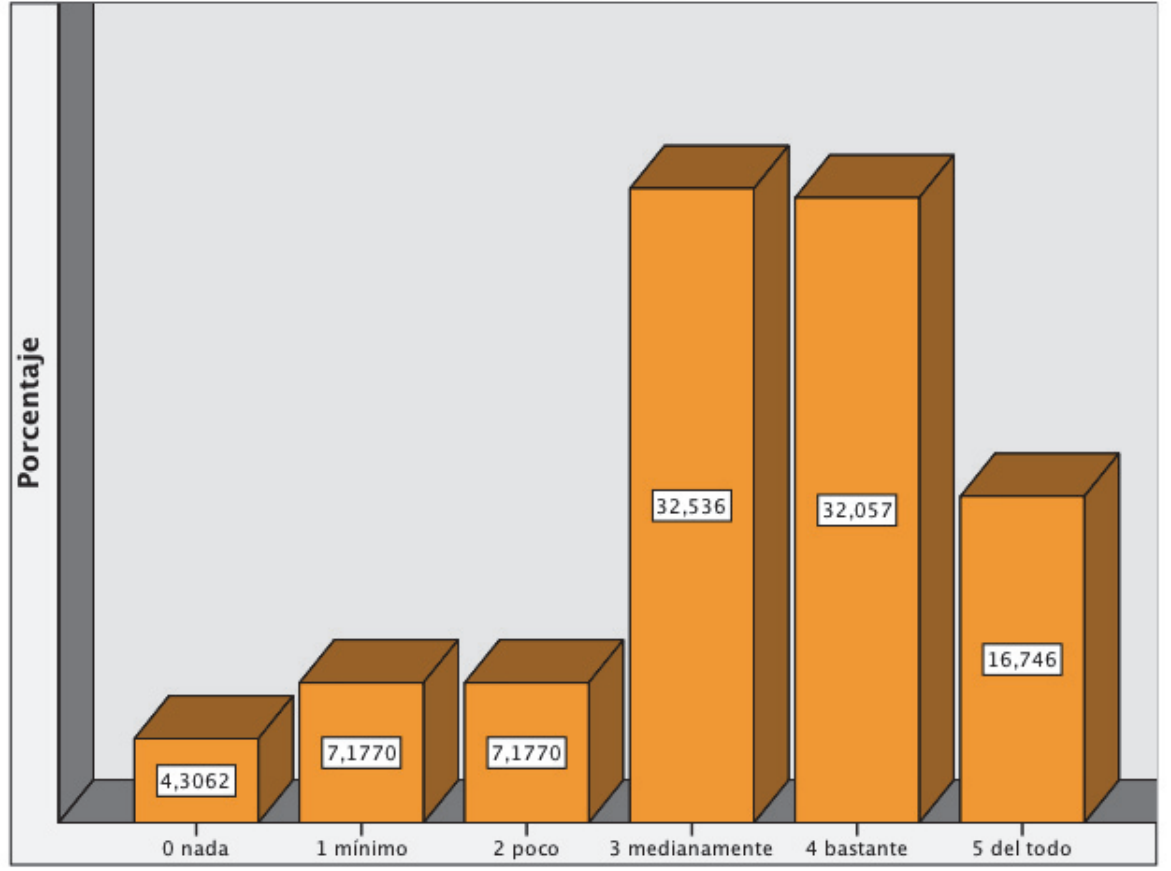

Elaboración propia. Mayo de 2015

Análisis: llama la atención la semejanza entre los gráficos 1.34 y 2.34 con la única diferencia de que el 0,1 y 2 tienen menores porcentajes en la 1.34 y el 3, 4 y 5 algo mayores. En ambas esferas ganan el 3 y 4: medianamente/bastante.

Estos resultados hacen pensar que el SNS persigue un ideal: salud para todos, a la vez que sabe que no es posible. Ya la OMS, en 1945, definió la salud como un ideal deseable por todos a la vez que imposible. 
Cuadro $n^{\circ} 2.35$

35. Igualdad/Liberación

\begin{tabular}{|l|r|r|r|r|}
\hline & Frecuencia & Porcentaje & $\begin{array}{c}\text { Porcentaje } \\
\text { válido }\end{array}$ & $\begin{array}{c}\text { Porcentaje } \\
\text { acumulado }\end{array}$ \\
\hline 0 nada & 12 & 5,7 & 5,7 & 5,7 \\
1 mínimo & 7 & 3,3 & 3,3 & 9,1 \\
2 poco & 16 & 7,7 & 7,7 & 16,7 \\
3 medianamente & 65 & 31,1 & 31,1 & 47,8 \\
4 bastante & 61 & 29,2 & 29,2 & 77,0 \\
5 del todo & 48 & 23,0 & 23,0 & 100,0 \\
Total & 209 & 100,0 & 100,0 & \\
\hline
\end{tabular}

Elaboración propia. Mayo de 2015

Gráfico n ${ }^{\circ} 2.35$

35. Igualdad/Liberación

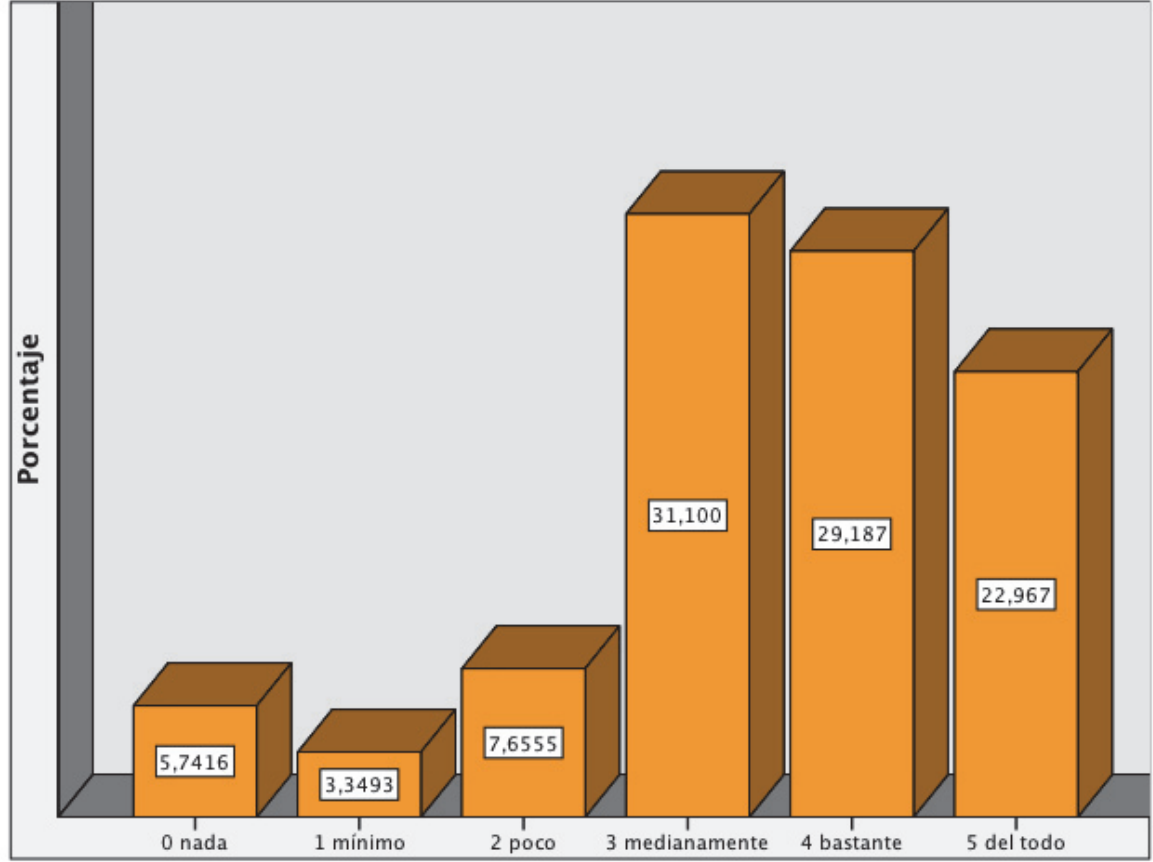

Elaboración propia. Mayo de 2015

Análisis: todas las puntuaciones están marcadas, con mayor representación del 3 y del 4 y 5 de forma decreciente. Este valor es también considerado por la muestra en estudio más importante en la VP que en el ME.

Existe un paralelismo claro entre el valor 26. Equidad y el 35. Igualdad, y los resultados son equiparables en ambas áreas. Esto pone de manifiesto la coherencia de las respuesta, la validez de las encuestas y que la igualdad ante la salud es uno de los valores del SNS. 
Cuadro $\mathrm{n}^{\circ} 2.36$

36. Imagen, prestigio social

\begin{tabular}{|l|r|r|r|r|}
\hline & Frecuencia & Porcentaje & $\begin{array}{c}\text { Porcentaje } \\
\text { válido }\end{array}$ & $\begin{array}{r}\text { Porcentaje } \\
\text { acumulado }\end{array}$ \\
\hline 0 nada & 2 & 1,0 & 1,0 & 1,0 \\
1 mínimo & 3 & 1,4 & 1,4 & 2,4 \\
2 poco & 11 & 5,3 & 5,3 & 7,7 \\
3 medianamente & 43 & 20,6 & 20,6 & 28,2 \\
4 bastante & 71 & 34,0 & 34,0 & 62,2 \\
5 del todo & 79 & 37,8 & 37,8 & 100,0 \\
Total & 209 & 100,0 & 100,0 & \\
\hline
\end{tabular}

Elaboración propia. Mayo de 2015

Gráfico ${ }^{\circ} 2.36$

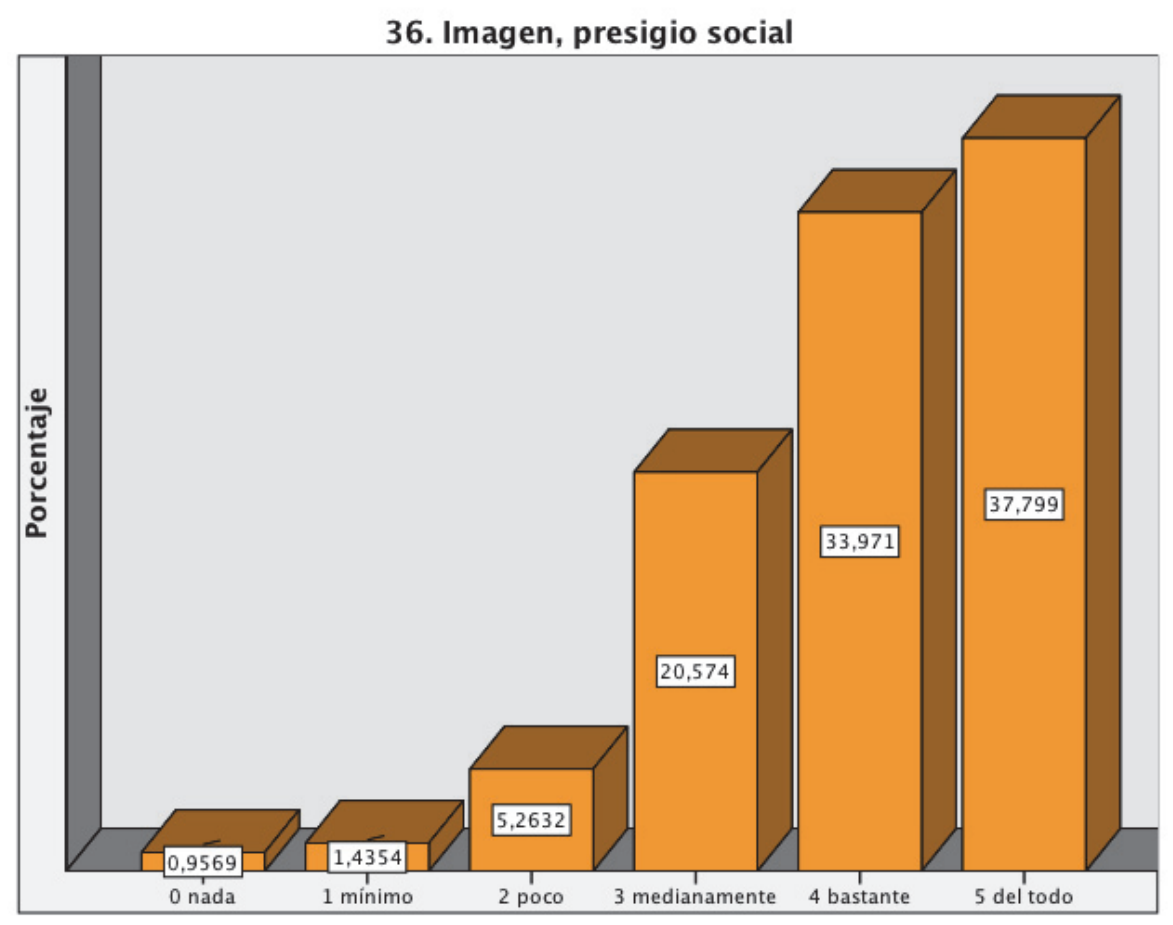

Elaboración propia. Mayo de 2015

Análisis: distribución en escalera ascendente con casi un $38 \%$ para el 5 frente al 22\% del 5 en la VP. El valor "Imagen, prestigio social" es considerado más importante en el ME que en la VP.

Este ítem, el 13. Competitividad, ambición y el 50. Productividad, resultados son características consideradas tradicionalmente masculinas $\mathrm{y}$ observamos que arrojan resultados similares. Son resultados acordes en la VP para una profesión feminizada, y en el ME en cuanto a que la gestión y dirección de empresas sigue en manos masculinas. 
Cuadro $n^{\circ} 2.37$

37. Imaginación, creatividad, fantasía

\begin{tabular}{|l|r|r|r|r|}
\hline & Frecuencia & Porcentaje & $\begin{array}{c}\text { Porcentaje } \\
\text { válido }\end{array}$ & $\begin{array}{r}\text { Porcentaje } \\
\text { acumulado }\end{array}$ \\
\hline 0 nada & 5 & 2,4 & 2,4 & 2,4 \\
1 mínimo & 11 & 5,3 & 5,3 & 7,7 \\
2 poco & 31 & 14,8 & 14,8 & 22,5 \\
3 medianamente & 65 & 31,1 & 31,1 & 53,6 \\
4 bastante & 56 & 26,8 & 26,8 & 80,4 \\
5 del todo & 41 & 19,6 & 19,6 & 100,0 \\
Total & 209 & 100,0 & 100,0 & \\
\hline
\end{tabular}

Elaboración propia. Mayo de 2015

Gráfico n ${ }^{\circ} 2.37$

37. Imaginación, creatividad, fantasia

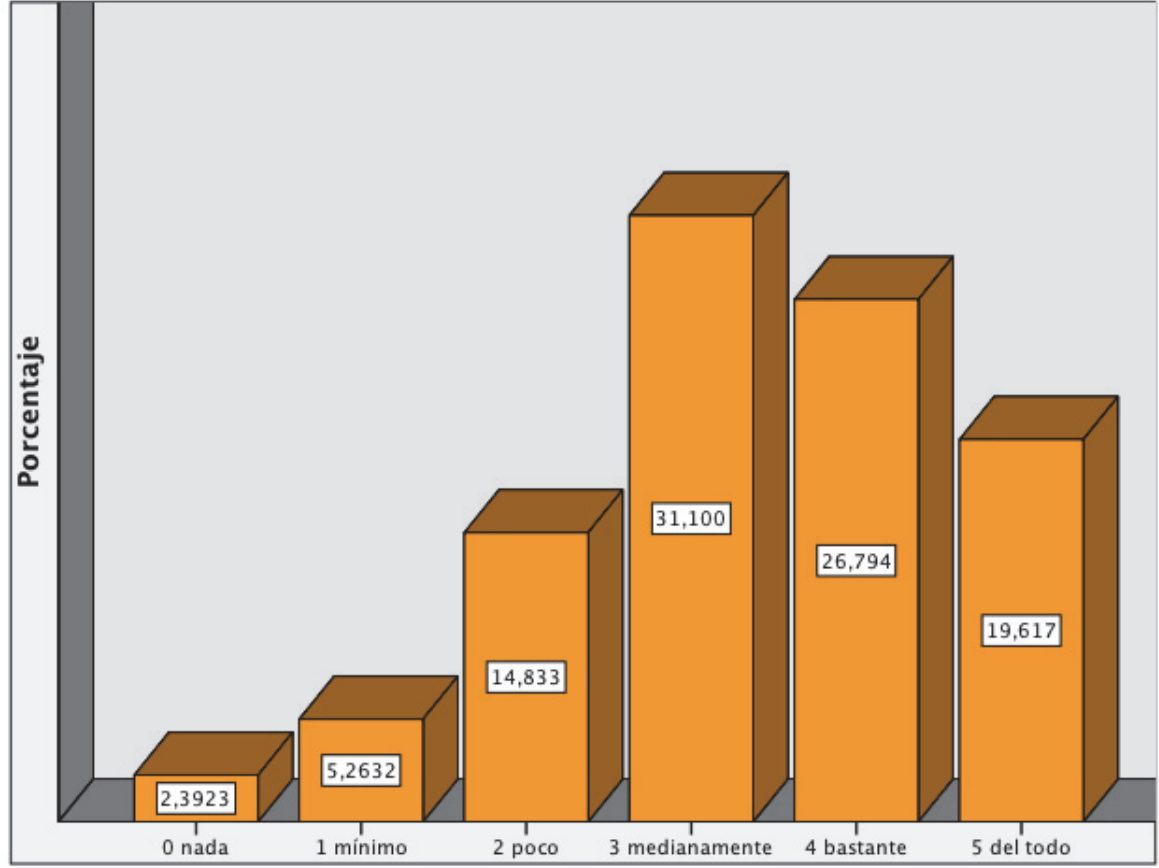

Elaboración propia. Mayo de 2015

Análisis: todas las puntuaciones están marcadas. Modelo en pirámide con preponderancia del 3/medianamente, en cambio en la VP vemos una distribución en pirámide asimétrica con sesgo a la derecha con casi un 38\% para el 4/bastante.

El alumnado percibe este valor desde la perspectiva de una administración pública, el SNS, con sus características (según Weber): legalidad de las normas, racionalidad de la división del trabajo, impersonalidad en las relaciones, jerarquía, normalización de los procedimientos, previsibilidad del funcionamiento... Esto deja poco espacio para la imaginación, creatividad, fantasía. 
Cuadro $\mathrm{n}^{\circ} 2.38$

38. Inconformismo, rebeldía ante la injusticia social

\begin{tabular}{|l|r|r|r|r|}
\hline & Frecuencia & Porcentaje & $\begin{array}{c}\text { Porcentaje } \\
\text { válido }\end{array}$ & $\begin{array}{r}\text { Porcentaje } \\
\text { acumulado }\end{array}$ \\
\hline 0 nada & 14 & 6,7 & 6,7 & 6,7 \\
1 mínimo & 24 & 11,5 & 11,5 & 18,2 \\
2 poco & 26 & 12,4 & 12,4 & 30,6 \\
3 medianamente & 77 & 36,8 & 36,8 & 67,5 \\
4 bastante & 36 & 17,2 & 17,2 & 84,7 \\
5 del todo & 32 & 15,3 & 15,3 & 100,0 \\
Total & 209 & 100,0 & 100,0 & \\
\hline
\end{tabular}

Elaboración propia. Mayo de 2015

Gráfico ${ }^{\circ} 2.38$

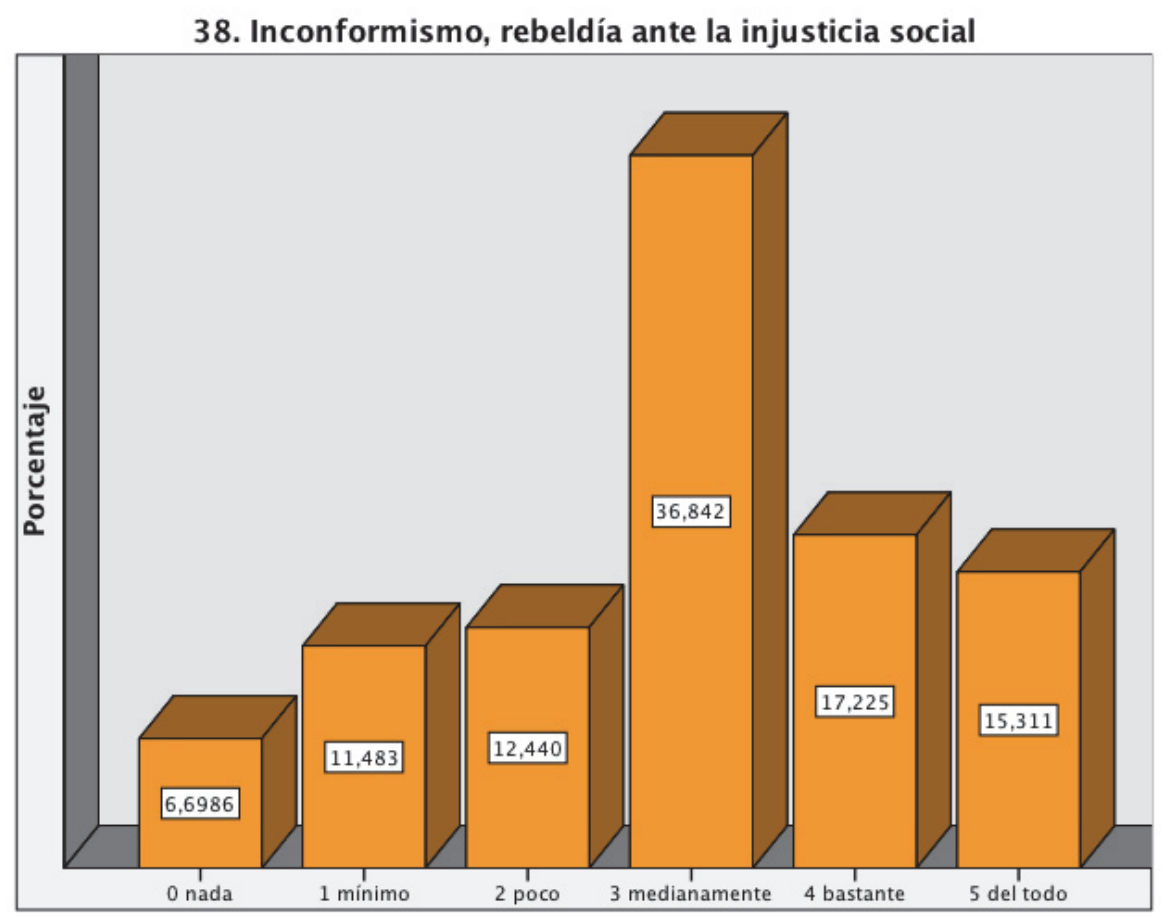

Elaboración propia. Mayo de 2015

Análisis: todas las puntuaciones están marcadas con mayor peso del 3. El "Inconformismo, rebeldía ante la injusticia social" es considerado medianamente importante en el ME, mientras que en la VP vemos una distribución en escalera ascendente revelándose como claramente importante.

Una administración pública, programada, jerarquizada y previsible en su funcionamiento, resulta difícil verla como inconformista o rebelde. Esto es lo que percibe el alumnado. Este ítem refuerza la coherencia de las encuestas. 
Cuadro n ${ }^{\circ} 2.39$

39. Independencia, iniciativa, autonomía de acción

\begin{tabular}{|l|r|r|r|r|}
\hline & Frecuencia & Porcentaje & $\begin{array}{c}\text { Porcentaje } \\
\text { válido }\end{array}$ & $\begin{array}{r}\text { Porcentaje } \\
\text { acumulado }\end{array}$ \\
\hline 0 nada & 4 & 1,9 & 1,9 & 1,9 \\
1 mínimo & 31 & 14,8 & 14,8 & 16,7 \\
2 poco & 15 & 7,2 & 7,2 & 23,9 \\
3 medianamente & 50 & 23,9 & 23,9 & 47,8 \\
4 bastante & 59 & 28,2 & 28,2 & 76,1 \\
5 del todo & 50 & 23,9 & 23,9 & 100,0 \\
Total & 209 & 100,0 & 100,0 & \\
\hline
\end{tabular}

Elaboración propia. Mayo de 2015

Gráfico n ${ }^{\circ} 2.39$

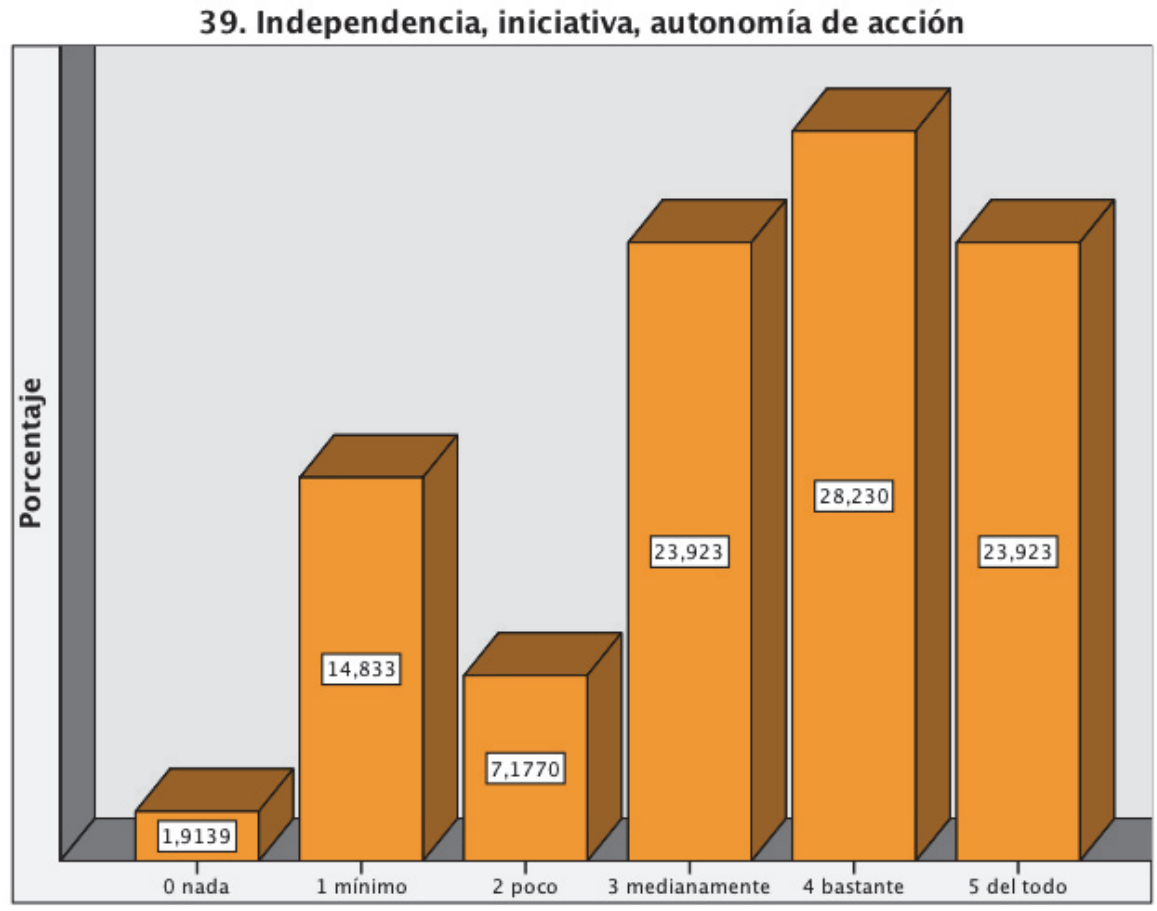

Elaboración propia. Mayo de 2015

Análisis: todas las puntuaciones están marcadas. El peso recae sobre el 3, 4 y 5 de forma bastante equivalente, mientras que en la VP este valor presenta un patrón en escalera ascendente con más de un 51\% para el 5 manifestándose claramente importante, en el ME su importancia no está tan clara.

Respuestas acordes a enfermería en el SNS, pues aunque la administración pública se caracteriza por tenerlo ya todo previsto, la enfermedad y la vida exigen tener iniciativa. 
Cuadro $\mathrm{n}^{\circ} 2.40$

40. Influencia, poder social (búsqueda de)

\begin{tabular}{|l|r|r|r|r|}
\hline & Frecuencia & Porcentaje & $\begin{array}{c}\text { Porcentaje } \\
\text { válido }\end{array}$ & $\begin{array}{r}\text { Porcentaje } \\
\text { acumulado }\end{array}$ \\
\hline 1 mínimo & 6 & 2,9 & 2,9 & 2,9 \\
2 poco & 9 & 4,3 & 4,3 & 7,2 \\
3 medianamente & 70 & 33,5 & 33,5 & 40,7 \\
4 bastante & 65 & 31,1 & 31,1 & 71,8 \\
5 del todo & 59 & 28,2 & 28,2 & 100,0 \\
Total & 209 & 100,0 & 100,0 & \\
\hline
\end{tabular}

Elaboración propia. Mayo de 2015

Gráfico ${ }^{\circ} 2.40$

40. Influencia, poder social (búsqueda de)

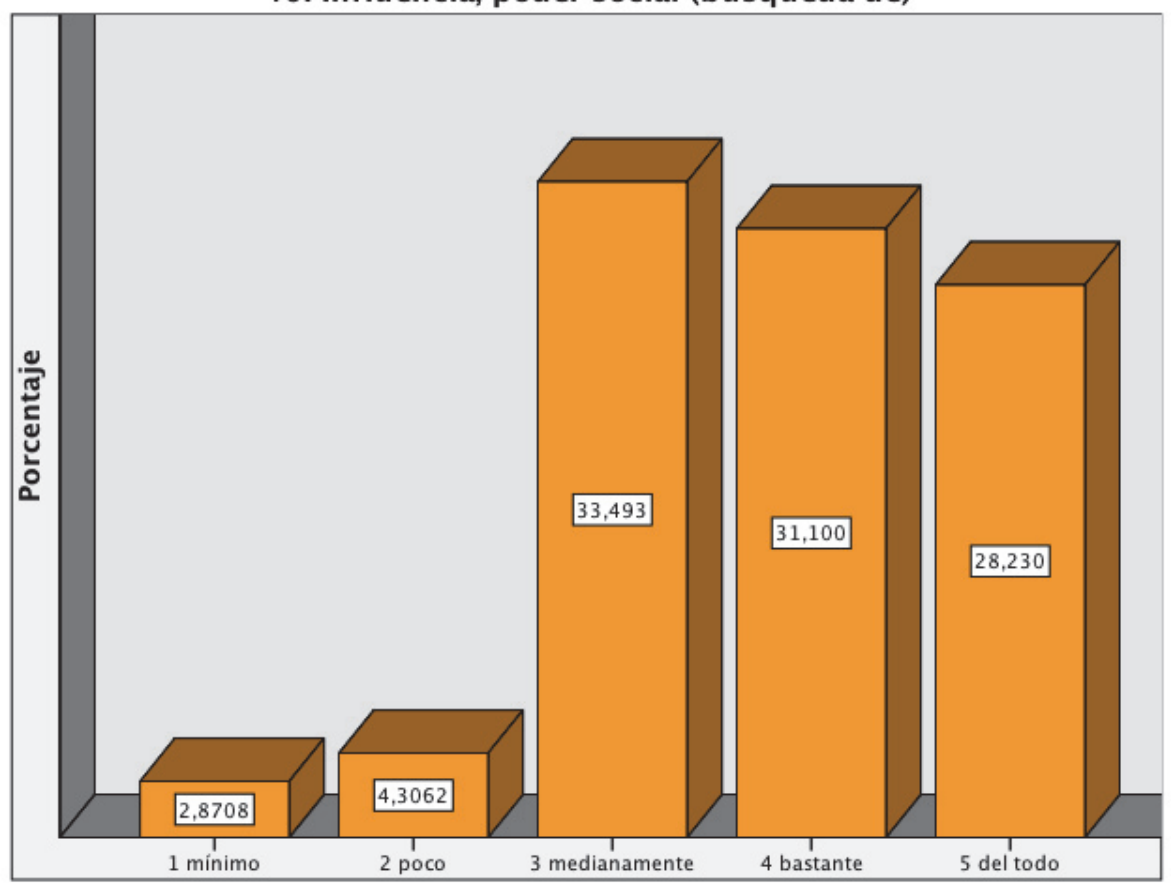

Elaboración propia. Mayo de 2015

Análisis: observamos un patrón en pirámide sesgada a la derecha, el porcentaje mayor corresponde al 3 con más del 33\%, el 0 no ha sido marcado y el 3,4 y 5 suman más del 92\%. Comparando esta figura con la 1.40 , vemos que la muestra en estudio considera que este valor es más importante en el ME que en la VP.

Una administración pública tiene per sé influencia y poder social y no busca más de la que le otorga la Ley. Resultados coherentes con los perfiles que trabajamos. 
Cuadro $n^{\circ} 2.41$

41. Lealtad/Fidelidad

\begin{tabular}{|l|r|r|r|r|}
\hline & Frecuencia & Porcentaje & $\begin{array}{c}\text { Porcentaje } \\
\text { válido }\end{array}$ & $\begin{array}{r}\text { Porcentaje } \\
\text { acumulado }\end{array}$ \\
\hline 0 nada & 3 & 1,4 & 1,4 & 1,4 \\
1 mínimo & 10 & 4,8 & 4,8 & 6,2 \\
2 poco & 14 & 6,7 & 6,7 & 12,9 \\
3 medianamente & 65 & 31,1 & 31,1 & 44,0 \\
4 bastante & 51 & 24,4 & 24,4 & 68,4 \\
5 del todo & 66 & 31,6 & 31,6 & 100,0 \\
Total & 209 & 100,0 & 100,0 & \\
\hline
\end{tabular}

Elaboración propia. Mayo de 2015

Gráfico $n^{\circ} 2.41$

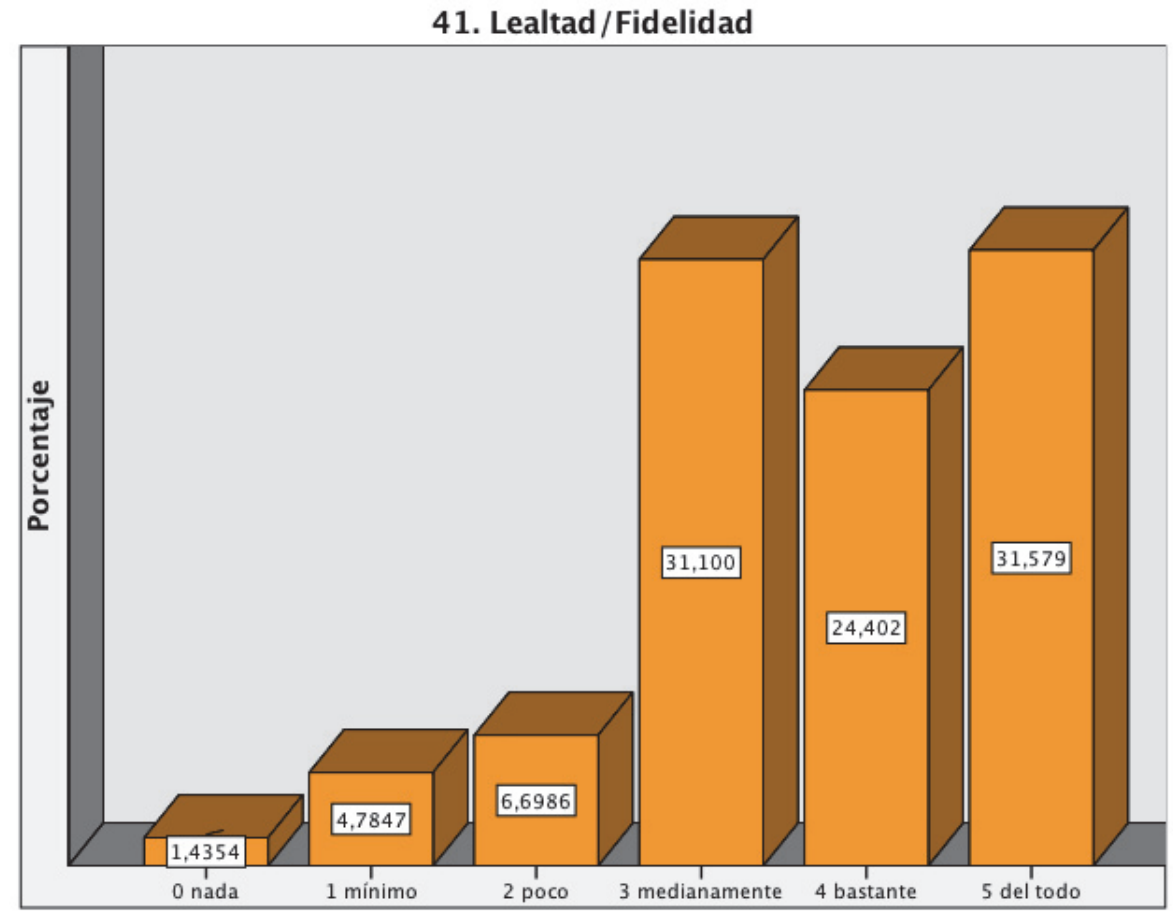

Elaboración propia. Mayo de 2015

Análisis: todas las puntuaciones están marcadas, distribución en pirámide sesgada a la derecha con mayor peso para el 3 y el 5. Sin embargo en la figura 1.41 observamos un modelo en escalera ascendente con más del 74\% para el 5 . El valor Lealtad/Fidelidad es considerado más importante en la VP que en el ME.

Estamos en un grupo de valores dirigidos a lo personal, por lo que las respuestas para el ME arrojan, coherentemente, resultados de menos importante que en la VP. Lo mismo ocurre con el ítem 43. Mundo en paz. 
Cuadro $n^{\circ} 2.42$

42. Moderación, tener pocos deseos

\begin{tabular}{|l|r|r|r|r|}
\hline & Frecuencia & Porcentaje & $\begin{array}{c}\text { Porcentaje } \\
\text { válido }\end{array}$ & $\begin{array}{r}\text { Porcentaje } \\
\text { acumulado }\end{array}$ \\
\hline 0 nada & 12 & 5,7 & 5,7 & 5,7 \\
1 mínimo & 21 & 10,0 & 10,0 & 15,8 \\
2 poco & 37 & 17,7 & 17,7 & 33,5 \\
3 medianamente & 67 & 32,1 & 32,1 & 65,6 \\
4 bastante & 53 & 25,4 & 25,4 & 90,9 \\
5 del todo & 19 & 9,1 & 9,1 & 100,0 \\
Total & 209 & 100,0 & 100,0 & \\
\hline
\end{tabular}

Elaboración propia. Mayo de 2015

Gráfico ${ }^{\circ} 2.42$

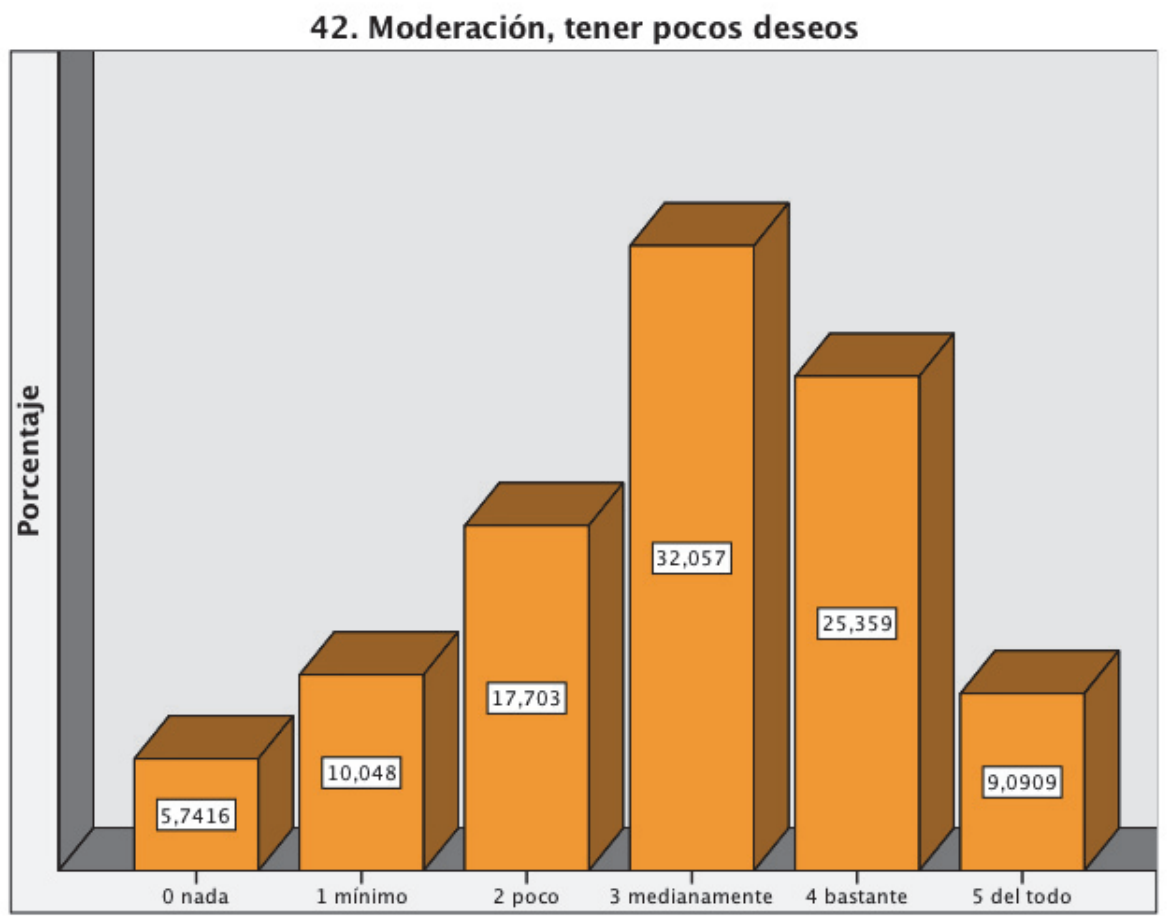

Elaboración propia. Mayo de 2015

Análisis: todas las puntuaciones han sido marcadas. Modelo en pirámide muy similar a la figura 1.42. el valor "Moderación, tener pocos deseos" es considerado de importancia media tanto en la esfera de la VP como en el ME.

Los resultados de este valor y los del 22. Deleite físico, Hedonismo son similares, para ambas esferas, presentan predominio del 3. Resulta llamativo que valores tan opuestos presenten resultados similares. 
Cuadro $n^{\circ} 2.43$

43. Mundo en paz

\begin{tabular}{|l|r|r|r|r|}
\hline & Frecuencia & Porcentaje & $\begin{array}{l}\text { Porcentaje } \\
\text { válido }\end{array}$ & $\begin{array}{c}\text { Porcentaje } \\
\text { acumulado }\end{array}$ \\
\hline 0 nada & 10 & 4,8 & 4,8 & 4,8 \\
1 mínimo & 11 & 5,3 & 5,3 & 10,0 \\
2 poco & 22 & 10,5 & 10,5 & 20,6 \\
3 medianamente & 60 & 28,7 & 28,7 & 49,3 \\
4 bastante & 43 & 20,6 & 20,6 & 69,9 \\
5 del todo & 63 & 30,1 & 30,1 & 100,0 \\
Total & 209 & 100,0 & 100,0 & \\
\hline
\end{tabular}

Elaboración propia. Mayo de 2015

Gráfico n ${ }^{\circ} 2.43$

43. Mundo en paz

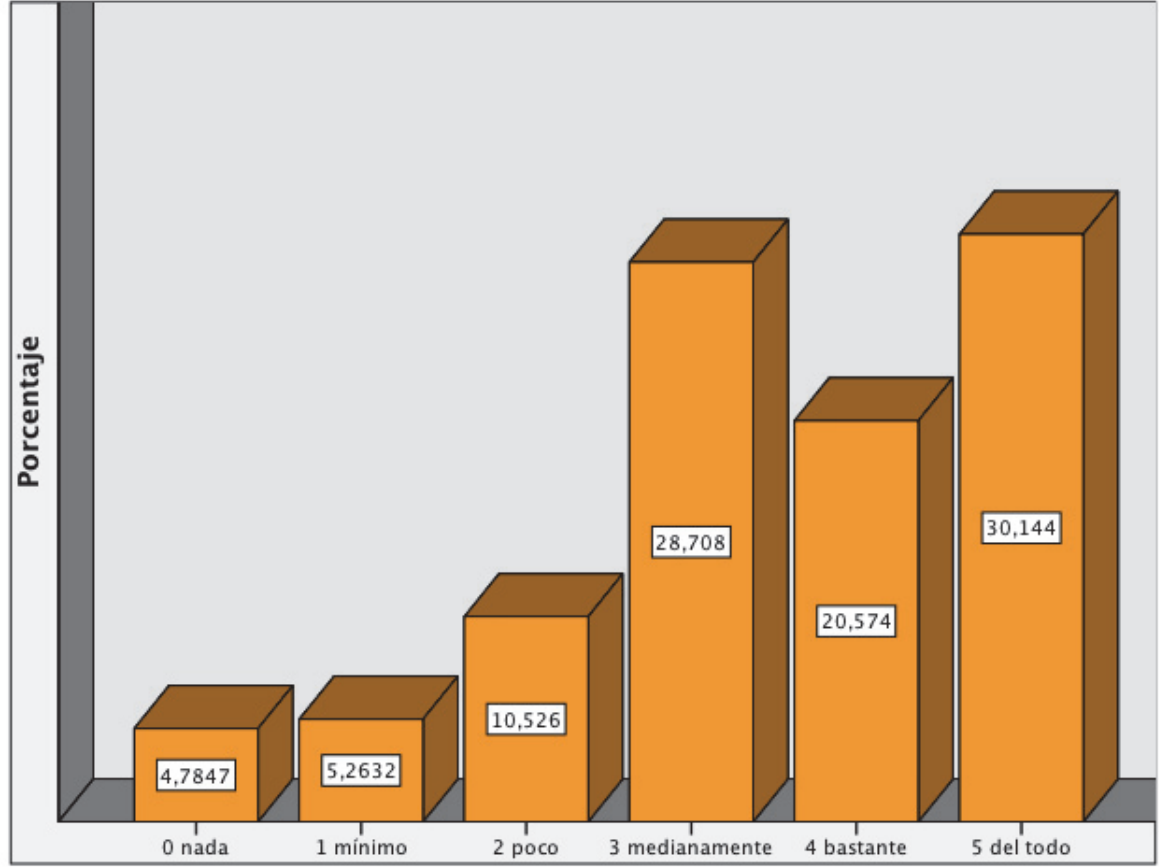

Elaboración propia. Mayo de 2015

Análisis: todas las puntuaciones han sido marcadas. Modelo en escalera aplanada con mayor peso en el 3 y 5 . En el gráfico 1.43 vemos una distribución en escalera ascendente. El valor "Mundo en paz" es considerado más importante en la VP que en el ME.

Este pertenece a un grupo de valores que van más dirigidos a lo personal, por lo que las respuestas para el ME y sobre todo si esta es una administración pública, arrojan, coherentemente, resultados de menos importante que en la VP. 
Cuadro $n^{\circ} 2.44$

44. Obediencia, cumplimiento

\begin{tabular}{|l|r|r|r|r|}
\hline & Frecuencia & Porcentaje & $\begin{array}{c}\text { Porcentaje } \\
\text { válido }\end{array}$ & $\begin{array}{r}\text { Porcentaje } \\
\text { acumulado }\end{array}$ \\
\hline 1 mínimo & 3 & 1,4 & 1,4 & 1,4 \\
2 poco & 12 & 5,7 & 5,7 & 7,2 \\
3 medianamente & 42 & 20,1 & 20,1 & 27,3 \\
4 bastante & 56 & 26,8 & 26,8 & 54,1 \\
5 del todo & 96 & 45,9 & 45,9 & 100,0 \\
Total & 209 & 100,0 & 100,0 & \\
\hline
\end{tabular}

Elaboración propia. Mayo de 2015

Gráfico ${ }^{\circ} 2.44$

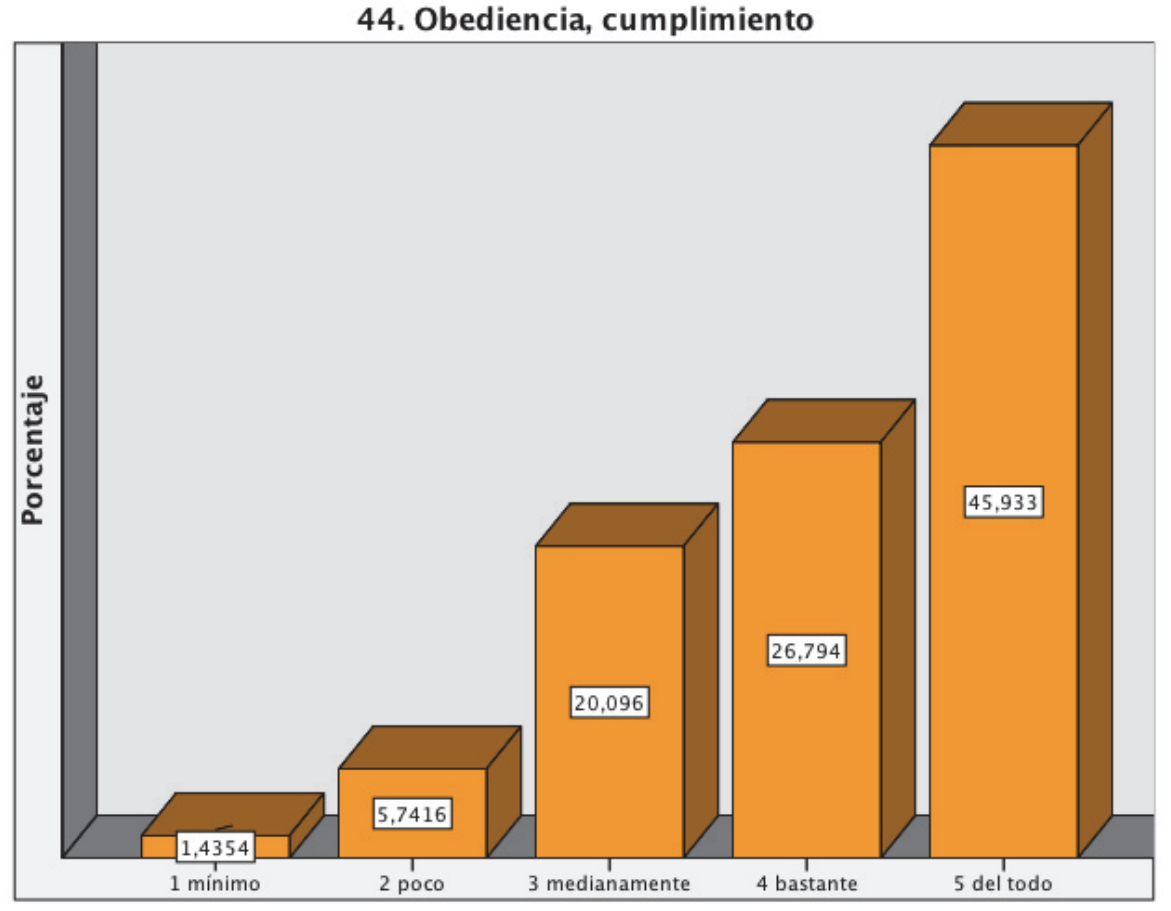

Elaboración propia. Mayo de 2015

Análisis: ausencia del 0, patrón en escalera ascendente con casi el 46\% para el 5. En el gráfico 1.44 vemos una distribución en pirámide con predominio del 4. El valor "obediencia/cumplimiento" es considerado más importante en el área del ME que en la VP.

Según Weber "El concepto de disciplina encierra el de una 'obediencia habitual' por parte de las masas sin resistencia ni crítica". Según los resultados obtenidos en esta encuesta podemos esperar unos profesionales disciplinados y por lo tanto eficientes. 
Cuadro $n^{\circ} 2.45$

45. Pasión, entusiasmo

\begin{tabular}{|l|r|r|r|r|}
\hline & Frecuencia & Porcentaje & $\begin{array}{c}\text { Porcentaje } \\
\text { válido }\end{array}$ & $\begin{array}{c}\text { Porcentaje } \\
\text { acumulado }\end{array}$ \\
\hline 0 nada & 3 & 1,4 & 1,4 & 1,4 \\
1 mínimo & 7 & 3,3 & 3,3 & 4,8 \\
2 poco & 13 & 6,2 & 6,2 & 11,0 \\
3 medianamente & 65 & 31,1 & 31,1 & 42,1 \\
4 bastante & 61 & 29,2 & 29,2 & 71,3 \\
5 del todo & 60 & 28,7 & 28,7 & 100,0 \\
Total & 209 & 100,0 & 100,0 & \\
\hline
\end{tabular}

Elaboración propia. Mayo de 2015

Gráfico n ${ }^{\circ} 2.45$

45. Pasión, entusiasmo

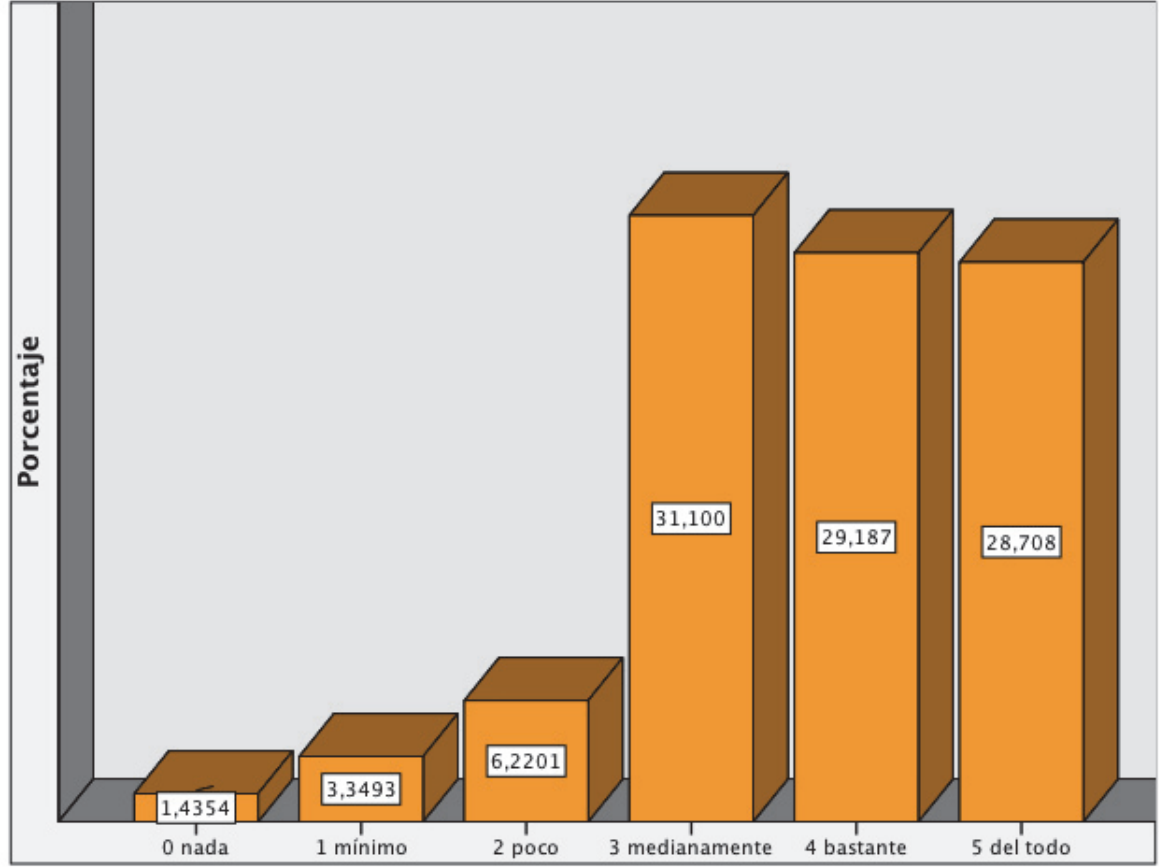

Elaboración propia. Mayo de 2015

Análisis: todas las puntuaciones están marcadas. El valor “Pasión/entusiasmo" presenta un modelo en pirámide en el ME mientras que en la VP aparece con un patrón en escalera ascendente. Es considerado más importante en la VP que en el ME.

El alumnado divide sus opiniones más o menos por igual entre el 3, 4 y 5. La respuesta es bastante lógica, porque si por un lado la salud despierta per sé pasión y entusiasmo siempre y en todos, por otro lado este valor no es una de las características de la administración pública 
Cuadro $n^{\circ} 2.46$

46. Patriotismo

\begin{tabular}{|l|r|r|r|r|}
\hline & Frecuencia & Porcentaje & $\begin{array}{c}\text { Porcentaje } \\
\text { válido }\end{array}$ & $\begin{array}{c}\text { Porcentaje } \\
\text { acumulado }\end{array}$ \\
\hline 0 nada & 23 & 11,0 & 11,0 & 11,0 \\
1 mínimo & 15 & 7,2 & 7,2 & 18,2 \\
2 poco & 46 & 22,0 & 22,0 & 40,2 \\
3 medianamente & 69 & 33,0 & 33,0 & 73,2 \\
4 bastante & 27 & 12,9 & 12,9 & 86,1 \\
5 del todo & 29 & 13,9 & 13,9 & 100,0 \\
Total & 209 & 100,0 & 100,0 & \\
\hline
\end{tabular}

Elaboración propia. Mayo de 2015

Gráfico ${ }^{\circ} 2.46$

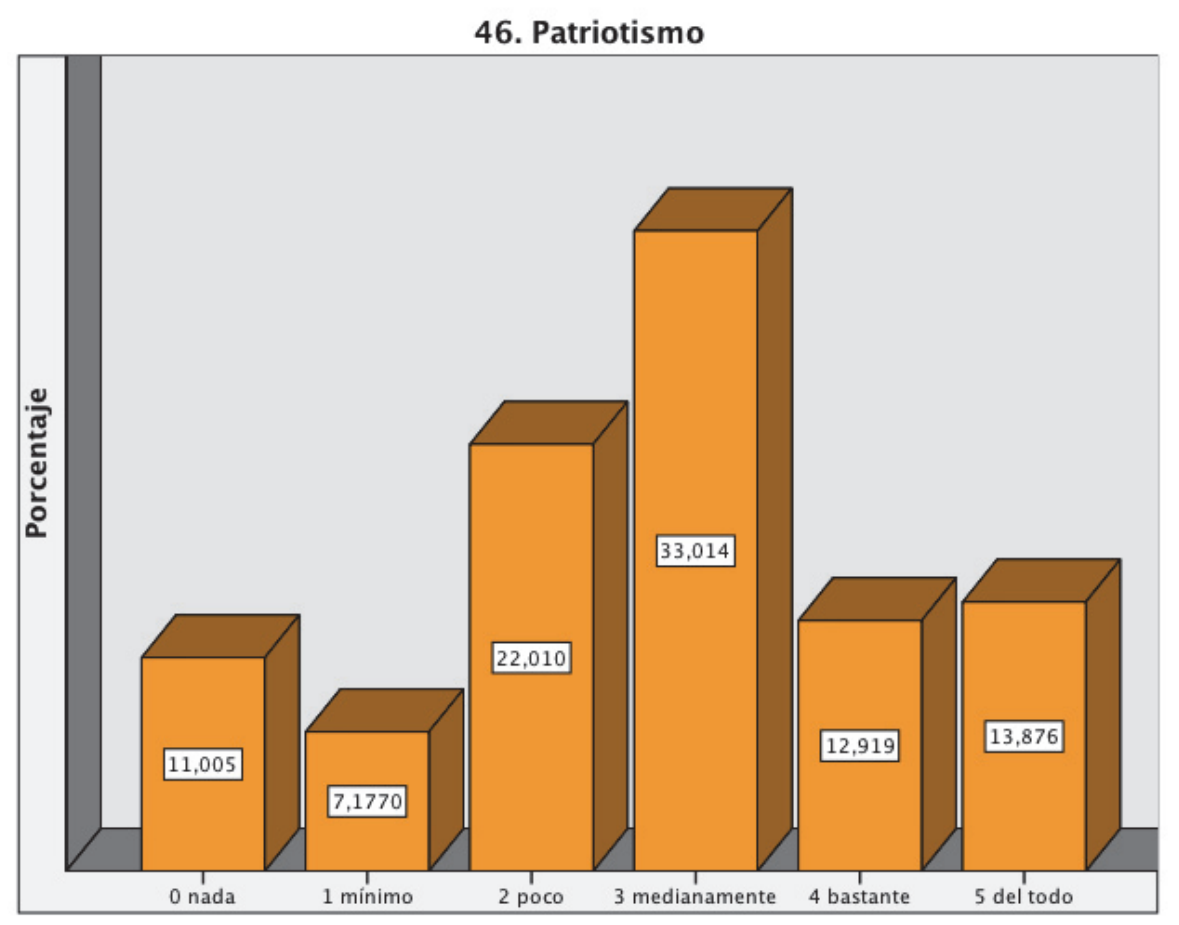

Elaboración propia. Mayo de 2015

Análisis: todos los valores están marcados, modelo en pirámide donde el 0 y el 5 tienen porcentajes similares pesando casi un 3\% más el 5, sin embargo en el área de la VP (gráfico 1.46) ocurre al revés, pesa más el 0. La muestra en estudio da poca importancia para ambas esferas al valor "Patriotismo".

Tratándose de un valor tan controvertido hoy, los resultados obtenidos reafirman la seriedad del alumnado al momento de elaborar las respuestas y en la validez de las encuestas. 
Cuadro $n^{\circ} 2.47$

47. Perseverancia/Paciencia

\begin{tabular}{|l|r|r|r|r|}
\hline & Frecuencia & Porcentaje & $\begin{array}{c}\text { Porcentaje } \\
\text { válido }\end{array}$ & $\begin{array}{r}\text { Porcentaje } \\
\text { acumulado }\end{array}$ \\
\hline 0 nada & 3 & 1,4 & 1,4 & 1,4 \\
1 mínimo & 8 & 3,8 & 3,8 & 5,3 \\
2 poco & 25 & 12,0 & 12,0 & 17,2 \\
3 medianamente & 45 & 21,5 & 21,5 & 38,8 \\
4 bastante & 70 & 33,5 & 33,5 & 72,2 \\
5 del todo & 58 & 27,8 & 27,8 & 100,0 \\
Total & 209 & 100,0 & 100,0 & \\
\hline
\end{tabular}

Elaboración propia. Mayo de 2015

Gráfico n ${ }^{\circ} 2.47$

\section{Perseverancia/Paciencia}

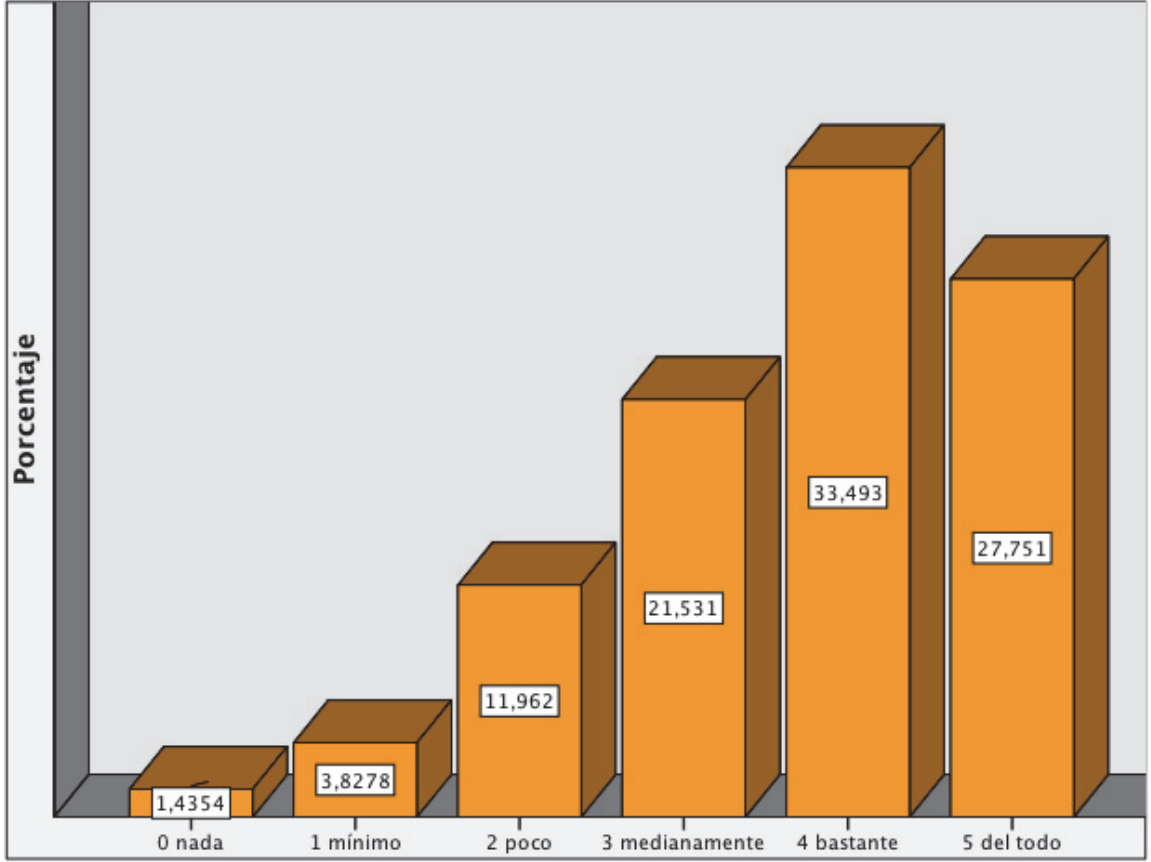

Elaboración propia. Mayo de 2015

Análisis: todos las puntuaciones están marcadas, patrón de pirámide sesgada a la derecha. En el gráfico 1.47 vemos una distribución en escalera ascendente. El valor "Perseverancia/Paciencia" es considerado importante en ambas esferas, pero más en la VP que en el ME.

Resultados que responden al perfil de enfermería y de feminización. Valor en relación directa con la eficiencia, humanización y la Confianza. 
Cuadro $n^{\circ} 2.48$

48. Placer intelectual

\begin{tabular}{|l|r|r|r|r|}
\hline & Frecuencia & Porcentaje & $\begin{array}{c}\text { Porcentaje } \\
\text { válido }\end{array}$ & $\begin{array}{r}\text { Porcentaje } \\
\text { acumulado }\end{array}$ \\
\hline 0 nada & 5 & 2,4 & 2,4 & 2,4 \\
1 mínimo & 6 & 2,9 & 2,9 & 5,3 \\
2 poco & 18 & 8,6 & 8,6 & 13,9 \\
3 medianamente & 61 & 29,2 & 29,2 & 43,1 \\
4 bastante & 64 & 30,6 & 30,6 & 73,7 \\
5 del todo & 55 & 26,3 & 26,3 & 100,0 \\
Total & 209 & 100,0 & 100,0 & \\
\hline
\end{tabular}

Elaboración propia. Mayo de 2015

Gráfico ${ }^{\circ} 2.48$

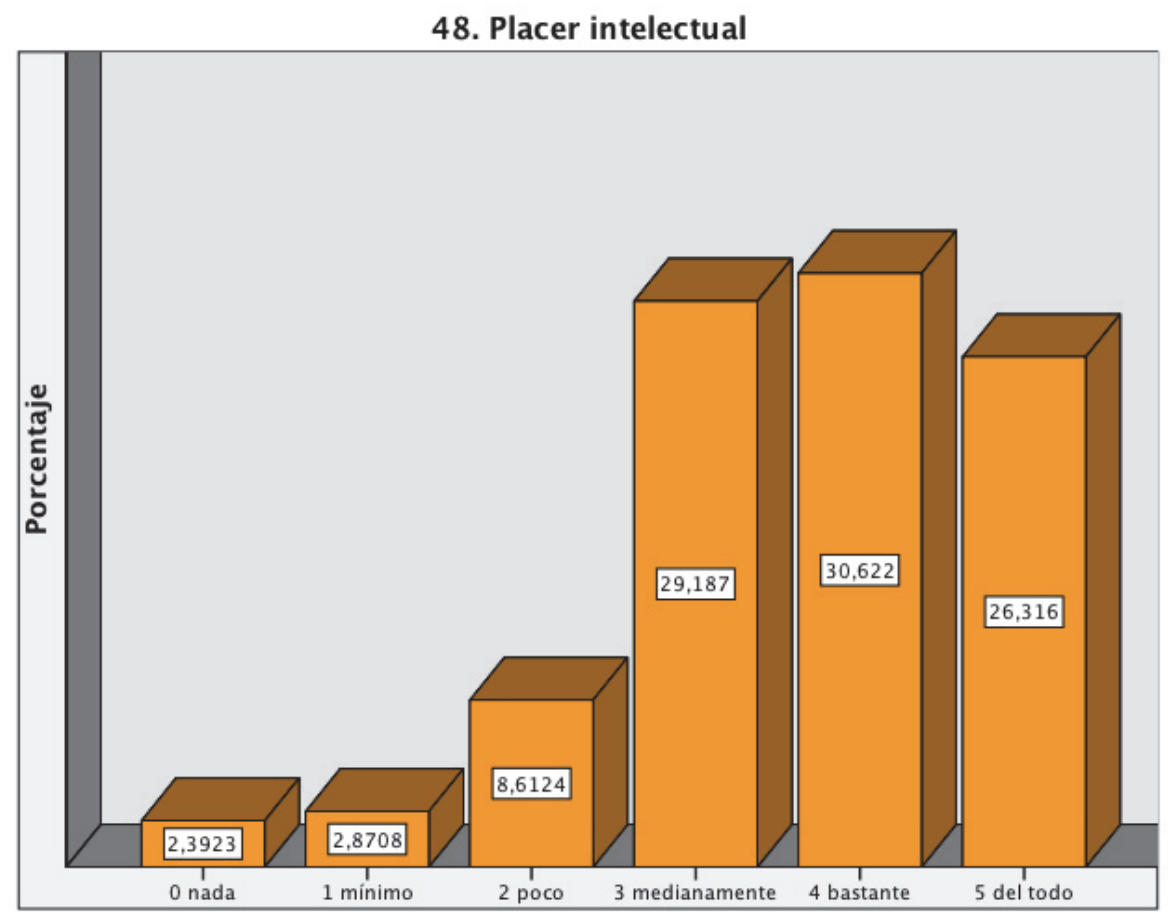

Elaboración propia. Mayo de 2015

Análisis: todas las puntuaciones están marcadas, la distribución se reparte sobre todo entre las puntuaciones 3, 4 y 5 con un modelo de escalera aplanada. El valor "Placer intelectual" se revela importante en el ME, aunque más en la VP.

Al igual que el valor 7. Aprendizaje continuo, el placer intelectual está relacionado con la seguridad en el ejercicio de la profesión y con la confianza que ha de inspirar en el paciente. También arroja resultados altos, acordes con una profesión que exige estar permanentemente al día. 
Cuadro n ${ }^{\circ} 2.49$

49. Placer sexual

\begin{tabular}{|l|r|r|r|r|}
\hline & Frecuencia & Porcentaje & $\begin{array}{c}\text { Porcentaje } \\
\text { válido }\end{array}$ & $\begin{array}{r}\text { Porcentaje } \\
\text { acumulado }\end{array}$ \\
\hline 0 nada & 56 & 26,8 & 26,8 & 26,8 \\
1 mínimo & 24 & 11,5 & 11,5 & 38,3 \\
2 poco & 25 & 12,0 & 12,0 & 50,2 \\
3 medianamente & 43 & 20,6 & 20,6 & 70,8 \\
4 bastante & 27 & 12,9 & 12,9 & 83,7 \\
5 del todo & 34 & 16,3 & 16,3 & 100,0 \\
Total & 209 & 100,0 & 100,0 & \\
\hline
\end{tabular}

Elaboración propia. Mayo de 2015

Gráfico no 2.49

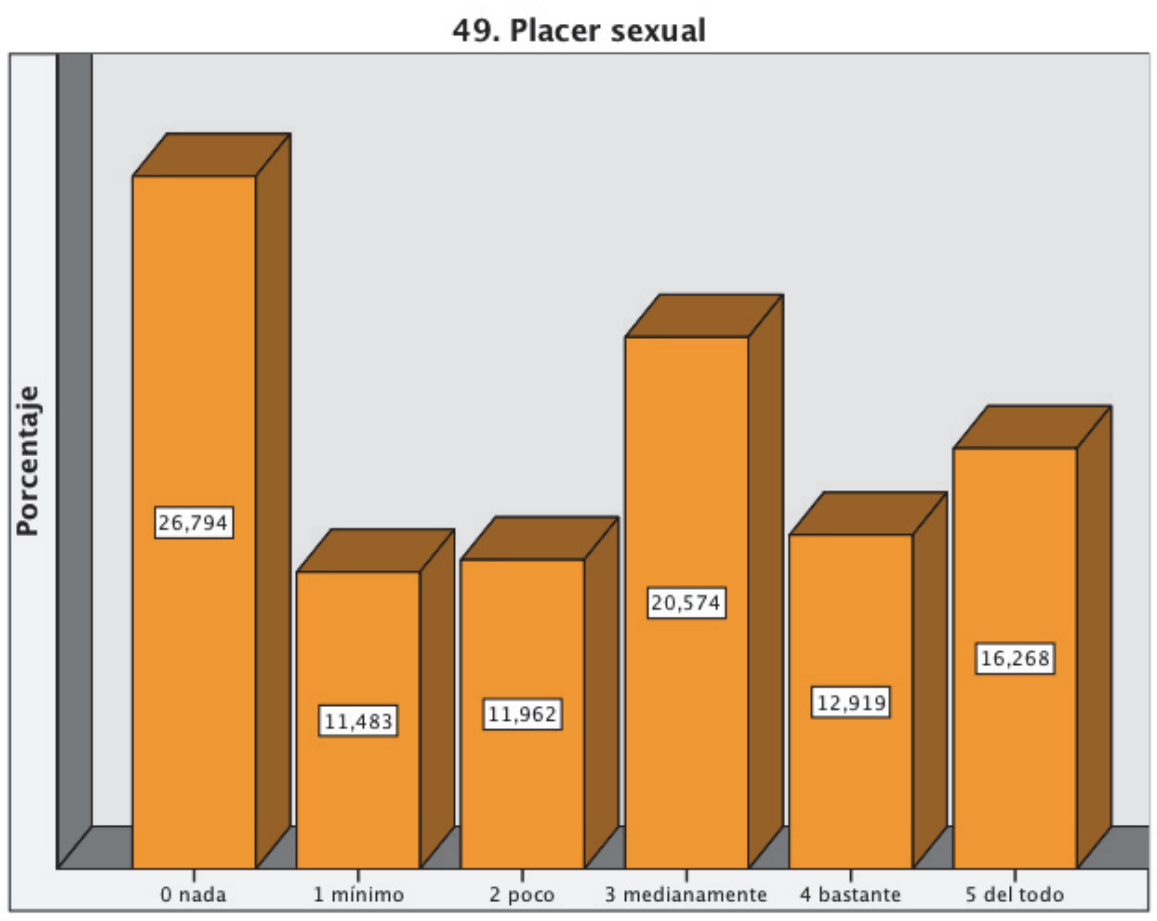

Elaboración propia. Mayo de 2015

Análisis: todas las puntuaciones están marcadas con claro predominio del 0 que representa más $1 / 4$ de la distribución. Modelo el L contrario al gráfico 1.49 que sigue un patrón de escalera ascendente. El valor "Placer sexual" es considerado importante en la VP y lo contrario en el ME.

Una cuarta parte del alumnado está de acuerdo en no ver relación entre el placer sexual y el ME. El resto se reparte entre todas las opciones demostrando el desconcierto que provoca esta pregunta, lo cual es muy coherente. 
Cuadro $\mathrm{n}^{\circ} 2.50$

50. Productividad, resultados

\begin{tabular}{|l|r|r|r|r|}
\hline & Frecuencia & Porcentaje & $\begin{array}{c}\text { Porcentaje } \\
\text { válido }\end{array}$ & $\begin{array}{r}\text { Porcentaje } \\
\text { acumulado }\end{array}$ \\
\hline 1 mínimo & 4 & 1,9 & 1,9 & 1,9 \\
2 poco & 4 & 1,9 & 1,9 & 3,8 \\
3 medianamente & 31 & 14,8 & 14,8 & 18,7 \\
4 bastante & 63 & 30,1 & 30,1 & 48,8 \\
5 del todo & 107 & 51,2 & 51,2 & 100,0 \\
Total & 209 & 100,0 & 100,0 & \\
\hline
\end{tabular}

Elaboración propia. Mayo de 2015

Gráfico $\mathrm{n}^{\mathrm{0}} 2.50$

50. Productividad, resultados

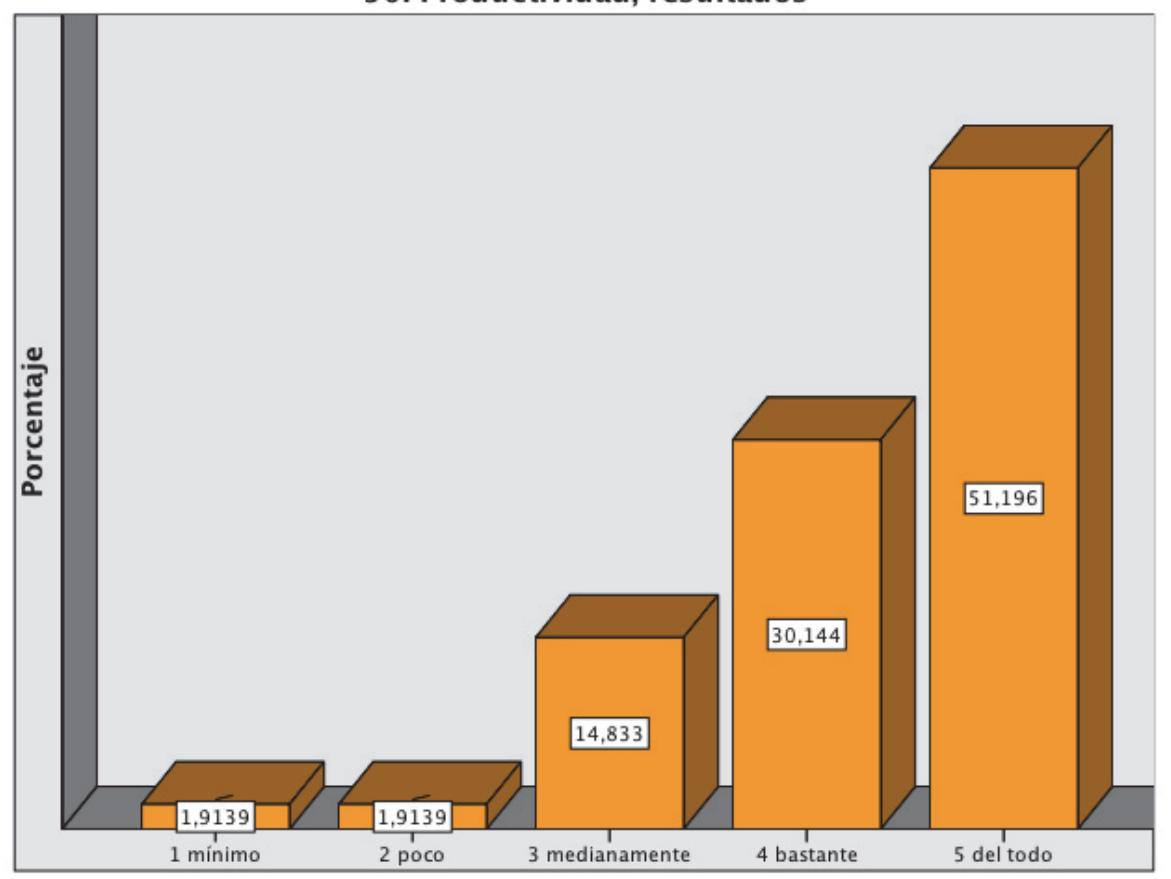

Elaboración propia. Mayo de 2015

Análisis: En la VP la distribución tiene el mayor peso en el 4 con más del $44 \%$, sumando el 4 y el 5 más del $78 \%$. En el ME el 4 y 5 suman más del $81 \%$ con más del $51 \%$ para el 5 y la distribución sigue un patrón de escalera ascendente. Este valor se revela más importante en el ME que en la VP.

Este ítem, el 13. Competitividad, ambición y el 36. Imagen, prestigio social comparten características tradicionalmente masculinas y observamos que arrojan resultados similares. Son resultados acordes en la VP para una profesión feminizada y en el ME en cuanto a que la gestión y dirección de empresas sigue en manos masculinas. 
Cuadro $n^{\circ} 2.51$

51. Realismo, pragmatismo, racionalidad

\begin{tabular}{|l|r|r|r|r|}
\hline & Frecuencia & Porcentaje & $\begin{array}{c}\text { Porcentaje } \\
\text { válido }\end{array}$ & $\begin{array}{c}\text { Porcentaje } \\
\text { acumulado }\end{array}$ \\
\hline 0 nada & 1 &, 5 &, 5 &, 5 \\
1 mínimo & 6 & 2,9 & 2,9 & 3,3 \\
2 poco & 11 & 5,3 & 5,3 & 8,6 \\
3 medianamente & 50 & 23,9 & 23,9 & 32,5 \\
4 bastante & 71 & 34,0 & 34,0 & 66,5 \\
5 del todo & 70 & 33,5 & 33,5 & 100,0 \\
Total & 209 & 100,0 & 100,0 & \\
\hline
\end{tabular}

Elaboración propia. Mayo de 2015

Gráfico $n^{\circ} 2.51$

51. Realismo, pragmatismo, racionalidad

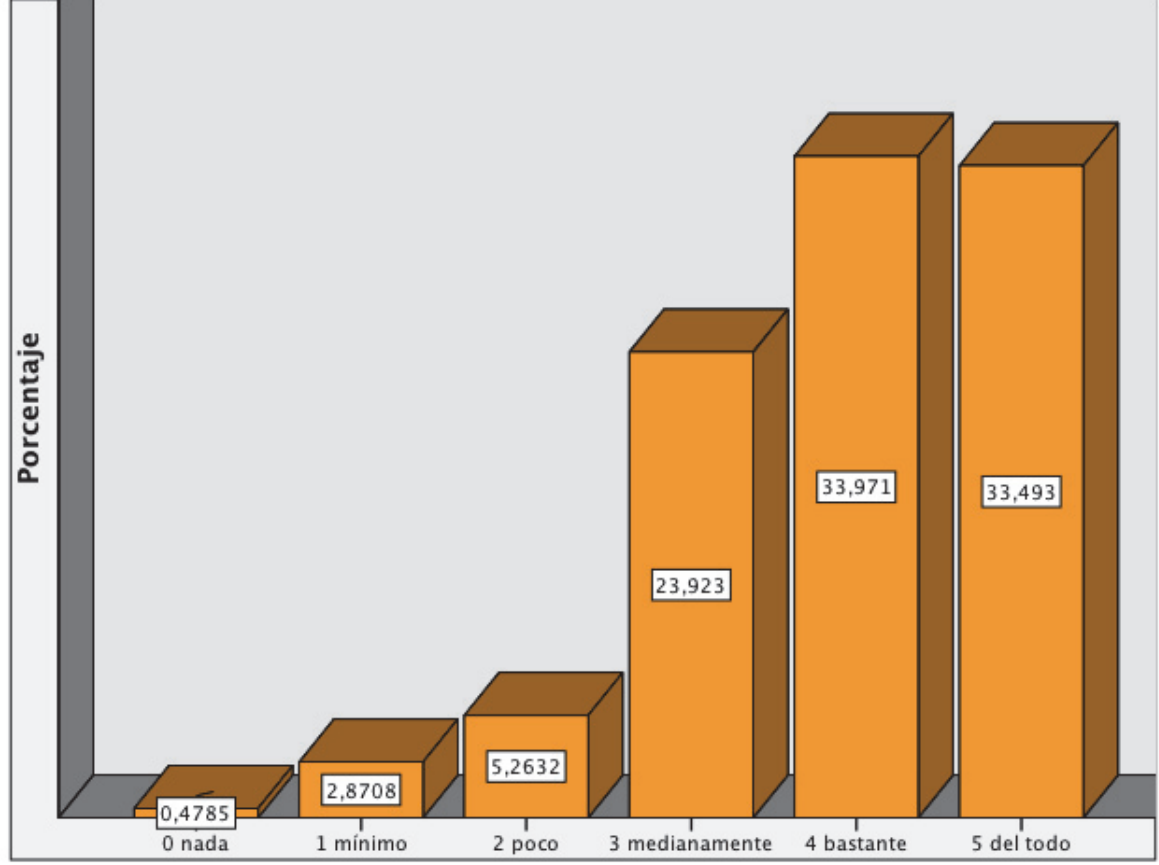

Elaboración propia. Mayo de 2015

Análisis: distribuciones muy similares en ambas esferas: VP y ME. Las diferencias son que en el gráfico 2.51 aparece el 0 y los porcentajes del 4 y 5 son algo más bajos. El valor "Realismo, pragmatismo, racionalidad" se comporta de forma similar en ambas áreas: modelo de pirámide asimétrica sesgada a la derecha, con algo más de importancia en la VP que en el ME.

Hemos visto que el idealismo es considerado medianamente importante en contraposición al realismo. Vemos que el alumnado da más importancia a lo positivo, real, racional, práctico que a lo ideal. 
Cuadro $n^{\circ} 2.52$

52. Reconocimiento emocional (darlo y buscarlo)

\begin{tabular}{|l|r|r|r|r|}
\hline & Frecuencia & Porcentaje & $\begin{array}{c}\text { Porcentaje } \\
\text { válido }\end{array}$ & $\begin{array}{r}\text { Porcentaje } \\
\text { acumulado }\end{array}$ \\
\hline 0 nada & 7 & 3,3 & 3,3 & 3,3 \\
1 mínimo & 17 & 8,1 & 8,1 & 11,5 \\
2 poco & 39 & 18,7 & 18,7 & 30,1 \\
3 medianamente & 40 & 19,1 & 19,1 & 49,3 \\
4 bastante & 51 & 24,4 & 24,4 & 73,7 \\
5 del todo & 55 & 26,3 & 26,3 & 100,0 \\
Total & 209 & 100,0 & 100,0 & \\
\hline
\end{tabular}

Elaboración propia. Mayo de 2015

Gráfico ${ }^{\circ} 2.52$

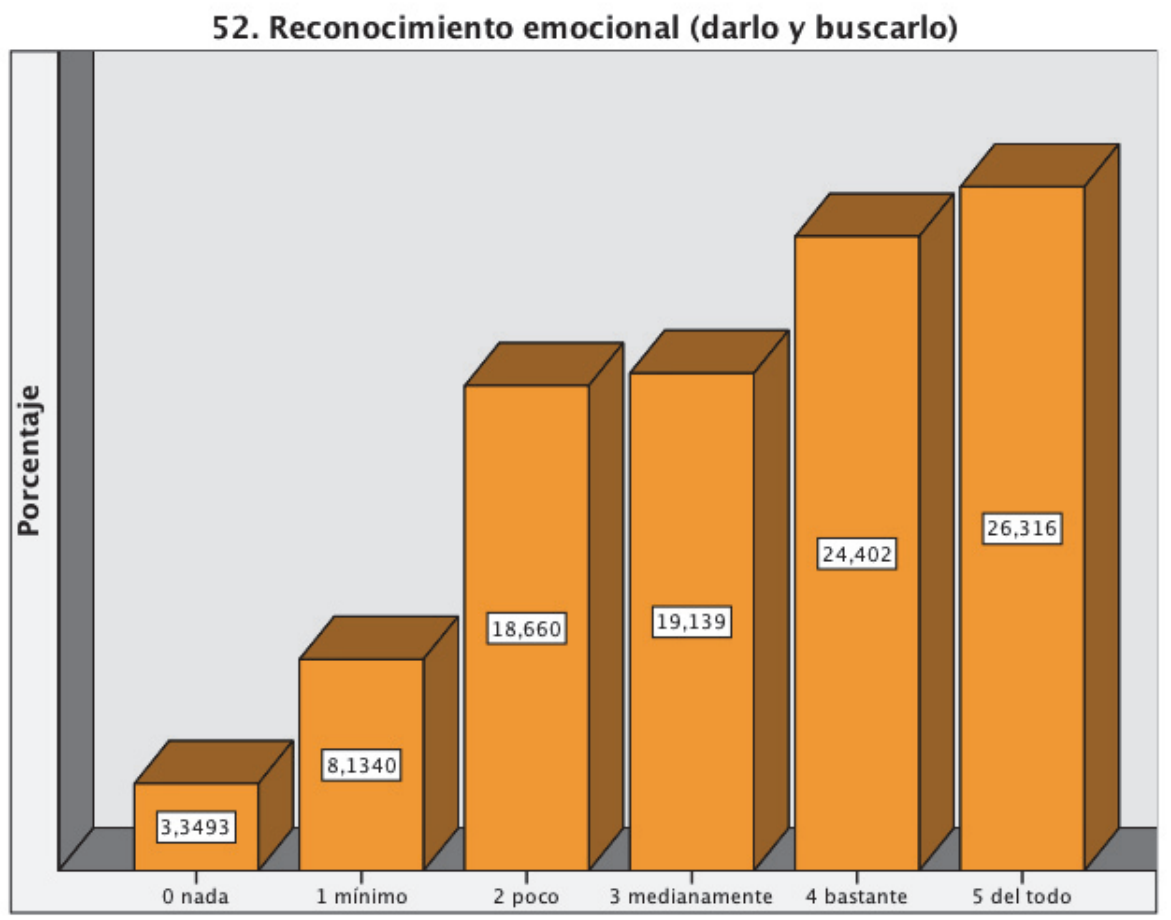

Elaboración propia. Mayo de 2015

Análisis: todas las puntuaciones han sido marcadas, distribución en escalera aplanada mientras que en la VP este valor presenta una distribución en escalera ascendente con casi el $50 \%$ para el 5 y en la que falta el 1 y el 0 solo ha sido marcado por una persona. Valor considerado más importante en la VP que en el ME.

El ME es percibido por el alumnado como más frío que lo individual, puntuado en el área de la VP. 
Cuadro $n^{\circ} 2.53$

53. Religiosidad

\begin{tabular}{|l|r|r|r|r|}
\hline & Frecuencia & Porcentaje & $\begin{array}{c}\text { Porcentaje } \\
\text { válido }\end{array}$ & $\begin{array}{r}\text { Porcentaje } \\
\text { acumulado }\end{array}$ \\
\hline 0 nada & 76 & 36,4 & 36,4 & 36,4 \\
1 mínimo & 30 & 14,4 & 14,4 & 50,7 \\
2 poco & 31 & 14,8 & 14,8 & 65,6 \\
3 medianamente & 47 & 22,5 & 22,5 & 88,0 \\
4 bastante & 17 & 8,1 & 8,1 & 96,2 \\
5 del todo & 8 & 3,8 & 3,8 & 100,0 \\
Total & 209 & 100,0 & 100,0 & \\
\hline
\end{tabular}

Elaboración propia. Mayo de 2015

Gráfico $n^{\circ} 2.53$

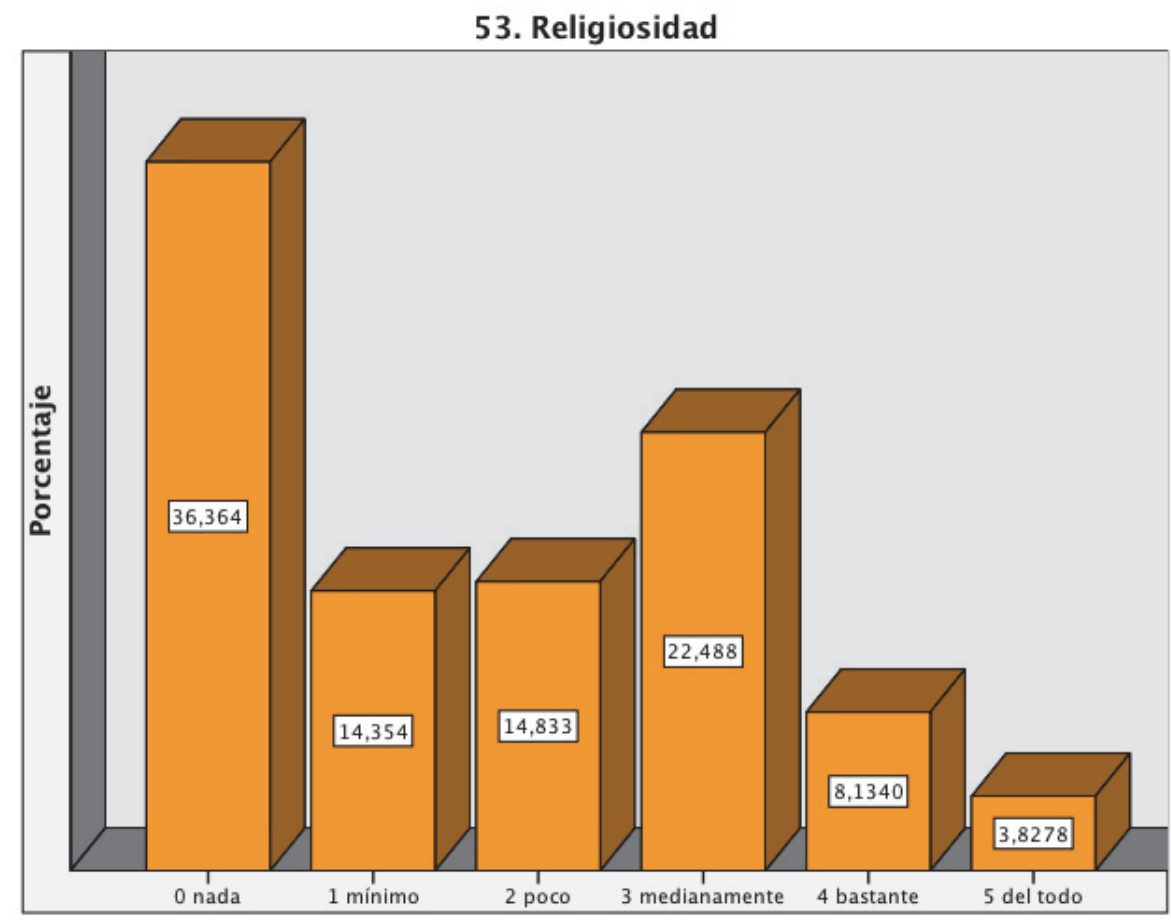

Elaboración propia. Mayo de 2015

Análisis: distribución en L, muy parecidas en ambas esferas. El valor "Religiosidad" no es considerado importante ni en la VP ni en el ME.

La religiosidad y el placer sexual en el ME muestran el mismo patrón, la opción más marcada es el 0 y el resto del alumnado se reparte entre las demás puntuaciones mostrando el desconcierto entre la pregunta y el tema tratado, lo cual no carece de coherencia. 
Cuadro $n^{\circ} 2.54$

54. Respeto y armonía con los demás

\begin{tabular}{|l|r|r|r|r|}
\hline & Frecuencia & Porcentaje & $\begin{array}{c}\text { Porcentaje } \\
\text { válido }\end{array}$ & $\begin{array}{r}\text { Porcentaje } \\
\text { acumulado }\end{array}$ \\
\hline 0 nada & 2 & 1,0 & 1,0 & 1,0 \\
1 mínimo & 7 & 3,3 & 3,3 & 4,3 \\
2 poco & 12 & 5,7 & 5,7 & 10,0 \\
3 medianamente & 58 & 27,8 & 27,8 & 37,8 \\
4 bastante & 50 & 23,9 & 23,9 & 61,7 \\
5 del todo & 80 & 38,3 & 38,3 & 100,0 \\
Total & 209 & 100,0 & 100,0 & \\
\hline
\end{tabular}

Elaboración propia. Mayo de 2015

Gráfico ${ }^{\circ} 2.54$

54. Respeto y armonía con los demás

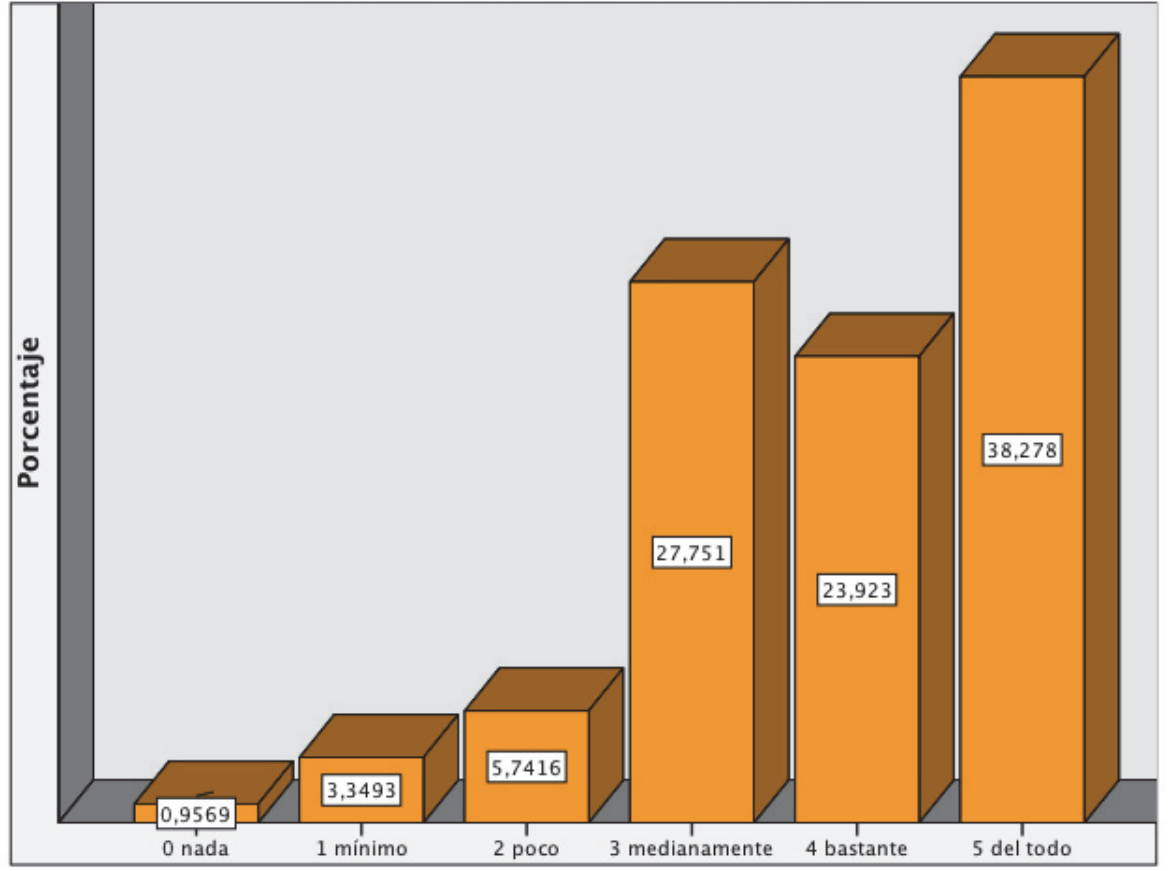

Elaboración propia. Mayo de 2015

Análisis: todas las puntuaciones han sido marcadas, al igual que en la VP en la que vemos una escalera ascendente con casi el 56\% para el 5. En el ME las puntuaciones se distribuyen más entre el 3, 4 y 5. El valor "Respeto y armonía con los demás" es importante en ambas esferas pero más aún en la VP.

La armonía es el tercero de los valores del ME de C. El resultado obtenido, tanto en un área como en la otra, es óptimo para considerar nuestra hipótesis como válida. 
Cuadro $n^{\circ} 2.55$

55. Respeto y armonía con uno mismo

\begin{tabular}{|l|r|r|r|r|}
\hline & Frecuencia & Porcentaje & $\begin{array}{c}\text { Porcentaje } \\
\text { válido }\end{array}$ & $\begin{array}{r}\text { Porcentaje } \\
\text { acumulado }\end{array}$ \\
\hline 0 nada & 2 & 1,0 & 1,0 & 1,0 \\
1 mínimo & 9 & 4,3 & 4,3 & 5,3 \\
2 poco & 18 & 8,6 & 8,6 & 13,9 \\
3 medianamente & 53 & 25,4 & 25,4 & 39,2 \\
4 bastante & 50 & 23,9 & 23,9 & 63,2 \\
5 del todo & 77 & 36,8 & 36,8 & 100,0 \\
Total & 209 & 100,0 & 100,0 & \\
\hline
\end{tabular}

Elaboración propia. Mayo de 2015

Gráfico $n^{\circ} 2.55$

55. Respeto y armonía con uno mismo

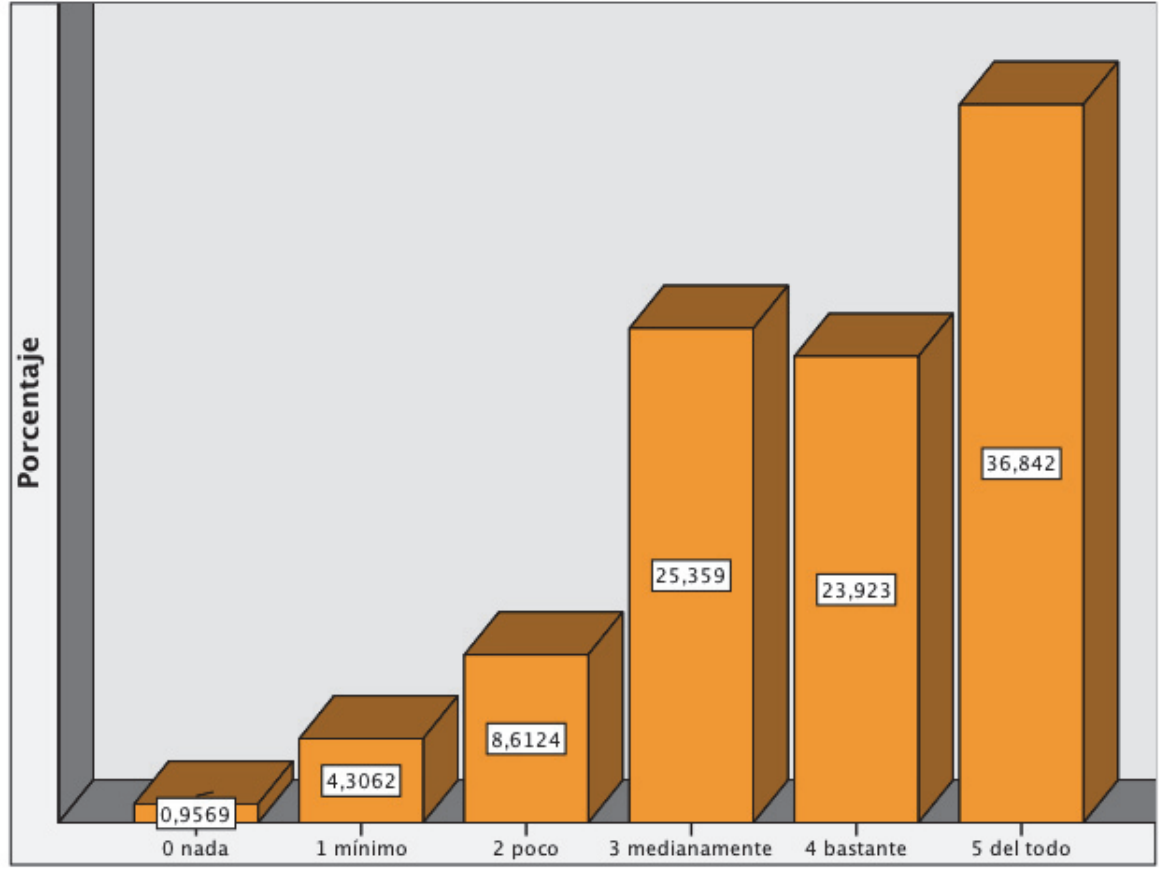

Elaboración propia. Mayo de 2015

Análisis: lo mismo que hemos observado para el valor "Respeto y armonía con los demás" vemos en "Respeto y armonía con uno mismo" que es considerado como importante en ambas esferas pero más en la VP. Modelo en escalera ascendente.

El mismo análisis cualitativo que en el valor anterior se puede hacer en este. 
Cuadro $\mathrm{n}^{\circ} 2.56$

56. Respeto y armonía medioambiental

\begin{tabular}{|l|r|r|r|r|}
\hline & Frecuencia & Porcentaje & $\begin{array}{c}\text { Porcentaje } \\
\text { válido }\end{array}$ & $\begin{array}{r}\text { Porcentaje } \\
\text { acumulado }\end{array}$ \\
\hline 0 nada & 11 & 5,3 & 5,3 & 5,3 \\
1 mínimo & 15 & 7,2 & 7,2 & 12,4 \\
2 poco & 15 & 7,2 & 7,2 & 19,6 \\
3 medianamente & 62 & 29,7 & 29,7 & 49,3 \\
4 bastante & 59 & 28,2 & 28,2 & 77,5 \\
5 del todo & 47 & 22,5 & 22,5 & 100,0 \\
Total & 209 & 100,0 & 100,0 & \\
\hline
\end{tabular}

Elaboración propia. Mayo de 2015

Gráfico $\mathrm{n}^{\mathrm{0}} 2.56$

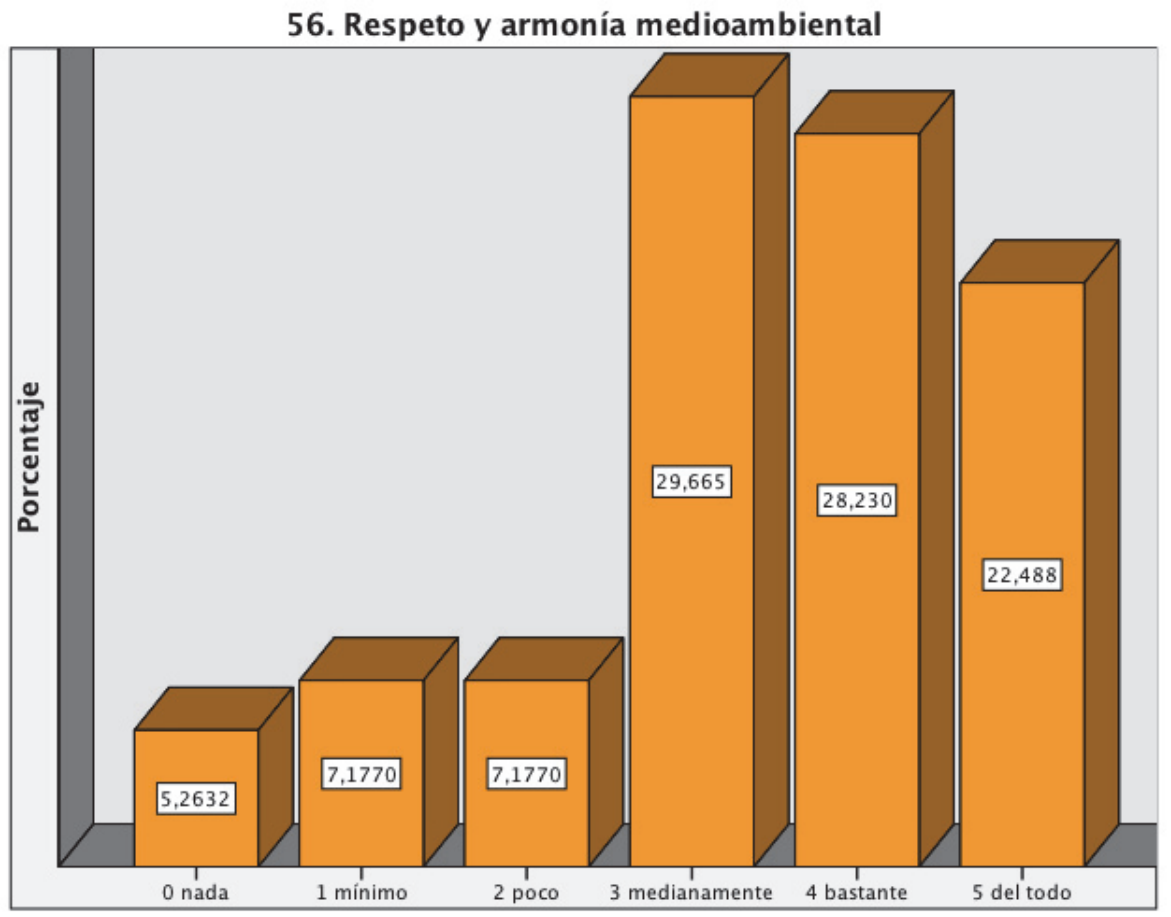

Elaboración propia. Mayo de 2015

Análisis: modelo en pirámide con sesgo a la derecha. Similar comportamiento en la VP y en el ME. Las respuestas coherentes. Valor importante en ambas esferas con más relevancia aún en la VP que en el ME.

El alumnado percibe el ME menos sensible en cuanto a la armonía con el medioambiente que en las dos anteriores armonías: con los demás y con uno mismo. Es de esperar que estos nuevos profesionales sean más cuidadosos con temas de contaminación y uso adecuado de los recursos. Resultado muy favorable para nuestro estudio. 
Cuadro $n^{\circ} 2.57$

57. Riesgo, aventura, estímulo, novedad

\begin{tabular}{|l|r|r|r|r|}
\hline & Frecuencia & Porcentaje & $\begin{array}{c}\text { Porcentaje } \\
\text { válido }\end{array}$ & $\begin{array}{r}\text { Porcentaje } \\
\text { acumulado }\end{array}$ \\
\hline 0 nada & 7 & 3,3 & 3,3 & 3,3 \\
1 mínimo & 11 & 5,3 & 5,3 & 8,6 \\
2 poco & 17 & 8,1 & 8,1 & 16,7 \\
3 medianamente & 98 & 46,9 & 46,9 & 63,6 \\
4 bastante & 44 & 21,1 & 21,1 & 84,7 \\
5 del todo & 32 & 15,3 & 15,3 & 100,0 \\
Total & 209 & 100,0 & 100,0 & \\
\hline
\end{tabular}

Elaboración propia. Mayo de 2015

Gráfico $n^{\circ} 2.57$

57. Riesgo, aventura, estímulo, novedad

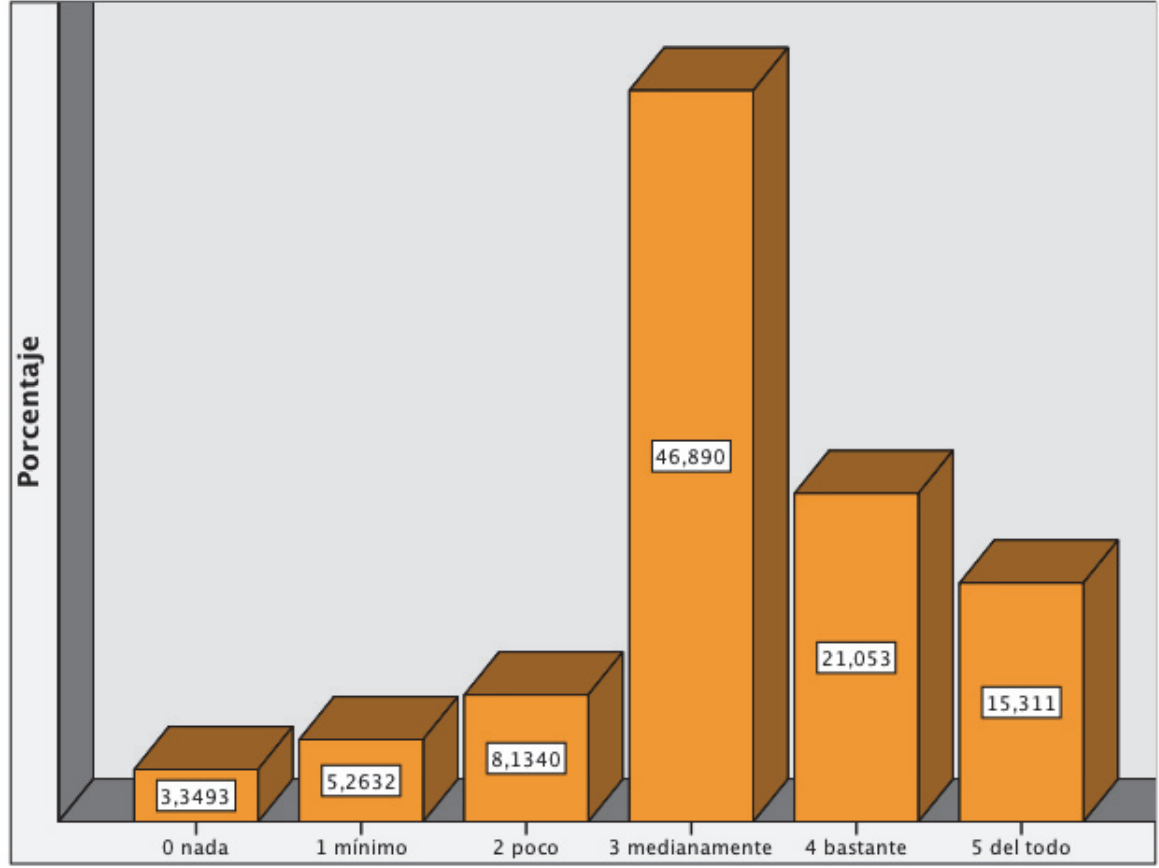

Elaboración propia. Mayo de 2015

Análisis: presencia de todas las puntuaciones en ambas esferas. En la VP observamos una pirámide sesgada a la derecha mientras que en el ME vemos una pirámide con el mayor peso, casi el 47\%, para el 3. El valor "Riesgo, aventura, estímulo, novedad" es considerado más importante en la VP que en el ME.

Se percibe a través de estos resultados las características de la administración pública, una de cuyas características es la previsibilidad que no deja sitio al riesgo, aventura, novedad. 
Cuadro $n^{\circ} 2.58$

58. Rigor técnico-profesional

\begin{tabular}{|l|r|r|r|r|}
\hline & Frecuencia & Porcentaje & $\begin{array}{c}\text { Porcentaje } \\
\text { válido }\end{array}$ & $\begin{array}{r}\text { Porcentaje } \\
\text { acumulado }\end{array}$ \\
\hline 1 mínimo & 2 & 1,0 & 1,0 & 1,0 \\
2 poco & 8 & 3,8 & 3,8 & 4,8 \\
3 medianamente & 48 & 23,0 & 23,0 & 27,8 \\
4 bastante & 79 & 37,8 & 37,8 & 65,6 \\
5 del todo & 72 & 34,4 & 34,4 & 100,0 \\
Total & 209 & 100,0 & 100,0 & \\
\hline
\end{tabular}

Elaboración propia. Mayo de 2015

Gráfico ${ }^{\circ} 2.58$

58. Rigor técnico-profesional

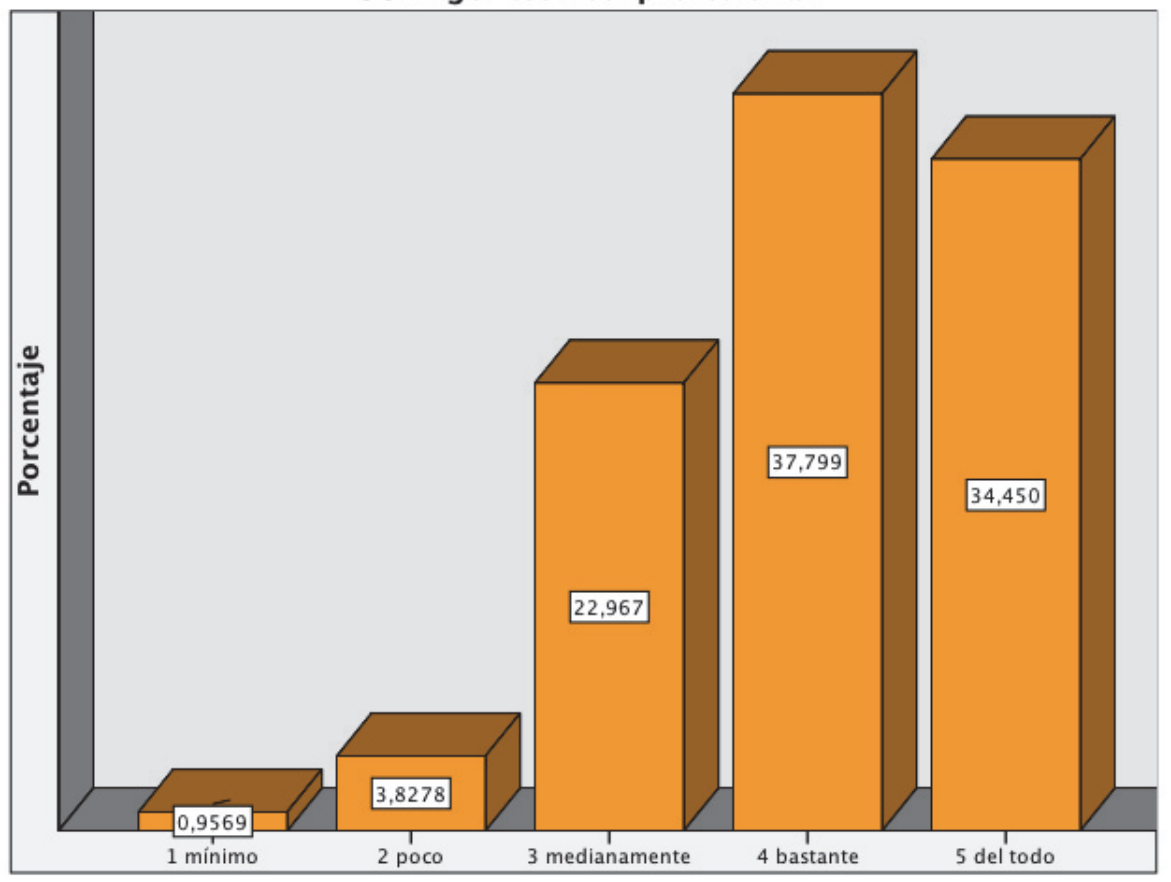

Elaboración propia. Mayo de 2015

Análisis: ausencia del 0 al igual que en el gráfico 1.58. Distribución muy parecida para ambas áreas, en pirámide sesgada a la derecha con mayor peso para el 4. El valor "Rigor técnico-profesional" es bastante importante en ambas esferas: VP y ME con similar comportamiento en uno y otro.

Este resultado está acorde con el perfil de enfermería que trabaja para la salud y la vida, estos valores superiores: salud y vida implican necesariamente rigor técnico-profesional tanto a nivel de la VP como del ME. 
Cuadro $n^{\circ} 2.59$

59. Salud/bienestar

\begin{tabular}{|l|r|r|r|r|}
\hline & Frecuencia & Porcentaje & $\begin{array}{c}\text { Porcentaje } \\
\text { válido }\end{array}$ & $\begin{array}{r}\text { Porcentaje } \\
\text { acumulado }\end{array}$ \\
\hline 0 nada & 2 & 1,0 & 1,0 & 1,0 \\
1 mínimo & 4 & 1,9 & 1,9 & 2,9 \\
poco & 17 & 8,1 & 8,1 & 11,0 \\
medianamente & 38 & 18,2 & 18,2 & 29,2 \\
4 bastante & 66 & 31,6 & 31,6 & 60,8 \\
5 del todo & 82 & 39,2 & 39,2 & 100,0 \\
Total & 209 & 100,0 & 100,0 & \\
\hline
\end{tabular}

Elaboración propia. Mayo de 2015

Gráfico no 2.59

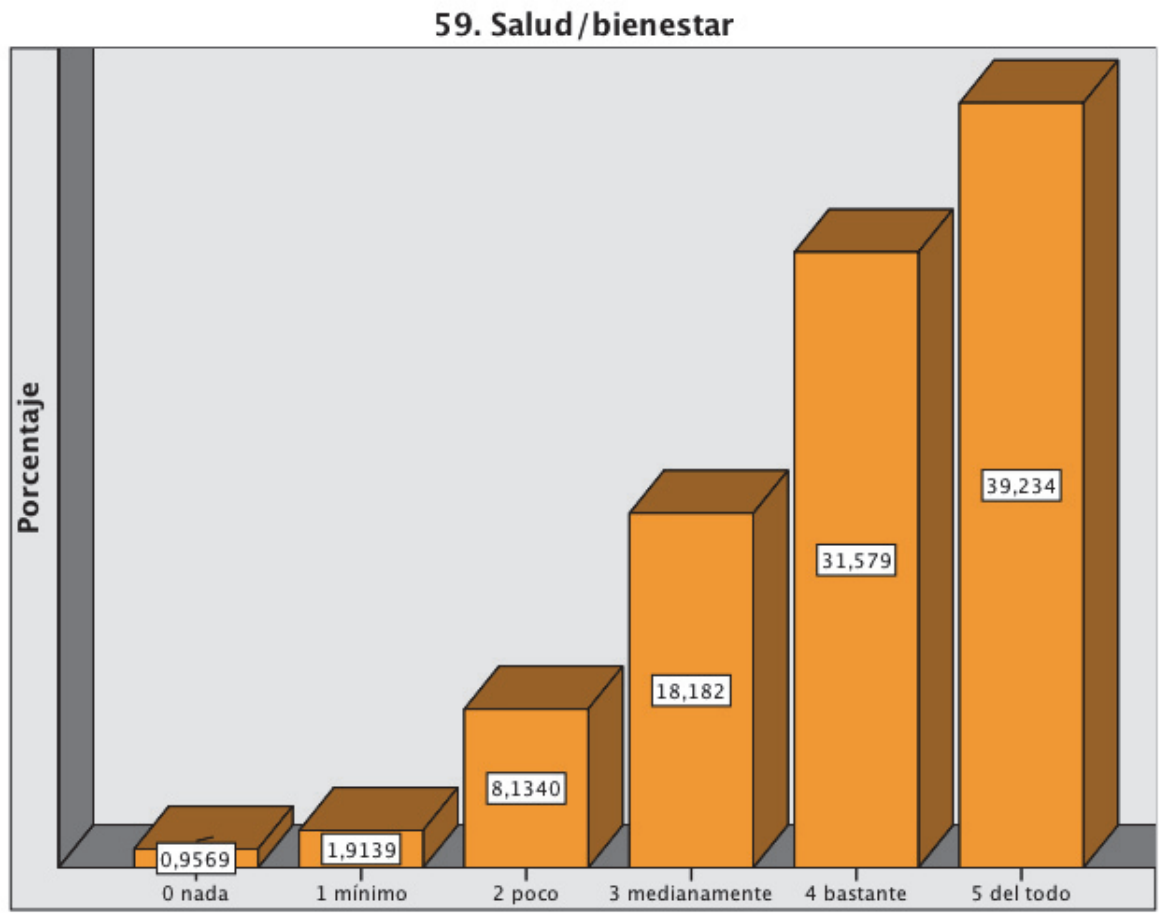

Elaboración propia. Mayo de 2015

Análisis: presencia de todas las puntuaciones. Modelo de escalera ascendente en ambas esferas pero con mayor importancia en la VP que en el ME. En la VP no aparece el 0, el 5 representa más del $61 \%$ y la suma del 4 y 5 supone más del 91\%. El valor "Salud, bienestar" es considerado importante en ambas áreas pero más en la VP.

Valor clave de la profesión de enfermería. El resultado obtenido es el esperable y favorable a nuestra tesis. 
Cuadro $n^{\circ} 2.60$

60. Seguridad

\begin{tabular}{|l|r|r|r|r|}
\hline & Frecuencia & Porcentaje & $\begin{array}{c}\text { Porcentaje } \\
\text { válido }\end{array}$ & $\begin{array}{c}\text { Porcentaje } \\
\text { acumulado }\end{array}$ \\
\hline 0 nada & 1 &, 5 &, 5 &, 5 \\
1 mínimo & 2 & 1,0 & 1,0 & 1,4 \\
2 poco & 12 & 5,7 & 5,7 & 7,2 \\
3 medianamente & 39 & 18,7 & 18,7 & 25,8 \\
4 bastante & 71 & 34,0 & 34,0 & 59,8 \\
5 del todo & 84 & 40,2 & 40,2 & 100,0 \\
Total & 209 & 100,0 & 100,0 & \\
\hline
\end{tabular}

Elaboración propia. Mayo de 2015

Gráfico ${ }^{\circ} 2.60$

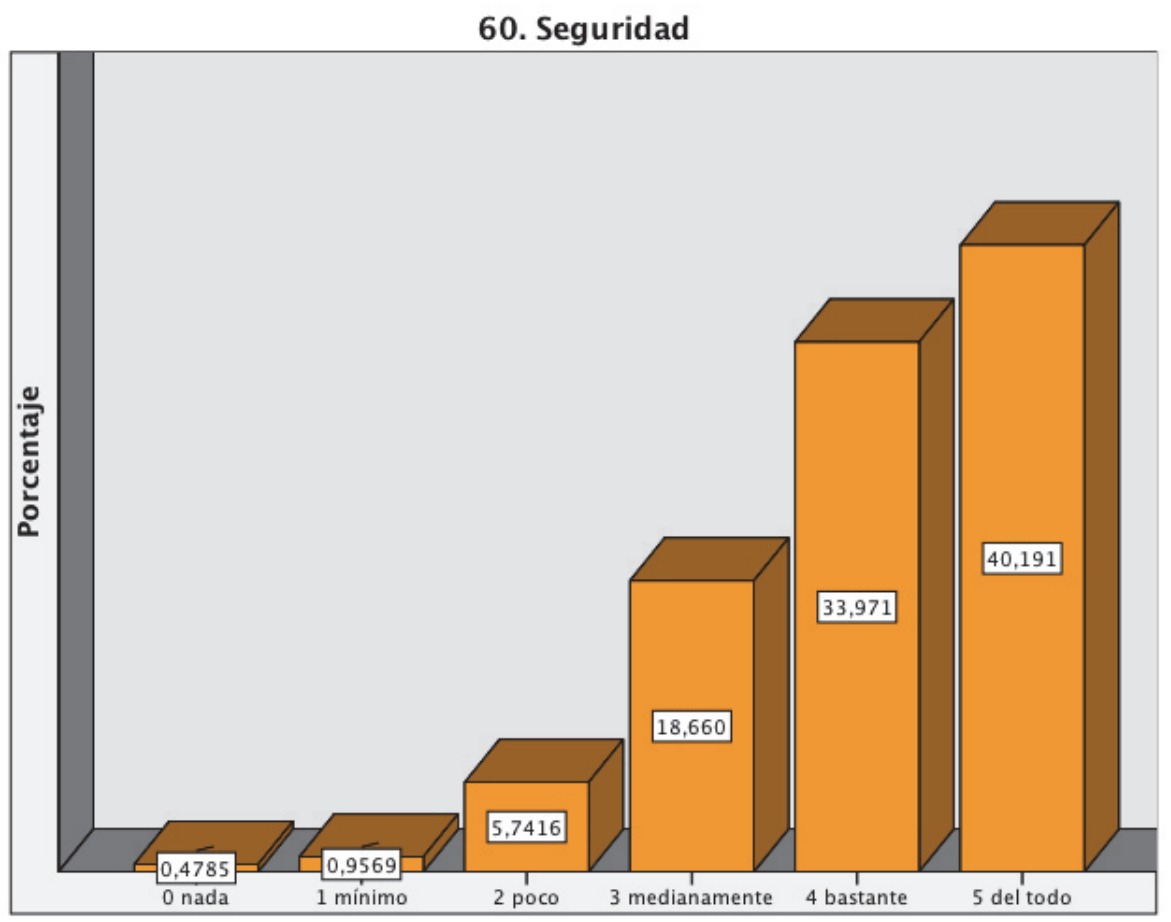

Elaboración propia. Mayo de 2015

Análisis: presencia de todas las puntuaciones. Modelo en escalera ascendente sumando el 4 y 5 más 74\%. Distribución muy parecida a la del mismo valor en la VP: gráfico 1.60. El valor "Seguridad" tiene un comportamiento similar en ambas esferas, siendo algo más importante en la VP.

La seguridad constituye el segundo bloque en el ME de C. Los resultados obtenidos son acordes a la docencia impartida y además también lo percibe para el ME. 
Cuadro $n^{0} 2.61$

61. Sentido de la vergüenza

\begin{tabular}{|l|r|r|r|r|}
\hline & Frecuencia & Porcentaje & $\begin{array}{c}\text { Porcentaje } \\
\text { válido }\end{array}$ & $\begin{array}{r}\text { Porcentaje } \\
\text { acumulado }\end{array}$ \\
\hline 0 nada & 17 & 8,1 & 8,1 & 8,1 \\
1 mínimo & 15 & 7,2 & 7,2 & 15,3 \\
2 poco & 44 & 21,1 & 21,1 & 36,4 \\
3 medianamente & 60 & 28,7 & 28,7 & 65,1 \\
4 bastante & 43 & 20,6 & 20,6 & 85,6 \\
5 del todo & 30 & 14,4 & 14,4 & 100,0 \\
Total & 209 & 100,0 & 100,0 & \\
\hline
\end{tabular}

Elaboración propia. Mayo de 2015

Gráfico $n^{\circ} 2.61$

\section{Sentido de la vergüenza}

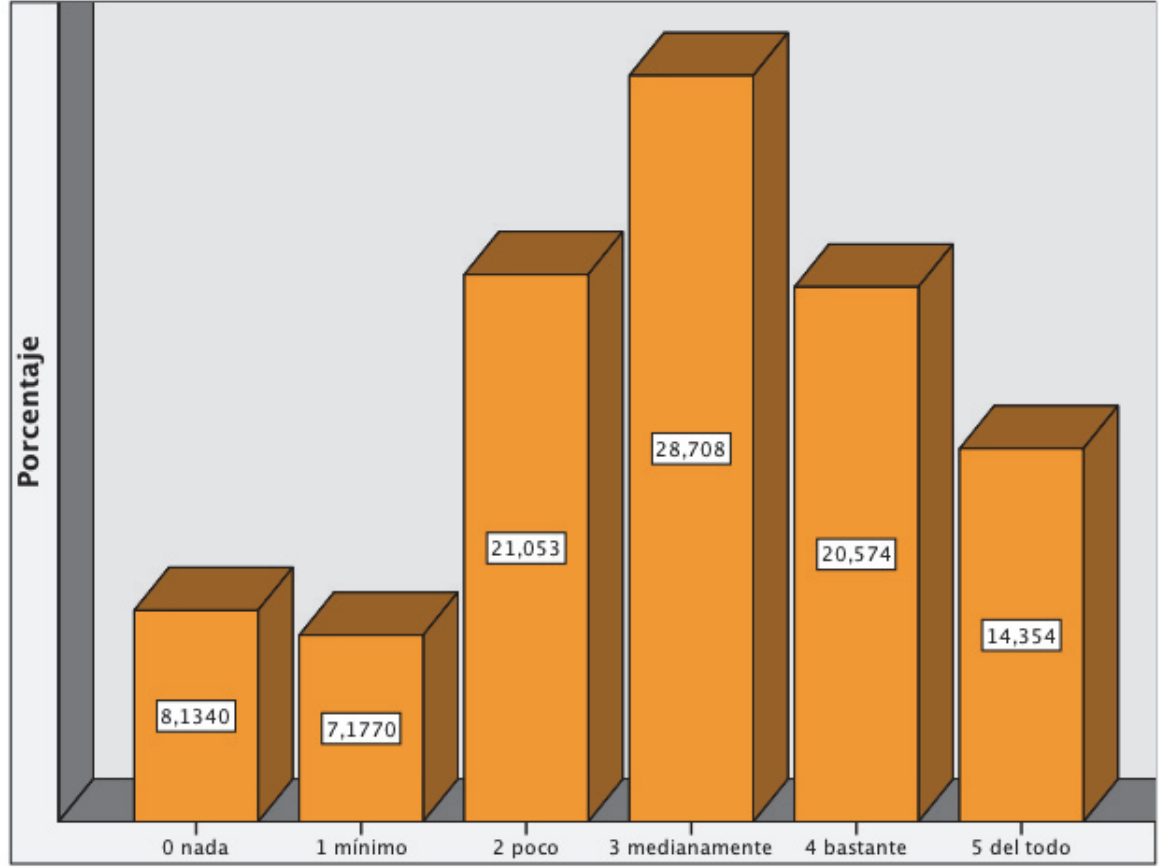

Elaboración propia. Mayo de 2015

Análisis: presencia de todas las puntuaciones con mayor representación del 3 que, al igual que en el gráfico 1.61, tampoco llega al 30\%. El valor "Sentido de la vergüenza" es considerado medianamente importante en ambas áreas con algo más de importancia en la VP donde el 4 y 5 suman más del $50 \%$ frente al $34 \%$ del gráfico 2.61 .

Se percibe a través de los resultados que el alumnado capta que la administración pública, en este caso el SNS, está por encima de la vergüenza y la puntúan como medianamente importante nada más. 
Cuadro $n^{\circ} 2.62$

62. Ser querido por los demás

\begin{tabular}{|l|r|r|r|r|}
\hline & Frecuencia & Porcentaje & $\begin{array}{c}\text { Porcentaje } \\
\text { válido }\end{array}$ & $\begin{array}{r}\text { Porcentaje } \\
\text { acumulado }\end{array}$ \\
\hline 0 nada & 7 & 3,3 & 3,3 & 3,3 \\
1 mínimo & 8 & 3,8 & 3,8 & 7,2 \\
2 poco & 29 & 13,9 & 13,9 & 21,1 \\
3 medianamente & 48 & 23,0 & 23,0 & 44,0 \\
4 bastante & 52 & 24,9 & 24,9 & 68,9 \\
5 del todo & 65 & 31,1 & 31,1 & 100,0 \\
Total & 209 & 100,0 & 100,0 & \\
\hline
\end{tabular}

Elaboración propia. Mayo de 2015

Gráfico ${ }^{\circ} 2.62$

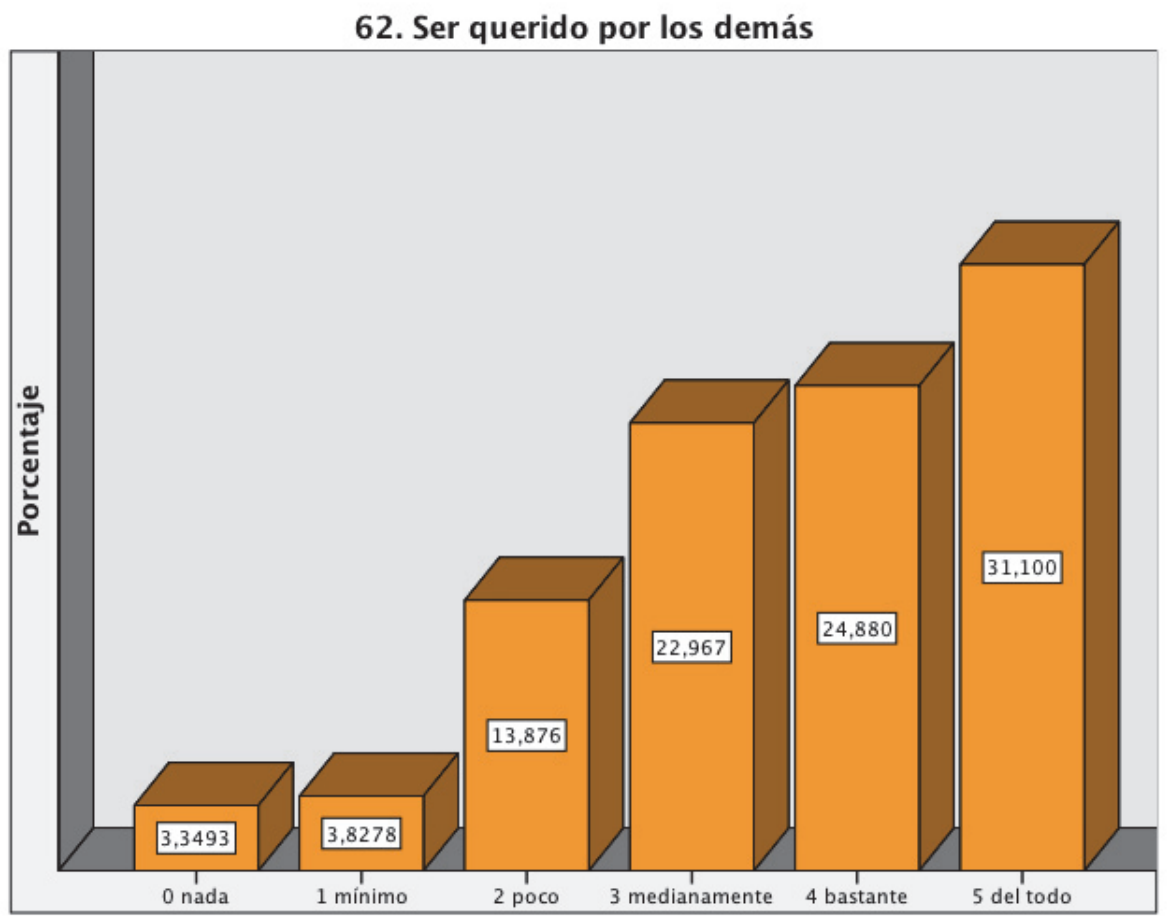

Elaboración propia. Mayo de 2015

Análisis: presencia de todas las puntuaciones. Modelo en escalera ascendente al igual que en el gráfico 1.62 en el que falta el 0 y el 5 representa más del $50 \%$ frente la $31 \%$ del gráfico 2.62 . El valor "Ser querido por los demás" es considerado importante en ambas esferas y más en la VP que en el ME.

La humanización que buscamos para el ejercicio de la enfermería se traduce favorablemente en estos resultados, pues ser querido por los demás es un valor en íntima relación con la humanización en el trato. 
Cuadro $n^{\circ} 2.63$

\section{Servicio/vocación}

\begin{tabular}{|l|r|r|r|r|}
\hline & Frecuencia & Porcentaje & $\begin{array}{c}\text { Porcentaje } \\
\text { válido }\end{array}$ & $\begin{array}{c}\text { Porcentaje } \\
\text { acumulado }\end{array}$ \\
\hline 1 mínimo & 8 & 3,8 & 3,8 & 3,8 \\
2 poco & 21 & 10,0 & 10,0 & 13,9 \\
3 medianamente & 42 & 20,1 & 20,1 & 34,0 \\
4 bastante & 77 & 36,8 & 36,8 & 70,8 \\
5 del todo & 61 & 29,2 & 29,2 & 100,0 \\
Total & 209 & 100,0 & 100,0 & \\
\hline
\end{tabular}

Elaboración propia. Mayo de 2015

Gráfico $n^{\circ} 2.63$

63. Servicio/vocación

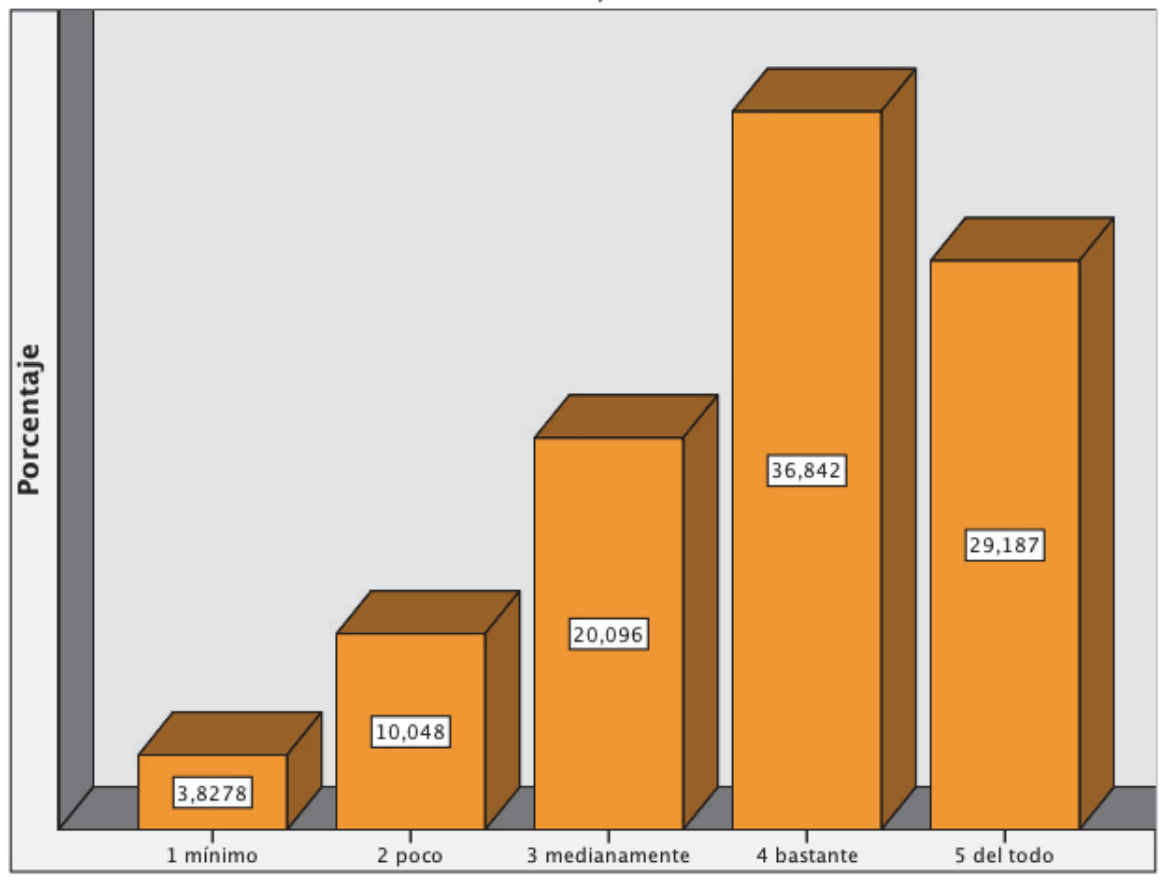

Elaboración propia. Mayo de 2015

Análisis: ausencia del 0, modelo en pirámide asimétrica con sesgo a la derecha. El gráfico 1.63 presenta una distribución en escalera ascendente con presencia del 0 y con casi el 46\% para el 5. El valor "Servicio, vocación" es importante en ambas esferas y más en la VP.

Resultados bastante de acuerdo con el perfil de enfermería. Valor relacionado con humanización. 
Cuadro $n^{\circ} 2.64$

64. Simplicidad, rapidez, agilidad

\begin{tabular}{|l|r|r|r|r|}
\hline & Frecuencia & Porcentaje & $\begin{array}{c}\text { Porcentaje } \\
\text { válido }\end{array}$ & $\begin{array}{r}\text { Porcentaje } \\
\text { acumulado }\end{array}$ \\
\hline 1 mínimo & 6 & 2,9 & 2,9 & 2,9 \\
2 poco & 9 & 4,3 & 4,3 & 7,2 \\
3 medianamente & 62 & 29,7 & 29,7 & 36,8 \\
4 bastante & 68 & 32,5 & 32,5 & 69,4 \\
5 del todo & 64 & 30,6 & 30,6 & 100,0 \\
Total & 209 & 100,0 & 100,0 & \\
\hline
\end{tabular}

Elaboración propia. Mayo de 2015

Gráfico $n^{0} 2.64$

64. Simplicidad, rapidez, agilidad

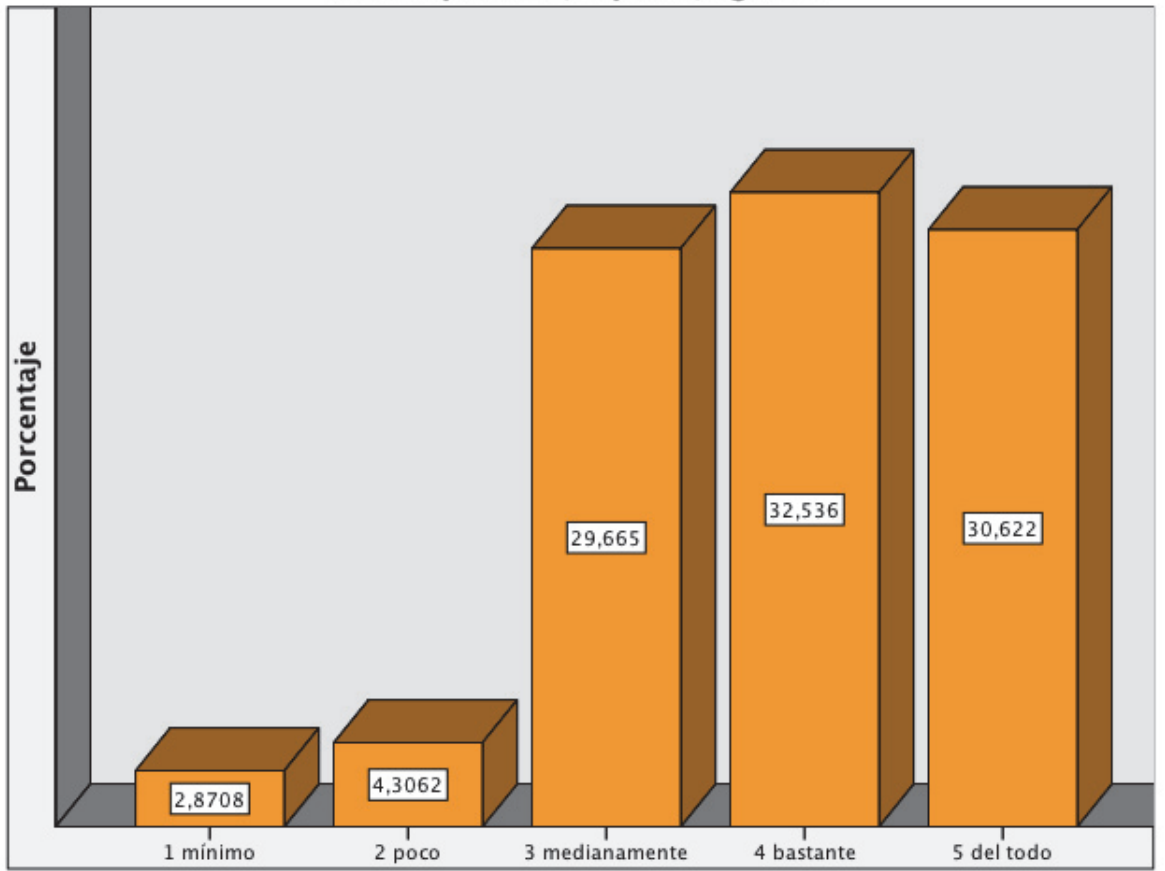

Elaboración propia. Mayo de 2015

Análisis: ausencia del 0, modelo en pirámide sesgada a la derecha con más del $63 \%$ para el 4 y 5 . Valor considerado importante en el ME y más aún en la VP donde, aunque aparece el 0 marcado por 2 personas: 0,9569\%, el 4 y 5 suman más del $74 \%$

Se observa a través de estos resultados que el alumnado percibe la rigidez de la administración pública pues el 3 medianamente recoge un tercio de las respuestas. 
Cuadro $n^{\circ} 2.65$

65. Solidaridad, generosidad

\begin{tabular}{|l|r|r|r|r|}
\hline & Frecuencia & Porcentaje & $\begin{array}{c}\text { Porcentaje } \\
\text { válido }\end{array}$ & $\begin{array}{r}\text { Porcentaje } \\
\text { acumulado }\end{array}$ \\
\hline 0 nada & 6 & 2,9 & 2,9 & 2,9 \\
1 mínimo & 8 & 3,8 & 3,8 & 6,7 \\
2 poco & 22 & 10,5 & 10,5 & 17,2 \\
3 medianamente & 55 & 26,3 & 26,3 & 43,5 \\
4 bastante & 51 & 24,4 & 24,4 & 67,9 \\
5 del todo & 67 & 32,1 & 32,1 & 100,0 \\
Total & 209 & 100,0 & 100,0 & \\
\hline
\end{tabular}

Elaboración propia. Mayo de 2015

Gráfico $n^{\circ} 2.65$

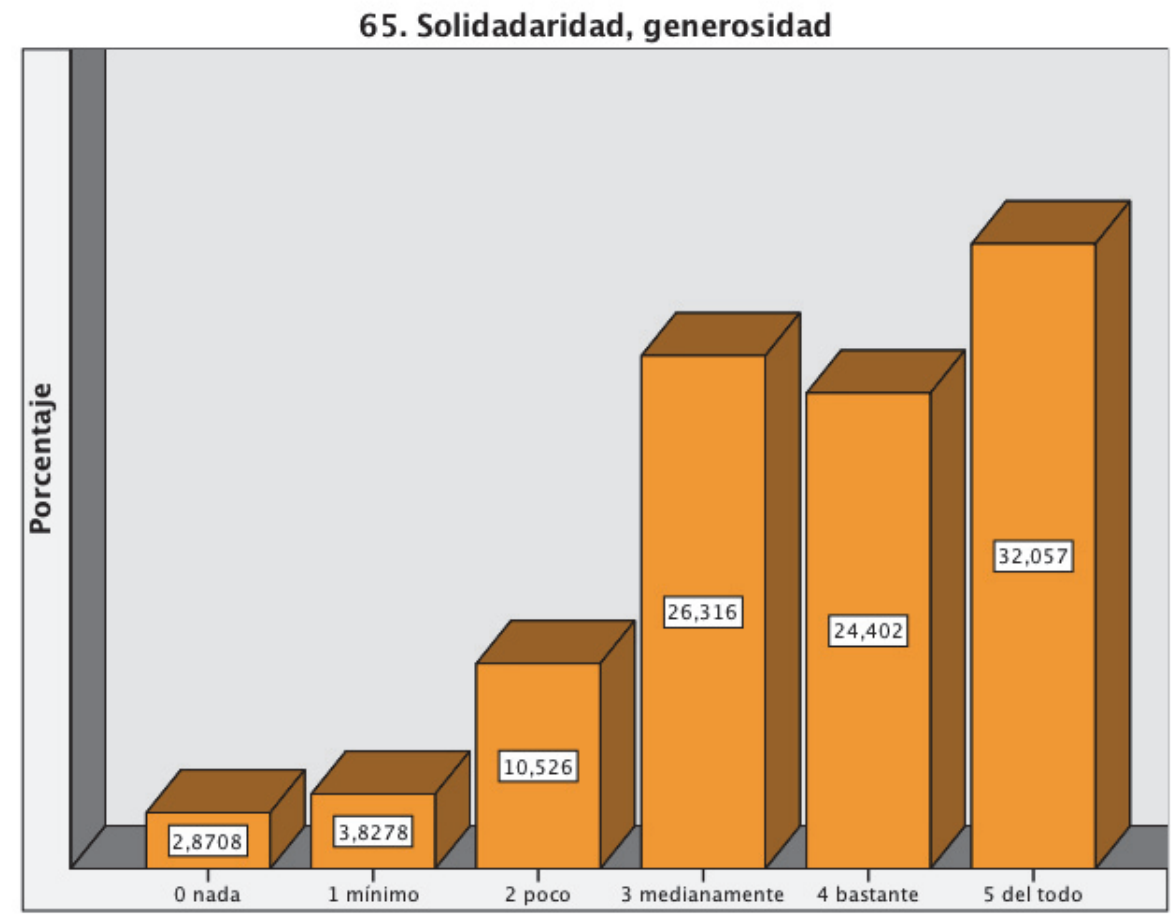

Elaboración propia. Mayo de 2015

Análisis: presencia de todas las puntuaciones. Modelo de escalera aplanada con porcentajes no muy alejados para el 3,4 y 5. En cambio en la VP vemos ausencia del 0 y un modelo en escalera ascendente con más del 53\% para el 5. El valor "Solidaridad, generosidad" es importante en ambas áreas y más en la VP que en el ME.

El alumnado percibe que el ME es menos solidario, generoso que la VP, pero incluso así lo puntúan como importante. Esto es favorable a nuestra hipótesis pues este es un valor crucial en el trabajo de enfermería. 
Cuadro $n^{\circ} 2.66$

66. Supervivencia material

\begin{tabular}{|l|r|r|r|r|}
\hline & Frecuencia & Porcentaje & $\begin{array}{c}\text { Porcentaje } \\
\text { válido }\end{array}$ & $\begin{array}{r}\text { Porcentaje } \\
\text { acumulado }\end{array}$ \\
\hline 0 nada & 2 & 1,0 & 1,0 & 1,0 \\
1 mínimo & 3 & 1,4 & 1,4 & 2,4 \\
2 poco & 12 & 5,7 & 5,7 & 8,1 \\
3 medianamente & 56 & 26,8 & 26,8 & 34,9 \\
4 bastante & 89 & 42,6 & 42,6 & 77,5 \\
5 del todo & 47 & 22,5 & 22,5 & 100,0 \\
Total & 209 & 100,0 & 100,0 & \\
\hline
\end{tabular}

Elaboración propia. Mayo de 2015

Gráfico ${ }^{\circ} 2.66$

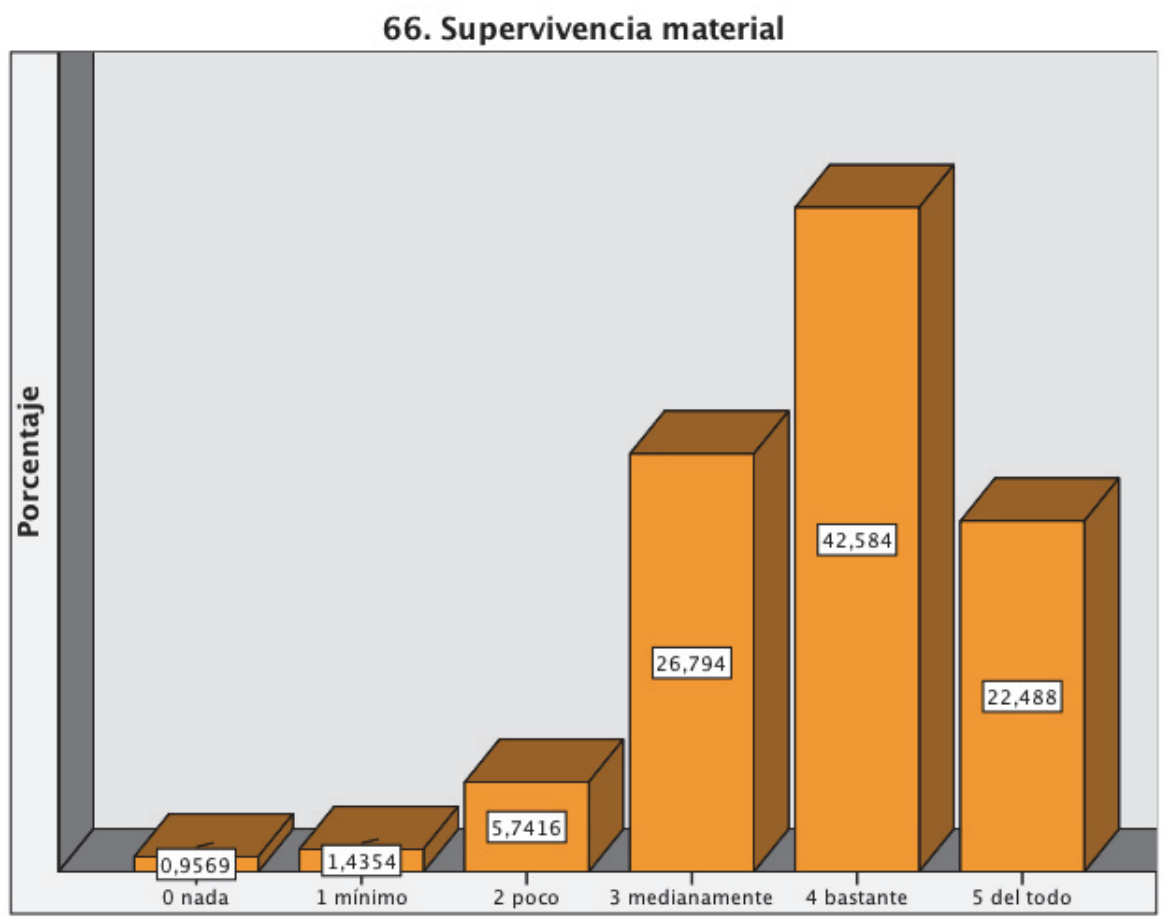

Elaboración propia. Mayo de 2015

Análisis: presencia de todas las puntuaciones. Modelo en pirámide asimétrica con sesgo a la derecha. El mayor porcentaje corresponde al 4 con más del 42\%. Valor bastante importante en el ME. En la VP vemos una distribución con ausencia del 1 y con los mayores porcentajes para el 3 y 4 . Con las cifras obtenidas este valor se revela algo más importante en el ME que en la VP.

El alumnado percibe que la sostenibilidad del SNS es bastante importante y esta es una de las preguntas estrella de nuestra tesis. 
Cuadro $n^{\circ} 2.67$

67. Tecnología/ciencia, innovación

\begin{tabular}{|l|r|r|r|r|}
\hline & Frecuencia & Porcentaje & $\begin{array}{c}\text { Porcentaje } \\
\text { válido }\end{array}$ & $\begin{array}{c}\text { Porcentaje } \\
\text { acumulado }\end{array}$ \\
\hline 0 nada & 1 &, 5 &, 5 &, 5 \\
1 mínimo & 5 & 2,4 & 2,4 & 2,9 \\
2 poco & 9 & 4,3 & 4,3 & 7,2 \\
3 medianamente & 36 & 17,2 & 17,2 & 24,4 \\
4 bastante & 81 & 38,8 & 38,8 & 63,2 \\
5 del todo & 77 & 36,8 & 36,8 & 100,0 \\
Total & 209 & 100,0 & 100,0 & \\
\hline
\end{tabular}

Elaboración propia. Mayo de 2015

Gráfico no 2.67

67. Tecnología/ciencia, innovación

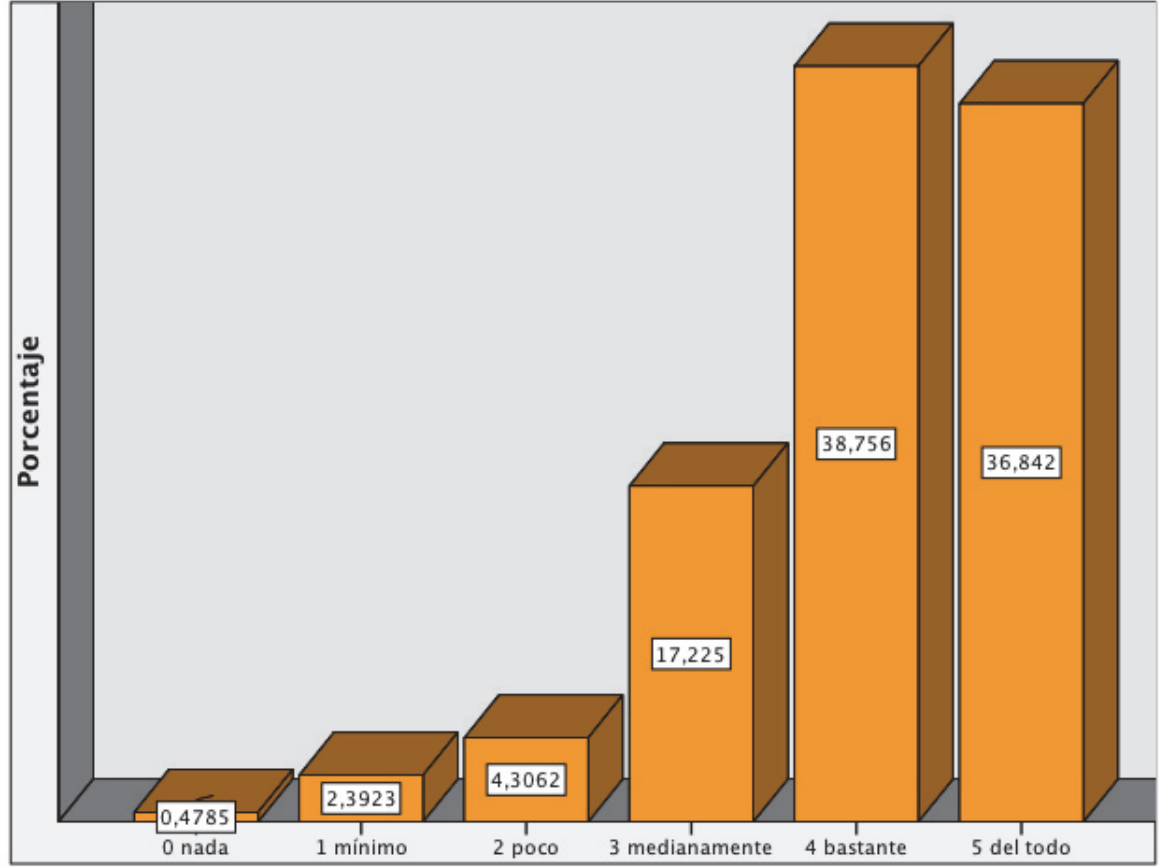

Elaboración propia. Mayo de 2015

Análisis: aparecen todas las puntuaciones. Distribución en pirámide asimétrica con sesgo a la derecha al igual que en el gráfico 1.67. Comportamiento similar en ambas esferas y por las cifras obtenidas se ve algo más de importancia en el ME pues el 4 y 5 suman más del 75\% frente al poco más de $64 \%$ en la VP.

Evidentemente para una empresa como el SNS este valor es considerado como muy importante. Resultado coherente con la realidad vivida diariamente. 
Cuadro $n^{\circ} 2.68$

68. Tiempo libre

\begin{tabular}{|l|r|r|r|r|}
\hline & Frecuencia & Porcentaje & $\begin{array}{c}\text { Porcentaje } \\
\text { válido }\end{array}$ & $\begin{array}{r}\text { Porcentaje } \\
\text { acumulado }\end{array}$ \\
\hline 0 nada & 12 & 5,7 & 5,7 & 5,7 \\
1 mínimo & 27 & 12,9 & 12,9 & 18,7 \\
2 poco & 47 & 22,5 & 22,5 & 41,1 \\
3 medianamente & 50 & 23,9 & 23,9 & 65,1 \\
4 bastante & 34 & 16,3 & 16,3 & 81,3 \\
5 del todo & 39 & 18,7 & 18,7 & 100,0 \\
Total & 209 & 100,0 & 100,0 & \\
\hline
\end{tabular}

Elaboración propia. Mayo de 2015

Gráfico ${ }^{\circ} 2.68$

68. Tiempo libre

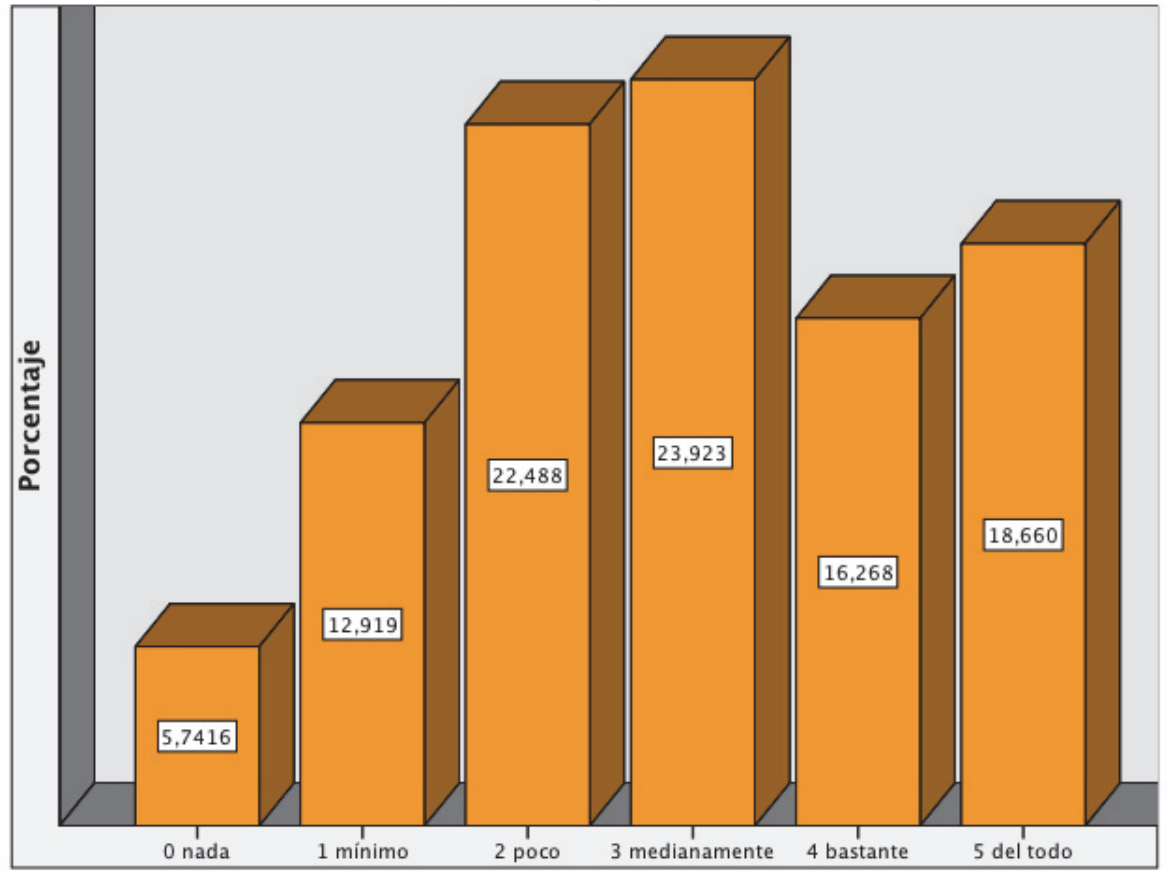

Elaboración propia. Mayo de 2015

Análisis: presencia de todas las puntuaciones, modelo en pirámide con porcentajes distribuidos de forma bastante equilibrada. El mismo valor en la VP presenta un modelo en escalera ascendente. El "Tiempo libre" se revela más apreciado en la VP que en el ME.

Resultado coherente con la realidad, este valor aparece como importante en la VP y no está tan claro para el ME. 
Cuadro $n^{\circ} 2.69$

69. Tradición, conservación

\begin{tabular}{|l|r|r|r|r|}
\hline & Frecuencia & Porcentaje & $\begin{array}{c}\text { Porcentaje } \\
\text { válido }\end{array}$ & $\begin{array}{r}\text { Porcentaje } \\
\text { acumulado }\end{array}$ \\
\hline 0 nada & 11 & 5,3 & 5,3 & 5,3 \\
1 mínimo & 19 & 9,1 & 9,1 & 14,4 \\
2 poco & 33 & 15,8 & 15,8 & 30,1 \\
3 medianamente & 72 & 34,4 & 34,4 & 64,6 \\
4 bastante & 52 & 24,9 & 24,9 & 89,5 \\
5 del todo & 22 & 10,5 & 10,5 & 100,0 \\
Total & 209 & 100,0 & 100,0 & \\
\hline
\end{tabular}

Elaboración propia. Mayo de 2015

Gráfico n ${ }^{\circ} 2.69$

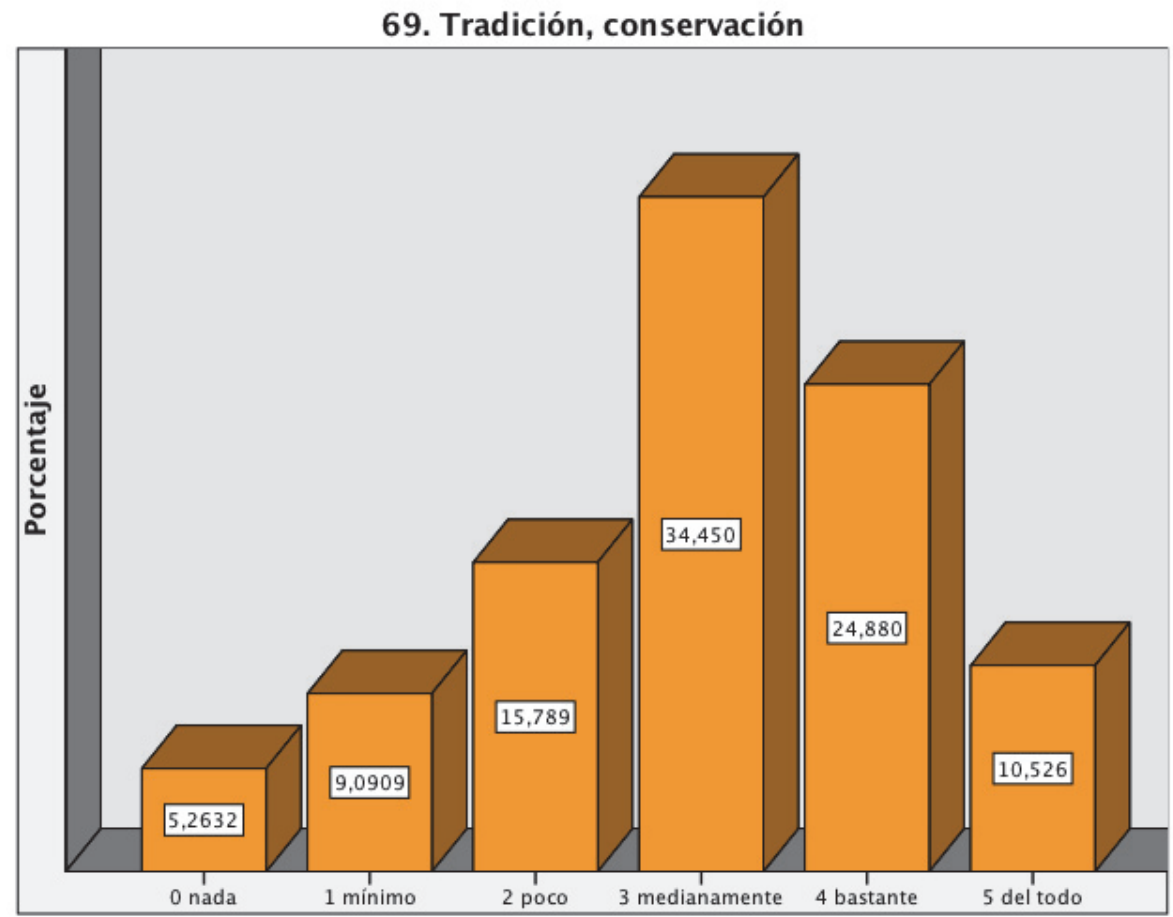

Elaboración propia. Mayo de 2015

Análisis: presencia de todas las puntuaciones. Modelo en pirámide con mayor peso para el 3. El valor "Tradición" es claramente considerado como medianamente importante en el ME. Si observamos el gráfico 1.69 tampoco aparece como un valor que gobierne de forma importante la VP.

El alumnado percibe más definido este valor en el ME que en la VP. Pero incluso así, las respuestas están muy repartidas, cosa normal en épocas de cambios vertiginosos. 
Cuadro $n^{\circ} 2.70$

70. Trascendencia, utilidad para otros

\begin{tabular}{|l|r|r|r|r|}
\hline & Frecuencia & Porcentaje & $\begin{array}{c}\text { Porcentaje } \\
\text { válido }\end{array}$ & $\begin{array}{c}\text { Porcentaje } \\
\text { acumulado }\end{array}$ \\
\hline 0 nada & 1 &, 5 &, 5 &, 5 \\
1 mínimo & 5 & 2,4 & 2,4 & 2,9 \\
2 poco & 19 & 9,1 & 9,1 & 12,0 \\
3 medianamente & 60 & 28,7 & 28,7 & 40,7 \\
4 bastante & 75 & 35,9 & 35,9 & 76,6 \\
5 del todo & 49 & 23,4 & 23,4 & 100,0 \\
Total & 209 & 100,0 & 100,0 & \\
\hline
\end{tabular}

Elaboración propia. Mayo de 2015

Gráfico ${ }^{\circ} 2.70$

70. Trascendencia, utilidad para otros

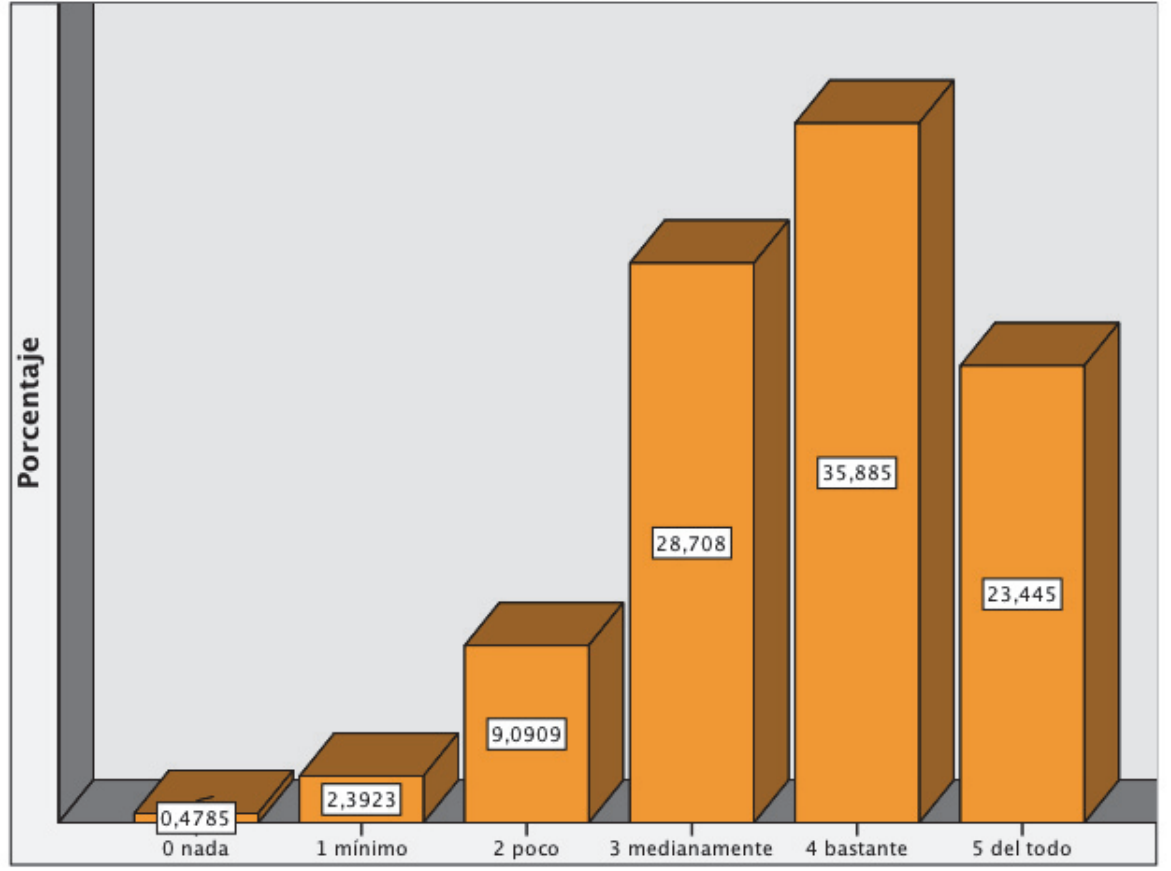

Elaboración propia. Mayo de 2015

Análisis: aparecen todas las puntuaciones, modelo en pirámide asimétrica con sesgo a la derecha, el porcentaje más alto corresponde al 4 con casi un $36 \%$, el 3 es cinco puntos más alto que el 5. El valor "Trascendencia, utilidad para otros" tiende a gobernar bastante/medianamente el ME. En la VP, el comportamiento de este valor es similar.

Resultados acordes con el perfil de enfermería, profesión que está al servicio de la salud ajena y del bienestar del enfermo. 
Cuadro $n^{\circ} 2.71$

71. Valentía, coraje

\begin{tabular}{|l|r|r|r|r|}
\hline & Frecuencia & Porcentaje & $\begin{array}{c}\text { Porcentaje } \\
\text { válido }\end{array}$ & $\begin{array}{r}\text { Porcentaje } \\
\text { acumulado }\end{array}$ \\
\hline 1 mínimo & 5 & 2,4 & 2,4 & 2,4 \\
2 poco & 48 & 23,0 & 23,0 & 25,4 \\
3 medianamente & 40 & 19,1 & 19,1 & 44,5 \\
4 bastante & 66 & 31,6 & 31,6 & 76,1 \\
5 del todo & 50 & 23,9 & 23,9 & 100,0 \\
Total & 209 & 100,0 & 100,0 & \\
\hline
\end{tabular}

Elaboración propia. Mayo de 2015

Gráfico $n^{\circ} 2.71$

71. Valentia, coraje

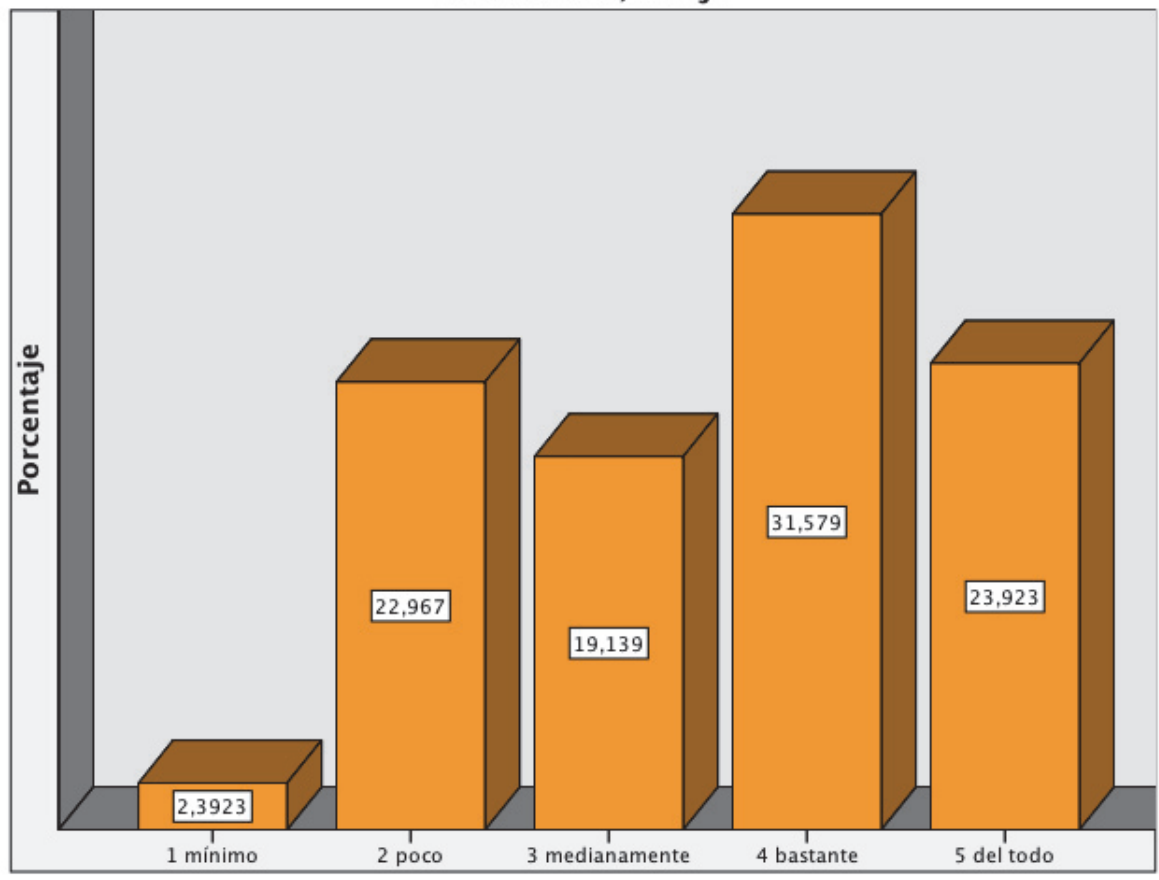

Elaboración propia. Mayo de 2015

Análisis: ausencia del 0. Patrón parecido al gráfico 1.71 con la diferencia de que el 2 que allí solo tiene 1,4354\%, aquí alcanza el 22,967\%, por lo que catalogamos el gráfico 2.71 de escalera aplanada. La muestra en estudio considera que el valor "Valentía, coraje" gobierna más la VP que el ME.

Decididamente la valentía, coraje no es percibida como importante para el ME cuando esta es una administración pública. 
Cuadro $n^{\circ} 2.72$

72. Verdad/sabiduría (búsqueda de la)

\begin{tabular}{|l|r|r|r|r|}
\hline & Frecuencia & Porcentaje & $\begin{array}{c}\text { Porcentaje } \\
\text { válido }\end{array}$ & $\begin{array}{r}\text { Porcentaje } \\
\text { acumulado }\end{array}$ \\
\hline 0 nada & 5 & 2,4 & 2,4 & 2,4 \\
1 mínimo & 8 & 3,8 & 3,8 & 6,2 \\
2 poco & 12 & 5,7 & 5,7 & 12,0 \\
3 medianamente & 40 & 19,1 & 19,1 & 31,1 \\
4 bastante & 72 & 34,4 & 34,4 & 65,6 \\
5 del todo & 72 & 34,4 & 34,4 & 100,0 \\
Total & 209 & 100,0 & 100,0 & \\
\hline
\end{tabular}

Elaboración propia. Mayo de 2015

Gráfico ${ }^{\circ} 2.72$

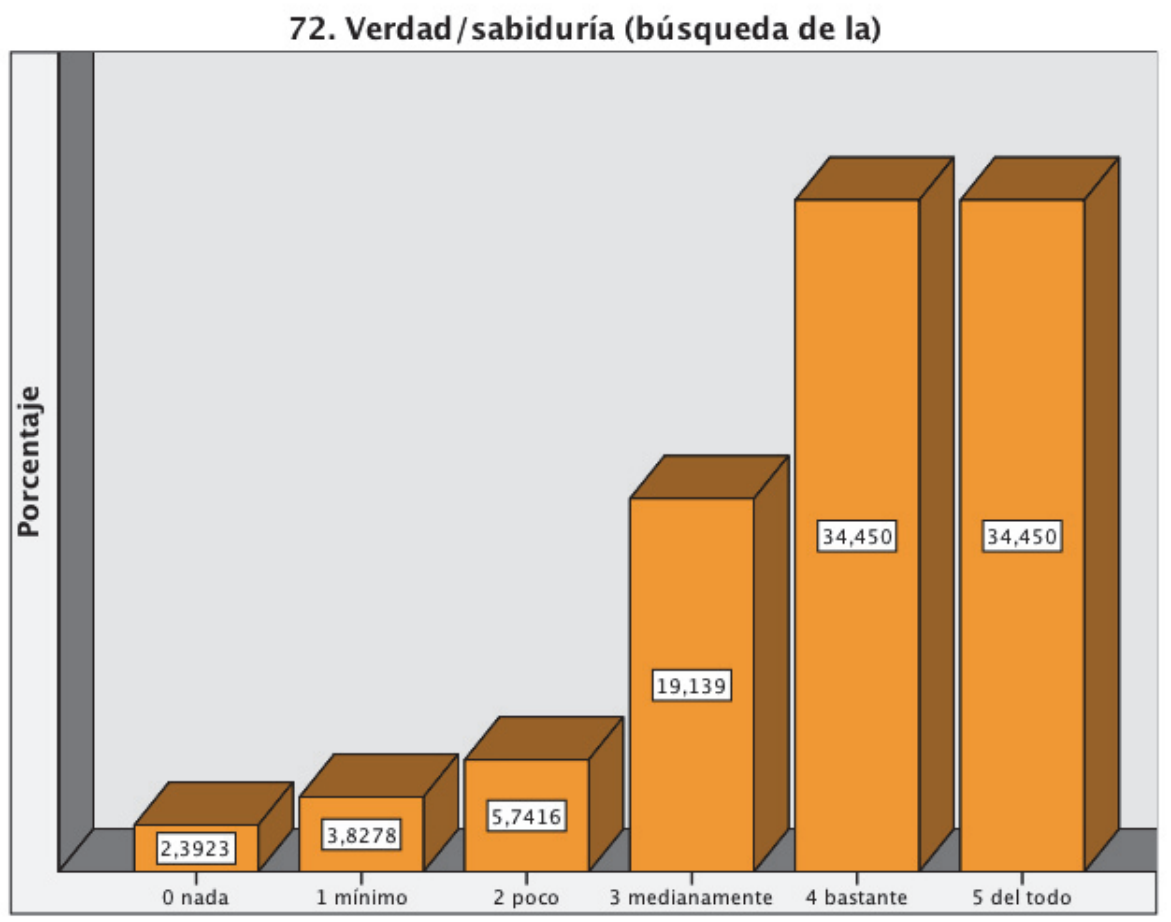

Elaboración propia. Mayo de 2015

Análisis: presencia de todas las puntuaciones. Modelo en escalera aplanada con igual porcentaje para el 4 y el 5 que suman entre ambos casi el 69\%, quedando el $41 \%$ para $0,1,2$ y 3 . Al compararlo con el gráfico 1.72 (en escalera ascendente con más del 54\% para el 5) vemos que 11 valor "Verdad/sabiduría (búsqueda de la )" gobierna más claramente la VP que el ME.

Pero en contraposición con el valor anterior, la verdad/sabiduría sí es percibida como importante para el ME siendo este el SNS. 

Compromiso social en la vida personal 

Cuadro $n^{\circ} 3.1$

12. Compartir, generosidad

\begin{tabular}{|l|r|r|r|r|}
\hline & Frecuencia & Porcentaje & $\begin{array}{c}\text { Porcentaje } \\
\text { válido }\end{array}$ & $\begin{array}{c}\text { Porcentaje } \\
\text { acumulado }\end{array}$ \\
\hline poco & 1 &, 5 &, 5 &, 5 \\
medianamente & 18 & 8,6 & 8,6 & 9,1 \\
mucho & 190 & 90,9 & 90,9 & 100,0 \\
Total & 209 & 100,0 & 100,0 & \\
\hline
\end{tabular}

Elaboración propia. Mayo de 2015

Gráfico n ${ }^{\circ} 3.1$

12. Compartir, generosidad

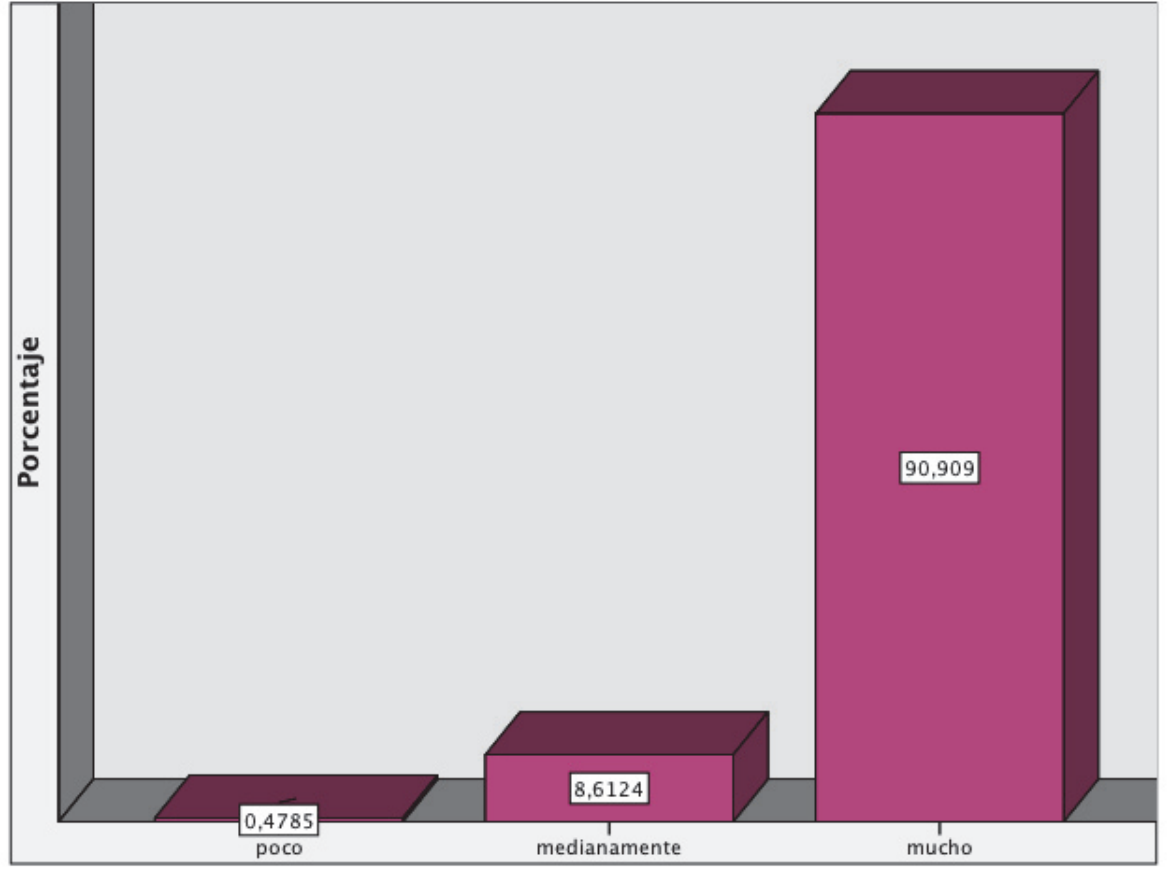

Elaboración propia. Mayo de 2015

Análisis: a la vista de este gráfico simplificado podemos ver con más claridad como la muestra en estudio considera que el valor "Compartir, generosidad" gobierna realmente mucho, casi un 91\%, la VP. 
Cuadro $n^{0} 3.2$

23. Derechos humanos, dignidad

\begin{tabular}{|l|r|r|r|r|}
\hline & Frecuencia & Porcentaje & $\begin{array}{c}\text { Porcentaje } \\
\text { válido }\end{array}$ & $\begin{array}{c}\text { Porcentaje } \\
\text { acumulado }\end{array}$ \\
\hline poco & 3 & 1,4 & 1,4 & 1,4 \\
medianamente & 26 & 12,4 & 12,4 & 13,9 \\
mucho & 180 & 86,1 & 86,1 & 100,0 \\
Total & 209 & 100,0 & 100,0 & \\
\hline
\end{tabular}

Elaboración propia. Mayo de 2015

Gráfico n 3.2

23. Derechos humanos, dignidad

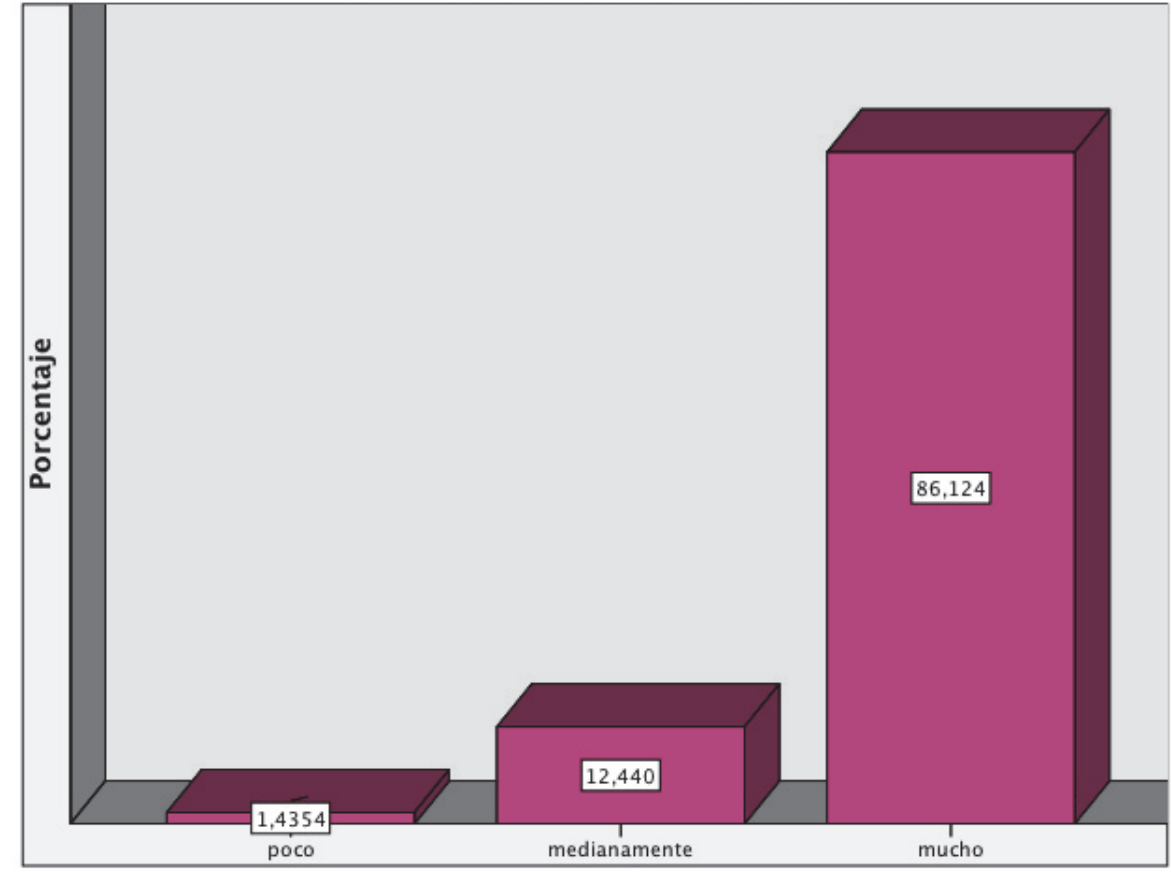

Elaboración propia. Mayo de 2015

Análisis: en el caso del valor "Derechos humanos, dignidad" con más de un $86 \%$ para la categoría simplificada "mucho", vemos que este valor es considerado como que gobierna realmente la VP. 
Cuadro $n^{\circ} 3.3$

26. Equidad, justicia en el día a día

\begin{tabular}{|l|r|r|r|r|}
\hline & Frecuencia & Porcentaje & $\begin{array}{c}\text { Porcentaje } \\
\text { válido }\end{array}$ & $\begin{array}{c}\text { Porcentaje } \\
\text { acumulado }\end{array}$ \\
\hline poco & 3 & 1,4 & 1,4 & 1,4 \\
medianamente & 30 & 14,4 & 14,4 & 15,8 \\
mucho & 176 & 84,2 & 84,2 & 100,0 \\
Total & 209 & 100,0 & 100,0 & \\
\hline
\end{tabular}

Elaboración propia. Mayo de 2015

Gráfico $\mathrm{n}^{\mathrm{o}} 3.3$

26. Equidad, justicia en el día a día

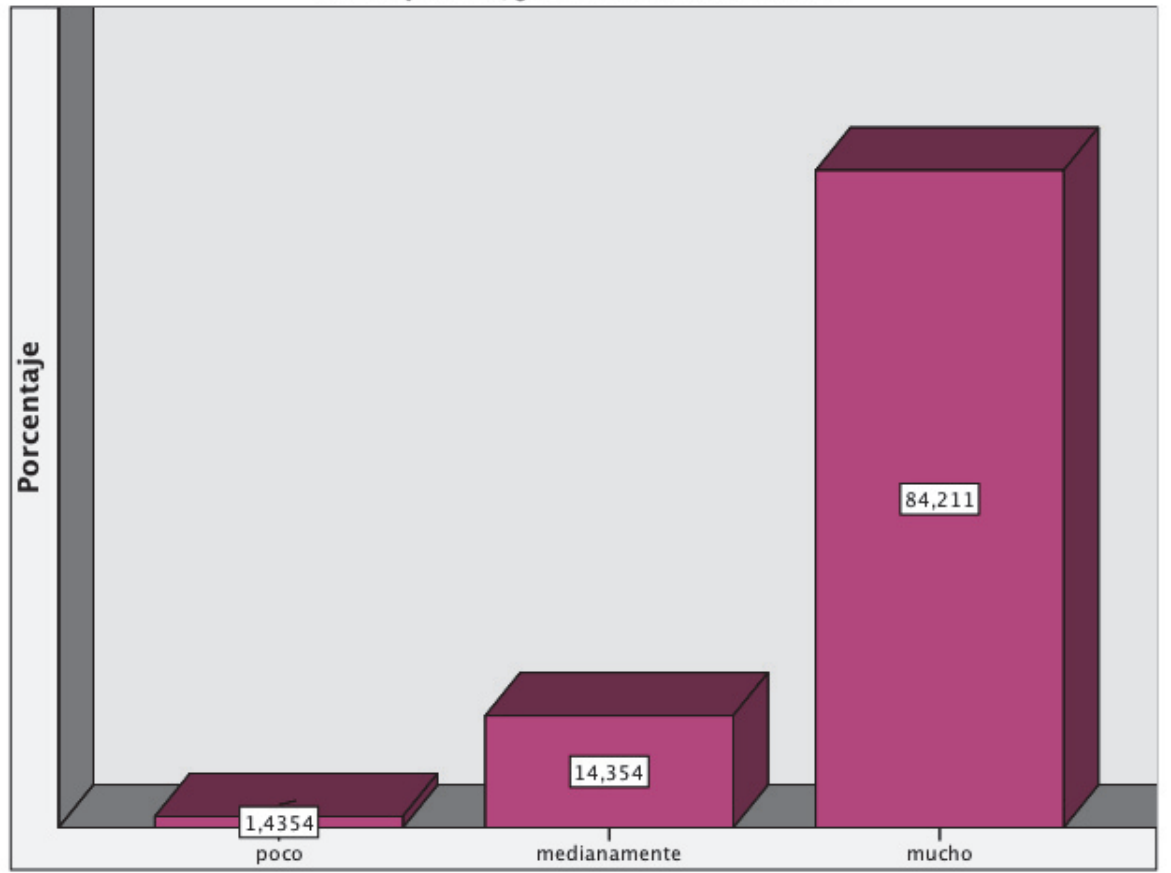

Elaboración propia. Mayo de 2015

Análisis: igualmente que en los anteriores, el valor "Equidad, justicia en el día a día", con más del 84\% para la categoría simplificad "mucho", se revela que gobierna realmente la VP. 
Cuadro $n^{\circ} 3.4$

32. Honestidad, honradez, transparencia, sinceridad

\begin{tabular}{|l|r|r|r|r|}
\hline & Frecuencia & Porcentaje & $\begin{array}{c}\text { Porcentaje } \\
\text { válido }\end{array}$ & $\begin{array}{c}\text { Porcentaje } \\
\text { acumulado }\end{array}$ \\
\hline poco & 2 & 1,0 & 1,0 & 1,0 \\
medianamente & 15 & 7,2 & 7,2 & 8,1 \\
mucho & 192 & 91,9 & 91,9 & 100,0 \\
Total & 209 & 100,0 & 100,0 & \\
\hline
\end{tabular}

Elaboración propia. Mayo de 2015

Gráfico $\mathrm{n}^{\circ} 3.4$

32. Honestidad, honradez, transparencia, sinceridad

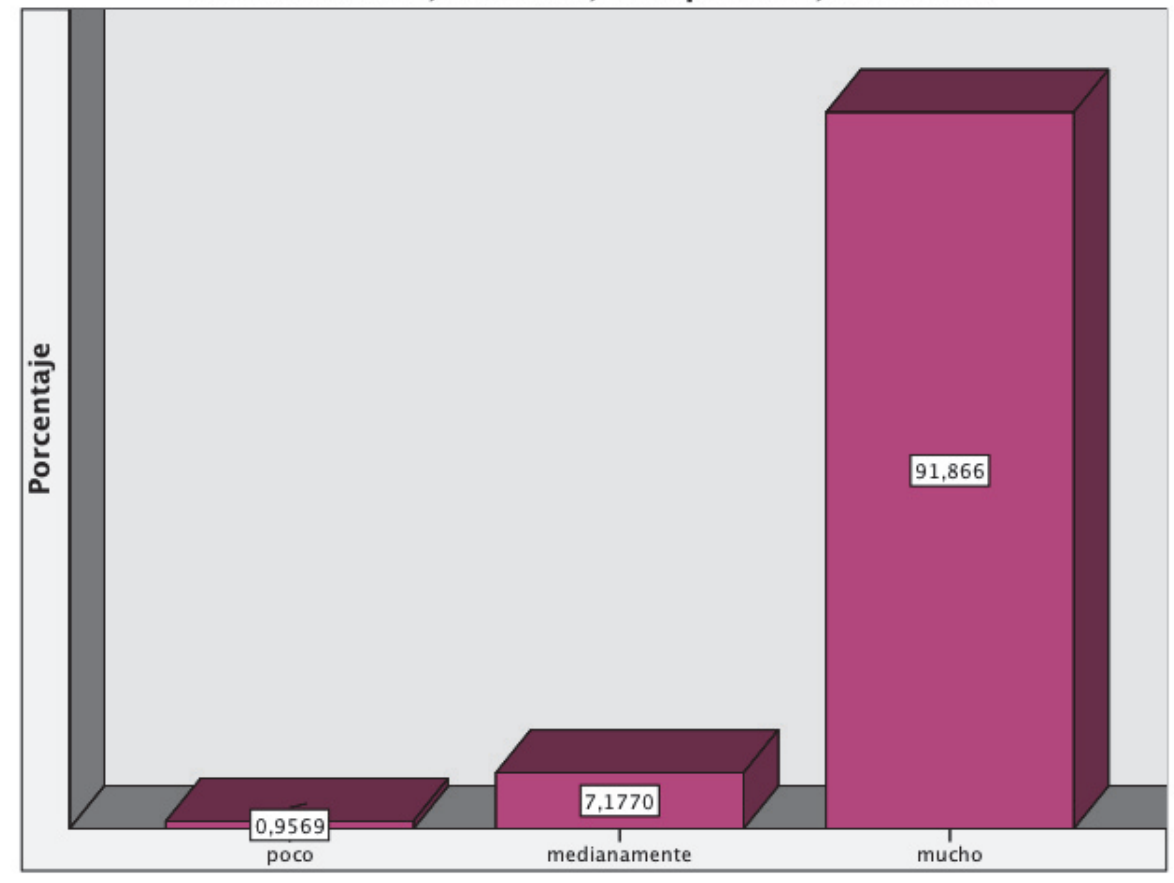

Elaboración propia. Mayo de 2015

Análisis: el valor "Honestidad, honradez, transparencia, sinceridad" también se revela, a través de más del 91\% para la categoría simplificad "mucho", como un valor que gobierna realmente la VP. 
Cuadro $\mathrm{n}^{\mathrm{0}} 3.5$

38. Inconformismo, rebeldía ante la injusticia social

\begin{tabular}{|l|r|r|r|r|}
\hline & Frecuencia & Porcentaje & $\begin{array}{c}\text { Porcentaje } \\
\text { válido }\end{array}$ & $\begin{array}{c}\text { Porcentaje } \\
\text { acumulado }\end{array}$ \\
\hline poco & 27 & 12,9 & 12,9 & 12,9 \\
medianamente & 49 & 23,4 & 23,4 & 36,4 \\
mucho & 133 & 63,6 & 63,6 & 100,0 \\
Total & 209 & 100,0 & 100,0 & \\
\hline
\end{tabular}

Elaboración propia. Mayo de 2015

Gráfico $n^{0} 3.5$

38. Inconformismo, rebeldía ante la injusticia social

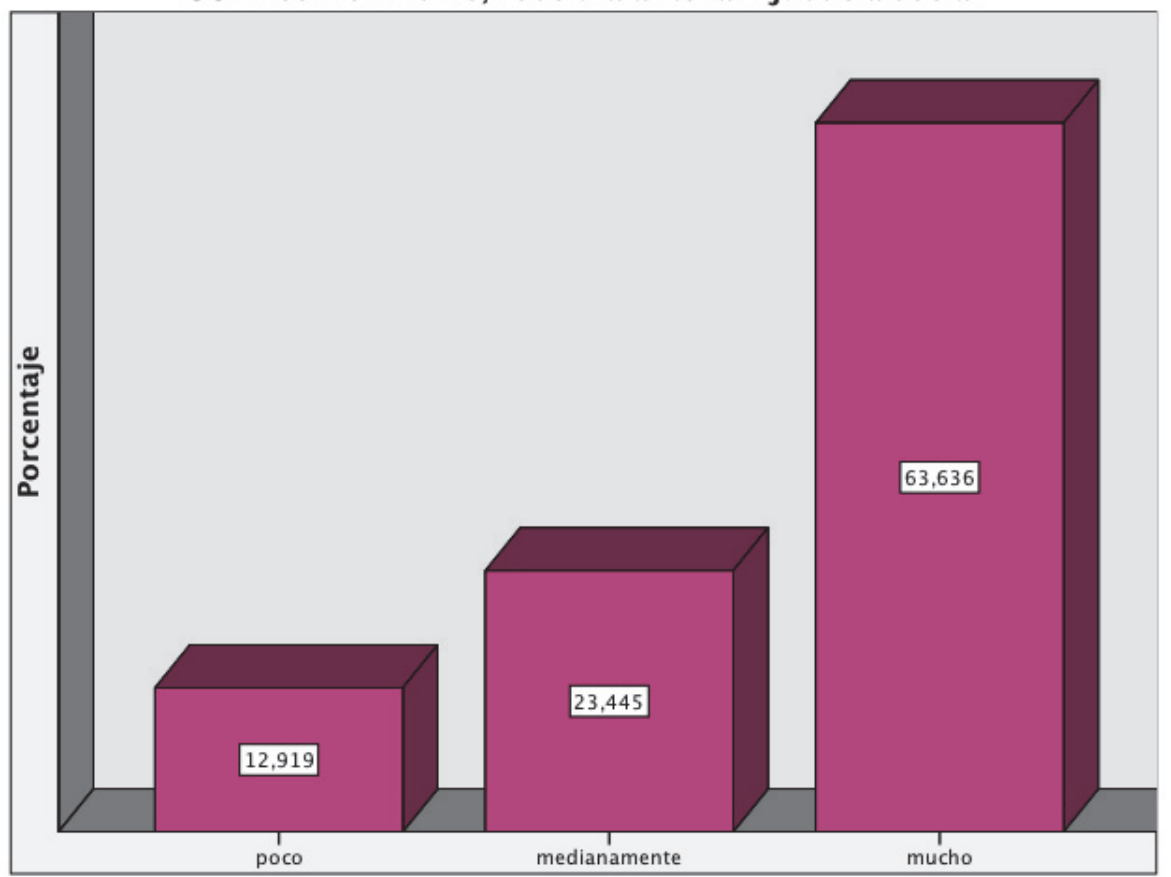

Elaboración propia. Mayo de 2015

Análisis: el "Inconformismo, rebeldía ante la injusticia" es otro valor que gobierna realmente la VP, sin embargo no tanto como los anteriores, pues la categoría simplificada "mucho" solo llega a algo más del 63\%. 
Cuadro $n^{\circ} 3.6$

39. Independencia, iniciativa, autonomía de acción

\begin{tabular}{|l|r|r|r|r|}
\hline & Frecuencia & Porcentaje & $\begin{array}{c}\text { Porcentaje } \\
\text { válido }\end{array}$ & $\begin{array}{c}\text { Porcentaje } \\
\text { acumulado }\end{array}$ \\
\hline poco & 9 & 4,3 & 4,3 & 4,3 \\
medianamente & 26 & 12,4 & 12,4 & 16,7 \\
mucho & 174 & 83,3 & 83,3 & 100,0 \\
Total & 209 & 100,0 & 100,0 & \\
\hline
\end{tabular}

Elaboración propia. Mayo de 2015

Gráfico $\mathrm{n}^{\mathrm{o}} 3.6$

39. Independencia, iniciativa, autonomía de acción

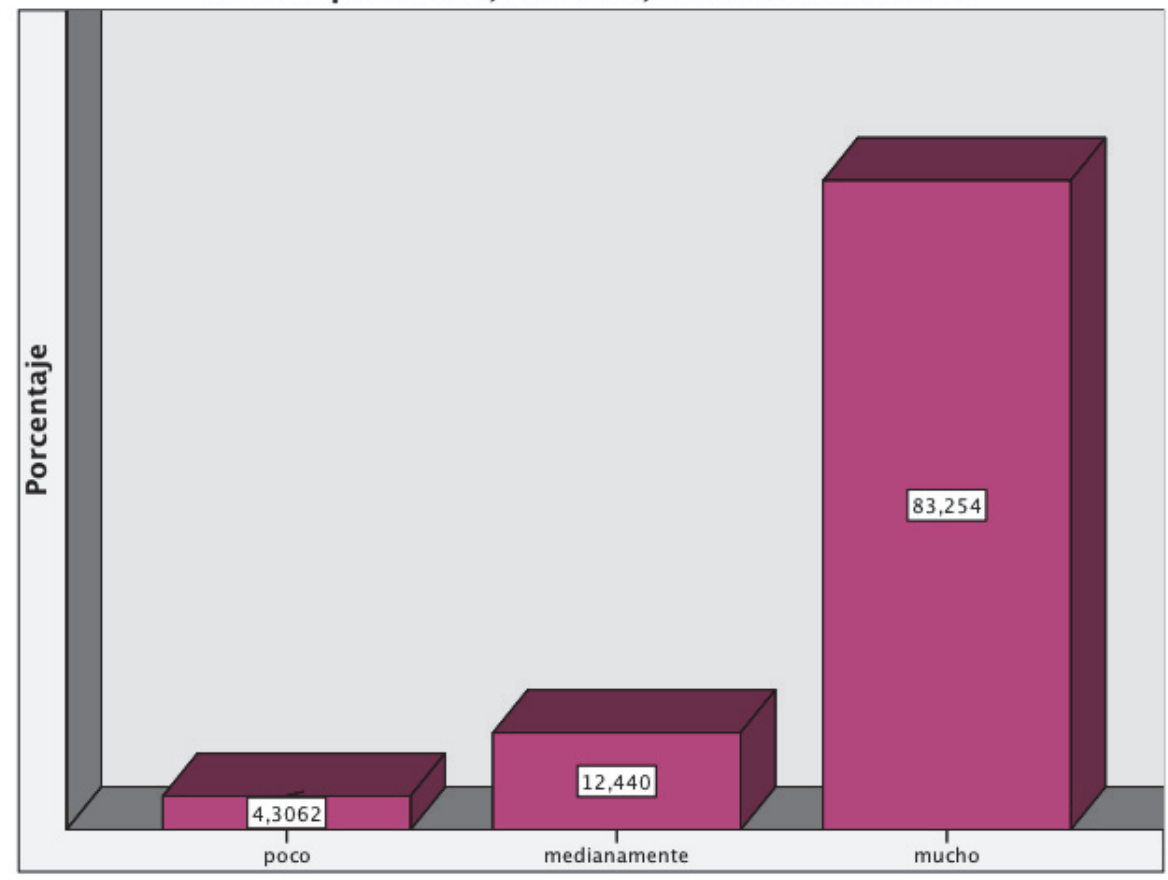

Elaboración propia. Mayo de 2015

Análisis: la "Independencia, iniciativa, autonomía de acción”, con más del $82 \%$ para la categoría simplificad "mucho", se revela también como un valor que gobierna realmente la VP. 
Cuadro $n^{\circ} 3.7$

43. Mundo en paz

\begin{tabular}{|l|r|r|r|r|}
\hline & Frecuencia & Porcentaje & $\begin{array}{c}\text { Porcentaje } \\
\text { válido }\end{array}$ & $\begin{array}{c}\text { Porcentaje } \\
\text { acumulado }\end{array}$ \\
\hline poco & 8 & 3,8 & 3,8 & 3,8 \\
medianamente & 33 & 15,8 & 15,8 & 19,6 \\
mucho & 168 & 80,4 & 80,4 & 100,0 \\
Total & 209 & 100,0 & 100,0 & \\
\hline
\end{tabular}

Elaboración propia. Mayo de 2015

Gráfico n 3.7

43. Mundo en paz

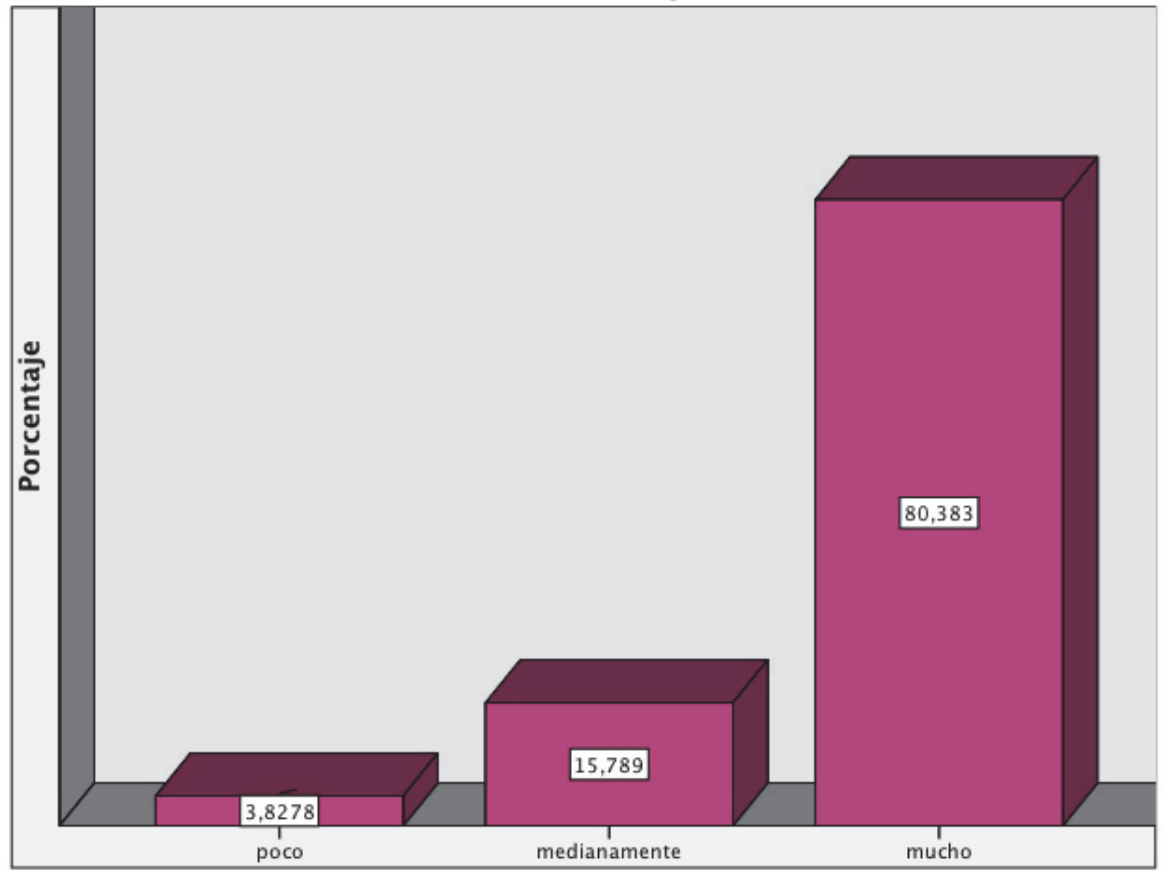

Elaboración propia. Mayo de 2015

Análisis: la paz como valor en el mundo, es considerada como un valor importante en la VP, con más del $80 \%$ para la categoría simplificada "mucho". 
Cuadro $n^{\circ} 3.8$

65. Solidaridad, generosidad

\begin{tabular}{|l|r|r|r|r|}
\hline & Frecuencia & Porcentaje & $\begin{array}{c}\text { Porcentaje } \\
\text { válido }\end{array}$ & $\begin{array}{c}\text { Porcentaje } \\
\text { acumulado }\end{array}$ \\
\hline poco & 5 & 2,4 & 2,4 & 2,4 \\
medianamente & 20 & 9,6 & 9,6 & 12,0 \\
mucho & 184 & 88,0 & 88,0 & 100,0 \\
Total & 209 & 100,0 & 100,0 & \\
\hline
\end{tabular}

Elaboración propia. Mayo de 2015

Gráfico n 3.8

65. Solidaridad, generosidad

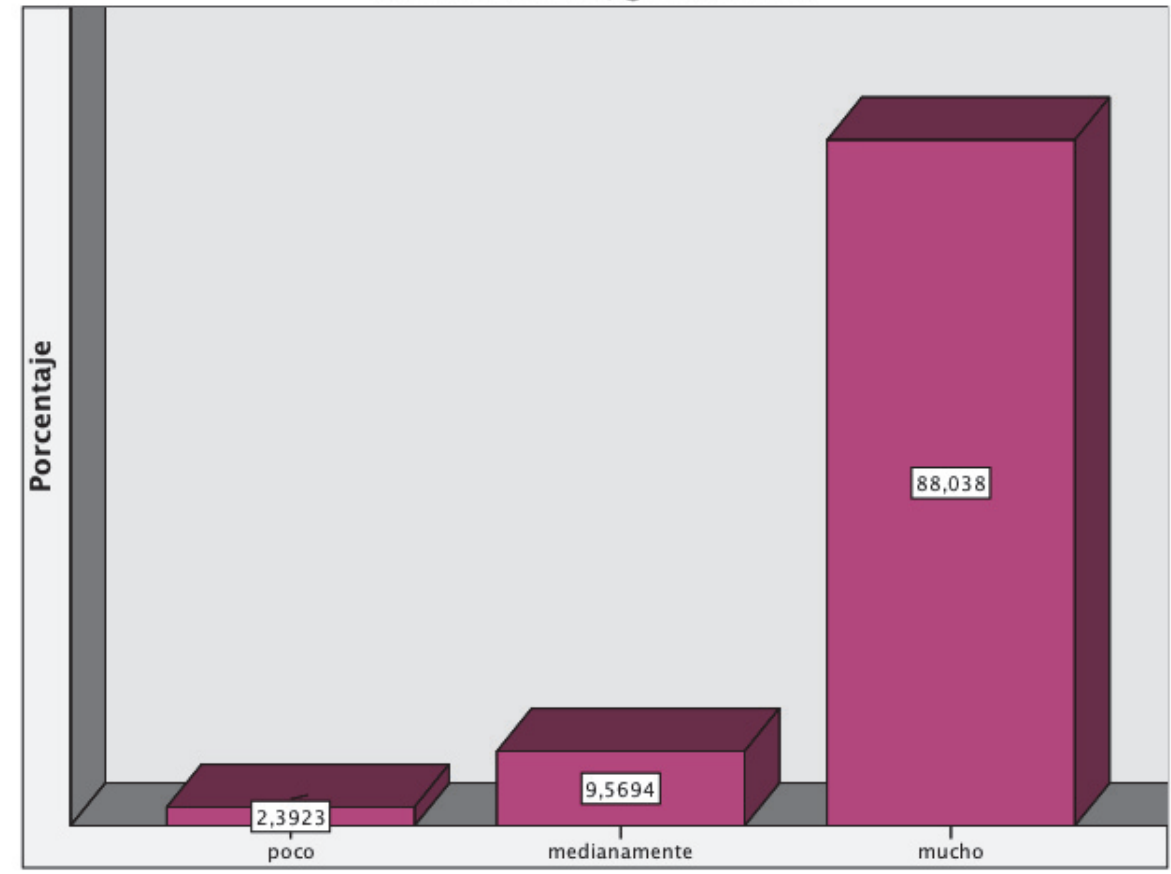

Elaboración propia. Mayo de 2015

Análisis: la "Solidaridad, generosidad" es otro de los valores que gobierna realmente la VP con más del $88 \%$ para la categoría simplificada "mucho". 
Compromiso social en el M. de la empresa 

Cuadro $n^{\circ} 4.1$

12. Compartir, generosidad

\begin{tabular}{|l|r|r|r|r|}
\hline & Frecuencia & Porcentaje & $\begin{array}{c}\text { Porcentaje } \\
\text { válido }\end{array}$ & $\begin{array}{c}\text { Porcentaje } \\
\text { acumulado }\end{array}$ \\
\hline poco & 48 & 23,0 & 23,0 & 23,0 \\
medianamente & 47 & 22,5 & 22,5 & 45,5 \\
mucho & 114 & 54,5 & 54,5 & 100,0 \\
Total & 209 & 100,0 & 100,0 & \\
\hline
\end{tabular}

Elaboración propia. Mayo de 2015

Gráfico ${ }^{\circ} 4.1$

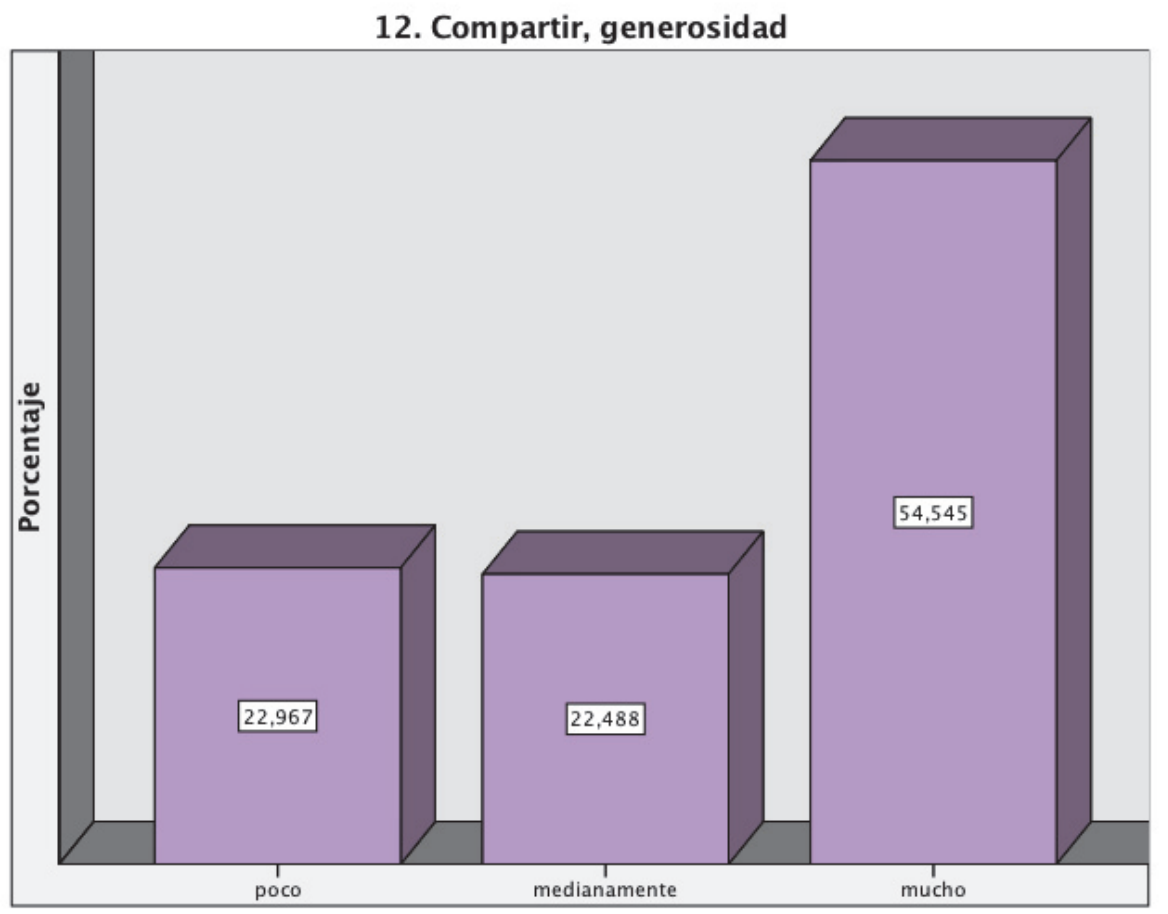

Elaboración propia. Mayo de 2015

Análisis: este valor, en la VP, llega a casi el 91\%, en cambio en el ME, sigue siendo más pesada la categoría "mucho" pero se queda en algo más del 54\%. La muestra en estudio considera que el "Compartir, generosidad, gobierna más la VP que el ME. 
Cuadro $n^{\circ} 4.2$

23. Derechos humanos, Dignidad

\begin{tabular}{|l|r|r|r|r|}
\hline & Frecuencia & Porcentaje & $\begin{array}{c}\text { Porcentaje } \\
\text { válido }\end{array}$ & \multicolumn{1}{c|}{$\begin{array}{c}\text { Porcentaje } \\
\text { acumulado }\end{array}$} \\
\hline poco & 24 & 11,5 & 11,5 & 11,5 \\
medianamente & 37 & 17,7 & 17,7 & 29,2 \\
mucho & 148 & 70,8 & 70,8 & 100,0 \\
Total & 209 & 100,0 & 100,0 & \\
\hline
\end{tabular}

Elaboración propia. Mayo de 2015

Gráfico $n^{\circ} 4.2$

23. Derechos humanos, Dignidad

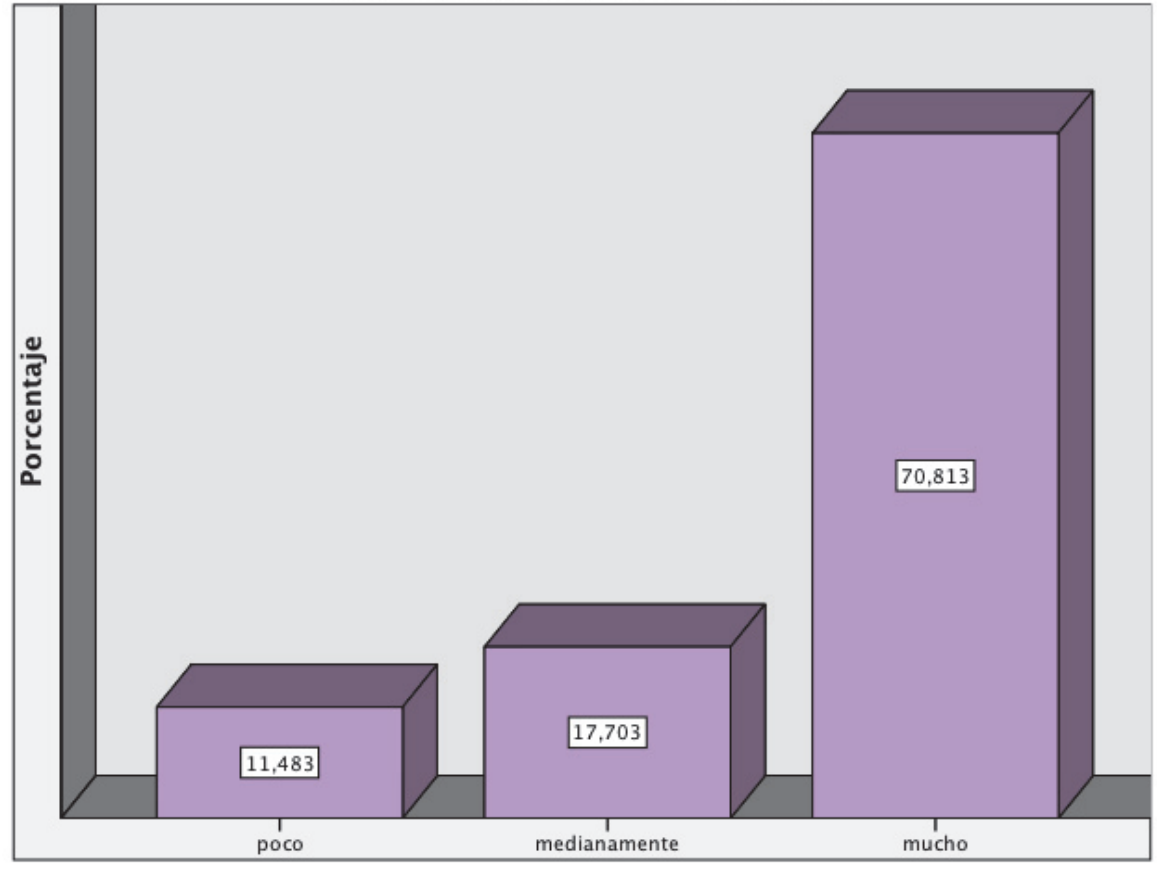

Elaboración propia. Mayo de 2015

Análisis: los "Derechos humanos, Dignidad" siguen siendo más importantes en la VP pero no se alejan demasiado en el ME en el que llegan a más del 70\% para la categoría simplificada "mucho" frente al algo más del $86 \%$ en la VP. 
Cuadro $\mathrm{n}^{\circ} 4.3$

26. Equidad, justicia en el día a día

\begin{tabular}{|l|r|r|r|r|}
\hline & Frecuencia & Porcentaje & $\begin{array}{c}\text { Porcentaje } \\
\text { válido }\end{array}$ & $\begin{array}{c}\text { Porcentaje } \\
\text { acumulado }\end{array}$ \\
\hline poco & 33 & 15,8 & 15,8 & 15,8 \\
medianamente & 58 & 27,8 & 27,8 & 43,5 \\
mucho & 118 & 56,5 & 56,5 & 100,0 \\
Total & 209 & 100,0 & 100,0 & \\
\hline
\end{tabular}

Elaboración propia. Mayo de 2015

\section{Gráfico $\mathrm{n}^{\circ} 4.3$}

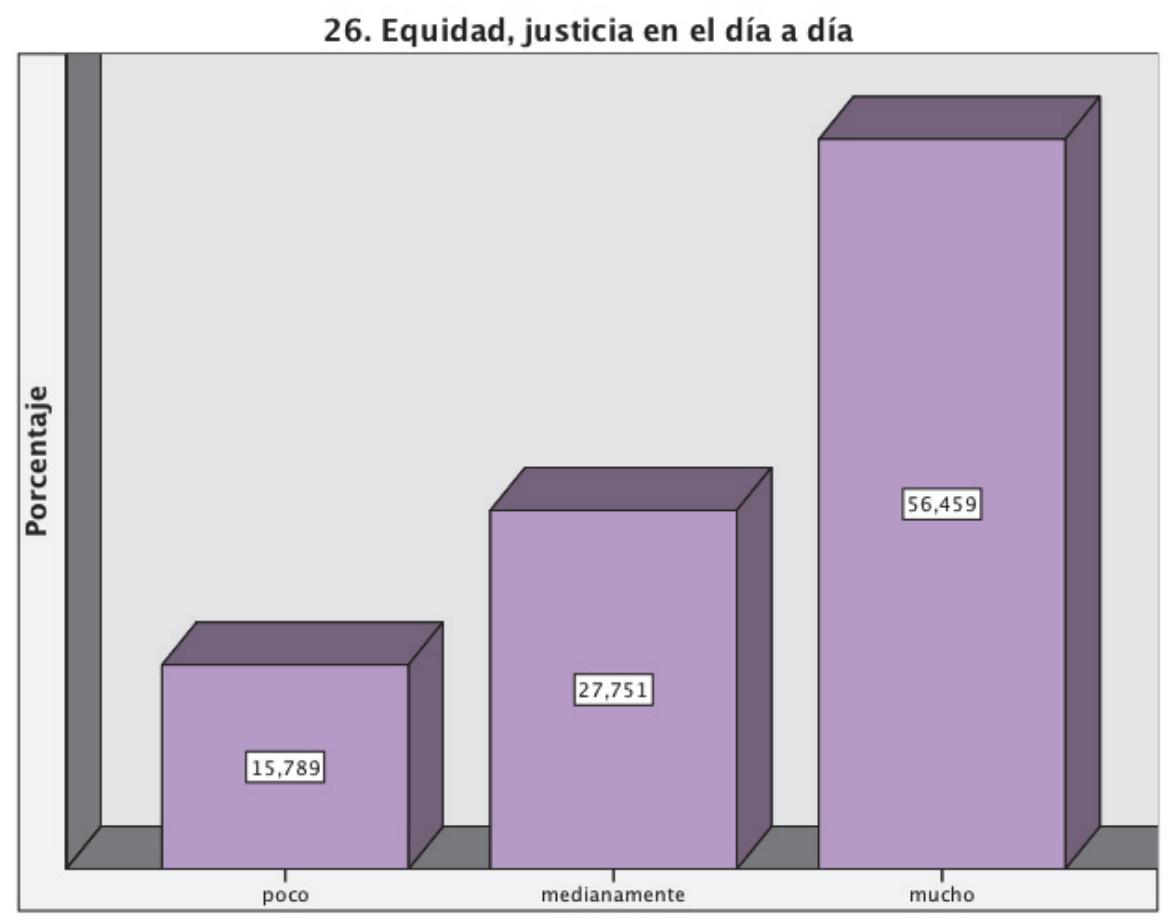

Elaboración propia. Mayo de 2015

Análisis: el valor "Equidad, justicia en el día a día" es considerado importante en el ME, pero menos que en la VP donde alcanzad más del $84 \%$ para la categoría simplificad "mucho" frente al 56\% en el ME. 
Cuadro $n^{\circ} 4.4$

32. Honestidad, honradez, transparencia, sinceridad

\begin{tabular}{|l|r|r|r|r|}
\hline & Frecuencia & Porcentaje & $\begin{array}{c}\text { Porcentaje } \\
\text { válido }\end{array}$ & $\begin{array}{c}\text { Porcentaje } \\
\text { acumulado }\end{array}$ \\
\hline poco & 37 & 17,7 & 17,7 & 17,7 \\
medianamente & 58 & 27,8 & 27,8 & 45,5 \\
mucho & 114 & 54,5 & 54,5 & 100,0 \\
Total & 209 & 100,0 & 100,0 & \\
\hline
\end{tabular}

Elaboración propia. Mayo de 2015

Gráfico n ${ }^{\circ} 4.4$

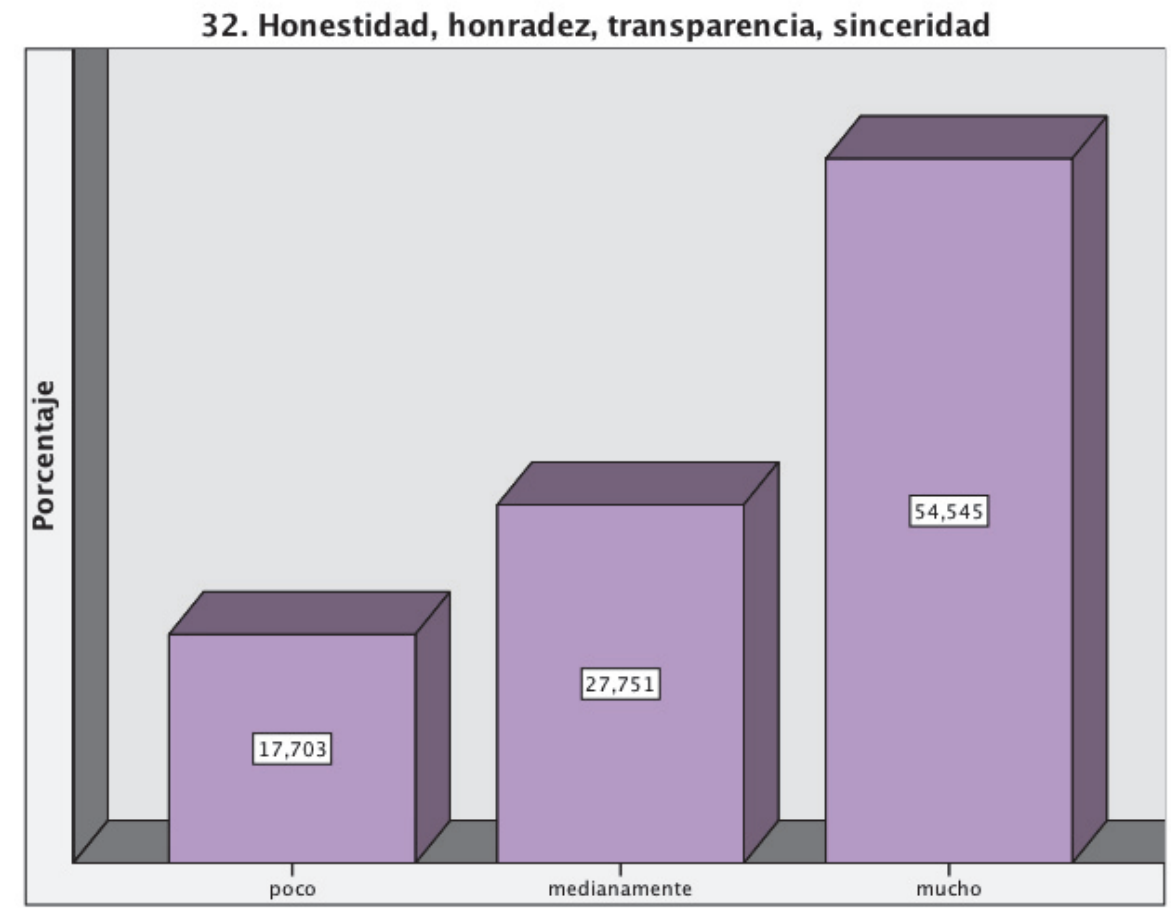

Elaboración propia. Mayo de 2015

Análisis: al igual que en los valores anteriores, la "Honestidad, honradez, transparencia, sinceridad" gobierna el ME con más de un 54\% para la categoría simplificad "mucho" pero menos que la VP en la que alcanza casi el 92\%. 
Cuadro $\mathrm{n}^{\circ} 4.5$

38. Inconformismo, rebeldía ante la injusticia social

\begin{tabular}{|l|r|r|r|r|}
\hline & Frecuencia & Porcentaje & $\begin{array}{c}\text { Porcentaje } \\
\text { válido }\end{array}$ & $\begin{array}{r}\text { Porcentaje } \\
\text { acumulado }\end{array}$ \\
\hline poco & 64 & 30,6 & 30,6 & 30,6 \\
medianamente & 77 & 36,8 & 36,8 & 67,5 \\
mucho & 68 & 32,5 & 32,5 & 100,0 \\
Total & 209 & 100,0 & 100,0 & \\
\hline
\end{tabular}

Elaboración propia. Mayo de 2015

Gráfico $n^{\circ} 4.5$

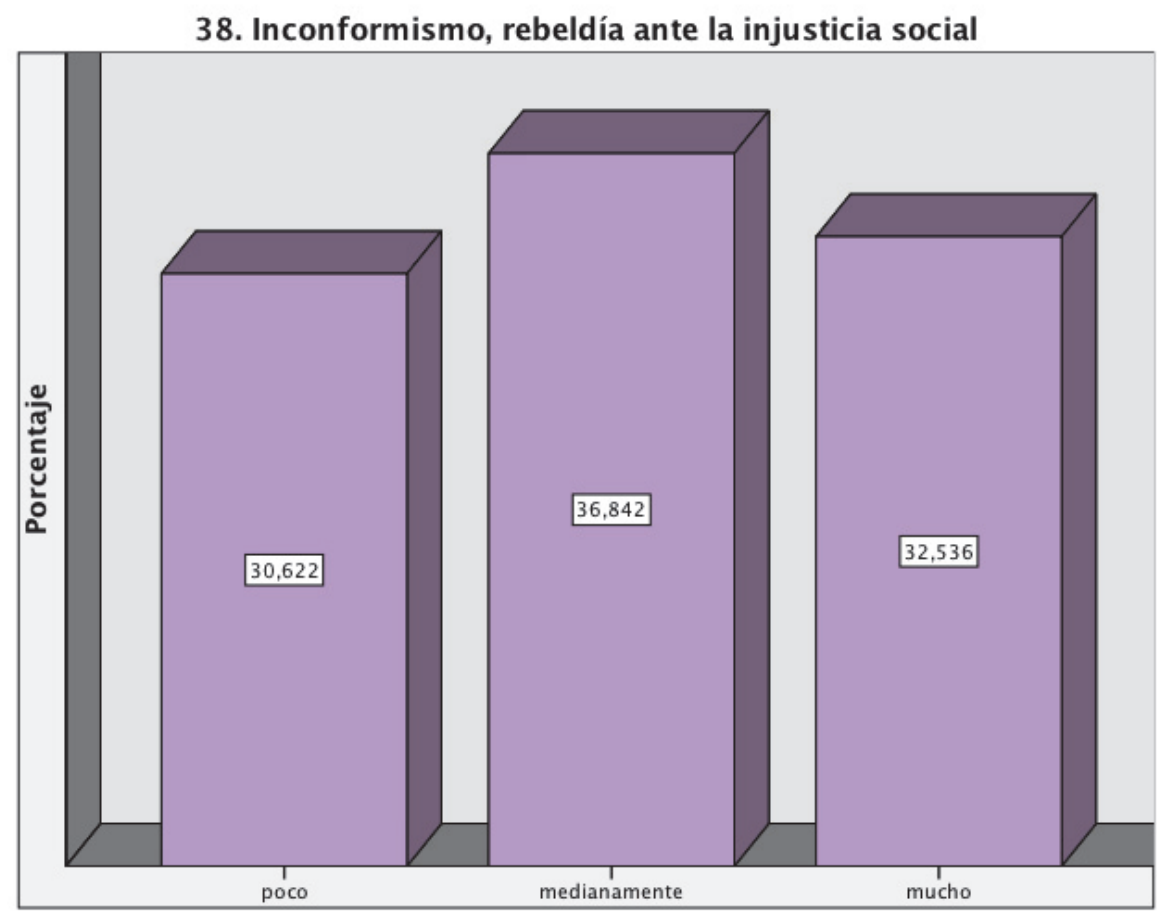

Elaboración propia. Mayo de 2015

Análisis: el "Inconformismo, rebeldía ante la injusticia" que se revela importante en la VP con más de un 63\% para la categoría simplificad "mucho", se queda en un "medianamente" en el ME. 
Cuadro $n^{\circ} 4.6$

39. Independencia, iniciativa, autonomía de acción

\begin{tabular}{|l|r|r|r|r|}
\hline & Frecuencia & Porcentaje & $\begin{array}{c}\text { Porcentaje } \\
\text { válido }\end{array}$ & $\begin{array}{c}\text { Porcentaje } \\
\text { acumulado }\end{array}$ \\
\hline poco & 50 & 23,9 & 23,9 & 23,9 \\
medianamente & 50 & 23,9 & 23,9 & 47,8 \\
mucho & 109 & 52,2 & 52,2 & 100,0 \\
Total & 209 & 100,0 & 100,0 & \\
\hline
\end{tabular}

Elaboración propia. Mayo de 2015

Gráfico n ${ }^{\circ} 4.6$

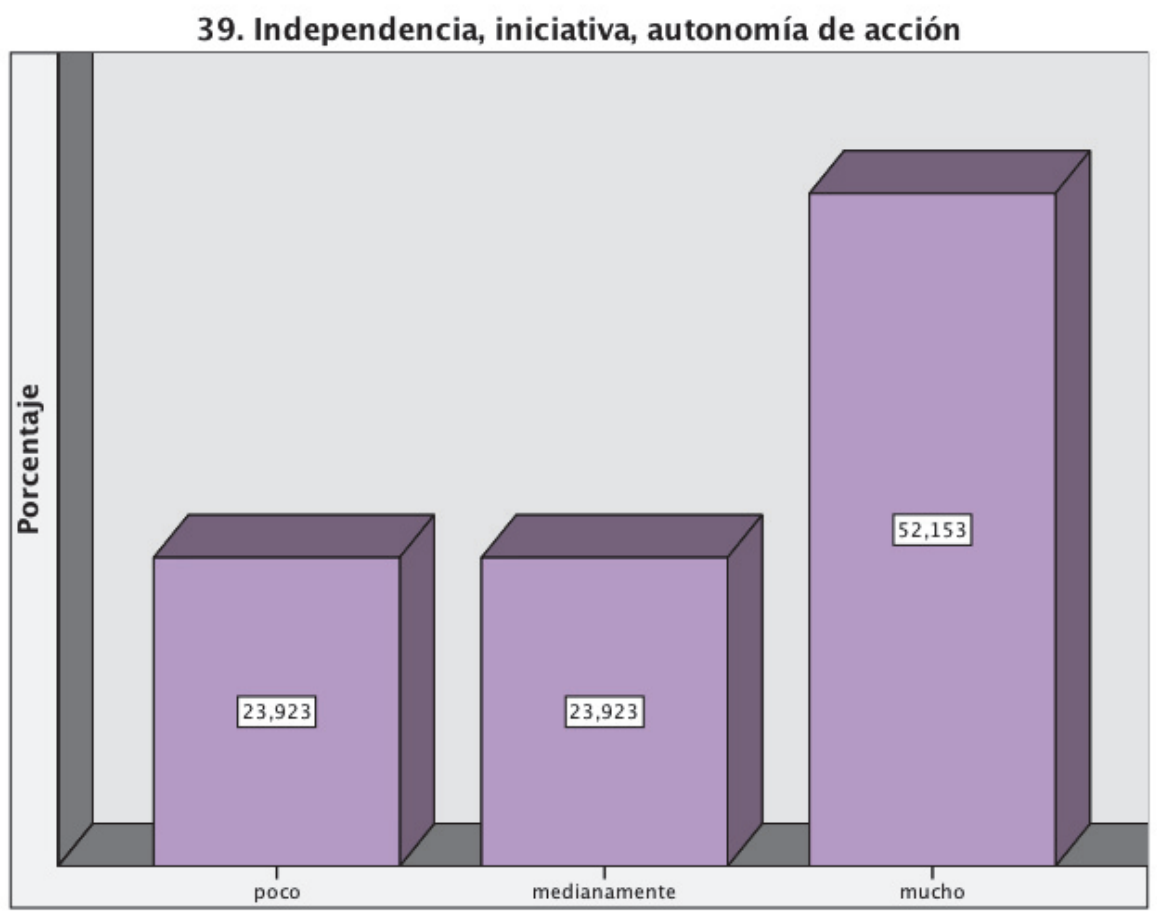

Elaboración propia. Mayo de 2015

Análisis: el valor "Independencia, iniciativa, autonomía de acción" se revela también menos importante en el ME que en la VP, aunque con más del $52 \%$ para la categoría simplificad "mucho" se puede decir que la muestra en estudio lo considera importante en esta esfera. 
Cuadro $\mathrm{n}^{\circ} 4.7$

43. Mundo en paz

\begin{tabular}{|l|r|r|r|r|}
\hline & Frecuencia & Porcentaje & $\begin{array}{c}\text { Porcentaje } \\
\text { válido }\end{array}$ & $\begin{array}{c}\text { Porcentaje } \\
\text { acumulado }\end{array}$ \\
\hline poco & 43 & 20,6 & 20,6 & 20,6 \\
medianamente & 60 & 28,7 & 28,7 & 49,3 \\
mucho & 106 & 50,7 & 50,7 & 100,0 \\
Total & 209 & 100,0 & 100,0 & \\
\hline
\end{tabular}

Elaboración propia. Mayo de 2015

Gráfico $n^{\circ} 4.7$

43. Mundo en paz

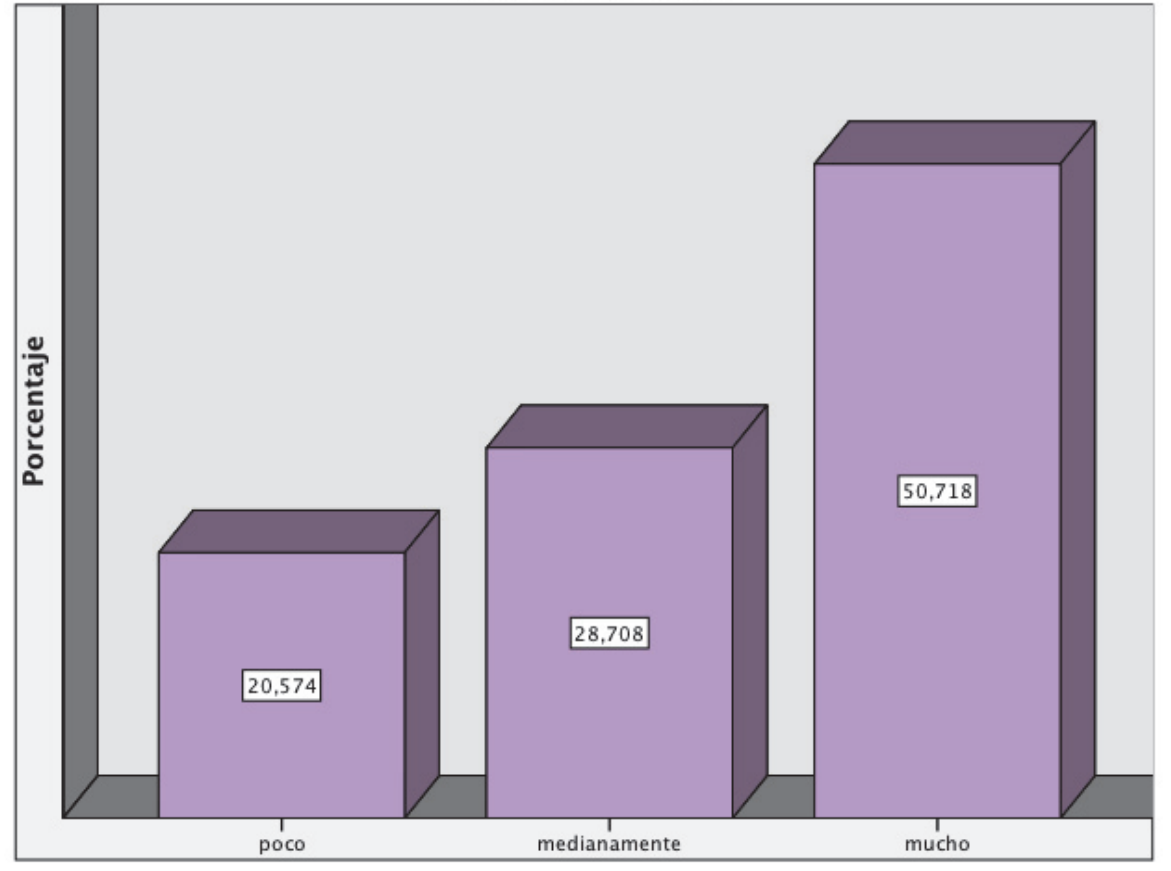

Elaboración propia. Mayo de 2015

Análisis: la paz en el mundo también es un valor que gobierna más la VP que el ME, en la primera esfera alcanza más del $80 \%$ para la categoría simplificada "mucho", quedándose en el 50, 718\% para la misma categoría en el ME. Sigue siendo, sin embargo más pesado el "mucho" que las otras dos categorías simplificadas "poco" y "medianamente" con el 20,574\% y el 28,708\% respectivamente. 
Cuadro $n^{\circ} 4.8$

65. Solidaridad, generosidad

\begin{tabular}{|l|r|r|r|r|}
\hline & Frecuencia & Porcentaje & $\begin{array}{c}\text { Porcentaje } \\
\text { válido }\end{array}$ & $\begin{array}{r}\text { Porcentaje } \\
\text { acumulado }\end{array}$ \\
\hline poco & 36 & 17,2 & 17,2 & 17,2 \\
medianamente & 55 & 26,3 & 26,3 & 43,5 \\
mucho & 118 & 56,5 & 56,5 & 100,0 \\
Total & 209 & 100,0 & 100,0 & \\
\hline
\end{tabular}

Elaboración propia. Mayo de 2015

Gráfico $n^{\circ} 4.8$

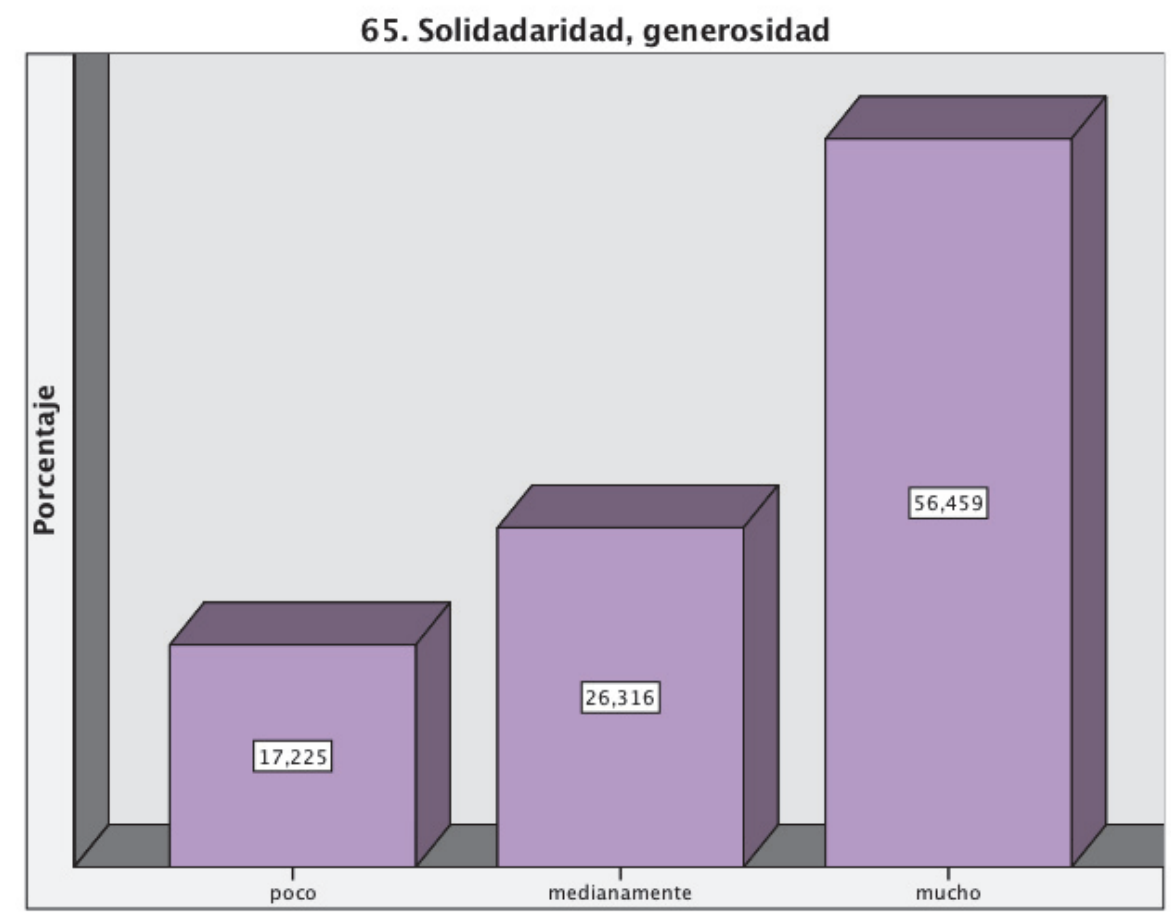

Elaboración propia. Mayo de 2015

Análisis: por último el valor "Solidaridad, generosidad" se revela como que gobierna el mundo de la empresa con más del 56\% para la categoría simplificada "mucho" pero menos que la VP en la que alcanza más del 88\%. 


\section{Análisis cualitativo de los gráficos 3 y 4 :}

En mi VP los resultados son inequívocos y demuestran lo interiorizado que enfermería tiene el compromiso social.

A nivel del ME estos 8 valores, aunque algo menos que en VP, también arrojan datos de muy importantes. Incluso hay uno, el 38. Inconformismo, rebeldía ante la injusticia social que se muestra como medianamente importante. Pero en conjunto podemos concluir que el alumnado de enfermería percibe el Compromiso social como importante para la Sanidad. 

Seguridad en la vida personal 

Cuadro $n^{0} 5.1$

1. Adaptación a los cambios, flexibilidad

\begin{tabular}{|l|r|r|r|r|}
\hline & Frecuencia & Porcentaje & $\begin{array}{c}\text { Porcentaje } \\
\text { válido }\end{array}$ & $\begin{array}{r}\text { Porcentaje } \\
\text { acumulado }\end{array}$ \\
\hline poco & 7 & 3,3 & 3,3 & 3,3 \\
medianamente & 29 & 13,9 & 13,9 & 17,2 \\
mucho & 173 & 82,8 & 82,8 & 100,0 \\
Total & 209 & 100,0 & 100,0 & \\
\hline
\end{tabular}

Elaboración propia. Mayo de 2015

Gráfico $n^{0} 5.1$

1. Adaptación a los cambios, flexibilidad

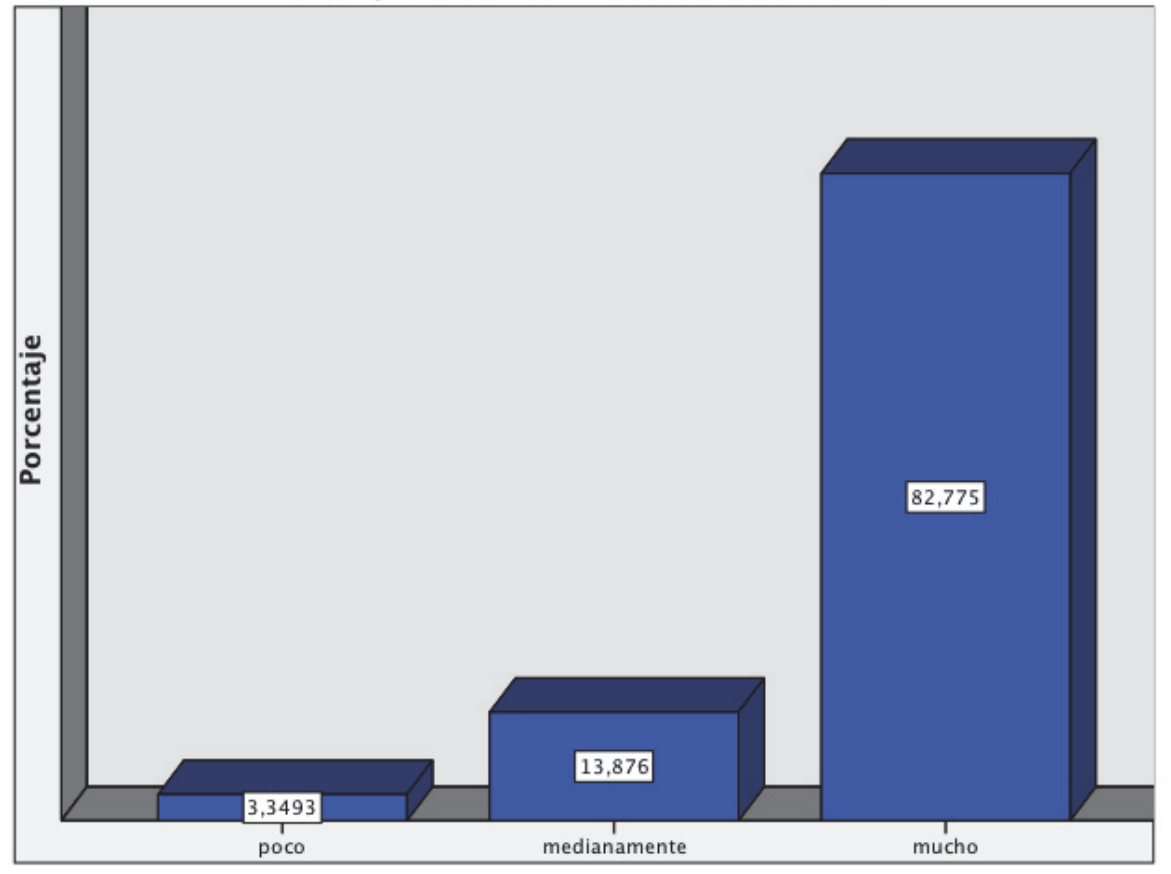

Elaboración propia. Mayo de 2015

Análisis: el valor "Adaptación a los cambios, flexibilidad” aparece con más del $82 \%$ para la categoría simplificada "mucho" revelándose como significativo en la VP. 
Cuadro $\mathrm{n}^{\circ} 5.2$

7. Aprendizaje continuo

\begin{tabular}{|l|r|r|r|r|}
\hline & Frecuencia & Porcentaje & $\begin{array}{c}\text { Porcentaje } \\
\text { válido }\end{array}$ & $\begin{array}{c}\text { Porcentaje } \\
\text { acumulado }\end{array}$ \\
\hline poco & 4 & 1,9 & 1,9 & 1,9 \\
medianamente & 28 & 13,4 & 13,4 & 15,3 \\
mucho & 177 & 84,7 & 84,7 & 100,0 \\
Total & 209 & 100,0 & 100,0 & \\
\hline
\end{tabular}

Elaboración propia. Mayo de 2015

\section{Gráfico $\mathrm{n}^{\mathrm{o}} 5.2$}

\section{Aprendizaje continuo}

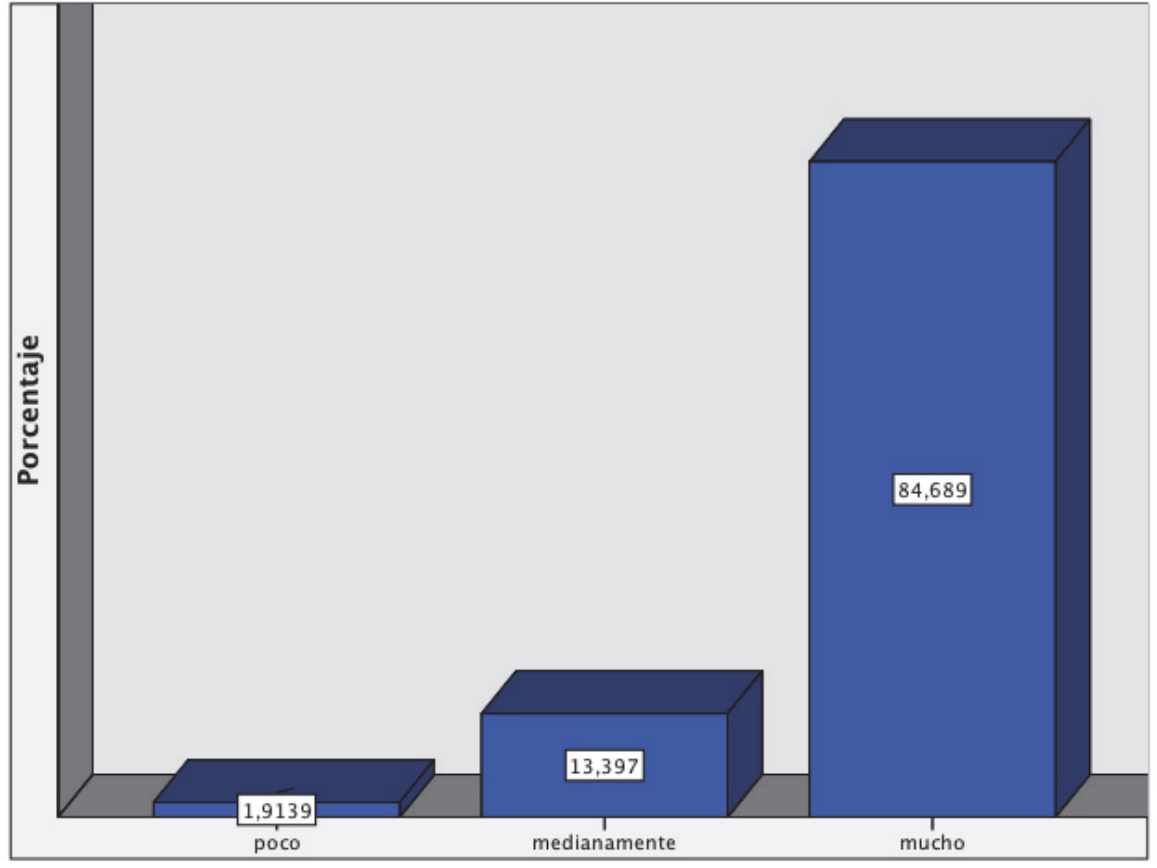

Elaboración propia. Mayo de 2015

Análisis: el valor “Aprendizaje continuo" con más del 84\% para la categoría simplificada "mucho" también evidencia que gobierna realmente mucho la VP. 
Cuadro $n^{\circ} 5.3$

48. Placer intelectual

\begin{tabular}{|l|r|r|r|r|}
\hline & Frecuencia & Porcentaje & $\begin{array}{c}\text { Porcentaje } \\
\text { válido }\end{array}$ & $\begin{array}{c}\text { Porcentaje } \\
\text { acumulado }\end{array}$ \\
\hline poco & 5 & 2,4 & 2,4 & 2,4 \\
medianamente & 36 & 17,2 & 17,2 & 19,6 \\
mucho & 168 & 80,4 & 80,4 & 100,0 \\
Total & 209 & 100,0 & 100,0 & \\
\hline
\end{tabular}

Elaboración propia. Mayo de 2015

Gráfico $\mathrm{n}^{\mathrm{o}} 5.3$

48. Placer intelectual

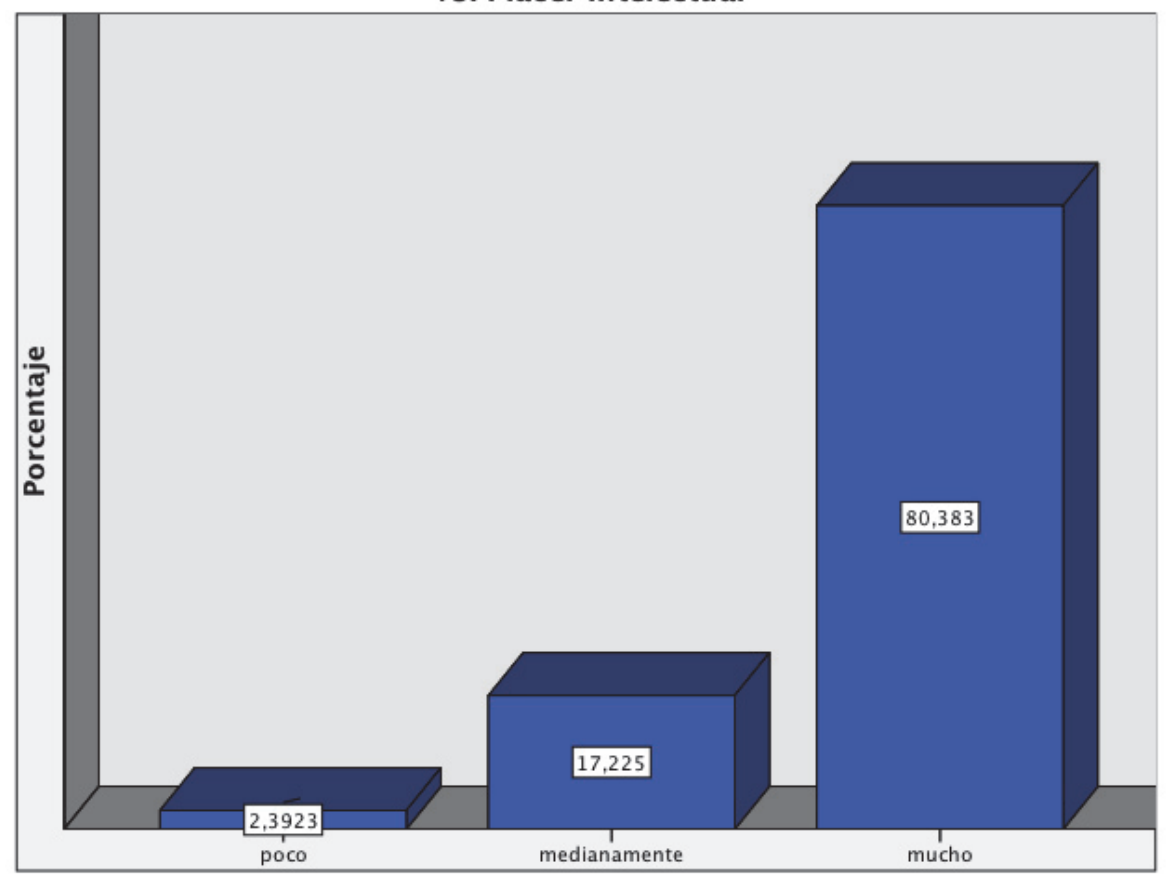

Elaboración propia. Mayo de 2015

Análisis: el valor "placer intelectual" íntimamente relacionado con el “Aprendizaje continuo" presenta también más del $80 \%$ para la categoría simplificada "mucho" por lo que vemos que gobierna realmente mucho la VP de la muestra en estudio. 
Cuadro $n^{\circ} 5.4$

58. Rigor técnico-profesional

\begin{tabular}{|l|r|r|r|r|}
\hline & Frecuencia & Porcentaje & $\begin{array}{c}\text { Porcentaje } \\
\text { válido }\end{array}$ & \multicolumn{1}{c|}{$\begin{array}{c}\text { Porcentaje } \\
\text { acumulado }\end{array}$} \\
\hline poco & 12 & 5,7 & 5,7 & 5,7 \\
medianamente & 45 & 21,5 & 21,5 & 27,3 \\
mucho & 152 & 72,7 & 72,7 & 100,0 \\
Total & 209 & 100,0 & 100,0 & \\
\hline
\end{tabular}

Elaboración propia. Mayo de 2015

Gráfico $n^{\circ} 5.4$

58. Rigor técnico-profesional

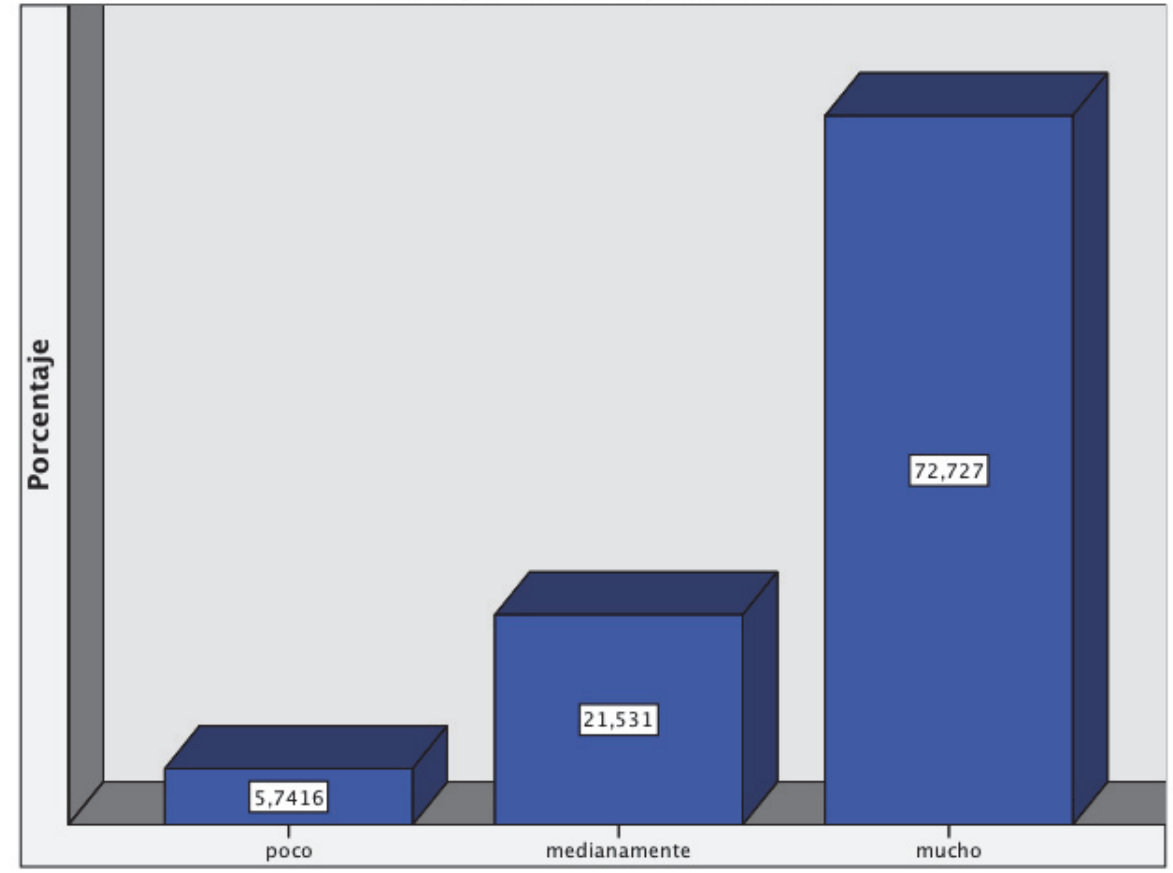

Elaboración propia. Mayo de 2015

Análisis: el "Rigor técnico-profesional", con más del $72 \%$ para la categoría simplificada "mucho" se presenta como otro valor que gobierna realmente mucho la VP. 
Cuadro $\mathrm{n}^{\circ} 5.5$

60. Seguridad

\begin{tabular}{|l|r|r|r|r|}
\hline & Frecuencia & Porcentaje & $\begin{array}{c}\text { Porcentaje } \\
\text { válido }\end{array}$ & $\begin{array}{c}\text { Porcentaje } \\
\text { acumulado }\end{array}$ \\
\hline poco & 6 & 2,9 & 2,9 & 2,9 \\
medianamente & 24 & 11,5 & 11,5 & 14,4 \\
mucho & 179 & 85,6 & 85,6 & 100,0 \\
Total & 209 & 100,0 & 100,0 & \\
\hline
\end{tabular}

Elaboración propia. Mayo de 2015

Gráfico $n^{\circ} 5.5$

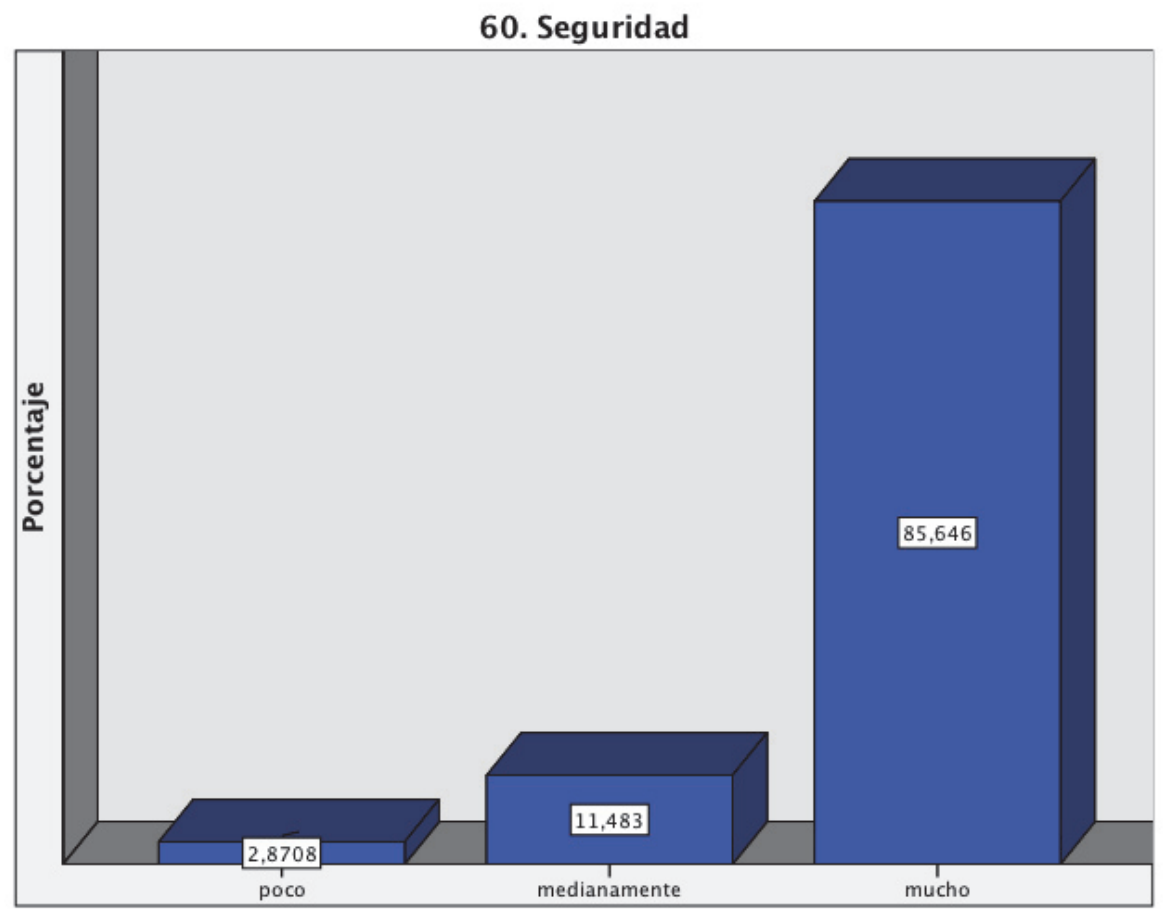

Elaboración propia. Mayo de 2015

Análisis: la "Seguridad" alcanza más del $85 \%$ para la categoría simplificada "mucho". También gobierna realmente mucho la VP. 
Cuadro $\mathrm{n}^{\circ} 5.6$

72. Verdad/sabiduría (búsqueda de la)

\begin{tabular}{|l|r|r|r|r|}
\hline & Frecuencia & Porcentaje & $\begin{array}{c}\text { Porcentaje } \\
\text { válido }\end{array}$ & $\begin{array}{c}\text { Porcentaje } \\
\text { acumulado }\end{array}$ \\
\hline poco & 2 & 1,0 & 1,0 & 1,0 \\
medianamente & 22 & 10,5 & 10,5 & 11,5 \\
mucho & 185 & 88,5 & 88,5 & 100,0 \\
Total & 209 & 100,0 & 100,0 & \\
\hline
\end{tabular}

Elaboración propia. Mayo de 2015

Gráfico n ${ }^{\circ} 5.6$

72. Verdad/sabiduría (búsqueda de la)

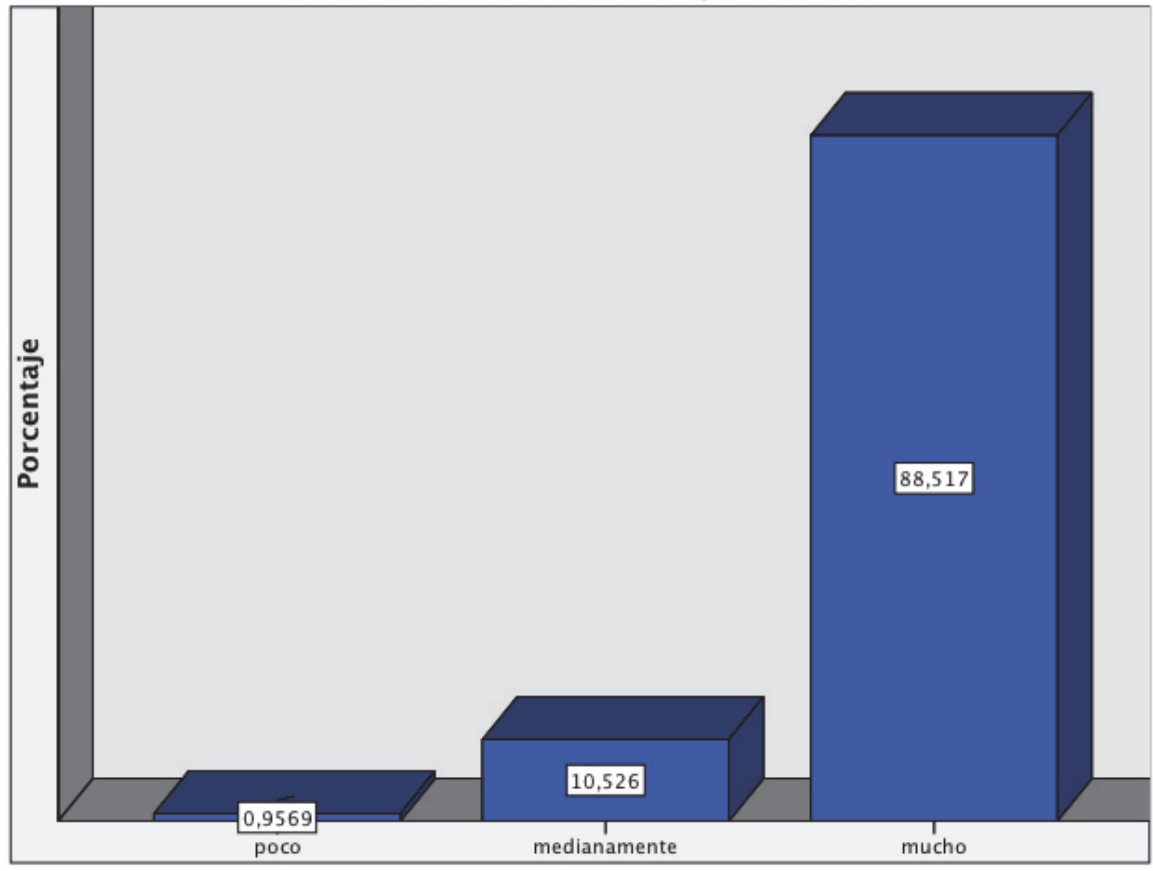

Elaboración propia. Mayo de 2015

Análisis: la "Verdad/sabiduría (búsqueda de la) supera el $86 \%$ para la categoría simplificada "mucho". Podemos afirmar que la muestra en estudio considera que gobierna realmente mucho su VP. 
Seguridad en el mundo de la empresa 

Cuadro $n^{\circ} 6.1$

1. Adaptación a los cambios, flexibilidad

\begin{tabular}{|l|r|r|r|r|}
\hline & Frecuencia & Porcentaje & $\begin{array}{c}\text { Porcentaje } \\
\text { válido }\end{array}$ & $\begin{array}{c}\text { Porcentaje } \\
\text { acumulado }\end{array}$ \\
\hline poco & 34 & 16,3 & 16,3 & 16,3 \\
medianamente & 50 & 23,9 & 23,9 & 40,2 \\
mucho & 125 & 59,8 & 59,8 & 100,0 \\
Total & 209 & 100,0 & 100,0 & \\
\hline
\end{tabular}

Elaboración propia. Mayo de 2015

Gráfico $n^{\circ} 6.1$

1. Adaptación a los cambios, flexibilidad

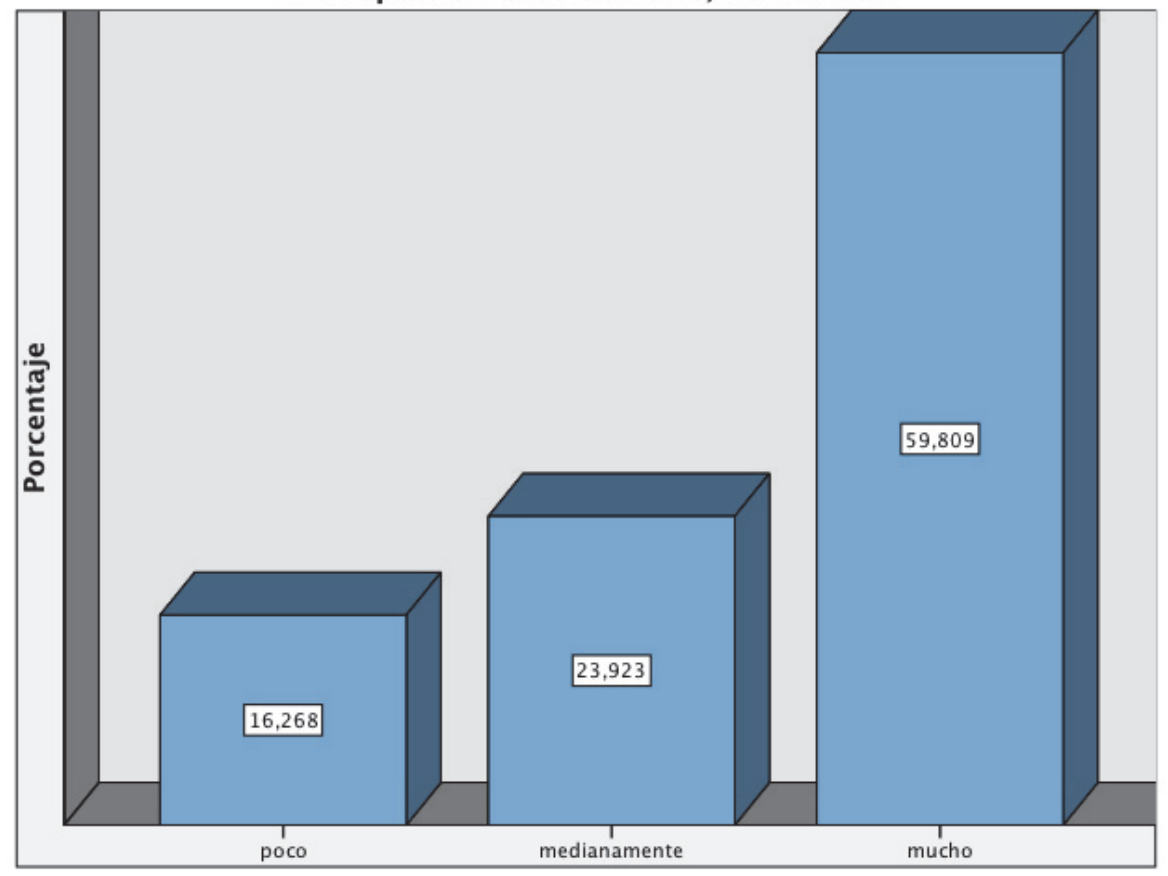

Elaboración propia. Mayo de 2015

Análisis: la "Adaptación a los cambios, flexibilidad" con más del 59\% para la categoría simplificada "mucho" se evidencia como que gobierna el ME, pero es considerado más importante por la muestra en estudio en la VP donde supera el $82 \%$. 
Cuadro $n^{\circ} 6.2$

7. Aprendizaje continuo

\begin{tabular}{|l|r|r|r|r|}
\hline & Frecuencia & Porcentaje & $\begin{array}{c}\text { Porcentaje } \\
\text { válido }\end{array}$ & $\begin{array}{r}\text { Porcentaje } \\
\text { acumulado }\end{array}$ \\
\hline poco & 16 & 7,7 & 7,7 & 7,7 \\
medianamente & 26 & 12,4 & 12,4 & 20,1 \\
mucho & 167 & 79,9 & 79,9 & 100,0 \\
Total & 209 & 100,0 & 100,0 & \\
\hline
\end{tabular}

Elaboración propia. Mayo de 2015

\section{Gráfico $n^{\circ} 6.2$}

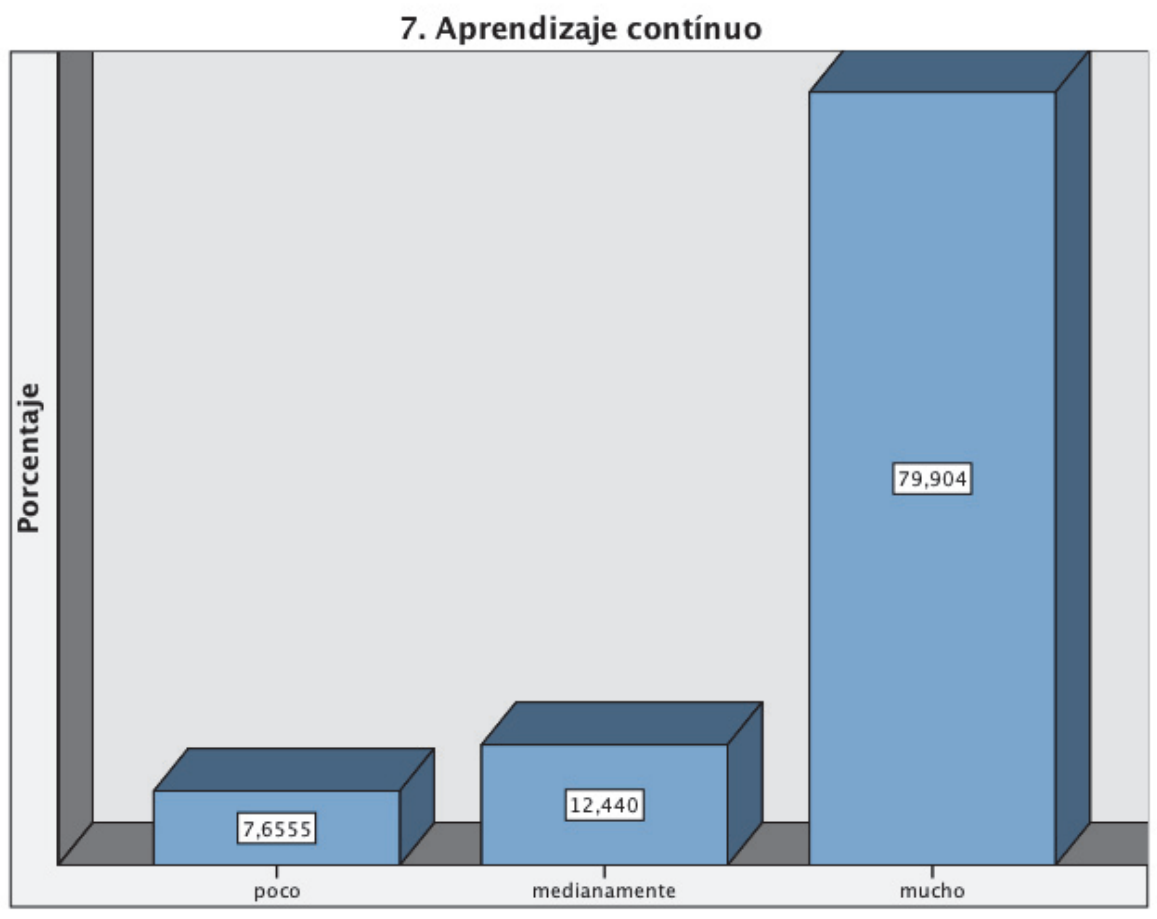

Elaboración propia. Mayo de 2015

Análisis: el "Aprendizaje continuo" con casi el 80\% para la categoría simplificada "mucho" se evidencia importante en el ME, y sigue el comportamiento de ser más importante en la VP en la que alcanza más del 84\%. 
Cuadro $n^{\circ} 6.3$

48. Placer intelectual

\begin{tabular}{|l|r|r|r|r|}
\hline & Frecuencia & Porcentaje & $\begin{array}{c}\text { Porcentaje } \\
\text { válido }\end{array}$ & $\begin{array}{r}\text { Porcentaje } \\
\text { acumulado }\end{array}$ \\
\hline poco & 29 & 13,9 & 13,9 & 13,9 \\
medianamente & 61 & 29,2 & 29,2 & 43,1 \\
mucho & 119 & 56,9 & 56,9 & 100,0 \\
Total & 209 & 100,0 & 100,0 & \\
\hline
\end{tabular}

Elaboración propia. Mayo de 2015

Gráfico $\mathrm{n}^{\mathrm{0}} 6.3$

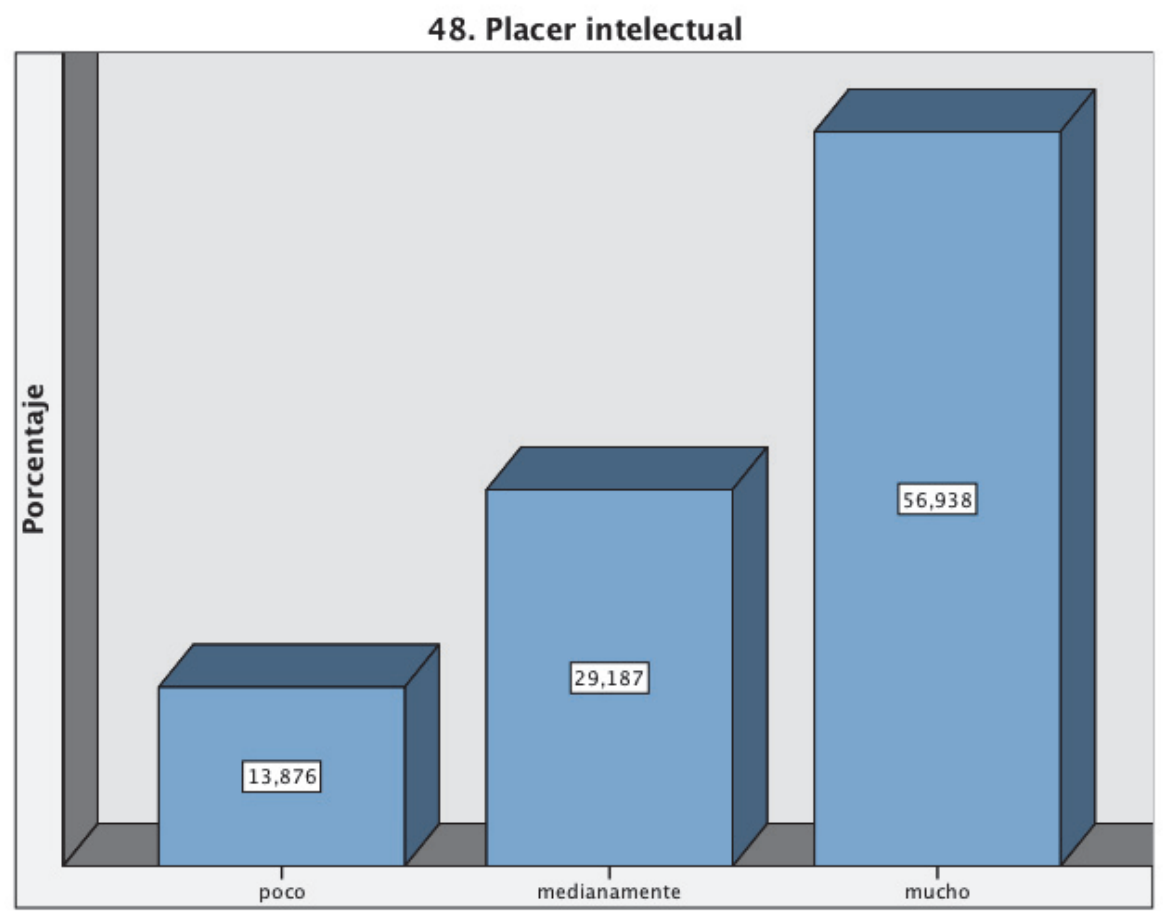

Elaboración propia. Mayo de 2015

Análisis: el valor "Placer intelectual" también gana en el ME con casi el $57 \%$ quedándose por debajo del $80 \%$ de la VP. 
Cuadro $n^{0} 6.4$

58. Rigor técnico-profesional

\begin{tabular}{|l|r|r|r|r|}
\hline & Frecuencia & Porcentaje & $\begin{array}{c}\text { Porcentaje } \\
\text { válido }\end{array}$ & \multicolumn{1}{c|}{$\begin{array}{c}\text { Porcentaje } \\
\text { acumulado }\end{array}$} \\
\hline poco & 10 & 4,8 & 4,8 & 4,8 \\
medianamente & 48 & 23,0 & 23,0 & 27,8 \\
mucho & 151 & 72,2 & 72,2 & 100,0 \\
Total & 209 & 100,0 & 100,0 & \\
\hline
\end{tabular}

Elaboración propia. Mayo de 2015

Gráfico $\mathrm{n}^{\mathrm{0}} 6.4$

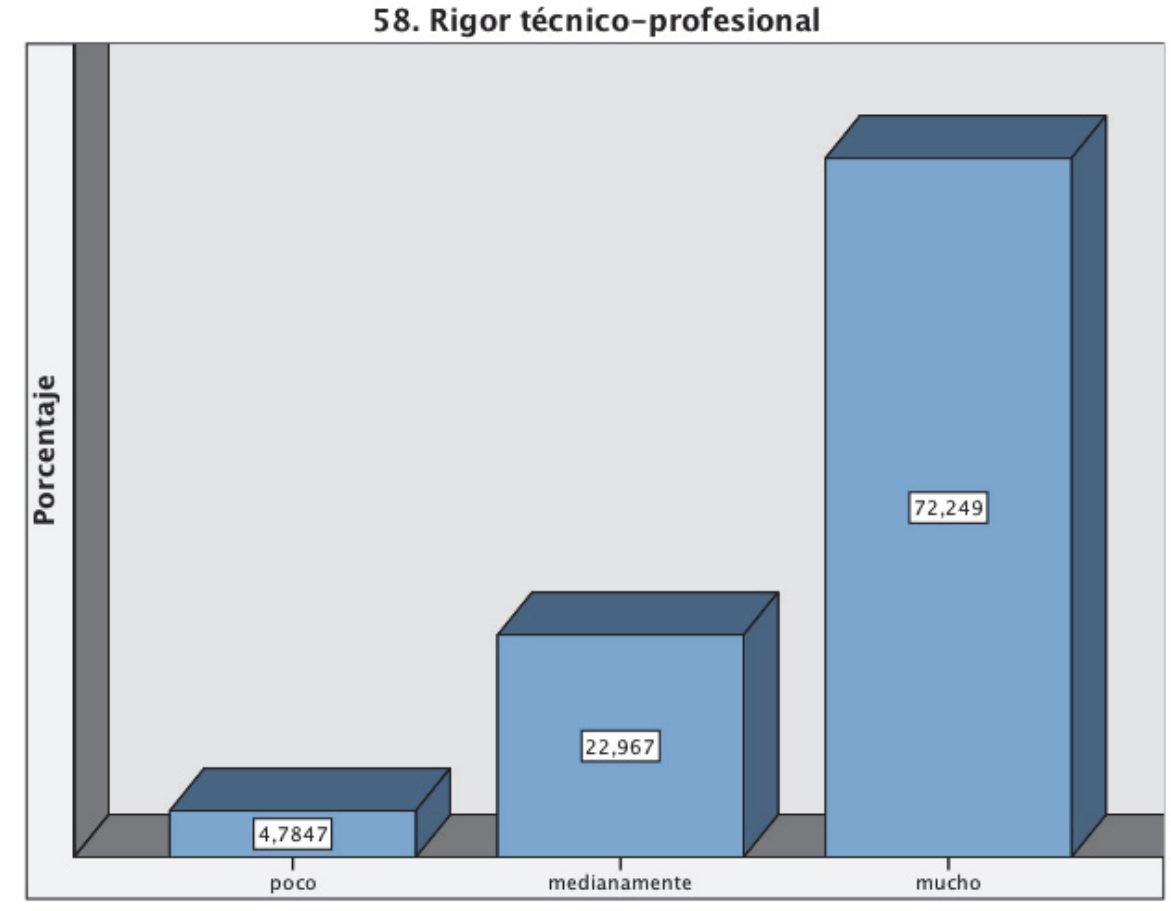

Elaboración propia. Mayo de 2015

Análisis: el valor "Rigor técnico-profesional" presenta prácticamente el mismo porcentaje en ambas esferas, el 72,727\% en la VP y el 72,249\% en el ME. Las categorías simplificadas "poco" y "medianamente" de este valor también recogen porcentajes equivalentes para ambas esferas. Es un valor con idéntico comportamiento en los dos ámbitos estudiados. 
Cuadro $n^{\circ} 6.5$

60. Seguridad

\begin{tabular}{|l|r|r|r|r|}
\hline & Frecuencia & Porcentaje & \multicolumn{1}{|c|}{$\begin{array}{c}\text { Porcentaje } \\
\text { válido }\end{array}$} & $\begin{array}{c}\text { Porcentaje } \\
\text { acumulado }\end{array}$ \\
\hline poco & 15 & 7,2 & 7,2 & 7,2 \\
medianamente & 39 & 18,7 & 18,7 & 25,8 \\
mucho & 155 & 74,2 & 74,2 & 100,0 \\
Total & 209 & 100,0 & 100,0 & \\
\hline
\end{tabular}

Elaboración propia. Mayo de 2015

Gráfico $\mathrm{n}^{0} 6.5$

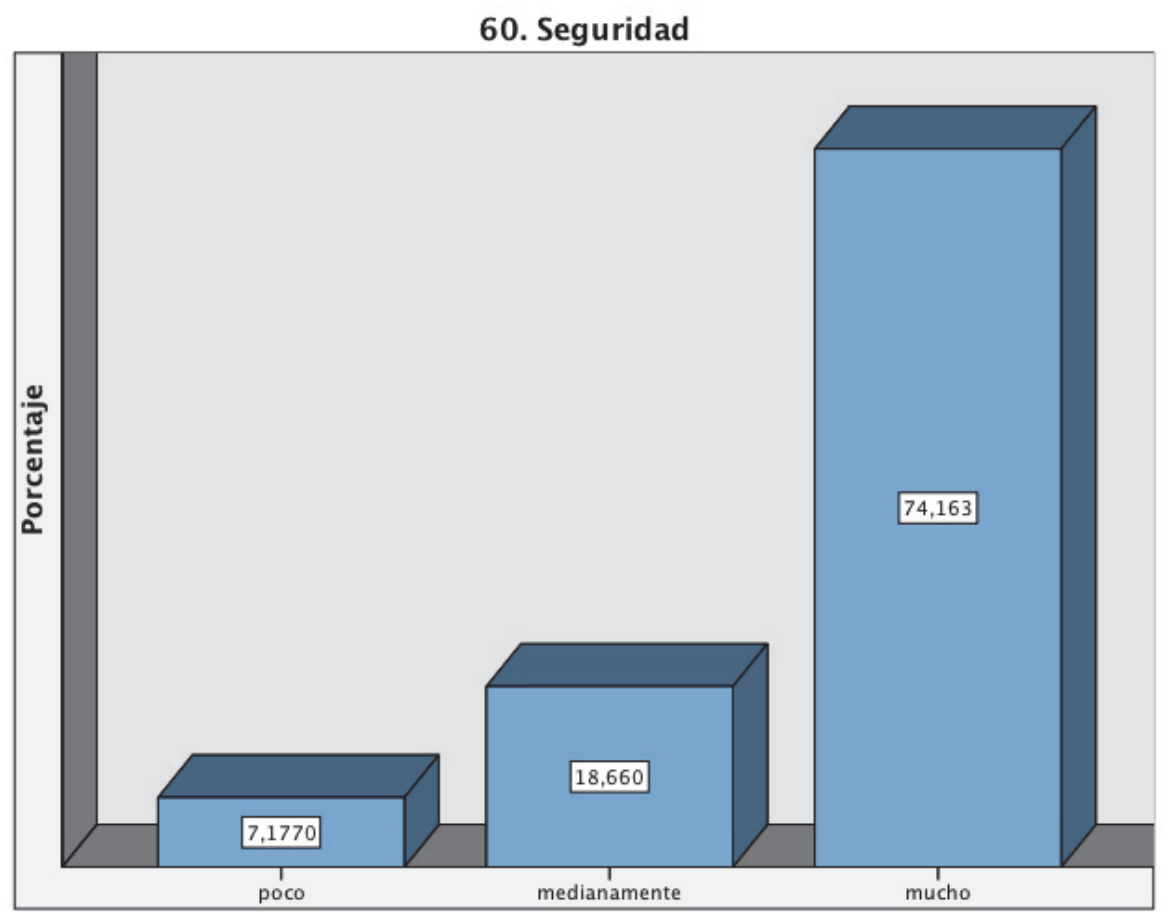

Elaboración propia. Mayo de 2015

Análisis: el valor "Seguridad" también se comporta de forma muy parecida en ambas esferas, pero llega un poquito más alto en la VP en la que alcanza más del $85 \%$ frente al poco más del 74\% del ME. 
Cuadro $n^{\circ} 6.6$

72. Verdad/sabiduría (búsqueda de la)

\begin{tabular}{|l|r|r|r|r|}
\hline & Frecuencia & Porcentaje & $\begin{array}{c}\text { Porcentaje } \\
\text { válido }\end{array}$ & $\begin{array}{c}\text { Porcentaje } \\
\text { acumulado }\end{array}$ \\
\hline poco & 25 & 12,0 & 12,0 & 12,0 \\
medianamente & 40 & 19,1 & 19,1 & 31,1 \\
mucho & 144 & 68,9 & 68,9 & 100,0 \\
Total & 209 & 100,0 & 100,0 & \\
\hline
\end{tabular}

Elaboración propia. Mayo de 2015

Gráfico n ${ }^{\circ} 6.6$

72. Verdad/sabiduría (bú squeda de la)

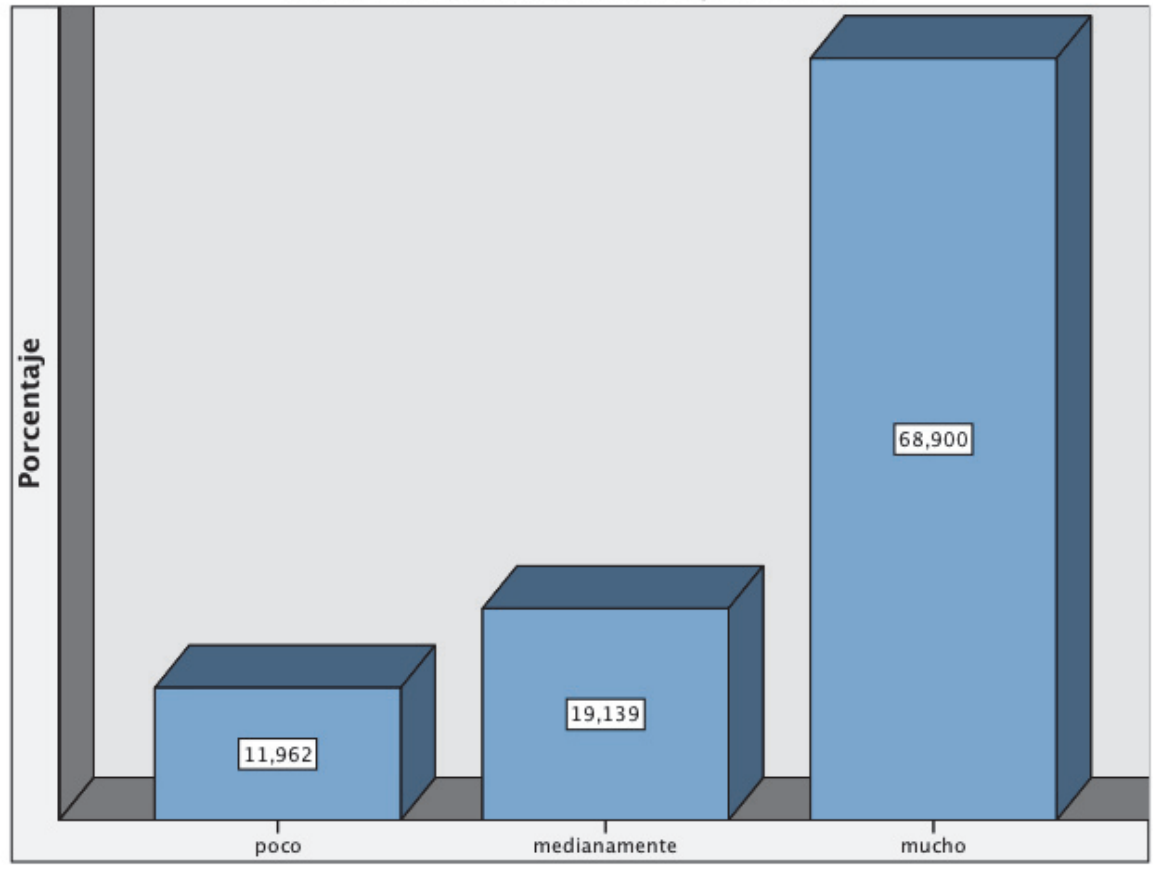

Elaboración propia. Mayo de 2015

Análisis: con la "Verdad/sabiduría" pasa lo mismo que con los valores anteriores, con casi el 69\% para la categoría simplificada "mucho" se revela como importante en el ME, sin embargo en la VP alcanza más del $88 \%$, por lo que vemos que la muestra en estudio considera que incide más en esta esfera de la VP que en el ME 


\section{ANÁLISIS CUALITATIVO DEL GRUPO SEGURIDAD:}

En mi VP estos 6 valores se manifiestan como muy importantes evidenciando que las enseñanzas recibidas por el alumnado han sido asimiladas e interiorizadas y viene a ocurrir como en los valores del Compromiso social. También se manifiestan como muy importantes aunque menos en el ME que en la VP. Ahora bien, en este caso ninguno arroja datos de medianamente importante, todos siguen el comportamiento de muy importantes. Podemos concluir que la docencia ha resultado efectiva. 

Armonía en la vida personal 

Cuadro $n^{\circ} 7.1$

3. Alegría, sentido del humor

\begin{tabular}{|l|r|r|r|r|}
\hline & Frecuencia & Porcentaje & $\begin{array}{c}\text { Porcentaje } \\
\text { válido }\end{array}$ & $\begin{array}{c}\text { Porcentaje } \\
\text { acumulado }\end{array}$ \\
\hline poco & 1 &, 5 &, 5 &, 5 \\
medianamente & 15 & 7,2 & 7,2 & 7,7 \\
mucho & 193 & 92,3 & 92,3 & 100,0 \\
Total & 209 & 100,0 & 100,0 & \\
\hline
\end{tabular}

Elaboración propia. Mayo de 2015

\section{Gráfico n $\mathrm{n}^{\mathrm{7}} 7.1$}

\section{Alegría, sentido del humor}

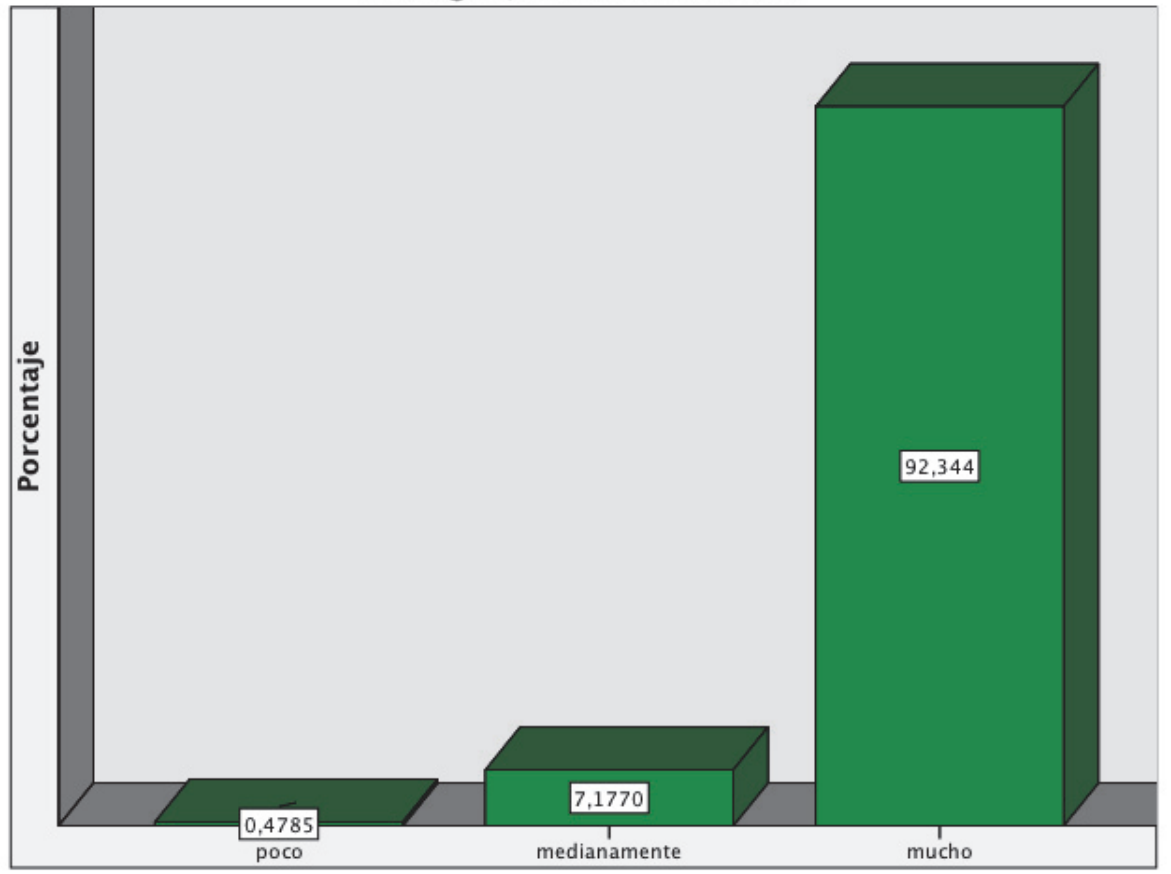

Elaboración propia. Mayo de 2015

Análisis: el valor "Alegría, sentido del humor" muestra, a través del gráfico simplificado, con evidencia que gobierna realmente la VP de la muestra en estudio pues más del 92\% corresponde a la categoría simplificada "mucho". 
Cuadro $\mathrm{n}^{\mathrm{0}} 7.2$

27. Equilibrio entre trabajo y vida familiar y personal

\begin{tabular}{|l|r|r|r|r|}
\hline & Frecuencia & Porcentaje & $\begin{array}{c}\text { Porcentaje } \\
\text { válido }\end{array}$ & \multicolumn{1}{c|}{$\begin{array}{c}\text { Porcentaje } \\
\text { acumulado }\end{array}$} \\
\hline poco & 3 & 1,4 & 1,4 & 1,4 \\
medianamente & 28 & 13,4 & 13,4 & 14,8 \\
mucho & 178 & 85,2 & 85,2 & 100,0 \\
Total & 209 & 100,0 & 100,0 & \\
\hline
\end{tabular}

Elaboración propia. Mayo de 2015

\section{Gráfico $\mathrm{n}^{\mathrm{0}} 7.2$}

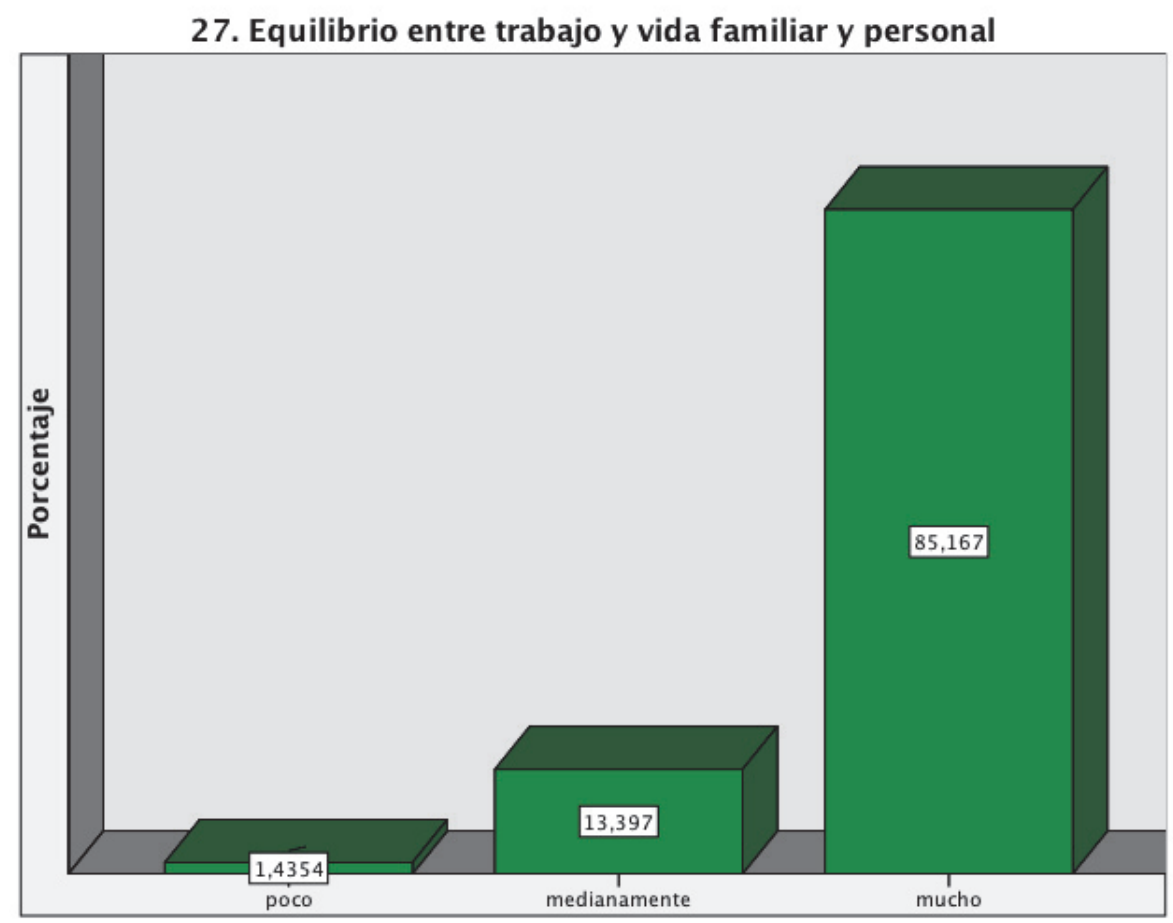

Elaboración propia. Mayo de 2015

Análisis: el "Equilibrio entre el trabajo y vida familiar y personal", al igual que el anterior se revela como un valor que gobierna realmente mucho la VP de la muestra en estudio. 


\section{Cuadro $n^{\circ} 7.3$}

37. Imaginación, creatividad, fantasía

\begin{tabular}{|l|r|r|r|r|}
\hline & Frecuencia & Porcentaje & $\begin{array}{c}\text { Porcentaje } \\
\text { válido }\end{array}$ & \multicolumn{1}{c|}{$\begin{array}{c}\text { Porcentaje } \\
\text { acumulado }\end{array}$} \\
\hline poco & 15 & 7,2 & 7,2 & 7,2 \\
medianamente & 52 & 24,9 & 24,9 & 32,1 \\
mucho & 142 & 67,9 & 67,9 & 100,0 \\
Total & 209 & 100,0 & 100,0 & \\
\hline
\end{tabular}

Elaboración propia. Mayo de 2015

Gráfico $\mathrm{n}^{\mathrm{o}} 7.3$

37. Imaginación, creatividad, fantasía

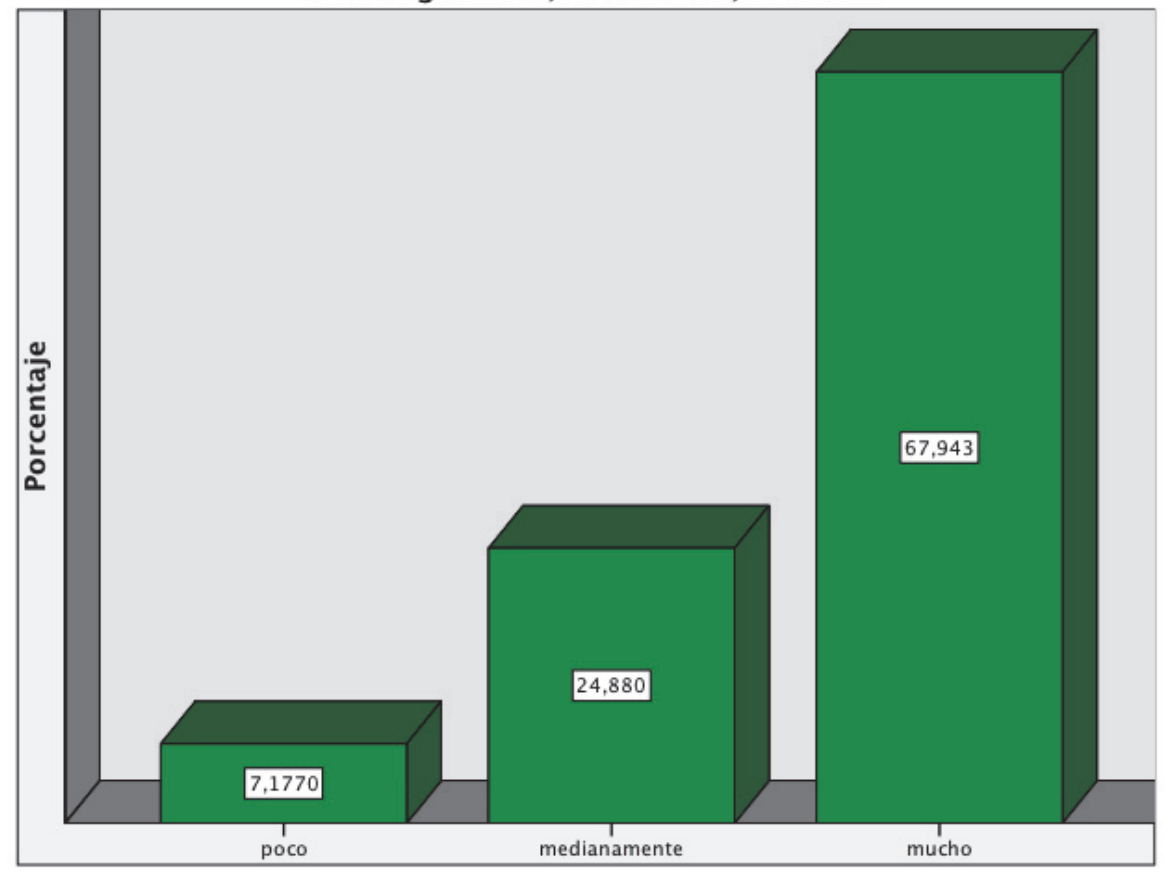

Elaboración propia. Mayo de 2015

Análisis: la "Imaginación, creatividad, fantasía" también se revela como un valor que realmente gobierna la VP aunque menos que los dos anteriores, pues solo llega casi al $68 \%$. 
Cuadro $\mathrm{n}^{\mathrm{o}} 7.4$

54. Respeto y armonía con los demás

\begin{tabular}{|l|r|r|r|r|}
\hline & Frecuencia & Porcentaje & $\begin{array}{c}\text { Porcentaje } \\
\text { válido }\end{array}$ & $\begin{array}{c}\text { Porcentaje } \\
\text { acumulado }\end{array}$ \\
\hline poco & 6 & 2,9 & 2,9 & 2,9 \\
medianamente & 13 & 6,2 & 6,2 & 9,1 \\
mucho & 190 & 90,9 & 90,9 & 100,0 \\
Total & 209 & 100,0 & 100,0 & \\
\hline
\end{tabular}

Elaboración propia. Mayo de 2015

Gráfico n ${ }^{\circ} 7.4$

54. Respeto y armonía con los demás

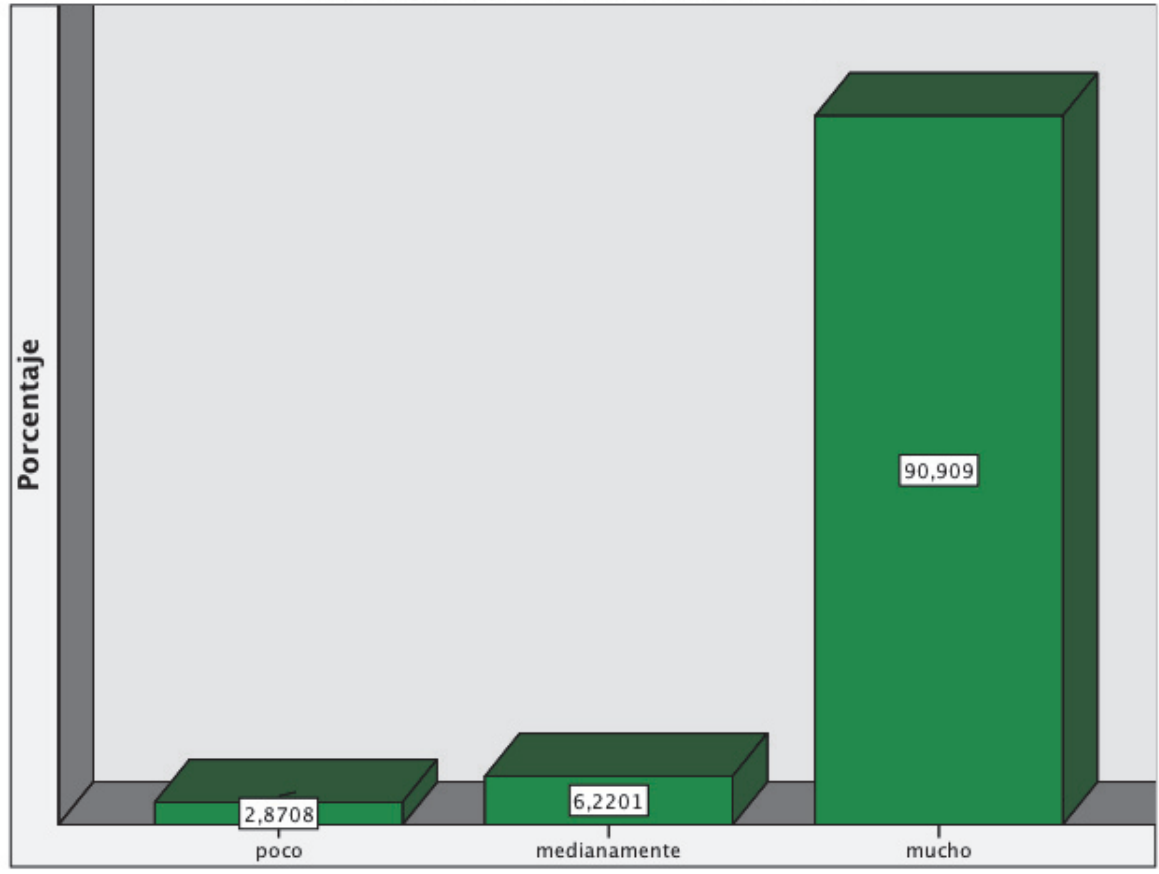

Elaboración propia. Mayo de 2015

Análisis: el "Respeto y armonía con los demás", con casi el 91\% para la categoría simplificada "mucho" se evidencia también como un valor que realmente gobierna la VP de la muestra en estudio. 
Cuadro $\mathrm{n}^{\mathrm{o}} 7.5$

55. Respeto y armonía con uno mismo

\begin{tabular}{|l|r|r|r|r|}
\hline & Frecuencia & Porcentaje & $\begin{array}{c}\text { Porcentaje } \\
\text { válido }\end{array}$ & $\begin{array}{c}\text { Porcentaje } \\
\text { acumulado }\end{array}$ \\
\hline poco & 3 & 1,4 & 1,4 & 1,4 \\
medianamente & 18 & 8,6 & 8,6 & 10,0 \\
mucho & 188 & 90,0 & 90,0 & 100,0 \\
Total & 209 & 100,0 & 100,0 & \\
\hline
\end{tabular}

Elaboración propia. Mayo de 2015

Gráfico $\mathrm{n}^{\mathrm{0}} 7.5$

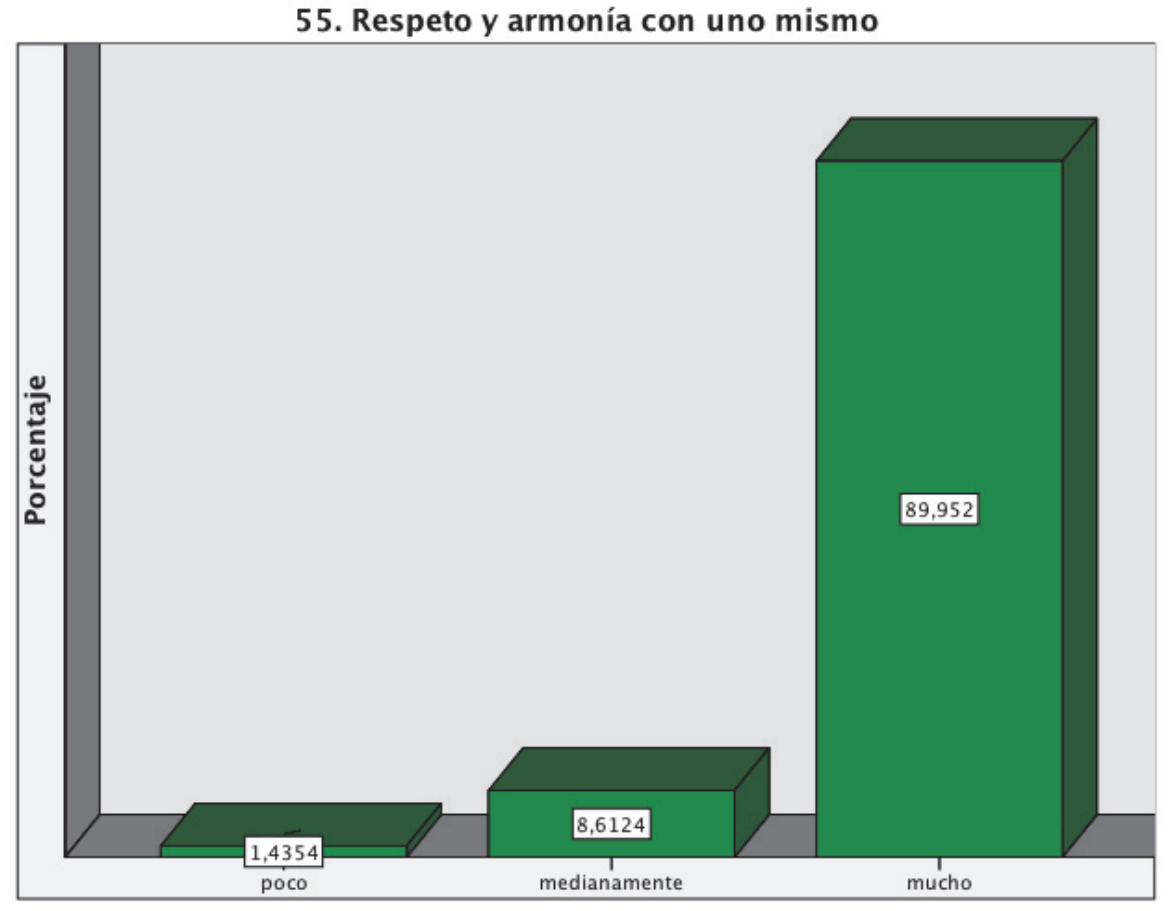

Elaboración propia. Mayo de 2015

Análisis: el "Respeto y armonía con uno mismo" con casi el 90\% sigue la misma línea. Llama la atención que la muestra en estudio, alumnado de enfermería llegue a mayor porcentaje para la categoría simplificada "mucho" en el caso del respeto a los demás que a uno mismo. 
Cuadro $n^{\circ} 7.6$

56. Respeto y armonía medioambiental

\begin{tabular}{|l|r|r|r|r|}
\hline & Frecuencia & Porcentaje & $\begin{array}{c}\text { Porcentaje } \\
\text { válido }\end{array}$ & \multicolumn{1}{c|}{$\begin{array}{c}\text { Porcentaje } \\
\text { acumulado }\end{array}$} \\
\hline poco & 5 & 2,4 & 2,4 & 2,4 \\
medianamente & 50 & 23,9 & 23,9 & 26,3 \\
mucho & 154 & 73,7 & 73,7 & 100,0 \\
Total & 209 & 100,0 & 100,0 & \\
\hline
\end{tabular}

Elaboración propia. Mayo de 2015

Gráfico n ${ }^{\circ} 7.6$

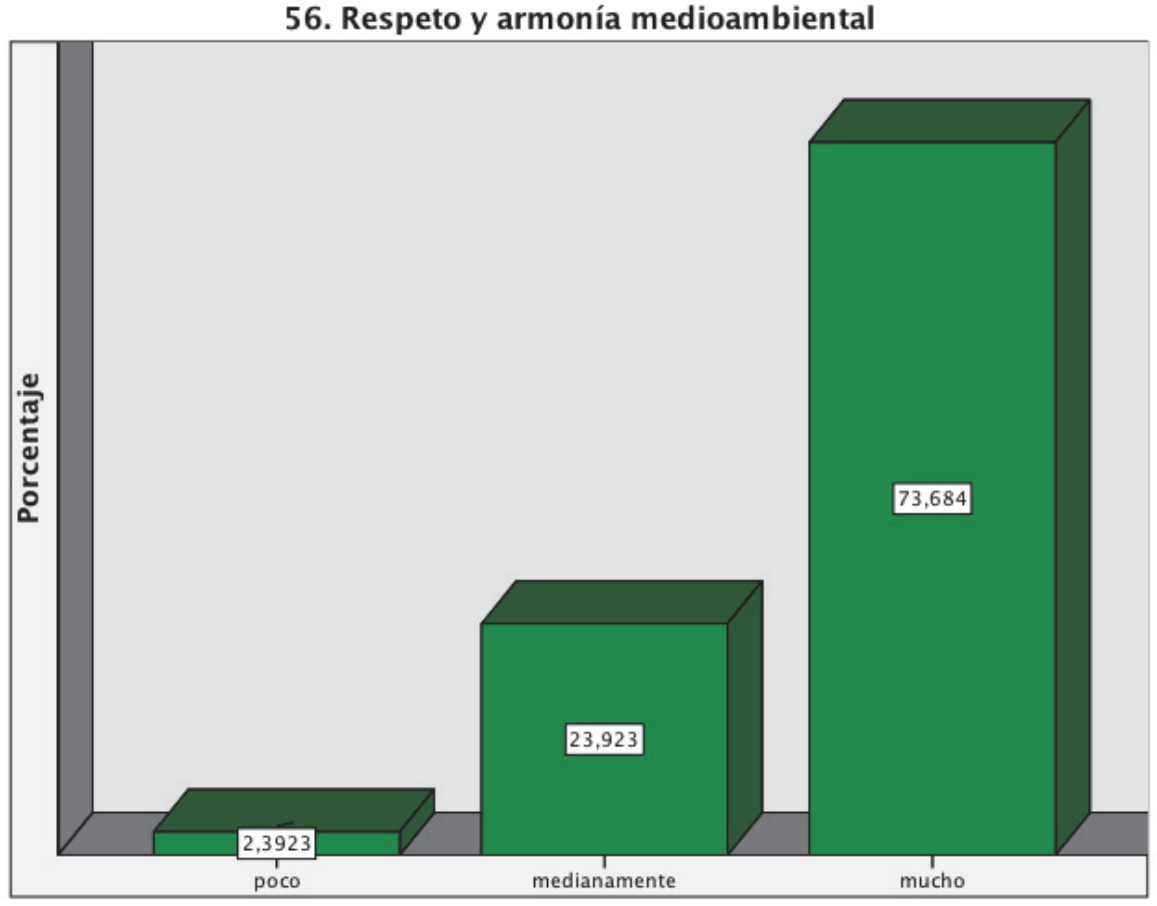

Elaboración propia. Mayo de 2015

Análisis: con más de un $73 \%$ para la categoría simplificada "mucho", el "Respeto y armonía con el medio ambiente" se revela como un valor gobernante de la VP, pero es llamativo que el más valorado sea el respeto por los demás, seguido del respeto por uno mismo y en menor cuantía el respeto por el medio ambiente. 
Cuadro $\mathrm{n}^{\mathrm{0}} 7.7$

59. Salud/bienestar

\begin{tabular}{|l|r|r|r|r|}
\hline & Frecuencia & Porcentaje & $\begin{array}{c}\text { Porcentaje } \\
\text { válido }\end{array}$ & $\begin{array}{c}\text { Porcentaje } \\
\text { acumulado }\end{array}$ \\
\hline poco & 6 & 2,9 & 2,9 & 2,9 \\
medianamente & 12 & 5,7 & 5,7 & 8,6 \\
mucho & 191 & 91,4 & 91,4 & 100,0 \\
Total & 209 & 100,0 & 100,0 & \\
\hline
\end{tabular}

Elaboración propia. Mayo de 2015

Gráfico $\mathrm{n}^{\mathrm{0}} 7.7$

59. Salud/bienestar

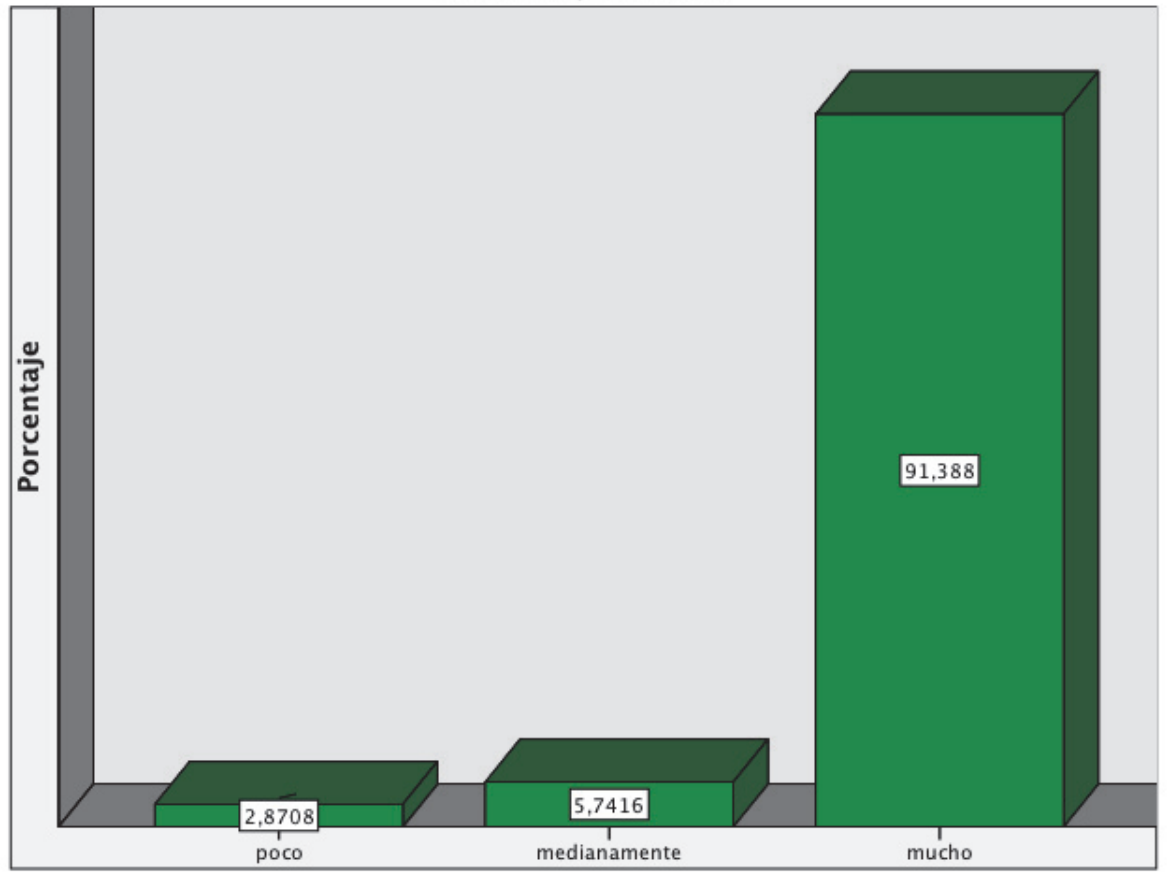

Elaboración propia. Mayo de 2015

Análisis: la "Salud/bienestar" es también un valor que gobierna realmente la VP de la muestra en estudio con más del 91\% para la categoría simplificada "mucho" 



\section{Armonía en el mundo de la empresa}



Cuadro $n^{\circ} 8.1$

3. Alegría, sentido del humor

\begin{tabular}{|l|r|r|r|r|}
\hline & Frecuencia & Porcentaje & $\begin{array}{c}\text { Porcentaje } \\
\text { válido }\end{array}$ & $\begin{array}{c}\text { Porcentaje } \\
\text { acumulado }\end{array}$ \\
\hline poco & 54 & 25,8 & 25,8 & 25,8 \\
medianamente & 52 & 24,9 & 24,9 & 50,7 \\
mucho & 103 & 49,3 & 49,3 & 100,0 \\
Total & 209 & 100,0 & 100,0 & \\
\hline
\end{tabular}

Elaboración propia. Mayo de 2015

Gráfico $n^{\circ} 8.1$

3. Alegría, sentido del humor

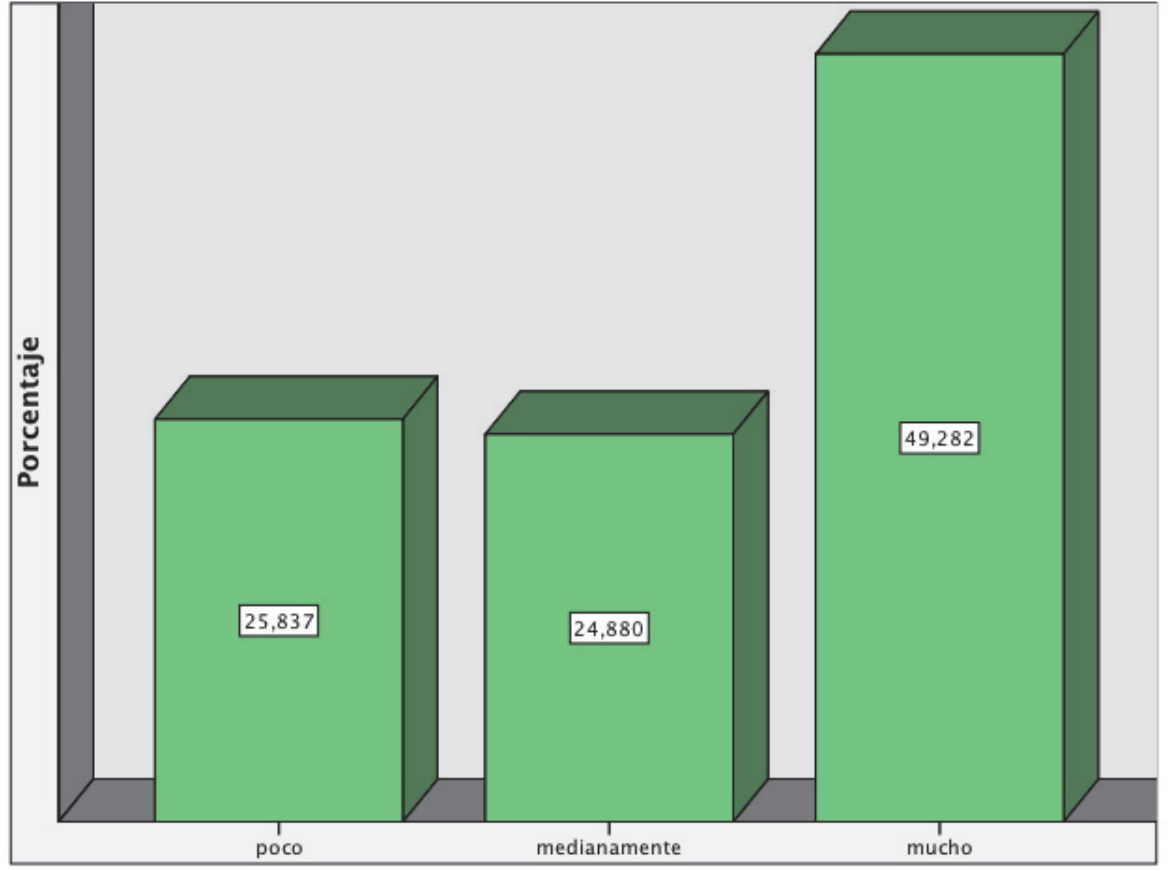

Elaboración propia. Mayo de 2015

Análisis: la muestra en estudio percibe que la "Alegría, sentido del humor" gobierna el ME, pero mucho menos que la VP en la que alcanza más del 92\% para la categoría simplificada "mucho" frente al poco más del $49 \%$ en el ME. 
Cuadro $n^{\circ} 8.2$

27. Equilibrio entre el trabajo y vida familiar y personal

\begin{tabular}{|l|r|r|r|r|}
\hline & Frecuencia & Porcentaje & $\begin{array}{l}\text { Porcentaje } \\
\text { válido }\end{array}$ & $\begin{array}{c}\text { Porcentaje } \\
\text { acumulado }\end{array}$ \\
\hline poco & 31 & 14,8 & 14,8 & 14,8 \\
medianamente & 65 & 31,1 & 31,1 & 45,9 \\
mucho & 113 & 54,1 & 54,1 & 100,0 \\
Total & 209 & 100,0 & 100,0 & \\
\hline
\end{tabular}

Elaboración propia. Mayo de 2015

\section{Gráfico $\mathrm{n}^{\circ} 8.2$}

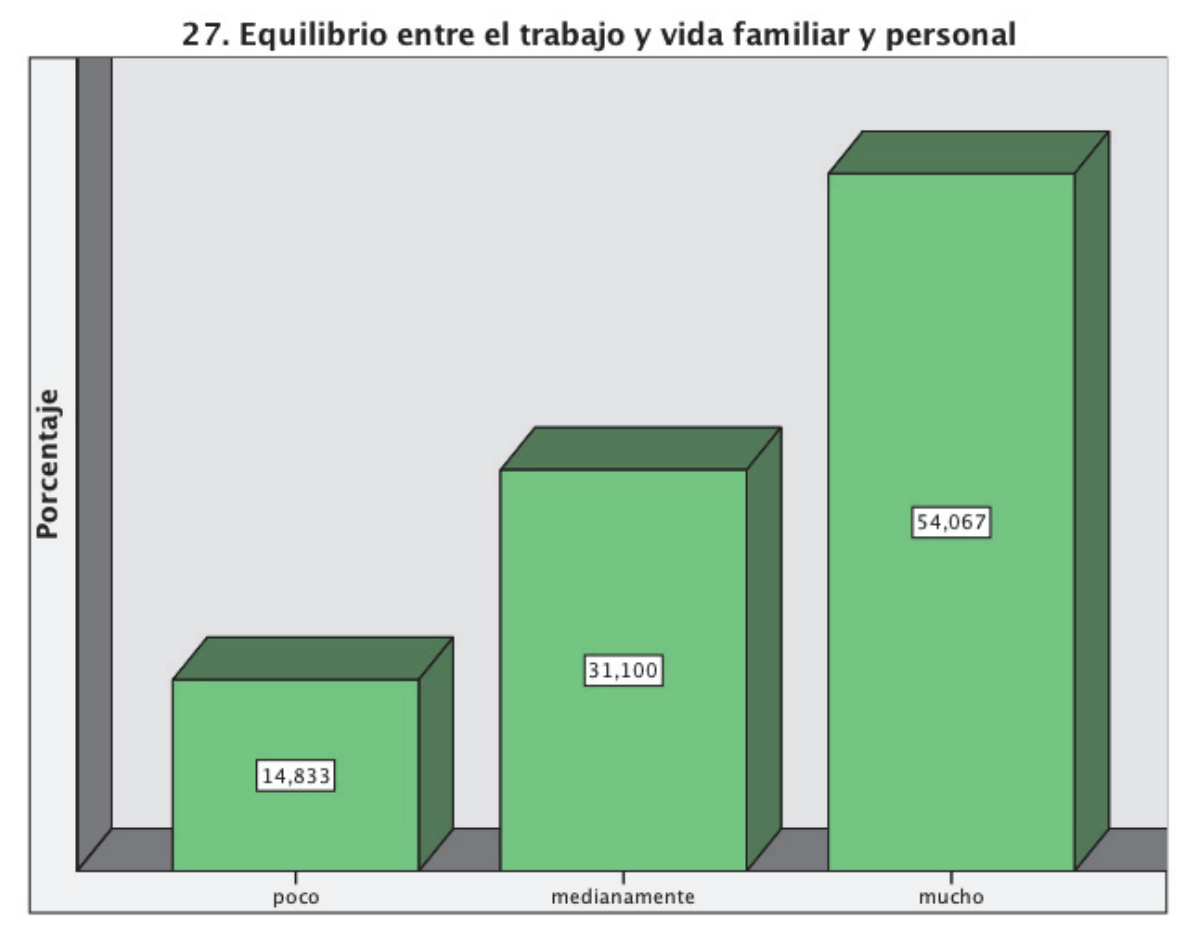

Elaboración propia. Mayo de 2015

Análisis: encontramos de nuevo que la percepción de la muestra encuestada en cuanto al valor "equilibrio entre el trabajo y vida familiar y personal" es que gobierna el ME pero mucho menos que la VP en la que alcanza más del $85 \%$ frente al 54\% que vemos en el ME. 
Cuadro $n^{\circ} 8.3$

37. Imaginación, creatividad, fantasía

\begin{tabular}{|l|r|r|r|r|}
\hline & Frecuencia & Porcentaje & $\begin{array}{c}\text { Porcentaje } \\
\text { válido }\end{array}$ & $\begin{array}{c}\text { Porcentaje } \\
\text { acumulado }\end{array}$ \\
\hline poco & 47 & 22,5 & 22,5 & 22,5 \\
medianamente & 65 & 31,1 & 31,1 & 53,6 \\
mucho & 97 & 46,4 & 46,4 & 100,0 \\
Total & 209 & 100,0 & 100,0 & \\
\hline
\end{tabular}

Elaboración propia. Mayo de 2015

\section{Gráfico $n^{\circ} 8.3$}

37. Imaginación, creatividad, fantasia

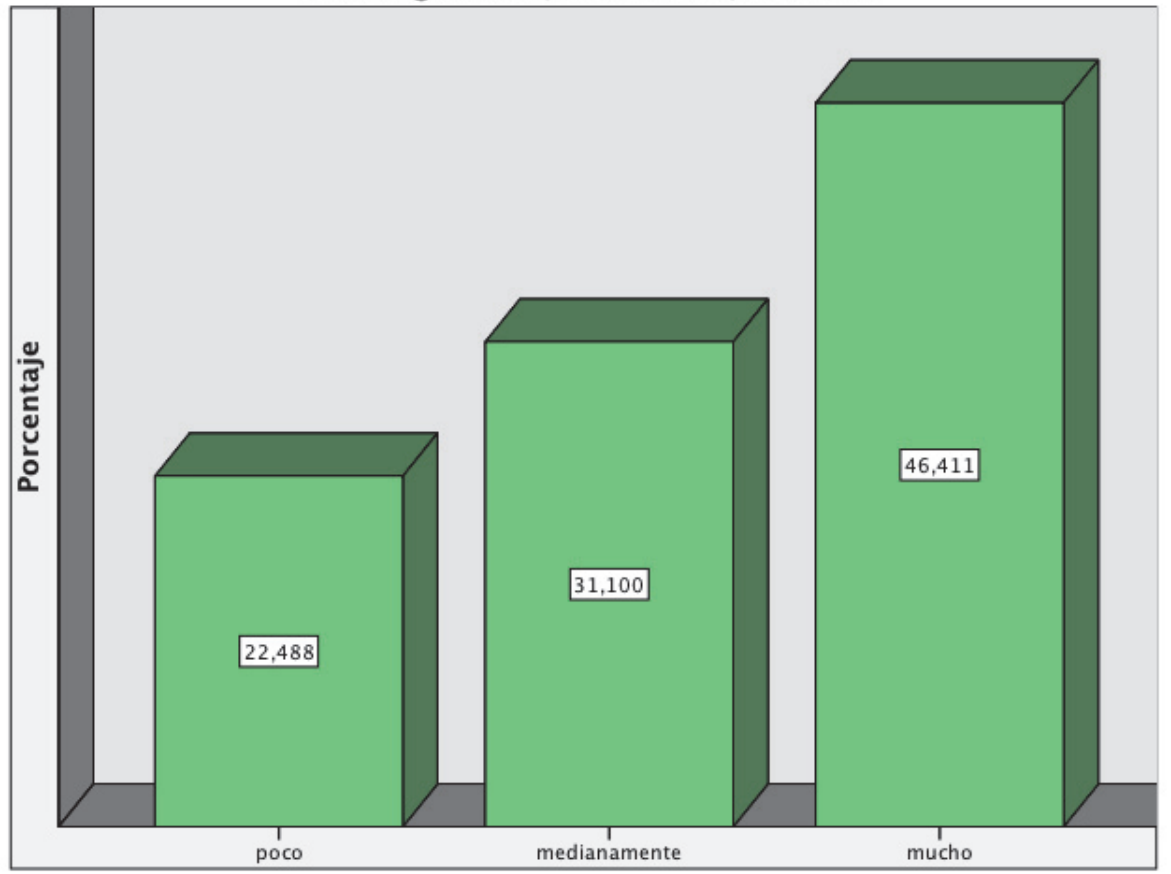

Elaboración propia. Mayo de 2015

Análisis: el valor "Imaginación, creatividad, fantasía" es considerado en algo más del $46 \%$ que gobierna mucho el ME y significativamente menos que en el área de la VP en la que alcanza casi el 68\%. 
Cuadro $n^{\circ} 8.4$

54. Respeto y armonía con los demás

\begin{tabular}{|l|r|r|r|r|}
\hline & Frecuencia & Porcentaje & $\begin{array}{c}\text { Porcentaje } \\
\text { válido }\end{array}$ & $\begin{array}{c}\text { Porcentaje } \\
\text { acumulado }\end{array}$ \\
\hline poco & 21 & 10,0 & 10,0 & 10,0 \\
medianamente & 58 & 27,8 & 27,8 & 37,8 \\
mucho & 130 & 62,2 & 62,2 & 100,0 \\
Total & 209 & 100,0 & 100,0 & \\
\hline
\end{tabular}

Elaboración propia. Mayo de 2015

Gráfico $n^{\circ} 8.4$

54. Respeto y armonía con los demás

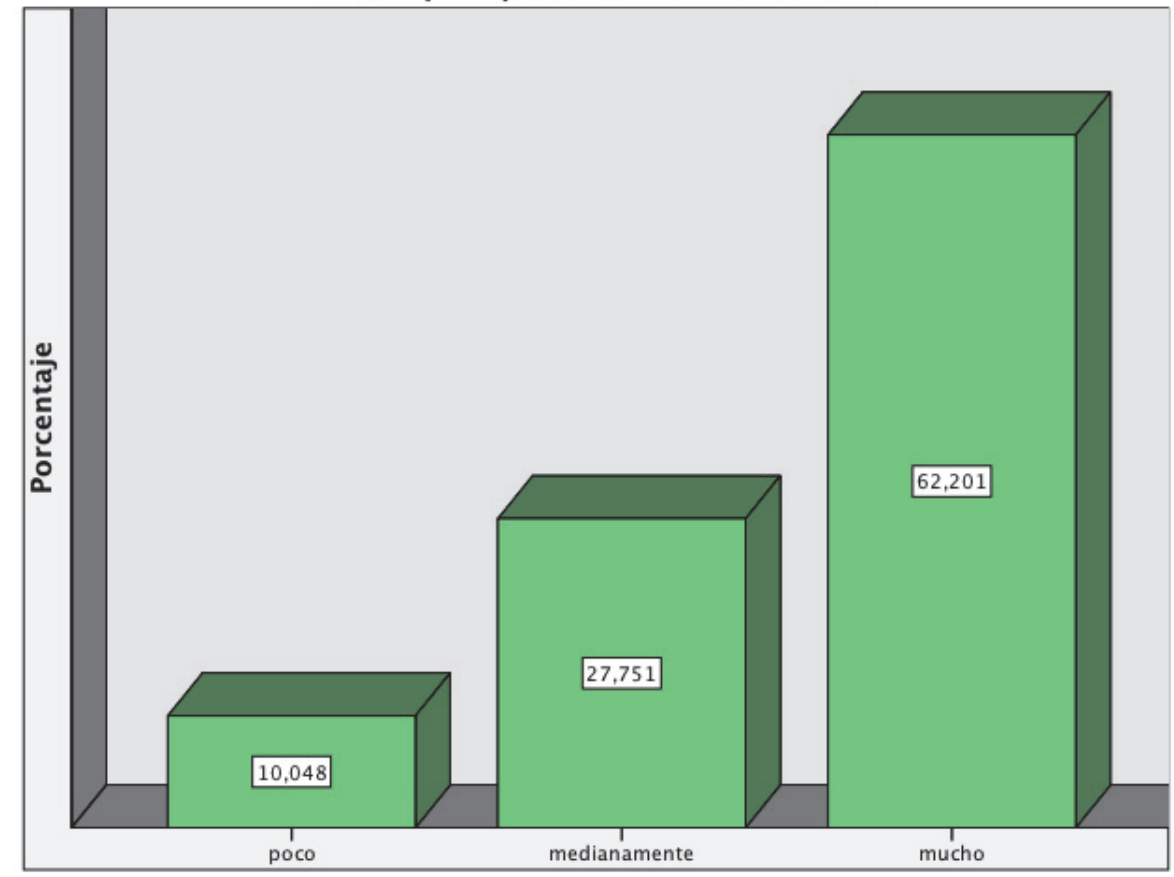

Elaboración propia. Mayo de 2015

Análisis: el "Respeto, armonía con los demás" se revela en el ME como un valor que gobierna mucho el ME pero menos que en el caso de la VP en la que alcanza casi el $91 \%$. 
Cuadro $n^{\circ} 8.5$

55. Respeto y armonía con uno mismo

\begin{tabular}{|l|r|r|r|r|}
\hline & Frecuencia & Porcentaje & $\begin{array}{c}\text { Porcentaje } \\
\text { válido }\end{array}$ & $\begin{array}{c}\text { Porcentaje } \\
\text { acumulado }\end{array}$ \\
\hline poco & 29 & 13,9 & 13,9 & 13,9 \\
medianamente & 53 & 25,4 & 25,4 & 39,2 \\
mucho & 127 & 60,8 & 60,8 & 100,0 \\
Total & 209 & 100,0 & 100,0 & \\
\hline
\end{tabular}

Elaboración propia. Mayo de 2015

\section{Gráfico n ${ }^{\circ} 8.5$}

55. Respeto y armonía con uno mismo

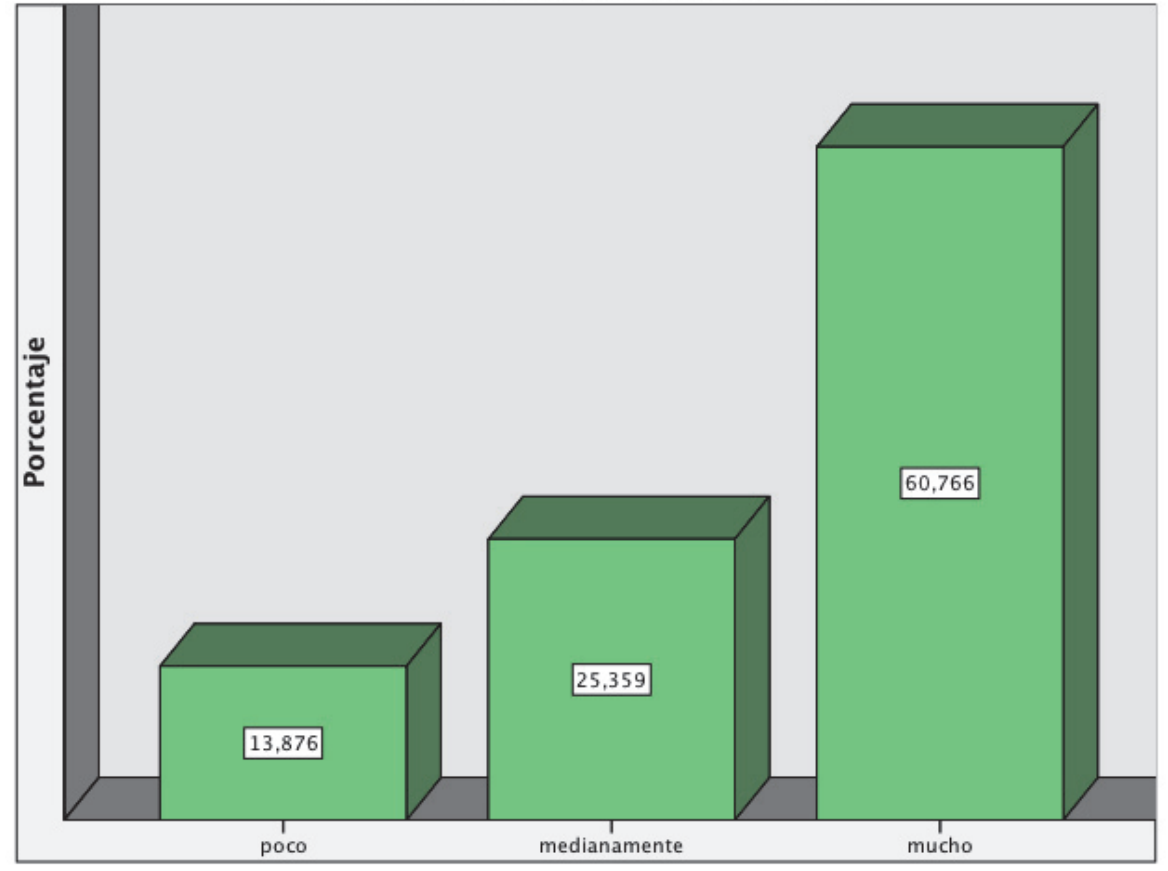

Elaboración propia. Mayo de 2015

Análisis: el "Respeto y armonía con uno mismo" también se revela como un valor que gobierna mucho el ME con casi el 61\% pero notablemente menos que en la VP en la que alcanza casi el 90\% y vuelve a darse el mismo fenómeno de que alcanza más porcentaje el respeto a los demás que a uno mismo. 
Cuadro $n^{\circ} 8.6$

56. Respeto y armonía medioambiental

\begin{tabular}{|l|r|r|r|r|}
\hline & Frecuencia & Porcentaje & $\begin{array}{c}\text { Porcentaje } \\
\text { válido }\end{array}$ & \multicolumn{1}{c|}{$\begin{array}{c}\text { Porcentaje } \\
\text { acumulado }\end{array}$} \\
\hline poco & 41 & 19,6 & 19,6 & 19,6 \\
medianamente & 62 & 29,7 & 29,7 & 49,3 \\
mucho & 106 & 50,7 & 50,7 & 100,0 \\
Total & 209 & 100,0 & 100,0 & \\
\hline
\end{tabular}

Elaboración propia. Mayo de 2015

Gráfico $\mathrm{n}^{\mathrm{o}} 8.6$

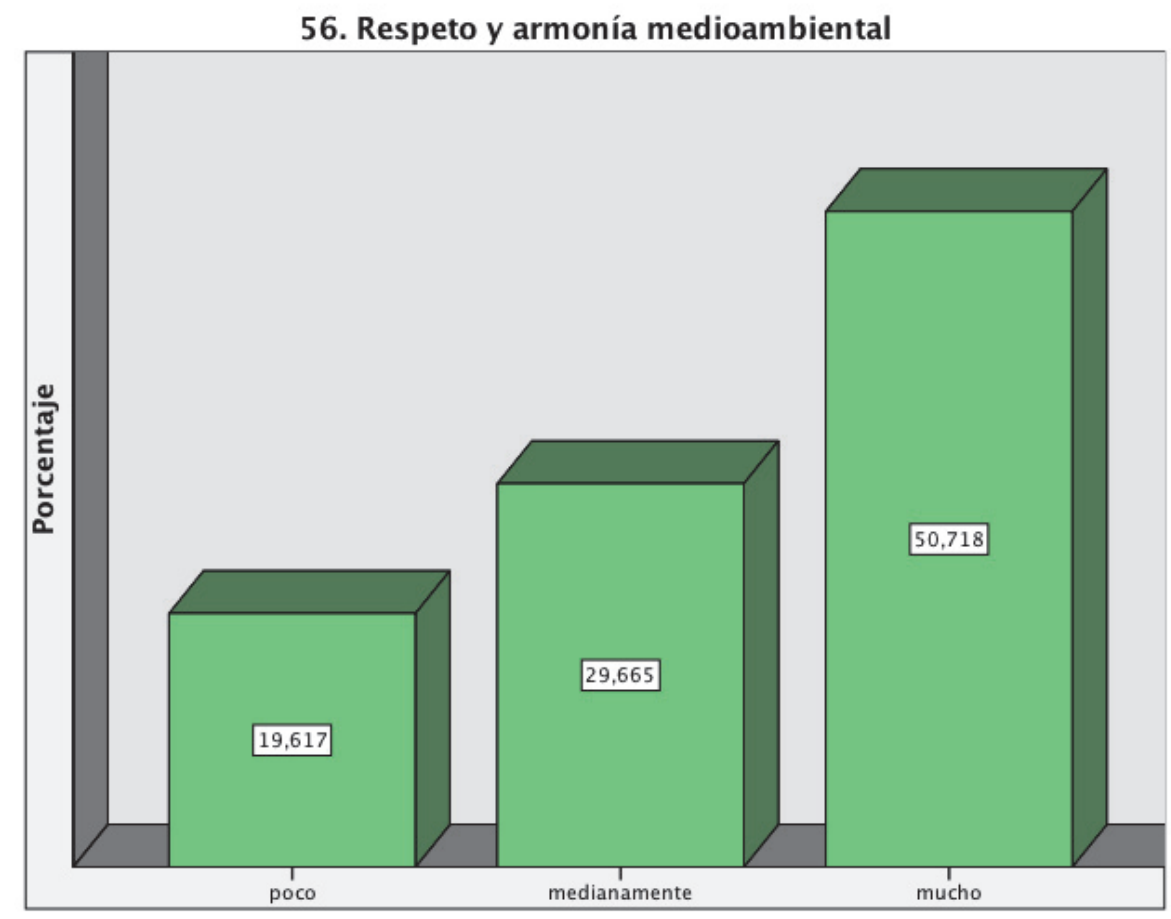

Elaboración propia. Mayo de 2015

Análisis: el "Respeto y armonía medioambiental" continua con el mismo comportamiento visto hasta ahora, obtiene mayor porcentaje que las otras dos categorías simplificadas, revelando que gobierna el ME pero menos que la VP y menos el respeto medioambiental que el respeto por uno mismo y por los demás. 
Cuadro $n^{\circ} 8.7$

59. Salud/bienestar

\begin{tabular}{|l|r|r|r|r|}
\hline & Frecuencia & Porcentaje & \multicolumn{1}{c|}{$\begin{array}{c}\text { Porcentaje } \\
\text { válido }\end{array}$} & $\begin{array}{c}\text { Porcentaje } \\
\text { acumulado }\end{array}$ \\
\hline poco & 23 & 11,0 & 11,0 & 11,0 \\
medianamente & 38 & 18,2 & 18,2 & 29,2 \\
mucho & 148 & 70,8 & 70,8 & 100,0 \\
Total & 209 & 100,0 & 100,0 & \\
\hline
\end{tabular}

Elaboración propia. Mayo de 2015

Gráfico $\mathrm{n}^{\mathrm{0}} 8.7$

\section{Salud/bienestar}

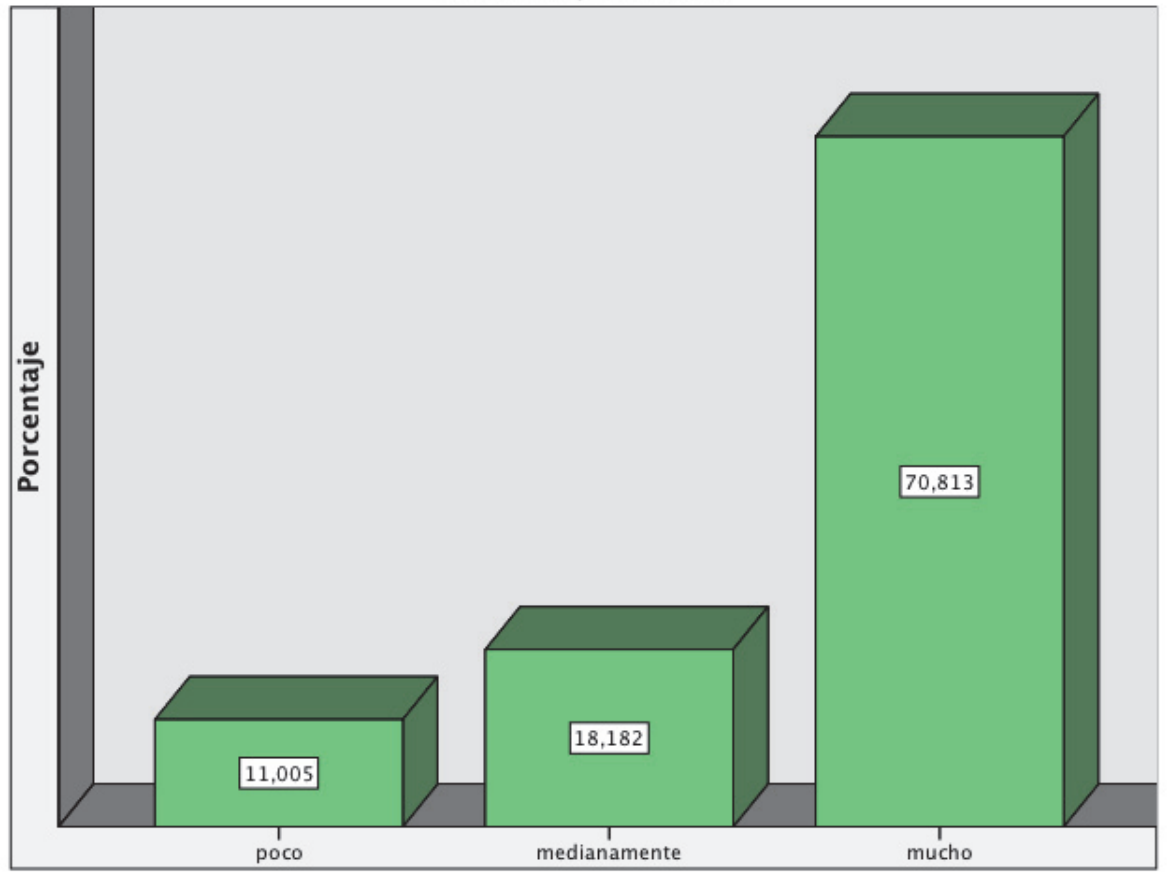

Elaboración propia. Mayo de 2015

Análisis: la "Salud/bienestar" con casi el $71 \%$ para la categoría simplificada "mucho" demuestra que gobierna el ME, y sigue el comportamiento observado para los anteriores valores, pues en la esfera de la VP alcanza más del $91 \%$. 
Análisis cualitativo del grupo Armonía:

Estos valores:

3. Alegría, sentido del humor

27. Equilibrio entre trabajo y vida familiar y personal

37. Imaginación, creatividad, fantasía

54. Respeto y armonía con los demás

55. Respeto y armonía con uno mismo

56. Respeto y armonía medioambiental

59. Salud/bienestar

indicadores de armonía, se manifiestan todos como muy importantes tanto en la VP como en el ME, y siguiendo la pauta de los grupos anteriores el alumnado los percibe con más fuerza en la VP que en el ME, presentando una gran diferencia entre la puntuación mucho y las otras dos. Este valor, la armonía, también podemos decir que está conseguido ampliamente. 
Confianza en la vida personal 

Cuadro $n^{\circ} 9.1$

9. Calidez, cercanía

\begin{tabular}{|l|r|r|r|r|}
\hline & Frecuencia & Porcentaje & $\begin{array}{c}\text { Porcentaje } \\
\text { válido }\end{array}$ & $\begin{array}{c}\text { Porcentaje } \\
\text { acumulado }\end{array}$ \\
\hline poco & 3 & 1,4 & 1,4 & 1,4 \\
medianamente & 19 & 9,1 & 9,1 & 10,5 \\
mucho & 187 & 89,5 & 89,5 & 100,0 \\
Total & 209 & 100,0 & 100,0 & \\
\hline
\end{tabular}

Elaboración propia. Mayo de 2015

Gráfico $n^{\circ} 9.1$

\section{Calidez, cercanía}

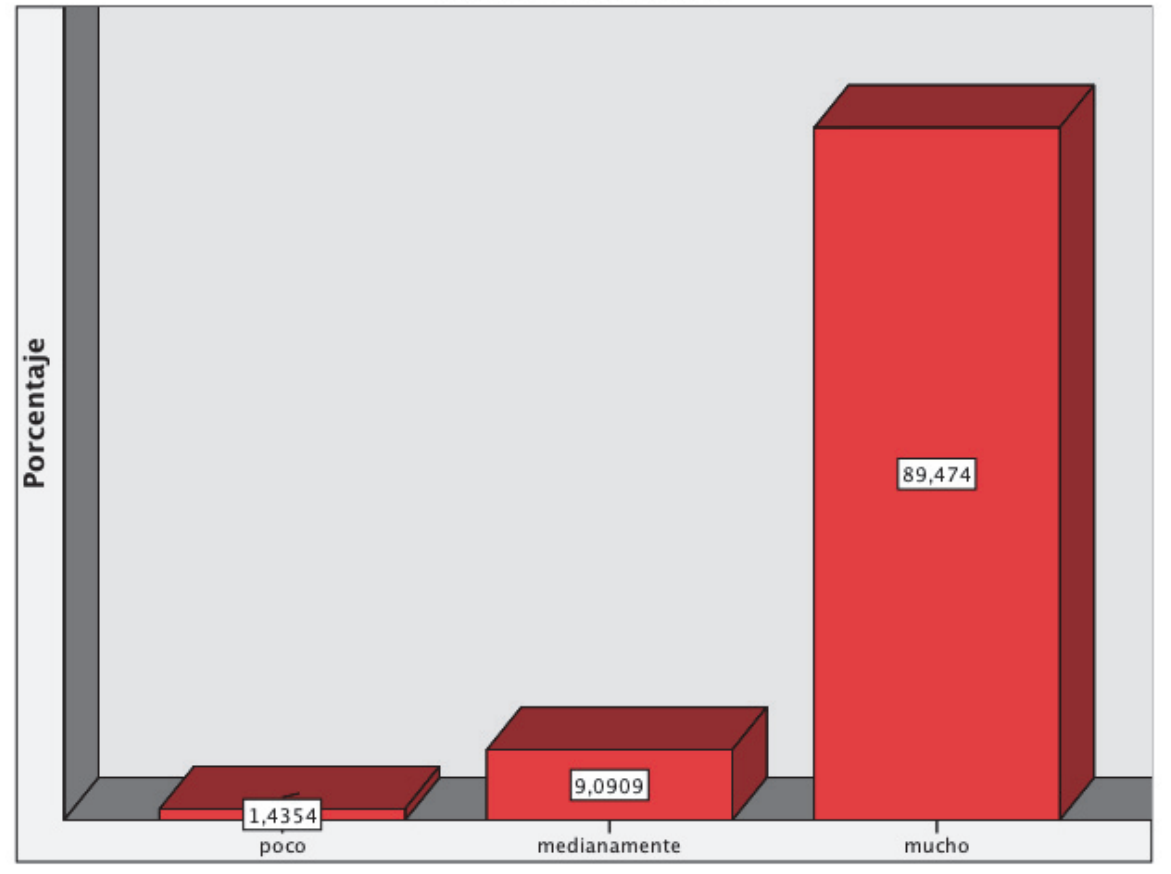

Elaboración propia. Mayo de 2015

Análisis: la "Calidez, cercanía", con casi el 90\% para la categoría simplificada "mucho" se revela como un valor que gobierna realmente mucho la VP de la muestra encuestada. 
Cuadro $n^{\circ} 9.2$

15. Confianza

\begin{tabular}{|l|r|r|r|r|}
\hline & Frecuencia & Porcentaje & $\begin{array}{c}\text { Porcentaje } \\
\text { válido }\end{array}$ & \multicolumn{1}{c|}{$\begin{array}{c}\text { Porcentaje } \\
\text { acumulado }\end{array}$} \\
\hline poco & 5 & 2,4 & 2,4 & 2,4 \\
medianamente & 36 & 17,2 & 17,2 & 19,6 \\
mucho & 168 & 80,4 & 80,4 & 100,0 \\
Total & 209 & 100,0 & 100,0 & \\
\hline
\end{tabular}

Elaboración propia. Mayo de 2015

Gráfico $n^{\circ} 9.2$

15. Confianza

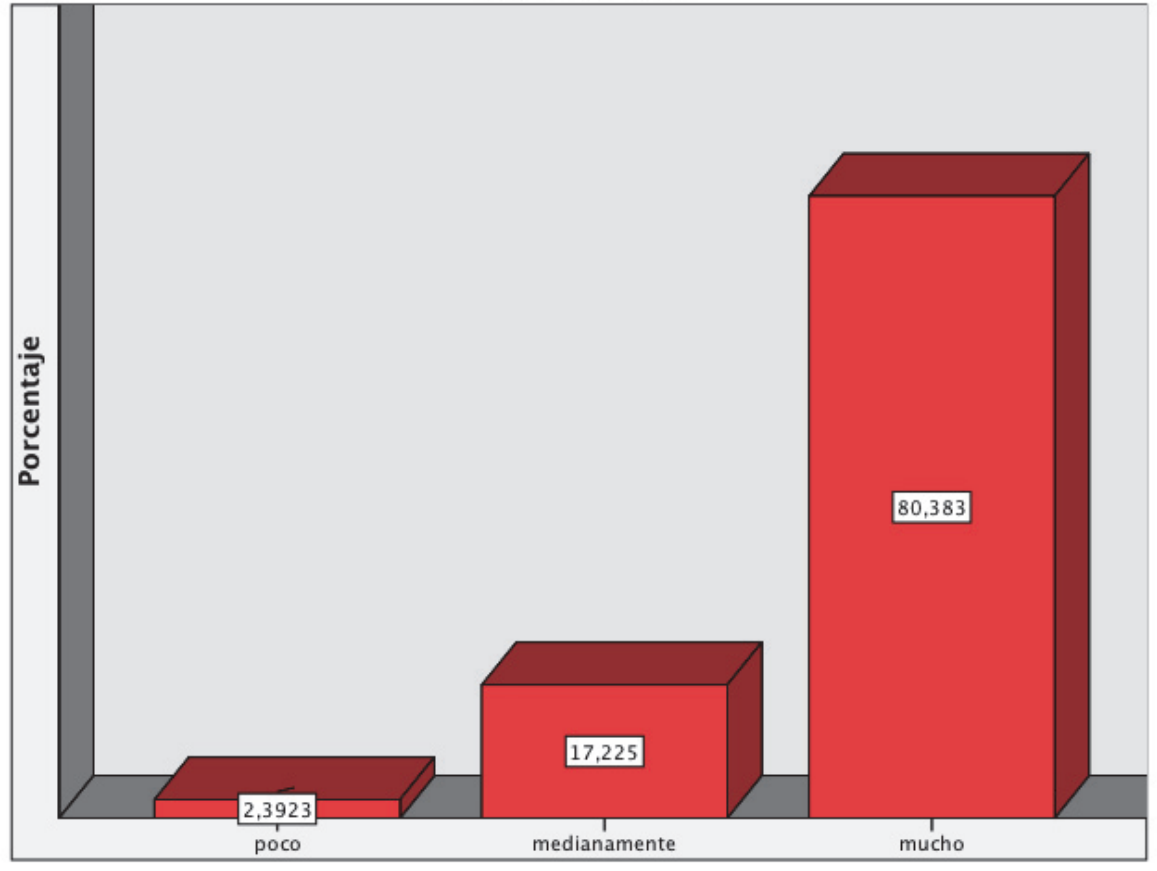

Elaboración propia. Mayo de 2015

Análisis: la "Confianza" sigue el mismo patrón que el valor anterior aunque con porcentaje algo más bajo, algo más del $80 \%$ para la categoría simplificada "mucho". 
Cuadro ${ }^{\circ} 9.3$

21. Creer y poner cariño en lo que se hace

\begin{tabular}{|l|r|r|r|r|}
\hline & Frecuencia & Porcentaje & $\begin{array}{c}\text { Porcentaje } \\
\text { válido }\end{array}$ & $\begin{array}{c}\text { Porcentaje } \\
\text { acumulado }\end{array}$ \\
\hline poco & 4 & 1,9 & 1,9 & 1,9 \\
medianamente & 10 & 4,8 & 4,8 & 6,7 \\
mucho & 195 & 93,3 & 93,3 & 100,0 \\
Total & 209 & 100,0 & 100,0 & \\
\hline
\end{tabular}

Elaboración propia. Mayo de 2015

Gráfico $\mathrm{n}^{\circ} 9.3$

21. Creer y poner cariño en lo que se hace

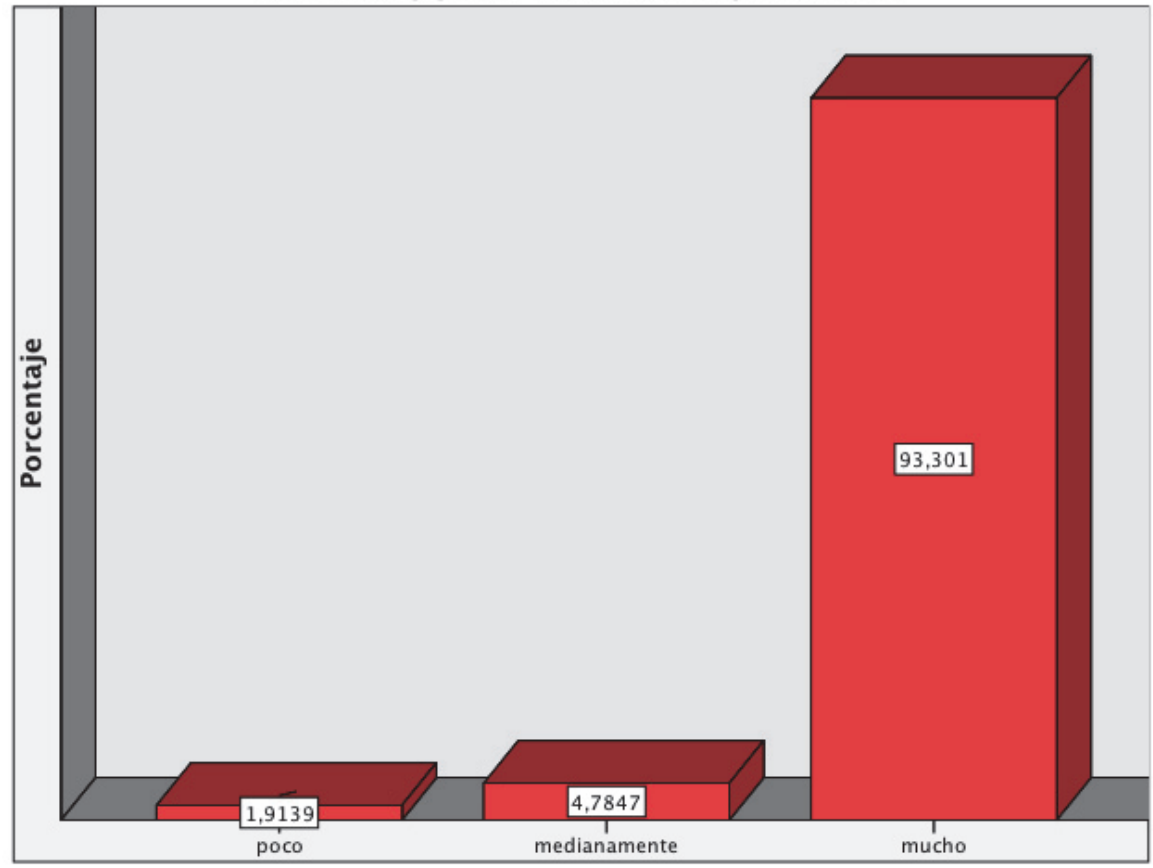

Elaboración propia. Mayo de 2015

Análisis: "Creer y poner cariño en lo que se pone" con más del 93\% para la categoría simplificada "mucho" evidencia su importancia en la VP. 
Cuadro $n^{\circ} 9.4$

24. Disfrutar del trabajo

\begin{tabular}{|l|r|r|r|r|}
\hline & Frecuencia & Porcentaje & $\begin{array}{c}\text { Porcentaje } \\
\text { válido }\end{array}$ & \multicolumn{1}{c|}{$\begin{array}{c}\text { Porcentaje } \\
\text { acumulado }\end{array}$} \\
\hline poco & 5 & 2,4 & 2,4 & 2,4 \\
medianamente & 23 & 11,0 & 11,0 & 13,4 \\
mucho & 181 & 86,6 & 86,6 & 100,0 \\
Total & 209 & 100,0 & 100,0 & \\
\hline
\end{tabular}

Elaboración propia. Mayo de 2015

Gráfico $n^{\circ} 9.4$

24. Disfrutar del trabajo

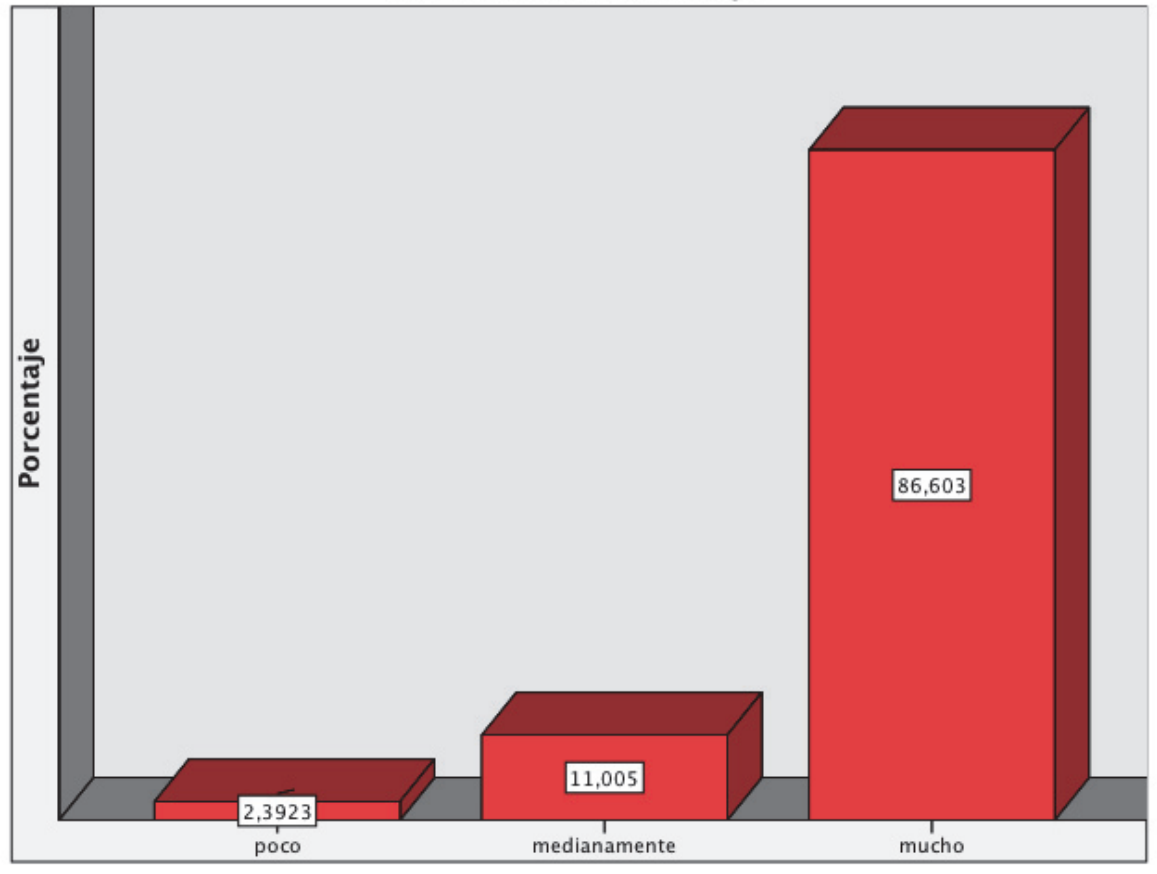

Elaboración propia. Mayo de 2015

Análisis: "Disfrutar del trabajo" es también un valor importante para la muestra encuestada, con más del $86 \%$ para la categoría simplificada "mucho". 
Cuadro $\mathrm{n}^{\circ} 9.5$

25. Eficacia, Planificación, Eficiencia

\begin{tabular}{|l|r|r|r|r|}
\hline & Frecuencia & Porcentaje & $\begin{array}{c}\text { Porcentaje } \\
\text { válido }\end{array}$ & $\begin{array}{c}\text { Porcentaje } \\
\text { acumulado }\end{array}$ \\
\hline poco & 5 & 2,4 & 2,4 & 2,4 \\
medianamente & 46 & 22,0 & 22,0 & 24,4 \\
mucho & 158 & 75,6 & 75,6 & 100,0 \\
Total & 209 & 100,0 & 100,0 & \\
\hline
\end{tabular}

Elaboración propia. Mayo de 2015

\section{Gráfico $n^{\circ} 9.5$}

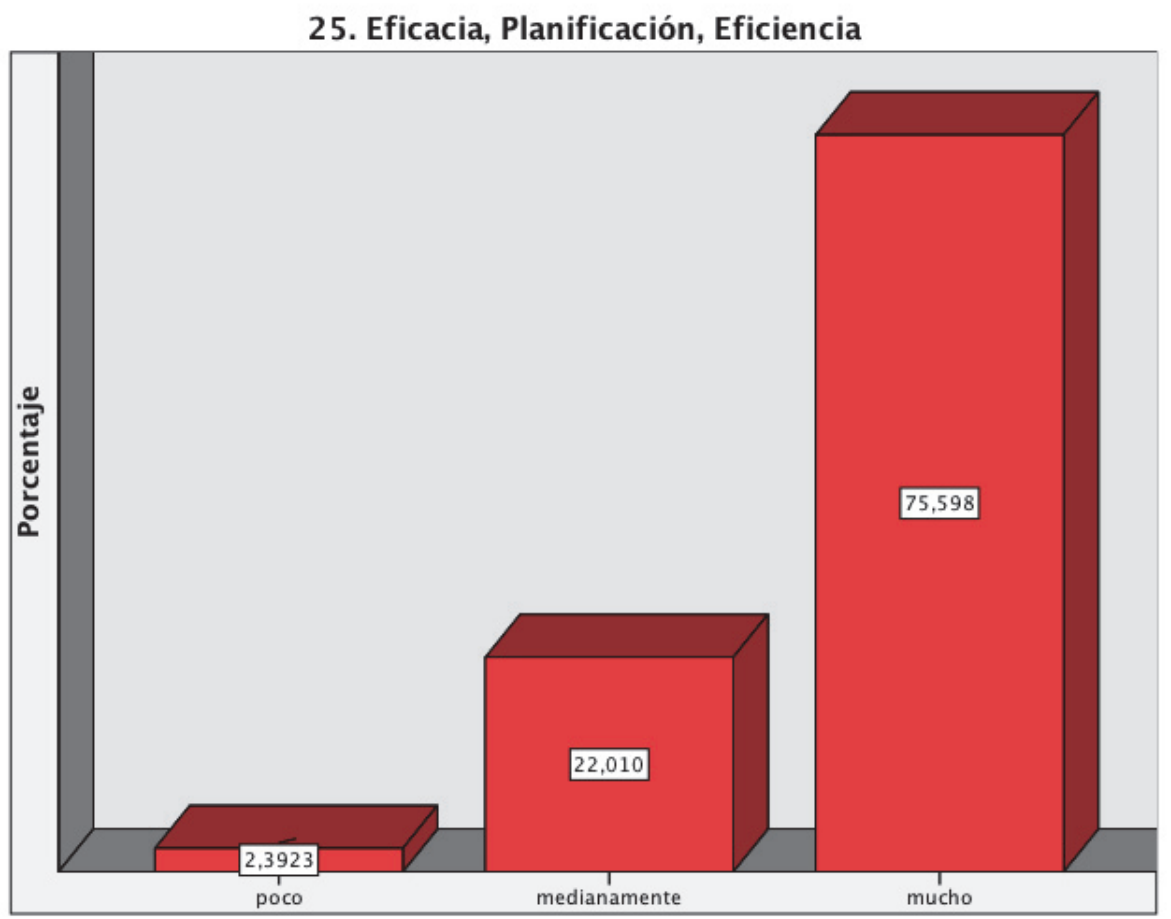

Elaboración propia. Mayo de 2015

Análisis: la "Eficacia, Planificación, Eficiencia" es, como era de esperar, un valor importante para personas que han elegido la Enfermería como profesión. Le dan más del 75\% para la categoría simplificada "mucho". 
Cuadro $n^{\circ} 9.6$

45. Pasión, entusiasmo

\begin{tabular}{|l|r|r|r|r|}
\hline & Frecuencia & Porcentaje & $\begin{array}{c}\text { Porcentaje } \\
\text { válido }\end{array}$ & \multicolumn{1}{c|}{$\begin{array}{c}\text { Porcentaje } \\
\text { acumulado }\end{array}$} \\
\hline poco & 3 & 1,4 & 1,4 & 1,4 \\
medianamente & 23 & 11,0 & 11,0 & 12,4 \\
mucho & 183 & 87,6 & 87,6 & 100,0 \\
Total & 209 & 100,0 & 100,0 & \\
\hline
\end{tabular}

Elaboración propia. Mayo de 2015

Gráfico $n^{\circ} 9.6$

45. Pasión, entusiasmo

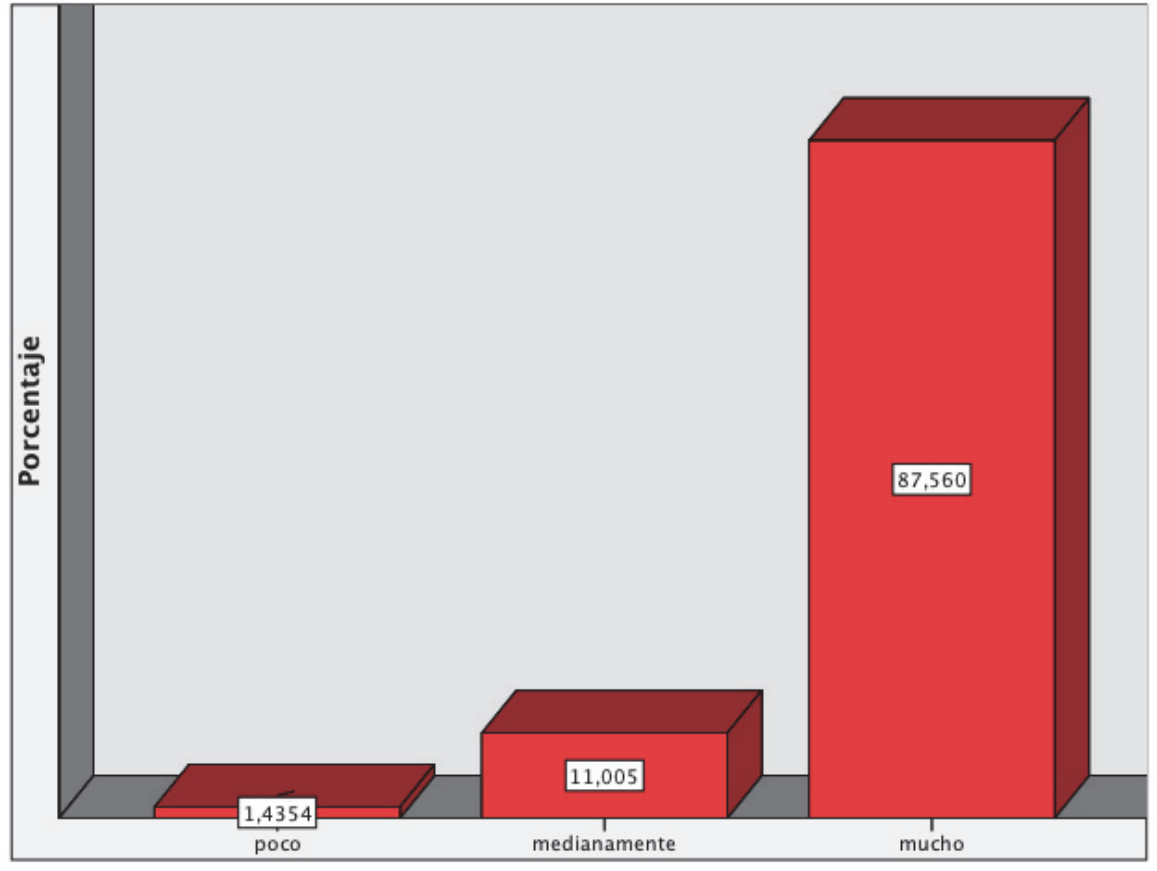

Elaboración propia. Mayo de 2015

Análisis: "Pasión, entusiasmo" con tan solo el 1,4\% para "poco", el 11\% para medianamente y más del $87 \%$ para la categoría simplificada "mucho", evidencia su importancia en la VP. 
Cuadro $\mathrm{n}^{\circ} 9.7$

47. Perseverancia/Paciencia

\begin{tabular}{|l|r|r|r|r|}
\hline & Frecuencia & Porcentaje & $\begin{array}{c}\text { Porcentaje } \\
\text { válido }\end{array}$ & $\begin{array}{c}\text { Porcentaje } \\
\text { acumulado }\end{array}$ \\
\hline poco & 21 & 10,0 & 10,0 & 10,0 \\
medianamente & 35 & 16,7 & 16,7 & 26,8 \\
mucho & 153 & 73,2 & 73,2 & 100,0 \\
Total & 209 & 100,0 & 100,0 & \\
\hline
\end{tabular}

Elaboración propia. Mayo de 2015

Gráfico n ${ }^{\circ} 9.7$

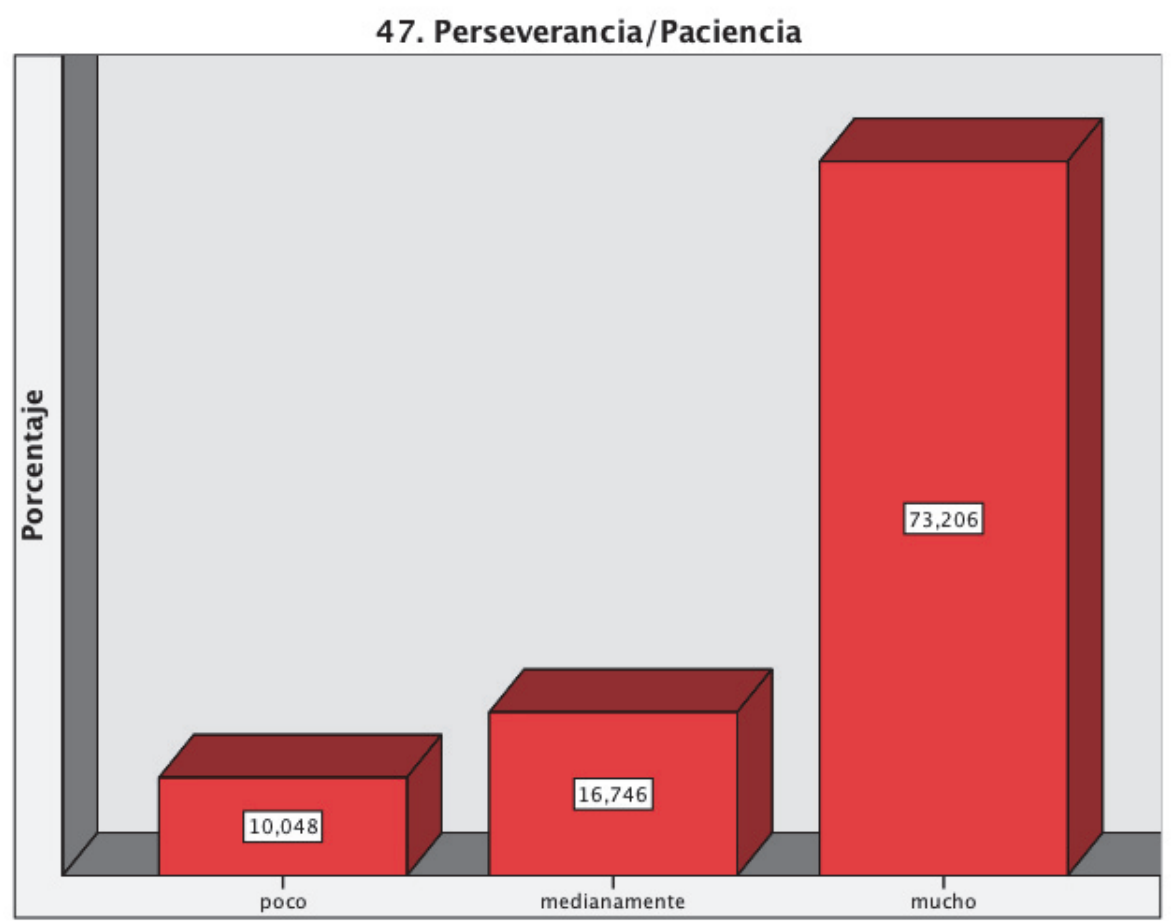

Elaboración propia. Mayo de 2015

Análisis: "Perseverancia, paciencia" es otro valor considerado importante por la muestra en estudio con más de un $73 \%$ para la categoría simplificada "mucho". 
Cuadro $n^{\circ} 9.8$

50. Productividad, resultados

\begin{tabular}{|l|r|r|r|r|}
\hline & Frecuencia & Porcentaje & $\begin{array}{c}\text { Porcentaje } \\
\text { válido }\end{array}$ & \multicolumn{1}{c|}{$\begin{array}{c}\text { Porcentaje } \\
\text { acumulado }\end{array}$} \\
\hline poco & 7 & 3,3 & 3,3 & 3,3 \\
medianamente & 39 & 18,7 & 18,7 & 22,0 \\
mucho & 163 & 78,0 & 78,0 & 100,0 \\
Total & 209 & 100,0 & 100,0 & \\
\hline
\end{tabular}

Elaboración propia. Mayo de 2015

Gráfico n ${ }^{\circ} 9.8$

50. Productividad, resultados

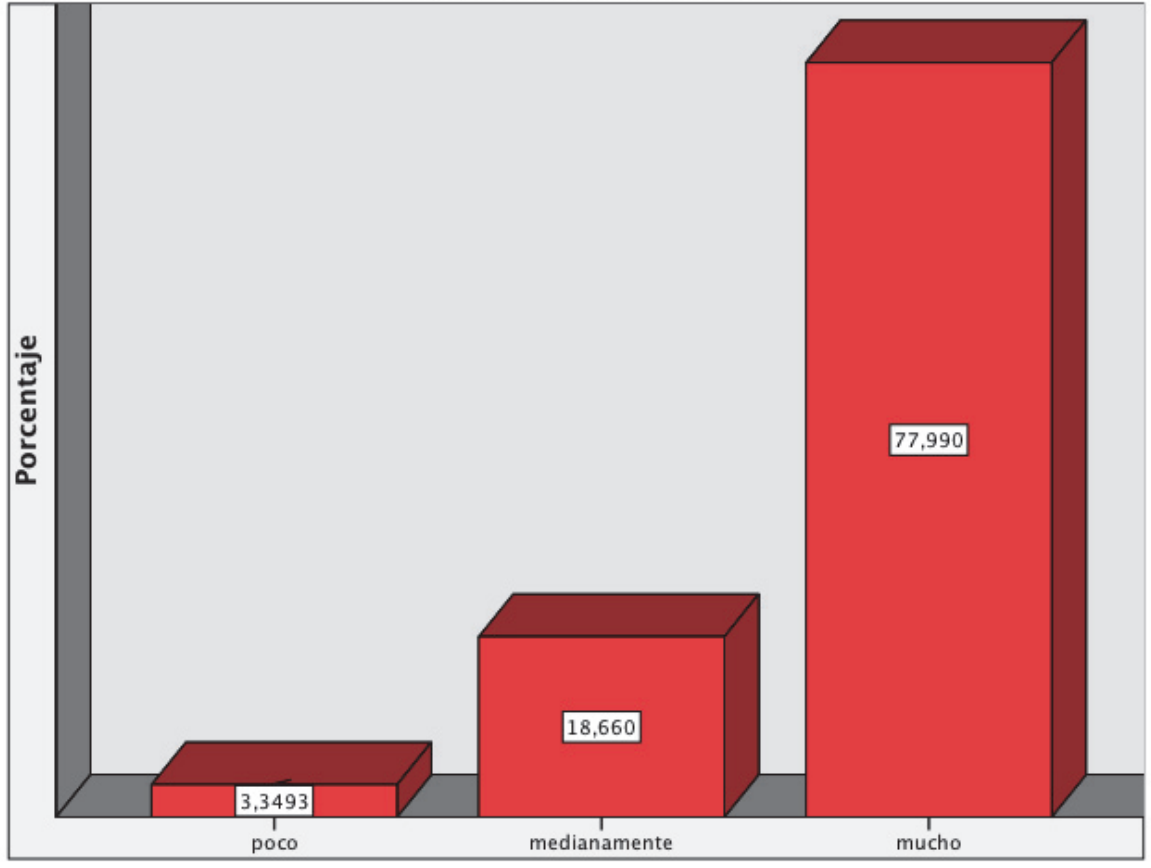

Elaboración propia. Mayo de 2015

Análisis: "Productividad, resultados" como era de esperar, con casi el 78\% para la categoría simplificada "mucho" es un valor importante en la VP. 
Cuadro $n^{\circ} 9.9$

62. Ser querido por los demás

\begin{tabular}{|l|r|r|r|r|}
\hline & Frecuencia & Porcentaje & $\begin{array}{c}\text { Porcentaje } \\
\text { válido }\end{array}$ & $\begin{array}{c}\text { Porcentaje } \\
\text { acumulado }\end{array}$ \\
\hline poco & 5 & 2,4 & 2,4 & 2,4 \\
medianamente & 19 & 9,1 & 9,1 & 11,5 \\
mucho & 185 & 88,5 & 88,5 & 100,0 \\
Total & 209 & 100,0 & 100,0 & \\
\hline
\end{tabular}

Elaboración propia. Mayo de 2015

\section{Gráfico n ${ }^{\circ} 9.9$}

\section{Ser querido por los demás}

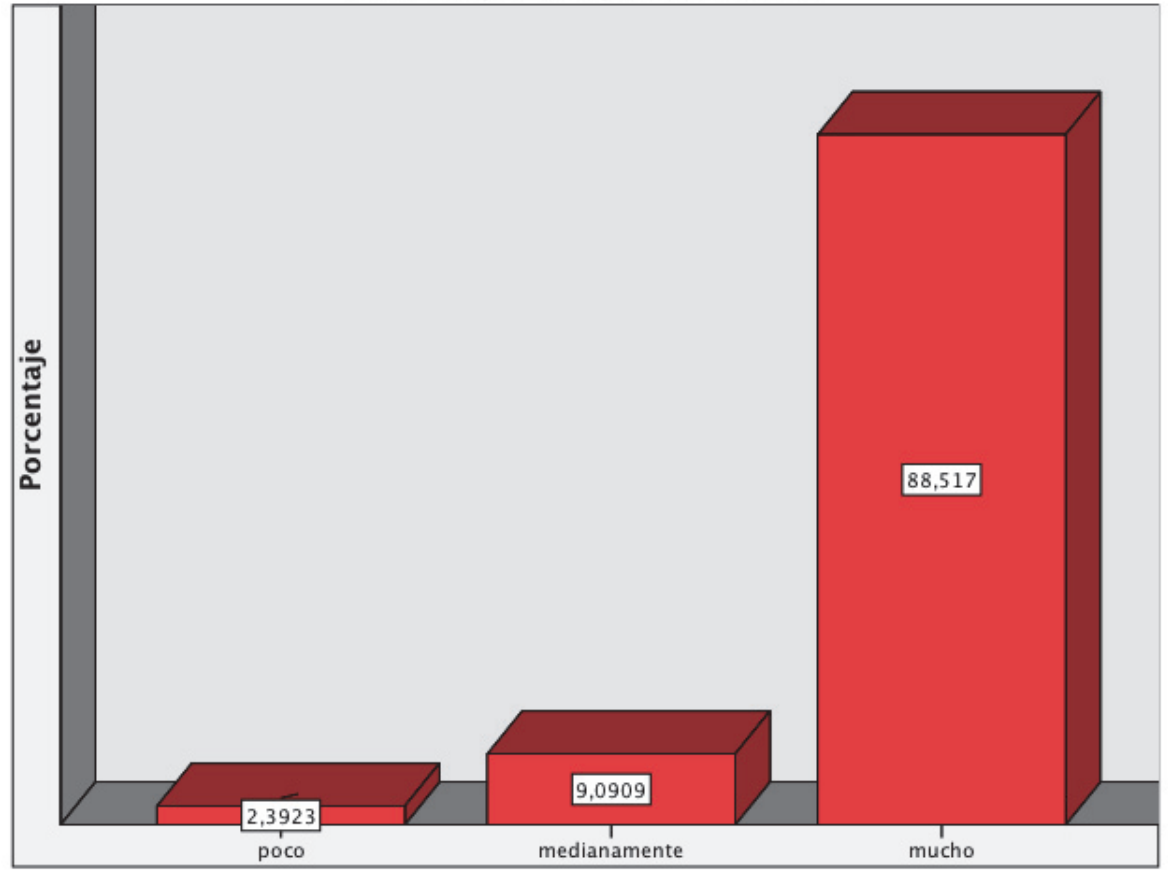

Elaboración propia. Mayo de 2015

Análisis: "Ser querido por los demás" alcanza más del 88\% para la categoría simplificada "mucho" mostrándose como un valor importante para la muestra en estudio. 
Cuadro $n^{0} 9.10$

63. Servicio/vocación

\begin{tabular}{|l|r|r|r|r|}
\hline & Frecuencia & Porcentaje & \multicolumn{1}{c|}{$\begin{array}{c}\text { Porcentaje } \\
\text { válido }\end{array}$} & $\begin{array}{c}\text { Porcentaje } \\
\text { acumulado }\end{array}$ \\
\hline poco & 11 & 5,3 & 5,3 & 5,3 \\
medianamente & 33 & 15,8 & 15,8 & 21,1 \\
mucho & 165 & 78,9 & 78,9 & 100,0 \\
Total & 209 & 100,0 & 100,0 & \\
\hline
\end{tabular}

Elaboración propia. Mayo de 2015

Gráfico $\mathrm{n}^{\circ} 9.10$

63. Servicio/vocación

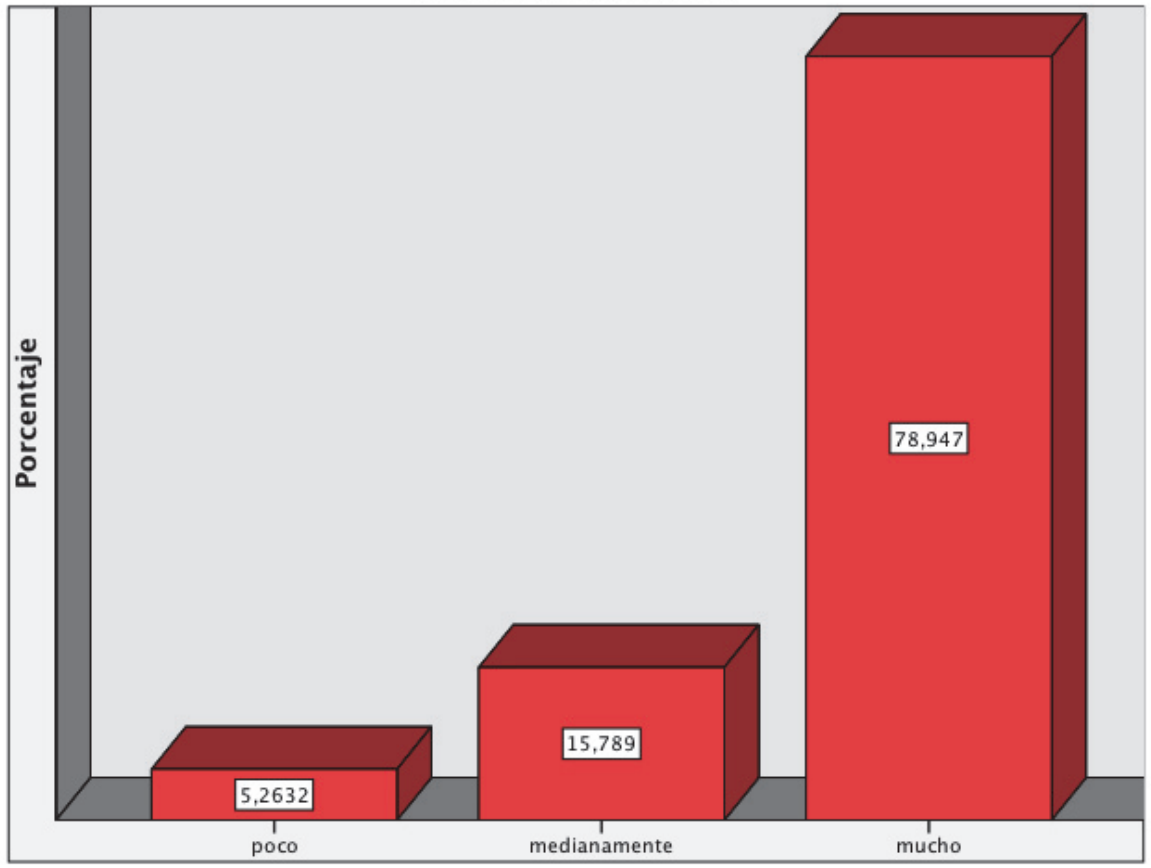

Elaboración propia. Mayo de 2015

Análisis: "Servicio/vocación", como era de esperar en personas que han elegido la Enfermería como profesión, alcanza un porcentaje alto para la categoría simplificada "mucho", casi el 79\%, revelándose como un valor muy apreciado por las personas encuestadas. 
Confianza en el mundo de la empresa 

Cuadro n ${ }^{\circ} 10.1$

9. Calidez, cercanía

\begin{tabular}{|l|r|r|r|r|}
\hline & Frecuencia & Porcentaje & \multicolumn{1}{|c|}{$\begin{array}{c}\text { Porcentaje } \\
\text { válido }\end{array}$} & $\begin{array}{c}\text { Porcentaje } \\
\text { acumulado }\end{array}$ \\
\hline poco & 34 & 16,3 & 16,3 & 16,3 \\
medianamente & 70 & 33,5 & 33,5 & 49,8 \\
mucho & 105 & 50,2 & 50,2 & 100,0 \\
Total & 209 & 100,0 & 100,0 & \\
\hline
\end{tabular}

Elaboración propia. Mayo de 2015

Gráfico n ${ }^{\circ} 10.1$

9. Calidez, cercanía

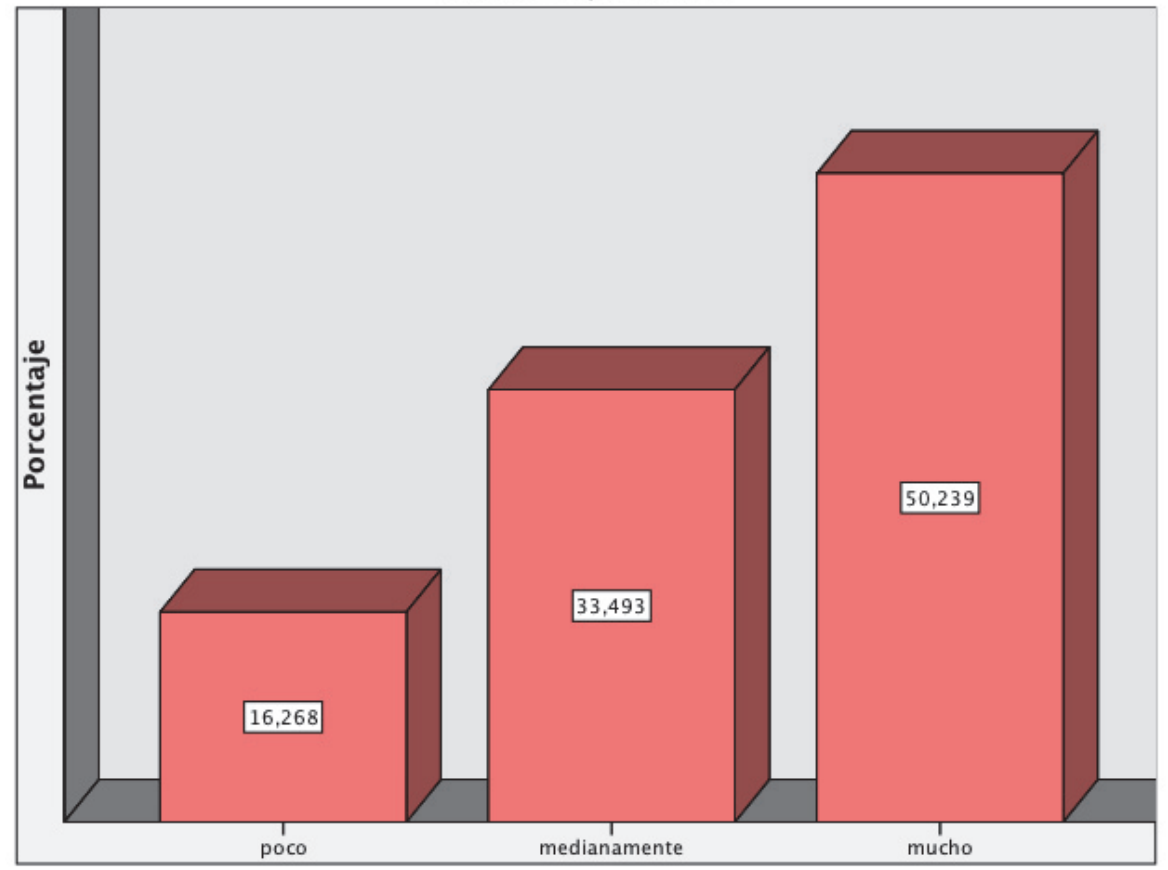

Elaboración propia. Mayo de 2015

Análisis: "Calidez, cercanía" en el ME sigue teniendo un porcentaje para la categoría simplificada "mucho" más alto que las otras dos categorías pero inferior al mismo valor en la VP en la que alcanza casi el 90\%. 
Cuadro $n^{\circ} 10.2$

15. Confianza

\begin{tabular}{|l|r|r|r|r|}
\hline & Frecuencia & Porcentaje & $\begin{array}{c}\text { Porcentaje } \\
\text { válido }\end{array}$ & $\begin{array}{c}\text { Porcentaje } \\
\text { acumulado }\end{array}$ \\
\hline poco & 34 & 16,3 & 16,3 & 16,3 \\
medianamente & 57 & 27,3 & 27,3 & 43,5 \\
mucho & 118 & 56,5 & 56,5 & 100,0 \\
Total & 209 & 100,0 & 100,0 & \\
\hline
\end{tabular}

Elaboración propia. Mayo de 2015

Gráfico $\mathrm{n}^{\mathrm{0}} 10.2$

15. Confianza

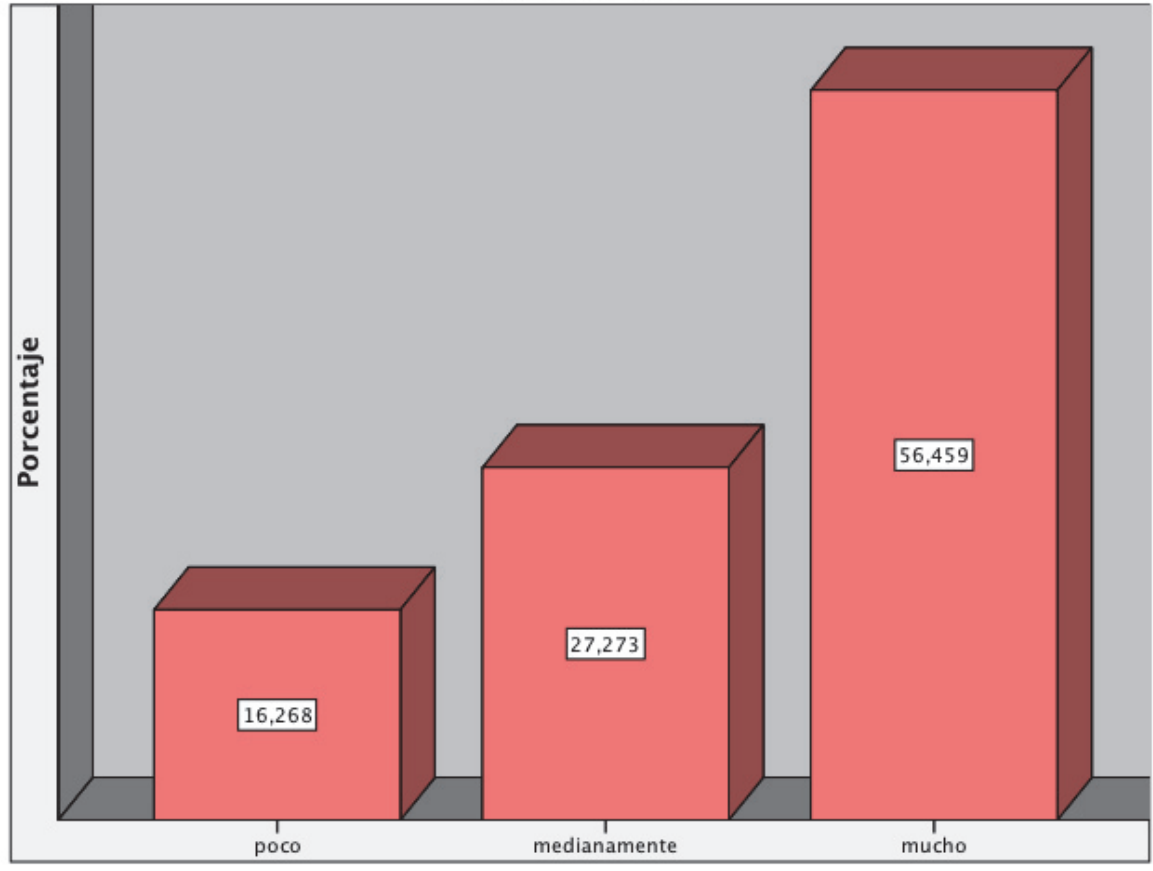

Elaboración propia. Mayo de 2015

Análisis: la "Confianza" se comporta de una manera muy similar a la "Calidez, cercanía" con más de un $80 \%$ en la VP, se queda en un 56,459\% para la categoría simplificada "mucho" en el ME. 
Cuadro $n^{\circ} 10.3$

21. Creer y poner cariño en lo que se hace

\begin{tabular}{|l|r|r|r|r|}
\hline & Frecuencia & Porcentaje & $\begin{array}{c}\text { Porcentaje } \\
\text { válido }\end{array}$ & \multicolumn{1}{c|}{$\begin{array}{c}\text { Porcentaje } \\
\text { acumulado }\end{array}$} \\
\hline poco & 28 & 13,4 & 13,4 & 13,4 \\
medianamente & 37 & 17,7 & 17,7 & 31,1 \\
mucho & 144 & 68,9 & 68,9 & 100,0 \\
Total & 209 & 100,0 & 100,0 & \\
\hline
\end{tabular}

Elaboración propia. Mayo de 2015

Gráfico ${ }^{\circ} 10.3$

21. Creer y poner cariño en lo que se hace

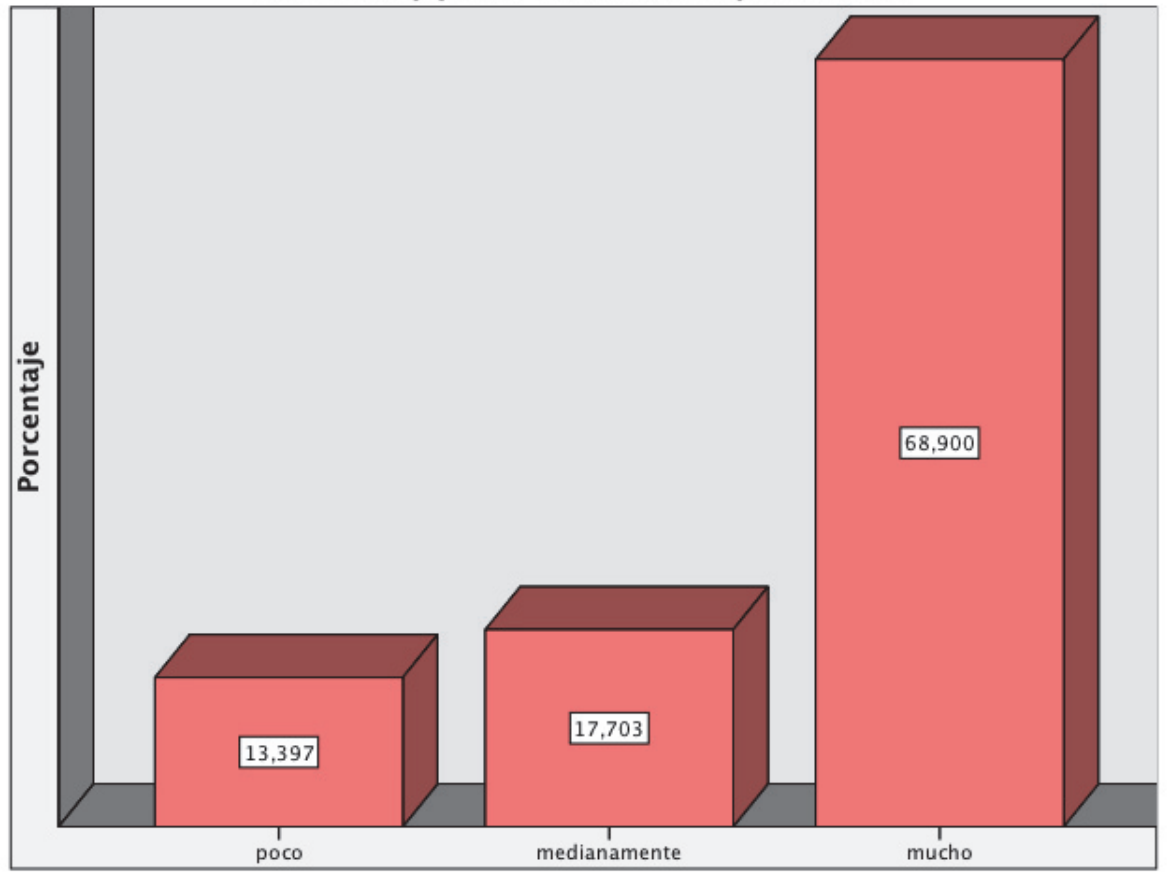

Elaboración propia. Mayo de 2015

Análisis: "Creer y poner cariño" en lo que se hace, que supera el 93\% en la VP, alcanza casi el 69\% en el ME. Lo consideramos un valor muy apreciado por la muestra en estudio. 
Cuadro $n^{\circ} 10.4$

24. Disfrutar del trabajo

\begin{tabular}{|l|r|r|r|r|}
\hline & Frecuencia & Porcentaje & $\begin{array}{c}\text { Porcentaje } \\
\text { válido }\end{array}$ & $\begin{array}{c}\text { Porcentaje } \\
\text { acumulado }\end{array}$ \\
\hline poco & 25 & 12,0 & 12,0 & 12,0 \\
medianamente & 47 & 22,5 & 22,5 & 34,4 \\
mucho & 137 & 65,6 & 65,6 & 100,0 \\
Total & 209 & 100,0 & 100,0 & \\
\hline
\end{tabular}

Elaboración propia. Mayo de 2015

Gráfico ${ }^{\circ} 10.4$

24. Disfrutar del trabajo

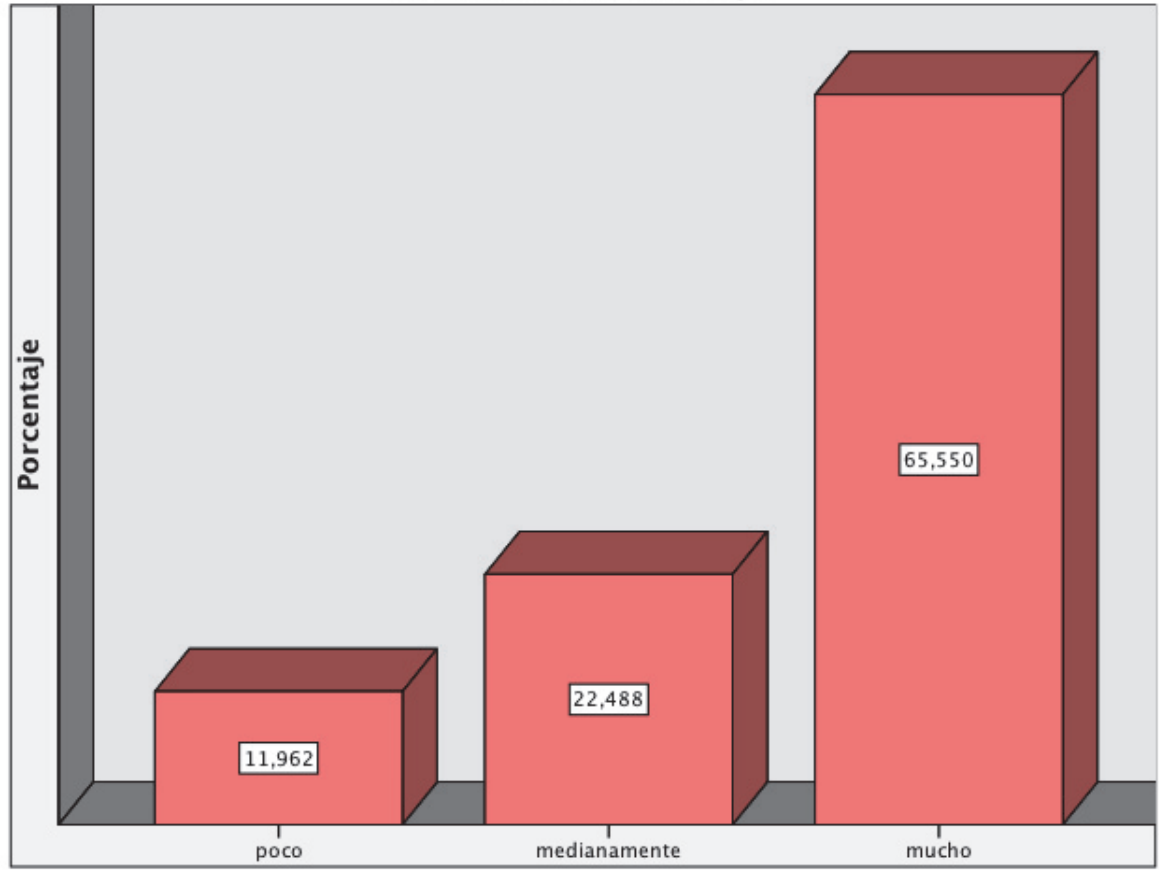

Elaboración propia. Mayo de 2015

Análisis: "Disfrutar en el trabajo" se comporta de una forma similar al valor anterior "Creer y poner cariño". Supera el $86 \%$ en la VP y el $65 \%$ en el ME, se puede considerar un valor muy apreciado por la muestra en estudio. 
Cuadro $\mathrm{n}^{\mathrm{o}} 10.5$

25. Eficacia, Planificación, Eficiencia

\begin{tabular}{|l|r|r|r|r|}
\hline & Frecuencia & Porcentaje & $\begin{array}{c}\text { Porcentaje } \\
\text { válido }\end{array}$ & $\begin{array}{c}\text { Porcentaje } \\
\text { acumulado }\end{array}$ \\
\hline poco & 9 & 4,3 & 4,3 & 4,3 \\
medianamente & 42 & 20,1 & 20,1 & 24,4 \\
mucho & 158 & 75,6 & 75,6 & 100,0 \\
Total & 209 & 100,0 & 100,0 & \\
\hline
\end{tabular}

Elaboración propia. Mayo de 2015

Gráfico $\mathrm{n}^{\mathrm{0}} 10.5$

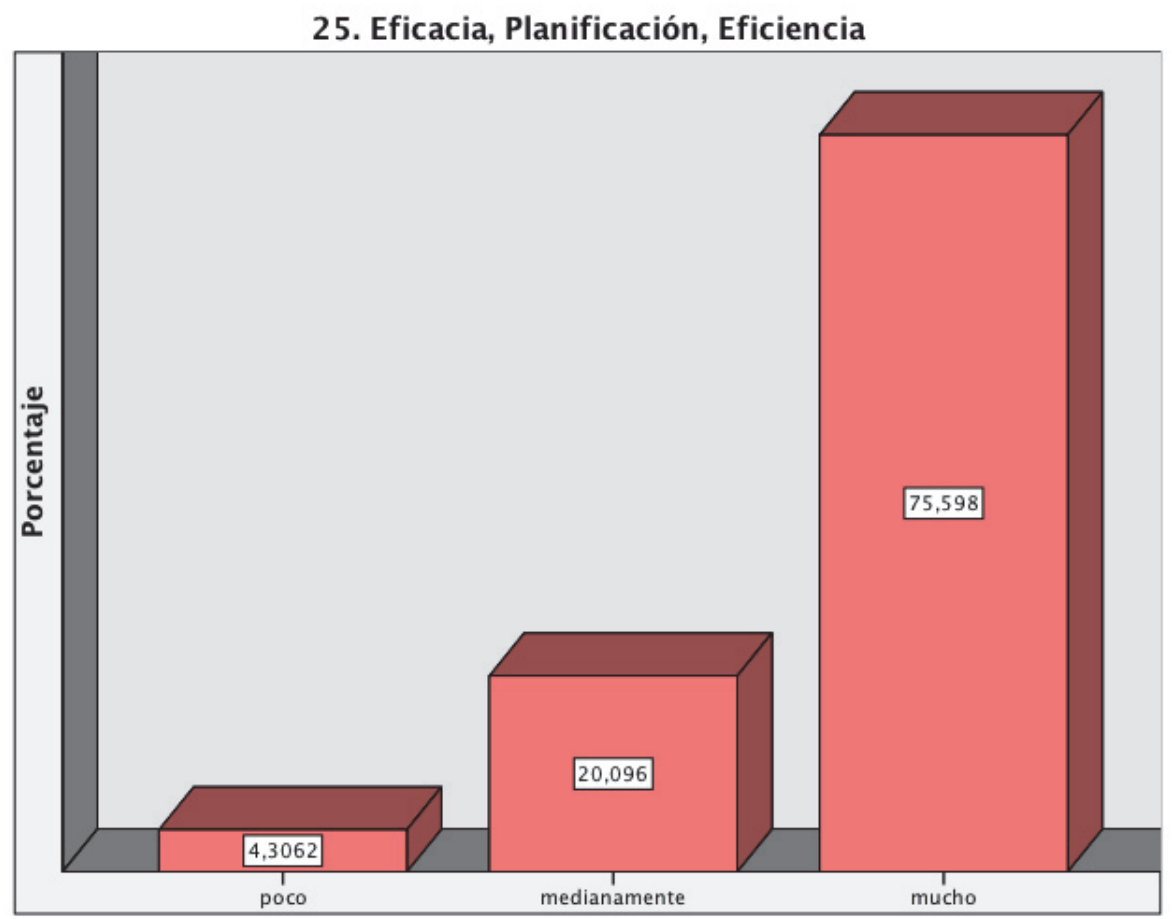

Elaboración propia. Mayo de 2015

Análisis: "Eficacia, Planificación, Eficiencia” presenta un comportamiento casi idéntico en la VP que en el ME. En la categoría simplificada "poco" tiene un porcentaje de algo más del $2 \%$ en la primera y del $4 \%$ en la segunda, par "medianamente" tiene un 22\% frente al 20\% y para "mucho" un 75,598 en las dos esferas evidenciándose como importante en ambas. 
Cuadro $n^{\circ} 10.6$

45. Pasión, entusiasmo

\begin{tabular}{|l|r|r|r|r|}
\hline & Frecuencia & Porcentaje & $\begin{array}{c}\text { Porcentaje } \\
\text { válido }\end{array}$ & $\begin{array}{c}\text { Porcentaje } \\
\text { acumulado }\end{array}$ \\
\hline poco & 23 & 11,0 & 11,0 & 11,0 \\
medianamente & 65 & 31,1 & 31,1 & 42,1 \\
mucho & 121 & 57,9 & 57,9 & 100,0 \\
Total & 209 & 100,0 & 100,0 & \\
\hline
\end{tabular}

Elaboración propia. Mayo de 2015

Gráfico n ${ }^{\circ} 10.6$

45. Pasión, entusiasmo

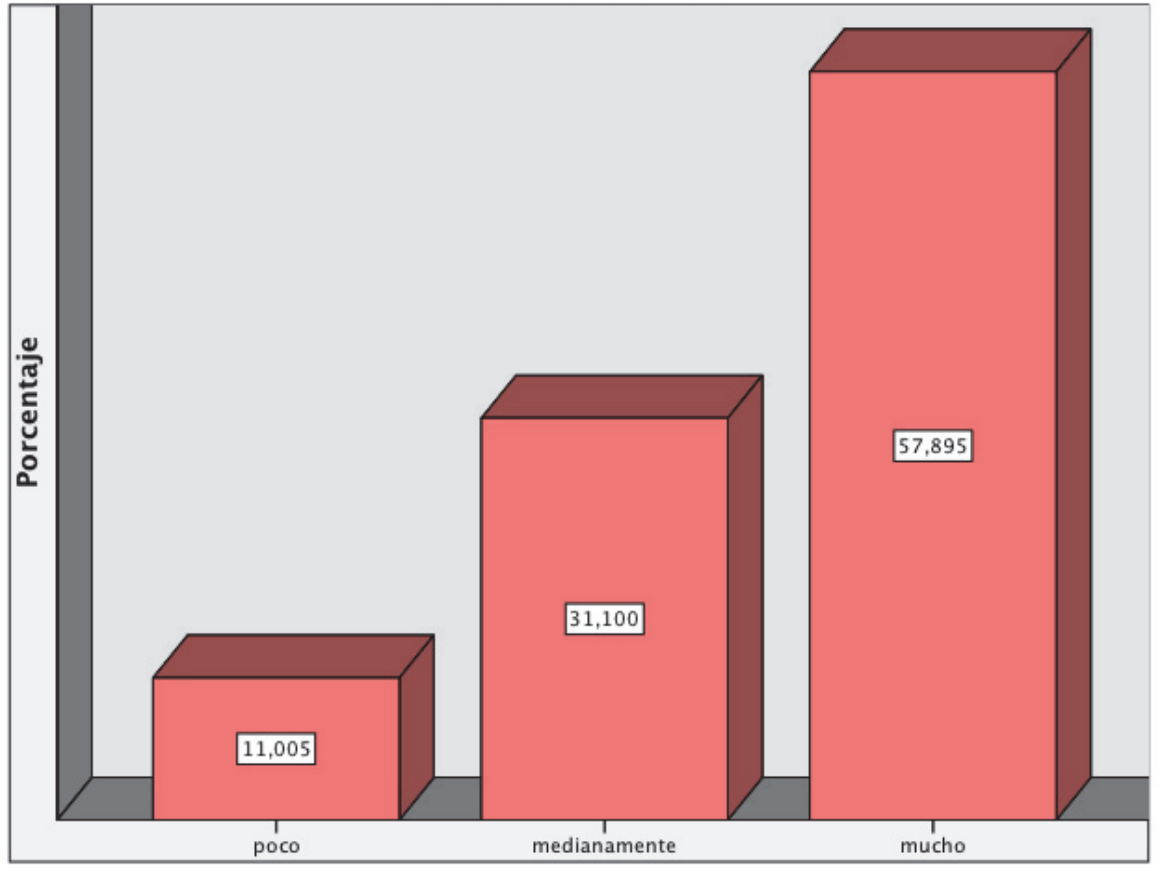

Elaboración propia. Mayo de 2015

Análisis: "Pasión, entusiasmo" que supera al $87 \%$ en la VP, se queda en algo más del 57\% en el ME. Lo podemos considerar importante para la muestra en estudio y más en la VP que en el ME. 
Cuadro ${ }^{\circ} 10.7$

47. Perseverancia/Paciencia

\begin{tabular}{|l|c|c|c|c|}
\hline & Frecuencia & Porcentaje & $\begin{array}{c}\text { Porcentaje } \\
\text { válido }\end{array}$ & $\begin{array}{c}\text { Porcentaje } \\
\text { acumulado }\end{array}$ \\
\hline poco & 36 & 17,2 & 17,2 & 17,2 \\
medianamente & 45 & 21,5 & 21,5 & 38,8 \\
mucho & 128 & 61,2 & 61,2 & 100,0 \\
Total & 209 & 100,0 & 100,0 & \\
\hline
\end{tabular}

Elaboración propia. Mayo de 2015

Gráfico ${ }^{\circ} 10.7$

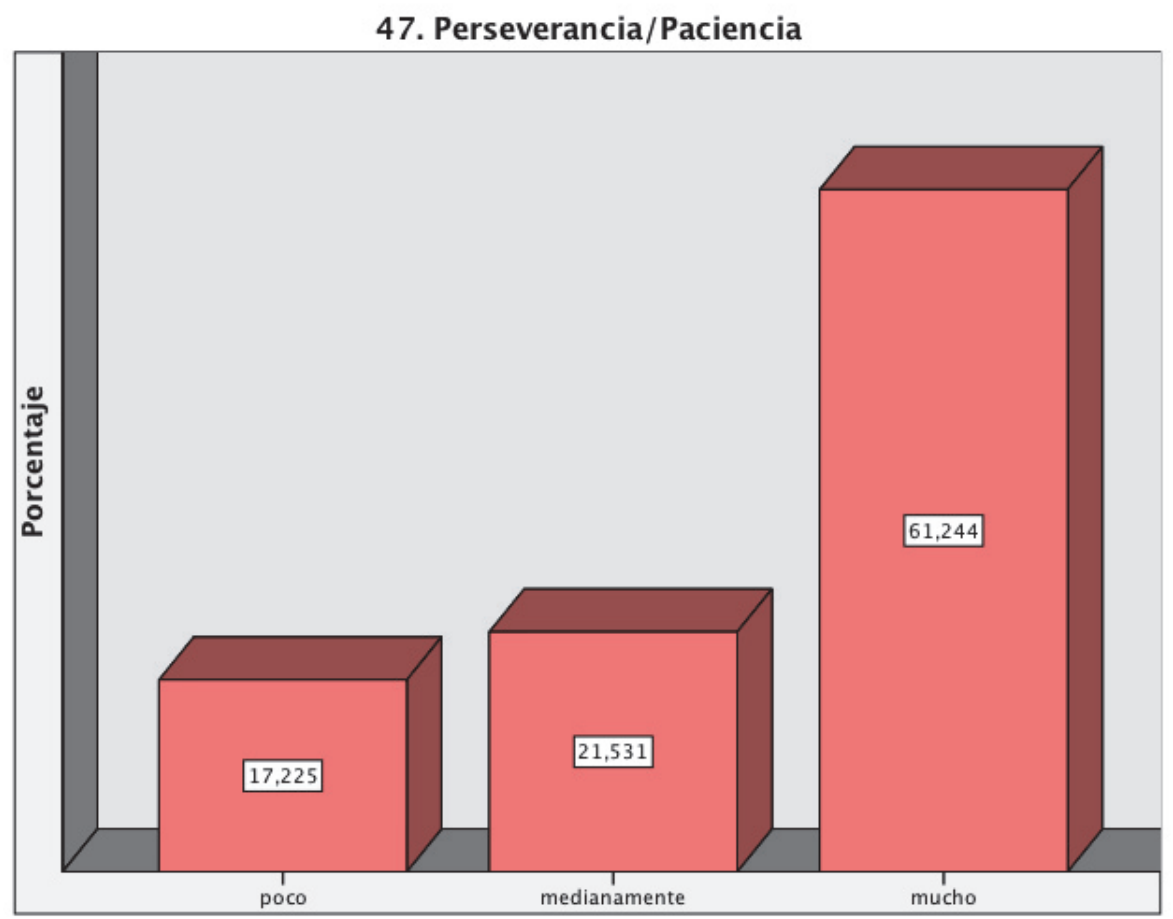

Elaboración propia. Mayo de 2015

Análisis: la "Perseverancia/Paciencia" mantiene un comportamiento parecido en ambas esferas y parecido también a los demás valores pues alcanza mayo porcentaje para la VP que para el ME, el $73 \%$ en la primera frente al $61 \%$ en el segundo. 
Cuadro $n^{\circ} 10.8$

50. Productividad, resultados

\begin{tabular}{|l|r|r|r|r|}
\hline & Frecuencia & Porcentaje & $\begin{array}{c}\text { Porcentaje } \\
\text { válido }\end{array}$ & $\begin{array}{c}\text { Porcentaje } \\
\text { acumulado }\end{array}$ \\
\hline poco & 8 & 3,8 & 3,8 & 3,8 \\
medianamente & 31 & 14,8 & 14,8 & 18,7 \\
mucho & 170 & 81,3 & 81,3 & 100,0 \\
Total & 209 & 100,0 & 100,0 & \\
\hline
\end{tabular}

Elaboración propia. Mayo de 2015

\section{Gráfico $\mathrm{n}^{\mathrm{o}} 10.8$}

\section{Productividad, resultados}

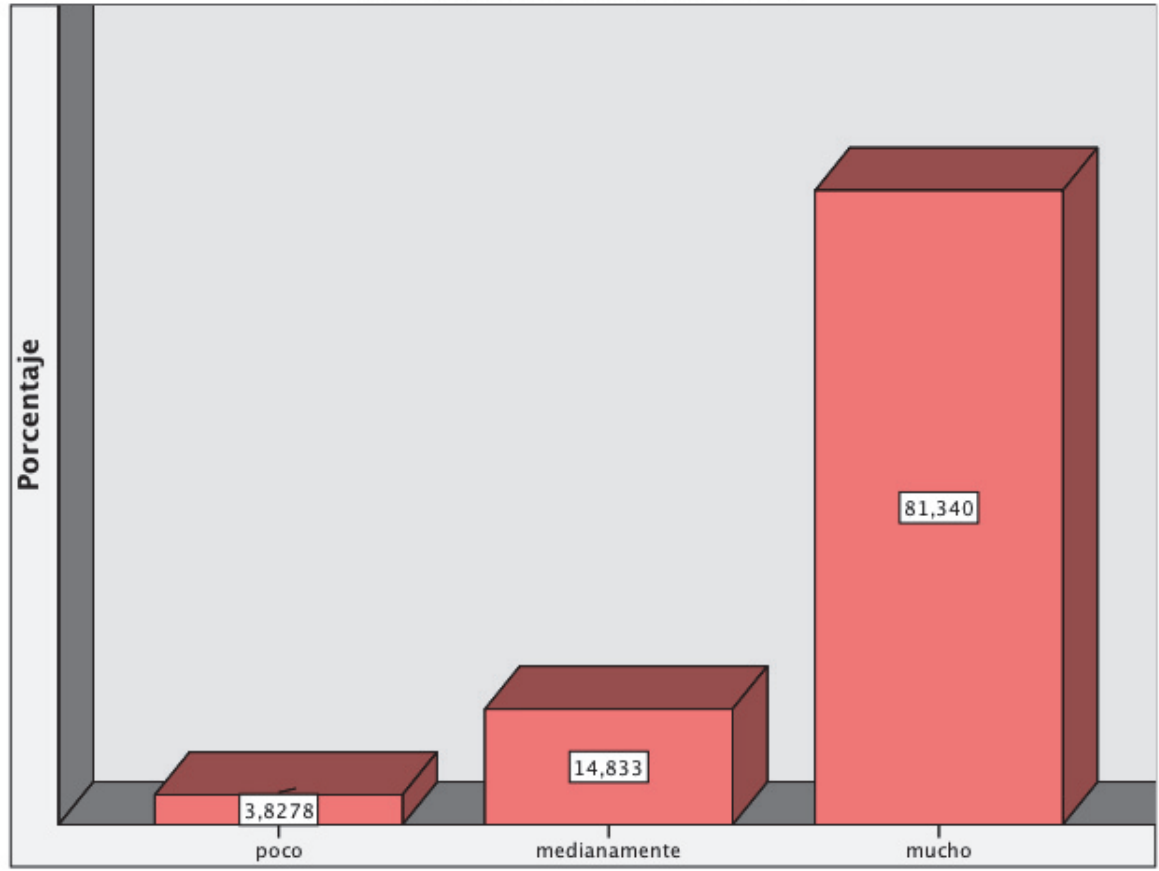

Elaboración propia. Mayo de 2015

Análisis: "Productividad, resultados" alcanza mayor porcentaje para la categoría simplificada "mucho" en el ME con algo más del 81\% que en la VP con casi el 78\%. En ambas esferas es un valor muy importante y no es raro que la muestra en estudio lo considere tan importante en el ME. 
Cuadro $n^{\circ} 10.9$

62. Ser querido por los demás

\begin{tabular}{|l|r|r|r|r|}
\hline & Frecuencia & Porcentaje & $\begin{array}{c}\text { Porcentaje } \\
\text { válido }\end{array}$ & $\begin{array}{c}\text { Porcentaje } \\
\text { acumulado }\end{array}$ \\
\hline poco & 44 & 21,1 & 21,1 & 21,1 \\
medianamente & 48 & 23,0 & 23,0 & 44,0 \\
mucho & 117 & 56,0 & 56,0 & 100,0 \\
Total & 209 & 100,0 & 100,0 & \\
\hline
\end{tabular}

Elaboración propia. Mayo de 2015

Gráfico ${ }^{\circ} 10.9$

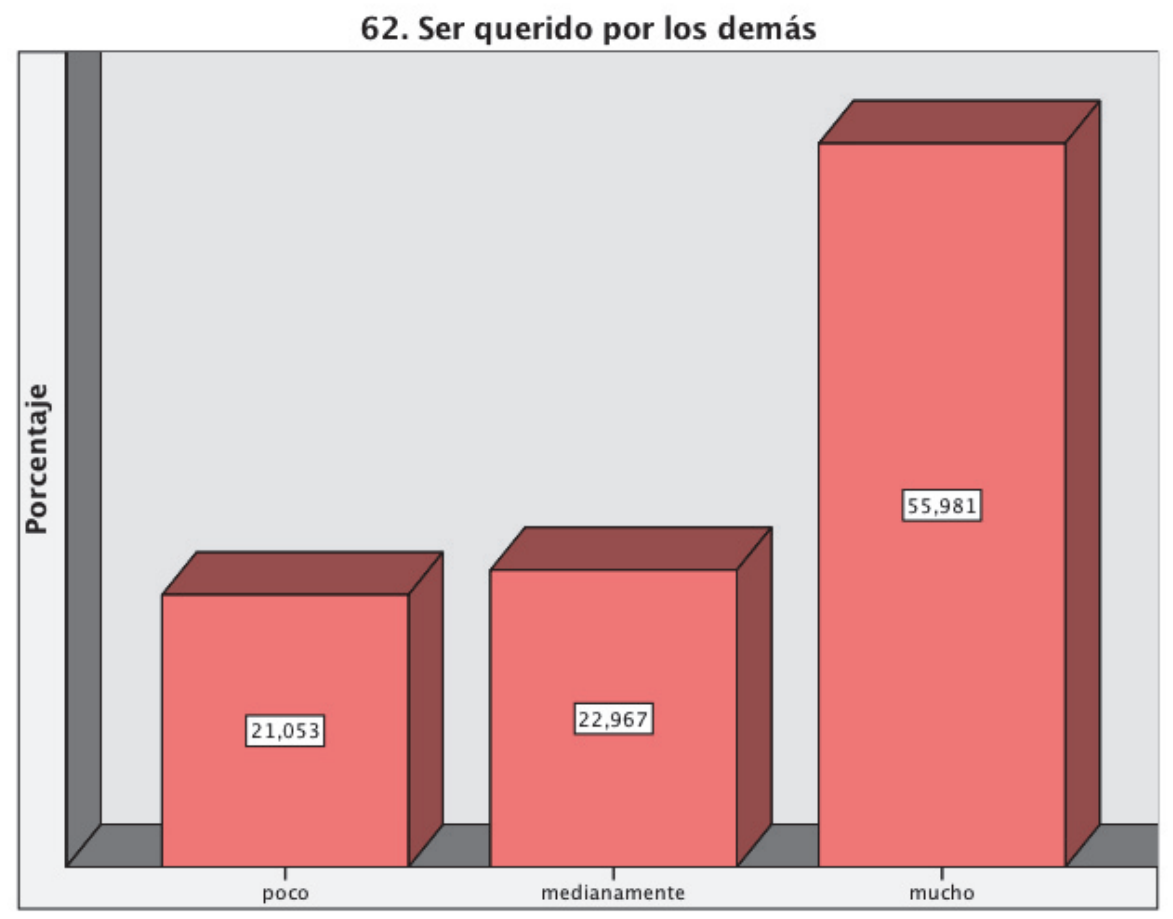

Elaboración propia. Mayo de 2015

Análisis: "Ser querido por los demás" supera el 88\% en la VP quedándose en casi el 56\% en el ME. El mismo comportamiento tienen los valores "Pasión, entusiasmo", “Confianza" y "Calidez, cercanía". Son valores que, si bien son importantes en ambas esferas, lo son mucho más en la VP que en el ME, según la percepción de la muestra en estudio. 
Cuadro $n^{\circ} 10.10$

63. Servicio/vocación

\begin{tabular}{|l|r|r|r|r|}
\hline & Frecuencia & Porcentaje & $\begin{array}{c}\text { Porcentaje } \\
\text { válido }\end{array}$ & $\begin{array}{c}\text { Porcentaje } \\
\text { acumulado }\end{array}$ \\
\hline poco & 29 & 13,9 & 13,9 & 13,9 \\
medianamente & 42 & 20,1 & 20,1 & 34,0 \\
mucho & 138 & 66,0 & 66,0 & 100,0 \\
Total & 209 & 100,0 & 100,0 & \\
\hline
\end{tabular}

Elaboración propia. Mayo de 2015

Gráfico $\mathrm{n}^{\circ} 10.10$

63. Servicio/vocación

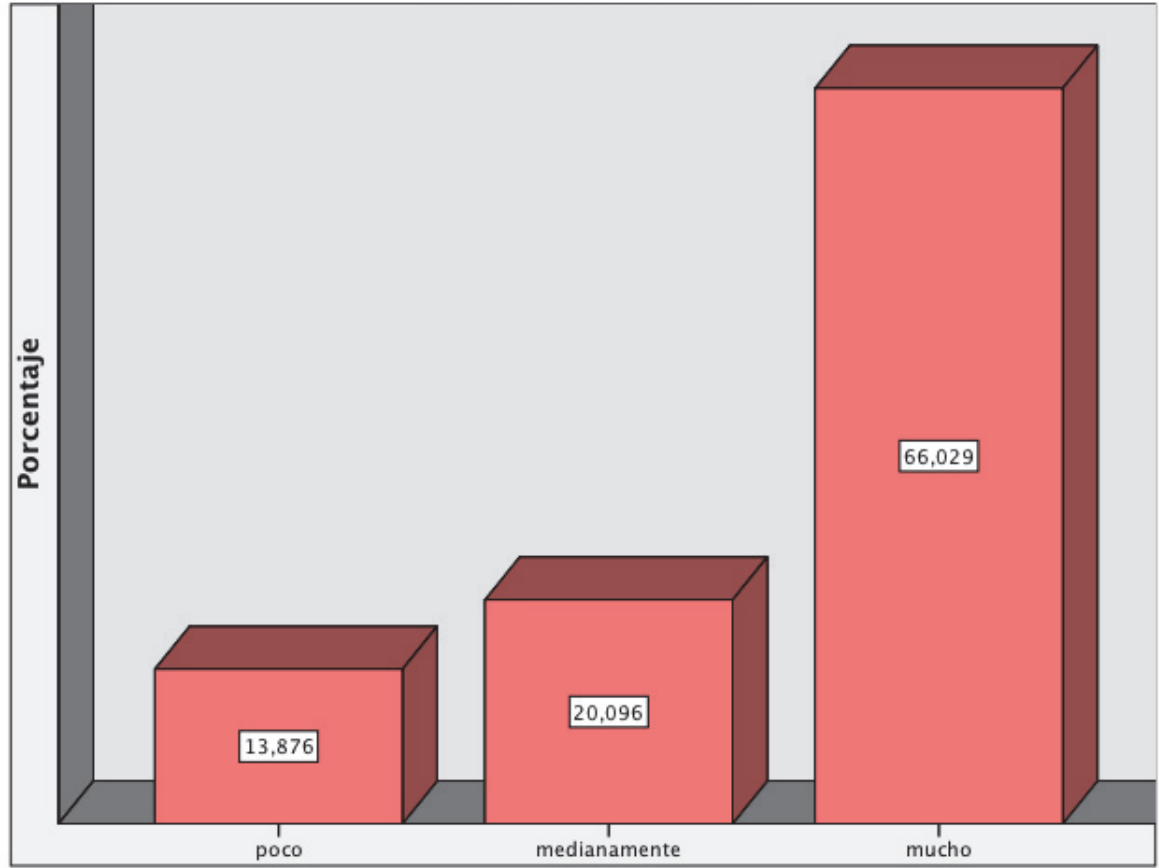

Elaboración propia. Mayo de 2015

Análisis: "Servicio/vocación" se manifiesta como un valor importante en el ME pues supera el 66\% para la categoría simplificada "mucho" y es como casi todos los demás valores mas puntuado aún en la VP con casi el 79\%. 


\section{Análisis cualitativo del grupo Confianza:}

los valores más relacionados con la confianza también se manifiestan como muy importantes en ambas esferas, y presentan una gran diferencia del mucho con respecto al medianamente y poco. El objetivo docente está logrado.

La confianza es el metavalor central del ME de C y según Salvador García es el centro del modelo triaxial. La confianza es esencial para el bienestar emocional y genera el ambiente necesario para que aparezca la iniciativa, la creatividad, el diálogo y el aprendizaje organizativo. El miedo y la confianza son polos opuestos, igual que el amor y el odio, o la guerra y la paz. 

Sostenibilidad en la Vida Personal 

Cuadro $n^{\circ} 11.1$

2. Ahorro, austeridad

\begin{tabular}{|l|r|r|r|r|}
\hline & Frecuencia & Porcentaje & \multicolumn{1}{c|}{$\begin{array}{c}\text { Porcentaje } \\
\text { válido }\end{array}$} & $\begin{array}{c}\text { Porcentaje } \\
\text { acumulado }\end{array}$ \\
\hline poco & 25 & 12,0 & 12,0 & 12,0 \\
medianamente & 64 & 30,6 & 30,6 & 42,6 \\
mucho & 120 & 57,4 & 57,4 & 100,0 \\
Total & 209 & 100,0 & 100,0 & \\
\hline
\end{tabular}

Elaboración propia. Mayo de 2015

Gráfico $n^{\circ} 11.1$

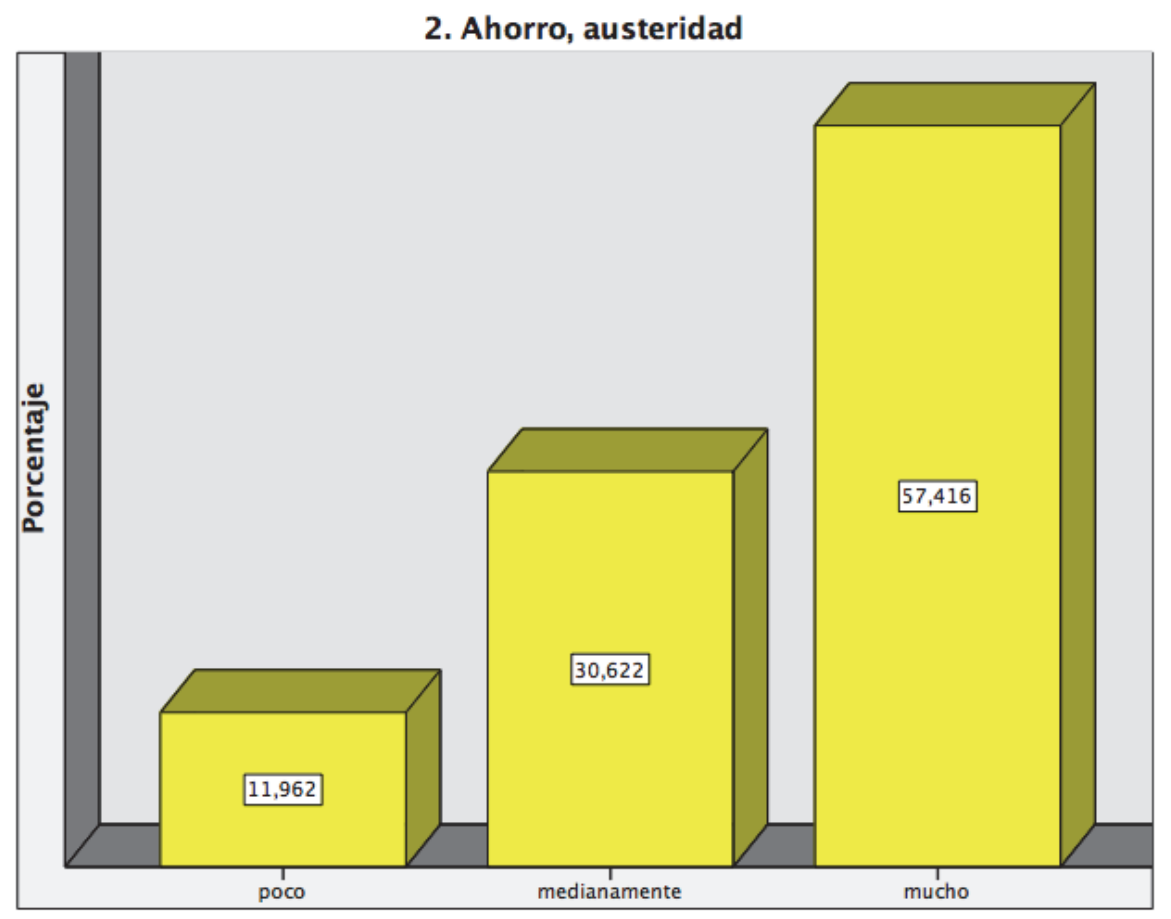

Elaboración propia. Mayo de 2015

Análisis: vemos una distribución en escalera ascendente. Más del $57 \%$ del alumnado considera el ahorro como muy importante en su VP. 
Cuadro $n^{0} 11.2$

25. Eficacia, Planificación, Eficiencia

\begin{tabular}{|l|r|r|r|r|}
\hline & Frecuencia & Porcentaje & $\begin{array}{c}\text { Porcentaje } \\
\text { válido }\end{array}$ & $\begin{array}{c}\text { Porcentaje } \\
\text { acumulado }\end{array}$ \\
\hline poco & 3 & 1,4 & 1,4 & 1,4 \\
medianamente & 41 & 19,6 & 19,6 & 21,1 \\
mucho & 165 & 78,9 & 78,9 & 100,0 \\
Total & 209 & 100,0 & 100,0 & \\
\hline
\end{tabular}

Elaboración propia. Mayo de 2015

Gráfico $n^{\circ} 11.2$

25. Eficacia, Planificación, Eficiencia

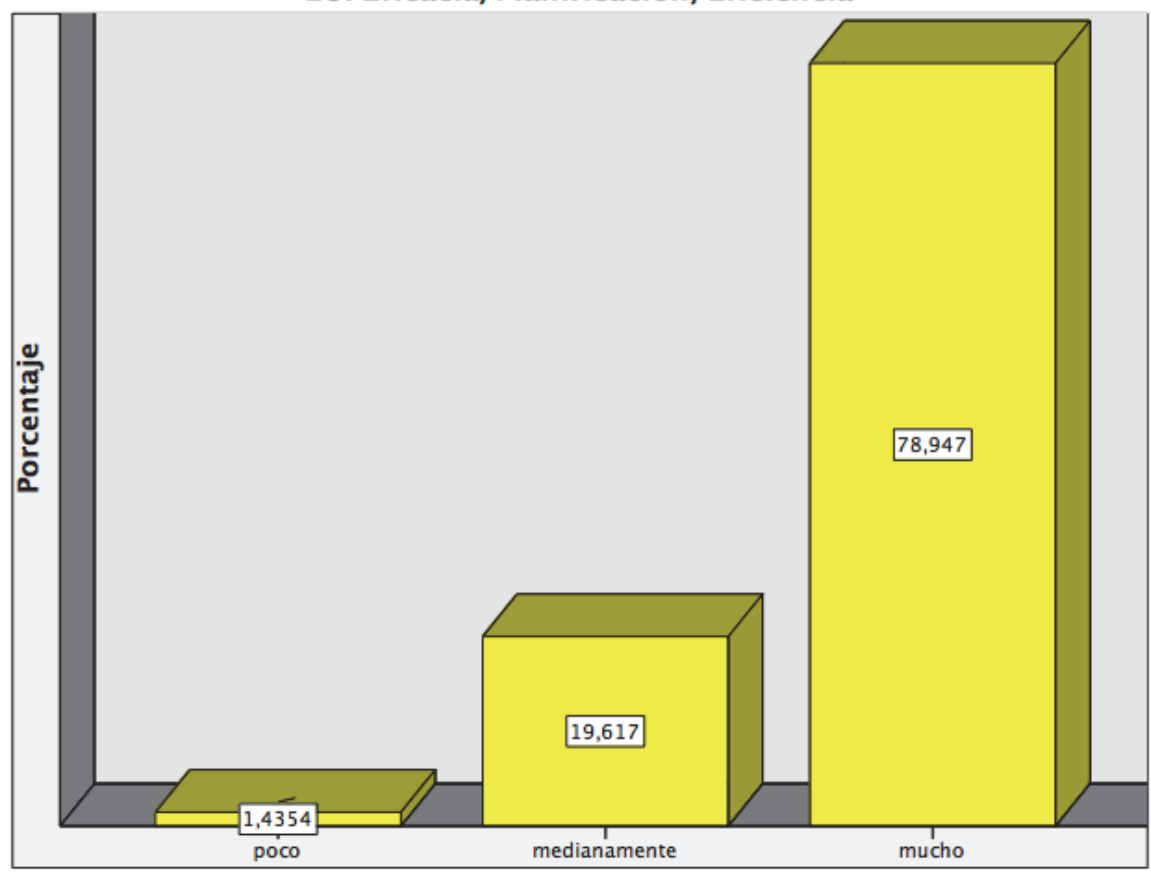

Elaboración propia. Mayo de 2015

Análisis: observamos un gráfico en escalera ascendente. Casi del $79 \%$ del alumnado considera muy importante el valor Eficacia, Planificación, Eficiencia en su VP. Este resultado resulta crucial para nuestra investigación. 
Cuadro $n^{\circ} 11.3$

Elaboración propia. Mayo de 2015

\section{8. Éxito económico}

\begin{tabular}{|l|r|r|r|r|}
\hline & Frecuencia & Porcentaje & $\begin{array}{c}\text { Porcentaje } \\
\text { válido }\end{array}$ & $\begin{array}{c}\text { Porcentaje } \\
\text { acumulado }\end{array}$ \\
\hline poco & 16 & 7,7 & 7,7 & 7,7 \\
medianamente & 58 & 27,8 & 27,8 & 35,4 \\
mucho & 135 & 64,6 & 64,6 & 100,0 \\
Total & 209 & 100,0 & 100,0 & \\
\hline
\end{tabular}

\section{Gráfico ${ }^{\circ} 11.3$}

\section{8. Éxito económico}

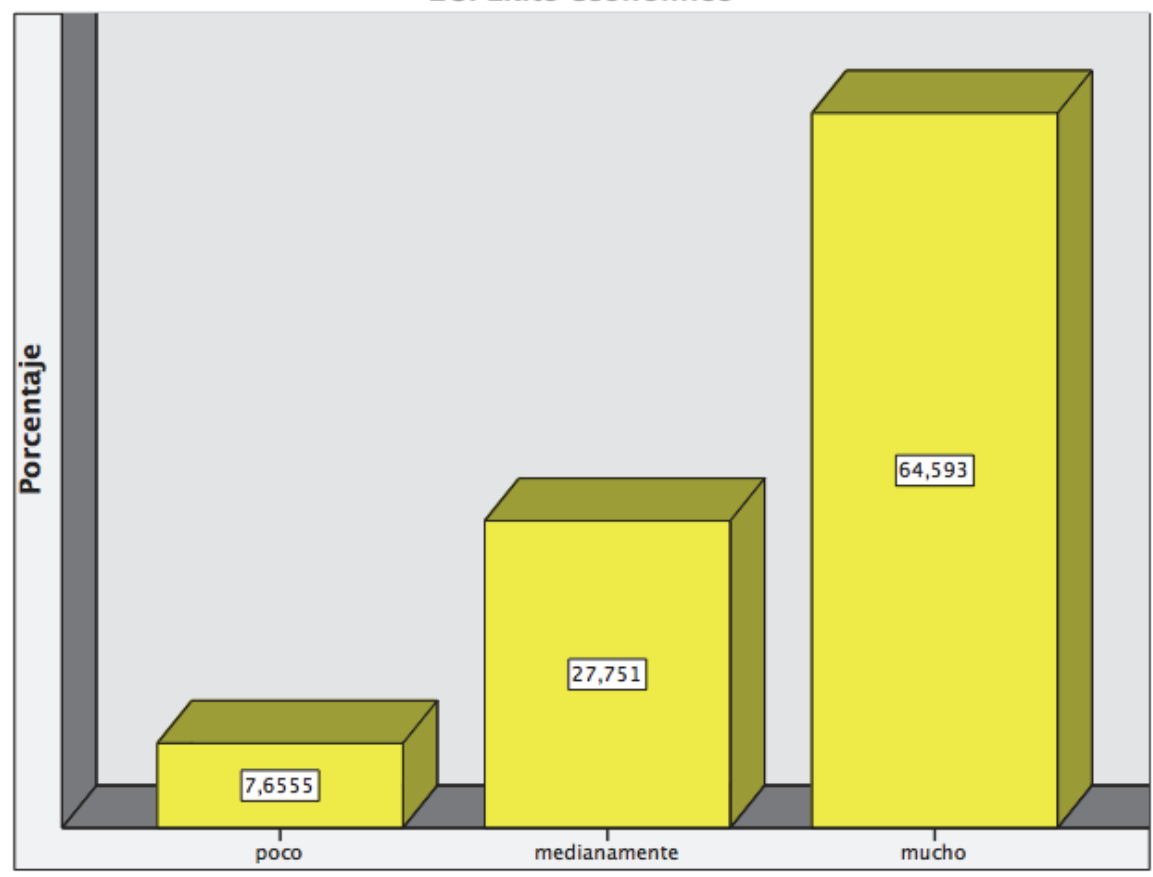

Elaboración propia. Mayo de 2015

Análisis: el éxito económico se revela también como muy importante para casi el $65 \%$ del alumnado. Modelo en escalera ascendente. 
Cuadro $n^{0} 11.4$

50. Productividad, resultados

\begin{tabular}{|l|r|r|r|r|}
\hline & Frecuencia & Porcentaje & $\begin{array}{l}\text { Porcentaje } \\
\text { válido }\end{array}$ & $\begin{array}{c}\text { Porcentaje } \\
\text { acumulado }\end{array}$ \\
\hline poco & 5 & 2,4 & 2,4 & 2,4 \\
medianamente & 33 & 15,8 & 15,8 & 18,2 \\
mucho & 171 & 81,8 & 81,8 & 100,0 \\
Total & 209 & 100,0 & 100,0 & \\
\hline
\end{tabular}

Elaboración propia. Mayo de 2015

Gráfico $n^{\circ} 11.4$

50. Productividad, resultados

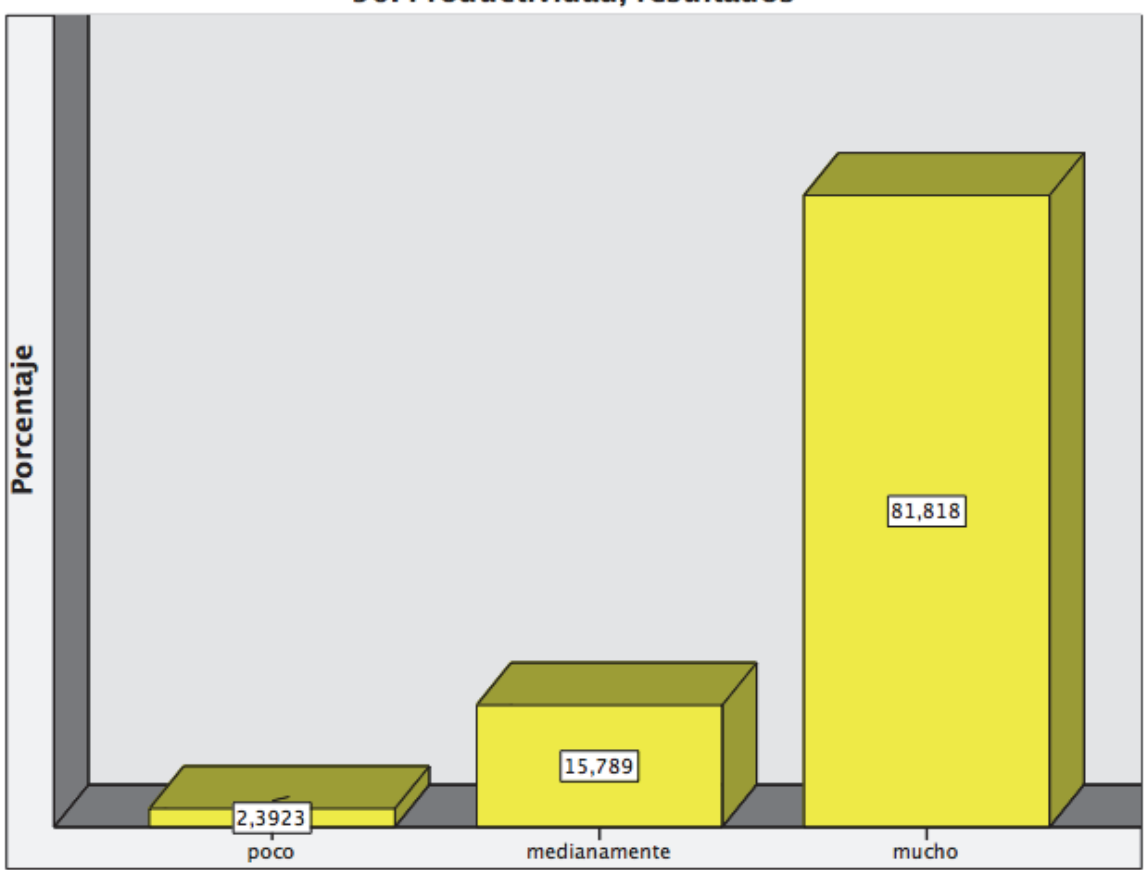

Elaboración propia. Mayo de 2015

Análisis: gráfico también, al igual que los anteriores en escalera ascendente. Casi el $82 \%$ del alumnado considera muy importante el valor Productividad, resultados en la VP. 
Cuadro $n^{\circ} 11.5$

66. Supervivencia material

\begin{tabular}{|l|r|r|r|r|}
\hline & Frecuencia & Porcentaje & $\begin{array}{c}\text { Porcentaje } \\
\text { válido }\end{array}$ & $\begin{array}{c}\text { Porcentaje } \\
\text { acumulado }\end{array}$ \\
\hline poco & 9 & 4,3 & 4,3 & 4,3 \\
medianamente & 61 & 29,2 & 29,2 & 33,5 \\
mucho & 139 & 66,5 & 66,5 & 100,0 \\
Total & 209 & 100,0 & 100,0 & \\
\hline
\end{tabular}

Elaboración propia. Mayo de 2015

\section{Gráfico $\mathrm{n}^{\mathrm{o}} 11.5$}

\section{Supervivencia material}

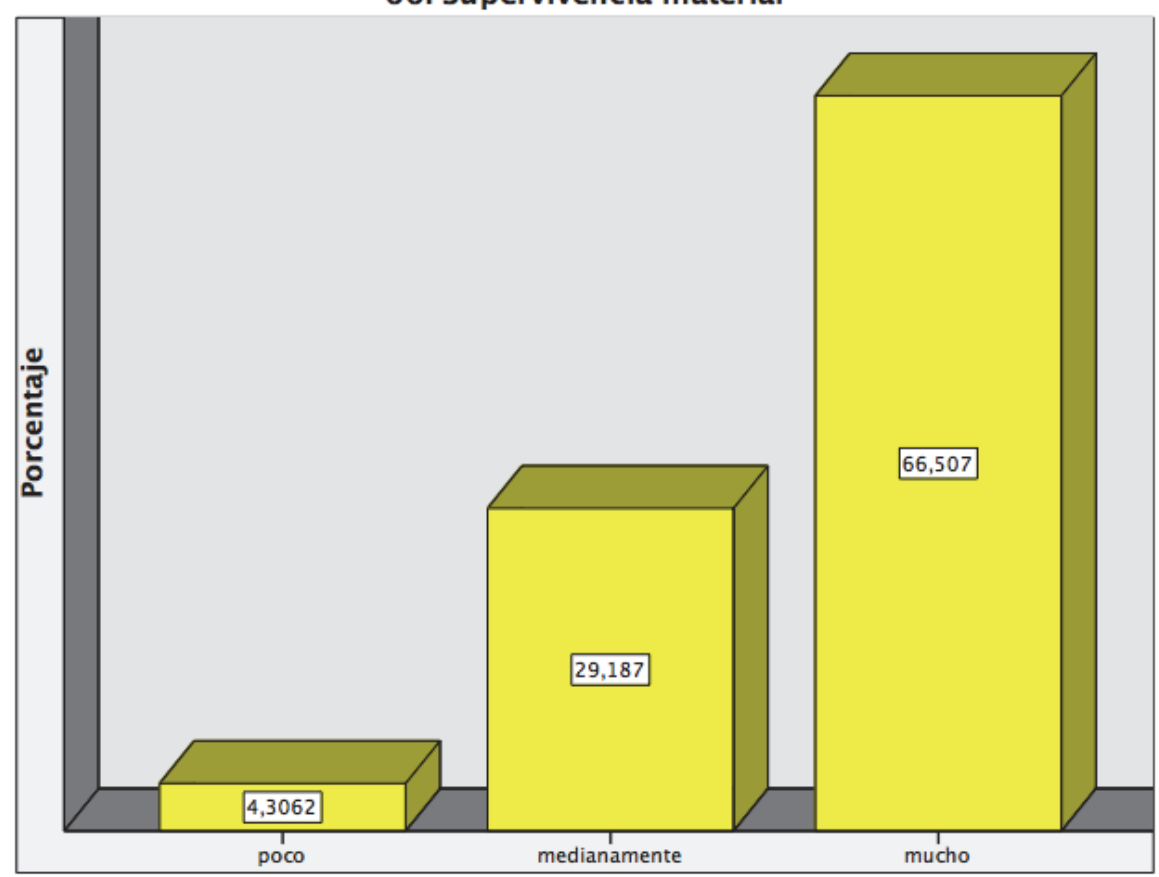

Elaboración propia. Mayo de 2015

Análisis: al igual que en los dos valores anteriores nos encontramos con una distribución en escalera ascendente y más del 66\% considera la supervivencia material como muy importante en su VP. 

Sostenibilidad en el Mundo de la Empresa 

Cuadro $n^{\circ} 12.1$

2. Ahorro, austeridad

\begin{tabular}{|l|r|r|r|r|}
\hline & Frecuencia & Porcentaje & $\begin{array}{l}\text { Porcentaje } \\
\text { válido }\end{array}$ & $\begin{array}{c}\text { Porcentaje } \\
\text { acumulado }\end{array}$ \\
\hline poco & 32 & 15,3 & 15,3 & 15,3 \\
medianamente & 59 & 28,2 & 28,2 & 43,5 \\
mucho & 118 & 56,5 & 56,5 & 100,0 \\
Total & 209 & 100,0 & 100,0 & \\
\hline
\end{tabular}

Elaboración propia. Mayo de 2015

Gráfico ${ }^{\circ} 12.1$

\section{Ahorro, austeridad}

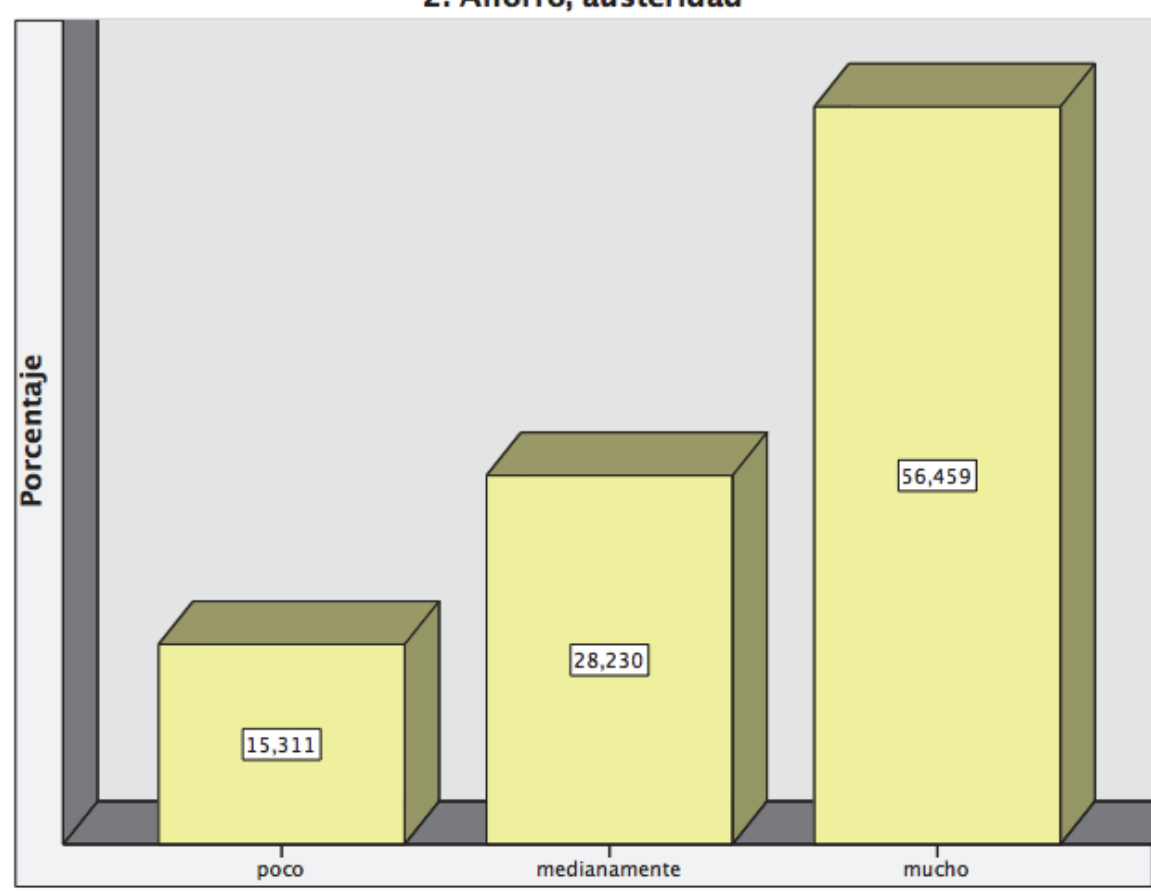

Elaboración propia. Mayo de 2015

Análisis: modelo en escalera ascendente. Más del $56 \%$ del alumnado percibe el ahorro como muy importante en el ME. 
Cuadro $n^{\circ} 12.2$

25. Eficacia, Planificación, Eficiencia

\begin{tabular}{|l|r|r|r|r|}
\hline & Frecuencia & Porcentaje & $\begin{array}{c}\text { Porcentaje } \\
\text { válido }\end{array}$ & $\begin{array}{c}\text { Porcentaje } \\
\text { acumulado }\end{array}$ \\
\hline poco & 9 & 4,3 & 4,3 & 4,3 \\
medianamente & 39 & 18,7 & 18,7 & 23,0 \\
mucho & 161 & 77,0 & 77,0 & 100,0 \\
Total & 209 & 100,0 & 100,0 & \\
\hline
\end{tabular}

Elaboración propia. Mayo de 2015

Gráfico $n^{0} 12.2$

25. Eficacia, Planificación, Eficiencia

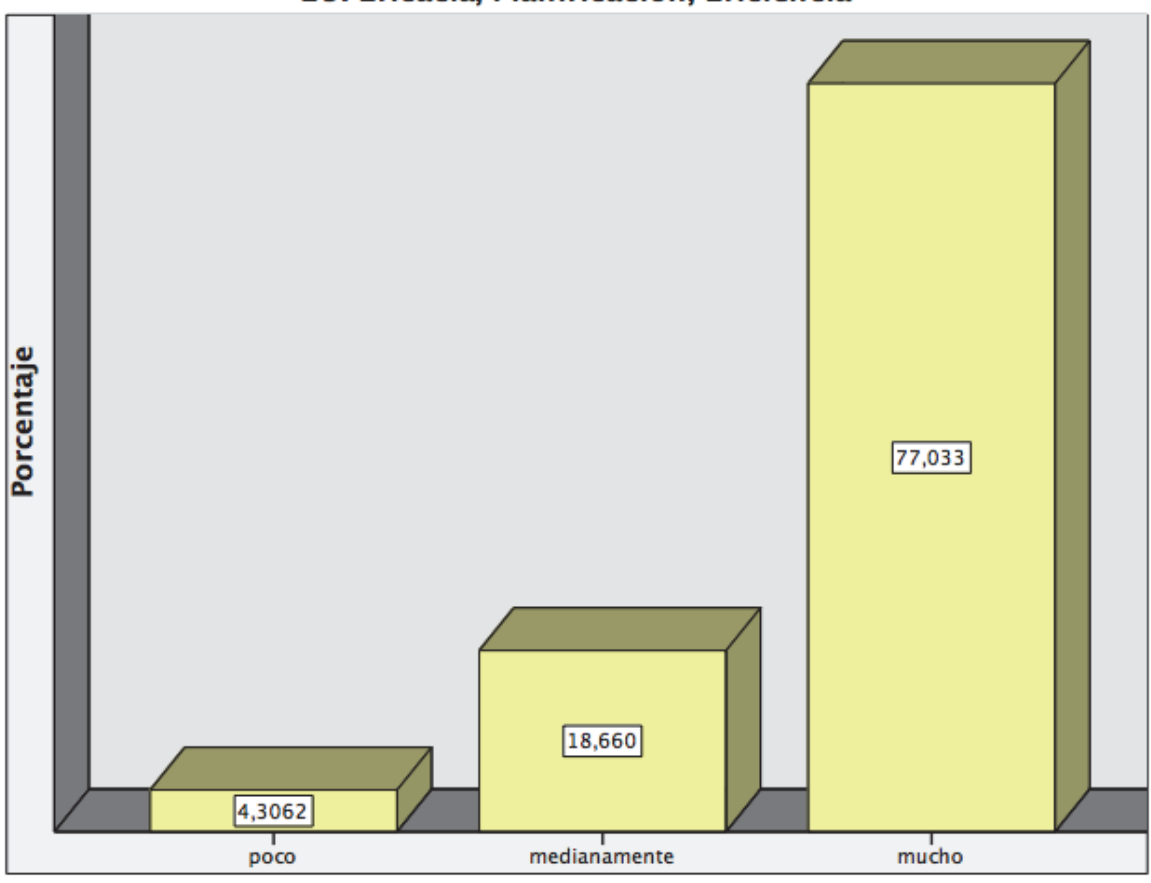

Elaboración propia. Mayo de 2015

Análisis: gráfico en escalera ascendente. Más del 77\% del alumnado también considera este valor muy importante en el ME. 
Cuadro ${ }^{\circ} 12.3$

28. Éxito económico

\begin{tabular}{|l|r|r|r|r|}
\hline & Frecuencia & Porcentaje & \multicolumn{1}{c|}{$\begin{array}{c}\text { Porcentaje } \\
\text { válido }\end{array}$} & $\begin{array}{c}\text { Porcentaje } \\
\text { acumulado }\end{array}$ \\
\hline poco & 24 & 11,5 & 11,5 & 11,5 \\
medianamente & 48 & 23,0 & 23,0 & 34,4 \\
mucho & 137 & 65,6 & 65,6 & 100,0 \\
Total & 209 & 100,0 & 100,0 & \\
\hline
\end{tabular}

Elaboración propia. Mayo de 2015

Gráfico ${ }^{\circ} 12.3$

\section{8. Éxito económico}

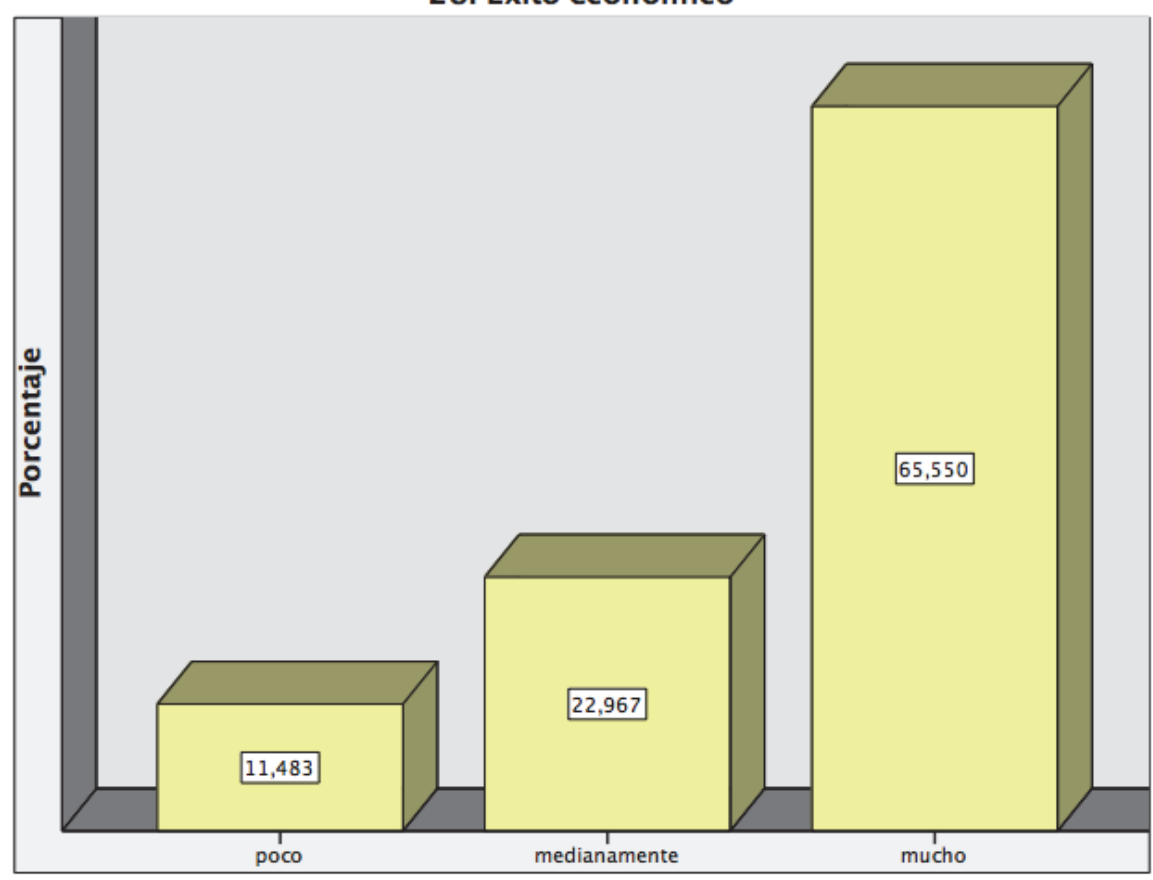

Elaboración propia. Mayo de 2015

Análisis: el éxito económico en le ME es percibido como muy importante por más del 65\% del alumnado. Distribución en escalera ascendente. 
Cuadro $n^{\circ} 12$.

50. Productividad, resultados

\begin{tabular}{|l|r|r|r|r|}
\hline & Frecuencia & Porcentaje & $\begin{array}{c}\text { Porcentaje } \\
\text { válido }\end{array}$ & $\begin{array}{c}\text { Porcentaje } \\
\text { acumulado }\end{array}$ \\
\hline poco & 8 & 3,8 & 3,8 & 3,8 \\
medianamente & 31 & 14,8 & 14,8 & 18,7 \\
mucho & 170 & 81,3 & 81,3 & 100,0 \\
Total & 209 & 100,0 & 100,0 & \\
\hline
\end{tabular}

Elaboración propia. Mayo de 2015

Gráfico $n^{0} 12.4$

50. Productividad, resultados

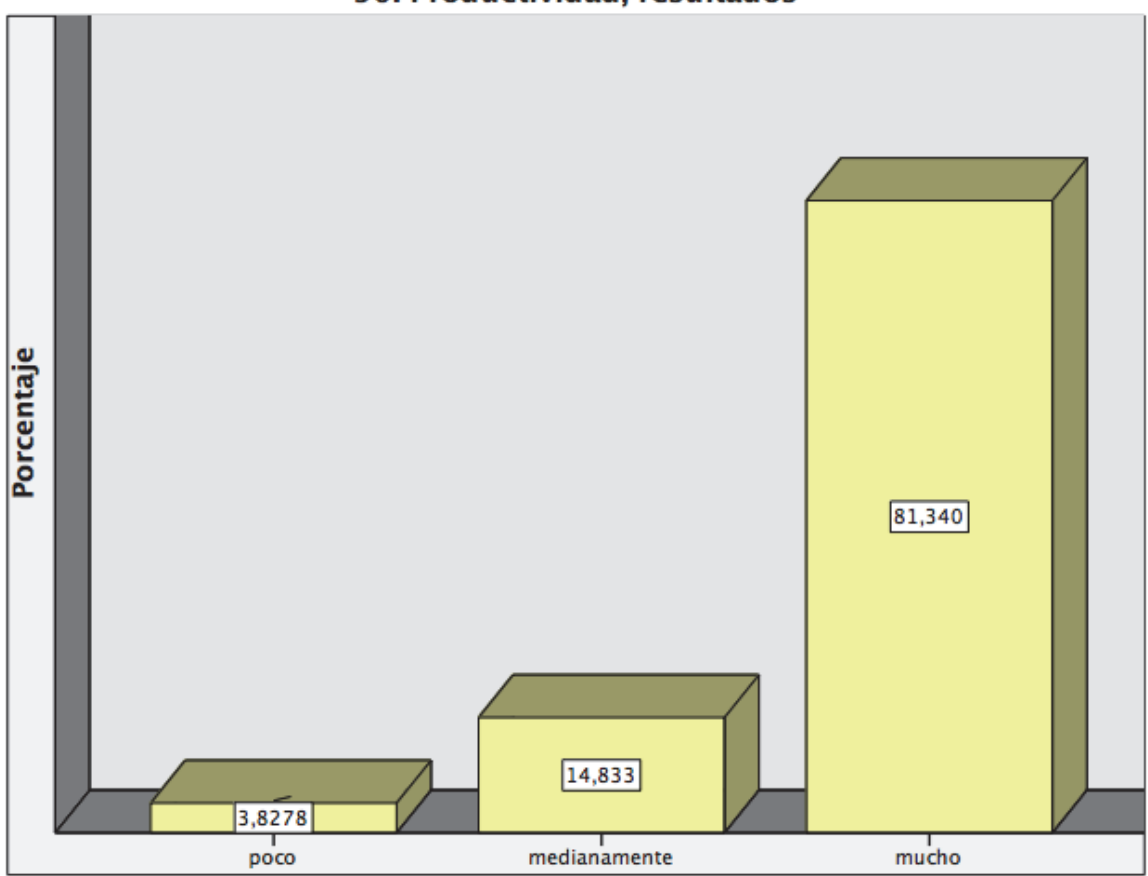

Elaboración propia. Mayo de 2015

Análisis: más del 81\% del alumnado percibe el valor Productividad, resultados como muy importante en el ME 
Cuadro $n^{\circ} 12.5$

66. Supervivencia material

\begin{tabular}{|l|r|r|r|r|}
\hline & Frecuencia & Porcentaje & $\begin{array}{c}\text { Porcentaje } \\
\text { válido }\end{array}$ & $\begin{array}{c}\text { Porcentaje } \\
\text { acumulado }\end{array}$ \\
\hline poco & 17 & 8,1 & 8,1 & 8,1 \\
medianamente & 56 & 26,8 & 26,8 & 34,9 \\
mucho & 136 & 65,1 & 65,1 & 100,0 \\
Total & 209 & 100,0 & 100,0 & \\
\hline
\end{tabular}

Elaboración propia. Mayo de 2015

Gráfico $n^{\circ} 12.5$

66. Supervivencia material

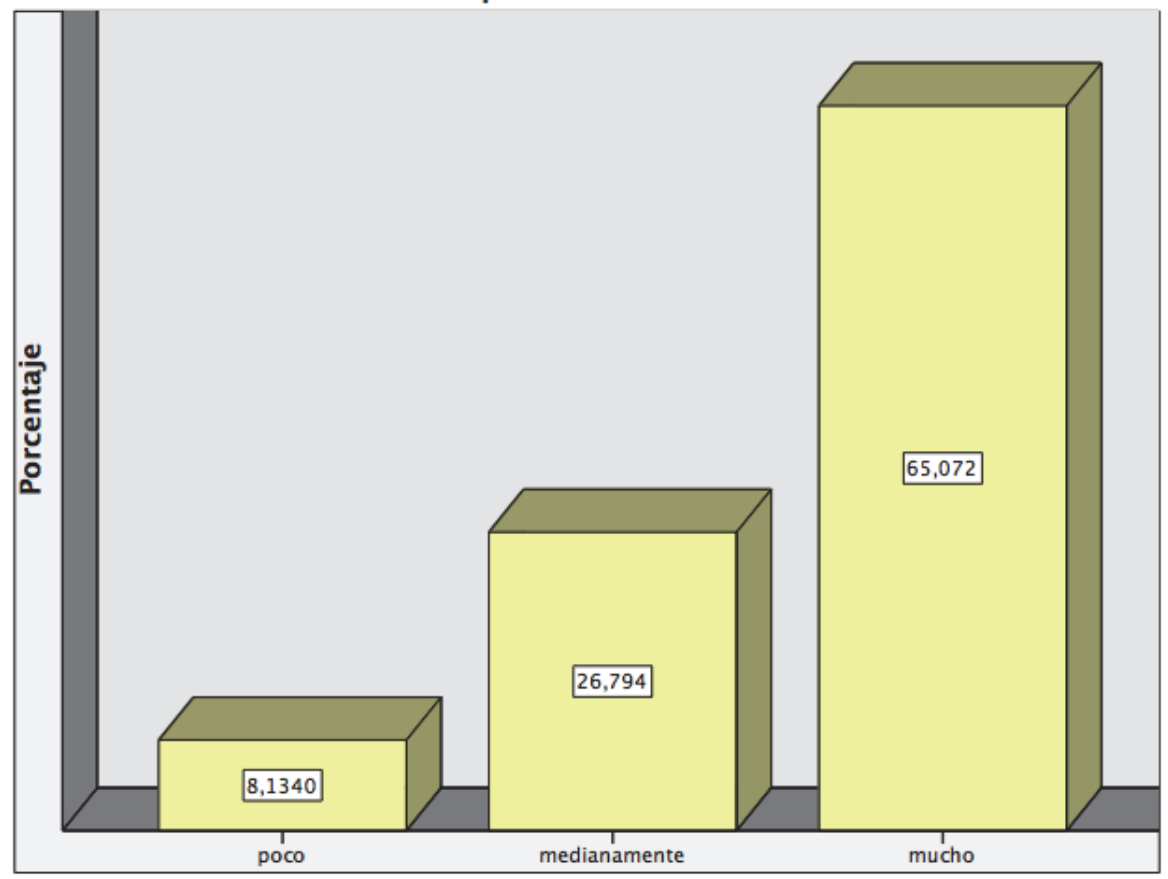

Elaboración propia. Mayo de 2015

Análisis: al igual que en los casos anteriores encontramos aquí una distribución en escalera ascendente. Más del $65 \%$ del alumnado considera que la supervivencia material es muy importante en el ME. 


\section{ANÁLISIS CUALITATIVO DEL GRUPO SOSTENIBILIDAD:}

Los 5 ítems son percibidos por el alumnado como muy importantes, y más aun a nivel del ME que de la VP. Resultados a favor de una mejor sostenibilidad del sistema. El alumnado percibe que la sostenibilidad del SNS es muy importante, y esta es una de las preguntas estrella de nuestra tesis. 
RESULTADOS 

En nuestro trabajo empírico, hemos obtenido dos cuadros y sendos gráficos de frecuencias y porcentajes por cada ítem del "Cuestionario de Valores 'MbV-72"” utilizado para realizar las encuestas, uno correspondiente a "mi vida personal" y otro al "mundo de la empresa". En total 144 cuadros con sus gráficos. Hemos coloreado los gráficos en verde y ocre respectivamente, para distinguirlos.

Del análisis de los resultados hemos observado distintos patrones de comportamiento de los datos obtenidos, que pasamos a exponer.

\section{Modelo 1: Escalera ascendente y modelo en pirámide asimétrica con sesgo a la derecha.}

Observamos que las respuestas se concentran entre el 4 y 5. El peso recae claramente en las puntuaciones altas. Aparece como una escalera ascendente o como una pirámide asimétrica con el peso en la parte derecha del gráfico. Consideramos que estos dos modelos, aunque algo diferentes en la morfología, significan lo mismo para nuestro estudio, pues representan valores catalogados como importantes por la muestra en estudio:
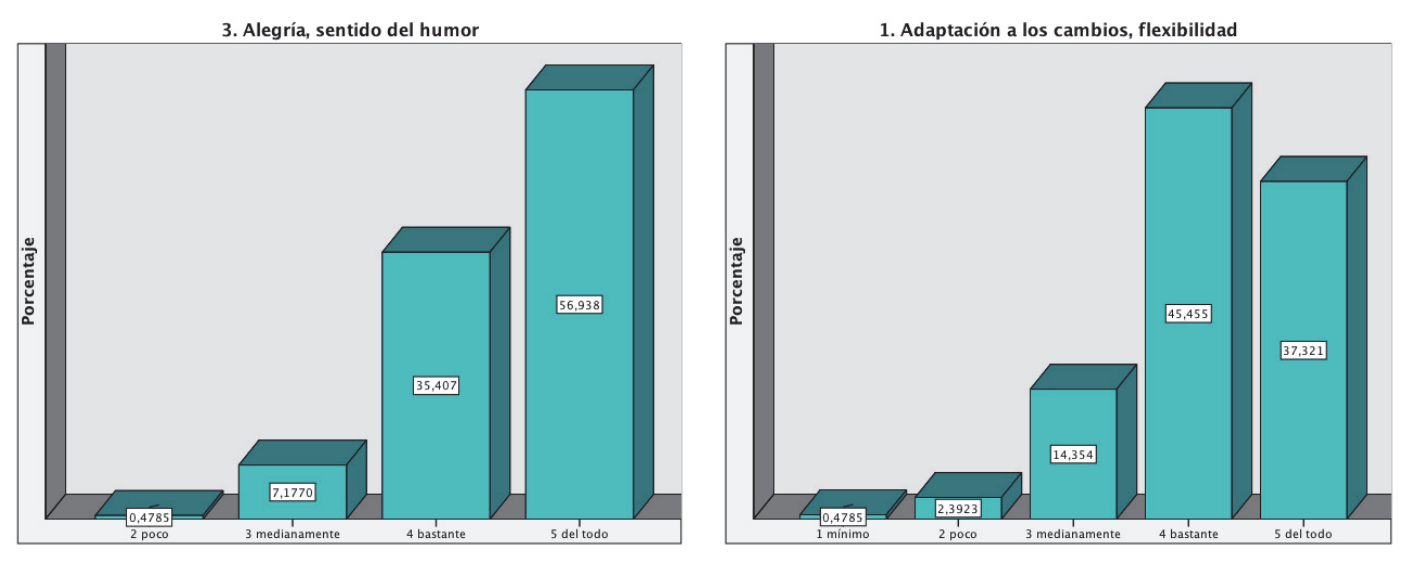

\section{Modelo 2: patrón en pirámide}

Respuestas distribuidas con mayor tendencia a valores centrales, el peso tira hacia el centro: “3, medianamente”. Dispersión de la importancia de ese valor 
para la muestra en estudio. El valor aparece como medianamente importante, ni poco ni mucho.

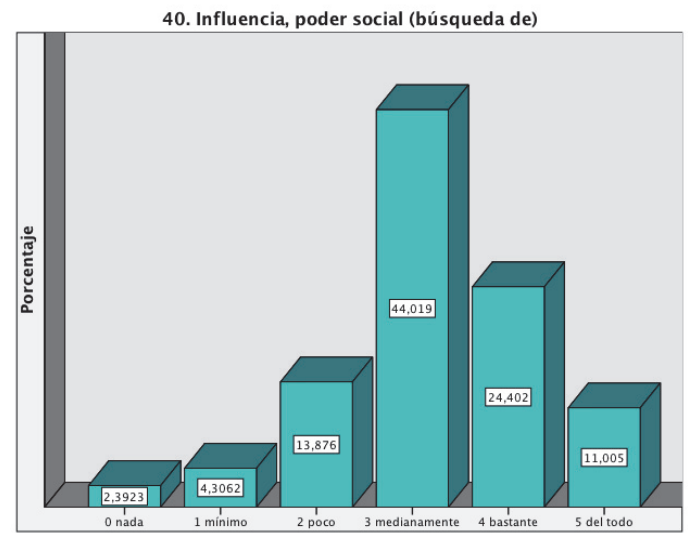

\section{Modelo 3: modelo en L}

Las respuestas se distribuyen entre todas las puntuaciones con preponderancia del 0 . Modelo inverso al primero (en escalera ascendente y en pirámide asimétrica con sesgo a la derecha). A este, lo denominamos modelo en L. Valores considerados poco o nada importantes

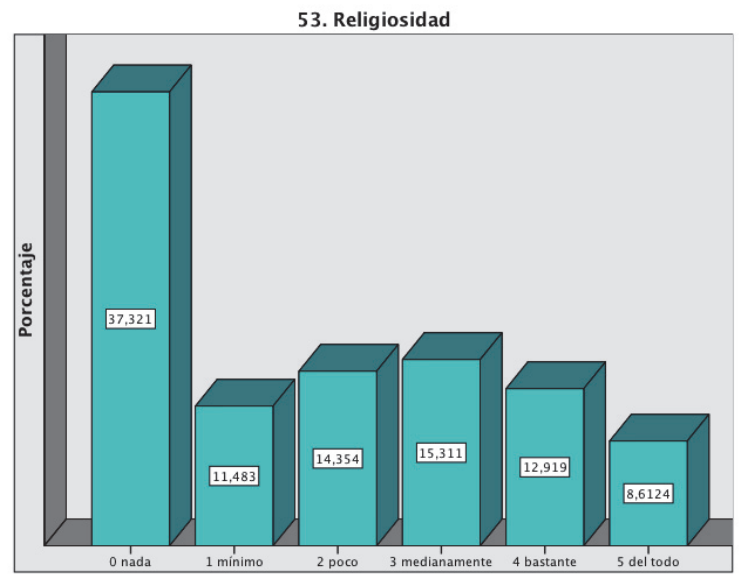

\section{Modelo 4: escalera aplanada}

Los porcentajes van subiendo en escalera a nivel de las puntuaciones bajas para luego variar poco a nivel de las puntuaciones más altas. Las respuestas 
difieren en la importancia otorgada al valor, una parte de la muestra en estudio lo considera medianamente importante y otras partes, más o menos iguales cuantitativamente, lo perciben como importante o muy importante. Las respuestas se distribuyen sin polarizarse en una opinión común a la mayoría.

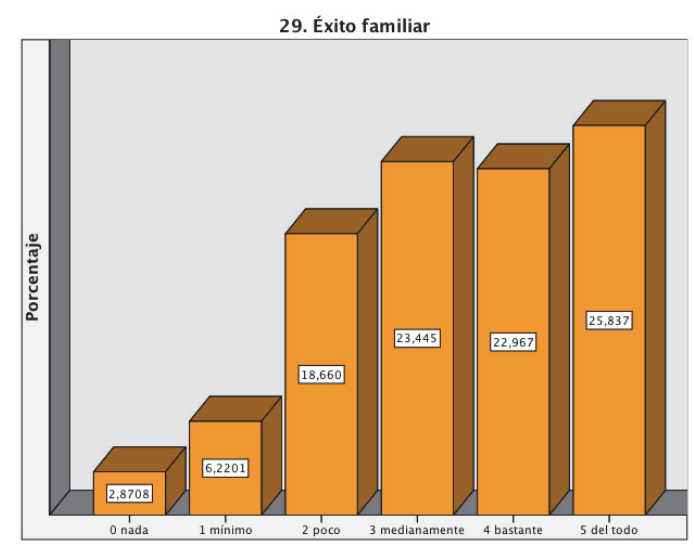

En el área de mi VP aparecen los modelos 1, 2 y 3 mientras que en el ME encontramos los cuatro modelos.

\section{Con el Modelo 1: Escalera ascendente y modelo en pirámide asimétrica con}

sesgo a la derecha, encontramos los siguientes ítems:

Vida Personal: 57 de los 72 ítems:

1. Adaptación a los cambios, flexibilidad.

3. Alegría, sentido del humor.

4. Amistad.

6. Apertura, diálogo, igualdad, franqueza.

7. Aprendizaje continuo.

9. Calidez, cercanía.

10. Coherencia.

11. Comodidad, vida confortable.

12. Compartir, generosidad.

14. Comunicación/información.

15. Confianza.

17. Control, orden, disciplina. 
18. Cooperación, colaboración, espíritu de equipo.

19. Cortesía.

20. Crecimiento/expansión.

21. Creer y poner cariño en lo que se hace.

23. Derechos humanos, Dignidad.

24. Disfrutar del trabajo.

25. Eficacia, Planificación, Eficiencia.

26. Equidad, justicia en el día a día.

27. Equilibrio entre el trabajo y vida familiar y personal.

29. Éxito familiar.

30. Expresividad/libertad.

31. Felicidad (búsqueda de la ).

32. Honestidad, honradez, transparencia, sinceridad.

33. Humildad, modestia.

34. Idealismo.

35. Igualdad/Liberación.

37. Imaginación, creatividad, fantasía.

38. Inconformismo, rebeldía ante la justicia.

39. Independencia, iniciativa, autonomía de acción.

41. Lealtad/Fidelidad.

43. Mundo en paz.

44. Obediencia, cumplimiento.

45. Pasión, entusiasmo.

47. Perseverancia/Paciencia.

48. Placer intelectual.

49. Placer sexual.

50. Productividad, resultados.

51. Realismo, pragmatismo, racionalidad.

52. Reconocimiento emocional (darlo y buscarlo).

54. Respeto y armonía con los demás.

55. Respeto y armonía con uno mismo.

56. Respeto y armonía medioambiental.

57. Riesgo, aventura, estímulo, novedad. 
58. Rigor técnico-profesional.

59. Salud/bienestar.

60. Seguridad.

62. Ser querido por los demás.

63. Servicio/vocación.

64. Simplicidad, rapidez, agilidad.

65. Solidaridad, generosidad.

67. Tecnología/ciencia, innovación.

68. Tiempo libre.

70. Trascendencia, utilidad para otros.

71. Valentía, coraje.

72. Verdad/sabiduría (búsqueda de la).

En el Mundo de la empresa, con estos modelos encontramos 39 de los 72 ítems:

1. Adaptación a los cambios, flexibilidad.

5. Anticipación, previsión.

7. Aprendizaje continuo.

10. Coherencia.

12. Compartir, generosidad.

13. Competitividad, ambición, trabajo duro.

14. Comunicación/información.

15. Confianza.

17. Control, orden, disciplina.

18. Cooperación, colaboración, espíritu de equipo.

19. Cortesía.

20. Crecimiento/expansión.

21. Creer y poner cariño en lo que se hace.

23. Derechos humanos, Dignidad.

24. Disfrutar del trabajo.

25. Eficacia, Planificación, Eficiencia. 
28. Éxito económico.

31. Felicidad (búsqueda de la).

36. Imagen, prestigio social.

40. Influencia, poder social (búsqueda de).

41. Lealtad/Fidelidad.

44. Obediencia, cumplimiento.

45. Pasión, entusiasmo.

47. Perseverancia/Paciencia.

50. Productividad, resultados.

51. Realismo, pragmatismo, racionalidad.

54. Respeto y armonía con los demás.

55. Respeto y armonía con uno mismo.

56. Respeto y armonía medioambiental.

58. Rigor técnico-profesional.

59. Salud/bienestar.

60. Seguridad.

62. Ser querido por los demás.

63. Servicio/vocación.

64. Simplicidad, rapidez, agilidad.

66. Supervivencia material.

67. Tecnología/ciencia, innovación.

70. Trascendencia, utilidad para otros.

72. Verdad/sabiduría (búsqueda de la).

\section{Modelo 2: patrón en pirámide}

En el área de mi Vida Personal: Con este modelo se presentan 14 de los 72 ítems:

2. Ahorro, austeridad.

5. Anticipación, previsión.

8. Arte/belleza, armonía estética.

13. Competitividad, ambición, trabajo duro.

16. Contemplación, meditación, serenidad. 
22. Deleite físico, Hedonismo.

28. Éxito económico.

36. Imagen, prestigio social.

40. Influencia, poder social (búsqueda de).

42. Moderación, tener pocos deseos.

46. Patriotismo.

61. Sentido de la vergüenza.

66. Supervivencia material.

69. Tradición, conservación.

En el Mundo de la empresa:

Con este modelo encontramos 20 de los 72 ítems:

4. Amistad.

6. Apertura, diálogo, igualdad, franqueza.

8. Arte/belleza, armonía estética.

9. Calidez, cercanía.

11. Comodidad, vida confortable.

16. Contemplación, meditación, serenidad.

22. Deleite físico, Hedonismo.

30. Expresividad/libertad.

33. Humildad, modestia.

34. Idealismo.

35. Igualdad/Liberación.

37. Imaginación, creatividad, fantasía.

38. Inconformismo, rebeldía ante la justicia.

39. Independencia, iniciativa, autonomía de acción.

42. Moderación, tener pocos deseos.

46. Patriotismo.

57. Riesgo, aventura, estímulo, novedad.

61. Sentido de la vergüenza.

68. Tiempo libre.

69. Tradición, conservación. 


\section{Modelo 3: modelo en $L$}

En el área de mi Vida Personal, con este modelo se presenta 1 de los 72 ítems:

53. Religiosidad.

En el Mundo de la empresa encontramos 2 los 72 ítems:

49. Placer sexual.

53. Religiosidad.

Modelo 4: escalera aplanada

En el área de mi Vida Personal: no encontramos ninguno.

En el Mundo de la empresa: con este modelo encontramos 11 de los 72 ítems:

2. Ahorro, austeridad.

3. Alegría, sentido del humor.

26. Equidad, justicia en el día a día.

27. Equilibrio entre el trabajo y vida familiar y personal.

29. Éxito familiar.

32. Honestidad, honradez, transparencia, sinceridad.

43. Mundo en paz.

48. Placer intelectual.

52. Reconocimiento emocional (darlo y buscarlo).

65. Solidaridad, generosidad.

71. Valentía, coraje. 


\section{VALORES CLARAMENTE IMPORTANTES PARA LA MUESTRA EN ESTUDIO:}

En el área de mi VP:

1. Adaptación a los cambios, flexibilidad.

3. Alegría, sentido del humor.

4. Amistad.

6. Apertura, diálogo, igualdad, franqueza.

12. Compartir, generosidad.

15. Confianza.

37. Imaginación, creatividad, fantasía.

38. Inconformismo, rebeldía ante la injusticia social.

39. Independencia, iniciativa, autonomía de acción.

41. Lealtad/Fidelidad.

43. Mundo en paz.

45. Pasión, entusiasmo.

48. Placer intelectual.

49. Placer sexual.

52. Reconocimiento emocional (darlo y buscarlo).

56. Respeto y armonía medioambiental.

57. Riesgo, aventura, estímulo, novedad.

61. Sentido de la vergüenza.

62. Ser querido por los demás.

65. Solidaridad, generosidad.

68. Tiempo libre.

71. Valentía, coraje.

En las áreas de mi VP y el ME: 15

14. Comunicación/información.

47. Perseverancia/Paciencia.

50. Productividad, resultados.

51. Realismo, pragmatismo, racionalidad. 
54. Respeto y armonía con los demás.

55. Respeto y armonía con uno mismo.

58. Rigor técnico-profesional.

59. Salud/bienestar.

60. Seguridad.

62. Ser querido por los demás.

63. Servicio/vocación.

64. Simplicidad, rapidez, agilidad.

67. Tecnología/ciencia, innovación.

70. Trascendencia, utilidad para otros.

72. Verdad/sabiduría (búsqueda de la).

\section{En el área del ME:}

13. Competitividad, ambición, trabajo duro.

36. Imagen, prestigio social.

44. Obediencia, cumplimiento.

\section{VALORES DE IMPORTANCIA MEDIA:}

\section{En el área de mi VP: 2}

2. Ahorro, austeridad.

40. Influencia, poder social (búsqueda de).

\section{En las áreas de mi VP y el ME: 1}

42. Moderación, tener pocos deseos.

\section{En el área del ME:}

37. Imaginación, creatividad, fantasía.

38. Inconformismo, rebeldía ante la injusticia social.

57. Riesgo, aventura, estímulo, novedad.

61. Sentido de la vergüenza.

69. Tradición, conservación. 


\section{VALORES DE POCA IMPORTANCIA:}

EN LAS ÁREAS DE MI VP y el ME:

46. Patriotismo VP y ME

53. Religiosidad VP y ME

\section{En el área del ME:}

49. Placer sexual ME

\section{VALORES SIMILARES EN AMBOS MUNDOS:}

5. Anticipación, previsión: pirámide

7. Aprendizaje continuo: escalera ascendente.

8. Arte/belleza, armonía estética: pirámide.

10. Coherencia: pirámide asimétrica con sesgo a la derecha.

14. Comunicación/información pirámide asimétrica con sesgo a la derecha (VP), escalera ascendente (ME)

16. Contemplación, meditación, serenidad, pirámide.

18. Cooperación, colaboración, espíritu de equipo, escalera ascendente.

19. Cortesía, pirámide asimétrica con sesgo a la derecha.

20. Crecimiento/expansión. pirámide asimétrica con sesgo a la derecha.

22. Deleite físico, Hedonismo, pirámide.

23. Derechos humanos, Dignidad, escalera ascendente.

25. Eficacia, Planificación, Eficiencia, pirámide sesgada a la derecha (VP), escalera ascendente (ME)

34. Idealismo, pirámide. Medianamente importante

42. Moderación, tener pocos deseos, pirámide.

46. Patriotismo, pirámide.

51. Realismo, pragmatismo, racionalidad, pirámide sesgada a la derecha.

53. Religiosidad, Modelo en L.

58. Rigor técnico-profesional, pirámide sesgada a la derecha.

59. Salud/bienestar, escalera ascendente. 
60. Seguridad, escalera ascendente.

61. Sentido de la vergüenza, pirámide.

62. Ser querido por los demás, escalera ascendente.

64. Simplicidad, rapidez, agilidad, pirámide asimétrica con sesgo a la derecha. 70. Trascendencia, utilidad para otros, pirámide asimétrica sesgada a la derecha.

\section{Valores con comportamiento diferentes en ambos mundos:}

4. Amistad: escalera ascendente (VP), pirámide (ME).

6. Apertura, diálogo, igualdad, franqueza: escalera ascendente (VP), pirámide (ME).

30. Expresividad/libertad: escalera ascendente (VP), pirámide (ME).

32. Honestidad, honradez, transparencia, sinceridad: escalera ascendente (VP), escalera aplanada (ME).

49. Placer sexual, escalera ascendente (VP), modelo en L (ME)

68. Tiempo libre, escalera ascendente (VP), pirámide (ME).

\section{Patrones de comportamiento de los}

\section{valores de compromiso social, seguridad, armonía, confianza y sostenibilidad.}

Tanto para el área de mi VP como para el ME obtenemos siempre el modelo en escalera ascendente. Solamente encontramos un ítem que presenta otro 
modelo: en pirámide; se trata de "38. Inconformismo, rebeldía ante la injusticia." en el sub-área de compromiso social en el ME.

Los resultados son inequívocos y demuestran lo interiorizado que enfermería tiene estos valores tanto en la VP como para el ME. 

DISCUSIÓN 



\section{LA ORGANIZACIÓN SANITARIA Y LA FEMINIZACIÓN DE}

\section{LA PROFESIÓN ENFERMERA}

De nuestro trabajo teórico observamos, en cuanto a la organización sanitaria y la feminización de la profesión enfermera, que entre los/las trabajadores del Sistema Nacional de Salud español predomina lo femenino y la profesión de Enfermería. Pero tradicionalmente las profesiones, y las sanitarias especialmente, han estado rígidamente distribuidas por sexo. Las profesiones, al igual que el resto de la sociedad, son algo construido y han sido ejercidas rígidamente por hombres o mujeres, asociando profesión y características de género como si fuera algo natural e inmutable a la vez que cambiaban en función de los valores hegemónicos del momento histórico.

Hasta los siglos XIX y XX en que la mujer consigue poner un pie en la Universidad, las profesiones de médico, boticario y veterinario fueron desempeñadas exclusivamente por hombres, mientras que enfermería y parteras eran practicadas por mujeres como si no pudiese ser de otra manera; esto era la consecuencia de políticas activas y mantenidas de exclusión de la mujer y de su reclusión en nichos laborales. La incorporación de valores considerados como masculinos a ciertas profesiones ha sido un proceso activo e incluso cambiante a lo largo del tiempo. Así vemos que en la alta Edad Media en que el cristianismo predica el altruismo puro y fundamenta la salvación eterna en la caridad, los cuidados al enfermo pasan a ser desempeñados en gran medida por hombres, $\mathrm{y}$ surgen órdenes masculinas conocidas como caballeros hospitalarios: Caballeros de Malta, Caballeros Teutónicos, Caballeros de San Lázaro... También vemos como en los siglos XVIII y XIX, la atención al parto que había sido un espacio tradicionalmente femenino se reconvirtió en masculino. Es más, en 1988 la OMS describe como natural lo construido al afirmar que la ambición, la competitividad, la agresividad, la dominación, la racionalidad y la objetividad corresponden a lo masculino mientras que la sumisión, la pasividad, la dependencia, el cuidado de los demás, la emotividad y la subjetividad constituyen el estereotipo femenino. Pero como muy bien apunta Simone de BEAUVOIR en el segundo sexo (2011, p. 45), tomando palabras prestadas de POULAIN DE LA BARRE: "Todo cuanto 
han escrito los hombres sobre las mujeres debe ser sospechoso, pues son a un tiempo juez y parte."

Dicho de otra manera, durante siglos la sociedad ha creído o ha querido creer que al hombre le nacían las características mencionadas, entre ellas la racionalidad, igual que le nacía la barba, solo por ser hombre y solo a los hombres. A lo largo del tiempo, el hombre ha escogido los mejores trabajos y también las mejores cualidades personales o ha dado más valor a aquellas que se atribuía a sí mismo. Incluso con profundas contradicciones a veces, pues el hombre es visto como racional y objetivo, mientras que la mujer aparece como emotiva y subjetiva en una sociedad cristiana con un Dios que es amor infinito.

Consideramos que las verdaderas características del carácter psicológico y conductual masculino y femenino están por determinar. Lo que sí es cierto es que hombres y mujeres presentan diferencias en su comportamiento y realizan el mismo trabajo con un carácter cualitativo diferente, por lo que la feminización de la Sanidad debe estudiarse desde una perspectiva cuantitativa descriptiva, pero también desde una perspectiva cualitativa. Atendiendo a esta última, una marcada diferenciación de género se manifiesta en cuanto a la dedicación a la profesión. Más de la mitad de los hombres tienen varias ocupaciones combinando la esfera hospitalaria con la no hospitalaria, y lo público con lo privado. Mientras que sólo una cuarta parte de las mujeres optan por el pluriempleo, priorizando la conciliación de la vida laboral y familiar sobre el máximo desarrollo de la carrera profesional.

En el caso concreto de la profesión veterinaria se han producido cambios notables. Hemos pasado del tradicional veterinario rural a un veterinario urbano que trabaja para las Administraciones Públicas o que está al frente de una clínica de animales pequeños. Estos puestos los vemos, cada vez con mayor frecuencia, ocupados por mujeres jóvenes.

Un punto fundamental en el estudio de la perspectiva cualitativa del trabajo femenino es la ética del cuidado de Carol Gilligan y de Nel Noddings

Por otro lado, encontramos tal y como planteó Gilligan, que las características que tradicionalmente han definido la "bondad" de las mujeres son su atención y sensibilidad a las necesidades de otros. Lo que permitió a Gilligan desarrollar su Ética del cuidado o de la dependencia en contraposición a la Ética 
de la justicia de Kohlberg basada en el pensamiento de Immanuel Kant y John Rawls que hace referencia a los derechos individuales y a las normas y obligaciones generales. Y atendiendo a las investigaciones de Nel Noddings, encontramos que todo comportamiento ético proviene de los sentimientos, área especialmente desarrollada en la mujer. Por todo ello no cabe duda que la feminización de las profesiones sanitarias traerá consigo notables cambios cualitativos que se harán notar más cada día.

La feminización de las profesiones sanitarias conlleva un cambio sustancial en el perfil profesional. Este cambio tiene aspectos cuantitativos $\mathbf{y}$ cualitativos, con respecto a estos últimos, la mujer trae consigo la ética del cuidado lo cual determina un cambio en los valores y una mayor humanización de la atención a la salud. Desde una perspectiva de género, observamos un hecho paradójico: cuidar es mantener la vida, la vida necesita cuidados desde que comienza hasta que termina, sin cuidados no habría vida, y sin vida no hay nada. Estos cuidados, los viene dando tradicionalmente la mujer y profesionalmente la Enfermería, con el arte y la generosidad propios de la ética del cuidado, y sin embargo no han sido nunca valorados, incluso han sido menospreciados.

\section{SOBRE LOS VALORES EN LAS CIENCIAS DE LA SALUD}

En las ciencias de la salud, varios son los valores que emergen: solidaridad, cooperación, vida-supervivencia, sensibilidad, compasión, amor, responsabilidad, incondicionalidad, sentido de pertenencia.

Lo vemos en el caso del cráneo desdentado de Dmanisi. Solidaria era, sin lugar a dudas, la actitud de aquellas personas que, hace 1,8 millones de años, gastaron o emplearon o invirtieron energías en mantener con vida a una persona que ya no lo podía hacer por sí misma. Y nos podemos preguntar por qué lo hacían. Para que se dé una acción tiene que haber algo atractivo en la propia acción y para que se repita tiene que haber algún beneficio. La atracción primitiva la podemos situar fácilmente en un sentimiento de amor hacia el desvalido desdentado, seguramente alguna relación de tipo familiar, serían sus hijas o hijos, 
sus seres queridos... que sentían compasión y dolor ante la perspectiva de la pérdida de esta persona cuyo cráneo nos habla hoy. Y ¿cual pudo ser la recompensa para que esa actitud se haya repetido hasta el presente? También es fácil imaginarlo, el conocimiento acumulado por la experiencia de la vida que así se podía transmitir de generación en generación facilitando la superación de los problemas que plantea la supervivencia y la creación de un acervo cultural que permitiera la aparición de la civilización. No podemos obviar que no solo cumplían de esta forma el mandato ontogenético del mantenimiento de la vida individual, sino también el filogenético del mantenimiento de la especie. Mandatos, ambos, de orden categórico, sobre todo el segundo. Así mismo podemos afirmar que el ser humano, tan desprovisto de mecanismos de defensa y ataque en comparación con otras especies animales, se hace hegemónico en el orden natural por, entre otros factores, la cooperación y solidaridad que lo caracteriza, consiguiendo que la unión de las competencias individuales dé lugar a una progresión geométrica en la que uno más uno es más que dos.

Estos mismos valores se vuelven a ver aquel 24 de junio de 1859 en Solferino cuando Henri Dunant, movido por la compasión, el compromiso social, por el amor y el sentido de pertenencia a la especie humana, la incondicionalidad, la sensibilidad y el humanismo con los más desvalidos, consigue unir, a la voz de "Tutti fratelli" los esfuerzos de los habitantes de los pueblos vecinos para auxiliar a los cuarenta mil caídos en el campo de batalla.

También se vuelven a ver después de la II Guerra mundial cuando empiezan a aparecer las ONG como agentes de desarrollo basadas en la solidaridad.

Y estos valores aparecen refrendados de forma notoria por el conjunto de la sociedad al ser premiadas estas acciones con el Nobel de la Paz, en 1901 para Henri Dunant y en 1999 para Médicos Sin Fronteras.

La Solidaridad es traída a la palestra también por Durkheim quien postula que es este valor es el que mantiene unida y cohesionada la sociedad moderna.

Pero también aparecen con aplastante insistencia otros valores como son el conocimiento, las destrezas prácticas, la objetividad, el rigor científico y la creatividad. 
El valor conocimiento resuena con fuerza en ciencias de la salud cuando se habla de la disección de cadáveres y la anatomía como ciencia base, la circulación de la sangre, el pulso, la respiración, Leeuwenhoek y el microscopio, Malpighi y la histología, Pasteur y Koch y la microbiología... y tantos y tantos nombres más que constituyen la historia de la medicina y de otras ciencias de la salud.

En Enfermería es Florence de Nightingale, quien aplicando con rigor sus avanzados conocimientos de estadística a la epidemiología consigue demostrar que la mayoría de las muertes en la guerra de Crimea (1853-1856) se producían por falta de cuidados y logra hacer caer la mortalidad del al 2\%. A su regreso, también logra fundar la primera escuela laica de enfermería en el mundo y surge la Enfermería como profesión cuando cumple tres requisitos: una formación reglada, una retribución por su práctica y un código ético que garantice su ejercicio. Pero todavía le faltará más de un siglo para que empiece a liberarse de la discriminación de género de la que es víctima.

La compasión y los cuidados como ética llevada hasta lo social y a la responsabilidad política y de Estado es lo que determina que se promulgue la Ley de la Dependencia y se implemente a nivel nacional.

La Compasión, Competencia, Confianza, Conciencia y Compromiso son la cinco C's que Mary Simone Roach, enfermera y filósofa canadiense, propone para su modelo de cuidados y sostiene que el cuidado es una actitud integrada de forma inherente a la propia condición del ser humano, y que la Enfermería es la profesionalización de la capacidad humana de cuidar a través de la adquisición de conocimientos y habilidades.

Para Milton Mayeroff cuidar es ayudar a otro a crecer, independientemente de que ese otro sea una persona, una obra, un proyecto, una idea... y sostiene que el cuidado implica una serie de valores: dedicación, confianza, humildad, honestidad, conocimiento del otro, respeto al proceso del otro, esperanza y valentía.

En el Manifiesto de Espinoso de Compludo los valores éticos, prácticos y emocionales recogidos como fundamentales para inspirar la buena práctica de la profesión enfermera son: Compromiso Social (respeto, dignidad, autonomía), Seguridad (entorno físico adecuado, calidad y competencia profesional), Armonía 
(bienestar, creatividad y alegría) y la Confianza como metavalor a impulsar para contribuir a la eficiencia y la humanización de la atención a la salud.

SALVADOR GARCÍA considera la confianza (creer en) junto con la coherencia (pensar-decir-hacer) como metavalores que se encuentran en el núcleo del modelo triaxial. Defiende esta centralidad con argumentos como que la confianza es un valor simplificador y antiburocrático, generador de fluidez vital y organizativa. Un valor que atrae a clientes, inversores, proveedores y futuros empleados, y que genera cohesión grupal y organizativa.

La confianza es esencial para el bienestar emocional y genera el ambiente necesario para que aparezca la iniciativa, la creatividad, el diálogo y el aprendizaje organizativo. El miedo y la confianza son polos opuestos, igual que el amor y el odio, o la guerra y la paz. El autor distingue entre la autoconfianza, creencia en uno mismo; la heteroconfianza, dirigida hacia los demás y la confiabilidad que es la confianza que inspiramos en los demás.

Postulamos como valores de las ciencias de la salud: la solidaridad, compromiso social, seguridad, armonía, confianza, alegría, amor-compasión, dignidad, respeto, autonomía de las personas, sensibilidad, equilibrio, bienestar, responsabilidad, conocimiento, competencia profesional, destrezas prácticas, objetividad, rigor científico y creatividad-innovación.

\section{LA DIRECCIÓN POR VALORES COMO HERRAMIENTAS DE GESTIÓN EFICAZ.}

El SNS español es una administración pública, pero también es una empresa. La Administración pública es la "Función del Estado que consiste en aplicar las leyes y cuidar de los intereses y el bienestar públicos.” En este sentido el SNS aplica el artículo 43 de la CE, la Ley 14/1986, de 25 de abril, General de Sanidad; y cuida de la salud de la población que habita en España.

Weber, teórico de las relaciones de poder y autoridad en las burocracias, sostiene que el poder es aquello que obliga a los individuos a obedecer incluso en contra de la propia voluntad, mientras que autoridad es aquello que logra el 
cumplimiento voluntario de las órdenes recibidas.

Dentro de los 3 tipos de autoridades que Weber describe, la tradicional, la carismática y la legal, racional o burocrática; el SNS pertenece a esta última; con sus características: legalidad de las normas, formalidad de las comunicaciones, racionalidad de la división del trabajo, impersonalidad en las relaciones, jerarquía de la autoridad, normalización de los procedimientos, competencia técnica y meritocracia, especialización de la administración, profesionalización de los funcionarios, previsibilidad del funcionamiento. Con las ventajas de la burocracia: control, previsibilidad y eficiencia; pero también con sus inconvenientes: rigidez y lentitud.

El SNS también es una empresa y como tal se comporta con respecto a los profesionales que desempeñan las funciones sanitarias en beneficio de los usuarios/pacientes.

Como empresa observamos que desarrolla una dirección por objetivos: DpO, pues todos los años firmamos los objetivos marcados y en función de su logro se establece el cobro de la productividad.

En algunos momentos, hasta se puede decir que existe una dirección por instrucciones, pues los profesionales de niveles jerárquicos superiores dan órdenes que cumplir a profesionales de escalas subordinadas. Esto es posible porque la DpI requiere ambientes muy estables que encuentra fácilmente en una administración pública. De esta forma se crean situaciones excesivamente monótonas y poco enriquecedoras que originan absentismo físico o psíquico. Sin embargo subyacen los valores pues las carreras sanitarias son vocacionales por lo que la implementación de la DpV en el SNS es fácil, hasta se puede decir que las características propias de las profesiones sanitarias lo demandan.

La $\mathrm{DpV}$ va más allá de la $\mathrm{DpO}$ y de la $\mathrm{DpI}$ englobándolas a ambas y superándolas. Parte de unas creencias esenciales, determina un enfoque metodológico propio y la aparición de un orden organizacional y creativo de orden superior necesarios en el contexto específicamente sanitario.

EI SNS es una Administración Pública y también una empresa en la que encontramos la DpO e incluso hasta la DpI y sin embargo subyacen los valores pues las carreras sanitarias son vocacionales. La implementación de 
la $\mathrm{DpV}$, que encontraría rápidamente eco con los valores propios del mundo sanitario, determinaría un enfoque metodológico propio y la aparición de un orden organizacional y creativo de orden superior necesarios en el contexto específicamente sanitario.

\section{DEL ESTUDIO EMPÍRICO}

En el área de mi VP, 57 ítems aparecen como "muy importantes", 14 como "medianamente importantes" y tan solo uno como "poco o nada importante", ninguno como poco definido.

En el área del ME encontramos 39 "muy importantes", 20 “medianamente importantes", 2 como poco o nada importantes y encontramos 11 ítems con respuestas poco definidas.

\begin{tabular}{|c|c|c|}
\hline & $\begin{array}{c}\text { Área de mi Vida } \\
\text { Personal }\end{array}$ & Área del Mundo Empresa \\
\hline Muy importante & 57 ítems & 39 ítems \\
\hline Medianamente importante & 14 ítems & 20 ítems \\
\hline Poco o nada importante & 1 ítems & 2 ítems \\
\hline Poco definido & 0 ítems & 11 ítems \\
\hline
\end{tabular}

La muestra encuestada presenta una percepción más definida con respecto a los valores que rigen su VP que en cuanto a los que rigen el ME.

Los grupos de ítems relacionados en cuanto al contenido presentan respuestas similares lo que afirma la coherencia interna de las respuestas y sostiene la validez y fiabilidad del presente trabajo.

\section{DENTRO DE LOS ÍTEMS PUNTUADOS COMO MUY} IMPORTANTE ENCONTRAMOS:

“1. Adaptación a los cambios, flexibilidad" que responde al perfil de enfermería pues teniendo competencias generalistas ha de adaptarse a servicios 
diversos.

“3. Alegría, sentido del humor” responde al perfil femenino y al de enfermería en cuanto profesión feminizada. Como hemos visto en la investigación teórica, la alegría y la sonrisa han constituido un rasgo esencial de la mujer en general y de la enfermera en particular.

“4. La amistad” está en relación con la solidaridad, valor que Durkheim consideraba el más importante de la sociedad pues determina la supervivencia de esta. Lo vemos también en el cráneo desdentado de Dmanisi y en la actitud de Henri Dunant en Solferino.

“5. Anticipación, previsión” nos parece coherente el resultado de muy importante obtenido para en el ME pues la enfermera debe realizar para cada paciente un plan de cuidados o proceso de atención de enfermería (PAE) dentro del cual debe anticiparse a los riesgos para prevenirlos.

“6. Apertura, diálogo, igualdad, franqueza” y "14. Comunicación, información" son valores fundamentales para desarrollar la empatía imprescindible para cuidar con dignidad al que sufre.

“7. Aprendizaje continuo” arroja resultados acordes con una profesión que exige estar permanentemente al día dados los avances de las ciencias de la salud.

“9. Calidez, cercanía” es un valor que establece un ambiente proclive a la Confianza, metavalor del $\mathrm{ME}$ de $\mathrm{C}$ por el que se quiere contribuir a la eficiencia y a la humanización de la atención a la salud en el trabajo.

“10. Coherencia”, valor esencial en general pues la falta de coherencia determinaría contradicciones internas que pondrían en peligro la eficiencia.

"11. Comodidad, vida confortable" este valor enlaza con el bienestar ubicado en la armonía del ME de C. No se pueden dar cuidados de calidad si no se considera que la comodidad del paciente es un valor importante.

“12. Compartir, generosidad", los resultados se ajustan al perfil del SNS, dedicado a mantener la salud de la población. "14. Comunicación/información”, es fundamental para desarrollar empatía, imprescindible para cuidar con dignidad al que sufre.

"15.Confianza", es el metavalor central que desde el ME de C nos comprometemos a impulsar para contribuir a la eficiencia y a la humanización de la atención a la salud desde el entorno de trabajo de enfermería. Para 
SALVADOR GARCÍA (2011) la confianza (creer en) es un metavalor que se encuentran en el núcleo del modelo triaxial. La confianza es esencial para el bienestar emocional y genera el ambiente necesario para que aparezca la iniciativa, la creatividad, el diálogo y el aprendizaje organizativo. El miedo y la confianza son polos opuestos, igual que el amor y el odio, o la guerra y la paz.

“18. Cooperación, colaboración, espíritu de equipo", valor fundamental para el trabajo sanitario y en particular para enfermería, pues se halla en el centro del equipo, enlazando los distintos niveles.

“19. Cortesía” relacionada con el respeto, la enfermera ha de ser cortés, que no servil.

“20. Crecimiento/expansión”, los resultados obtenidos se ajustan a profesionales de las ciencias de la salud en continua expansión, y especialmente de enfermería que procede de un pasado de exclusión y debe crecer para recuperar el terreno que le pertenece.

“21. Creer y poner cariño en lo que se hace”, valor intrínsecamente relacionado con la Confianza que es el metavalor de Espinoso de Compludo para contribuir a la eficiencia y a la humanización.

“23. Derechos humanos, Dignidad”, evidentemente, esperábamos que enfermería arrojara resultados de "muy importante" para este valor que es uno de los que compone el Compromiso social en el ME de C.

"24. Disfrutar del trabajo", este valor, junto con el "21. Creer y poner cariño en lo que se hace", están relacionados con la Confianza, metavalor central para la eficiencia y la humanización de la atención a la salud desde nuestros entornos de trabajo.

“25. Eficacia, Planificación, Eficiencia", este es el valor "princeps" de nuestro estudio. El alumnado ha captado la importancia que tiene y se pueden esperar muy buenos resultados en la vida laboral de estos profesionales.

“26. Equidad, justicia en el día a día”, resultados acordes al tipo de empresa que está al servicio de los valores salud y vida, valores de categoría absoluta, por encima de connotaciones sociales.

“31. Felicidad (búsqueda de la )” para sí mismo y para los demás debe ser un objetivo para profesionales al cuidado de la salud y de la vida; pues ambas, salud y vida, se relacionan intrínsecamente con la felicidad que no puede ser plena 
si falta alguna de aquellas.

“32. Honestidad, honradez, transparencia, sinceridad”, en este valor, fundamental dentro de lo que es el Compromiso social, observamos unos resultados acordes a la docencia dada. Nos hacen intuir que alcanzaremos favorablemente nuestra hipótesis.

“33. Humildad, modestia”, resultados coherentes en una profesión tradicionalmente feminizada y que ha estado tan marcada, en tiempos pasados, por las enseñanzas de la religión para la mujer.

“34. Idealismo", estos resultados hacen pensar que el SNS persigue un ideal: salud para todos, a la vez que sabe que no es posible. Ya la OMS, en 1945, definió la salud como un ideal deseable por todos a la vez que imposible.

“35. Igualdad/Liberación”, existe un paralelismo claro entre el valor 26. Equidad y el 35. Igualdad, y los resultados son equiparables en ambas áreas. Esto pone de manifiesto la coherencia de las respuesta, la validez de las encuestas y que la igualdad ante la salud es uno de los valores del SNS.

“36. Imagen, prestigio social”, este ítem, el 13. Competitividad, ambición y el 50. Productividad, resultados tienen en común que responden a características tradicionalmente masculinas y observamos que arrojan resultados similares, medianamente importante en VP y muy importantes en ME. Son resultados acordes en la VP para una profesión feminizada, y en el ME en cuanto a que la gestión y dirección de empresas sigue en manos masculinas.

“37. Imaginación, creatividad, fantasía”, nos hace esperar un resultado favorable a nuestra tesis pues este valor en alza permite innovación, cosa que necesita toda profesión, y más la enfermería que ha estado tan oprimida. En el ME de $\mathrm{C}$ se habla expresamente de la creatividad.

“40. Influencia, poder social (búsqueda de)”, una administración pública tiene per sé influencia y poder social y no busca más de la que le otorga la Ley.

“44. Obediencia, cumplimiento", según Weber "El concepto de disciplina encierra el de una 'obediencia habitual' por parte de las masas sin resistencia ni crítica". Según los resultados obtenidos en esta encuesta podemos esperar unos profesionales disciplinados y por lo tanto eficientes.

"45. Pasión, entusiasmo", valor relacionado con la eficiencia, humanización y por lo tanto con la Confianza como metavalor. 
“47. Perseverancia/Paciencia", resultados que responden al perfil de enfermería y de feminización. Valor en relación directa con la eficiencia, humanización y la Confianza como metavalor.

“48. Placer intelectual”, al igual que el valor 7. Aprendizaje continuo está relacionado con la seguridad en el ejercicio de la profesión y con la confianza que ha de inspirar en el paciente. También arroja resultados altos, acordes con una profesión que exige estar permanentemente al día dados los avances de las ciencias de la salud.

“58. Rigor técnico-profesional”, este resultado está acorde con el perfil de enfermería que trabaja para la salud y la vida, estos valores superiores: salud y vida implican necesariamente rigor técnico-profesional tanto a nivel de la VP como del ME. "62. Ser querido por los demás”, la humanización que buscamos para el ejercicio de la enfermería se traduce favorablemente en estos resultados, pues ser querido por los demás es un valor en íntima relación con la humanización en el trato.

“63. Servicio/vocación”, valor relacionado con humanización.

“64. Simplicidad, rapidez, agilidad", valor fundamental para obtener buenos resultados con menos medios, es decir para una alta eficiencia. En cuanto al ME, se observa a través de estos resultados que el alumnado percibe la rigidez de la administración pública pues el 3 medianamente recoge un tercio de las respuestas.

"65. Solidaridad, generosidad", valor relacionado con el Compromiso social que es el primero del ME de $\mathrm{C}$ y también con el valor 12. Compartir, generosidad que arroja resultados similares, lo cual evidencia la validez de las respuestas obtenidas. Estos resultados son muy favorables para dar por cierta nuestra hipótesis.

“66. Supervivencia material”, el alumnado percibe que la sostenibilidad del SNS es bastante importante y esta es una de las preguntas estrella de nuestra tesis.

“67. Tecnología/ciencia, innovación”, al igual que decíamos para 57. Riesgo, aventura, estímulo, novedad, ambos valores coinciden en la innovación y ambos han sido muy bien puntuados, lo cual responde al perfil de una profesión con ansias de crecer. 
“70. Trascendencia, utilidad para otros”, se evidencia muy importante para enfermería, profesión que está al servicio de la salud ajena y del bienestar del enfermo.

“71. Valentía, coraje”, decíamos al hablar de la dimensión psicológica del vocablo valor: valentía, que la RAE la define como "Cualidad del ánimo, que mueve a acometer resueltamente grandes empresas y a arrostrar los peligros."; y que de hecho esta definición engloba las tres dimensiones: la psicológica o coraje, la ético-estratégica y la económico-empresarial (conducta emprendedora que asume riesgos).

“72. Verdad/sabiduría (búsqueda de la)”, existe evidentemente una relación de este valor con otros como 58. Rigor técnico-profesional, 60. Seguridad, 67. Tecnología/ciencia, innovación y en todos hemos obtenido resultados similares que coinciden con el perfil de enfermería, profesión en desarrollo.

\section{EN CUANTO A LOS ÍTEMS PUNTUADOS COMO MEDIANAMENTE IMPORTANTES ENCONTRAMOS:}

“2. Ahorro, austeridad”, el alumnado percibe mayor importancia para ahorro/austeridad dentro de la empresa que en la propia vida personal con lo que demuestra ser consciente de la necesidad del buen uso de los recursos en el SNS.

“5. Anticipación, previsión”, resultados adecuados al perfil de enfermería por cuanto la enfermera debe realizar para cada paciente un plan de cuidados o proceso de atención de enfermería (PAE) dentro del cual debe anticiparse a los riesgos para prevenirlos.

"8. Arte/belleza, armonía estética", el alumnado percibe el arte/belleza, armonía estética como más importante en la VP que en el ME, lo cual tiene lógica interna.

"13. Competitividad, ambición, trabajo duro", este ítem, en cuanto a la competitividad, ambición, el 36. Imagen, prestigio social y el 50. Productividad, resultados tienen en común que responden a características tradicionalmente atribuidas a lo masculino y observamos que arrojan resultados similares, medianamente importante en VP y muy importantes en ME. Son resultados 
acordes en la VP para una profesión feminizada, y en el ME en cuanto a que la gestión y dirección de empresas sigue en manos masculinas.

“16. Contemplación, meditación, serenidad”, valor intrínsecamente ligado a la seguridad que debe tener la enfermera en el desempeño de su trabajo y debe transmitir a sus enfermos.

“22. Deleite físico, Hedonismo”, lógicamente, una profesión a la que siempre se le ha pedido auto-sacrificio y entrega no puede ver este valor como muy importante. “28. Éxito económico” resultados acordes con la percepción por parte del alumnado de que el éxito económico es importante para la sostenibilidad del sistema. "46. Patriotismo", tratándose de un valor tan controvertido hoy, los resultados obtenidos demuestran la seriedad del alumnado al momento de elaborar las respuestas y por lo tanto, la validez de las encuestas.

“57. Riesgo, aventura, estímulo, novedad”, se percibe a través de estos resultados las características de la administración pública, una de cuyas características es la previsibilidad que no deja sitio al riesgo, aventura, novedad.

"66. Supervivencia material", los resultados evidencian que nos encontramos ante una profesión tradicionalmente feminizada que se ha desarrollado a través de la abnegación y la entrega. En cuanto al ME, el alumnado percibe que la sostenibilidad del SNS es bastante importante y esta es una de las preguntas estrella.

“69. Tradición, conservación”, los resultados traducen coherentemente el momento actual, en que los cambios acontecen a velocidad exponencial.

\section{EN CUANTO A LAS PREGUNTAS MARCADAS COMO POCO O NADA IMPORTANTES ENCONTRAMOS:}

“49. Placer sexual”, una cuarta parte del alumnado está de acuerdo en no ver relación entre el placer sexual y el ME. El resto se reparte entre todas las opciones demostrando el desconcierto que provoca esta pregunta, lo cual es muy coherente.

“53. Religiosidad”, llama la atención como una profesión tradicionalmente feminizada y ejercida durante siglos por monjas, secularizada no hace mucho, presente este resultado. 
En cuanto a las preguntas marcadas como poco definidas encontramos:

“2. Ahorro, austeridad", el alumnado demuestra ser consciente de la necesidad del buen uso de los recursos en el SNS.

“3. Alegría, sentido del humor", las respuestas ponen de manifiesto que el alumnado ve su futuro profesional con alegría, y no es una profesión exenta de esfuerzo, lo que hace pensar que tienen vocación.

“26. Equidad, justicia en el día a día” ítem relacionado con el Compromiso social. Resultados acordes al tipo de empresa que está al servicio de los valores salud y vida, valores de categoría absoluta, por encima de connotaciones sociales.

“27. Equilibrio entre el trabajo y vida familiar y personal” el alumnado considera que la empresa mira menos por este valor que ellos mismos en su vida personal, resultado coherente con la vida real.

"65. Solidaridad, generosidad", el alumnado percibe que el ME es menos solidario, generoso que la VP, pero incluso así lo puntúan como importante. Esto es favorable a nuestra hipótesis pues este es un valor crucial en el trabajo de enfermería.

Los ítems relacionados con los valores del Manifiesto de Compludo: Compromiso social, Seguridad, Armonía, Confianza así como los ítems relacionados con la Sostenibilidad del sistema muestran de forma inequívoca lo interiorizado que enfermería tiene estos valor en ambas áreas: Vida Personal y Mundo de la Empresa.

Podemos concluir después de nuestro estudio que el proceso docente llevado a cabo sobre los estudiantes de Enfermería en cuanto a la educación en valores ha sido efectivo. Los nuevos profesionales poseen un potencial en valores que deberá tenerse en cuenta cuando se haga la planificación estratégica de recursos humanos en el sistema sanitario, ya que teniendo en cuenta estas cualidades contribuiremos a dar un servicio más profesional e inequívocamente más eficaz. 

CONCLUSIONES 

PRIMERA. La feminización de las profesiones sanitarias conlleva un cambio sustancial en el perfil profesional. Este cambio tiene aspectos cuantitativos y cualitativos; respecto a estos últimos mantenemos que la mujer trae consigo la ética del cuidado lo cual determina un cambio en los valores y una mayor humanización de la atención a la salud. Desde una perspectiva de género, observamos un hecho paradójico: cuidar es mantener la vida, y la vida necesita cuidados desde que comienza hasta que termina, ya que sin cuidados no habría vida, y sin vida no hay existencia. Estos cuidados los ha venido proporcionando tradicionalmente la mujer y profesionalmente la Enfermería, en base al arte y la generosidad innatos a la ética del cuidado. Sin embargo nunca han sido suficientemente valorados, e incluso en ocasiones han llegado a ser menospreciados.

SEGUNDA. Se defienden como valores de las Ciencias de la Salud: la solidaridad, el compromiso social, la seguridad, la armonía, la confianza, la alegría, el amor-compasión, la dignidad, el respeto, la autonomía de las personas, la sensibilidad, el equilibrio, el bienestar, la responsabilidad, el conocimiento, la competencia profesional, las destrezas prácticas, la objetividad, el rigor científico y la creatividad-innovación.

TERCERA. El Sistema Nacional de Salud español es una Administración Pública gestionada como una empresa pública en la que encontramos la Dirección por Objetivos e incluso hasta la Dirección por Instrucciones, y donde subyacen los valores al ser profesiones sanitarias vocacionales. La implementación de la Dirección por Valores, que encontraría rápidamente eco con los valores propios del mundo sanitario, determinaría un enfoque metodológico propio y la aparición de un orden organizacional y creativo de orden superior necesarios en el contexto específicamente sanitario. La eficacia del SNS se verá positivamente afectada tanto en el plano teórico como en el práctico.

CUARTA. Del trabajo de campo deducimos que en el área de mi VP, 57 ítems aparecen como "muy importantes", 14 como "medianamente importantes" y tan 
solo uno como "poco o nada importante", ninguno como poco definido. En el área del ME encontramos 39 ítems "muy importantes", 20 "medianamente importantes", 2 como poco o nada importantes y encontramos 11 ítems con respuestas poco definidas.

QUINTA. La muestra encuestada presenta una percepción más definida con respecto a los valores que rigen su VP que en cuanto a los que rigen el ME. Los grupos de ítems relacionados en cuanto al contenido presentan respuestas similares lo que afirma la coherencia interna de las respuestas y sostiene la validez y fiabilidad del trabajo empírico. La muestra perfectamente válida tiene el sesgo de género, que caracteriza la idiosincrasia de los profesionales sanitarios estudiados.

SEXTA. Los ítems relacionados con los valores del Manifiesto de Compludo: Compromiso social, Seguridad, Armonía, Confianza, así como los ítems relacionados con la Sostenibilidad del sistema, muestran de forma inequívoca lo interiorizado: Enfermería tiene estos valores en ambas áreas: Vida Personal y Mundo de la Empresa. Valores que conducen inequívocamente a lograr una mayor eficacia del SNS, si son tenidos en cuenta en la función gestora de dirección, como herramienta básica.

SEPTIMA. Afirmar después de nuestro estudio que el proceso docente llevado a cabo sobre los estudiantes de Enfermería en cuanto a la educación en valores ha sido efectivo. Los nuevos profesionales poseen un potencial en valores que deberá tenerse en cuenta cuando se haga la planificación estratégica de recursos humanos en el Sistema Sanitario, ya que teniendo en cuenta estas cualidades contribuiremos a dar un servicio más profesional y consecuentemente más eficaz 
BIBLIOGRAFÍA 

AA.VV: (2010). Doctas, doctoras y catedráticas. Cien años de acceso libre de la mujer a la Universidad. Barcelona: Generalitat de Catalunya. Consell Interuniversitari de Catalunya.

ALCOBERRO, R. (2014). Filosofía i pensament. Introducción a Max Weber (1864-1920). Obtenido el 12-2-2015, de: http://www.alcoberro.info/V1/weber.htm

ALfONSO AGUILAR, P. (2010). Eficiencia en Salud Pública. Revista Archivo Médico de Camagüey, volumen 14. Obtenido 10-11-2012, de: http://www.revistaamc.sld.cu/index.php/amc/article/view/2123/600

ALONSO PEÑA, J. R. (2014). Los tres cristos de Michigan. Obtenido el 29-62014, de: http://jralonso.es/2013/01/27/los-tres-jesucristos-de-michigan/

ALTHUSSER, L., y BALIBAR, É. (2004). Para leer El Capital. Obtenido el 145-2014, de:http://books.google.es/books?id=P9WmHBcZIUYC\&printsec=frontcover $\underline{\& d q}=\mathrm{el}+$ capital $\& \mathrm{hl}=\mathrm{es} \& \mathrm{sa}=\mathrm{X} \& \mathrm{ei}=\mathrm{dvd} 4 \mathrm{U} 7 \mathrm{i} 7 \mathrm{GqL} 30 \mathrm{gWz}$ oGgBg\&ved $=0 \mathrm{CG}$ $\underline{\text { MQ6AEwCA\# } \mathrm{v}=\text { onepage } \& \mathrm{q}=\mathrm{e} 1 \% 20 \text { capital } \& \mathrm{f}=\text { false. }}$

ALVARADO GARCÍA, A. (2004). La ética del cuidado. Aquichan, No 4, pp. 3039. Obtenido el 21-6-2014, de: http://dialnet.unirioja.es/servlet/autor? codigo $=1869739$

ÁlVAREZ CONDE, E., FIGUERUELO, Á., NUÑO GÓMEZ, L., y CANCIO ÁLVAREZ, M.D. (2009). Estudios interdisciplinares sobre igualdad. Madrid: Iustel.

ÁLVAREZ NEBREDA, C.C. (1998). Glosario de términos para la administración y gestión de los servicios sanitarios. Madrid: Díaz de Santos.

ALZAGA VILLAAMIL, O. (1985). "Comentarios a las leyes políticas dirigidos por Oscar Alzaga Villaamil. Constitución Española de 1978." Tomo VIII, 


\section{BIBLIOGRAFÍA}

Revista de Derecho Público. Madrid: Editorial REVISTA DE DERECHO PRIVADO.

ARISTÓTELES (n.d.). Ética a Nicómaco. Obtenido el 14-12-2013, de: www.uruguaypiensa.org.uy/imgnoticias/650.pdf . (n.d.). La gran moral. Obtenido el 10-12-2013, de:

http://soldemayo.es/libros/ApX_Autor_A/Aristoteles\%20$\% 20 \mathrm{La} \% 20$ gran $\% 20$ moral.doc.

ASAMBLEA GENERAL DE LAS NACIONES UNIDAS (2015). Declaración Universal de los Derechos Humanos (1948). París. Obtenido el 5-4-2015, de: http://www.un.org/es/documents/udhr/

BALAGUER CALLEJÓN, F. (2002). "El Estado social y democrático de Derecho. Significado, alcance y vinculación de la cláusula del Estado social." Granada: Comares.

BALAGUER PERIGÜELL, E., y BALLESTER AÑÓN, R. (n.d.). En el nombre de los niños: La Real Expedición Filantrópica de la Vacuna (1803-1806). Asociación Española de Pediatría. Obtenido el 16-2-2014, de: http://www.aeped.es/sites/default/files/documentos/prologo.pdf

BALLESTEROS PEÑA, S. (2012). Unidades de soporte vital básico y avanzado en España: análisis de la situación actual. Anales del Sistema Sanitario de Navarra 2012, SciELO España, pp. 219-228.

BARBER PÉREZ, P., y GONZÁLEZ LÓPEZ-VALCÁRCEL, B. (2009). Oferta y necesidad de especialistas médicos en España (2008-2025). Madrid: Ministerio de Sanidad y Consumo.

BARRA ALMAGIÁ, E. (1987). El desarrollo moral: una introducción a la teoría de Kohlberg. Revista Latinoamericana de Psicología, vol.19, n 1 , 1987, pp. 7-18. Fundación Universitaria Konrad Lorenz. Colombia. Obtenido el 16-12013, de: http://www.redalyc.org/pdf/805/80519101.pdf 
BASANTA, E., OMART, E., y BRUNETTI, J. (2002). La psicología del desarrollo moral según Piaget y Kohlberg: antecedentes y prospectivas. Revista argentina de psicología. (2002) de la asociación de Psicólogos de Buenos Aires. Año XXXIV, no 45, pp. 9-24. Obtenido el 7-1-2014, de: http://www.eticar.org/descargas/La $\% 20$ psicologia $\% 20 \mathrm{del} \% 20$ desarrollo\%20 moral\%20segun $\% 20$ Piaget $\% 20 \mathrm{y} \% 20$ Kolhberg $\% 20$ antecedentes $\% 20 \mathrm{y} \% 20 \mathrm{pr}$ ospectivas.pdf

BELDA PLANS, P. (1991). La Noción de Valor en la Escuela Fenomenológica. Husserlian Phenomenology in a New Key. Springer, pp. 79-91.

BELTRÁn LlerA, J., y BUENO ÁlVAREZ, J.A. (1995). Psicología de la Educación. Barcelona: Editorial Boixerau Universitaria.

BENHABIB, S. (1992). Una revisión del debate sobre las mujeres y la teoría moral. Isegoría, pp. 37-63. Obtenido el 15-6-2014, de: http://isegoria.revistas.csic.es/index.php/isegoria/article/view/323/324

BERDASQUERA CORCHO, D., CRUZ MARTÍNEZ, G., y SUÁREZ LARREINAGA, C.L. (2000). La vacunación: Antecedentes históricos en el mundo. Revista Cubana de Medicina General Integral, 16(4), pp. 375-378.

BERGMAN, R. (2004). Caring for the ethical ideal: Nel Nodding on moral education. Journal of Moral Education, Vol. 33 ( $\left.\mathrm{N}^{\mathrm{o}} 2\right)$, pp. 149-162. Obtenido el 22-06-2014, de: http://www.bamaed.ua.edu/ELPTS/681/Readings/NElNoddings.pdf

BERNABEU MESTRE, J., y GASCÓN PÉREZ, E. (1999). Historia de la enfermería de salud pública en España: (1860-1977). Alicante: Universidad de Alicante.

BEUCHOT, M. (2004). Introducción a la filosofía de santo Tomás de Aquino. Salamanca: Editorial San Esteban.

BEVERIDGE, W. (1987). Las bases de la seguridad social; The basis of the social security. México D.F.: Fondo de cultura económica. 


\section{BIBLIOGRAFÍA}

BILBENY, N. (1992). ¿Cómo pensar los valores morales a partir de Kant?. Obtenido el 8-12-2013, de: http://scholar.google.es/scholar?hl=es\&q=+valores $+\% 2 \mathrm{~B}+\mathrm{kant} \& \mathrm{btnG}=\& 1 \mathrm{r}=$

BIRABEN, J. (1979). La diffusion de la vaccination en France au XIXe siècle, Annales de Bretagne et des pays de l'Ouest 1979, Presses Universitaires de Rennes. Obtenido el 23-10-2014, de: http://www.persee.fr/web/revues/home/prescript/article/abpo_03990826_1979 num 86_2_2981

BLANCHARD, K., y OCONNOR, M. (1997). Dirección por valores. Barcelona: Gestión 2000.

BLASCO LAHOZ, J.F. (2013). Legislación básica sobre asistencia sanitaria. Textos legales. Valencia: tirant lo blanch.

BLÁZQUEZ-RODRIGUEZ, M.I. (2005). Los componentes de género y su relación con la enfermería. Index de Enfermería, 14 (51), pp. 50-54.

BOEREE, C.G. (2006). Abraham Maslow, 1908-1970. Personality Theories. Obtenido el 25-11-2015, de: http://citeseerx.ist.psu.edu/viewdoc/download?doi=10.1.1.467.890\&rep=rep 1 \&type $=$ pdf

BOIX, A. (2011, 2 de mayo) El timo del modelo Alzira. EL PAIS.

BONILlA BALLESTEROS, Á.R., y TRUJILlO GARCÍA, S. (2005). Análisis comparativo de cinco teorías sobre el desarrollo moral. Bogotá: Pontificia Universidad Javeriana. Facultad de Psicología.

Obtenido el 15-6-2014, de: http://javeriana.edu.co/biblos/tesis/psicologia/tesis 15.pdf.

BOWEN HERRERA, A. (1992). Introducción a la Seguridad Social. Capítulo IV: El advenimiento de la Seguridad Social contemporánea. p.72 a 79. Santiago de Chile: Editorial Jurídica de Chile. 
CAAMAÑO, C., MARTÍNEZ, J.R., ALONSO, M., HERNÁNDEZ, A., MARTÍNEZ-RENEDO, E., y SAINZ, A. (2006). Indicadores de calidad de los cuidados de enfermería hospitalarios. Revista de calidad asistencial, 21(3), pp. 143-149.

CABANillas BermúdeZ, J.M. (1997). El Pacto de Toledo: análisis descriptivo del sistema nacional de la seguridad social en España. Madrid: Tecnos.

CADUTO, M.J. (1992). Guía para la enseñanza de valores ambientales. Bilbao: Los libros de la catarata.

CALVO SÁNCHEZ, M.D. (2008). Actualización legal en materia sanitaria. In: DAE, ed, Enfermería del trabajo. Madrid: DAE, pp. 43-62.

CALVO SÁNCHEZ, M.D., y MOMPART GARCÍA, M.P. (2006). Actualización del Sistema Nacional de Salud: la reforma legal española. In: DAE, ed, Enfermería viva S 21. España: DAE, pp. 37-53.

CALVO SÁNCHEZ, M.D., y RIVERO ORTEGA, R. (2008). SANIDAD. In: LEX NOVA, ed, Derecho Público de Castilla y León. $1^{\mathrm{a}}$ edn. España: LexNova, pp. 897-913.

CANO-CABALLERO GÁLVEZ, M.D. (2004). Enfermería y género tiempo de reflexión para el cambio. Index de Enfermería, 13(46), pp. 34-39.

CARACUEL QUIRÓS, M.P. (2003). Valores éticos en la prensa escrita española,(1960-1965 y 1990-1995), Universidad Complutense de Madrid, Servicio de Publicaciones, Obtenido 10-12-2013, de: http://eprints.ucm.es/tesis/inf/ucm-t26906.pdf

CARDONA SÁNCHEZ, A. (2000). Formación de valores: Teoría, reflexiones y propuestas. Mexico, D.F.: Grijalbo, S.A. de C.V.

CARRERAS, LL., EIJO, P., ESTANY, A., GÓMEZ, Mª T., GUICH, R., et al. (1995). Cómo educar en valores: materiales, textos, recursos y técnicas. Madrid: Narcea Ediciones. 
CELMA VICENTE, M., y ACUÑA DELGADO, Á. (2009). Influencia de la feminización de la enfermería en su desarrollo profesional. Revista de antropología experimental, (9), pp. 119-136.

CHAMIZO VEGA, C. (2004). La perspectiva de género en Enfermería: comentarios y reflexiones. Index de Enfermería, 13(46), pp. 40-44.

COLliÈre, M. (1992). Promouvoir la vie. De la pratique des femmes soignantes aux soins infirmiers. Paris: InterEditions Masson.

COLÓN DE CARVAJAL FIBLA, B. (2011). Hacia un modelo social de Administración Pública: de la Burocracia a la Gobernanza. Obtenido el 241-2015, de: http://noticias.juridicas.com/articulos/15-DerechoAdministrativo/201101-564123582.html

COMISIÓN EUROPEA y DURAO BARROSO, J.M., (2010). COMUNICACIÓN DE LA COMISIÓN EUROPA 2020. Una estrategia para un crecimiento inteligente, sostenible e integrador. Bruselas. Obtenido el 4-1-2015, de: http://eurlex.europa.eu/LexUriServ/LexUriServ.do?uri=COM:2010:2020:FIN:ES:PD $\underline{\mathrm{F}}$

COMITÉ DE ÉTICA ASISTENCIAL DE SARQUAVITAE (2011). Guía práctica para profesionales de la salud. Barcelona: Edita: www.sarquavitae.es. Obtenido el 5-4-2015, de: http://www.trabajosocialbadajoz.es/colegio/wpcontent/uploads/2011/05/LA-VIRTUD-EN-EL-CUIDAR.pdf

COMPONENTE DOCENTE UNIVERSIDAD DE LOS ANDES (2012).

Paradigmas Psicológicos de la Educación. Venezuela: Universidad de los Andes. Obtenido el 28-6-2014, de:

http://portafoliodayana.wordpress.com/2012/06/10/paradigmaspsicologicos-de-la-educacion/

COMTE, A. (1852). Cours de Philosophie positive. Paris: Borrani et Droz, libraires. Obtenido el 18-5-2014, de: 
http://books.google.es/books?hl=es\&lr=\&id=TUxaAAAAYAAJ\&oi=fnd\&p $\mathrm{g}=\mathrm{PA} 5 \& \mathrm{dq}=$ Auguste + Comte $\&$ ots $=$ LBN8KoPsxa\&sig $=\mathrm{v} \_$oZ-ilEkH51$\underline{\text { JnBUwa7LaRyUsE\#v }=\text { onepage } \& \mathrm{q}=\text { Auguste } \% 20 \text { Comte } \& \mathrm{f}=\text { false. }}$

CONSEJERÍA DE SALUD Y BIENESTAR SOCIAL, JUNTA DE ANDALUCÍA (2012). Resultados y Calidad del Sistema Sanitario Público de Andalucía. Edición 2012. Eficiencia. Obtenido el 11-2-2015 de:

http://www.calidadsaludandalucia.es/es/eficiencia.html.

COROMINES, J., y RODRÍGUEZ, J.A.P. (2008). Breve diccionario etimológico de la lengua castellana. Madrid: Gredos.

CORTÉS PÉREZ, S.A. (2014). El cuidado como objetivo político-social, una nueva mirada desde la ética del cuidado. Obtenido el 22-06-2014, de : http://www.unavarra.es/digitalAssets/158/158837 6 pCortesPerez_eticadelCuidado.pdf

CRESPO SESMERO, M. (2013). Edmund Husserl. Philosophica: Enciclopedia filosófica online Obtenido el 5-12-2013, de: http://www.philosophica.info/archivo/2011/voces/husserl/Husserl.html

CUEVAS, J.C. (2014). Psicología y empresas. Renovando empresas con talento humano. Obtenido el 1-07-2014, de:

http://psicologiayempresa.com/diferencias-entre-valores-actitudes-interesesy-necesidades.html

DAVIS, A.J. (2006). El cuidar y la ética del cuidar en el siglo XXI: qué sabemos y qué debemos saber. Barcelona: Col- legi Oficial de Infermeria de Barcelona. Obtenido el 4-4-2015, de:

http://www.coib.cat/uploadsBO/Noticia/Documents/ANNE\%20DAVIS\%20 CASTELLà_DEF.pdf.

DE BEAUVOIR, S. (2011). El segundo sexo. Madrid: Ediciones Cátedra.

DE LA ROSA TORNER, A., MARÍN FERRER, M., y TARAZONA GINÉS, E. (2005). La experiencia del" Modelo Alzira" del hospital de La Ribera-área 


\section{BIBLIOGRAFÍA}

10 salud: la consolidación del modelo. Revista de administración sanitaria siglo XXI, 3(1), pp. 83-98.

DEGRAAF, K.R., MARRINER-TOMEY, A., MOSSMAN, C.L., y

SLOBODNIK, M. (1994). Florencia Nightingale. Enfermería moderna. Modelos y teorías en enfermería. Madrid: Mosby/Doyma Libros, pp. 73-87.

DELGADO, M. (2013). Los valores y la ética en el pensamiento estratégico.

Obtenido el 10-12-2013, de:

http://www.uru.edu/fondoeditorial/articulos/Mariadelgado/LOS\%20VALOR ES\%20Y\%20LA\%20ÉTICA.pdf

DESING, J. (2002). Castillo real de Neuschwanstein. Lechbruck: Wilhelm Kienberger Lechbruck.

DÍAZ MEDINA, A., ET AL. (2007). La Igualdad como compromiso: estudios de género en homenaje a la profesora Ana Díaz Medina. Salamanca: Ediciones Universidad de Salamanca.

DOMÍNGUEZ-ALCÓN, C. (1986). Los cuidados y la profesión enfermera en España. Madrid: Pirámide.

DOMÍNGUEZ-ALCÓN, C., RODRIGUEZ, J.A., y DE MIGUEL, J.M. (1983). Sociología y enfermería. Madrid: Pirámide.

DONAHUE, M.P., y RUSSAC, P.A. (1999). Historia de la enfermería. Madrid: Harcourt.

DRUCKER, P. (1954). The Practice of Management. New York: Harper and Row.

DUNANT, H. (1982). Recuerdos de Solferino. Ginebra: Editado por el CICR.

DURKHEIM, É. (1993). Escritos selectos: selección e introducción de Anthony Giddens. Buenos Aires: Ediciones Nueva Visión. 
ECHEGOYEN OLLETA, J. (2013) Filosofia medieval y moderna. Kant.

Obtenido el 27-11-2013, de: http://www.e-torredebabel.com/Historia-de-lafilosofia/Filosofiamedievalymoderna/Kant/Principal-Kant.htm

ELOLA SOMOZA, J. (2004). Gestión del Sistema Nacional de Salud ¿se puede? ¿ se debe? ¿cómo? Revista de administración sanitaria siglo XXI, 2(3), pp. 375-386.

ESPASA-CALPE (2006). Enciclopedia Universal Ilustrada Europeo-Americana. Madrid: Espasa-Calpe.

ETZIONI, A., y ETZIONI, E. (1969). Los cambios sociales: fuentes, tipos y consecuencias. México, D.F.: Fondo de Cultura Económica.

EUROPEAN UNION, Official Journal of the European Union (2013). Regulation (EU) $N^{o} 1291 / 2013$ of The European Parliament and of The Council of 11 December 2013 establishing Horizon 2020 - the Framework Programme for Research and Innovation (2014-2020) and repealing Decision $N^{\circ}$ 1982/2006/EC. Europe edn. Obtenido el 21-1-2015, de: http://inea.ec.europa.eu/download/legal framework/regulation 12912013 e stablishing_h2020.pdf

FABELO CORZO, J.R. (2004). Los valores y sus desafios actuales. LibrosEnRed. Obtenido el 16-1-2014, de: http://educarteoax.com/pedagogizando/descargas/otros/los_valores.pdf

FABELO CORZO, J.R. (2011). Prólogo: lugar de Risieri Frondizi en el pensamiento axiológico latinoamericano. Biblioteca virtual de Filosofía y Pensamiento cubanos. Obtenido el 16-1-2014, de: http://biblioteca.filosofia.cu/php/export.php?format $=$ htm\&id=2531\&view $=1$

FABELO CORZO, J.R. (2011) Epílogo: Valoración del pensamiento axiológico de Risieri Frondizi. Biblioteca virtual de Filosofía y Pensamiento cubanos. Obtenido el 16-1-2014, de: http://biblioteca.filosofia.cu/php/export.php?format=htm\&id=2541\&view $=1$ 


\section{BIBLIOGRAFÍA}

FAJARDO TRASOBARES, M.E., y GERMÁN BES, C. (2004). Influencia del género en el reconocimiento de los cuidados enfermeros visibles e invisibles. Index de Enfermería, 13(46), pp. 09-12.

FEDERACIÓN DE ASOCIACIONES PARA LA DEFENSA DE LA SANIDAD PÚBLICA, (2011). Análisis del Informe de la Fundación Bamberg. "El modelo de futuro de gestión de la Sanidad". Obtenido el 30-11-2014, de: http://www.actasanitaria.com/fileset/doc_63604_FICHERO_NOTICIA_299 09.pdf

FERNÁNDEZ RÍOS, M., y SÁNCHEZ, J.C. (1997). EFICACIA ORGANIZACIONAL. Concepto, desarrollo y evaluación. Madrid: Ediciones Díaz de Santos.

FERRÁNDIZ MANJAVACAS, F.A. (2014). Algunas cuestiones relativas a la eficacia y eficiencia del Sistema sanitario público en España. Obtenido el 10-2-2015, de: http://eprints.ucm.es/6660/1/9815.pdf

FIGUERUELO BURRIEZA, Á. (1996). Los derechos fundamentales en el Estado Social y su eficacia en las relaciones privadas. In: UNIVERSIDAD EXTERNADA DE COLOMBIA, ed, Memorias del Congreso Internacional: "Derecho Público, filosofía y sociología jurídicas: perspectivas para el próximo milenio". Bogotá. Colombia: Consejo Superior de la Judicatura., pp. 239-295.

. (2003). Significado y funciones del Derecho Constitucional. Revista de Investigaciones Jurídicas de la Escuela Libre de Derecho. México, Núm. 7, pp. 723-739.

. (2010). Democracia y liberalismo en el pensamiento de Ortega y Gasset. In: EDITORIAL POMARES. GRANADA, ed, Derecho, Ciencias y Humanidades. Granada: Pomares, pp. 213-230.

FIGUERUELO, Á., y IBÁÑEZ MARTÍNEZ, M.L. (2006). El reto de la efectiva igualdad de oportunidades. Granada: Comares. 
FIGUERUELO, Á., IBÁÑEZ MARTÍNEZ, M.L., y MERINO HERNÁNDEZ, R.M. (2007). Igualdad ¿para qué? :(a propósito de la Ley Orgánica para la Igualdad efectiva de Mujeres y Hombres). Granada: Editorial Comares.

FIGUERUELO, Á., POZO PÉREZ, M.D., IBÁÑEZ MARTÍNEZ, M.L., y LEÓN ALONSO, M. (2008). Estudios interdisciplinares sobre igualdad y violencia de género. Granada: Comares.

Figueruelo, Á., POZO PÉREZ, M.D., y LEÓN ALONSO, M. (2012). ¿Por qué no hemos alcanzado la igualdad? Santiago de Compostela: Andavira.

FIGUERUElo, Á., DEL POZO PÉREZ, M., LEÓN ALONSO, M., GALLARDO RODRÍGUEZ, A. (2012). Igualdad: retos para el siglo XXI. Santiago de Compostela: Andavira.

FIGUERUELO, Á., y UNIVERSIDAD DE SALAMANCA (2005). Las mujeres en la constitución europea: estudios multidisciplinares de género. Salamanca: Ediciones Universidad de Salamanca.

FITZPATRICK, S. (2008). En busca de la administración pública eficiente. Capital Humano, $n^{\circ} 221$, pág. 106. Mayo, 2008, Obtenido el 1-2-2015, de: http://www2.congreso.gob.pe/sicr/cendocbib/con4_uibd.nsf/F04BCA54497 D82A105257C3700742928/\$FILE/en_busca.pdf

FLÓREZ MIGUEL, C. (1983). Génesis de la razón histórica. Salamanca: Universidad de Salamanca.

FRAILE CALLE, L. (2011). Estilos de aprendizaje e identificación de actitudes y variables vinculadas al uso de las TICs en los alumnos de Enfermería de la Universidad de Salamanca (Tesis doctoral). Universidad de Salamanca, Salamanca.

FRANKL, V.E., y ALLPORT, G.W. (1991). El hombre en busca de sentido. Barcelona: Herder.

FRONDIZI, R. (1997). ¿Qué son los valores? Introducción a la Axiología. México: Fondo de Cultura Económica. 
GALBRAITH, J.K., RODRÍGUEZ-CAMPOAMOR, H., y ESTEFANÍA, J. (1989). Historia de la economía. Barcelona: Ariel.

GALINDO CAMACHO, M. (2000). Teoría de la Administración Pública. México: Editorial PORRÚA.

GARCÉS FERRER, J. (1988). Valores humanos:(principales concepciones teóricas). Valencia: NAU llibres.

GARCÍA BAÑÓN, A.M., SAINZ OTERO, A., y BOTELLA RODRÍGUEZ, M. (2004). La enfermería vista desde el género. Index de Enfermería, 13(46), pp. $45-48$.

GARCÍA BARRIOS, S., CALVO CHARRO, E., y UNIVERSIDAD DE MÁlAGA (1992). Historia de la enfermería. Málaga: Universidad de Málaga.

GARCÍA MORENTE, M., FRONDIZI, R., y PUCCIARELLI, E. (1980). Lecciones preliminares de filosofía. México D.F.: Editorial Porrúa. Obtenido el 10-2-2014, de: http://losdependientes.com.ar/uploads/s57qpakr1d.pdf

GARCÍA SÁNCHEZ, S. (2002). Dirección por valores y liderazgo posconvencional en el contexto sanitario público. Cuadernos de Gestión, 8 (Supl 1), pp. 4-12.

GARCÍA SÁNCHEZ, S. (2011). Un modelo triaxial de valores pragmáticos, éticos y emocionales. Liderazgo y Valores. Obtenido el 14-10-16, de: http://cvirtual2.i13.ub.edu/repository/coursefilearea/file.php/1/mf/master060 7/course-packages/sal_mgcss_lv/rec_pdf/es/GCSS_a2m3t3_2011_IL3.pdf

GARCÍA, S., DOLAN, S. (1997). La dirección por valores (DpV): el cambio más allá de la dirección por objetivos. Madrid etc.: McGraw-Hill.

GASUlL VILELLA, M., SOLANILlA DEMESTRE, L., y PUYOL GONZÁLEZ, Á. (2005) La ética del cuidar y la atención de enfermería. 
Obtenido el 15-6-2014, de:

http://openaccess.uoc.edu/webapps/o2/bitstream/10609/1242/1/31802tfc.pdf

GERMÁN BÉS, C. (2004). Género y enfermería. Index de Enfermería, 13(46), pp. 07-08.

GIDDENS, A. (2000). Sociología. Madrid: Alianza Editorial.

GILLIGAN, C. (1985). La moral y la teoría: psicología del desarrollo femenino. México, D.F.: Fondo de Cultura Económica.

GIMÉNEZ GLÜCK, D. (2004). Juicio de igualdad y tribunal constitucional. Barcelona: Bosch.

GOBIERNO DE ESPAÑA (1997). Ley 15/1997, de 25 de abril, sobre habilitación de nuevas formas de gestión del Sistema Nacional de Salud. BOE $n^{\circ} 100$, Obtenido el 28-12-2014, de: https://www.boe.es/boe/dias/1997/04/26/pdfs/A13449-13450.pdf,

GOBIERNO DE ESPAÑA (2003). Real Decreto 1277/2003, de 10 de octubre, por el que se establecen las bases generales sobre la autorización de centros, servicios y establecimientos sanitarios. MADRID: BOE $\mathrm{n}^{\circ} 254$.

GOBIERNO DE ESPAÑA (1995). "Pacto de Toledo: aprobación del documento referente al análisis de los problemas estructurales del sistema de seguridad social y de las principales reformas que deberán acometerse". Boletín Oficial de las Cortes Generales, Congreso de los Diputados, 12 de abril de 1995. Número 134. Obtenido el 24-5-2014, de: http://www.informacioncgt.info/legislacion/acuerdos-marco/pacto-toledo.pdf

GOBIERNO DE ESPAÑA, INSTITUTO NACIONAL DE GESTIÓN SANITARIA (2013) INGESA, Obtenido el 10-11-2013, de: http://www.ingesa.eu,

\section{GOBIERNO DE ESPAÑA, MINISTERIO DE ECONOMÍA Y} COMPETITIVIDAD, y CDTI, (2014). Horizonte 2020. Obtenido el 8-112014, de: http://www.cdti.es/recursos/doc/5811 10111011201320716.pdf 
GOBIERNO DE ESPAÑA, MINISTERIO DE EDUCACIÓN CULTURA Y DEPORTE, (2014) Europa 2020. Obtenido el 7-11-2014, de: http://www.mecd.gob.es/redie-eurydice/PrioridadesEuropeas/estrategia2020.html

GOBIERNO DE ESPAÑA, MINISTERIO DE EMPLEO Y SEGURIDAD SOCIAL (2013). Seguridad Social. Obtenido el 2-11-2013, de: http://www.seg-social.es/Internet_1/index.htm.

GOBIERNO DE ESPAÑA, MINISTERIO DE SANIDAD, SERVICIOS SOCIALES E IGUALDAD (2014). Plan Estratégico de Igualdad de Oportunidades 2014-2016. Obtenido el 8-11-2014, de: http://www.inmujer.gob.es/actualidad/PEIO/docs/PEIO2014-2016.pdf

GOBIERNO DE ESPAÑA, MINISTERIO DE SANIDAD, SERVICIOS SOCIALES E IGUALDAD (2013). Sistema Nacional de Salud. España 2012 (monografía en Internet). Obtenido el 20-1-2013, de: http://www.msssi.gob.es/organizacion/sns/docs/sns2012/SNS012.pdf

GÓNGORA-BIACHI, R. A. (1997). El bicentenario del inicio de la vacunación. Revista Biomédica, 7, pp. 241-244. Obtenido el 10-11-2013, de: http://www.cirbiomedicas.uady.mx/revbiomed/pdf/rb96748.pdf

GONZALEZ ALLENDE, I. (2009). ¿Ángeles en la batalla?: Representaciones de la enfermera en Champourcin y Urraca Pastor durante la guerra civil española. Spanish language and literature (paper 35). Obtenido el 22-112013, de:http://digitalcommons.unl.edu/modlangspanish/35.

GRANDMONTAGNE, A. G., (1998). Psicología de la educación sociopersonal. Madrid: Editorial Fundamentos.

GRAU, N. C. (2004). La democratización de la Administración Pública. Los mitos a vencer en Política y gestión pública. Caracas: CLAS.

GRUPO DE ESTUDIOS DE LA ASOCIACIÓN PARA LA DEFENSA DE LA SANIDAD PÚBLICA (ADSP) DE SALAMANCA (2011). 30 años de 
sanidad en España/30 años de la ADSP de salamanca. Salamanca: ADSP de Salamanca, gráficas Varona.

HERCE, J. A., Alonso, J., MESEGUER, J. A., y CORDÓN, J. A. F. (2000). La reforma de las pensiones ante la revisión del Pacto de Toledo. Barcelona: " la Caixa".

HERNÁNDEZ CONESA, J. (1995). Historia de la enfermería: un análisis histórico de los cuidados de enfermería. Madrid etc.: InteramericanaMcGraw-Hill.

HERNÁNDEZ MARTÍN, F., DEL GALLEGO LASTRA, R., ALCARAZ GONZÁLEZ, S. ET AL. (1997). La enfermería en la historia: Un análisis desde la perspectiva profesional. Cultura de los cuidados. Revista de enfermería y humanidades, (2), pp. 21-35.

HERÓDOTO DE HALICARNASO. (2000). Los nueve libros de la historia. Trad.Padre Bartolomé Poú (1727-1802). Obtenido el 12-4-13, de: http://www.ebooksbrasil.org/eLibris/nuevelibros.html

HERSH, R.H., PAOLITTO, D.P., y REIMER, J. (2002). El crecimiento moral de Piaget a Kohlberg. Madrid: Narcea.

INSTITUCIÓN EDUCATIVA EL PEDREGAL (2015). Marco Referencial del Proyecto educativo Institucional. Obtenido el 3-4-2015, de: http://master2000.net/recursos/menu/117/1810/mper arch 11073 pei.pdf

INSTITUTO NACIONAL DE ESTADÍSTICA, INE (2013). Estadística de Profesionales Sanitarios Colegiados. Año 2012. Notas de Prensa 21 mayo 2013. Obtenido el 21-5-2013, de: http://www.ine.es

JUNTA DE CASTILLA Y LEÓN y SACYL (2015). Área de salud de Salamanca. Obtenido el 7-1-2015, de:

http://www.saludcastillayleon.es/institucion/es/organizacion/ordenacionsistema-sanitario/guia-ordenacion-sanitaria-castilla-leon-2007/area-salud$\underline{\text { salamanca }}$ 
KAPLAN, R. S., NORTON, D. P., y SANTAPAU, A. (1997). El cuadro de mando integral. Obtenido el 16-11-2014, de:

http://www.factorhuma.org/attachments secure/article/8312/UC QCI cast.p df.

KOHLBERG, L. (1992). Psicología del desarrollo moral. Bilbao: Desclée de Brouwer.

KWAME ANTHONY APPIAH (2010). Experimentos de ética. Madrid: katz Editores.

LAZARTE MORO, A. M. (2005). Más allá de una "comunidad escolar justa". 135 ESE Departamento de Educación Universidad de Navarra, $\mathrm{N}^{\circ} 8$, pp. 135-144. Obtenido el 22-06-2014, de: http://dspace.unav.es/dspace/bitstream/10171/8871/1/Nb.pdf

LENARDÓN, F. R. (2007). Administración pública, control social y eficiencia. Enfoques, núm. XIX, 1-2, pp. 55-88. Obtenido el 27-1-2015, de: http://www.uap.edu.ar/wp-content/uploads/2015/02/09-LenardónAdministración-pública.pdf

LEÓN ALONSO, M. (2010). La protección constitucional de la salud en el marco del estado social y democrático de derecho (tesis doctoral). Universidad de Salamanca, Salamanca.

Ley 14/1986, de 25 de abril, General de Sanidad, B.O.E nº 102, pp. 1520715224 , de 29 de abril.

LINDE NAVAS, A. (2009). La educación moral según Lawrence Kohlberg: una utopía realizable. Universidad del Valle. Obtenido el 7-12-2013, de:http://www.scielo.org.co/scielo.php?pid=S0120$\underline{46882009000100001 \& \text { script }=\text { sci arttext }}$

LÓPEZ ALONSO, M. (2011). El cuidado: un imperativo para la Bioética. Madrid: Universidad Comillas (miembro de la Unión de Editoriales Universitarias Españolas UNE). 
LÓPEZ DE LA VIEJA, T., BARRIOS, O., FIGUERUELO, Á., VELAYOS, C., y CARBAJO, J. (2006). Bioética y Feminismo. Salamanca: AQUILAFUENTE, Ediciones Universidad de Salamanca.

LÓPEZ FERNÁNDEZ, Ma P. (2009). El concepto de anomia de Durkheim y las aportaciones teóricas posteriores. Iberóforum. Revista de Ciencias Sociales de la Universidad Iberoamericana, 4(8), pp. 130-147.

LOZANO PEÑA, C., HUESO MONTORO, C., y MUÑOZ VINUESA, A. (2014). GOMERES. Historia, cultura y pensamiento enfermero. Granada: Facultad de ciencias de la salud de la Universidad de Granada. Obtenido el 15-52013, de: http://index-f.com/gomeres/?cat=2.

MANEME CERRAGERÍA, L. M. (2013). Eficacia, Eficiencia, Efectividad en el desempeño del trabajo. Obtenido el 26-1-2015, de:

http://actualidadempresa.com/eficacia-eficiencia-y-efectividad-en-eldesempeno-del-trabajo/

MAQUIAVELO, N. (2014) El príncipe. Obtenido el 7-1-2014, de: http://www.philosophia.cl/biblioteca/Maquiavelo/E1\%20pr\%EDncipe.pdf

MARÍN FERRER, M., y DE ROSA TORNER, A. (2007). Las nuevas formas de gestión sanitaria "Modelo Alzira". Madrid: Instituto de estudios económicos. Obtenido el 2-12-2014, de: http://www.actasanitaria.com/fileset/doc_39677_FICHERO_NOTICIA_ 217 84.pdf;

MARQUÉS SÁNCHEZ, P. (2006). Experiencia docente en Administración de Servicios de Enfermería: observatorio de innovación empresarial basado en valores. Educare21-Esp-, pp. 26.

MARQUÉS SÁNCHEZ, P., FARRERONS NOGUERA, L., ARIAS RAMOS, N., y QUIROGA SÁNCHEZ, E. (2012). Las relaciones informales: un valor añadido en la gestión de personas. Enfermería Global. Obtenido el 14-42014, de: http://scielo.isciii.es/scielo.php?pid=S1695$\underline{61412012000200020 \& \text { script }=\text { sci } \_ \text {arttext\&tlng }=\text { es }}$ 
MARQUÉS SÁNCHEZ, P., PÉREZ RIVERA, J., QUIROGA SÁNCHEZ, E., y ARIAS RAMOS, N. (2012). Análisis de la percepción de valores en los alumnos universitarios de Enfermería. Revista Iberoamericana de educación e investigación en Enfermería 2012; 2(2):26-32.

MARTÍN GARCÍA, M. (2015). ¿Cómo se paga la Sanidad Pública? Los diversos modelos. La Sanidad no se vende. Manual para la defensa de la Sanidad Pública. Madrid-España: Ediciones Akal, pp. 73-81.

MARTÍNEZ FRANCO, Y. A., RUBIANO LAMPREA, A., y VENEGAS FORERO, M. L. (2008). Pedagogía del cuidado: una pedagogía que involucra la convivencia y la paz. Universidad de la Sabana. Facultad de Educación. Chia, Cundinamarca, Colombia. Obtenido el 25-6-2014, de: http://intellectum.unisabana.edu.co:8080/jspui/bitstream/10818/2475/1/1219 14.pdf

MARTÍNEZ GÓMEZ, J. A. (2010), En torno a la axiología y los valores. Obtenido el 15-5-2014, de: www.eumed.net/rev/cccss/07/jamg3.htm

MARX, K. (2007). Contribución a la crítica de la economía política. México D.F.: Siglo XXI. Obtenido el 15-5-2014, de:http://books.google.es/books?id=i8PYOo5719gC\&printsec $=$ frontcover\&dq $=\mathrm{C}$ ontribución $+\mathrm{a}+\mathrm{la}+\mathrm{cr} \% \mathrm{C} 3 \%$ ADtica + de + la + econom $\% \mathrm{C} 3 \% \mathrm{ADa}+$ pol $\% \mathrm{C} 3 \% \mathrm{ADtic}$ $\mathrm{a} \& \mathrm{hl}=\mathrm{es} \& \mathrm{sa}=\mathrm{X} \& \mathrm{ei}=\mathrm{b} \_Z 4 U 828 \mathrm{Lqa50QWowICYCw \& ved=0CDQQ6AEwAA \# v}$ $=$ onepage $\& q=$ Contribución $\% 20 \mathrm{a}$.

MASLOW, A. H. (1991). Motivación y personalidad. Madrid: Ediciones Díaz de Santos, S. A.

MAYEROFF, M. (1971). On Caring. New York USA: HarperCollins Publishers.

MOKATE, K. M. (2002). Eficacia, eficiencia, equidad y sostenibilidad: ¿qué queremos decir? Obtenido el 20-1-2013, de:

http://www.cepal.org/ilpes/noticias/paginas/9/37779/gover_2006_03_eficacia_ef iciencia.pdf 
NARDONI, E. (1993). La Justicia en la Mesopotamia antigua. Revista Bíblica, 55(52), pp. 4- Obtenido el 26-1-2014, de:

http://www.revistabiblica.org.ar/articulos/rb55_193.pdf.

NIELFA CRISTÓBAL, G. (2001). Trabajo, legislación y género en la España contemporánea: los orígenes de la legislación laboral. Privilegios o eficiencia, pp. 39-53. Obtenido el 19-6-2014, de:

http://www.unizar.es/eueez/cahe/nielfa.pdf

NIETZSCHE, F. (2006). La voluntad de poder. Madrid: Edaf.

NIGHTINGALE, F. (1990). Notas sobre enfermería. Qué es y qué no es. Barcelona: Masson, S.A.

NOBLE, V. (1992). A helping hand from the guys. Women respond to the men's movement. San Francisco: HarperCollins.

NODDINGS, N. (1984). Caring, a feminine approach to ethics and moral education. Berkeley: University of California Press.

NUÉVALOS RUÍZ, C. (2008). Desarrollo moral y valores ambientales. (Tesis doctoral). Valencia: Universitat de Valencia.

ORDI I FERNÁNDEZ, J. (2009). Ludwig Wittgenstein. Obtenido el 18-3-2014, de: http://www.philosophica.info/voces/wittgenstein/Wittgenstein.html

ORGANIZACIÓN MUNDIAL DE LA SALUD (1946). Constitución de la Organización Mundial de la Salud. Nueva York, Obtenido el 29-12-2014, de: http://www.who.int/governance/eb/who_constitution_sp.pdf

ORGANIZACIÓN MUNDIAL DE LA SALUD (2013). Acerca de la OMS. Obtenido el 27-10-2013, de: http://www.who.int/about/es/

ORTEGA GUTIÉRREZ, D. (1999). Los valores de la polis en la sofística y en Platón. Obtenido el 14-12-2013, de: http://hdl.handle.net/10115/987

ORTEGA Y GASSET, J. (2004). Introducción a una estimativa ¿Qué son los valores? Madrid: Ediciones Encuentro. 


\section{BIBLIOGRAFÍA}

. (2003) El Hombre y la gente. Madrid: Alianza Editorial.

ORTIZ GÓMEZ, T. (2007). La práctica sanitaria en la historia ¿una cuestión femenina? Obtenido el 20-5-2013, de: http://hdl.handle.net/10481/14970

ORTIZ-GÓMEZ, T., BIRRIEL-SALCEDO, J., y ORTEGA DEL OLMO, R. (2004). Género, profesiones sanitarias y salud pública. Gaceta Sanitaria, 18, pp. 189-194.

Obtenido el 5-8-2013, de: http://scielo.isciii.es/scielo.php?pid=s021391112004000400030\&script=sci_arttext

OXFORD UNIVERSITY PRESS (2015). Oxford Dictionaries Language Matters. Obtenido el 25-4-2015, de: http://www.oxforddictionaries.com/es/definicion/espanol/dignidad

PALACIOS NAVARRO, S. (n. d.). Los valores humanos y la comprensión de la desobediencia civil. Revista de Psicodidáctica. Obtenido el 6-7-2014, de: http://www.redalyc.org/articulo.oa?id=17517792009

PARA RODRÍGUEZ-SANTANA, I. (REDACTOR Y COORDINADOR), (2011, 25 de abril). XXV Aniversario de la ley General de Sanidad. El Modelo de Futuro de Gestión de la Salud. Propuestas para un debate. (Informe Bamberg). Madrid: Fundación Bamberg.

PARENTINI, M. R. (2002). Historia de la enfermería: aspectos relevantes desde sus orígenes hasta el siglo XX. Montevideo, Uruguay: Ediciones Trilce.

PEIRÓ, S., ARTELLS, J. J., y MENEU, R. (2011). Identificación y priorización de actuaciones de mejora de la eficiencia en el Sistema Nacional de Salud. Gaceta Sanitaria, 25(2), pp. 95-105.

PEMÁN GAVÍN, J. (2006). Asistencia sanitaria y sistema nacional de salud: estudios jurídicos. Granada: Comares.

PÉREZ-DELGADO, E., y GARCÍA-ROS, R. (1991). La psicología del desarrollo moral. Madrid: Siglo XXI de España editores. 
PICAS CONTRERAS, J. (2006). Los límites de la solidaridad. Las ONG y el mercado de "bienes simbólicos". Obtenido el 10-6-2013, de: http://www.ugr.es/ pwlac/G22_08Joan_Picas_Contreras.html

PLATÓN (1984). Diálogos. Obra completa en nueve volúmenes. Volumen IV: República. Madrid: Gredos.

POSADA, A. (2003). Recordando al Instituto de Reformas Sociales. Revista del Ministerio de trabajo y asuntos sociales. Centenario del Instituto de Reformas Sociales, $\mathrm{n}^{0}$ extra, pp. 17-25. Obtenido el 1-3-2014, de: http://www.empleo.gob.es/es/publica/pub_electronicas/destacadas/revista/numer os/ExtraDTrab03/Estudios01.pdf

PRATS, J., (2013, 10 de Julio). Los impagos ahogan el modelo privado valenciano. EL PAÍS. Obtenido el 2-12-2014, de: http://sociedad.elpais.com/sociedad/2013/07/10/actualidad/1373488581_513886. html

PROVEEDORA, F. (2005). Respetándose los principios de eficacia, eficiencia, equidad y gratuidad de los servicios. Obtenido el 1-12-2013, de: http://saludygestion.com/archives/ALZIRA.pdf

PULIDO QUECEDO, M. (1993). LA CONSTITUCIÓN ESPAÑOLA. Con la Jurisprudencia del Tribunal Constitucional. Pamplona: Editorial ARANZADI.

RAMIÓ JOFRE, A. (2005). Valores y actitudes profesionales. Estudio de la práctica profesional enfermera en Catalunya. (Tesis doctoral). Barcelona: Universitat de Barcelona.

RAMIÓ, C. (2010). Teoría de la Organización y Administración Pública. Barcelona: TECNOS.

RAMÍREZ MARTÍN, S.M. (2004). El legado de la Real Expedición Filantrópica de la Vacuna (1803-1810): las Juntas de Vacuna. Asclepio, 56 (1), pp. 33- 
62. Obtenido el 24-2-2014, de:

http://asclepio.revistas.csic.es/index.php/asclepio/article/view/71/74

RAVENTÓS, D. (1999). El derecho a la existencia. Barcelona: Ariel.

RAWLS, J. (2006). Teoría de la Justicia. Cambridge: The Belknap Press of Harvard University Press, Cambridge, Mass.

Obtenido el 12-6-2014, de: http:/www.google.es/url?sa=t\&rct=j\&q=\&esrc=s\&source=web\&cd=2\&ved $=0 \mathrm{CCsQFjAB} \& u r l=\mathrm{http} \% 3 \mathrm{~A} \% 2 \mathrm{~F} \% 2 \mathrm{Fwww}$.liberallibertario.org $\% 2 \mathrm{Fhome} \% 2 \mathrm{Fin}$ dex.php\%2Fdocumentos-partidarios\%2Fdoc_download\%2F140-john-rawlsteoria-de-lajusticia\&ei=kIeZU9WSIIX50gXWmIHQBA\&usg=AFQjCNHVFG7DqJhFzjqL Tv28OKyxvBBMNg\&sig2=I4QCI19261z-

0_tZNwFGJA\&bvm=bv.68911936,d.ZGU

RAYNAUD, P. (2001). Diccionario Akal de filosofía política. Madrid: Ediciones AKAL.

REAL ACADEMIA ESPAÑOLA (MADRID, ESPAÑA), (2007). Diccionario de la lengua española. 22a, en CD-ROM, versión 10 edición. Pozuelo de Alarcón Madrid: Espasa Calpe.

REALE, G., y ANTISERI, D. (2007). Historia de la filosofía. Bogotá: Editorial San Pablo.

REGUERO, B. (1996). La reflexión de lo social a través del discurso axiológico. Facultad de Psicología. UNAM, México. Obtenido el 9-12-2013, de: http://catedradh.unesco.unam.mx/ver2000/valhtm1.htm

RINCÓN VERDERA, J.C. (2006). Filosofía de la Educación y Teoría de los Valores: el subjetivismo y el objetivismo. Educacio I Cultura, 19, pp. 2632.

RIVERO YSERN, E., SÁNCHEZ BLANCO, Á., DOMÍNGUEZ BERRUETA DE JUAN, M., y APRELL LASAGABASTER, C. (2011). El nuevo derecho 
administrativo: libro homenaje al prof. Enrique Rivero Ysern. Salamanca: Ratio Legis.

ROACH, M. S. (1987). The Human Act of Caring: A blueprint for the Health Professions. Ottawa: Canadien Hospital Association.

RODRIGUEZ ÁVILA, N. (2008). Manual de sociología de las profesiones. Barcelona: Ediciones de la Universidad de Barcelona.

ROKEACH, M. (1979). Understanding human values individual and societal. New York: Free Press.

ROMERO DE SAN PÍO, E. (2013). La ética de la responsabilidad en los cuidados de enfermería. Revista de Seapa, XI, pp. 31-35. Obtenido el 22-62014 ,

de: http://www.seapaonline.org/UserFiles/File/Revistas/invierno\%202013/La\%2 0etica $\% 20$ de $\% 201$ a $\% 20$ responsabilidad $\% 20$ en $\% 201$ os\%20cuidado $\% 20 \mathrm{de} \% 20$ enf ermeria.pdf

ROS, M., y VALDINEY V. GOUVEIA (2001). Psicología Social de los valores humanos: desarrollos teóricos, metodológicos y aplicados. Revista Interamericana de Psicología. Obtenido el 24-7-2014, de: http://www.redalyc.org/pdf/2313/231318052006.pdf

RUANO DE LA FUENTE, Y. (1996). Racionalidad y conciencia trágica. La modernidad según Max Weber. Madrid: Trota. . (2001). La libertad como destino. El sujeto moderno en Max Weber. Madrid: Biblioteca Nueva.

RUIZ BERRIO, J. (2005). Pedagogía y Educación ante el siglo XXI. Madrid: Ruiz Berrio, J. Editor, imprime: Gráficas Loureiro.

SALAS IGLESIAS, P. M. (2012). El reformismo social y sanitario de Concepción Arenal, una contribución a la identidad de la enfermería contemporánea. Alicante: Editorial Club Universitario. 
SAMET LETICHEVSKY, S. (2011) ¿Qué son los valores? Recordando el libro de Risieri Frondizi. Obtenido el 10-2-2014, de: http://www.nodulo.org/ec/2011/n108p14.htm

SÁNCHEZ HERNÁNDEZ, A. J. (2005). Análisis filosófico del concepto valor. Obtenido el 8-12-2013, de: http://scielo.sld.cu/scielo.php?script=sci_arttext\&pid=s172781202005000200009

SÁNCHEZ-MIGALLÓN GRANADOS, S. (2013). Franz Brentano, Max Sheller. Philosophica: Enciclopedia filosófica. Obtenido el 15-12-2013, de: http://www.philosophica.info/archivo/2009/voces/brentano/Brentano.html

SANGUINETI RAYMOND, W., MARTÍN HERNÁNDEZ, M. L., y FIGUERUELO, Á. (2011). Propuestas para la igualdad de género en la negociación colectiva:estudio a partir de la negociación colectiva en Castilla y León. Albacete: Bomarzo.

SERRANO MARTÍNEZ, G. (1984). Problemática psicosocial de los valores humanos. Boletín de Psicología No 3, 1984. pp. 7-37. Obtenido el 26-62014, de: http://www.uv.es/seoane/boletin/previos/N3-1.pdf

SERVICIO DE SALUD DE CASTILLA Y LEÓN (2013). Salud Castilla y León: SACYL. Obtenido el 10-11-2013, de: http://www.saludcastillayleon.es/es/

SILES GONZÁLEZ, J. (2005). La eterna guerra de la identidad enfermera: un enfoque dialéctico y deconstruccionista. Index de Enfermería, 14 (50), pp. 07-09.

SOLARES, B., Primavera (1996). Max Weber y el carácter problemático de la sociología como ciencia. Obtenido el 8-5-2014, de: http://biblioteca.itam.mx/estudios/estudio/letras44/notas2/sec_1.html

TORRES AMAT, F., y DIEZ MONAR, J. (1954). La Santa Biblia: Antiguo y Nuevo Testamento. Madrid: Luis Uriarte. 
UNIVERSIDAD DE CANTABRIA (2013). Las leyes de Ur-Nammu. Obtenido el 15-11-2013, de: http://ocw.unican.es/humanidades/historia-del-proximooriente/modulo-2/las-leyes-de-ur-nammu

UNIVERSIDAD COMPLUTENSE DE MADRID (2013). Kant en español. Obtenido el 11-11-2013, de: http://pendientedemigracion.ucm.es/info/kantesp/

\section{UNIVERSIDAD COMPLUTENSE DE MADRID y FACULTAD DE} FILOSOFÍA (2013). Cuaderno de materiales. Revista de Filosofía. Obtenido el 22-12-2013, de: http://www.filosofia.net/materiales/

UNIVERSIDAD DE ALCALÁ y GÓMEZ PANTOJA, J. L. (2013). El código de Hammurabi. Obtenido el 10-10-2013, de: http://www2.uah.es/histant/pantoja/schola/Materiales\%20docentes/Hammurabi.p $\mathrm{df}$

UNIVERSIDAD FRANCISCO MARROQUÍN (2014). Sitio escolástico.

Obtenido el 27-5-2014, de: http://escolasticos.ufm.edu/index.php?title=Portada

URCOLA TELLERIA, J. L. (2000). Lograr resultados. Factores claves de dirección: orientados a la obtención de resultados. Capítulo 2: pp. 61-80. Madrid: ESIC Editorial.

VALBUENA, M., MORILlO, R., y SALAS, D. (2006). Sistema de valores en las organizaciones. Omnia, 12 (3), pp. 60-78.

VÁZQUEZ VEGA, P. (2010). La feminización de las profesiones sanitarias. Bilbao: Fundación BBVA.

VENTOSA ESQUINALDO, F. (1984). Historia de la enfermería española. Madrid: Ciencia 3.

VERA, H. (2002). Representaciones y clasificaciones colectivas. La teoría sociológica del conocimiento de Durkheim. Sociológica, 17(50), pp. 103121; Obtenido el 7-5-2014, de: http://www.revistasociologica.com.mx/pdf/5005.pdf 
VERNEAUX, R. (1977). Historia de la filosofía moderna. Obtenido el 22-22014, de: http://201.147.150.252/handle/123456789/686

VILLAPALOS, G., y LÓPEZ, A. (2002). El libro de los valores. Barcelona: Planeta.

VILLAR EZCURRA, A. (2010). El yo inasible de Pascal frente a la fortaleza del sujeto cartesiano. Isegoría, (42), pp. 265-278; Obtenido el 22-2-2014, de: http://isegoria.revistas.csic.es/index.php/isegoria/article/viewArticle/695

WEBER, M. (1964). Economía y sociedad. Madrid: FONDO DE CULTURA ECONÓMICA. . (2009). La ética protestante y el espíritu del capitalismo. Madrid: Editorial Reus.

WORLD HEALTH ORGANIZATION (1978). Declaration of Alma-Ata. International conference on primary health care, Alma-Ata, USSR 1978, pp. 12.

ZAVALA, I. (1998). La sociología de los valores. Obtenido el 4-5-2014, de: http://biblioweb.tic.unam.mx/valores_distantes/C1ESquema.htm 